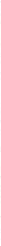

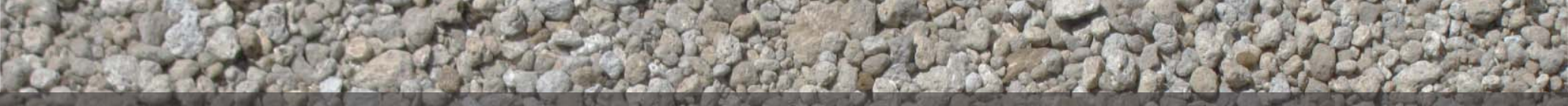

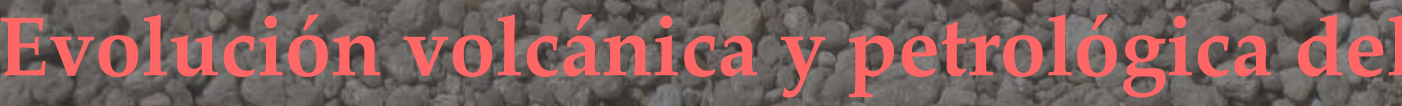

Solcan ay

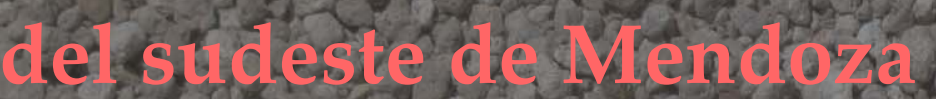

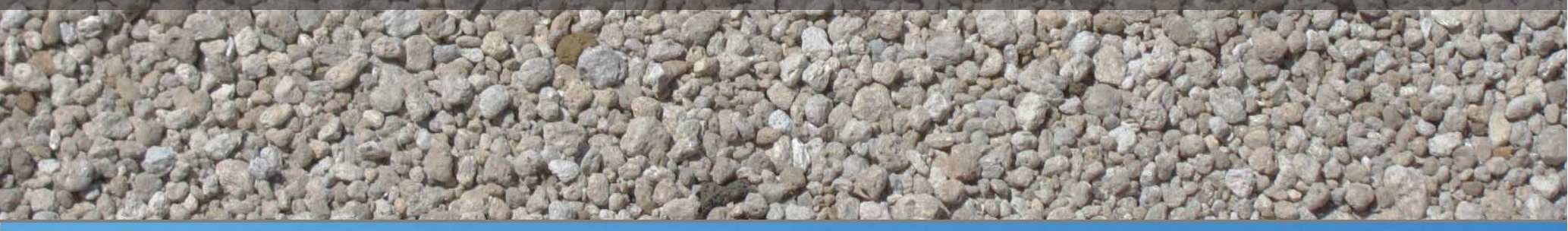

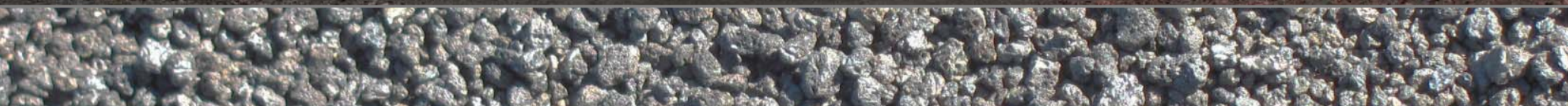

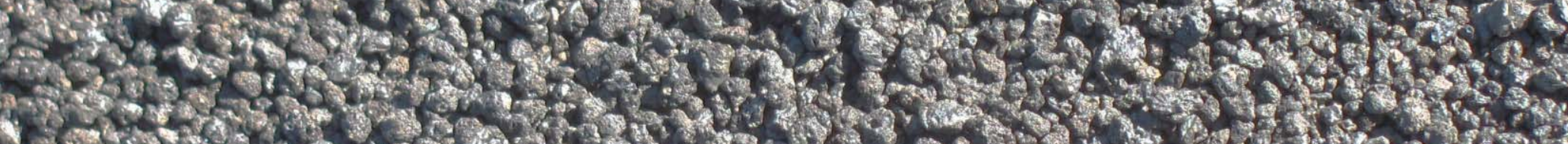

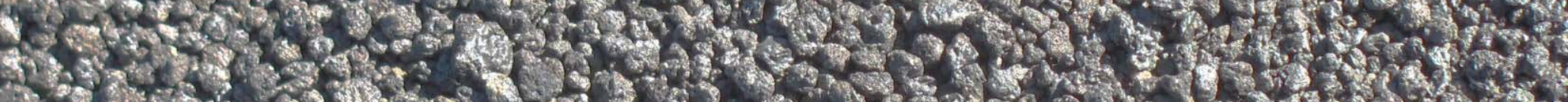

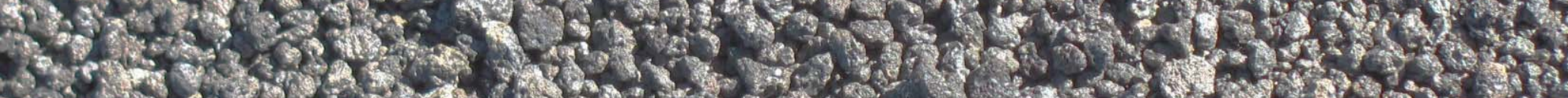

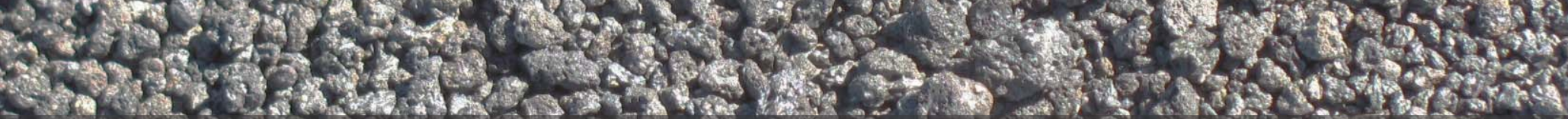

Irene R. Hernando

2012
Director: Dr. Eduardo J. Llambias Co-director: Dr. Pablo D. González

Facultad de Ciencias Naturales y Museo - Universidad Nacional de La Plata Centro de Investigaciones Geológicas (CONICET-UNLP)

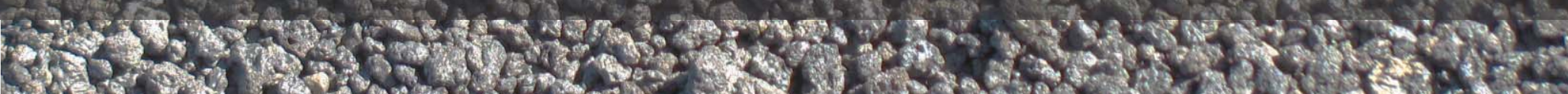

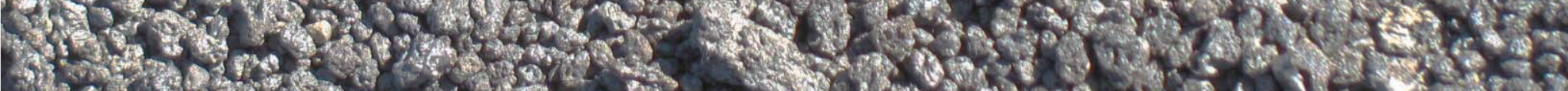




\section{Evolución volcánica y petrológica del volcán Payún Matrú, retroarco andino del sudeste de Mendoza}

Irene R. Hernando

2012

Director: Dr. Eduardo J. Llambías

Co-Director: Dr. Pablo D. González

Facultad de Ciencias Naturales y Museo

Universidad Nacional de La Plata

Centro de Investigaciones Geológicas (CONICET-UNLP) 


\section{Índice general}

$\begin{array}{lr}\text { Introducción } & 1\end{array}$

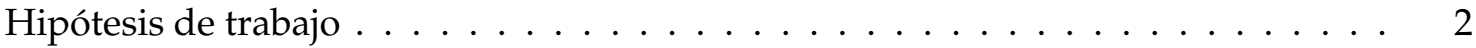

Objetivos .......................... 3

1. Antecedentes 4

1.1. Marco general . . . . . . . . . . . . . . . . . . . . . . 4

1.1.1. Regiones morfoestructurales . . . . . . . . . . . 6

1.1.2. Lineamiento Cortaderas-Cinturón volcánico Tromen-Domuyo . . . . . 8

1.2. Evolución volcano-tectónica entre $\operatorname{los} 35^{\circ}$ y $38^{\circ} \mathrm{S} \ldots \ldots \ldots$

1.3. Información Geofísica . . . . . . . . . . . . . . . . . . . . . 11

1.4. Volcanismo en Payenia . . . . . . . . . . . . . . . . . . . . . . . . . . . . . . . . . . . . . .

1.4.1. Campo Volcánico Llancanelo . . . . . . . . . . . . . . . . . . . . 15

1.4.2. Campo Volcánico Payún Matrú . . . . . . . . . . . . . . . . . . . . . . . . . . . . . . . . . . . 18

1.4.2.1. Estratigrafía . . . . . . . . . . . . . . . 18

2. Metodología 25

2.1. Tareas de campo . . . . . . . . . . . . . . . . . . . . 25

2.2. Tareas de gabinete . . . . . . . . . . . . . . . . . . . 25

2.2.1. Recopilación de información previa . . . . . . . . . . . . . . . . . . . . . . . . . . . 25

2.2.2. Confección de un GIS . . . . . . . . . . . . . . . . . . . . . . . 26

2.2.3. Cálculos . . . . . . . . . . . . . . . . . . . . 26

2.2.4. Estudios petrográficos . . . . . . . . . . . . . . . 27

2.2.5. Geoquímica de roca total . . . . . . . . . . . . . . . 27

2.2.6. Geoquímica isotópica . . . . . . . . . . . . . . . . . 27

2.2.7. Análisis de la química mineral . . . . . . . . . . . . . . . . . . . . . . . . . . . . . . . 28

2.2.8. Dataciones radimétricas . . . . . . . . . . . . . . . . . . . . . 29

3. Estratigrafía del CVPM 31

3.1. Morfología volcánica . . . . . . . . . . . . . . . . . . . . 31

3.1.1. Cálculo volumétrico del Payún Matrú y Payún Liso . . . . . . . . . . . 34 
3.2. Estratigrafía del CVPM . . . . . . . . . . . . . . . . . 34

3.2.1. Columnas estratigráficas . . . . . . . . . . . . . . . . . . . . . . . . . . . . . 48

3.3. Edades radimétricas . . . . . . . . . . . . . . . . . . . 40

3.3.1. Edades radimétricas previas . . . . . . . . . . . . . . . . . . . . . . 40

3.3.2. Nuevas edades radimétricas . . . . . . . . . . . . . . . 46

4. Descripción geológica del CVPM 49

4.1. Volcán Payún Matrú . . . . . . . . . . . . . . . . . . . . . . . . . . . . . . . . . . . . . 49

4.1.1. Traquitoides Pre-caldera (T pre) . . . . . . . . . . . . . . . . . . . . . 49

4.1.2. Ignimbrita Portezuelo $(\operatorname{Ig} P) \ldots \ldots \ldots \ldots \ldots$

4.1.2.1. Litofacies de la Ignimbrita Portezuelo . . . . . . . . . . . . 56

4.1.2.2. Interpretación de las facies ignimbríticas . . . . . . . . . . . . 66

4.1.3. Traquiandesitas Post-caldera (TA pos) . . . . . . . . . . . . . . 67

4.1.4. Traquitas Post-caldera (T pos) . . . . . . . . . . . . . . . . . . 69

4.1.4.1. Traquitas en bloque $(T b q) \ldots \ldots . \ldots . \ldots 69$

4.1.4.2. Conos Pumíceos $(C p z) \ldots \ldots \ldots 71$

4.1.4.3. Traquitas vítreas $(T v) \ldots \ldots \ldots \ldots$. . . . . . . 77

4.1.4.4. Relación y comparación entre las litofacies de Traquitas Post-

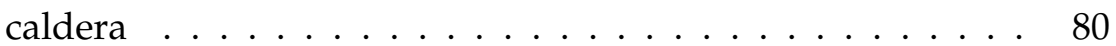

4.2. Campos basálticos este y oeste . . . . . . . . . . . . . . . 81

4.3. Volcán Payún Liso . . . . . . . . . . . . . . . . . . . . . . . 86

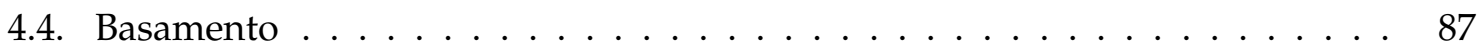

5. Control estructural sobre el volcanismo $\quad 89$

5.1. Estructuras regionales y el CVPM . . . . . . . . . . . . . . . . . . . 89

5.2. Las erupciones como indicadoras de esfuerzos . . . . . . . . . . . . . . . 90

5.3. Distribución y morfología de centros eruptivos . . . . . . . . . . . . . . . . 91

5.3.1. Influencia de la caldera . . . . . . . . . . . . . . . 96

5.4. Orientación del campo de esfuerzos en el CVPM . . . . . . . . . . . . . . . 98

5.5. Caldera del Payún Matrú ～. . . . . . . . . . . . . . . . . . . . . 100

$\begin{array}{ll}\text { 6. Análisis petrográfico } & 103\end{array}$

6.1. Texturas mineralógicas en el CVPM . . . . . . . . . . . . . . . . . . . . . . . . . . . . . 103

6.2. Traquitoides Pre-caldera . . . . . . . . . . . . . . . . . . . . . . 108

6.2.1. Subunidad $1 \ldots \ldots \ldots$. . . . . . . . . . . . . . 108

6.2.2. Subunidad $2 \ldots \ldots \ldots \ldots$. . . . . . . . . . . . . 110

6.2.3. Subunidad $3 \ldots \ldots \ldots \ldots$. . . . . . . . . . . . . . 114

6.2.4. Subunidad $4 \ldots \ldots \ldots \ldots \ldots \ldots$

6.2.5. Subunidad 5 . . . . . . . . . . . . . . . . . . . . . 121

6.3. Ignimbrita Portezuelo . . . . . . . . . . . . . . . . . . . . . 121 
6.3.1. Cristaloclastos . . . . . . . . . . . . . . . . . . . 122

6.3.2. Vitroclastos y cristaloclastos . . . . . . . . . . . . . . . . . . 123

6.3.2.1. Facies de alto grado (emLT y emLT(v)) . . . . . . . . . . 123

6.3.2.2. Facies de grado medio a bajo (mLT) . . . . . . . . . . . . 125

6.3.2.3. Facies con clastos de spatter traquíticos (emLT(cc) y mLT(cc)) 125

6.3.2.4. Otras facies (dsLT, sLT, sT y mT) . . . . . . . . . . . . . . . . . . 126

6.4. Traquiandesitas Post-caldera . . . . . . . . . . . . . . 126

6.4.1. Plagioclasas . . . . . . . . . . . . . . . . . . . 127

6.4.2. Minerales máficos . . . . . . . . . . . . . . . . . . . . . . . . . 129

6.4.3. Colada intra-caldera . . . . . . . . . . . . . . . . . . . . . . . . 129

6.5. Traquitas Post-caldera . . . . . . . . . . . . . . . . . . . . 133

6.5.1. Traquitas en bloque . . . . . . . . . . . . . . . . . . . . . . . . . . . . . . . . . . . . . . . . . . . . . .

6.5.2. Traquitas vítreas . . . . . . . . . . . . . . . . 136

6.5.3. Conos pumíceos . . . . . . . . . . . . . . . . . . . . . 138

6.6. Basaltos Pre- y Post-caldera . . . . . . . . . . . . . . . . . . . . 139

6.6.1. Olivinas . . . . . . . . . . . . . . . . . . . . . . . . 140

6.6.2. Clinopiroxenos . . . . . . . . . . . . . . . . . . . 140

6.6.3. Plagioclasas . . . . . . . . . . . . . . . . . . . . . . . 142

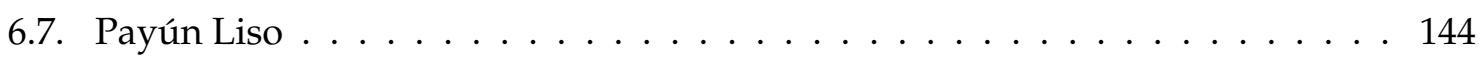

6.7.1. Lavas . . . . . . . . . . . . . . . . . . . . . . . . 144

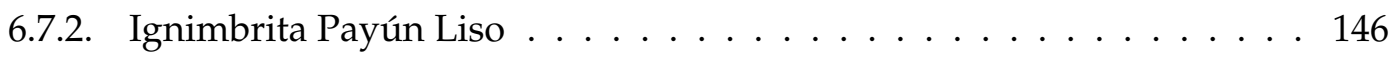

6.8. Síntesis de la petrografía del Payún Matrú . . . . . . . . . . . . . . . . . 146

7. Geoquímica y análisis isotópico de roca total 150

7.1. Clasificación de las rocas del CVPM . . . . . . . . . . . . . . . . 150

7.1.1. Norma CPIW . . . . . . . . . . . . . . . . . . . . . . 155

7.2. Diagramas de variación . . . . . . . . . . . . . . . . . 157

7.3. Diagramas multielementos . . . . . . . . . . . . . . . . . . . . . . . . . . . 161

7.3.1. Diagrama de Tierras Raras ． . . . . . . . . . . . . . . . . . . 161

7.3.2. Diagrama Spider de elementos incompatibles . . . . . . . . . . . . . . . 165

7.4. Discriminación tectónica . . . . . . . . . . . . . . . . . . . . 169

7.5. Fraccionamiento y magmas primarios . . . . . . . . . . . . . . . . . . . . . . . . 172

7.5.1. $\quad \# \mathrm{Mg} \ldots \ldots \ldots \ldots \ldots$

7.5.2. Covariaciones Cr-Y . . . . . . . . . . . . . . . . . . . 173

7.5.3. Otras evidencias de fraccionamiento en basaltos . . . . . . . . . . . . 175

7.6. Fuente mantélica . . . . . . . . . . . . . . . . . . . 176

7.7. Isótopos de Sr y Nd . . . . . . . . . . . . . . . . . . . . . 179

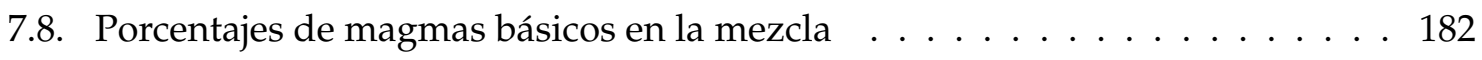

7.9. Síntesis . . . . . . . . . . . . . . . . . . . . . . . . . . 184 
8. Composición química mineral $\mathbf{1 8 5}$

8.1. Feldespatos . . . . . . . . . . . . . . . . . . 186

8.1.1. Traquitoides Pre-caldera . . . . . . . . . . . . . . . . . . . 186

8.1.2. Ignimbrita Portezuelo . . . . . . . . . . . . . . . . . . . . . . 189

8.1.3. Traquiandesitas Post-caldera . . . . . . . . . . . . . . . . . . 189

8.1.4. Traquitas Post-caldera . . . . . . . . . . . . . . . . . . . . 195

8.1.5. Basaltos Pre- y Post-caldera . . . . . . . . . . . . . . . . . . . . 195

8.1.6. Comparación entre unidades . . . . . . . . . . . . . . . . 199

8.2. Olivinas . . . . . . . . . . . . . . . . . . . . . . . 200

8.3. Piroxenos . . . . . . . . . . . . . . . . . . . . . . . 201

8.4. Anfíboles . . . . . . . . . . . . . . . . . . . . . 206

8.5. Micas . . . . . . . . . . . . . . . . . . . . . . . . 207

8.6. Vidrio volcánico . . . . . . . . . . . . . . . . . . . . . . . . . . . . 208

8.7. Cálculos geobarométricos . . . . . . . . . . . . . . . 208

8.7.1. Termómetros con vidrios . . . . . . . . . . . . . . . . . . 208

8.7.2. Termómetro olivina-fundido . . . . . . . . . . . . . . . . . . . . . . 209

8.7.3. Termobarómetros feldespato alcalino/plagioclasa-fundido . . . . . . . 210

8.7.4. Termobarómetros con clinopiroxeno-fundido . . . . . . . . . . . . . 211

8.7.5. Termobarómetros que involucran al ortopiroxeno . . . . . . . . . . . . 211

8.7.6. Termobarómetros con anfíbol . . . . . . . . . . . . . . . . . . 213

8.7.7. Termómetros con anfíbol-plagioclasa . . . . . . . . . . . . . . 213

8.7.8. Interpretación de los datos termobarométricos . . . . . . . . . . . . . 214

8.8. Cálculos de viscosidad . . . . . . . . . . . . . . . . . . . . . . 216

9. Discusión $\quad 218$

9.1. Origen del volcanismo en el CVPM . . . . . . . . . . . . . . . . . . . . . . . . . . . . . . . . . . . . . .

9.1.1. Inicio de Payenia . . . . . . . . . . . . . . . . . . . . 218

9.1.2. Fuente de los magmas y régimen de subducción . . . . . . . . . . . . 219

9.1.3. Mecanismos de fusión . . . . . . . . . . . . . . . . . . . . . . . . . . . . 224

9.2. Naturaleza del volcanismo en el CVPM . . . . . . . . . . . . . . . . . . 224

9.2.1. Dos estilos de volcanismo . . . . . . . . . . . . . . . . . . . . . . 224

9.2.2. Magmas basálticos . . . . . . . . . . . . . . . . . . . . 225

9.2.3. Series magmáticas . . . . . . . . . . . . . . . . . . 227

9.2.4. Magmas traquíticos . . . . . . . . . . . . . . . . . . . . 229

9.2.5. El Daly Gap . . . . . . . . . . . . . . . . . . . . . . . . . . 231

9.3. Mezcla de magmas . . . . . . . . . . . . . . . . . . . . . . 232

9.3.1. Evidencias a macroescala . . . . . . . . . . . . . . 232

9.3.2. Evidencias a meso-escala: mixing vs. mingling . . . . . . . . . . . . . . . . . . . . . . . 232

9.3.3. Evidencias a microescala y geoquímicas . . . . . . . . . . . . . 235 
9.3.3.1. Etapa pre-caldera del Payún Matrú . . . . . . . . . . . . . 237

9.3.3.2. Etapa sin-caldera del Payún Matrú . . . . . . . . . . . . . . 239

9.3.3.3. Etapa post-caldera del Payún Matrú . . . . . . . . . . . . . . 240

9.3.3.4. Basaltos Pre- y Post-caldera . . . . . . . . . . . . . . . 241

9.3.4. Modelos de mezcla en el CVPM . . . . . . . . . . . . . . . . . . 241

9.3.4.1. Erupción de la Ignimbrita Portezuelo . . . . . . . . . . . . . 245

9.3.4.2. La particularidad de la Ignimbrita Portezuelo en el CVPM . . 248

9.4. Evolución del CVPM . . . . . . . . . . . . . . . . . . . . . . 248

9.4.1. Etapa pre-caldera . . . . . . . . . . . . . . . . . . . 248

9.4.2. Etapa sin-caldera . . . . . . . . . . . . . . . . . . 251

9.4.3. Etapa post-caldera . . . . . . . . . . . . . . . . . . . . 253

$\begin{array}{ll}\text { Conclusiones } & 257\end{array}$

$\begin{array}{ll}\text { Bibliografía } & 262\end{array}$

$\begin{array}{ll}\text { Anexo I: Mapa geológico del CVPM } & 279\end{array}$

$\begin{array}{ll}\text { Anexo II: Análisis químicos de roca total } & 281\end{array}$

Anexo III: Análisis isotópico de Sr y Nd en roca total 297

Anexo IV: Análisis de la química mineral 299

Feldespatos . . . . . . . . . . . . . . . . 300

Olivina . . . . . . . . . . . . . . . . . . . . . 323

Piroxenos . . . . . . . . . . . . . . . . . . 326

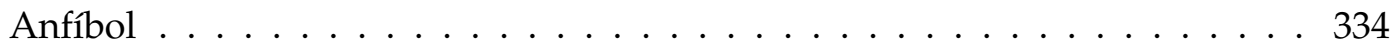

Biotita . . . . . . . . . . . . . . . . . . . 337

Vidrio volcánico . . . . . . . . . . . . . . . . . . . . . . . . . 338

Anexo V: Cálculos de porcentajes de magmas máficos y félsicos en la mezcla de magmas 


\section{Agradecimientos}

A Eduardo Llambías, por ofrecerme un lugar de trabajo tan particular y especial, por estar siempre predispuesto a las discusiones y charlas geológicas y siempre respetando la opinión ajena, y por hacerse cargo de los costos de las campañas cuando no había subsidios.

A Pablo González, por ayudarme a ser prolija y organizada en los trabajos de campo, lo cual fue fundamental para concretar la tesis, y por asesorarme en otro montón de cosas.

A la gente de Recursos Naturales Renovables de Malargüe, en especial Ramón Martínez, Jorge Fernandez, Guillermo Sánchez, Leonardo Orozco, por darme una ayuda enorme e inprescindible en las campañas y siempre con buena predisposición. ¡Gracias por todo!

A la familia Mancilla, en recuerdo de los mates compartidos y la primer visita a la caldera.

A "Perico" Forquera, por alojarnos en su hogar y llevarnos a la "fisura" inalcanzable del Payún, por los mates y las comidas.

A la familia Moya: Mirta, Goyo y Gertrudis, por el alojamiento, la comida y los mates y por alcanzarnos al faldeo también inalcanzable del Payún. ¡Gracias Goyo por las charlas lugareñas!

A mis ayudantes de campo: Ariel Schiuma, Lucas Olivo, Matías Galina, Esteban Margueliche, Gerardo "Tito" Páez y Federico González Soto, por el aguante y las pilas que pusieron en las campañas. ¡Gracias chicos!

A Ana María Sato, por la ayuda económica y la enseñanza en técnicas de laboratorio.

A Juan Franzese, por los innumerables consejos, las discusiones sobre aspectos estructurales del trabajo y las correcciones de manuscritos que me han servido mucho, y por la buena onda y predisposición.

A Eugenio Aragón, por ayudarme cada vez que lo necesité con las charlas y sugerencias que han enriquecido notablemente al trabajo.

A Alfredo Benialgo, por ayudarme con las imágenes y otras cuestiones informáticas, por estar siempre dispuesto a ayudar.

A Marcelo "Chino" Arnosio, por los consejos y charlas que han mejorado y encaminado a la tesis, y por estar cada vez que lo necesité.

A los becarios y becarias del CIG, por las ayudas en un millón de pequeñas y no tan pequeñas cosas que conforman una gran ayuda, por los mates y las cervezas y la buena 
onda que eso genera.

A la gente del CIG, por generar un ambiente cómodo y distendido en el que me sentí a gusto.

A Claudia Cavarozzi, por la ayuda y buena predisposición cada vez que la consulté.

A Ricardo Varela, Valeria García y Kei Sato por la importante asistencia en la preparación de muestras para el análisis de isótopos de Sr.

A la gente que conocí en la Universidad de San Pablo, Brasil: Silvio Vlach, Marcos Mansueto, Miguel Basei, por la gran ayuda que me dieron allí cuando estaba más que perdida. ¡Gracias Marcos por los bombones de cumpleaños!

A Andreas Richter, por ayudarme con el inglés y otras correcciones.

A Rita, Amelia y Mercedes, por todos los favores que les pedí, jespero no haber sido muy pesada!

A Diego Fracchia, por la provición de artículos importantisimos y la buena predisposición.

A mis amigos que me bancaron a pesar de todo en el último año de la tesis y entendieron mi estado de alteración.

A mis tíos Dante y Elsa, por la cálida bienvenida en San Pablo, y los paseos, las comidas y la compañía. ¡Gracias!

A mi familia, por bancarme los estudios y ayudarme a poner los pies en la tierra cuando fue necesario, y porque es la familia, ique le voy a hacer!.

A Luciano, por todo, por el aguante, por ayudarme en cálculos y otro montón de cosas más, y por estar. 


\section{Resumen}

El Payún Matrú es el volcán más importante volumétricamente del Campo Volcánico Payún Matrú (CVPM). Este es un volcán compuesto en forma de escudo con una caldera en su cúspide de $8 \mathrm{~km}$ de diámetro. El CVPM contiene, además, al estratovolcán Payún Liso y a campos basálticos monogénicos. El CVPM se ubica al sur de la provincia de Mendoza $\left(36^{\circ}-\right.$ $\left.37^{\circ} \mathrm{S}\right)$, y forma parte de la denominada Provincia Basáltica Payenia, o simplemente Payenia. Payenia ( $34^{\circ}-38^{\circ} \mathrm{S}$, centro-sur de Mendoza) de edad Pliocena-Holocena, se conforma principalmente por basaltos alcalinos. Se ubica en una posición de retroarco en la Zona Volcánica Sur de los Andes Centrales y, además del CVPM, abarca al Campo Volcánico Llancanelo junto a otros centros volcánicos dispersos al norte del mismo, y al escudo basáltico de Auca Mahuida al sur del CVPM.

El CVPM presenta lavas y rocas piroclásticas alcalinas, variando desde basaltos y traquibasaltos en los campos basálticos, hasta traquitas en los volcanes Payún Matrú y Payún Liso. El CVPM es Pleistoceno-Holoceno y presenta dos campos basálticos adyacentes al Payún Matrú, distribuidos en una franja E-O con el Payún Matrú en una posición central en la misma, e interrumpidos por dicho volcán. En el presente trabajo se propuso estudiar los procesos de mezcla de magmas que pudieron haber ocurrido en el volcán Payún Matrú, entre los magmas traquíticos alojados en la cámara del volcán y magmas basálticos. La hipótesis de trabajo consiste en que los magmas basálticos de una procedencia relativamente profunda, no pudieron ascender hasta la superficie en la zona del Payún Matrú debido a que, durante su ascenso, quedaron atrapados en la cámara magmática de dicho volcán. Como consecuencia, se habría producido la mezcla entre magmas basálticos y traquíticos.

Antes de focalizar el trabajo en la mezcla de magmas, y debido al limitado y desactualizado conocimiento sobre el CVPM, se procedió a realizar un mapeo a escala 1:60.000, en conjunto con una nueva propuesta de la estratigrafía del campo volcánico. Además, se realizaron tareas habituales de petrografía, análisis de la geoquímica de roca total y mineralógica, isotopía de $\mathrm{Sr}$ y $\mathrm{Nd}$ y dataciones radimétricas, para completar la caracterización de las rocas del Payún Matrú y campos basálticos. También se realizó un análisis de estructural de conos de escoria y erupciones fisurales, con el objetivo de hacer inferencias sobre los campos de esfuerzos regionales. El volcán Payún Liso no fue estudiado en detalle, al no ser el objetivo de la tesis. 
Durante la evolución del Payún Matrú se produjo una única erupción explosiva importante, la cual depositó ignimbritas en un radio de $35 \mathrm{~km}$ alrededor del volcán (Ignimbrita Portezuelo) y, además, produjo el colapso del edificio volcánico y la formación de la caldera del Payún Matrú. La Ignimbrita Portezuelo se utilizó como capa guía debido a su extensión areal y fácil reconocimiento, y también por marcar un evento único en el CVPM. Así, se separó al CVPM en tres etapas: pre-, sin- y post-caldera.

La etapa pre-caldera del CVPM es la de mayor duración, abarcando alrededor de $600 \mathrm{ka}$, siendo la roca más antigua datada de 700 ka. En esta etapa hubo un intenso volcanismo en el Payún Matrú, Payún Liso y campos basálticos. Las rocas pre-caldera del Payún Matrú fueron agrupadas en la unidad de Traquitoides Pre-caldera, la cual es fundamentalmente traquítica aunque presenta una amplia variedad litológica. Las rocas de los campos basálticos están representadas por la unidad de Basaltos Pre-caldera, las cuales afloran principalmente al este del Payún Matrú. La etapa sin-caldera es la de menor duración, y la unidad que la representa es la Ignimbrita Portezuelo, además de la caldera misma. No se pudo determinar una edad radimétrica de la ignimbrita, aunque su edad está acotada entre 148 y $82 \mathrm{ka}$.

La etapa post-caldera se continuó con actividad en los campos basálticos y Payún Matrú, aunque aparentemente no en el volcán Payún Liso. Las primeras lavas de esta etapa en el Payún Matrú son de composición intermedia, conformando la unidad de Traquiandesitas Post-caldera. Posteriormente, la composición de las emisiones cambió abruptamente hacia traquitas, conformando a la unidad de Traquitas Post-caldera. Esta unidad presenta tanto lavas de diferente morfología como depósitos piroclásticos pumíceos de caída, y por lo tanto se la dividió en tres litofacies: Traquitas en bloque, Conos pumíceos y Traquitas vítreas. Las erupciones basálticas continuaron al este y oeste de la caldera, con las unidades Basaltos Post-caldera I y II, con mayor intensidad en el lado oeste.

Los análisis geoquímicos e isotópicos de roca total permitieron hacer inferencias sobre la fuente y evolución de los magmas. Estos análisis sugieren que los basaltos se originaron en un manto con granate, o transicional al campo de la espinela, a una profundidad mayor a los $60 \mathrm{~km}$. Los basaltos eruptados no representan magmas primarios, sino que estos tuvieron un período de almacenamiento en la base de la corteza o discontinuidad de Mohorovicic, durante el cual se fraccionaron. La diferenciación del magma basáltico dio origen, a su vez, a los magmas traquíticos del Payún Matrú.

Mediante el estudio textural y mineralógico de las rocas del CVPM, se identificaron evidencias de mingling de magmas, así como desequilibrios mineralógicos que indican o sugieren la mezcla de magmas con hibridación. Durante la etapa pre-caldera del Payún Matrú, se registraron numerosas lavas con texturas y composiciones mineralógicas que indican desequilibrios producidos principalmente por la mezcla e hibridación entre magmas traquíticos y basálticos. También existen otras lavas durante esta etapa sin estas evidencias, sugiriendo períodos de inyección de la cámara traquítica por magmas basálticos, y períodos en que la cámara evolucionó como un sistema cerrado. 
La Ignimbrita Portezuelo no muestras signos de hibridación, aunque la erupción explosiva pudo haber estado desencadenada por la inyección de magma básico en la cámara traquítica del Payún Matrú. Las lavas que le siguieron, de la unidad Traquiandesitas Postcaldera, presentan en su mayoría evidencias de mezcla de magmas (mingling e hibridación). Esto no es así en las Traquitas Post-caldera, en donde no se encuentran estas evidencias y el magma traquítico es producto de diferenciación sin recarga de magmas básicos en la cámara del Payún Matrú. 


\section{Abstract}

The Payún Matrú is volumetrically the most important volcano in the Payún Matrú Volcanic Field (PMVF). It is a shield-like composite volcano with a summit caldera $8 \mathrm{~km}$ wide. The PMVF includes also the Payún Liso stratovolcano and basaltic fields. The PMVF is located in southern Mendoza province ( $\left.36^{\circ}-37^{\circ} \mathrm{S}\right)$, and it belongs to the Payenia Basaltic Province, or Payenia. Payenia ( $34^{\circ}-38^{\circ}$ S, south-centre Mendoza) of Pliocene-Holocene age, comprises mostly alkaline basalts. It is located in the back-arc of the Southern Volcanic Zone of Central Andes and, besides of the PMVF, it comprises the Llancanelo Volcanic Field (LLVF) along other scattered volcanic centers north of LLVF, and the Auca Mahuida shield volcano south of PMVF.

The PMVF presents alkaline lavas and pyroclastic rocks, ranging from basalts and trachybasalts in the basaltic fields, to trachytes in the Payún Matrú and Payún Liso volcanoes. The PMVF is Pleistocene-Holocene and presents two basaltic fields adyacents to Payún Matrú, distributed in a E-W zone, and interrupted by it. The purpose of this work is to study magma mixing processes that may have occurred in Payún Matrú, between the trachytic magmas located in the magma chamber of the volcano and basaltic magmas. The hypothesis consists in that the relatively deep sourced basaltic magmas could not erupt in the Payún Matrú volcano, due to the entrapment of this magmas in the Payún Matrú magma chamber. In consecuence, magma mixing between basaltic and trachytic magmas occurred.

Before focusing this work in magma mixing processes, and due to the limited and outdated knowledge of the PMVF, a geologic map in 1:60,000 scale toghether with a new stratigraphic scheme proposal were performed. Also, regular tasks of petrography, bulk rock and mineralogical geochemical analysis, $\mathrm{Sr}$ and $\mathrm{Nd}$ isotopy and radimetric datings were performed, to complete the characterization of Payún Matrú and basaltic fields rocks. An structural analysis of scoria cones and fissural eruptions was performed, with the purpose to infer the regional stress field. The Payún Liso volcano was not studied in detail, since it is not the subject of the present work.

An important explosive eruption took place during the evolution of Payún Matrú, which deposited ignimbrites $35 \mathrm{~km}$ away from the volcano (Portezuelo Ignimbrite), and lead to the collapse of the volcanic edifice and formation of Payún Matrú caldera. The Portezuelo Ignimbrite was used as a guide horizon due to its areal extension and easy recognition, and 
because it represents an unique event in PMVF. The PMVF was separated in three stages: pre- syn- and post-caldera.

The pre-caldera stage of PMVF is the longest, lasting around $600 \mathrm{ka}$, being the oldest rock dated in $700 \mathrm{ka}$. In this stage, an intense volcanism occurred in Payún Matrú, Payún Liso and basaltic fields. The pre-caldera rocks of Payún Matrú were grouped in the Pre-caldera Trachytes unit, which is basically trachytic but presents a wide range in compositions. The basaltic fields rocks are represented by the Pre-caldera Basalts unit, which outcrop mainly east of Payún Matrú. The syn-caldera stage is the shortest, and it is represented by the Portezuelo Ignimbrite and by the Payún Matrú caldera. The radimetric dating of this unit was not possible, although its age is constrained between 148 and $82 \mathrm{ka}$.

The post-caldera stage continued with activity in both the basaltic fields and Payún Matrú, but probably not in Payún Liso. The first lavas of this stage in Payún Matrú are of intermediate composition, forming the Post-caldera Trachyandesites unit. Afterwards, there was an abrupt change in the composition of the emitted products, with eruptions of trachytic compositions, grouped in the Post-caldera Trachytes unit. This unit presents lavas of variable morphology along with pyroclastic pumiceous fall deposits, and therefore it was divided in three lithofacies: Blocky Trachytes, Pumiceous Cones and Vitreous Trachytes. Basaltic eruptions continued east and west of Payún Matrú caldera, grouped in the Post-caldera Basalts I and II units, and with greater intesity in the western zone.

Bulk rock geochemical and isotopic analysis allowed to infer the source and evolution of the magmas. These analysis suggest a mantle source of the magmas, in the garnet field or transisional to the spinel field, with depths of fusion greater than $60 \mathrm{~km}$. The erupted basalts are not primary magmas, having a residence period in the lower crust or Mohorovicic discontinuity during which they fractionated. Basaltic differentiation produced the trachytic magmas of Payún Matrú.

Through textural and mineralogical study of PMVF rocks, magma mingling textures were recognized, and mineralogical disequilibrium textures were identified, which indicate magma mixing processes and hybridization. In several lavas of the pre-caldera stage of Payún Matrú, mineralogical compositions and textures, which indicate mixing between basaltic and trachytic magmas, were found. There are also other lavas in this stage without these evidences, suggesting periods of injection of the trachytic magma chamber by basaltic magmas, and periods in which the magma chamber evolved as a closed system.

The Portezuelo Ignimbrite does not show evidences of hybridization, although the explosive eruption may have been triggered by a basaltic injection in the Payún Matrú trachytic chamber. Most of the Post-caldera Trachyandesites unit lavas have mingling and mixing evidences. This is not so in the latest Post-caldera Trachytes, in which the trachytic magma is a product of differentiation without recharge of the Payún Matrú chamber by basic magmas. 


\section{Introducción}

El volcán Payún Matrú forma parte del Campo Volcánico Payún Matrú (CVPM) (Bermúdez y Delpino, 1989), y es el volcán más importante en cuanto a volumen en dicho campo. El CVPM abarca, además, al volcán Payún Liso y a dos campos basálticos situados al este y oeste del Payún Matrú, e interrumpidos por el mismo. El CVPM se ubica en el centro-sur de la provincia de Mendoza, entre $36^{\circ}-37^{\circ} \mathrm{S}$ y $68^{\circ} 30^{\prime}-70^{\circ} \mathrm{O}$, abarcando un área de $5.200 \mathrm{~km}^{2}$ (Bermúdez et al., 1993), y forma parte de la Provincia Basáltica de Payenia (Polanski, 1954), de edad Pliocena-Holocena (Bermúdez y Delpino, 1989).

El volcán Payún Matrú es principalmente traquítico y presenta en su cúspide una caldera de forma aproximadamente circular, de $8 \mathrm{~km}$ de diámetro. Una característica importante y la cual es el motivo del presente trabajo, es que la caldera se ubica entre dos campos basálticos adyacentes, mientras que en el interior de la misma no se encuentran basaltos (Fig.1). Este particular diseño, en el cual magmas basálticos de proveniencia relativamente profunda son interrumpidos por la presencia de un volcán con composiciones más evolucionadas, y cuyos productos provendrían de una cámara magmática relativamente somera, sugieren la presencia de procesos de mezcla de magmas en el CVPM.

La mezcla de magmas de composiciones contrastantes o no, es un fenómeno ígneo frecuente, tanto en rocas volcánicas como en plutónicas (Kusçu y Floyd, 2001; Hibbard, 1981; Murphy et al., 2000). En ocasiones la mezcla puede llevarse a cabo por completo, dando lugar a la formación de rocas híbridas de una composición intermedia entre ambos extremos composicionales. En estos casos, en los cuales no se preservan parcelas de los magma originales sino que resulta en una roca de aspecto homogéneo, el proceso se denomina mixing. En otros casos, el proceso de mezcla de magmas es incompleto, preservándose parcelas de magma de una determinada composición en forma de enclaves o simplemente como inclusiones de formas irregulares, dentro de un magma huésped de otra composición diferente (proceso denominado mingling) (Sparks y Marshall, 1986; Hibbard, 1995; Best y Christiansen, 2001).

La mezcla de magmas puede ser un proceso significativo en la evolución de un volcán, no sólo porque produce una mayor variedad litológica, sino porque además puede desencadenar una erupción, generalmente explosiva (Cas y Wright, 1987; Leonard et al., 2002; Snyder, 2000; Shane et al., 2007; Mandeville et al., 1996). La inyección de un magma básico en una cámara magmática más evolucionada puede iniciar erupciones por una serie de mo- 


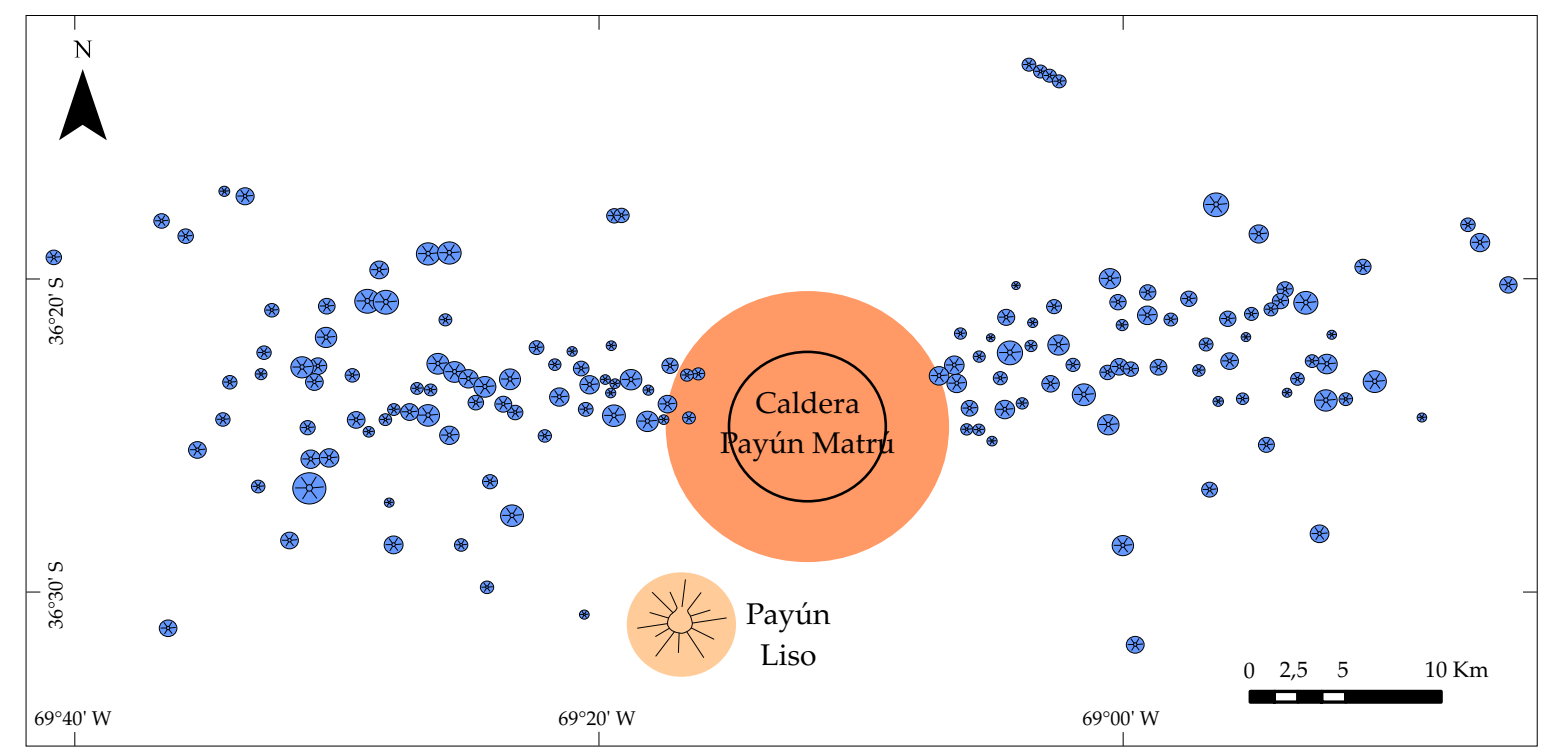

Figura 1: Diagrama esquemático en donde se muestra a la caldera del Payún Matrú, junto con numerosos conos de escoria (en azul) al este y oeste de la misma, localizados en una franja amplia en sentido este-oeste. El estratovolcán Payún Liso se encuentra al sudoeste del Payún Matrú.

tivos, como son la convección y exsolución de volátiles del magma más evolucionado y de menor temperatura, lo cual aumenta la presión interna de la cámara, produciendo la erupción. También puede deberse a un aumento en el volumen de la cámara magmática por la inyección de otro magma, fracturando el techo de la misma si se supera la resistencia de la roca de caja (Cas y Wright, 1987). La liberación de la presión confinante conlleva, a su vez, a una mayor exsolución de volátiles y al crecimiento de las burbujas, pudiendo desencadenar también una erupción explosiva. Si el contenido de volátiles de los magmas involucrados en la mezcla no es lo suficientemente alto, la erupción resultante es efusiva, sin la producción de piroclastos (Cas y Wright, 1987).

\section{Hipótesis de trabajo}

La hipótesis de trabajo se basa en suponer que la erupción explosiva que produjo las ignimbritas ampliamente distribuidas del Payún Matrú, fue consecuencia de la introducción de un magma basáltico en la cámara magmática traquítica somera del volcán. El magma basáltico, a mayor temperatura, habría provocado un aumento de la energía interna en la cámara magmática, activando corrientes convectivas dentro de la misma y favoreciendo la exsolución de los gases. La mezcla de magmas de composiciones tan disímiles produjo, a su vez, un aumento en la presión interna dentro de la cámara del Payún Matrú. Cuando la presión interna sobrepasó la resistencia del techo de la cámara magmática, se produjo la 
ruptura de la misma y la consecuente descompresión del magma, liberando la fase volátil y produciendo una violenta explosión que vació parcialmente a dicha cámara. La caldera se habría producido como consecuencia del colapso del techo de la cámara magmática.

\section{Objetivos}

El objetivo general de la tesis consiste en analizar la posiblilidad de la mezcla entre los magmas basálticos y traquíticos del Payún Matrú, así como su incidencia en la formación de las rocas piroclásticas que produjeron el colapso de la caldera.

Como objetivos particulares, cabe mencionar:

- La actualización del esquema estratigráfico previo (Llambías, 1966; González Díaz, 1972), y la elaboración de un mapa detallado de las diferentes unidades y litofacies del Payún Matrú y sus alrededores.

- La realización de un estudio mineralógico-textural de las rocas volcánicas del Payún Matrú y, en particular, de las rocas piroclásticas a fin de determinar si contienen evidencias de la mezcla de magmas.

- El estudio del volcanismo basáltico a fin de comprender la importancia de su distribución regional y su relación con el volcanismo traquítico del Payún Matrú.

- El análisis de las litofacies de las rocas piroclásticas, para comprender los mecanismos de transporte y de depositación que tuvieron lugar.

- El análisis de la relación del magmatismo del CVPM con la subducción andina. 


\section{Capítulo 1}

\section{Antecedentes}

\subsection{Marco general}

Si bien el desarrollo del arco volcánico Andino en Sudamérica es de conocida importancia, el volcanismo de retroarco Cuaternario no posee el mismo grado de desarrollo, estando éste más restringido al sur del segmento de subducción subhorizontal pampeano (al sur

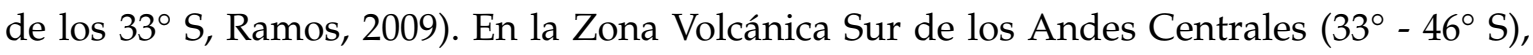
se desarrolló un extenso volcanismo en el retroarco andino, específicamente en el extremo norte de dicha zona $\left(34^{\circ}-38^{\circ} \mathrm{S}\right)$. Este volcanismo, principalmente de basaltos alcalinos, fue agrupado en la denominada Provincia Basáltica Payenia, o simplemente Payenia (Polanski, 1954), y posteriormente denominada Provincia Basáltica Andino-Cuyana (PBAC) por Bermúdez y Delpino (1989). Payenia se ubica en el centro-sur de la provincia de Mendoza y norte de Neuquén, y fue asignada al Plioceno-Holoceno (Bermúdez y Delpino, 1989).

Payenia es más joven que 5 Ma, de acuerdo a Llambías et al. (2010), o 2 Ma de acuerdo a Ramos y Folguera (2010), y es la provincia basáltica de retroarco de esta edad más grande de Sudamérica (Folguera et al., 2009), cubriendo un área de 15.900 km² (Bermúdez et al., 1993). Payenia se ubica a aproximadamente $500 \mathrm{~km}$ de la fosa oceánica, paralelamente al frente volcánico activo, y posee un ancho de $130 \mathrm{~km}$ (Llambías et al., 2010) (Fig. 1.1). En Payenia se pueden distinguir tres sectores: un sector septentrional que incluye relativamente pocos centros volcánicos monogenéticos, entre $34^{\circ}$ y $34^{\circ} 30^{\prime}$ S; un sector central extenso en donde se encuentran dos campos volcánicos importantes (Llancanelo y Payún Matrú), entre los $34^{\circ} 30^{\prime}$ y 37³0' S; y un sector sur que incluye al escudo basáltico de Auca Mahuida, al norte de Neuquén (Ramos y Folguera, 2010). La ubicación en Payenia de Auca Mahuida es variable según los autores: Bermúdez et al. (1993) y Bermúdez y Delpino (1989) no lo incluyen como parte de lo que denominan PBAC; Llambías et al. (2010) lo ubica en Payenia con dudas, y Ramos y Folguera (2010) sí lo incluyen. El Macizo del Tromen, situado al NO del escudo Auca Mahuida en la provincia de Neuquén, no es considerado por algunos autores como parte de Payenia (Llambías et al., 2010), aunque sí lo es para Ramos y Folguera (2010). 


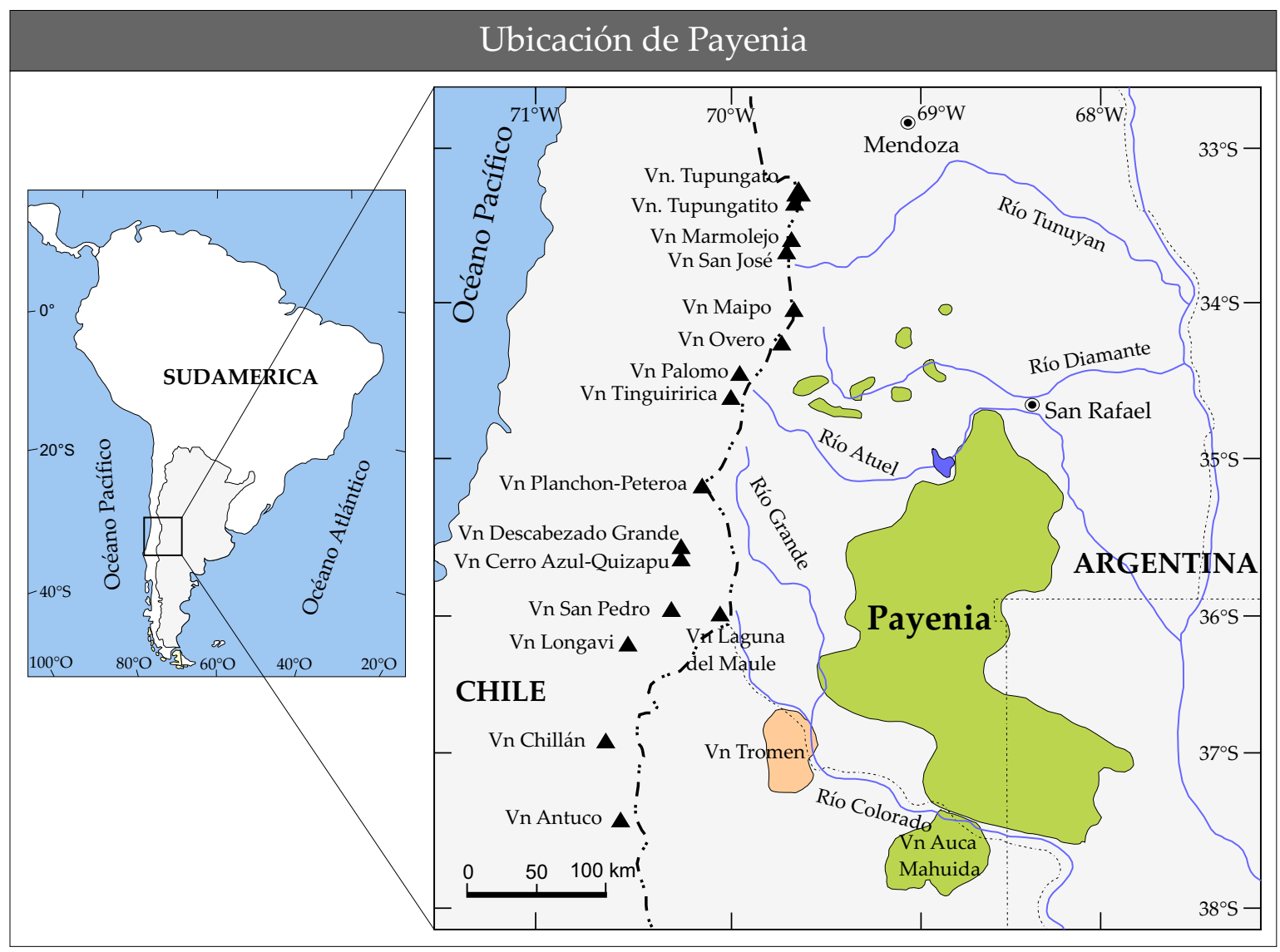

Figura 1.1: Ubicación geográfica del campo basáltico de Payenia. El volcán Tupungato cerca de los $33^{\circ} \mathrm{S}$ marca el comienzo hacia el sur de la Zona Volcánica Sur. En triángulos negros se marcan volcanes del arco volcánico activo. Extensión de Payenia en base a Kay et al. (2006) y Ramos y Folguera (2010). Límite suroeste de Payenia en línea punteada roja, según Llambías et al. (2010). Volcanes del arco según (Sruoga et al., ined).

La actividad ígnea de arco y retroarco en el sur de Mendoza y norte de Neuquén fue importante desde el Mioceno temprano, aunque con una interrupción en el Mioceno tardíoPlioceno temprano (Llambías et al., 2010). En el Holoceno el volcanismo posee una menor extensión que en el Pleistoceno, y se restringe a la zona de los volcanes Payún Matrú y Tromen (Llambías et al., 2010). El volcanismo de retroarco en el norte neuquino desaparece al sur del volcán Auca Mahuida, coincidiendo con el lineamiento Cortaderas (Ramos, 1978) o con el Cinturón Tromen-Domuyo (Llambías et al., 2010). La actividad en Payenia es contemporánea con el volcanismo de arco con fusión de la corteza inferior debajo de la Cordillera Principal en el Cuaternario (Ramos y Folguera, 2010). El volcanismo de arco esta expresado por abundantes riolitas, ignimbritas y calderas a lo largo del arco principal durante el Pleistoceno (Hildreth et al., 1984). 


\subsubsection{Regiones morfoestructurales}

Entre $\operatorname{los} 35^{\circ}$ y $38^{\circ} \mathrm{S}$, de oeste a este, se encuentran cinco regiones morfoestructurales bien definidas: la Cordillera de La Costa, el Valle Central Chileno, el Cinturón orogénico, la Faja Deprimida Central y el antepaís (Bermúdez y Delpino, 1989; Llambías et al., 2010). El antepaís está representado por el Bloque de San Rafael, con mayores afloramientos en el límite norte de Payenia. Comprende una serie de unidades diversas, desde sedimentarias, metamórficas e ígneas, que abarcan un amplio espectro de edades: desde el Mesoproterozoico hasta el Triásico inferior alto (Cingolani et al., 2001). En el antepaís, y durante el Mioceno tardío, se desarrollaron volcanes poligénicos con afinidad calcoalcalina, como el Plateado, Nevado, Pelado, Chorreado y Sierra Chorreada entre otros (Llambías et al., 2010) (Fig. 1.2).

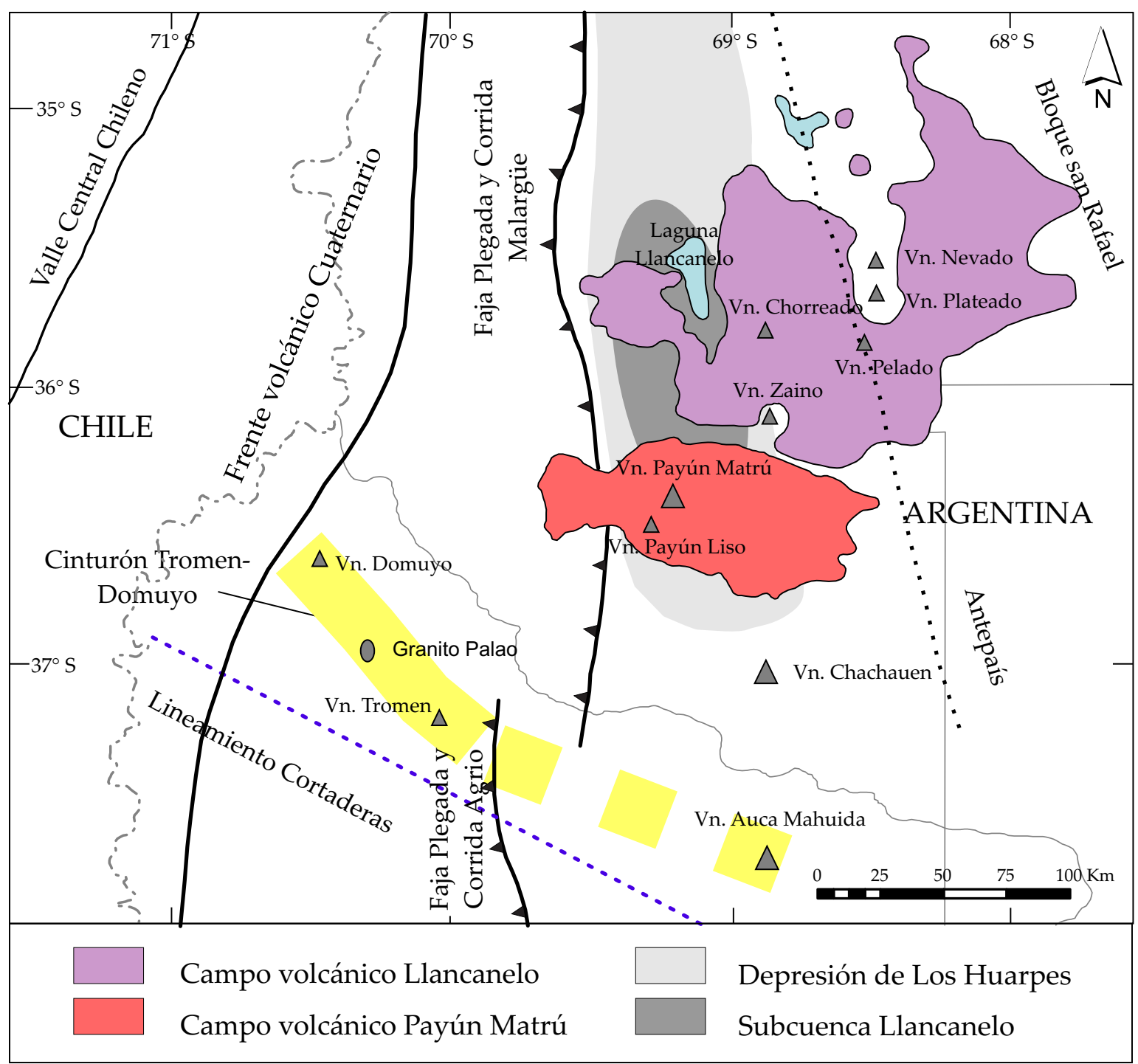

Figura 1.2: Mapa de Payenia con las regiones morfoestructurales. Basado en Bermúdez et al. (1993), Kay et al. (2006) y Llambías et al. (2010). 
Payenia se encuentra delimitada por dos regiones morfoestructurales bien diferenciables: al oeste el cinturón orogénico, y al este el antepaís. Payenia abarca una región morfoestructural entre ambas, en la denominada Depresión Central o Faja Deprimida Central de orientación N-S, y se extiende sobre el antepaís al este y muy restringidamente sobre la región oriental del cinturón orogénico (Llambías et al., 2010) (Fig. 1.2). La Faja Deprimida Central incluye la Depresión de los Huarpes y la Subcuenca de Llancanelo, la cual originalmente se incluía en la Depresión de los Huarpes. La Faja Deprimida Central consiste en una faja paralela a los Andes, limitada al oeste por las fajas plegadas y corridas de Malargüe al norte y Agrio al sur, y limitada al este por el antepaís (Fig. 1.2). Abarca desde los $35^{\circ} \mathrm{S}$ hasta el volcán Auca Mahuida, aunque al sur de los $36^{\circ}$, en donde se encuentra el campo volcánico del Payún Matrú, pierde definición por no aflorar el antepaís al este (Llambías et al., 2010). En la Figura 1.2 se esquematizan la Depresión de los Huarpes y la Subcuenca Llancanelo, continuándose la Faja Deprimida Central hacia el sur.

Principalmente al norte del Payún Matrú, se encuentra la Depresión de los Huarpes (Polanski, 1954), con relleno sedimentario continental del Terciario y Cuaternario. El espesor sedimentario del Cenozoico en la Depresión de los Huarpes es de alrededor de 1000 m (Ostera y Dapeña, 2003). En la región al sur del Río Salado en la Depresión de los Huarpes, el drenaje es endorreico y ocupado por la laguna Llancanelo en su parte más deprimida. Por tal motivo, esta zona se la denominó Subcuenca Llancanelo (Llambías et al., 2010). Por otra parte, al sur del Payún Matrú no tuvo lugar la sedimentación cenozoica, y los centros volcánicos como el Auca Mahuida y Chachauén se asientan en discordancia sobre rocas Cretácicas y Paleógenas, mientras que otros centros menores, como el volcán Los Loros, se asientan sobre depósitos de terrazas Cuaternarias (Llambías et al., 2010). El Payún Matrú marca una diferencia importante en la Faja Deprimida Central por dos motivos: por desaparecer al sur del mismo la sedimentación Cuaternaria, y por perder definición el límite este de la faja, al no estar claro el límite del antepaís.

El Cinturón orogénico comprende la región montañosa de los Andes con la Cordillera Principal y las Fajas Plegadas y Corridas de Agrio y Malargüe (Llambías et al., 2010) (Fig. 1.2). La Cordillera Principal posee actividad volcánica del arco actual sobre un basamento de rocas ígneas y sedimentarias paleozoicas, mezosoicas y terciarias (Bermúdez y Delpino, 1989; Tormey et al., 1991). En cuanto al arco volcánico Pleistoceno-Holoceno, éste se extiende a lo largo del límite Argentino-Chileno y a 280-320 km de la fosa oceánica. La mayoría de los centros volcánicos se ubican al oeste o sobre el límite, como los volcanes Azufre-PlanchónPeteroa, complejo de la caldera Diamante-Maipo, Descabezado Grande, Quizapu, Azul, San Pedro, Longavi, Antuco, Chillán y la caldera Calabozos (Bermúdez y Delpino, 1989; Tormey et al., 1991) (Fig. 1.1). Los centros volcánicos del arco andino Plioceno-Pleistoceno inferior están localizados inmediatamente al este (Bermúdez y Delpino, 1989). El Tupungato marca el limite norte de la Zona Volcánica Sur (Fig. 1.1), que pasa hacia el norte a la zona de subducción subhorizontal Pampeano (Ramos, 2009). 
La Faja Plegada y Corrida de Malargüe se extiende desde el sur de Mendoza hasta la latitud del volcán Maipo ( $34^{\circ} 10^{\prime}$ S) al pie de los Andes, y tuvo una intensa actividad durante el Mioceno tardío (Silvestro y Atencio, 2009). La Faja Plegada y Corrida Agrio tuvo un pico de deformación en el Cretácico tardío, y fue reactivada también compresivamente en el Mioceno tardío (Zapata y Folguera, 2005).

\subsubsection{Lineamiento Cortaderas-Cinturón volcánico Tromen-Domuyo}

El lineamiento Cortaderas fue propuesto por Ramos (1978) para explicar las diferencias en la geología del sur de Mendoza y norte de Neuquén. Este lineamiento no posee una expresión morfológica clara en superficie, presenta una orientación NO y su traza pasaría por el sur de la Cordillera del Viento, por Chos Malal y por el sur del escudo basáltico de Auca Mahuida (Fig. 1.2). El retroarco puede dividirse en dos por este lineamiento, ya que al sur y norte del mismo existen importantes diferencias (Kay et al., 2006):

- al norte del lineamiento son abundantes las rocas volcánicas del retroarco Mioceno al Holoceno.

- la extensión Mesozoica es menos importante al norte del lineamiento.

- la deformación Neógena contraccional es más importante al norte del lineamiento.

- al sur del lineamiento las rocas de retroarco Miocenas a Holocenas están ausentes.

El lineamiento Cortaderas constituye, esencialmente, el limite entre el volcanismo Neógeno de retroarco, y marca el límite sur de la zona de subducción somera del Mioceno (Kay et al., 2006).

Llambías et al. (2010) proponen la existencia del cinturón volcánico Tromen-Domuyo, ubicado inmediatamente al norte del lineamiento Cortaderas, y compartiendo la misma orientación NO (Fig. 1.2). Posee un ancho de $40 \mathrm{~km}$ y contiene a los volcanes Tromen, Tilhue y Domuyo, junto con el lacolito monzogranítico Palao y conos de escoria basálticos, todos ellos de edad Pleistocena. En el cinturón volcánico Tromen-Domuyo es donde coexisten las fajas plegadas y corridas de Agrio y Malargüe (Llambías et al., 2010). No está claro si el Cinturón volcánico Tromen-Domuyo se continúa hasta el volcán Auca Mahuida, pudiendo estar este último relacionado al volcanismo de Payenia paralelo al arco, o al cinturón previamente mencionado (Llambías et al., 2010).

\subsection{Evolución volcano-tectónica entre $\operatorname{los} 35^{\circ}$ y $38^{\circ} \mathrm{S}$}

En Oligoceno tardío a Mioceno temprano (24-20 Ma) se produjeron cambios importantes en el régimen de subducción, ya que la placa de Nazca reemplazó a la Placa de Farallón, cuando esta fue consumada por la subducción (Ramos y Kay, 2006). En los andes neuquinos 
(y sur de Mendoza), existió un régimen extensional el cual se extendió al retroarco, asociado con un roll-back negativo de la placa oceánica (Kay et al., 2006; Ramos y Kay, 2006). Una evidencia de esto es la erupción de basaltos alcalinos miocenos, con una afinidad geoquímica de intraplaca, a una distancia de hasta $550 \mathrm{~km}$ de la trinchera (Kay et al., 2006; Ramos y Kay, 2006). Al norte del lineamiento Cortaderas, la extensión se restringió al eje del arco volcánico (Ramos y Kay, 2006).

La evolución Neógena comenzó con una compresión importante en el Mioceno medio a tardío, momento en que cesa el régimen extensional y comienza un régimen contraccional, por somerización de la placa de Nazca a los 19-16 Ma (Kay et al., 2006). Esta etapa contraccional perduró hasta el Mioceno tardío, finalizando a los 4 Ma (Kay et al., 2006). En este período se formaron la Faja Plegada y Corrida de Malargüe y los volcanes andesíticos con afinidad geoquímica de arco de edad Miocena, los cuales cubren discordantemente a los depósitos del Mesozoico (Ramos y Folguera, 2005, 2010).

Al norte y sur del lineamiento Cortaderas hubo diferencias importantes en cuanto al magmatismo, la deformación y la sedimentación (Ramos y Kay, 2006). Al norte del lineamiento, la actividad volcánica fue mucho más importante, y la deformación compresional en la Faja Plegada y Corrida de Malargüe se propagó hacia el este, en conjunto con la depositación de sedimentos sinorogénicos en la Cuenca de Río Grande (o Depresión de los Huarpes) (Ramos y Kay, 2006). En cambio, al sur del Lineamiento Cortaderas, tanto la deformación compresiva como el magmatismo estuvieron más restringidos. Allí, el magmatismo tuvo lugar en el arco volcánico, y la deformación compresiva invirtió la Cuenca de intra-arco de Cura Mallin ubicada en la Cordillera Principal y, en menor medida, reactivó la Faja Plegada y Corrida de Agrio, cuya etapa principal de deformación fue en el Cretácico (Ramos y Kay, 2006).

En el retroarco, entre los 16 y $14 \mathrm{Ma}$, no hubo prácticamente actividad volcánica (Kay et al., 2006). Entre los 14 y $10 \mathrm{Ma}$, el magmatismo de arco en el centro y sur de Mendoza se propagó hacia el este, con erupciones andesíticas y deformación contraccional en el retroarco, junto con un engrosamiento cortical (Kay et al., 2006; Ramos y Kay, 2006). Entre los 10.7 a 7 Ma cesó nuevamente el volcanismo en el retroarco (Kay et al., 2006). En el Mioceno tardío, entre los 8 y $5 \mathrm{Ma}$, es cuando se produjo el máximo desarrollo de la subducción somera, con la generación de volcanes compuestos con afinidad de arco magmático en el retroarco (Kay et al., 2006). Un ejemplo es el complejo volcánico de Chachauén, de edad entre 7,3 y $4,8 \mathrm{Ma}$, ubicado a $500 \mathrm{~km}$ de la fosa oceánica, con magmas que indican una componente de subducción (Kay, 2002; Kay et al., 2004, 2006). Otros volcanes originados de forma similar y con la misma afinidad geoquímica, son el Cerro Nevado y Plateado, ubicados más al norte que el Chachauén (Fig. 1.2).

En esta etapa compresional Miocena se invirtieron las viejas estructuras extensionales de la Cuenca Neuquina, y el Macizo del Tromen fue levantado entre los 12 y 4 Ma (Kay et al., 2006). La Cordillera Principal presentó un sistema de corrimientos con vergencia al 
este y, además, la deformación fue migrando hacia el este, estando relacionada la última etapa de deformación en el Mioceno tardío con el levantamiento del Bloque de San Rafael (Ramos y Folguera, 2005, 2010). La falla que produjo el levantamiento del Bloque San Rafael se encuentra expuesta a la altitud de la ciudad homónima, y se continúa hacia el sur, donde es cubierta por basaltos en las cercanías del Cerro Nevado (Ramos y Folguera, 2010). Los modelos de elevación digital muestran que el Cerro Nevado, el Payún Matrú y Auca Mahuida, a pesar de la altura debida al edificio volcánico, poseen sus bases construidas sobre un basamento levantado (Ramos y Folguera, 2010).

Posteriormente, en el Mioceno tardío-Plioceno, se produjo una extensión generalizada y el Bloque San Rafael, previamente levantado, fue afectado por fallas normales. En el Plioceno-Holoceno existió nuevamente a un régimen de subducción normal por el empinamiento de la placa de Nazca, y cesó la compresión, pasándose a un régimen extensional (Kay et al., 2006; Ramos, 1978). Durante este período, fue extenso el volcanismo máfico al norte del lineamiento Cortaderas, desde el arco al retroarco lejano, con magmas alcalinos de intraplaca en el escudo basáltico de Auca Mahuida y el resto de Payenia (Bermúdez et al., 1993; Kay et al., 2004, 2006; González Díaz, 1972; Llambías, 1966). La deformación extensional se propagó desde el antepaís hacia los pies de la Cordillera Principal, con la formación de la fosa de Locopué, el desarrollo de fallas normales rodeando al Macizo del Tromen y el colapso del Bloque de San Rafael previamente levantado (Bermúdez et al., 1993; Kay et al., 2006; Ramos y Kay, 2006). Al sur del lineamiento Cortaderas la deformación extensional estuvo más restringida, limitándose al arco y zona occidental del retroarco (Ramos y Kay, 2006).

El último evento distensivo en el Holoceno se localiza en el Payún Matrú, donde las erupciones se encuentran a lo largo de fracturas $\mathrm{N} 60^{\circ} \mathrm{O}$ o E-O, o simplemente como conos dispersos (Bermúdez et al., 1993). La cuenca de Río Grande (Ramos y Kay, 2006) o subcuenca Llancanelo (Llambías et al., 2010) fue afectada en el Plio-Cuaternario por fallas extensionales, rellena con depósitos sinorogénicos (Bermúdez y Delpino, 1989; Ramos y Kay, 2006). Esta presenta secuencias Paleógenas y Neógenas (Miocenas), cubiertas en discordancia por depósitos Pliocenos-Cuaternarios, actualmente con subsidencia activa en la laguna de Llancanelo, la cual es bordeada al este por una falla normal (Ramos, 1978).

En el margen NE del Bloque San Rafael, en el frente orogénico actual, se encuentran estructuras del Cuaternario tardío caracterizadas por desplazamientos importantes de rumbo y contracción (Ramos y Folguera, 2005). La faja plegada y corrida del Cretácico y Mioceno, actualmente inactiva, presenta signos interpretados como extensión en el PliocenoPleistoceno por Ramos y Kay (2006), aunque de acuerdo a Galland et al. (2007) existió un régimen compresivo en el volcán Tromen. 


\subsection{Información Geofísica}

En la zona de estudio y alrededores se han realizado estudios geofísicos, los cuales permiten hacer inferencias acerca de las condiciones y profundidades de la corteza y el manto. Los terremotos en la zona de Wadatti-Benioff e imágenes sísmicas, revelan que la inclinación promedio de la placa de Nazca en las latitudes de Payenia es de $25^{\circ}$ desde los 50 a $100 \mathrm{~km}$ de profundidad de la placa, y de $40^{\circ}$ desde 100 a $200 \mathrm{~km}$ de profundidad de la misma (Burd et al., 2008). De acuerdo con este esquema, la profundidad de la placa de Nazca proyectada por debajo del Payún Matrú, sería de 300 km o más (Burd et al., 2008). Midiendo la conductividad eléctrica en una transecta a los $36,7^{\circ} \mathrm{S}$, entre $\operatorname{los} 67^{\circ}$ y $70^{\circ} \mathrm{O}$, se puede observar una zona conductiva de alto ángulo debajo del CVPM. Esta zona presenta una raíz a mas de $200 \mathrm{~km}$ de profundidad, justo por encima de la proyección de la placa de Nazca. Esto sugeriría que el Payún Matrú esta muestreando el manto a más de 200 km de profundidad (Burd et al., 2008).

En otros estudios sísmicos de la Zona Volcánica Sur, puede distinguirse a la placa oceánica que subducta hasta una profundidad de $100 \mathrm{~km}$, la cual se correlaciona perfectamente con los sismos de la zona de Benioff, por debajo del arco volcánico activo (Yuan et al., 2006). A $100 \mathrm{~km}$ de profundidad, directamente al este de la placa subductada, se visualiza un rasgo subhorizontal el cual podría pertenecer a un remanente de la placa oceánica de subducción somera, posiblemente del Mioceno tardío (Yuan et al., 2006). En la sección estudiada, la discontinuidad de Mohorovicic se distingue a una profundidad de 30 a $40 \mathrm{~km}$. La corteza tiene $40 \mathrm{~km}$ de espesor en el arco y transición al retroarco, y se adelgaza a un espesor de $35 \mathrm{~km}$ en el antearco y en la cuenca neuquina (Yuan et al., 2006).

Gilbert et al. (2006) estudiaron las velocidades sísmicas subcorticales en la zona de los $36^{\circ} \mathrm{S}$, revelando la presencia de zonas de baja velocidad interpretadas como parcelas de fundidos parciales debajo de los centros volcánicos de retroarco. Esta zona de baja velocidad posee $20 \mathrm{~km}$ de espesor, entre los $40 \mathrm{~km}$ y $60 \mathrm{~km}$ de profundidad, y tiene al menos $250 \mathrm{~km}$ de ancho, coincidiendo con la extensión de las erupciones Cuaternarias en el retroarco. Esta zona de bajas velocidades sísmicas podría ser la base de la litosfera en la zona de retroarco (Gilbert et al., 2006). Coincidente con el área de baja velocidad sísmica cortical en el retroarco, se encuentra una zona con corteza atenuada (discontinuidad de Mohorovicic hasta $30 \mathrm{~km}$ de profundidad) y de 200-250 km de ancho (Wagner et al., 2005; Gilbert et al., 2006; Ramos y Folguera, 2010).

Otra fuente de información sobre la geometría de la litósfera oceánica subductada proviene de modelos tomográficos del manto, realizadas a partir de perturbaciones de las ondas P en el mismo. Aragón et al. (2011) presentan, para la zona entre la Patagonia norte y la zona de subducción somera pampeana, secciones tomográficas en las cuales se advierten diferencias con la latitud. Al sur del CVPM, a una latitud de aproximadamente $40^{\circ} \mathrm{S}$, las tomografías indican la existencia de una zona de subducción normal, con la placa oceánica 
distinguible hasta una profundidad de alrededor de $350 \mathrm{~km}$ (Aragón et al., 2011). Al norte del CVPM, a una latitud de aproximadamente $34^{\circ} \mathrm{S}$, las tomografías muestran a la placa oceánica con subducción somera. El CVPM estaría situado entonces, en la transición entre un régimen de subducción somera al norte, y uno de subducción normal al sur.

\subsection{Volcanismo en Payenia}

Previamente a la actividad volcánica de edad Pliocena-Holocena de Payenia, hubo un pico de actividad en el Mioceno medio a superior, el cual dio origen al plateau basáltico de Palaoco (Narciso et al., 2001). Este se encuentra ubicado en una posición de retroarco al igual que los basaltos posteriores (Llambías et al., 2010). Sus afloramientos son extensos en el sur de Mendoza y el norte de Neuquén, desde la cordillera Andina hasta el Bloque de San Rafael en el antepaís (Llambías et al., 2010). Durante el Mioceno tardío y el Plioceno temprano, entre 8 y $5 \mathrm{Ma}$, hubo un periodo sin registro de actividad volcánica en el retroarco, interpretado como un período con subducción somera transitorio, durante el cual se formaron los volcanes Chachauén y Plateado, ambos con una afinidad geoquímica de arco (Kay, 2002; Kay et al., 2004, 2006; Ramos y Kay, 2006). Ramos (2009) lo denominó subducción plana de Payenia, y le asignó una edad entre 13 y 5 Ma.

Posteriormente, ocurrió un pico de actividad volcánica en el Plioceno tardío-Holoceno con el desarrollo de un extenso volcanismo basáltico alcalino, activo desde hace 5 Ma y abarcando un área de $15.900 \mathrm{~km}^{2}$ (Bermúdez y Delpino, 1989; Bermúdez et al., 1993; Folguera et al., 2009; Llambías et al., 2010). Otros autores estiman una edad más joven para el comienzo de esta actividad volcánica, de 2 Ma (Ramos y Folguera, 2010). El volcanismo durante el Holoceno está más restringido que en el Pleistoceno, habiendo signos de actividad en el volcán Tromen, Payún Matrú y en el Río Salado sobre la Faja Plegada y Corrida de Malargüe (Llambías et al., 2010).

Payenia contiene alrededor de 400 conos de escoria (Bermúdez et al., 1993), cuya existencia sugiere que sobre esta región actuaron esfuerzos extensionales en el Plioceno-Pleistoceno (Llambías et al., 2010). La alineación de conos en dirección ONO, oblicuas al eje de la cordillera, es frecuente (Llambías et al., 2010). La química y estilo eruptivo es compatible con un régimen tectónico transpresional que se inició en el Plioceno mientras se desarrollaba una convergencia más oblicua en el margen andino (Kay, 2002; Kay et al., 2004). Este cambio en los esfuerzos se evidencia en el desplazamiento rotacional hacia el oeste del arco Plioceno a reciente, entre los $38^{\circ}$ y $40^{\circ} \mathrm{S}$ (Kay, 2002; Kay et al., 2004).

La afinidad geoquímica de los basaltos de Payenia es mayormente de intraplaca (Kay, 2002; Kay et al., 2004, 2006). Las rocas corresponden a traquibasaltos, basaltos y basanitas en ese orden de abundancia, pertenecientes a la serie alcalina, y son el resultado de un bajo grado de fusión parcial de una fuente mantélica con granate (Bertotto et al., 2009) y enriquecida (Kay, 2002; Kay et al., 2004). Estudios isotópicos de Sr en basaltos de Payenia indican 
un rango entre 0,70350 y 0,70445, mientras que la correlación con los isótopos de $\mathrm{Nd}$ se encuentra dentro del arreglo del manto y es similar a los basaltos OIB, aunque los isótopos de $\mathrm{Pb}$ difieren de los basaltos OIB (Stern et al., 1990). Además de los centros monogénicos, se desarrollaron otros volcanes poligenéticos como el Payún Matrú, Payún Liso y Auca Mahuida, también con afinidad de intraplaca, los cuales se consideran relacionados a un régimen extensional (Ramos y Kay, 2006).

En el sector norte de Payenia, entre los $34^{\circ}$ y $34^{\circ} 30^{\prime} \mathrm{S}$, el volcanismo se desarrolló escasamente en el Pleistoceno (0,434 Ma y 0,07 Ma) (Folguera et al., 2009; Ramos y Folguera, 2010). Este segmento concentra menos del $10 \%$ de la actividad en Payenia (Ramos y Folguera, 2010).

De acuerdo con Ramos y Folguera (2010), el sector sur de Payenia comprende dos campos volcánicos, el del Tromen y Auca Mahuida, junto con algunos conos basálticos menores a o largo del Río Colorado. El Auca Mahuida es un escudo basáltico asentado sobre estratos del Cretácico, siendo mayormente de edad Pleistocena (0,8 a 1,7 Ma) (Ramos y Folguera, 2010). El volcán Tromen, descripto como el plateau del Tromen, presenta principalmente una afinidad de intraplaca, y solamente la parte basal de 4 Ma de edad posee afinidad de arco (Kay et al., 2006).

En la Faja Plegada y Corrida Malargüe se desarrolla en forma restringida el volcanismo de retroarco con conos monogénicos bien preservados, específicamente en el área de La Pasarela en el Río Grande, y también en el Río Salado (Llambías et al., 2010). Estos conos de escoria están relacionados a estructuras NO-SE (dirección frecuente en la subcuenca de Llancanelo), y menos notoriamente con estructuras N-S, paralelas a los corrimientos (Llambías et al., 2010). Para los mismos se estima una edad Pleistocena (Marchetti et al., 2006). La edad de las lavas que endicaron el Río Grande ha sido datada por isótopos cosmogénicos $\left({ }^{3} \mathrm{He}\right)$ en $41 \pm 1 \mathrm{ka}$ (promedio de tres muestras) por Marchetti et al. (2006).

En Payenia hubo tres picos de actividad volcánica, de varios miles de años de duración, los cuales fueron definidos como épocas eruptivas (Bermúdez et al., 1993):

I. Epoca eruptiva Chapualitense (eech), dividida a su vez en inferior y superior, de edad Plioceno-Pleistoceno inferior (eech inferior de 5,1-2,6 Ma y eech superior de 2-1,5 Ma).

II. Epoca eruptiva Puentelitense (eep), de edad Pleistoceno medio a superior (650-100 ka).

III. Epoca eruptiva Tromenlitense (eet), de edad Holoceno y llegando a épocas históricas, también dividida en inferior y superior.

A cada época eruptiva se le asignó un Grupo. Así, pueden distinguirse el Grupo Chapúa, el Grupo Puente y el Grupo Tromen (Bermúdez et al., 1993). Las tres épocas eruptivas se diferencian por su grado de erosión y de preservación de las formas volcánicas. En los 
conos de escoria pertenecientes a la eech, pueden diferenciarse los diques alimentadores preferentemente radiales, así como las rocas del conducto central (Bermúdez et al., 1993). Los conos de la eep se preservan casi intactos, mostrando solamente una erosión incipiente, en donde pueden reconocerse sus cráteres aunque no así la estructura interna del cono (Bermúdez et al., 1993). Por último, los conos basálticos de la eet se encuentran conservados perfectamente, y muchos presentan campos de bombas en su posición original (Bermúdez et al., 1993).

Payenia presenta dos campos volcánicos importantes: al norte el Campo Volcánico Llancanelo (CVLL), y al sur el Campo Volcánico Payún Matrú (CVPM) (Bermúdez y Delpino, 1989; Bermúdez et al., 1993). En el CVLL se encuentran basaltos de la eech, los cuales presentan la mayor afinidad geoquímica con las rocas de arco, y son parcialmente contemporáneos con los centros andesíticos como el Nevado. Estos llevan la herencia de la transición entre el régimen compresional al extensional que comenzó en el Plioceno (Bermúdez et al., 1993). Geoquímicamente, las rocas de la eep en CVLL y CVPM, presentan características intermedias entre las rocas de arco y las de islas oceánicas (OIB). Las rocas de la eet del CVPM son las más alcalinas (Bermúdez et al., 1993; Kay et al., 2006; Bertotto et al., 2009).

Una característica destacable de los basaltos alcalinos de Payenia es la escasez de xenolitos mantélicos, los que sí son frecuentes en los basaltos de retroarco de Patagonia (Bermúdez et al., 1993; Llambías et al., 2010). Han sido encontrados xenolitos del manto al norte del Río Colorado únicamente en tres localidades de Mendoza y La Pampa (Bertotto, 2000, 2002b,a). Estos xenolitos fueron encontrados en basaltos del Grupo Puente y Chapúa, y son peridotitas en facies de espinela. A partir de los mismos se infiere que tuvieron una profundidad de entre 45 y $70 \mathrm{~km}$, representando ésta la profundidad mínima de la formación de los basaltos (Bertotto, 2000, 2002b,a; Llambías et al., 2010). De acuerdo a los patrones geoquímicos de los elementos traza, los basaltos fueron originados en el manto en facies de granate, lo cual indica una profundidad de formación mayor que los xenolitos y, a su vez, sugiere que los basaltos no están relacionados con las inclusiones peridotíticas (Llambías et al., 2010).

Las erupciones del retroarco en Payenia se deben a la fusión del manto previamente hidratado en el período de subducción somera del Mioceno (Kay et al., 2004). El empinamiento de la zona de subducción expuso a un manto hidratado con una temperatura de fusión más baja que antes de la hidratación, a una cuña astenosférica convectiva espesa, produciendo la fusión extendida (Kay, 2002; Kay et al., 2004, 2006). El volumen de magma eruptado es difícil de explicar en base únicamente a un wet spot mantélico sobre una zona de subducción empinada. Una posible causa para lo anterior consiste en que, si el manto se mantuvo relativamente caliente desde el Jurásico, pequeñas perturbaciones del mismo (probablemente dadas por cambios en la geometría de subducción) podrían ser las responsables de la generación extensa de magmas basálticos (Kay et al., 2006). Otras observaciones que conducen a esta afirmación son la escasez de fundidos silícicos y la ausencia de contaminación cortical en la región. Esto último refleja la existencia de una corteza inferior refractaria que ya per- 
dió sus componentes de fusión en el Permo-Triásico, cuando hubo un evento extensivo de fusión de la corteza (Kay, 2002).

\subsubsection{Campo Volcánico Llancanelo}

La laguna Llancanelo se sitúa a 1.376 m.s.n.m. en un ambiente desértico y cubre un área de $370 \mathrm{~km}^{2}$ aproximadamente. La laguna evolucionó como un gran depocentro regional durante el Plioceno- Cuaternario (Violante et al., 2010), controlado por un hemigraben y limitado al este por una falla normal (Ramos y Folguera, 2010). El sector oriental del Campo Volcánico Llancanelo se asienta sobre un basamento permotriásico del Bloque de San Rafael (Bermúdez y Delpino, 1989).

El CVLL abarca un área de $10.700 \mathrm{~km}^{2}$, y posee alrededor de 200 centros eruptivos, siendo la gran mayoría conos basálticos monogénicos con una menor cantidad de centros poligénicos (Bermúdez y Delpino, 1989; Bermúdez et al., 1993). Estos centros se hallan alineados en dos direcciones: N-S con alineamientos hasta $10 \mathrm{~km}$ de largo, y estructuras más notorias de rumbo NO-SE, con alineamientos de conos de hasta $70 \mathrm{~km}$ de largo, sobre el Bloque San Rafael (Bermúdez y Delpino, 1989).

La edad de los basaltos está poco definida, desde el Pleistoceno inferior pudiendo llegar hasta el Holoceno (Risso et al., 2008). El Pleistoceno inferior se corresponde con el Chapualitense (Basalto III y IV) de Groeber (1946) (Bermúdez y Delpino, 1989). Algunos conos de escoria localizados en el sector oriental de este campo volcánico, se asignan al Pleistoceno superior, y son correlacionables con el Puentelitense (Basaltos V) de Groeber (1946) (Bermúdez y Delpino, 1989). Otros conos son de edad Pleistoceno superior-Holoceno, y son correlacionables con el Tromenlitense (Basaltos VI y VII) de Groeber (1946) (Bermúdez y Delpino, 1989).

La morfología de las lavas basálticas es pahoehoe en el sector occidental del campo volcánico, y de morfología intermedia entre a a yahoehoe en el sector más oriental, el cual se apoya sobre el Bloque de San Rafael (Bermúdez y Delpino, 1989). Bermúdez et al. (1993) han descripto túneles de lava que dan lugar a cavernas, en el sector oriental. El \# Mg en los basaltos varía ampliamente, presentando un grupo de ellos \# Mg entre 70 y 74, por lo que son considerados magmas primarios. Otro grupo presenta un \# Mg entre 68 y 63, por lo que se considera que no son magmas primarios y que han sufrido procesos de fraccionamiento previamente a su erupción (Bermúdez y Delpino, 1989).

Como es de esperar, se han encontrado en las zonas aledañas a la laguna Llancanelo evidencias de hidromagmatismo, con centros eruptivos descriptos como anillos de tobas y conos de cenizas, sumando en total 27 centros eruptivos (Risso et al., 2008). 


\subsubsection{Campo Volcánico Payún Matrú}

Dentro del Engolfamiento Neuquino en su parte norte, se desarrolla el Campo Volcánico Payún Matrú. Este se prolonga hacia el limite sur del Bloque San Rafael, con un sustrato de rocas Mesozoicas y Terciarias (Bermúdez y Delpino, 1989). Este campo volcánico ubicado al sur del CVLL, ocupa un área elevada de $5.200 \mathrm{~km}^{2}$ entre los $36^{\circ}-37^{\circ} \mathrm{S}$ y $68^{\circ} 30^{\prime}-69^{\circ} 40^{\prime} \mathrm{O}$, y se encuentra a 100-200 km de la Cordillera Principal (Bermúdez et al., 1993). Como ya ha sido mencionado, el CVPM es un alto que funciona como límite sur para la sedimentación Cuaternaria en la Depresión de los Huarpes (Llambías et al., 2010). El nombre Payún Matrú, de acuerdo con los pobladores locales, deriva de las palabras Payún (barbudo) y Matrú (chivo) (González Díaz, 1972).

El CVPM contiene abundantes conos de escoria basálticos junto con dos volcanes compuestos: el Payún Matrú con una caldera en su cúspide, y el Payún Liso con la morfología típica de un estratovolcán (Fig. 1.3). El Payún Liso fue construido durante el Pleistoceno, siendo la roca más vieja datada de $285 \pm 5$ ka y la más joven de $261 \pm 4$ ka (Germa et al., 2010; Ramos y Folguera, 2010). El volumen estimado para este volcán es de $40 \mathrm{~km}^{3}$ (Germa et al., 2010). En cuanto a la edad del Payún Matrú, fue propuesta como Plioceno tardío-Cuaternario (Bermúdez et al., 1993; Kay et al., 2006; Ramos y Kay, 2006), PleistocenoHoloceno (Llambías, 1966; González Díaz, 1972) y posteriormente, basándose en edades radimétricas, se restringió la actividad de dicho volcán a los últimos 300 ka (Germa et al., 2010). El volumen estimado para el Payún Matrú es de 240 km³ (Germa et al., 2010). El volcán Payún Matrú es de forma achatada, y por el perfil que se observa en la pared topográfica de la caldera, fue considerado un estratovolcán (Llambías, 1966).

Los basaltos eruptaron en dos pulsos, de los cuales el más antiguo es Pleistoceno superior (0,2-0,5 Ma), y es correlacionable con el Puentelitense o Basalto V de Groeber (1946), mientras que el pulso más moderno es Holoceno, correlacionable con el Tromenlitense (Basalto VI y VII) de Groeber (1946) (Bermúdez y Delpino, 1989; Bermúdez et al., 1993). No hay testigos de erupciones en los últimos 200 años, aunque si hay tradiciones orales que no pueden remontarse a más de algunos cientos de años, las cuales indican que hubo actividad volcánica en el área en tiempos históricos (Inbar y Risso, 2001b).

En cuanto a la morfología de los flujos basálticos, existe una clara diferencia entre los dos pulsos mencionados: las lavas pertenecientes al pulso más antiguo poseen una morfología pahoehoe, mientras que las lavas más modernas son aa (Bermúdez y Delpino, 1989; Bermúdez et al., 1993). Según el \# Mg, que varía entre 63 y 68, los basaltos no son considerados primarios, habiendo procesos de fraccionamiento involucrados en su formación (Bermúdez y Delpino, 1989). El volcanismo basáltico al este del Payún Matrú se relaciona a fracturas E-O, siendo la mayor de $25 \mathrm{~km}$ de longitud y alcanzando el borde de la caldera (Bermúdez y Delpino, 1989). En estas fracturas es donde nace una colada basáltica pahoehoe, considerada la de mayor longitud en el mundo, con $181 \mathrm{~km}$ de longitud, llegando hasta La Pampa (Pas- 


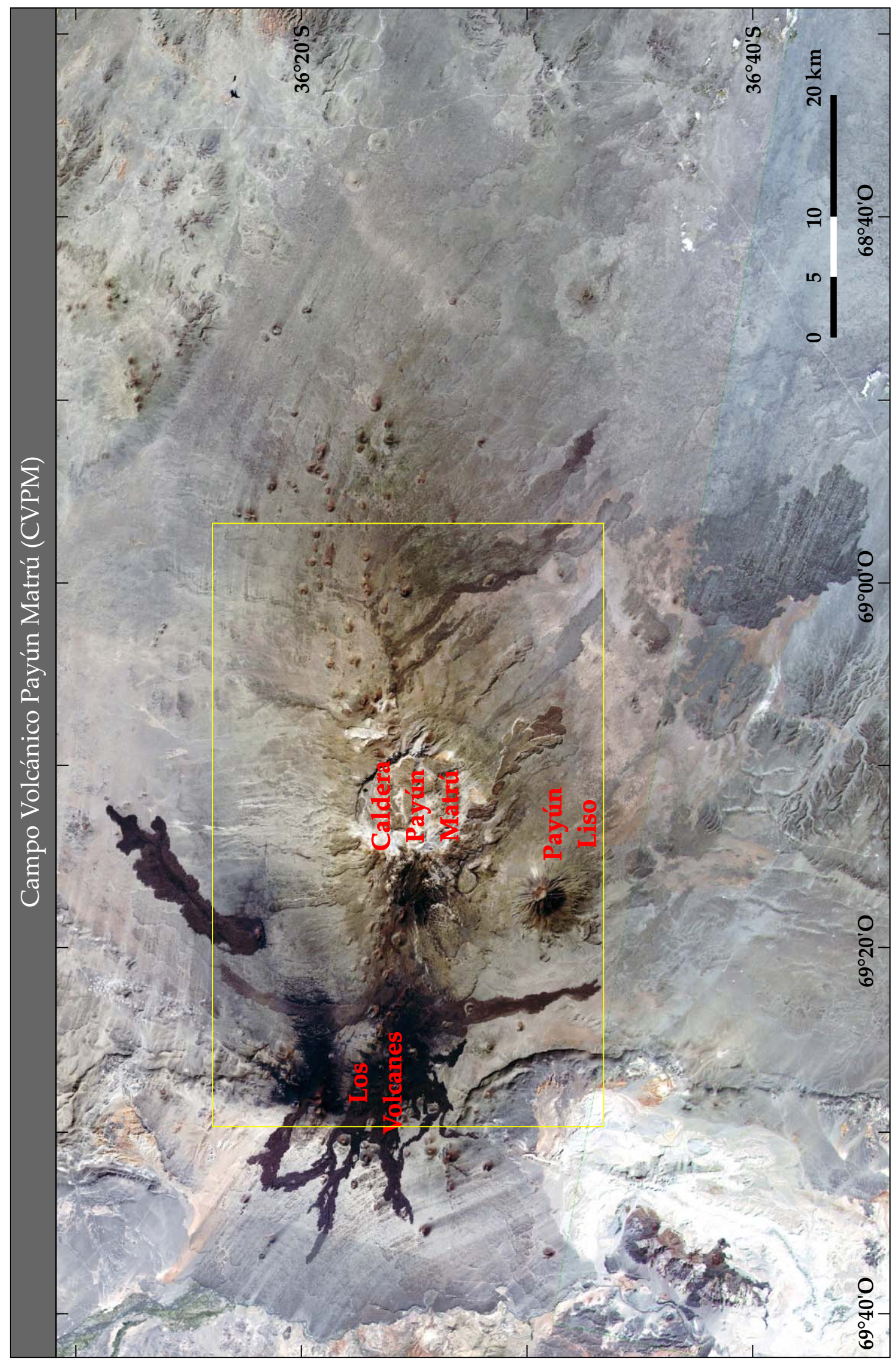

Figura 1.3: Imagen satelital LANDSAT 7 del CVPM. En recuadro se encierra el área estudiada en el presente trabajo. 
querè et al., 2008). Al oeste de la caldera se encuentra un área denominada Los Volcanes, con pendiente hacia el Río Grande, donde los flujos basálticos alcanzan en conjunto $100 \mathrm{~m}$ de espesor (Bermúdez y Delpino, 1989) (Fig. 1.3). Los basaltos pertenecientes a los Grupos Chapúa, Puente y Tromen se apoyan sobre rocas basálticas Eocenas-Oligocenas y Miocenas, en el sector oriental (Bermúdez et al., 1993). En el área de Los Volcanes, los basaltos se apoyan sobre rocas sedimentarias Mesozoicas y depósitos de piedemonte Terciarios (Bermúdez et al., 1993).

Inbar y Risso (2001a) e Inbar y Risso (2001b) han realizado estudios geomorfológicos en el CVPM, acerca de los yardangs desarrollados mayormente en la ignimbrita del Payún Matrú, y también sobre conos de escoria. Los yardangs presentan un muy buen desarrollo principalmente en la región sur y sudoeste del Payún Matrú, con una dirección de $320^{\circ}$, la cual coincide con la dirección de los vientos predominantes. También se desarrollan los yardangs sobre los flujos basálticos de El Mollar de edad Holocena (González Díaz, 1972).

\subsubsection{Estratigrafía}

La estratigrafía del CVPM fue descripta en primera instancia por Groeber (1937) y Groeber (1946), y luego fue mejorada por estudios posteriores de Llambías (1966), González Díaz (1970), González Díaz (1972) y Bermúdez et al. (1993). Llambías (1966) distinguió una división primaria entre un volcanismo central (correspondiente al volcán Payún Matrú) y uno adventicio (correspondiente a los campos basálticos al este y oeste del Payún Matrú). En la Figura 1.4 se muestra la estratigrafía previa al presente trabajo del CVPM.

\section{APARATO VOLCANICO CENTRAL (PAYÚN MATRÚ):}

1)_Domo andesítico" (Groeber, 1937), Andesitas y traquiandesitas de La Nariz (Llambías, 1966), Fm Payún Matrú (González Díaz, 1972): El nombre proviene del Cerro La Nariz, en donde se observa un extenso perfil de esta unidad (Fig. 1.5). Las rocas de esta unidad se encuentran por debajo de las Tobas del Portezuelo, sin presentar una base expuesta. En el perfil de La Nariz se exhibe una sucesión de mantos lávicos y brechosos que alternan con pequeñas lentes sedimentarias, con cenizas y rodados del mismo volcán (Llambías, 1966). Las lavas son principalmente mesosilícicas (andesitas, traquiandesitas y traquitas), con una menor participación de material piroclástico (Llambías, 1966; González Díaz, 1972). Las lavas se distinguen por ser, en general, porfíricas con fenocristales de plagioclasa y piroxeno (Llambías, 1966). Esta unidad fue asignada al Cuaternario inferior por Llambías (1966), al Plioceno-Pleistoceno inferior por Bermúdez et al. (1993), y al Pleistoceno probablemente inferior por (González Díaz, 1972). Germa et al. (2010) presenta una datación radimétrica de una lava traquítica en $168 \pm 4$ ka.

González Díaz (1972) distinguió 5 variedades litológicas y les asignó la categoría de miembros, siendo estos, del más antiguo al más moderno: I) Miembro Cerro Negro; II) Miembro Nariz del Payún; III) Miembro Cerro Bayo; IV) Miembro de la Cueva; V) Miembro 


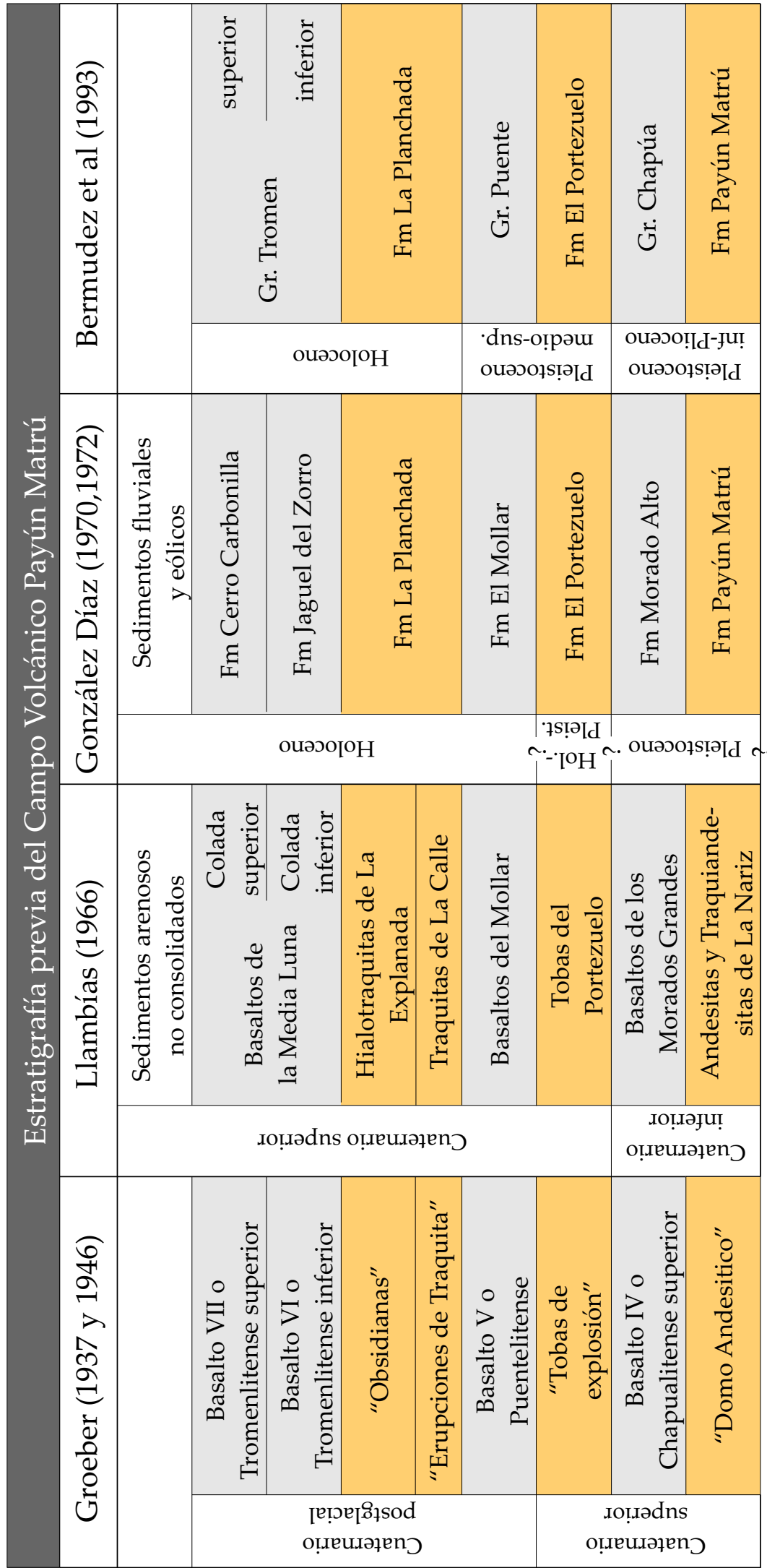

Figura 1.4: Cuadro con la estratigrafía previa al presente trabajo en el CVPM. 
del Bardón. Los afloramientos de esta formación se disponen en forma de semicírculo alrededor de la depresión de la caldera, con un máximo desarrollo en la parte este de la misma y una superficie de $170 \mathrm{~km}^{2}$.

I. Miembro Cerro Negro: borde $\mathrm{N}$ de la caldera, con una escarpa de $50 \mathrm{~m}$ de altura máxima, y cubierto por la Fm Portezuelo.

II. Miembro Nariz del Payún: está representado por la pared topográfica de la caldera con más de 200 m de altura, y constituye el margen oriental de la misma (Fig. 1.5).

III. Miembro Cerro Bayo: es el denominado Filo Blanco, al NE de la caldera y de $6 \mathrm{~km}$ de longitud, junto a otros afloramientos reducidos al N de los Morados Grandes (Fig. 1.5).

IV. Miembro de la Cueva: parte S y E del edificio antiguo del Payún Matrú (no presenta González Díaz (1972) elementos que permitan separarlo del Miembro Nariz del Payún, aunque los diferencia por un rasgo morfológico-estructural, por el tipo de disyunción en lajas).

V. Miembro del Bardón: ladera SE de la caldera.

En el presente trabajo no se distingue entre los miembros mencionados por González Díaz (1972), ya que las relaciones de campo no son claras, tal como fue mencionado por el mismo González Díaz. Por otra parte, las escasas dataciones radimétricas disponibles no concuerdan con lo propuesto por González Díaz (1972), como se verá posteriormente.

2)_ "Tobas de explosión” (Groeber, 1937), Tobas del Portezuelo (Llambías, 1966), Fm El Portezuelo (González Díaz, 1972):_Son ignimbritas de composición andesítica y traquiandesítica (González Díaz, 1972). El nombre proviene de los extensos afloramientos ubicados en el Portezuelo de los Payunes (área entre el Payún Matrú y el Payún Liso). Estos depósitos piroclásticos están relacionados con la formación de la caldera del Payún Matrú (Groeber, 1937; Llambías, 1966). Los afloramientos más alejados de la caldera están en el Cerro La Olla, a $27 \mathrm{~km}$ del borde norte, y cubren un área de $2.200 \mathrm{~km}^{2}$ (González Díaz, 1972). El volumen estimado para esta unidad es de $25 \mathrm{~km}^{3}$ (Germa et al., 2010) y $33 \mathrm{~km}^{3}$ (Llambías et al., 2010). El origen de la ignimbrita fue atribuido a la inyección de un magma basáltico en la cámara traquítica del Payún Matrú (Llambías et al., 2010) y, también a la despresurización por causas tectónicas sin evidencias de mezcla de magmas (Germa et al., 2010).

Esta unidad fue dividida por Llambías (1966) en: I) Tobas de aglutinación densa y, II) Tobas sin aglutinación o con aglutinación parcial. Ambas tobas fueron depositadas durante el mismo evento eruptivo, aunque separadamente, es decir, no representan diferentes zonas de enfriamiento y soldadura de un mismo paquete piroclástico. 
I. Las Tobas de aglutinación densa presentan una matriz vítrea negra, y afloran principalmente en la ladera noreste de la caldera. Los depósitos en los fondos de los valles alcanzan hasta $50 \mathrm{~m}$ de espesor en la Quebrada de la Cueva y Huaico de la Fortuna (Fig. 1.5). Los depósitos de laderas y cumbres presentan espesores mucho menores, hasta $5 \mathrm{~m}$ de espesor. Cubren de forma parcial a la Andesitas y traquiandesitas de La Nariz.

II. En las tobas sin aglutinación o con aglutinación parcial, el grado de soldadura varía desde una leve deformación de las trizas vítreas hasta conformar rocas sin ningún signo de soldadura. En general son de color rojizo, a veces grises, y poseen gran cantidad de clastos líticos volcánicos. Presentan una distribución areal extensa, al norte y sur de la caldera. En el Portezuelo de los Payunes se desarrollaron yardangs en la ignimbrita en dirección NO-SE, producto de la erosión eólica.

La edad de estas ignimbritas fue asignada a diferentes épocas según los diferentes autores: al Pleistoceno medio a superior (Bermúdez et al., 1993), probablemente al limite PleistocenoHoloceno (González Díaz, 1972), y al Cuaternario superior (Llambías, 1966). Posteriormente, la edad fue restringida entre 168 y $82 \mathrm{ka}$, de acuerdo a dataciones de lavas previas y posteriores a la ignimbrita (Germa et al., 2010).

3)_Basalto V o Puentelitense (Groeber, 1946), Basaltos del Mollar (Llambías, 1966), Fm El Mollar (González Díaz, 1972), Gr. Puente (Bermúdez et al., 1993): Comprenden a las lavas basálticas y traquibasálticas olivínicas posteriores a la formación de la caldera, es decir, cubren a las Tobas del Portezuelo y, a su vez, están cubiertas por las coladas de Traquitas de la Calle (Llambías, 1966; González Díaz, 1972). También se agrupan en esta unidad a los basaltos ubicados en la ladera occidental del Payún Matrú (Fig. 1.5). El nombre de la unidad proviene del paraje El Mollar situado al NO del Portezuelo de los Payunes. Por sus rasgos morfológicos González Díaz (1972) los considera Holocenos, aunque Bermúdez et al. (1993) le asigna una edad Pleistoceno medio a superior y Llambías (1966) Cuaternario superior. Una colada lávica intracaldera fue datada en $82 \pm 2$ ka (Germa et al., 2010).

4) "erupciones de traquita" de (Groeber, 1937), Traquitas de La Calle (Llambías, 1966), Miembro "escoriales de traquita" de la Fm La Planchada (González Díaz, 1972): Son lavas traquiticas posteriores a los Basaltos de Mollar, y presentan características morfológicas y litológicas similares (Llambías, 1966). Las coladas de traquitas de esta unidad nacen frecuentemente en las fracturas anulares de la caldera, y algunas de las laderas del Payún Matrú (Ej: Farellones de la Portada, Fig. 1.5). Son rocas de color gris claro, porfíricas mayormente con fenocristales de feldespato alcalino. La longitud de las coladas varía entre 4,5 y $10 \mathrm{~km}$, con alturas de entre 150 y 200 m, y el volumen estimado para la unidad es de 14,4 km³ (Llambías, 1966). La edad de esta unidad es Cuaternaria superior (Llambías, 1966), y se ubica dentro de lo que González Díaz (1972) denomina Fm La Planchada, descripta a continuación. Germa et al. (2010) dataron tres lavas de esta unidad, siendo estas de $26 \pm 2,15 \pm 1$ y $7 \pm 1 \mathrm{ka}$. 


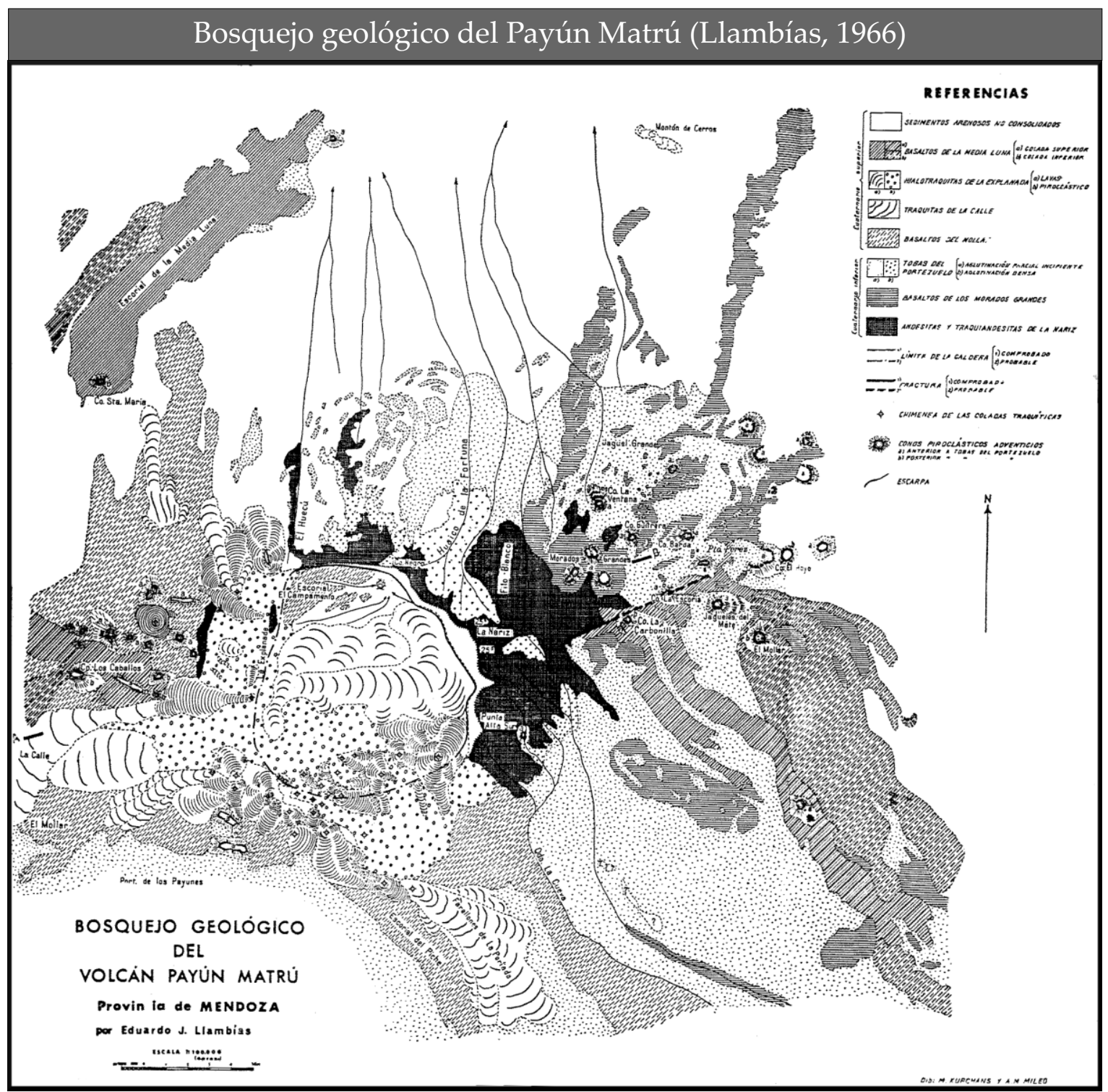

Figura 1.5: Mapa geológico del CVPM, realizado por Llambías (1966) en su tesis doctoral. 
5) “Obsidianas" (Groeber, 1937), Hialotraquitas de La Explanada (Llambías, 1966), Fm La Planchada (González Díaz, 1972):_Esta unidad está constituida por coladas lávicas y material piroclástico inconsolidado, siendo este último componente abundante en el borde oeste y sur de la caldera (Llambías, 1966; González Díaz, 1972). El material piroclástico está compuesto por fragmentos pumíceos de tamaño lapilli hasta bombas, de textura vítrea y de hasta $1 \mathrm{~m}$ de diámetro. Las coladas de lava hialotraquíticas negras se apoyan sobre estos depósitos piroclásticos, y son muy abundantes en la ladera sur de la caldera (Llambías, 1966) (Fig. 1.5). El tamaño de estas coladas es menor que el de las coladas de Traquitas de La Calle, alcanzando una longitud de 4,3 km y un espesor de $30 \mathrm{~m}$ (Llambías, 1966). El volumen estimado para esta unidad es de $1 \mathrm{~km}^{3}$, siendo $0,6 \mathrm{~km}^{3}$ de hialotraquitas y el resto de material piroclástico (Llambías, 1966). González Díaz (1972) distingue 4 miembros: I) Pumicitas de La Planchada; II) Brechas pumíceas del flanco sur del Payún Matrú; III) escoriales de traquita (equivalente a las Traquitas de La Calle); IV) escoriales de traquita vítrea ("obsidianas" de Groeber (1937)). Esta unidad fue asignada al Cuaternario superior (Llambías, 1966) y al Holoceno (González Díaz, 1972; Bermúdez et al., 1993). Una edad realizada sobre el material piroclástico arrojó una edad de $37 \pm 2$ ka (Germa et al., 2010).

\section{APARATOS VOLCANICOS ADVENTICIOS:}

1) Basalto IV o Chapualitense superior (Groeber, 1946), Basaltos de Los Morados Grandes (Llambías, 1966), Fm Morado Alto (González Díaz, 1972), Gr. Chapúa (Bermúdez et al., 1993): Abarcan a todos los basaltos posteriores a las Andesitas y traquiandesitas de La Nariz, y anteriores a las Tobas del Portezuelo (Llambías, 1966; González Díaz, 1972). Esta unidad aflora principalmente en la ladera oriental del Payún Matrú, y se encuentran escasos conos de escoria aislados en la ladera occidental, cubiertos por basaltos posteriores (Fig. 1.5). El nombre de la unidad proviene de los Morados Grandes, los cuales son los conos de escoria de mayor tamaño. Todos los basaltos son olivínicos y con una morfología pahoehoe (Llambías, 1966; González Díaz, 1972). La edad de esta unidad es Pleistoceno superior con dudas (González Díaz, 1972), y Plioceno-Pleistoceno inferior (Llambías, 1966; Bermúdez et al., 1993). Una edad radimétrica disponible de una colada basáltica aflorante en el valle del Río Grande, arrojó una edad de $233 \pm 11$ ka (Germa et al., 2010).

2) Basalto VI y VII o Tromelitense inferior y superior (Groeber, 1946), Basaltos de la Media Luna (Llambías, 1966), Fm Jagüel del Zorro y Fm Cerro La Carbonilla (González Díaz, 1972), Gr Tromen (Bermúdez et al., 1993): Estas unidades son basaltos que cubren a los Basaltos del Mollar, sin presentar una relación clara con las hialotraquitas por no estar ambas unidades en contacto (Llambías, 1966). Se pueden distinguir coladas de lava más jóvenes que otras de esta misma unidad, aunque dada la naturaleza discontinua de las lavas, es difícil trasladar esa misma relación a otros sitios (Llambías, 1966). El Tromelitense inferior de Groeber (1946) se corresponde a la colada inferior de los Basaltos de la Media Luna de Llambías (1966), a la Fm Jagüel del Zorro de González Díaz (1972) y al Gr. Tromen inferior de Bermúdez et al. (1993). El Tromelitense superior o Basalto VII de Groeber (1946) se corres- 
ponde con la colada superior de los basaltos de la Media Luna de Llambías (1966), con la Fm Cerro La Carbonilla de González Díaz (1972), y con el Grupo Tromen superior de Bermúdez et al. (1993). Al igual que la unidad anterior, los basaltos son porfíricos con fenocristales de plagioclasa y olivina (Llambías, 1966). Estas lavas y conos de escoria fueron asignados al Cuaternario superior, por no encontrarse signos de erosión (Llambías, 1966), y al Holoceno (González Díaz, 1972; Bermúdez et al., 1993). 


\section{Capítulo 2}

\section{Metodología}

\subsection{Tareas de campo}

Las tareas de campo se desarrollaron principalmente entre los años 2007 y 2010, realizándose también dos campañas breves en 2005 y 2006, previamente al comienzo de la tesis doctoral, y sumando en total 105 días netos. Las tareas de campo fueron orientadas al control y mejoramiento de la estratigrafía previamente propuesta, así como al mapeo de detalle del área de estudio, en escala 1:50.000. Para ello se utilizaron técnicas cartográficas de uso corriente, como fotografías aéreas, imágenes satelitales y posicionaminto GPS. Para ajustar la estratigrafía, y debido a la discontinuidad espacial de las lavas y otros productos volcánicos, se realizaron, paralelamente al mapeo, numerosas columnas estratigráficas parciales en diferentes sitios del CVPM, abarcando áreas relativamente pequeñas (Fig. 2.1). Estas fueron luego integradas por áreas mayores, para establecer finalmente la estratigrafía de todo el campo volcánico.

Se recolectaron muestras representativas de las diferentes unidades propuestas, para los posteriores análisis de petrografía, geoquímica de roca total, isotopía de $\mathrm{Sr}$ y $\mathrm{Nd}$, de química mineral mediante la utilización de microsonda electrónica, y para dataciones radimétricas.

\subsection{Tareas de gabinete}

\subsubsection{Recopilación de información previa}

Se recopiló la información geológica existente del CVPM en particular, y de Payenia en general. Se interpretaron fotografías aéreas a escala 1:50.000, e imágenes satelitales, para la confección del fotomapa y la identificación de las localidades claves para el estudio del volcanismo. Asimismo, y para poder llevar a cabo el presente trabajo, fue necesaria la investigación bibliográfica acerca de diversos temas relacionados, como son la geoquímica de rocas volcánicas, la petrología, la generación de magmas, la mezcla de magmas, rocas 


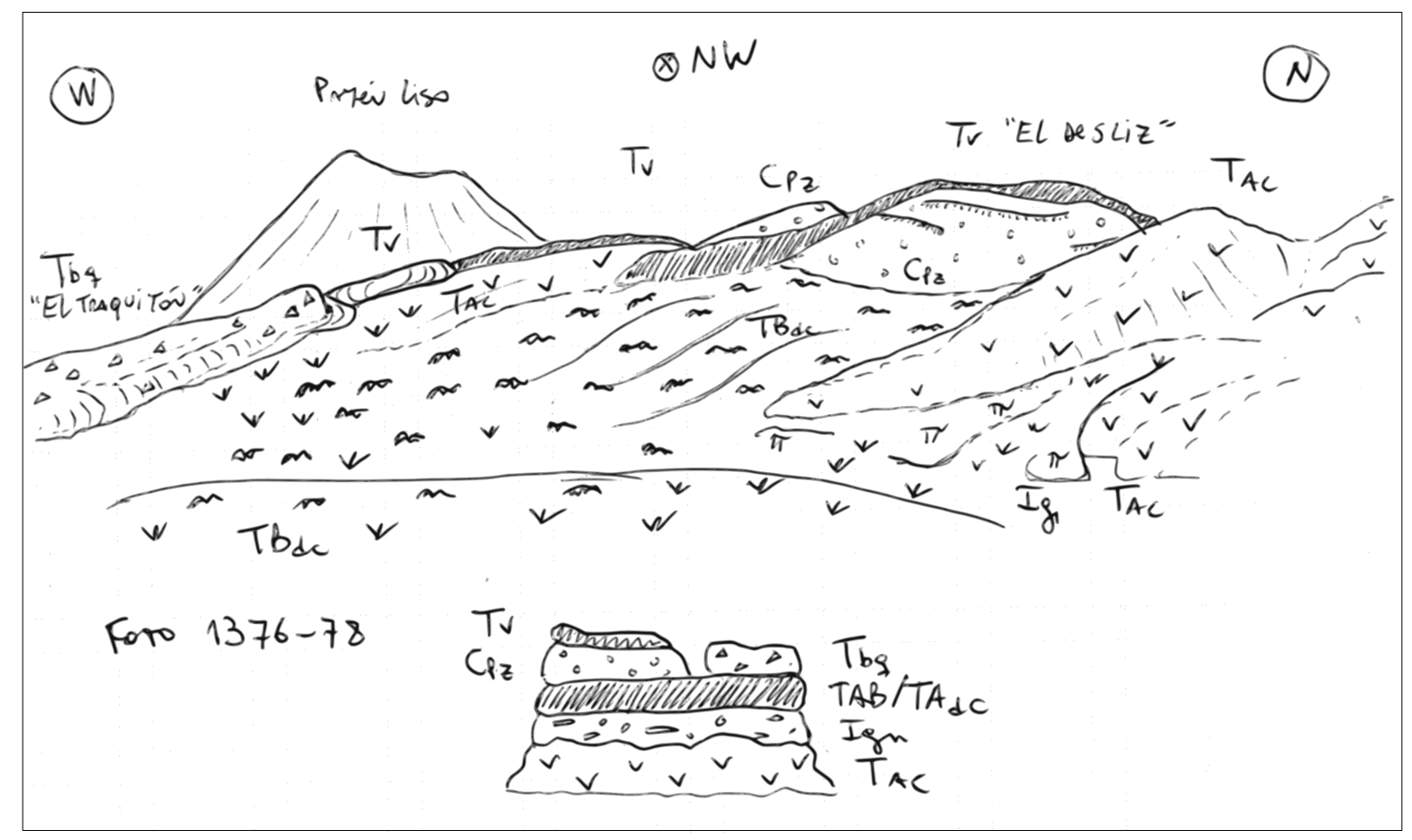

Figura 2.1: Dibujo digitalizado de la libreta de campo, mostrando las unidades estratigráficas observadas y su relación temporal en el flanco sudeste de la caldera del Payún Matrú.

piroclásticas y calderas, etc.

\subsubsection{Confección de un GIS}

En base al mapeo geológico realizado durante las sucesivas campañas, se confeccionó un sistema de información geográfico del área de estudio, en donde se procuró integrar no solo las unidades mapeables y las estructuras observadas, sino también los sitios de recolección de las muestras para diferentes fines, así como información relacionada, como su composición química.

\subsubsection{Cálculos}

Para los cálculos volumétricos del Payún Matrú y Payún Liso se utilizó el Modelo de Elevación Digital (DEM) del terreno SRTM (Shuttle Radar Topography Mission, Rodríguez et al., 2005), el cual posee una resolución de $90 \mathrm{~m}$. Los cálculos fueron realizados con la herramienta "grdvolume" del paquete GMT (General Mapping Tools, Wessel y Smith, 1995).

Para un conjunto de lavas con evidencias de mezcla de magmas se realizó una estimación con el método de cuadrados mínimos de los porcentajes de magmas máficos y félsicos originarios. Para esto se utilizó una adaptación del método descripto por Bryan et al. (1969), modificado para restringir los porcentajes estimados de contribución a la mezcla a valores 
no negativos (la implementación del cálculo se realizó utilizando el software matemático Octave, con la asistencia del Dr. Luciano P. O. Mendoza, UNLP).

También se realizaron cálculos de termobarometría y viscosidad de los magmas, de acuerdo a las metodologías explicadas en el Capítulo 8.

\subsubsection{Estudios petrográficos}

Los cortes delgados de las muestras recolectadas en el campo fueron confeccionados en el laboratorio de cortes delgados del Centro de Investigaciones Geológicas (CIG, CONICETUNLP). Se utilizaron microscopios petrográficos pertenecientes al CIG (Nikon eclipse e200), mientras que las microfotografías fueron tomadas con una cámara de video adosada (Leica DFC290 HD). Se seleccionaron 190 muestras para el estudio petrográfico detallado, tanto del Payún Matrú como de los campos basálticos adyacentes, y minoritariamente del Payún Liso.

\subsubsection{Geoquímica de roca total}

Se recolectaron y seleccionaron para su análisis geoquímico 58 muestras representativas de todo el CVPM. La preparación previa de las muestras, antes de su envío al laboratorio geoquímico, fue realizada en los laboratorios del CIG, el cual cuenta con equipos para trituración y molienda de rocas. El polvo de roca resultante fue enviado a Ontario, Canadá, para ser analizado por el laboratorio ActLabs ltd. Los elementos mayoritarios y minoritarios fueron analizados mediante el método fusión de metaborato/tetraborato de litio ICP (Inductively Coupled Plasma), el cual posee un límite de detección de 0,01 \% para los elemen-

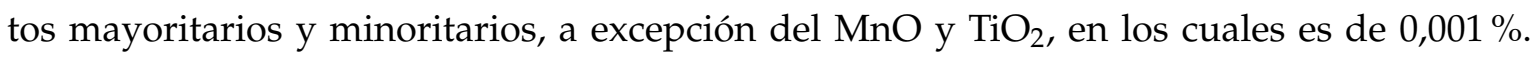
Los elementos traza se analizaron mediante el método ICP/MS (Inductively Coupled Plasma Emission Mass Spectrometry).

\subsubsection{Geoquímica isotópica}

Para el estudio isotópico de ${ }^{87} \mathrm{Sr} /{ }^{86} \mathrm{Sr}$ se seleccionaron 16 muestras, del total de muestras analizadas geoquímicamente, teniendo en cuenta los contenidos de $\mathrm{Rb}$ y Sr, así como la posición estratigráfica y geográfica. Las muestras molidas fueron tratadas con $\mathrm{HNO}_{3}-\mathrm{HF}$, con la colaboración del Dr. Ricardo Varela y la Lic. Valeria García en el CIG, y el Sr natural fue separado a través de columnas de resina. Las determinaciones por fluorescencia de rayos $\mathrm{X}$ de los contenidos de $\mathrm{Rb}$ y $\mathrm{Sr}$, y la espectrometría de masas fueron realizadas en el Centro de Pesquisas Geocronológicas (CPGeo), de la Universidad de São Paulo, Brazil, como se detalla en Varela et al. (2000).

Posteriormente, 15 de las 16 muestras analizadas con el método mencionado fueron estudiadas para determinar las relaciones isotópicas de ${ }^{143} \mathrm{Nd} /{ }^{144} \mathrm{Nd}$. Las muestras molidas 
fueron enviadas al Instituto de Geología y Geografía, de la Universidad de Copenhagen, Dinamarca. Allí se analizaron tanto a los isótopos de $\mathrm{Nd}$, como también los de Sr, para poder realizar comparaciones entre ambos isótopos, analizados con la misma metodología. Las técnicas y equipos utilizados son los que se mencionan en Kalsbeek y Frei (2006).

\subsubsection{Análisis de la química mineral}

La química mineral fue determinada mediante la microsonda electrónica del Laboratorio de Microscopía y Microsonda electrónica (Departamento de Mineralogía y Petrología) del Instituto de Geociencias de la Universidad de San Pablo, Brasil. La microsonda electrónica es un equipo JEOL - SUPERPROBE JXA-8600 S con cinco espectrómetros WDS (wavelenghtsdispersive spectrometers) para la obtención de microanálisis cuantitativos. Este equipo es compatible con un sistema automatizado VOYAGER THERMO-NORAN de hardware y software. Para el estudio de los cristales se utilizó una corriente del haz de electrones de 20,10 $\pm 0,10$ $\mathrm{n} \AA$, con un voltaje de aceleración de electrones de $15 \mathrm{kV}$ para todos los minerales. Con respecto a los feldespatos alcalinos y plagioclasas, se utilizó un diámetro de haz enfocado de $10 \mu \mathrm{m}$, mientras que para el resto de los minerales se usó uno de $5 \mu \mathrm{m}$.

Previamente a la utilización del equipo de microsonda electrónica, se seleccionaron por medio de un microscopio petrográfico los cristales a ser analizados con la microsonda. Estos cristales se fotografiaron para poder identificar luego los puntos estudiados en la fotografía. Posteriormente, las secciones fueron metalizadas con carbono nativo para inducir su conductividad eléctrica durante la irradiación electrónica, tarea realizada por el personal técnico del laboratorio. Sobre las secciones metalizadas se procedió a la identificación final de los cristales, y a la ubicación de cada uno de ellos en un sistema de coordenadas ortogonales, para su rápida localización en el equipo de microsonda.

De las 13 muestras analizadas, se seleccionaron principalmente cristales de plagioclasas o feldespatos alcalinos, además de minerales máficos para su caracterización (olivinas, clinopiroxenos, anfíboles y biotita). En los feldespatos alcalinos sin zonación visible, se analizaron tres puntos por cristal (centro, medio y borde), mientras que en el caso de las plagioclasas fueron generalmente analizados más puntos, debido a las zonaciones que presentaban. En el caso de los minerales máficos, se analizaron en general dos puntos por cristal (centro y borde), a excepción de aquellos con una zonación visible ópticamente, en los cuales se analizaron más puntos.

La fórmula de los feldespatos alcalinos y plagioclasas fue calculada en base a 32 átomos de oxígeno, y 20 cationes, según Deer et al. (2001). Para el cálculo de porcentaje de anortita, al Ca se le sumó también el Sr, por ser este mineral un reemplazo del Ca, y por ocupar el mismo sitio en la estructura de los feldespatos. Similarmente para el cálculo del porcentaje de ortosa, se le sumó al K el Ba. La fórmula de las olivinas fue calculada en base a 4 oxígenos, según Deer et al. (1992). La composición de los piroxenos se realizó en base a Morimoto et al. 
(1988) y Morimoto et al. (1989), en base a 6 átomos de oxigeno y 4 cationes. Los anfíboles fueron clasificados según Leake et al. (1997), modificado por Leake et al. (2004), con una fórmula mineral basada en 22 oxígenos. La fórmula de las micas se realizó en base a 20 átomos de oxígeno, según Deer et al. (2001), y fueron clasificadas según Rieder et al. (1998).

\subsubsection{Dataciones radimétricas}

Las dataciones radimétricas fueron realizadas mediante el método ${ }^{40} \mathrm{Ar}^{39} \mathrm{Ar}$, debido al rango de edades posibles en el CVPM y a la composición de sus lavas traquíticas con contenidos abundantes de feldespatos potásicos, los cuales son altamente útiles para este método. Se seleccionaron cuatro muestras para su datación, procurando abarcar tanto lavas modernas como antiguas. Se seleccionaron tres muestras del Payún Matrú, una perteneciente a la unidad pre-caldera y ubicada en la parte más baja del perfil de la caldera, por lo cual podría representar a las lavas más antiguas aflorantes en el volcán. Otra muestra corresponde a la Ignimbrita Portezuelo, la cual marca un evento clave en la evolución volcánica del CVPM. En este caso, la muestra escogida es de fiammes porfíricos con feldespatos alcalinos. La última muestra del Payún Matrú elegida corresponde a una colada traquítica ubicada en el borde norte de la caldera, la cual podría representar a las coladas más recientes. Por último, se seleccionó una lava pre-caldera del campo basáltico situado al este de la caldera, ya que todas las dataciones radimétricas disponibles al momento eran de coladas basálticas situadas al oeste de la misma.

En el CIG fueron preparadas las muestras para su envío al laboratorio radimétrico. Con las muestras del Payún Matrú, se procedió en primer instancia a la trituración, luego a una molienda leve, y a un tamizado para separar los tamaños de grano en los cuales se encontraban los fenocristales. Los fenocristales de feldespato alcalino fueron separados de la pasta con una lupa binocular mediante la técnica de picking. Se procuró seleccionar cristales lo más grandes posibles, sin adhesiones de pasta o vidrio, y sin inclusiones ni cribados. Con respecto a la muestra de basalto, el proceso fue el mismo, salvo que se seleccionó pasta volcánica, sin incluir fenocristales. Los cristales y fragmentos de pasta fueron enviados para su análisis a la Universidad de Wisconsin-Madison, EEUU.

La muestra basáltica fue molida y tamizada a 250-350 $\mu \mathrm{m}$, y los fenocristales fueron removidos magnéticamente o por separación por densidad utilizando yoduro de metileno. Los microfenocristales que sobrevivieron a la separación mecánica o pasta con evidencias de alteración fueron removidas por la técnica de picking con un microscopio binocular. Los separados de pasta sin fenocristales fueron pesados y envueltos en paquetes de láminas de 99,99\% cobre, y ubicados en discos de aluminio de 2,5 cm de diámetro con sanidina de la toba Fish Canyon de 28,201 Ma (Kuiper et al., 2008), la cual monitorea la fluencia de neutrones. La muestra y el estandar fueron irradiadas en la Universidad Estatal de Oregon con un reactor TRIGA-type en el instrumento CLICIT (Cadmium-Lined In-Core Irradiation 
Tube) por una hora. En el Laboratorio de Geocronología de Gases Raros de la Universidad de Wisconsin-Madison, fueron calentados incrementalmente paquetes de pasta volcánica de $200 \mathrm{mg}$ utilizando un horno resistivo de alto vacío (double-vacuum) acoplado a un línea de extracción de gases de $300 \mathrm{~cm}^{3}$.

Antes de introducir las muestras, el horno vacío fue calibrado, midiendo incrementos de $100{ }^{\circ} \mathrm{C}$ a lo largo del rango de temperaturas del experimento. En base a esta calibración, las muestras fueron desgasificadas a $550{ }^{\circ} \mathrm{C}$ durante 60 minutos de manera de eliminar grandes cantidades de argón atmosférico. Los experimentos automáticos consistieron en la realización de 9 a 10 pasos entre 650 y $1250{ }^{\circ} \mathrm{C}$; cada uno de estos pasos incluyó un incremento de la temperatura de 2 minutos, hasta alcanzar la temperatura deseada, la cual fue mantenida por 15 minutos, más 15 minutos más para la extracción de los gases. Los gases emitidos fueron recolectados durante y luego del periodo de calentamiento utilizando tres recolectores SAES C50, dos de los cuales operaron a $\sim 450{ }^{\circ} \mathrm{C}$, mientras que el tercero lo hizo a temperatura ambiente. Los análisis de isótopos de Argón fueron realizados utilizando un espectómetro de masas MAP215-50 por medio de un único multiplicador de electrones Balzers SEM-217, y los datos isotópicos fueron calculados utilizando el software ArArCalc versión 2.5 (Koppers, 2002). Las incertezas en las edades listadas en la Tabla 3.1 a), para cada muestra individual, tienen un nivel de confidencia del $95 \%$, mientras que las constantes de decaimiento utilizadas son las provistas por Min et al. (2000).

Para el análisis de las rocas del Payún Matrú, granos de sanidina fueron empaquetados en aluminio, colocados sobre discos de $1,5 \mathrm{~cm}$ de diámetro, e irradiados junto con monitores de flujo durante una hora. Esto fue llevado a cabo en el reactor TRIGA de la Universidad Estatal de Oregon, dentro del instrumento CLICIT (Cadmiun-Lined In-Core Irradiation Tube). Sanidina proveniente de la toba Fish Canyon de 28,201 Ma (Kuiper et al., 2008) fue utilizada como monitor del flujo de neutrones. En el Laboratorio de Geocronología de Gases Raros de la Universidad de Wisconsin-Madison las muestras de sanidina, junto con las muestras de referencia, fueron fundidas utilizando el láser de $\mathrm{CO}_{2}$ de 25 Watts siguiendo la metodología descripta por Smith et al. (2008). La discriminación de masas se consiguió analizando el cociente ${ }^{40} \mathrm{Ar} /{ }^{36} \mathrm{Ar}$ durante toda la sesión, y fue calculado en relación a una razón ${ }^{40} \mathrm{Ar} /{ }^{36} \mathrm{Ar}$ de 295,5 (Steiger y Jaeger, 1977). 


\section{Capítulo 3}

\section{Estratigrafía del Campo Volcánico Payún Matrú}

Como se ha mencionado previamente, el campo volcánico Payún Matrú consiste en dos volcanes poligenéticos compuestos (Payún Matrú y Payún Liso), y numerosos conos de escoria y coladas basálticas situados al este y oeste del Payún Matrú, conformando dos campos basálticos interrumpidos por dicho volcán (Fig. 3.1). El área estudiada abarca una superficie de $1.580 \mathrm{~km}^{2}$, con una extensión de $50 \mathrm{~km}$ en el sentido E-O (entre $69^{\circ} 10^{\prime}$ y $68^{\circ} 55^{\prime} \mathrm{O}$ ) y 31,6 km en sentido N-S (entre $36^{\circ} 33^{\prime}$ y $36^{\circ} 15^{\prime}$ S) (Fig. 1.3).

\subsection{Morfología volcánica}

Los volcanes poligenéticos presentan una amplia gama de morfologías. De una manera muy simple, los volcanes poligenéticos pueden dividirse en construccionales, comprendiendo estos a los volcanes compuestos y excavacionales como las calderas (Németh y Martin, 2007; Davidson y Da Silva, 2000).

Un volcán compuesto se define como un edificio construccional relativamente grande y de una vida activa larga (miles de años), que presenta tanto productos lávicos como piroclásticos, y que pueden hacer erupción a partir de uno o más conductos (Carrasco-Núñez et al., 2010; Davidson y Da Silva, 2000). En esta definición, se incluyen no solo a los clásicos estratovolcanes y a los volcanes en escudo, sino también a otras morfologías volcánicas más complejas. Dentro de estas morfologías más complejas se encuentran los volcanes compuestos en forma de escudo (shieldlike), los cuales presentan bajas pendientes, comúnmente con un cráter o caldera en su cúspide, con una gran diversidad de composiciones, y formados esencialmente por lavas y con menor participación de piroclástos (Davidson y Da Silva, 2000).

El volcán Payún Matrú es claramente poligenético, dada la abundancia y variedad de sus productos volcánicos. Como se mencionó anteriormente, presenta en su cúspide una 


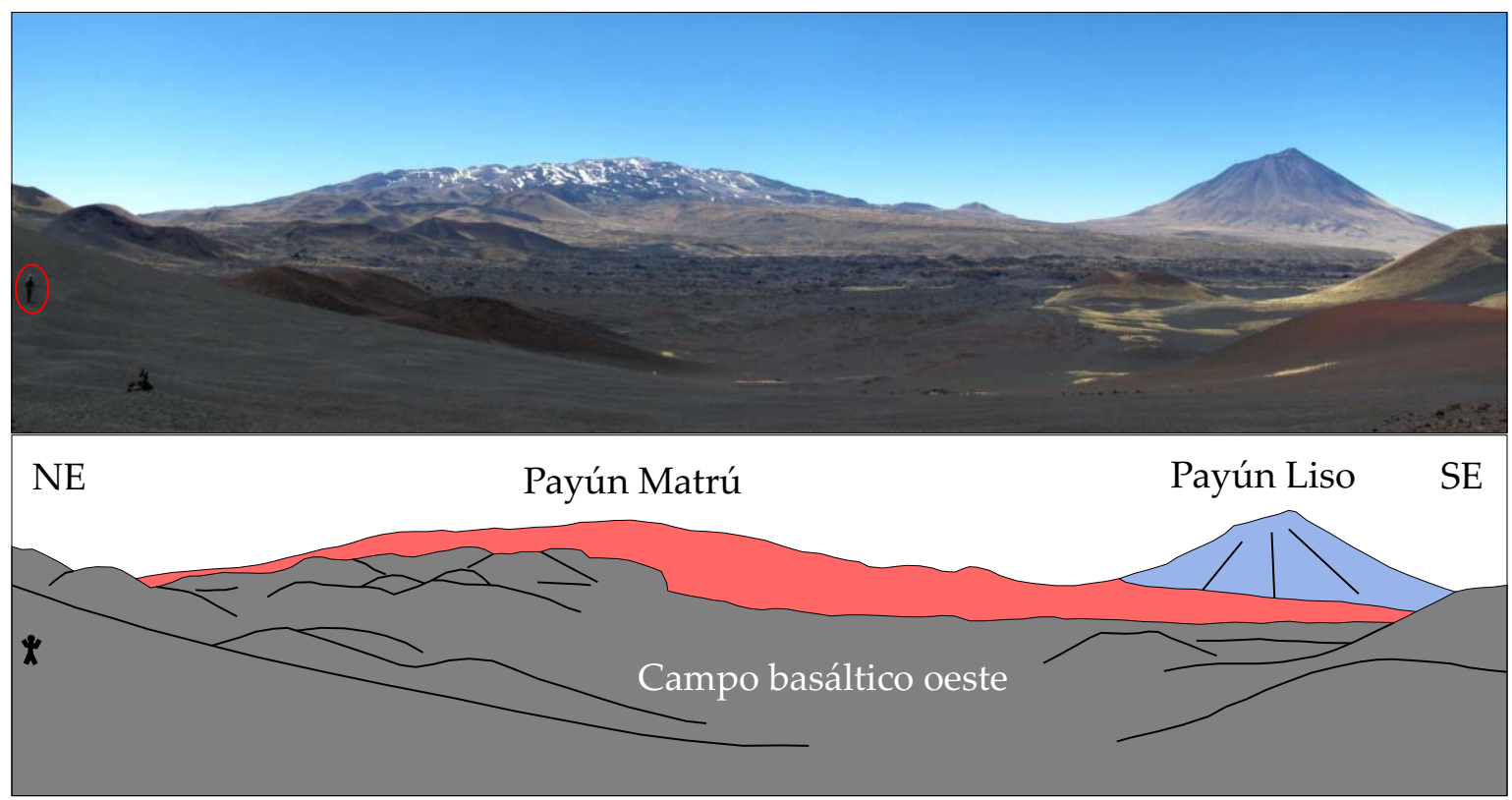

Figura 3.1: Foto del CVPM desde el oeste, mirando hacia el este. Persona a la izquierda de escala.

caldera de $8 \mathrm{~km}$ de diámetro. El volcán se eleva $1.800 \mathrm{~m}$ aproximadamente por sobre la planicie circundante, con una base de $16 \mathrm{~km}$ en sentido E-O, y de $20 \mathrm{~km}$ en sentido N-S. Estos valores son aproximados, dado que las suaves pendientes en la base del volcán hacen que el límite entre el volcán y la planicie circundante sea difuso.

El Payún Matrú presenta una forma achatada, con pendientes relativamente suaves en comparación con un estratovolcán, y las erupciones se produjeron a través de varios centros emisores y no a través de un solo conducto central, como ocurre en los típicos estratovolcanes. Si bien presenta una ignimbrita de amplia distribución, junto con otros depósitos piroclásticos de menor extensión, el cuerpo del volcán está conformada por productos lávicos. Sobre las bases de las definiciones mencionadas, el Payún Matrú presenta características de más de un tipo morfológico, y posee tanto formas construccionales y excavacionales. Este conjunto de características están de acuerdo con la definición de un volcán compuesto en forma de escudo (shieldlike), con una caldera superpuesta a un antiguo volcán compuesto, y a su vez cubierta por numerosas erupciones posteriores provenientes de varios conductos, que le dan la forma general achatada (Fig. 3.2 a y b).

En un claro contraste, el volcán Payún Liso posee pendientes más pronunciadas, con un cráter central y una forma cónica levemente asimétrica, dado que el sustrato en el cual se asienta va perdiendo altura hacia el sur. Presenta una altura de $1.700 \mathrm{~m}$ respecto de su base, la cual tiene aproximadamente de $8 \mathrm{~km}$ de diámetro, y un cráter de $1 \mathrm{~km}$ de diámetro. Si bien este volcán no se ha estudiado en detalle, puede afirmarse en primera instancia que los productos emitidos aflorantes son principalmente lavas, con menor proporción de rocas 


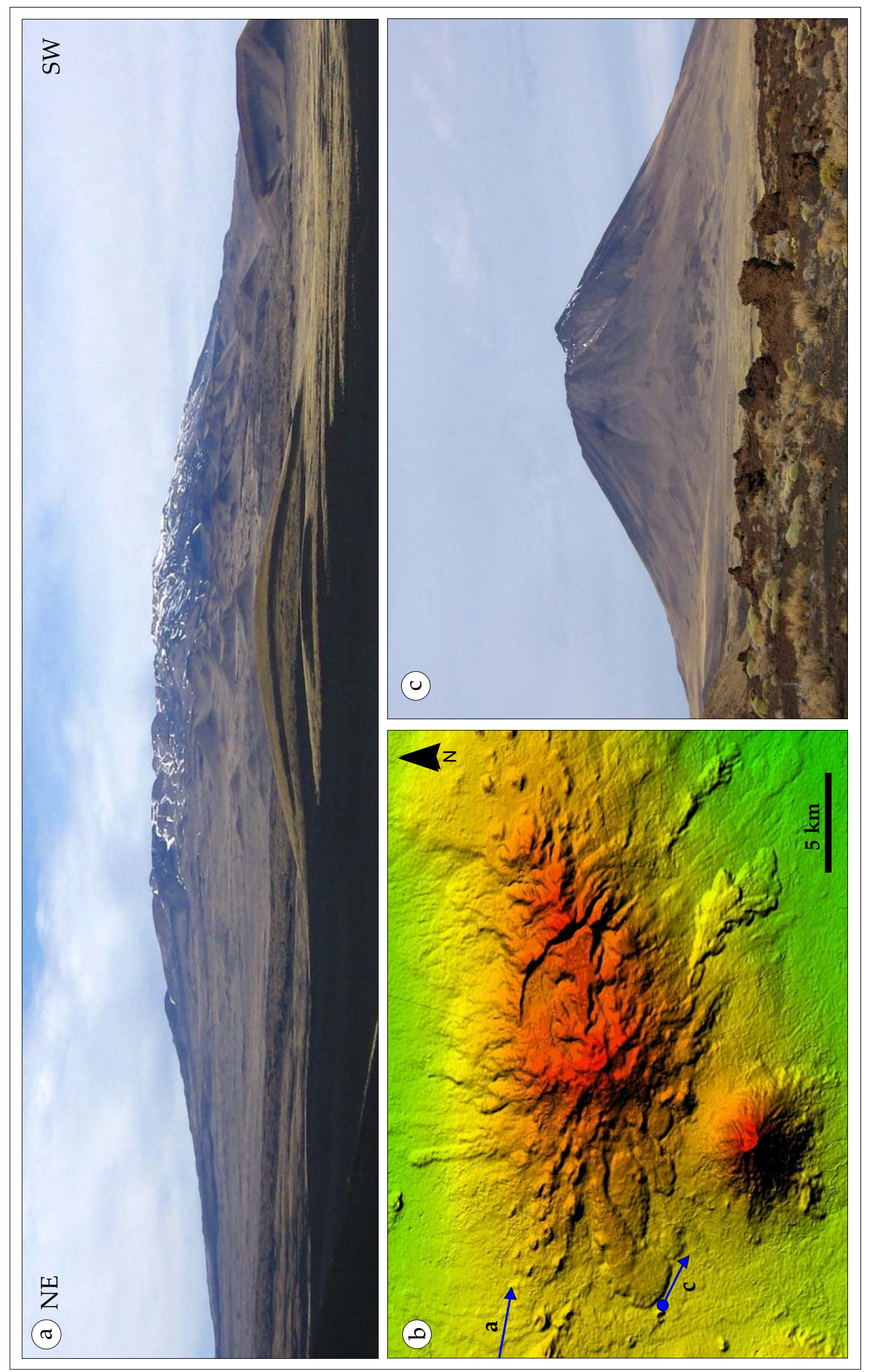

Figura 3.2: a) Foto del volcán Payún Matrú, desde el NO de dicho volcán. Distancia del tope plano del volcán: $8 \mathrm{~km}$. b) DEM (SRTM) mostrando las morfologías contrastantes de los volcanes Payún Matrú (centro de la figura) y Payún Liso (al SO del anterior). c) Foto del Payún Liso visto desde el NO. El cráter es de $1 \mathrm{~km}$ de diámetro. Las flechas azules a y c indican desde donde fueron tomadas las fotografías (fuera del DEM en el caso de la foto a). 
piroclásticas (ignimbritas), siendo también claramente un volcán poligenético. De acuerdo con las características morfológicas, el Payún Liso es un volcán compuesto de tipo cono simple, ampliamente conocido en la literatura como estratovolcán (Fig. 3.2 b y c).

\subsubsection{Cálculo volumétrico del Payún Matrú y Payún Liso}

Se estimó el volumen de ambos volcanes con el Modelo de Elevación Digital (DEM) del terreno SRTM (Shuttle Radar Topography Mission, Rodríguez et al., 2005) (Fig. 3.3). Al calcular el volumen del Payún Matrú, se procuró no abarcar el área de los campos basálticos del este y oeste, ni la del Payún Liso. Por tal motivo, se calculó el volumen dentro del polígono indicado en la Figura 3.3. Este volumen fue estimado adoptando una curva de nivel base, y calculando el volumen contenido entre el plano horizontal definido por esta curva de nivel y la superficie del DEM (volumen encerrado dentro del polígono elegido). El volumen así obtenido es estimativo, dado que tanto el polígono elegido como la cota de base son arbitrarias, aunque basadas en la morfología y la estratigrafía del volcán. Además, para los cálculos se consideró una base plana sin irregularidades, suposición también aproximada.

Para el Payún Matrú, se calcularon tres volúmenes con tres cotas inferiores distintas: una a los $2.000 \mathrm{~m}$, otra a los $2.200 \mathrm{~m}$ y otra a los $2.500 \mathrm{~m}$. Los volúmenes para cada una de las cotas inferiores elegidas resultaron $236,6 \mathrm{~km}^{3}, 171,7 \mathrm{~km}^{3}$ y $95,1 \mathrm{~km}^{3}$, respectivamente. Teniendo en cuenta la extensión de los productos del Payún Matrú, el cálculo más ajustado parece ser aquel que corresponde al plano inferior de cota $2.200 \mathrm{~m}$, con un volumen de alrededor de $172 \mathrm{~km}^{3}$.

Como puede verse, los volúmenes estimados varían considerablemente al cambiar la curva de nivel elegida para el cálculo. Por otra parte, hay que considerar que no se conoce la base del volcán, y que es poco probable que sea exactamente plana, hecho que contribuye también a la incertidumbre de los volúmenes estimados. Germa et al. (2010) reconstruyeron la morfología del volcán previa al colapso y formación de la caldera, y estimaron el volumen del Payún Matrú en $240 \mathrm{~km}^{3}$, valor cercano a aquel obtenido para la cota inferior de 2.000 $\mathrm{m}$. Si bien el valor exacto del volumen no puede obtenerse con precisión, si puede darse un orden de magnitud para el mismo.

En el caso del Payún Liso, se eligió una cota base de 2.000 m, resultando en un volumen de $35,8 \mathrm{~km}^{3}$, considerablemente menor al estimado para el Payún Matrú. Este valor resulta cercano al volumen calculado por Germa et al. (2010), el cual es de 40 km³.

\subsection{Estratigrafía del CVPM}

Como resultado del mapeo geológico llevado a cabo en este trabajo, se realizaron algunas modificaciones al esquema estratigráfico propuesto por Groeber (1946) y mejorado fundamentalmente por Llambías (1966). La nueva estratigrafía propuesta no es regional para toda 


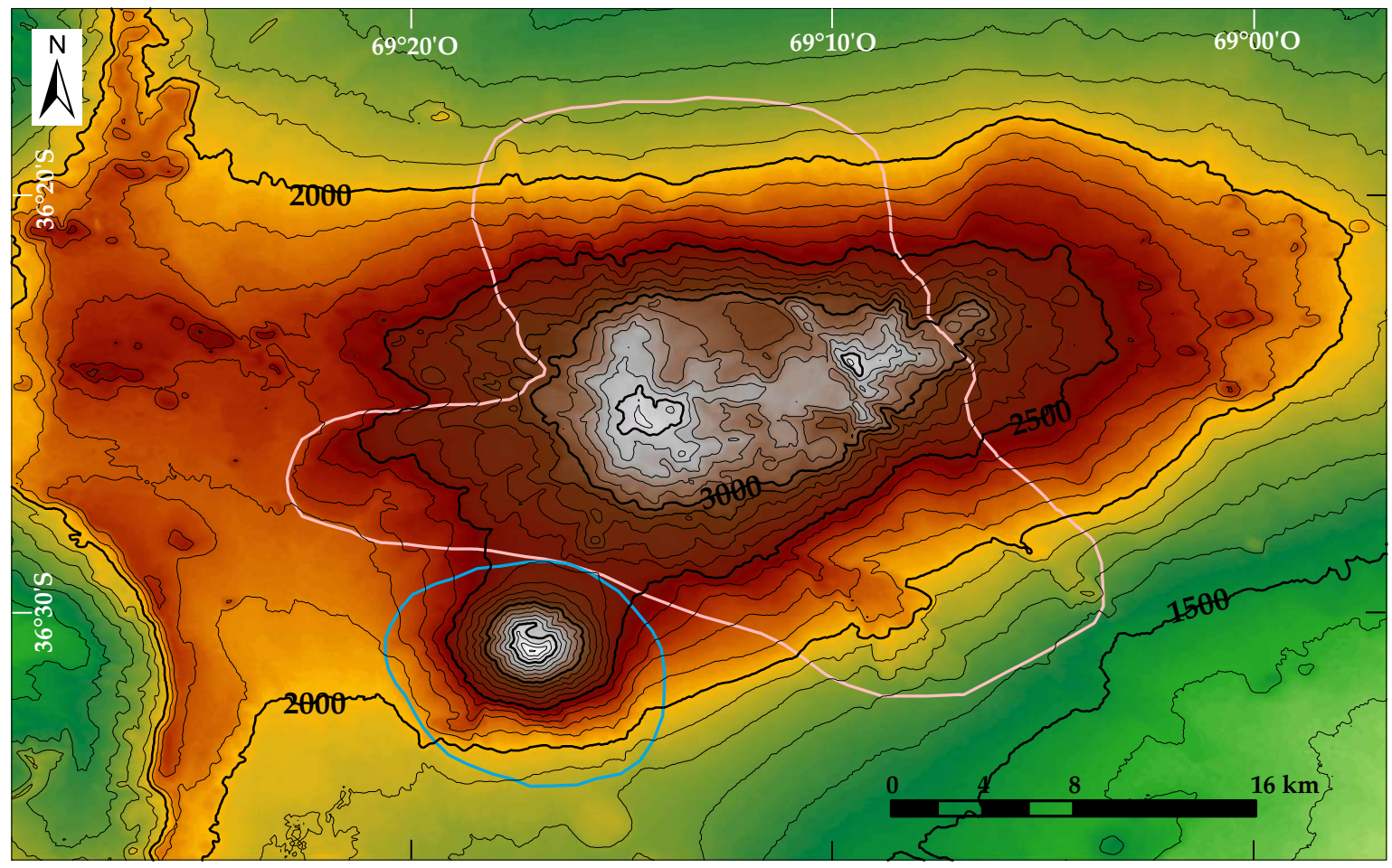

Figura 3.3: DEM (SRTM) con curvas de nivel con una equidistancia de $100 \mathrm{~m}$. En rosa claro se indica el polígono dibujado para calcular el volumen del Payún Matrú, y en celeste el del Payún Liso.

la provincia de Payenia, sino que incluye solamente el Campo Volcánico Payún Matrú. Esto se debe a que la estratigrafía propuesta, al igual que la de Llambías (1966), es específica de este campo volcánico, no pudiendo ser extrapolada a otros sitios, y a que las correlaciones con los basaltos del Campo Volcánico Llancanelo no son directas.

Los criterios para diferenciar las unidades y litofacies volcánicas son variados. La principal división radica en la distinción entre los productos propios de los campos basálticos, y aquellos pertenecientes al volcán Payún Matrú y Payún Liso. Esta división es importante, ya que marca no sólo diferencias en la composición de las lavas y rocas piroclásticas, sino también otras diferencias tales como la formación de un campo volcánico relativamente extenso con numerosos conos monogénicos (campo basálticos), y la formación de volcanes compuestos (volcanes Payún Matrú y Payún Liso). A su vez, estas diferencias morfológicas y composicionales señalan otra característica importante, la cual no es descriptiva sino interpretativa: los magmas de los campos basálticos no provendrían en principio de la/las cámaras magmáticas del Payún Matrú, sino de un reservorio ubicado a mayor profundidad.

La Ignimbrita Portezuelo es fácilmente reconocible en el campo y presenta gran extensión areal. Esto permite utilizarla como horizonte guía para diferenciar los productos anteriores y posteriores a la misma, tanto para el Payún Matrú como para los campos basálticos. 
Además, esta ignimbrita representa a un evento importante en la historia del Payún Matrú, ya que a partir de su erupción se formó la caldera en dicho volcán. De esta manera puede distinguirse, para todo el CVPM, una etapa pre-caldera (rocas anteriores a la ignimbrita), una etapa sin-caldera (representada por la Ignimbrita Portezuelo en sí misma y la caldera del Payún Matrú), y una etapa post-caldera (rocas posteriores a la ignimbrita). En el caso del Payún Matrú, además de la ignimbrita, se utilizaron otros criterios para establecer su estratigrafía, siendo estos morfológicos, composicionales, y de la naturaleza explosiva o efusiva de los productos volcánicos.

En los campos basálticos, los criterios para separar las unidades no fueron composicionales (dada la relativa homogeneidad litológica) ni morfológicos (aunque se advierte una diferencia en este aspecto). La Ignimbrita Portezuelo fue utilizada para diferenciar basaltos anteriores y posteriores a la misma y, a su vez, los basaltos post-ignimbrita fueron divididos en dos unidades. Esta división se debe a que dentro de los basaltos post-caldera, existen coladas y conos de escoria que cubren a otras coladas basálticas también post-caldera, y a que se distingue una diferencia en el grado de preservación y la cubierta vegetal y/o sedimentaria entre las mismas. Así, los campos basálticos tienen tres unidades (de la más antigua a la más moderna): Basaltos Pre-caldera ( $B$ pre), Basaltos Post-caldera I (B posI) y Basaltos Post-caldera II (B posII).

El volcán Payún Matrú posee cuatro unidades: Traquitoides Pre-caldera (T pre), Ignimbrita Portezuelo ( $I g$ P), Traquiandesitas Post-caldera (TA pos) y finalmente Traquitas Postcaldera ( $T$ pos). Esta última unidad de Traquitas Post-caldera fue subdividida en tres litofacies: Traquitas en bloque $(T b q)$, Conos pumíceos $(C p z)$ y Traquitas vítreas $(T v)$. Las diferencias se deben a las marcadas diferencias morfológicas de las lavas, y a la presencia de depósitos piroclásticos en el caso de los conos pumíceos, aunque no presentan diferencias significativas en su composición. El Payún Liso, al no haber sido abordado en el presente trabajo, es descripto brevemente como una única unidad indiferenciada $(P L)$.

La Figura 3.4 muestra el esquema estratigráfico presentado aquí y su comparación con el realizado por Llambías (1966). En el presente trabajo se propone que la actividad volcánica en los campos basálticos y en el Payún Matrú son contemporáneas, por lo cual el esquema estratigráfico es dividido en dos columnas, y no en una sola columna con intercalación de unidades basálticas y traquíticas del volcanismo central.

En referencia a la Figura 3.4, es necesario hacer algunas aclaraciones:

- Los Basaltos del Mollar (Llambías, 1966) fueron divididos en dos unidades, ya que originalmente se agruparon en esta unidad lavas pertenecientes tanto al Payún Matrú como a los campos basálticos, las cuales difieren no sólo en su ubicación espacial, sino también en su composición (Fig. 3.4). Las coladas de los Basaltos del Mollar que nacen del borde anular de la caldera, fueron agrupadas en el presente trabajo en las Traquiandesitas Post-caldera, las cuales además son de una composición más silícica, 


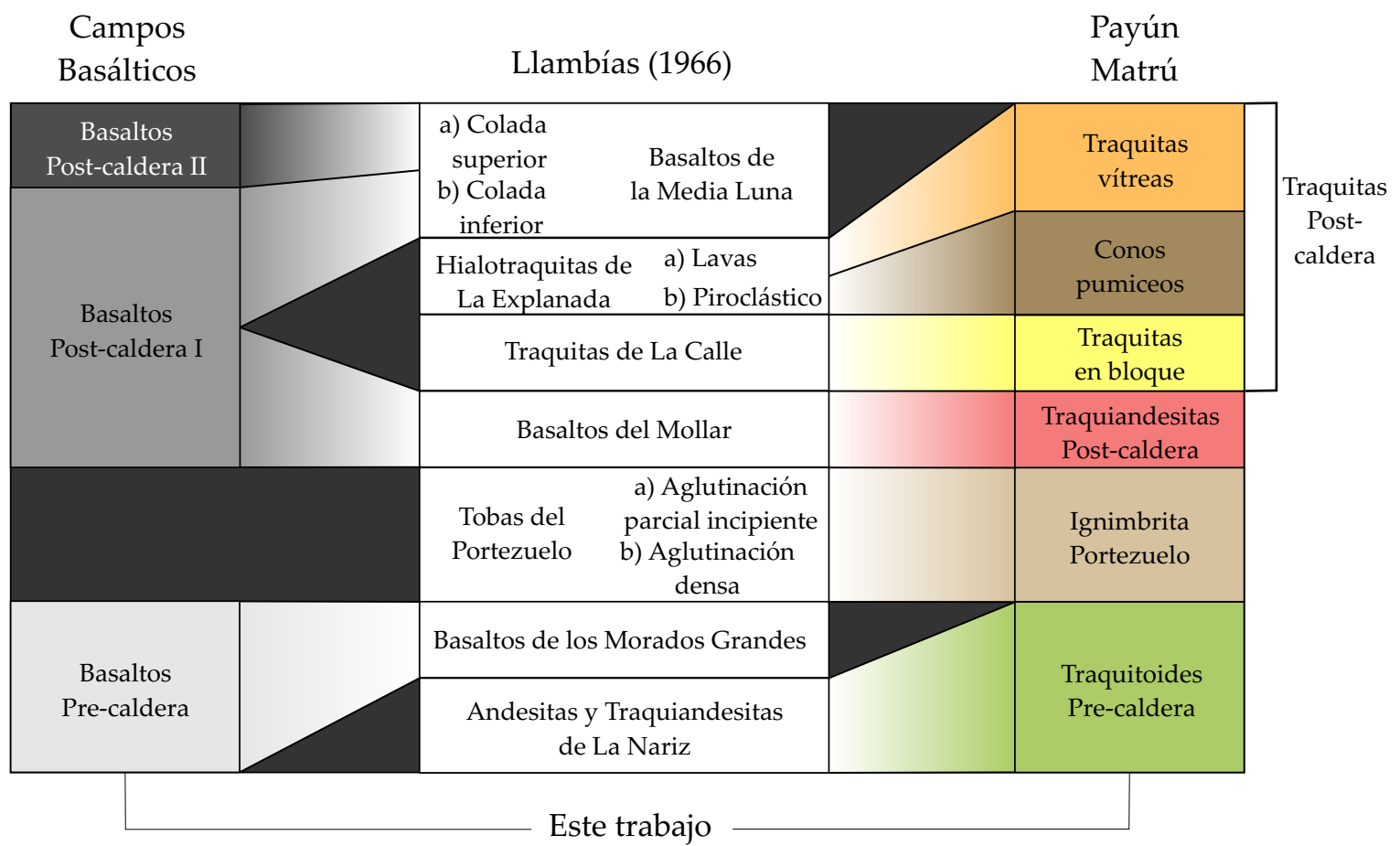

Figura 3.4: Diagrama que muestra la estratigrafía propuesta en este trabajo y su comparación con la estratigrafía realizada por Llambías (1966).

como se verá más adelante.

- La unidad de Basaltos Post-caldera I está compuesta por aquella parte de los Basaltos del Mollar de Llambías (1966) no incluida en las Traquiandesitas Post-caldera, y por la colada inferior de los Basaltos de la Media Luna (Llambías, 1966), ya que son prácticamente indistinguibles entre sí en el campo, y no se dispone de dataciones suficientes de estas lavas que justifiquen tal separación (Fig. 3.4).

- La Ignimbrita Portezuelo fue agrupada en una sola unidad sin tener en cuenta el grado de soldadura, a diferencia del esquema propuesto por Llambías (1966). Esto es debido a que se consideró innecesaria esta distinción a los fines de establecer la estratigrafía, aunque sí es útil para un estudio de detalle de la Ignimbrita Portezuelo. Además, el grado de soldadura de la ignimbrita puede variar considerablemente tanto verticalmente como lateralmente, dificultando el mapeo de zonas de mayor y menor grado de soldadura.

- Las Hialotraquitas de La Explanada, con productos lávicos y piroclásticos (Llambías, 1966), se corresponden con las litofacies Traquitas vítreas y Conos pumíceos, respectivamente, de la unidad Traquitas Post-caldera (Fig. 3.4).

- El orden con que se muestran las tres litofacies pertenecientes a las Traquitas Post- 
caldera no se corresponde exactamente con el orden estratigráfico, como se verá más adelante. Este ordenamiento dado tiene por objeto aclarar las correspondencias en la nomenclatura.

En la Figura 3.5 se muestra el mapa geológico de síntesis del Campo Volcánico Payún Matrú, mientras que en el Anexo I se presenta la versión completa a escala 1:60.000. En la Figura 3.6 se muestran dos vistas diferentes del CVPM en el área mapeada, en primer lugar desde el NO y en segundo lugar desde el SE. Las imágenes fueron confeccionadas superponiendo el mapa geológico (exceptuando estructuras) sobre una representación de la topografía de la región en base al Modelo Digital de Elevaciones ASTER (ASTER GDEM, 2009).

\subsubsection{Columnas estratigráficas}

En una primera instancia, y con el fin de definir la estratigrafía general del CVPM, se confeccionaron numerosas columnas estratigráficas parciales, abarcando áreas relativamente pequeñas en las cuales fue posible distinguir la relación estratigráfica entre las diferentes coladas lávicas y depósitos piroclásticos. Luego, estas columnas estratigráficas parciales fueron agrupadas abarcando áreas mayores (Fig. 3.7), para delinear y comprender la estratigrafía de todo el campo volcánico. Esto fue necesario dada la discontinuidad espacial de los productos volcánicos, a excepción de la Ignimbrita Portezuelo.

La confección de columnas estratigráficas por sectores pudo llevarse a cabo debido a dos factores: la excelente preservación de las formas volcánicas, lo cual permite fácilmente su reconocimiento, especialmente en la etapa post-caldera, y también debido a la dispersión del volcanismo en el Payún Matrú en diferentes centros de emisión. Este hecho permitió una menor superposición de los sucesivos productos volcánicos, lográndose así un mejor control estratigráfico que el que se encontraría en el caso de erupciones emitidas a través de un sólo conducto central (como ocurre en el Payún Liso).

Como puede observarse en la Figura 3.7, los sectores a y g al oeste y este de la caldera, respectivamente, presentan mayormente unidades basálticas, mientras que en el sector de la caldera (e) estas están ausentes. Esta importante diferencia fue lo que motivó el presente trabajo, tal como fue señalado en la introducción.

La zona f, al sur de la caldera, presenta mayormente unidades traquíticas del Payún Matrú, junto con el estratovolcán Payún Liso, mientras que los basaltos están prácticamente ausentes (Fig. 3.7 y 3.8 a). El Payún Liso está cubierto por la Ignimbrita Portezuelo en el flanco norte del mismo, indicando que su construcción fue previa a la erupción explosiva y, además, no se observan flujos recientes.

En el sector d, ubicado en el borde oeste de la caldera, existe una compleja interdigitación de unidades basálticas y traquíticas, mostrando el pasaje complejo entre ambos dominios (Fig. 3.7 y 3.8 b). En el sector oeste cercano a la caldera (b y c) se encuentran tanto unidades 


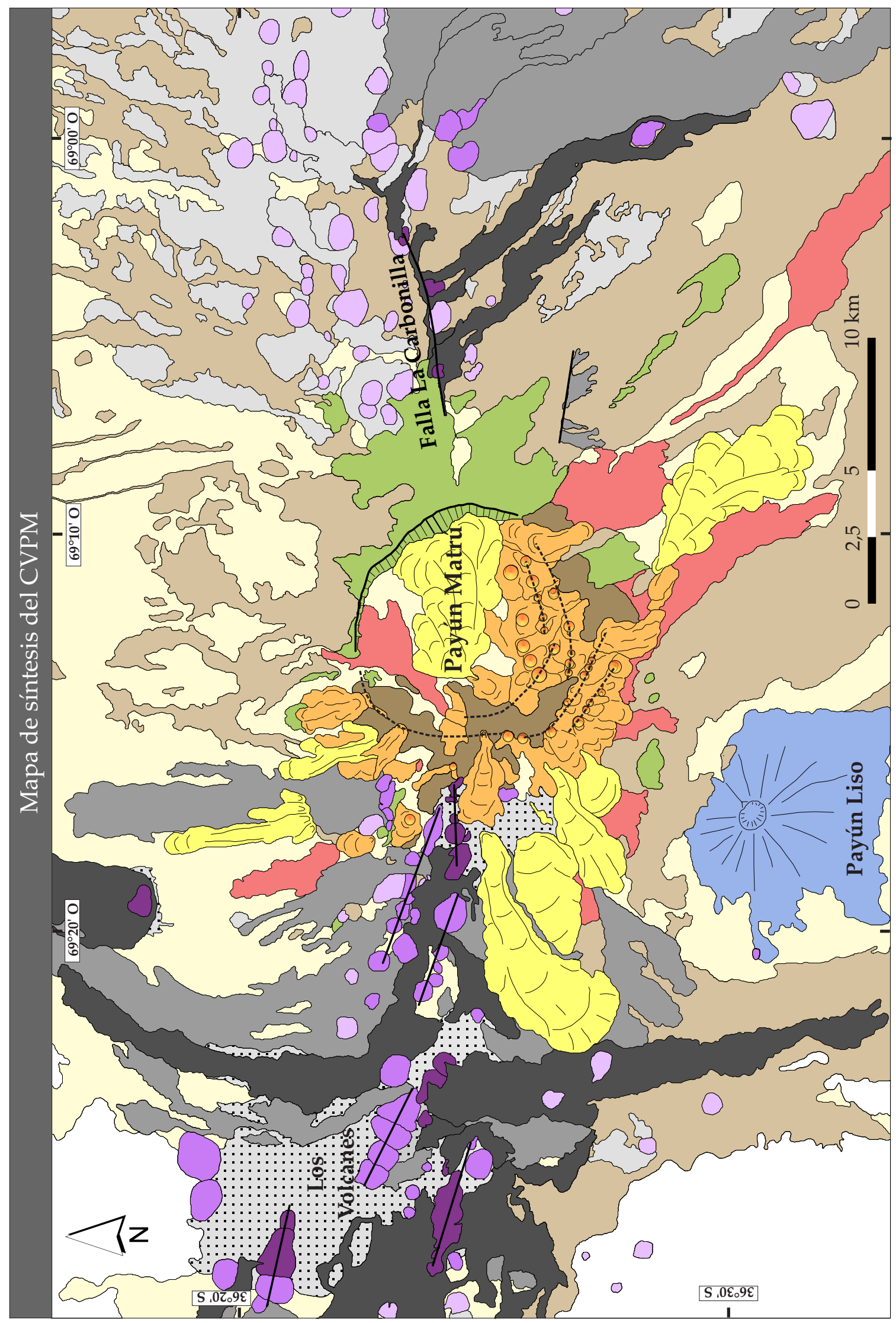

Figura 3.5: Mapa geológico de síntesis del CVPM. Referencias en la próxima página. 


\begin{tabular}{|c|c|c|c|c|}
\hline \multicolumn{5}{|c|}{ Referencias } \\
\hline 0 & $T v$ & & $\begin{array}{llll}\mathbf{a} & \mathbf{b} & & \text { B posII }\end{array}$ & Cubierta de escoria lapillitica \\
\hline & Cpz & T pos & a b $B$ posI & Sedimentos modernos \\
\hline & $T b q$ & & a b B pre & Basamento indiferenciado \\
\hline & TA pos & & a) lavas & Pared topográfica de la caldera \\
\hline & $\operatorname{Ig} P$ & & b) Conos de escoria & $\begin{array}{l}\text { Fracturas indicadas por } \\
\text { alineamiento de centros emisores }\end{array}$ \\
\hline & Tpre & & $P L$ & Fracturas inferidas \\
\hline
\end{tabular}

Figura 3.5: Referencias del mapa resumido del CVPM. Payún Matrú está conformado por las siguientes unidades: $T$ pos (Traquitas Post-caldera); $T v$ (litofacies de Traquitas vítreas); $C$ $p z$ (litofacies de Conos pumíceos); T bq (litofacies de Traquitas en bloque); TA pos (Traquiandesitas Post-caldera); Ig P (Ignimbrita Portezuelo); $T$ pre (Traquitoides Pre-caldera). Campos basálticos: B posII (Basaltos Post-caldera II); B posI (Basaltos Post-caldera I); B pre (Basaltos Pre-caldera). Payún Liso indiferenciado: $P L$.

basálticas como traquíticas del Payún Matrú, con coladas traquíticas y traquiandesíticas que nacen en las cercanías del borde de la caldera y que fluyen hacia los flancos del volcán.

A partir de estas columnas estratigráficas por sectores, puede llegarse a un esquema estratigráfico general del Campo Volcánico Payún Matrú, el cual refleja la contemporaneidad del volcanismo fisural basáltico con el volcanismo central del Payún Matrú, y también con el del Payún Liso en la etapa pre-caldera (Fig. 3.9).

\subsection{Edades radimétricas}

\subsubsection{Edades radimétricas previas}

Germa et al. (2010) realizaron 14 dataciones con el método ${ }^{40} \mathrm{Ar}-{ }^{39} \mathrm{Ar}$ en los volcanes Payún Matrú y Payún Liso, y también en el campo basáltico del oeste. Si bien los autores no ubicaron las muestras datadas en un esquema estratigráfico, aquí se les ha asignado la unidad/litofacies correspondiente de acuerdo a la estratigrafía propuesta, teniendo en cuenta su ubicación a partir de las coordenadas publicadas. En la Figura 3.10a se indica la localización de cada una de las muestras, junto con las tres muestras datadas en el presente trabajo. En la tabla de la Figura 3.10b se reproducen los datos presentados por Germa et al. (2010).

De las 14 muestras analizadas por Germa et al. (2010), seis corresponden al Payún Matrú, cuatro al Payún Liso y cuatro al campo basáltico del oeste. Las dataciones del Payún Liso indican un rango acotado de edad, entre $261 \pm 4$ y $285 \pm 5$ ka (Germa et al., 2010). En el caso 


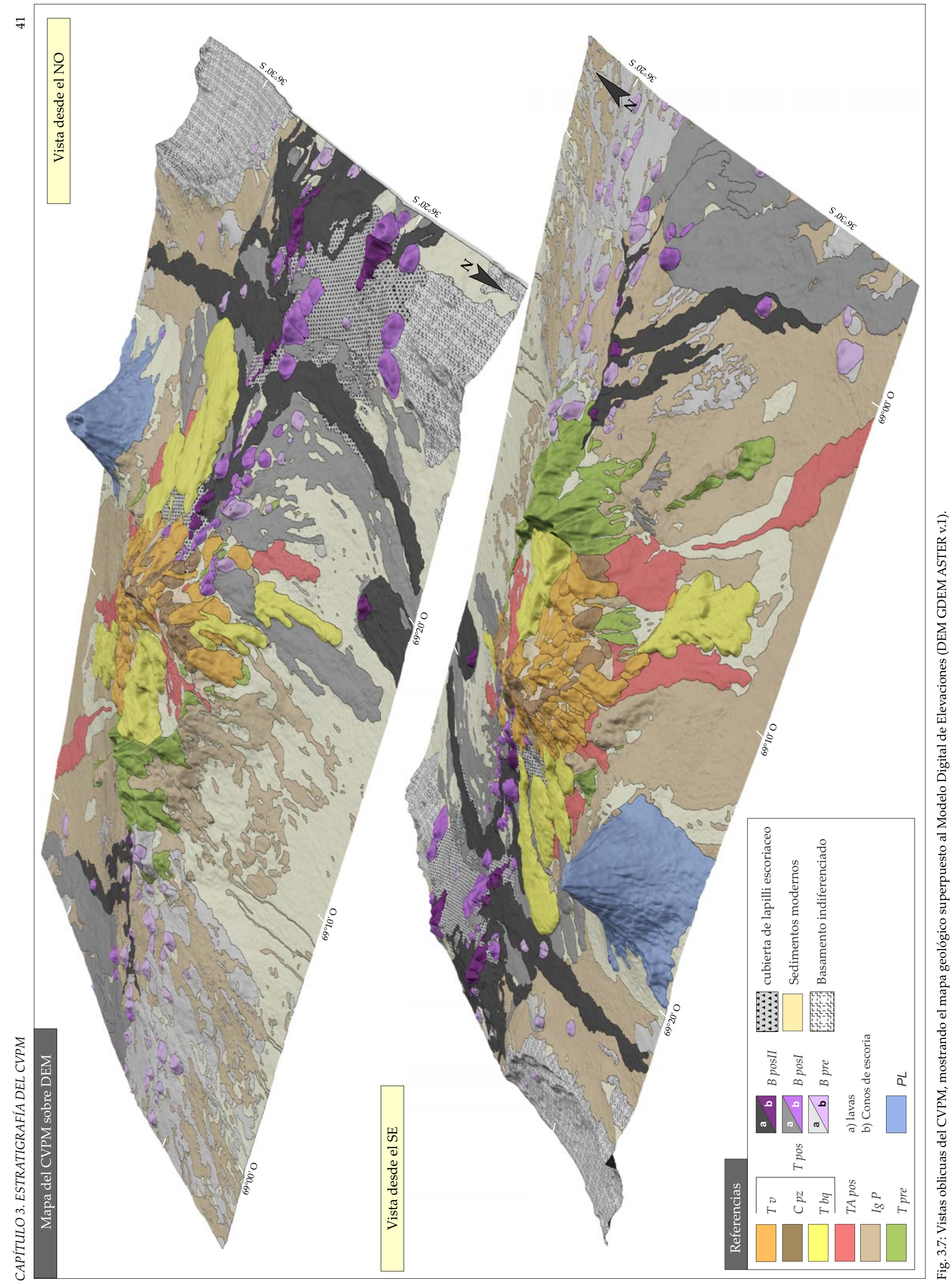




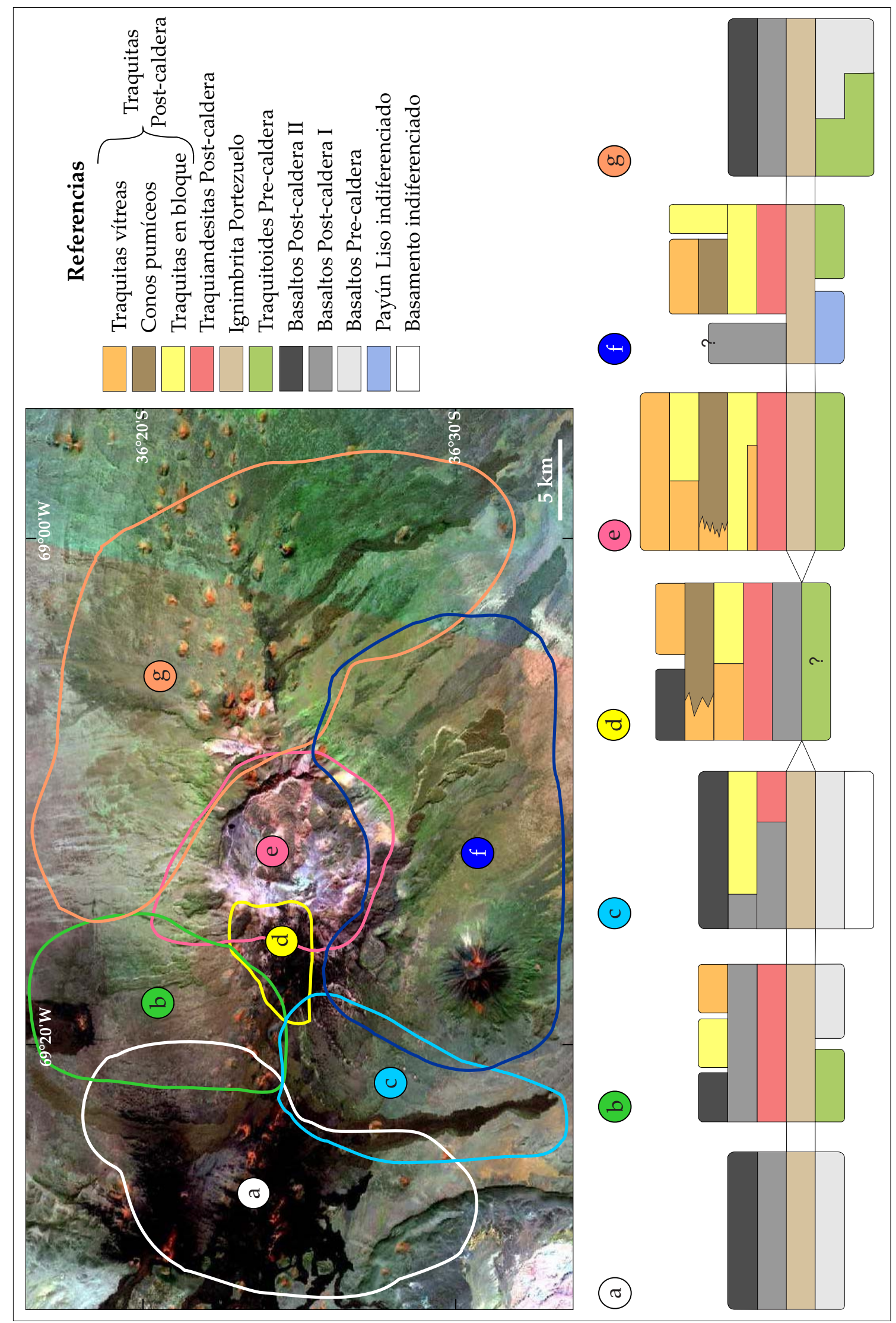

Figura 3.7: Imagen satelital LANDSAT 7, mostrando las áreas en donde se realizaron columnas estratigráficas parciales (a-g). 


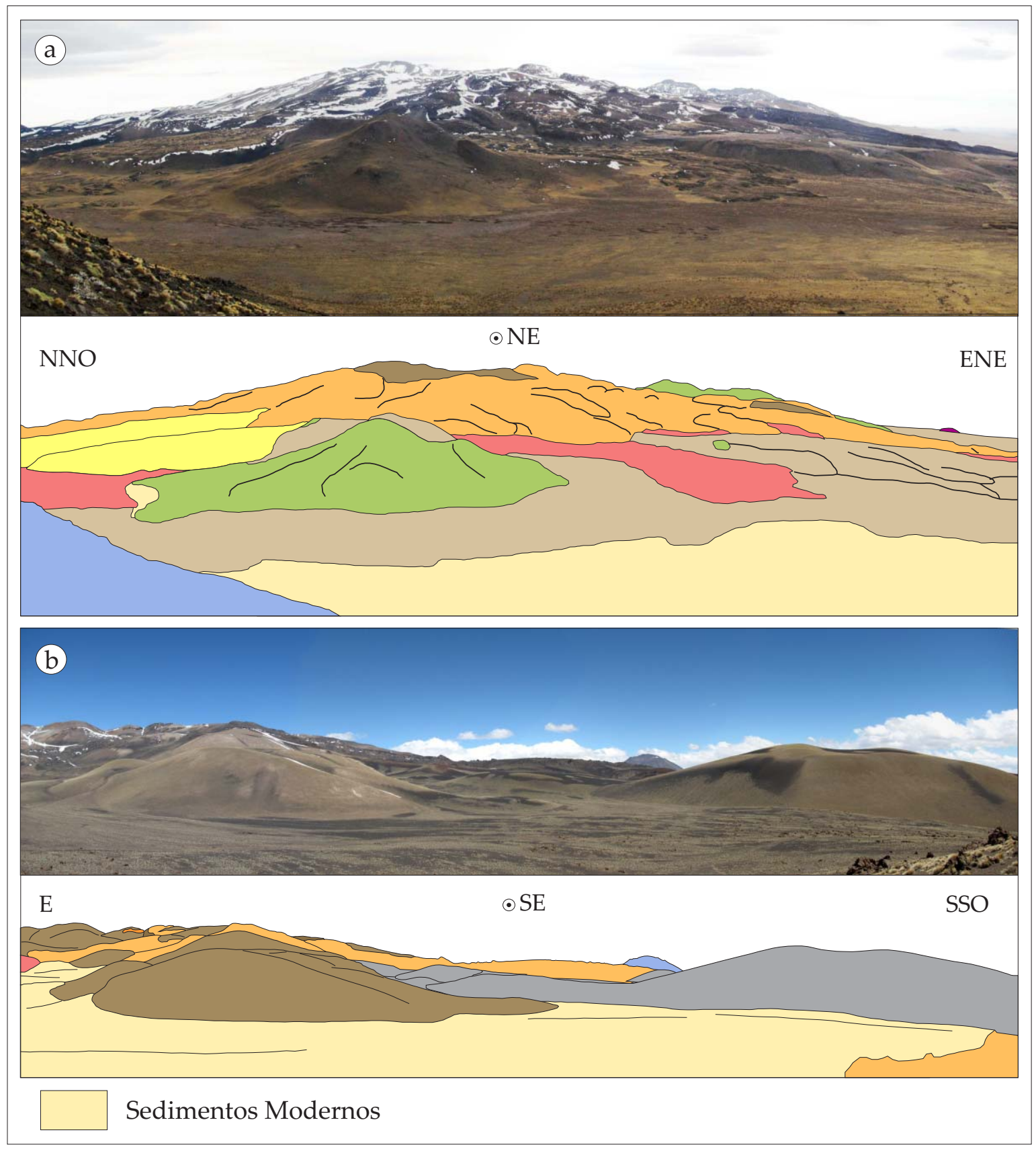

Figura 3.8: a) Foto desde el cráter del volcán Payún Liso hacia el flanco sur del Payún Matrú. Se observan las relaciones estratigráficas mostradas en el sector $\mathrm{f}$ de la Figura 3.7, a excepción de las coladas basálticas las cuales están fuera de la foto. La foto abarca $10 \mathrm{~km}$ de un extremo a otro de la misma. Para las referencias, ver Figura 3.7. b) Foto desde el oeste de la caldera hacia el SE, ilustrando en parte la estrecha asociación espacial entre las unidades del Payún Matrú y las del campo basáltico del oeste. Ancho de la foto aproximado: 1,8 km. 


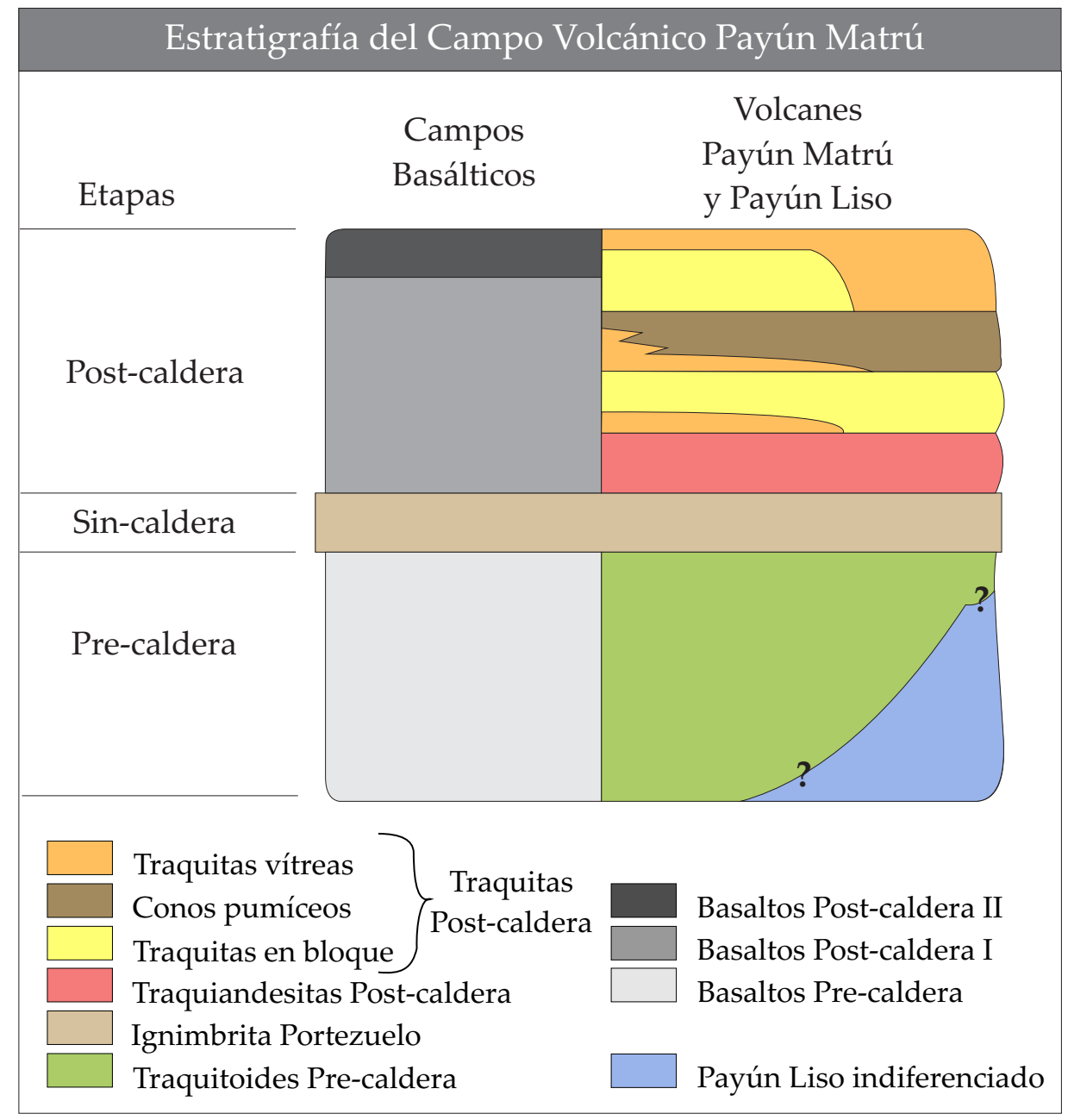

Figura 3.9: Esquema estratigráfico del Campo Volcánico Payún Matrú. Los signos de interrogación en la base y techo del Payún Liso se deben a que existen dudas acerca de su comienzo, y también en menor medida de su finalización.

del Payún Matrú, una lava pre-caldera arrojó una edad de $168 \pm 4$ ka, la colada intra-caldera de las Traquiandesitas Post-caldera es de $82 \pm 2 \mathrm{ka}$, y cuatro muestras de las Traquitas Postcaldera se encuentran en un rango entre $37 \pm 2$ y $7 \pm 1$ ka (litofacies $C p z$ y $T$ bq) (Fig. 3.10 b). Con respecto a las lavas basálticas al oeste del Payún Matrú, para una lava pre-caldera resultó una edad de $233 \pm 11 \mathrm{ka}$, mientras que para tres lavas post-caldera (asignadas a la unidad $B$ posI) se obtuvo un rango de edad entre $28 \pm 5$ y $<7$ ka (Fig. 3.10 b). La datación de $<7$ ka, correspondiente a una colada al SO del Payún Matrú (muestra 88AB, Fig. 3.10) sería poco confiable, debido a que la misma está cubierta por la colada de Traquitas en bloque "La Calle", la cual fue datada en $26 \pm 2 \mathrm{ka}$. Además, en la tabla de datos presentada por Germa et al. (2010), los contenidos de ${ }^{40} \mathrm{Ar}$ de esta muestra en particular son marcadamente menores que en el resto $(<0,1 \%)$, presentando así mismo una gran dispersión en las edades utilizadas para obtener el valor promedio (incluyendo una edad negativa en $-8 \pm 6$ ka y otra 
a Ubicación de las muestras datadas (Germa et al. 2010 y este trabajo)

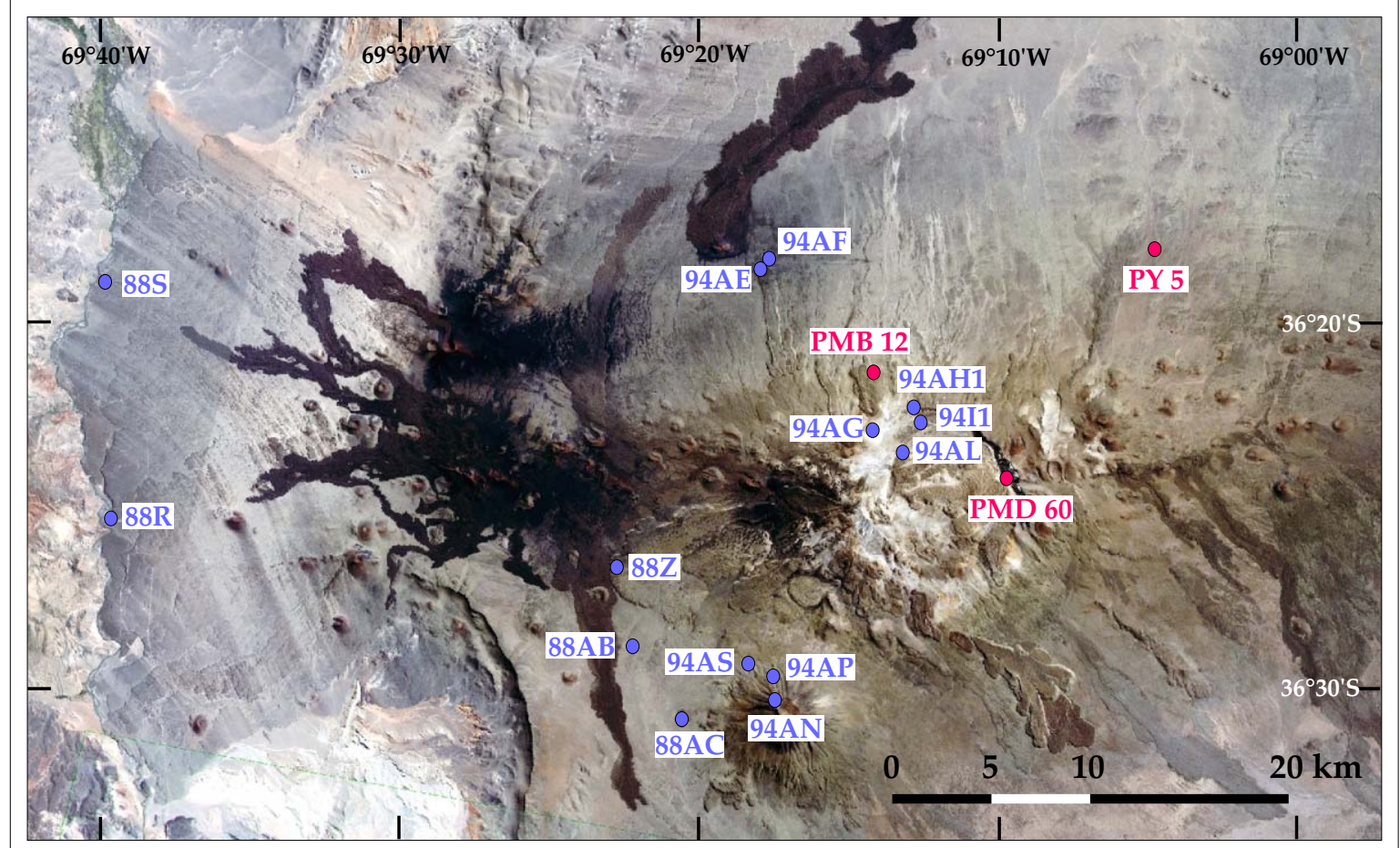

b) $\quad$ Edades ${ }^{40} \mathrm{Ar} /{ }^{39}$ Ar por Germa et al. (2010)

\begin{tabular}{|ccccc|}
\hline Muestra & S & O & Edad (ka) & Unidad asignada \\
\hline $88 \mathrm{AC}$ & $36^{\circ} 30^{\prime} 47.9^{\prime \prime}$ & $69^{\circ} 20^{\prime} 43.5^{\prime \prime}$ & $285 \pm 5$ & PL \\
$94 \mathrm{AP}$ & $36^{\circ} 29^{\prime} 42.6^{\prime \prime}$ & $69^{\circ} 17^{\prime} 41.3^{\prime \prime}$ & $272 \pm 5$ & PL \\
$94 \mathrm{AN}$ & $36^{\circ} 30^{\prime} 20.5^{\prime \prime}$ & $69^{\circ} 17^{\prime} 27.6^{\prime \prime}$ & $264 \pm 6$ & PL \\
$94 \mathrm{AS}$ & $36^{\circ} 29^{\prime} 16.9^{\prime \prime}$ & $69^{\circ} 18^{\prime} 20.7^{\prime \prime}$ & $261 \pm 4$ & $\mathrm{PL}$ \\
$88 \mathrm{R}$ & $36^{\circ} 25^{\prime} 26.0^{\prime \prime}$ & $69^{\circ} 39^{\prime} 36.3^{\prime \prime}$ & $233 \pm 11$ & B pre \\
$94 \mathrm{AH} 1$ & $36^{\circ} 22^{\prime} 26.1^{\prime \prime}$ & $69^{\circ} 12^{\prime} 48.5^{\prime \prime}$ & $168 \pm 4$ & T pre \\
$94 \mathrm{I} 1$ & $36^{\circ} 22^{\prime} 49.1^{\prime \prime}$ & $69^{\circ} 12^{\prime} 36.5^{\prime \prime}$ & $82 \pm 2$ & TA pos \\
$94 \mathrm{AG}$ & $36^{\circ} 23^{\prime} 7.8^{\prime \prime}$ & $69^{\circ} 14^{\prime} 6.9^{\prime \prime}$ & $37 \pm 2$ & $\mathrm{C}$ pz (T pos) \\
$94 \mathrm{AF}$ & $36^{\circ} 18^{\prime} 28.6^{\prime \prime}$ & $69^{\circ} 17^{\prime} 48.1^{\prime \prime}$ & $28 \pm 5$ & B posI \\
$88 \mathrm{Z}$ & $36^{\circ} 26^{\prime} 31.6^{\prime \prime}$ & $69^{\circ} 22^{\prime} 50.6^{\prime \prime}$ & $26 \pm 2$ & $\mathrm{~T}$ bq (T pos) \\
$88 \mathrm{~S}$ & $36^{\circ} 18^{\prime} 47.9^{\prime \prime}$ & $69^{\circ} 39^{\prime} 50.3^{\prime \prime}$ & $26 \pm 5$ & B posI \\
$94 \mathrm{AE}$ & $36^{\circ} 18^{\prime} 34.3^{\prime \prime}$ & $69^{\circ} 17^{\prime} 55.5^{\prime \prime}$ & $15 \pm 1$ & $\mathrm{~T}$ bq (T pos) \\
$94 \mathrm{AL}$ & $36^{\circ} 23^{\prime} 37.5^{\prime \prime}$ & $69^{\circ} 13^{\prime} 08.8^{\prime \prime}$ & $7 \pm 1$ & $\mathrm{~T}$ bq (T pos) \\
$88 \mathrm{AB} *$ & $36^{\circ} 28^{\prime} 55.8^{\prime \prime}$ & $69^{\circ} 22^{\prime} 21.7^{\prime \prime}$ & $<7$ & B posI \\
\hline
\end{tabular}

Figura 3.10: a) Ubicación de las muestras datadas en este trabajo (en rosa) y por Germa et al. (2010) (en azul). b) Tabla de edades radimétricas obtenidas por Germa et al. (2010). En la última columna se indica la unidad/litofacies asignada de acuerdo al actual esquema estratigráfico de este trabajo. *: Edad dudosa, ver explicación en el texto. 
en $10 \pm 7 \mathrm{ka})$.

Muñoz Bravo et al. (1989) presentan una datación de una ignimbrita dacítica, ubicada al oeste del Payún Matrú (sin localización exacta), y la cual es asignada por los autores a la caldera de dicho volcán. La edad de esta ignimbrita es de 0,8 0,6 Ma, y fue obtenida mediante el método K-Ar en roca total. La edad obtenida por Muñoz Bravo et al. (1989) no es coherente con el rango de edad que debería tener la Ignimbrita Portezuelo, de acuerdo con las dataciones de Germa et al. (2010) y las presentadas en este trabajo. González Díaz (1979) presenta una edad radimétrica K-Ar en roca total de un basalto olivínico del Payún Liso, la cual es de 0,8 $\pm 0,5 \mathrm{Ma}$. Otras edades no publicadas y realizadas mediante el método K-Ar en roca total, por la Secretaría de Minería, corresponden a: i) una traquiandesita en la "Sierra de Payún Matrú arriba" de edad 0,18 \pm 0,18 Ma; un traquibasalto de la "Colada de Los Reales", al oeste del Payún Matrú, con una edad de 0,3 $\pm 0,3$ Ma; iii) un basalto del Payún Liso, con una edad de 0,55 $\pm 0,45 \mathrm{Ma}$, y finalmente, iv) un traquibasalto del flanco norte del Payún Liso, de edad 0,65 \pm 0,5 Ma. Cabe destacar el gran error que poseen estas dataciones, tanto las realizadas por la Secretaría de Minería como las presentadas por Muñoz Bravo et al. (1989) y González Díaz (1979).

\subsubsection{Nuevas edades radimétricas}

Con el objetivo de acotar la edad del volcanismo fueron seleccionadas tres muestras del Payún Matrú, más una muestra del campo basáltico este, para su datación por el método ${ }^{40} \mathrm{Ar}^{39} \mathrm{Ar}$. Las cuatro muestras representativas, tres del Payún Matrú y una del campo basáltico este, fueron seleccionadas según el siguiente esquema: una muestra que represente en lo posible las rocas más antiguas aflorantes (etapa pre-caldera), una muestra de la Ignimbrita Portezuelo (etapa sin-caldera), una muestra que represente a las coladas más modernas (etapa post-caldera), y por último, una muestra de una lava basáltica del campo este (precaldera).

La edad de la lava pre-caldera elegida del Payún Matrú, se ubica en la parte inferior del perfil de "La Nariz" y fue datada en 700,6 \pm 10,6 ka (Fig. 3.10, muestra PMD 60). Este resultado indica un lapso de tiempo considerable para la evolución pre-caldera del Payún Matrú, de por lo menos $550 \mathrm{ka}$. También extendería la vida de todo el campo volcánico, si se tiene en cuenta que los basaltos fisurales y los traquitoides del Payún Matrú se encuentran relacionados genéticamente, siendo los magmas traquíticos formados mediante el fraccionamiento de los magmas basálticos, como se verá más adelante.

La Ignimbrita Portezuelo no pudo ser datada, debido a que los cristales de feldespato alcalino de la muestra seleccionada arrojaron escaso Ar, por lo cual la edad obtenida no resulta confiable. La muestra más moderna elegida pertenece a la litofacies de Traquitas vítreas de la unidad Traquitas Post-caldera, emitida en el borde norte de la caldera (Fig. 3.10, muestra PMB 12), y fue datada en 20,2 $\pm 6,5 \mathrm{ka}$. Esta edad se encuentra dentro del rango de 


\section{Nuevas edades del CVPM}

(a)

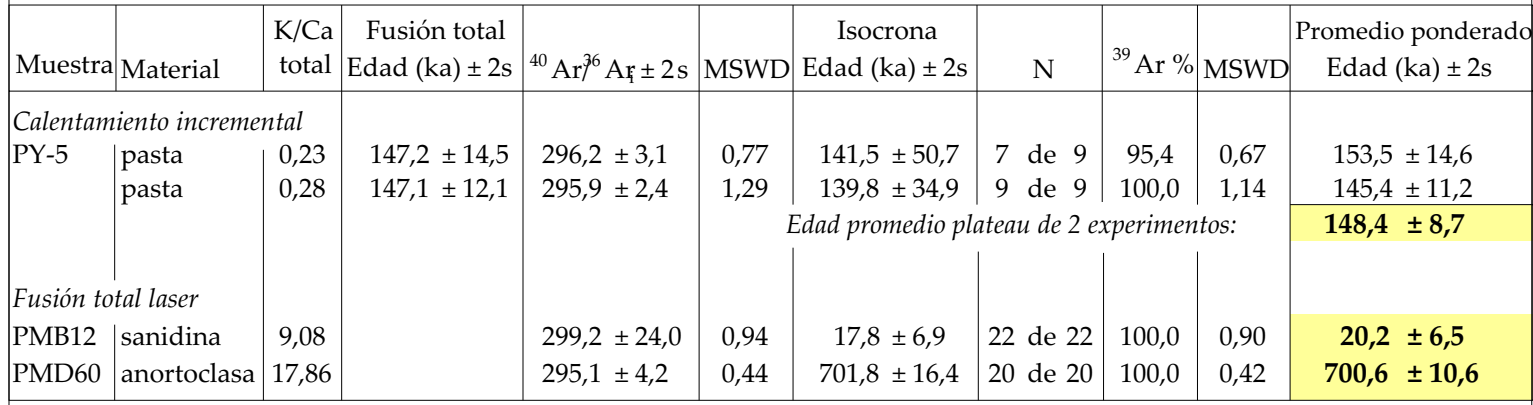

(b)

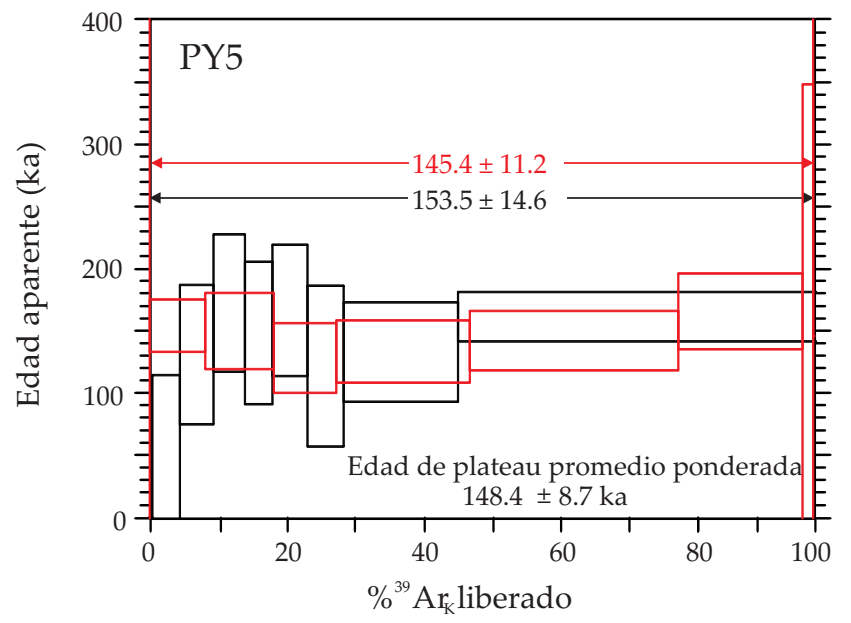

Tabla 3.1: a) Tabla con edades radimétricas. b) Diagrama con el plateau de edades del Basalto Pre-caldera (muestra PY 5).

edades previas disponibles de la litofacies Traquitas en bloque de la misma unidad (Germa et al., 2010), confirmando la complejidad estratigráfica e intercalación de estas litofacies, tal como puede observarse en el campo en algunos sectores.

El basalto datado ubicado en el campo basáltico del este proviene de unos conos de escoria cercanos a la caldera, denominados "Morados Grandes" (Fig. 3.10, muestra PY 5). El motivo de la elección de esta muestra pre-caldera es que las dataciones de los basaltos fisurales previas pertenecen todas al campo del oeste y a que, además, estas son en su mayoría post-caldera. La edad obtenida es de $148,4 \pm 8,7 \mathrm{ka}$, por lo cual la edad de la Ignimbrita Portezuelo queda acotada entre 148 y $82 \mathrm{ka}$.

Dos conclusiones importantes pueden resaltarse a partir de las edades radimétricas disponibles (tanto las previas como las nuevas). En primer lugar, el rango de edades de los basaltos fisurales y los volcanes Payún Matrú y Payún Liso se superponen, lo cual constituye una prueba más de la contemporaneidad de estos diferentes estilos de volcanismo. Por otro lado, el tiempo de vida del Payún Matrú es considerable, de al menos 700 ka. Si bien 
este valor es mayor al que se esperaba, no resulta extraño al considerar los diversos tiempos de vida activa que pueden presentar los volcanes compuestos. Los sistemas volcánicos pueden permanecer activos durante largos períodos de tiempo entre los picos de actividad. Dos ejemplos los constituyen el Monte Santa Helena en EEUU, el cual estuvo activo desde 940 ka, y el volcán Tatara-San Pedro (Chile), activo desde 930 ka (Davidson y Da Silva, 2000). 


\section{Capítulo 4}

\section{Descripción geológica del Campo Volcánico Payún Matrú}

Las unidades pertenecientes al volcán Payún Matrú, y aquellas correspondientes a los campos basálticos se describirán principalmente, en este capítulo, en base a las observaciones de campo. Aunque las clasificaciones geoquímicas del CVPM se mostrarán en el capítulo 7, en el presente capítulo se utilizarán solamente con fines descriptivos. Dado que a lo largo del capítulo es necesario hacer referencia a determinados sitios del CVPM, se brinda un mapa geológico de síntesis con los nombres propios de cada cuerpo volcánico o lugar mencionados (Fig. 4.1).

\subsection{Volcán Payún Matrú}

\subsubsection{Traquitoides Pre-caldera (T pre)}

Esta unidad representa a la etapa pre-caldera del Payún Matrú en su totalidad, y está conformada por una gran variedad de litologías y cuerpos volcánicos. Los Traquitoides Pre-caldera constituyen una unidad mayormente efusiva, con coladas lávicas y escasos domos, y presenta también, en menor proporción, ignimbritas y rocas volcaniclásticas. La composición de los productos efusivos varía entre traquiandesitas basálticas, traquiandesitas y traquitas, con un marcado predominio de estas últimas sobre el resto de las composiciones.

La estratigrafía detallada de la etapa pre-caldera del Payún Matrú es compleja y no fue desarrollada, debido a que los afloramientos ubicados en la pared topográfia de la caldera son discontinuos y la cubierta de coluvio es importante (Fig. 4.2 a y b), junto con el hecho de que los cuerpos volcánicos son de poca extensión lateral y no se encuentran capas guía. Por lo tanto, no es posible hacer correlaciones entre los distintos afloramientos separados de esta unidad, ni aún en la continuidad de la pared de la caldera.

Los Traquitoides Pre-caldera constituían un volcán poligenético compuesto en forma de 


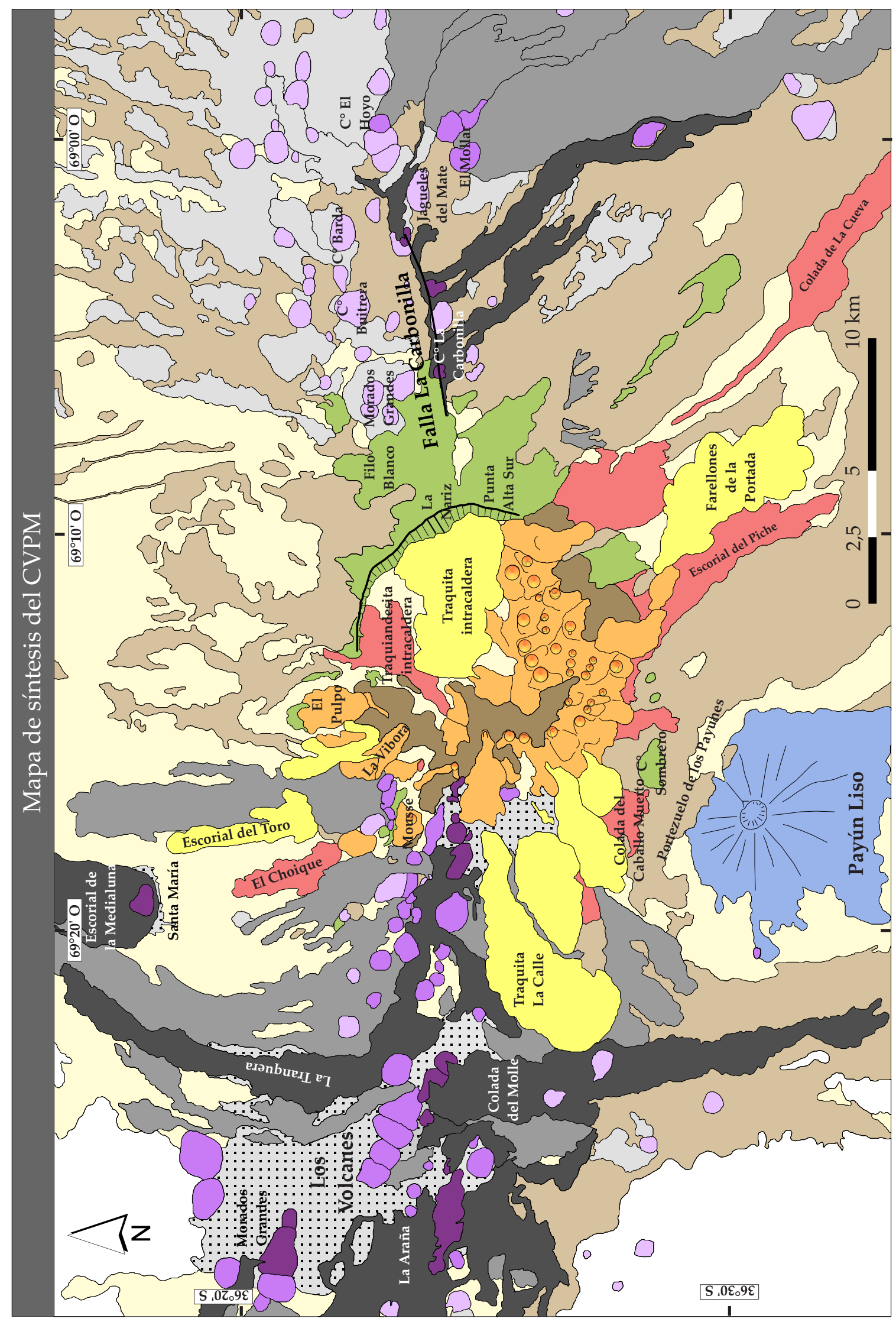

Figura 4.1: Mapa geológico de síntesis del CVPM con los nombres propios de conos de escoria, coladas y otros sitios. Referencias como en la Figura 3.5. 
escudo, lo cual queda evidenciado por la forma en que la Ignimbrita Portezuelo, la cual cubre a esta unidad pre-caldera, se adapta al relieve previo. Afloran principalmente en el borde norte a sureste de caldera y en la ladera noreste a sudeste del Payún Matrú (Fig. 3.5), en menor proporción en el flanco sur extra-caldera, y son escasas al oeste y norte de la misma. A lo largo de la pared topográfica de la caldera (desde el borde $\mathrm{N}$ al SE de la misma), y especialmente en el sector denominado "La Nariz" (Fig. 4.1), se exhibe un corte del antiguo edificio del Payún Matrú. En "La Nariz" la altura de la escarpa es máxima, llegando a los $500 \mathrm{~m}$ y disminuyendo hacia el norte (Fig. $4.2 \mathrm{a}$ ), en donde se pierde por estar cubierta por lavas y otros productos volcánicos posteriores.

Al este de la caldera se encuentran algunos centros de emisión de Traquitas Pre-caldera, alineados en una franja en sentido E-O, como el denominado "Filo Blanco" que, aunque se extiende hacia el norte, el centro de emisión se encuentra en esta franja (Fig. 4.1). En la ladera sureste del Payún Matrú son conspicuos los afloramientos de la etapa pre-caldera, en la denominada "Punta Alta Sur" (Fig. 4.1) y también otras lavas algo más al sur. En este sector, pero más alejada de la caldera, se halla una colada lávica traquítica parcialmente cubierta por la Ignimbrita Portezuelo (Fig. 3.5).

En el flanco sur de la caldera se encuentran remanentes de una antigua colada traquítica, un volcán relativamente pequeño, denominado "Cerro Sombrero" en el presente trabajo (Fig. 4.1), y también otro cuerpo con forma dómica, todos ellos cubiertos casi en su totalidad por la ignimbrita, sobre todo en las laderas enfrentadas con la caldera. Este pequeño volcán y el cuerpo de forma dómica mencionado se ubican en una línea que une a los volcanes Payún Matrú con el Payún Liso, conformando un lineamiento NE-SO.

Al oeste de la caldera los únicos afloramientos atribuibles con dudas, a esta unidad, son escasos (Fig. 3.5). No se observa que la Ignimbrita Portezuelo cubra a estos afloramientos, a excepción de los que están más alejados de la caldera, y se encuentran parcialmente cubiertos por lavas post-caldera, por lo que su posición estratigráfica está en duda. Debido a que sus características litológicas son afines a los Traquitoides Pre-caldera y no a las unidades post-caldera (una diferencia significativa como se verá en el capítulo 6), se asignan por lo tanto a la primera unidad.

La pared interna de la caldera exhibe lavas que en ocasiones forman cuerpos tabulares tipo coladas, otras veces forman cuerpos más ecuantes tipo domos, y en otras ocasiones los afloramientos son tan reducidos que no puede distinguirse una geometría clara (Fig. 4.2 a). En el borde sur de la pared, se encuentra un domo cortado por el colapso de la caldera (Fig. 4.2 c). También se observan algunos diques de pocos metros de espesor, perpendiculares a la pared de la caldera u oblicuos a la misma, verticales a subverticales ( $72-88^{\circ}$ de inclinación) (Fig. 4.2 d). Las rocas volcaniclásticas encontradas son brechas o conglomerados, generalmente monomícticos y pueden ser tanto clasto sostén como matriz sostén.

Por último, se encuentran escasas ignimbritas en la etapa pre-caldera. En "La Nariz", se observa una capa tabular de una ignimbrita negra/rojiza, debajo de unas lavas grises 


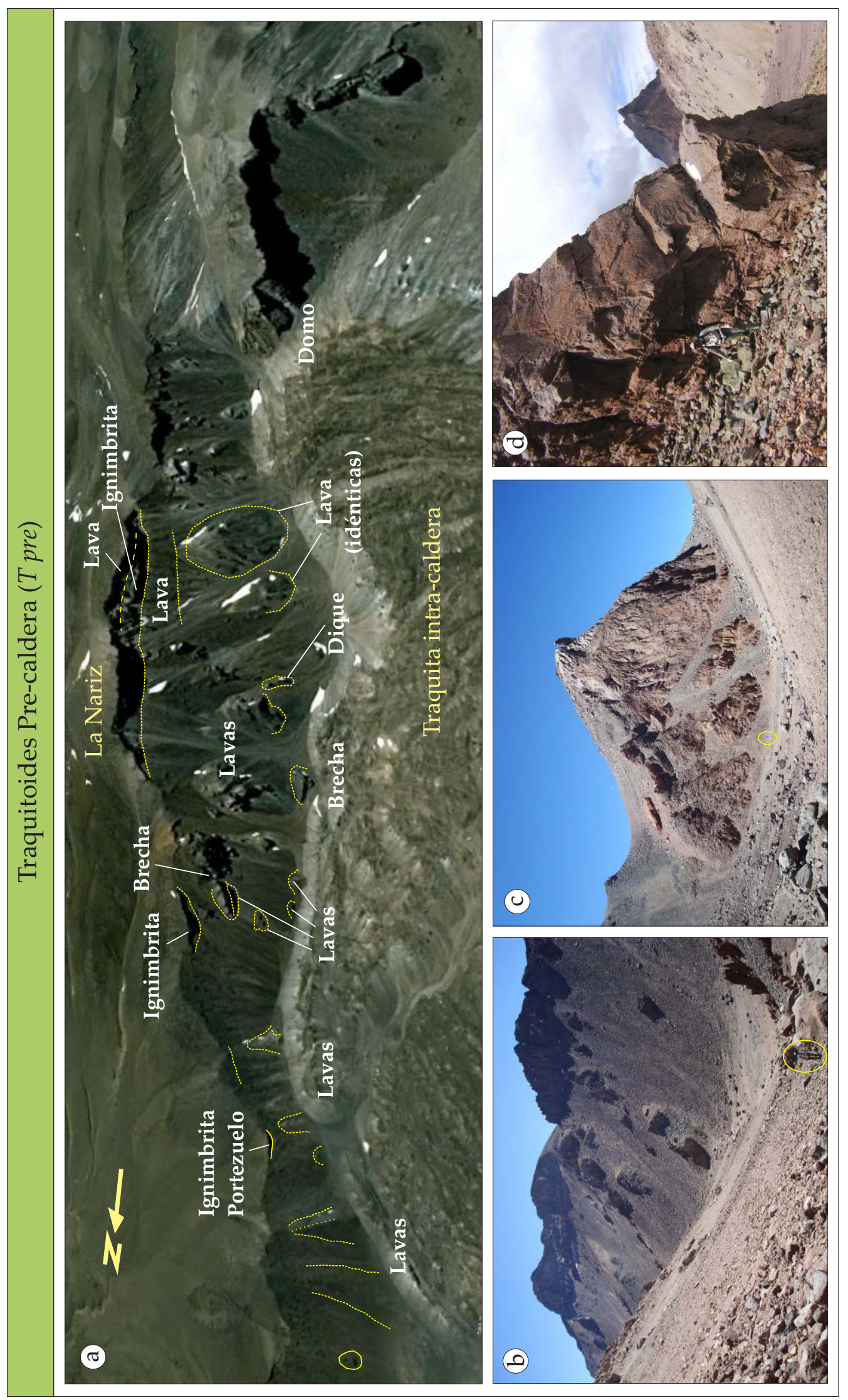

Figura 4.2: a) Imagen de Google Earth oblicua mostrando la pared de la caldera en el sector de "La Nariz". El ancho de la imagen es de 4,5 km. b) Frente de colada traquítica intracaldera a la izquierda, y pared interna de la caldera en "La Nariz" a la derecha. Círculo con persona para escala. c) Domo pre-caldera, persona encerrada en el círculo para escala (no visible). d) Dique traquítico al pie de "La Nariz". 


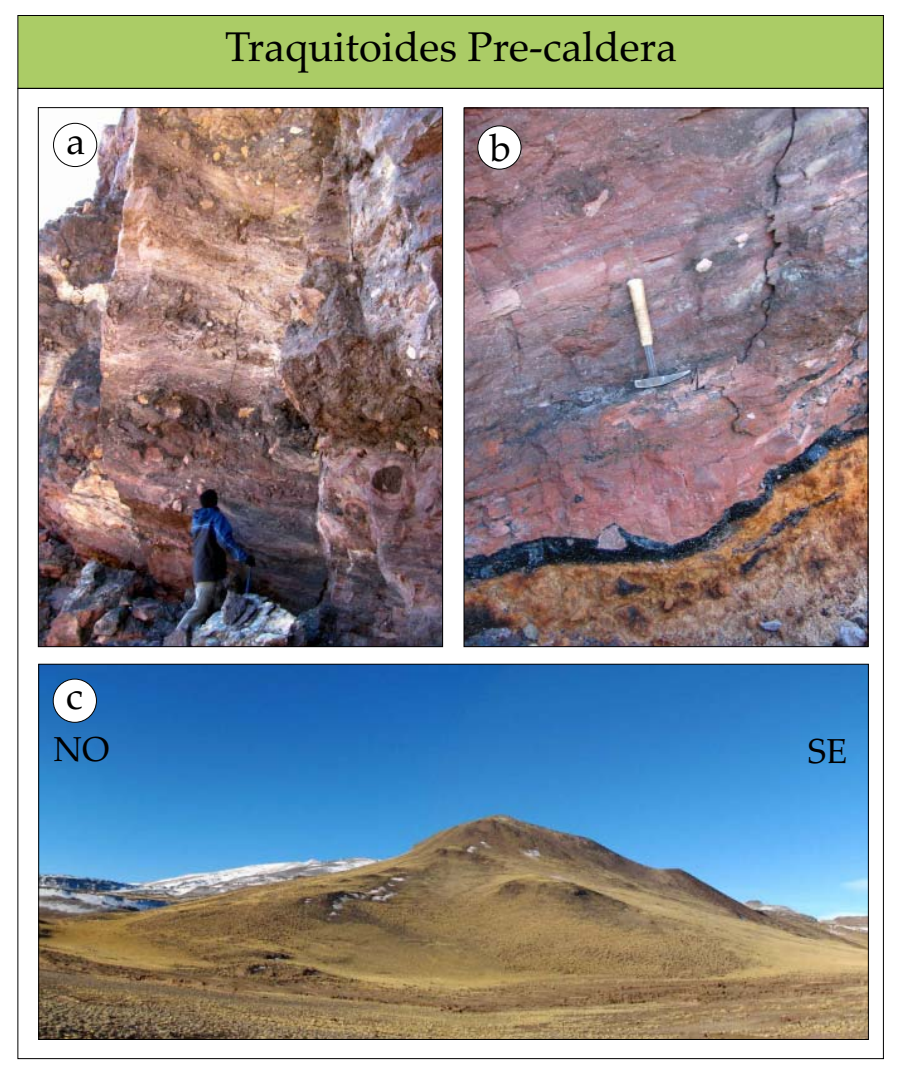

Figura 4.3: a) Ignimbrita pre-caldera aflorante en la pared interna de la misma. b) Base de la misma ignimbrita de la foto anterior, con un depósito de caída proximal y la ignimbrita con una base vítrea de pocos centímetros de espesor. c) "Cerro Sombrero", en la ladera sur del Payún Matrú, visto desde el "Portezuelo de los Payunes". La base tiene 2,3 km de diámetro.

(Fig. 4.2). Esta ignimbrita es de alto grado, con textura eutaxítica y bloques de fragmentos líticos volcánicos de hasta $1 \mathrm{~m}$ de diámetro. Adyacente a "La Nariz" en su borde norte, se encuentra otro afloramiento de ignimbritas de diferentes características. Posee en la base un depósito volcaniclástico de $35 \mathrm{~cm}$ de espesor compuesto mayormente por pómez de tamaños variados, de hasta $10 \mathrm{~cm}$ de diámetro, clasto sostén y mal seleccionado. Por estas características se lo interpreta como un depósito de caída proximal. Le sigue la ignimbrita de aproximadamente $12 \mathrm{~m}$ de espesor, que posee en su base una capa vítrea negra delgada, con cristales de hasta $5 \mathrm{~mm}$ de largo y líticos angulosos volcánicos (traquíticos) de hasta algunos centímetros de diámetro. Por encima, en contacto neto, continúa una ignimbrita negra de muy alto grado, con líticos dispersos de hasta $50 \mathrm{~cm}$ de diámetro y una matriz de textura pseudofluidal, que rodea y envuelve a los fragmentos líticos pero sin signos de reomorfismo.

No se encuentran evidencias de la formación de una caldera debido a la erupción de estas ignimbritas. Esto podría deberse a que el volumen eruptado no fue lo suficientemente grande como para desestabilizar al edificio volcánico y producir su colapso. Para que se lle- 
gue a la formación de una caldera es necesario que se alcance un volumen crítico de material eruptado, el cual depende fuertemente de la relación de aspecto de la caldera (profundidad de la cámara magmática sobre el diámetro de la misma) (Geyer et al., 2006).

En síntesis, la variedad litológica y de cuerpos volcánicos y volcaniclásticos que se observan en el sector de La Nariz indica la complejidad de un perfil expuesto de un antiguo estratovolcán.

\subsubsection{Ignimbrita Portezuelo (Ig $P$ )}

En la zona conocida como el "Portezuelo de los Payunes" entre el Payún Matrú y el Payún Liso, los afloramientos de la Ignimbrita Portezuelo son extensos y presentan una escasa cobertura sedimentaria o de lavas posteriores, de ahí su nombre (Fig. 4.4 a). La Ignimbrita Portezuelo está distribuida radialmente alrededor de la caldera, alcanzando una distancia máxima desde la misma de aproximadamente $40 \mathrm{~km}$. Esta unidad no está expuesta en el interior de la caldera, debido al intenso volcanismo posterior que ocupa gran parte del interior de la misma, y también al relleno sedimentario moderno en la zona más baja.

Los afloramientos se extienden principalmente al norte y sur de la caldera, estando muy restringidos al oeste de la misma, donde los escasos y restringidos afloramientos están cubiertos por la actividad post-caldera en el campo basáltico del oeste (Fig. 3.5). Al este de la caldera, si bien hubo actividad post-caldera, esta no fue tan intensa como para cubrir por completo a la ignimbrita. A su vez, esta se encuentra cubriendo parcialmente al volcanismo pre-caldera, tanto basáltico como traquítico (Fig. 3.5). En la ladera norte del Payún Matrú los afloramientos de la Ignimbrita Portezuelo forman dos grandes lóbulos contiguos, aunque los afloramientos no se terminan en el frente de los lóbulos sino que se continúan hacia el norte, ampliamente cubiertos por sedimentos actuales (Fig. 3.5).

La Ignimbrita Portezuelo es de composición traquítica, como se detallará en el capítulo 7. Los espesores son ampliamente variables, y no siempre presentan su base expuesta. El espesor puede variar desde 10-15 m (sin base expuesta), hasta menos de 0,5 m (con base y techo expuestos). Esta variabilidad en los espesores, junto con la falta de información sobre la ignimbrita intra-caldera, hacen que los cálculos de volumen sean especulativos. Considerando que el diámetro de la caldera es de aproximadamente $8 \mathrm{~km}$, y que ésta es casi circular, el área que ocupa es de aproximadamente $50 \mathrm{~km}^{2}$. Por ejemplo, si existiera una ignimbrita intra-caldera rellenando a la misma, y si esta tuviera un espesor de $100 \mathrm{~m}$, no se estaría considerando un volumen de $5 \mathrm{~km}^{3}$ (sin el cálculo a DRE). Este volumen no considerado aumenta, por supuesto, si la ignimbrita enterrada en la caldera tuviera un espesor mayor. Debido a que en el sector norte de la pared topográfica de la caldera se encuentra a la Ignimbrita Portezuelo cortada por el colapso, es posible suponer que sí existe una ignimbrita intra-caldera, cubierta por completo por productos volcánicos y sedimentarios más jóvenes.

El volumen de la Ignimbrita Portezuelo fue calculado en trabajos previos, dando valores 


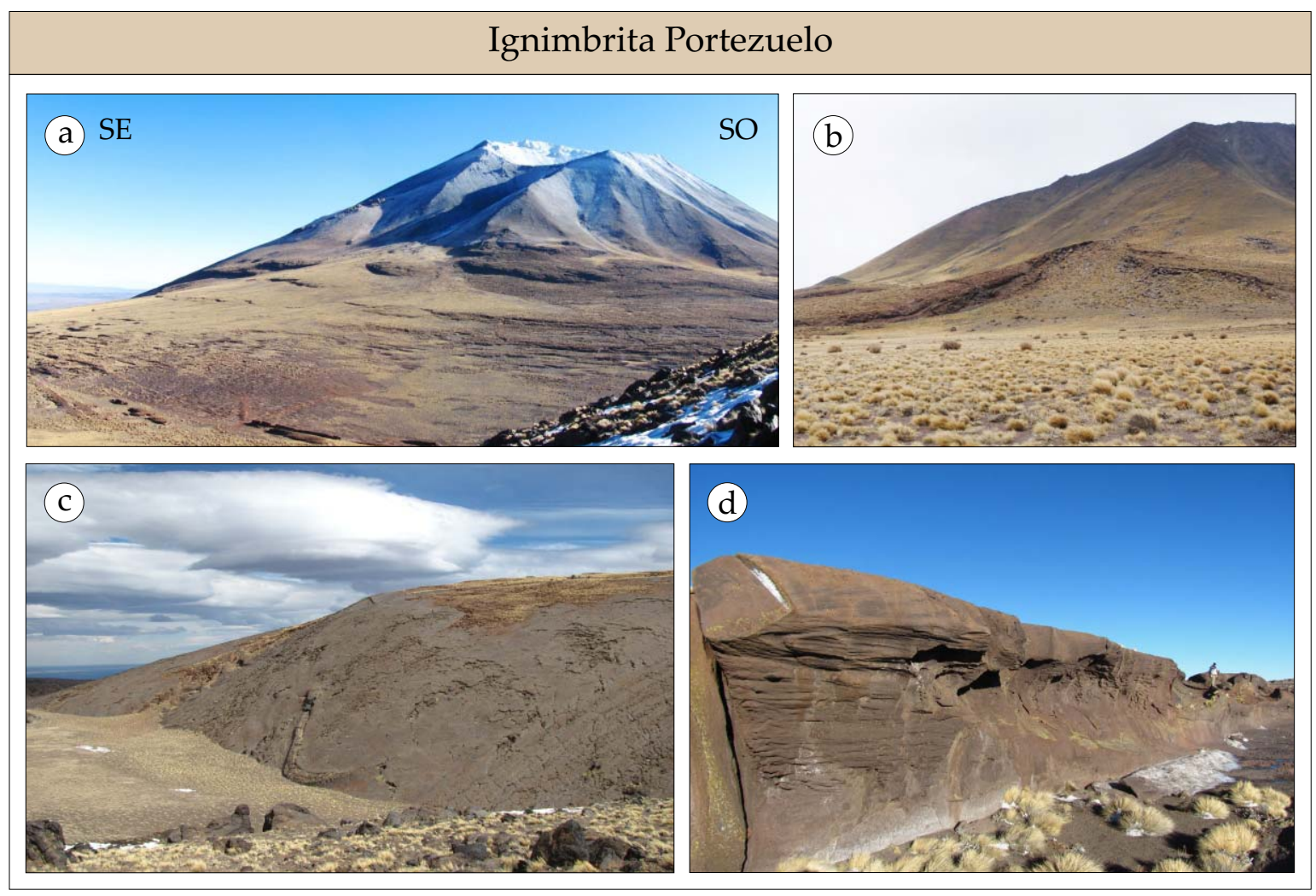

Figura 4.4: Fotos de los afloramientos de la Ignimbrita Portezuelo al sur del Payún Matrú. a) "Portezuelo de los Payunes", con la ignimbrita cubierta incipientemente y yardangs alineados en la dirección del viento. b) Afloramientos de la ignimbrita trepando un alto en la base del Payún Liso, y adelgazándose en el sector más alto. c) Loma pre-caldera (entre el "C $\mathrm{C}^{\circ}$ Sombrero" y la caldera) con la ignimbrita trepando y cubriendo casi por completo a la loma de aproximadamente $60 \mathrm{~m}$ de alto. d) Yardangs en el "Portezuelo de los Payunes" (ver persona de escala), con microyardangs en la pared lateral.

de $25 \mathrm{~km}^{3}$ (Germa et al., 2010) y $33 \mathrm{~km}^{3}$ (Llambías et al., 2010). Aunque existen imprecisiones debidas a los cambios de espesores, la falta de exposición de la base de la ignimbrita y el desconocimiento sobre la ignimbrita intra-caldera, el volumen calculado es útil para asignar un orden de magnitud al mismo, siendo éste de unas pocas decenas de $\mathrm{km}^{3}$. El Índice de Explosividad Volcánico (VEI: Volcanic Explosivity Index), obtenido directamente a partir del volumen de la ignimbrita, y sin tener en cuenta otros factores desconocidos como la altura de la columna eruptiva, arroja un valor de 6. Este valor, aunque no es de los mayores, es de importancia significativa ya que abarca erupciones con un volumen entre $10^{10}$ y $10^{11} \mathrm{~m}^{3}$ (Pyle, 2000).

Si bien se sabe que las ignimbritas rellenan valles y se adelgazan en las zonas más altas de los mismos, también son capaces de sortear obstáculos, dejando sus depósitos en zonas relativamente altas. La altura de los obstáculos que pueden ser sorteados por las corrientes piroclásticas depende de la tasa de erupción y tiene una dependencia compleja con la dis- 
tancia desde la fuente (Woods et al., 1998). Puede observarse en numerosos sitios cómo la Ignimbrita Portezuelo fue depositada sobre un terreno más elevado que su entorno. Tal es el caso de las ignimbritas del flanco N y NE del Payún Liso, cuyos afloramientos están elevados unos $300 \mathrm{~m}$ por sobre la base del mismo (Fig. 4.4 b), o también el domo pre-caldera y el volcán " $\mathrm{C}^{\circ}$ Sombrero" ubicados al pie sur del Payún Matrú, los cuales están extensamente cubiertos por la ignimbrita (en especial el margen que enfrenta al Payún Matrú) (Fig. 4.4 c). También existen numerosos conos de escoria parcialmente cubiertos por la ignimbrita, tanto al este como al oeste de la caldera (como los Morados Grandes).

La ignimbrita Portezuelo presenta rasgos geomorfológicos distintivos, siendo estos yardangs previamente citados por Llambías (1966) e Inbar y Risso (2001b). Estos consisten en rasgos de erosión eólica lineales, paralelos a la dirección de los vientos predominantes, y con una morfología de "barco invertido", o crestones. La altura de estas crestas es variable, llegando a los $3 \mathrm{~m}$ de alto aproximadamente (Fig. $4.4 \mathrm{~d}$ ). Se observan sobre todo en el "Portezuelo de los Payunes", en donde los vientos se canalizan entre los volcanes Payún Matrú y Payún Liso en una dirección ONO-ESE.

\subsubsection{Litofacies de la Ignimbrita Portezuelo}

Durante el presente trabajo no fue realizado un análisis exhaustivo de las facies presentes en la Ignimbrita Portezuelo, ni de su variación espacial. Sin embargo, debido a los frecuentes cambios laterales y verticales de las facies litológicas, resulta conveniente hacer una descripción somera de la ignimbrita en diferentes sectores alrededor de la caldera.

En primer lugar se definirán una serie de facies de ignimbritas, descriptas con poco detalle y sin un estudio granulométrico ni de componentes detallado, siguiendo la nomenclatura de Branney y Kokelaar (2002). Estas son (ver abreviaturas utilizadas en la Figura 4.6):

- Facies mLT: Ignimbrita de colores rojizos/rosados, masiva, con fragmentos pumíceos sin compactación significativa, con cristales (feldespatos, biotita, clinopiroxeno y olivina) y líticos de rocas volcánicas variadas (dominan del tipo traquítico/traquiandesíticas) sub- angulosos. Esta facies es la más habitual y ocupa la mayor superficie.

- Facies emLT: Ignimbrita de colores oscuros variados, masiva y con textura eutaxítica, con fiammes elongados (pueden conservar cierta vesicularidad, sin estar completamente colapsados), cristales (feldespatos, biotita, clinopiroxeno y olivina) y líticos volcánicos de características similares a la facies anterior.

- Facies emLT(v): Ignimbrita negra, masiva y eutaxítica como el caso anterior, pero la matriz es vítrea de color negro, con aspecto de vitrófiro. Presenta fiammes elongados, además de cristales y líticos similares a la facies emLT.

- Facies emLT(cc): Ignimbrita generalmente rojiza, con las características de la facies emLT, pero que además posee clastos no completamente solidificados al momento de 


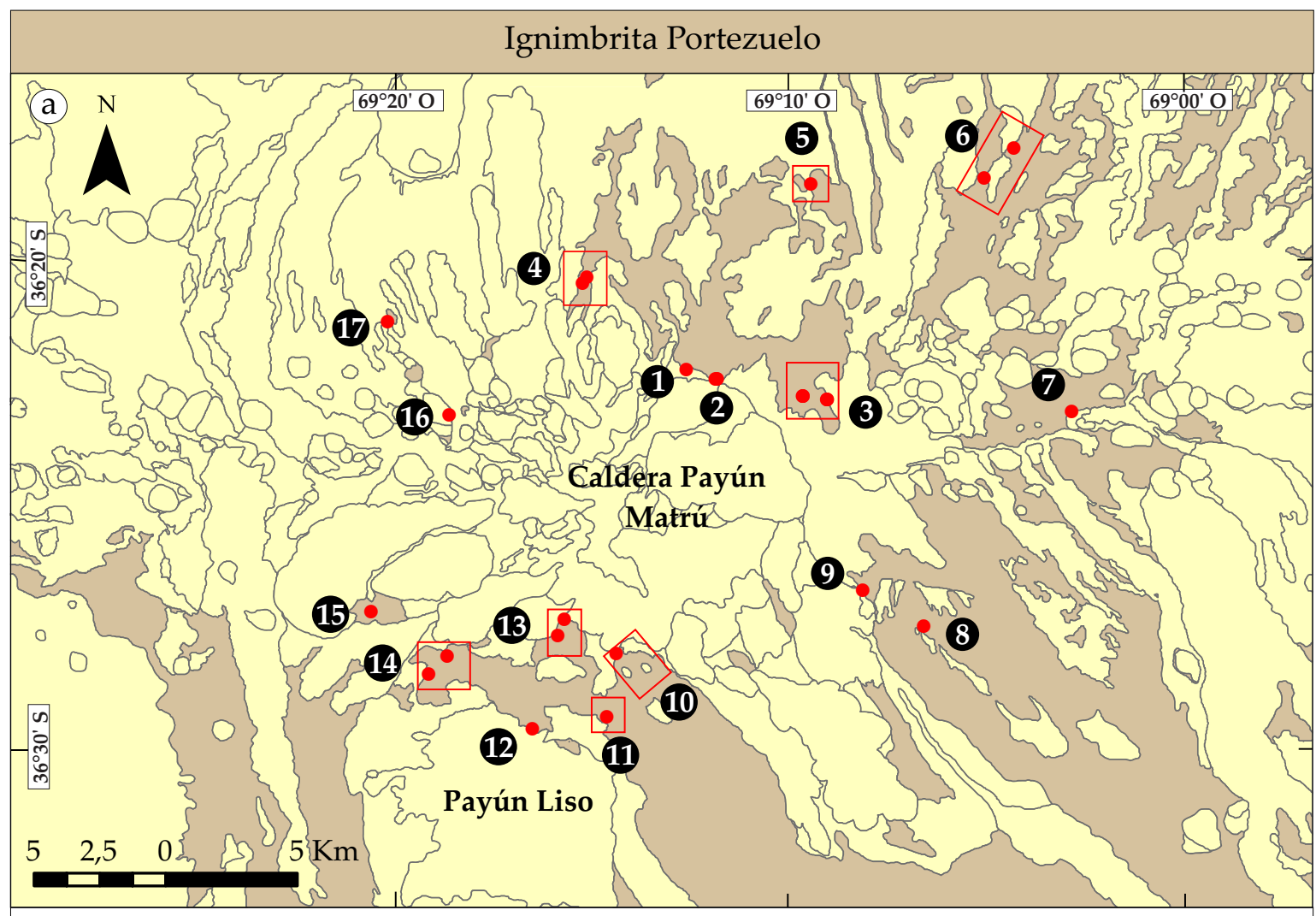

(1)
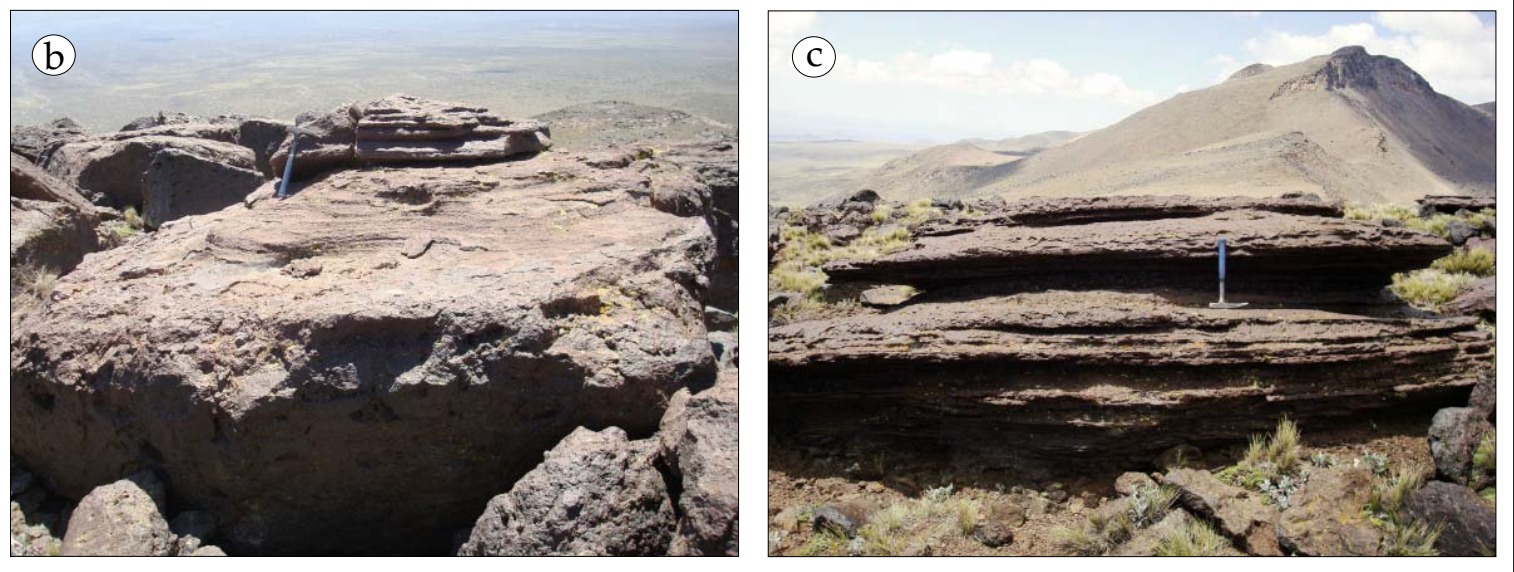

Figura 4.5: a) Mapa geológico resaltando solamente los afloramientos de la Ignimbrita Portezuelo (en el área abarcada por el mapa geológico realizado). Los números indican los sitios en los cuales se describieron las litofaces ignimbríticas. b y c) Detalle de la ignimbrita en el punto 1. Ver explicación en el texto. 


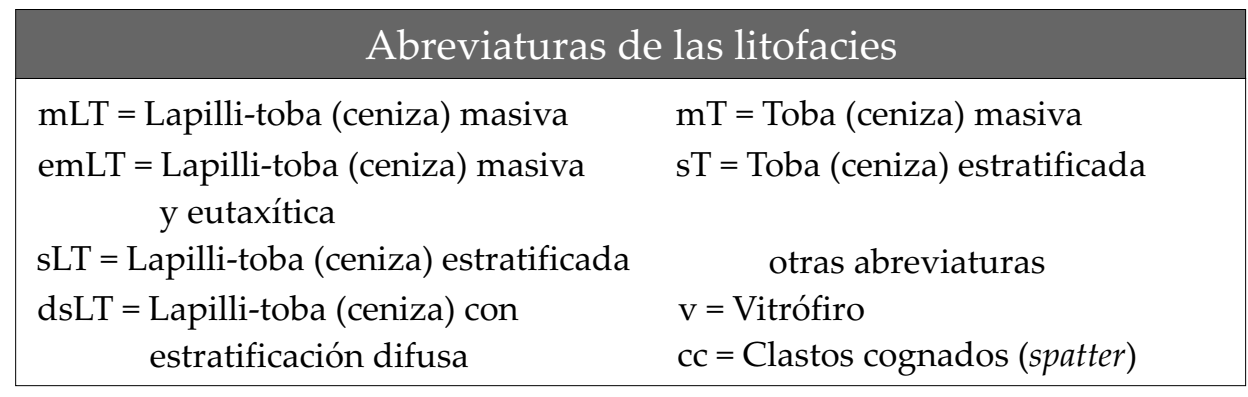

Figura 4.6: Lista de las abreviaturas utilizadas en la caracterización de litofacies ignimbríticas, principalmente de acuerdo a Branney y Kokelaar (2002). La abreviatura LT no hace referencia a abundancias relativas entre lapilli y ceniza.

la depositación, interpretados como clastos de spatter. Estos son de contornos redondeados, ecuantes a discoidales, color negro, porfíricos fundamentalmente con feldespatos (pocos mafitos como biotita, clinopiroxeno y olivina), y generalmente con el centro con mayor contenido en vesículas que el borde más compacto (estructura similar a las bombas volcánicas).

- Facies mLT(cc): Ignimbrita rojiza/rosada, con las características de la facies mLT, pero que además posee clastos de spatter negros, porfíricos con la misma mineralogía que la ya descripta. Estos clastos de spatter son a veces de contornos redondeados y formas ovoidales, y otras son de forma y contorno muy irregular, con engolfamientos pronunciados rellenas con matriz y un contacto neto con la misma.

- Facies sLT o dsLT: Ignimbrita rojiza con fragmentos pumíceos sin colapsar, los cuales pueden ser muy escasos, con una estratificación muy fina de expresión variable, desde muy marcada (facies sLT) hasta difusa (facies dsLT). Cantidad menor de fragmentos líticos volcánicos.

- Facies mT: Ignimbrita rojiza/rosada, masiva, muy rica en matriz y con escasos fragmentos pumíceos de hasta pocos milímetros de largo (una fracción minoritaria de los clastos puede salirse del tamaño ceniza). Además posee cristales de feldespatos, biotita, clinopiroxeno y olivina, y escasos líticos volcánicos de hasta muy pocos milímetros de diámetro. Se diferencia de la facies mLT en la mayor proporción de matriz y en el pequeño tamaño de fragmentos de pómez y líticos.

- Facies sT: Al igual que la anterior, es una ignimbrita rojiza/rosada, muy rica en matriz y con muy escasos fragmentos pumíceos de hasta pocos milímetros de largo (una fracción minoritaria de los clastos puede apartarse del tamaño ceniza), pero además posee laminación paralela. Mayor cantidad de cristales (de los mismos minerales ya nombrados) que de fragmentos líticos, los cuales son escasos. 


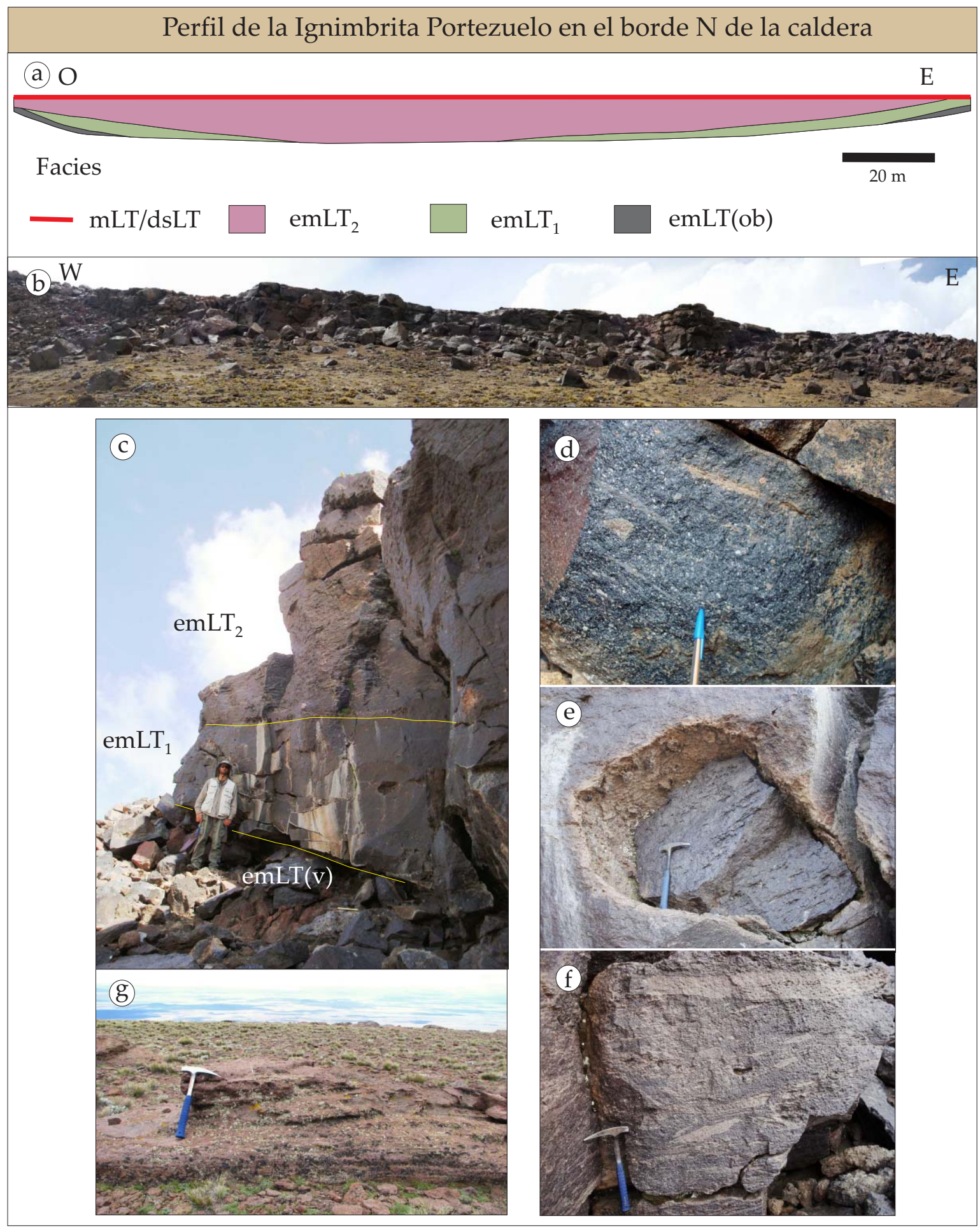

Figura 4.7: a) Panel que muestra la distribución de facies en el perfil expuesto de la Ignimbrita Portezuelo, en el borde norte de la caldera. b) Foto de perfil. c) Contacto entre las facies ignimbríticas. d) Facies emLT(v). e) Clasto lítico en ignimbrita en facies emLT 1 . f) Facies $\mathrm{emLT}_{2}$. g) Ignimbrita en facies dsLT a mLT. 
La Figura 4.5a muestra un mapa resumido del CVPM en el cual se resalta los afloramientos de la Ignimbrita Portezuelo, dejando el resto de las unidades de un mismo color. En puntos rojos y rectángulos se indican 17 sitios en donde fueron caracterizadas las litofacies de la ignimbrita. A continuación se describe someramente a la Ignimbrita Portezuelo en los sitios marcados en la Figura 4.5 a:

1. La ignimbrita se compone de dos facies diferentes en contacto neto. Comienza con una capa de espesor desconocido (al menos $1 \mathrm{~m}$ ) de facies $\mathrm{mLT}$ con matriz color gris medio a rojiza, con fiammes gris oscuro de hasta unos pocos centímetros de largo y hasta 5 $\mathrm{mm}$ de ancho. Los fragmentos líticos son escasos. Por encima se encuentra una capa de espesor variable entre $30 \mathrm{~cm}$ y 1,5 m con techo plano y lajoso, de facies sLT. No se observan pómez aunque sí presenta abundantes cristales con tamaños que alcanzan los 2-3 mm.

2. Borde norte de la caldera, en donde se encuentra un corte de la ignimbrita de aproximadamente $150 \mathrm{~m}$ de largo, y $10 \mathrm{~m}$ de espesor máximo. En este sitio se observa como la Ignimbrita Portezuelo suaviza el relieve previo, con mayores espesores en la zona más baja del relieve previo, adelgazándose hacia los sectores más altos (Fig. 4.7 a). Se distinguen cuatro tipos diferentes de una ignimbrita masiva, eutaxíticas y no eutaxíticas (facies emLT y mLT, según Branney y Kokelaar (2002)). En la Figura 4.7 a se esquematiza la distribución de las facies. La base del perfil se observa solamente en los extremos del mismo, y está cubierta por derrubio moderno en la parte central, que ocupa la mayor parte de la sección (Fig. 4.7 b). En la base en los extremos del perfil, la facies presente es la emLT(v), de hasta $1 \mathrm{~m}$ de espesor (poco visible en la Figura 4.7 c, detalle en Figura 4.7 d). Presenta fiammes gris medio de 2 a $10 \mathrm{~cm}$ de largo y $2 \mathrm{~mm}$ a $1 \mathrm{~cm}$ de ancho, y cristales hasta $5 \mathrm{~mm}$ de largo. Los líticos son generalmente menores al centímetro aunque se encuentran algunos mayores. Le sigue en contacto neto, y con una superficie de discontinuidad (Fig. $4.7 \mathrm{c}$ ), una ignimbrita gris (en facies emLT 1 ). Posee un espesor variable, con un máximo de $3 \mathrm{~m}$. Presenta fiammes gris medio que alcanzan hasta $15 \mathrm{~cm}$ de largo y $2 \mathrm{~cm}$ de ancho. Los fragmentos líticos son generalmente menores al centímetro, pero también se encuentran unos pocos de tamaño significativamente mayor (uno de $98 \times 80 \mathrm{~cm}$, Fig. 4.7 e, y otro de $25 \times 16 \mathrm{~cm}$, como ejemplos), de composición traquítica. Estos líticos mayores no se encuentran soldados a la matriz, y la matriz que los rodea presenta una aureola color castaño. Se continúa hacia arriba, en contacto neto (Fig. $4.7 \mathrm{c}$ ), una ignimbrita (facies emLT 2 ) de espesor variable desde cero hasta 9-10 m (la base no es visible por estar tapada por derrubio). Presenta una matriz gris oscuro con un tono violáceo y una mayor abundancia de fiammes castaño claro (Fig. 4.7 f), con dimensiones desde pocos centímetros alcanzando $1 \mathrm{~m}$ de largo y $10 \mathrm{~cm}$ de ancho. Posee zonas reducidas en donde la ignimbrita presenta vesículas abundantes. Presenta cristales en abundancia y menor proporción de fragmentos líti- 
cos, generalmente de un diámetro menor a los $10 \mathrm{~cm}$. Por último, sobre la facies de ignimbrita anterior, se observa una capa de espesor variable y delgada, desde 5-10 cm de espesor en el borde del perfil, y de hasta $40 \mathrm{~cm}$ de espesor algunos metros más hacia el norte, de facies dsLT a mLT (Fig. 4.7 g). En donde esta capa posee los mayores espesores, se distingue una laminación gruesa paralela. Presenta una matriz color gris medio con un tono violáceo, y con menor grado de soldadura que las previamente descriptas. Presenta pómez en general menores al centímetro, aunque pueden alcanzar 10 cm de largo.

3. Las ignimbritas aflorantes en este sitio poseen características químicas diferentes al resto de las muestras analizadas de la Ignimbrita Portezuelo, tal como se verá en el Capítulo 7. Es de color violáceo oscuro, en facies emLT con fiammes castaños, de hasta algunos centímetros de largo y pocos milímetros de ancho.

4. La ignimbrita posee en este sector un espesor desconocido, ya que su base no aflora y, además, refleja la topografía previa (Fig. 4.8 a). Es rojiza en superficie meteorizada pero gris en superficie fresca, en facies mLT. Tiene pómez rojizos que alcanzan los 10 cm de largo. Los cristales son menores a los $5 \mathrm{~mm}$ de largo, y los líticos alcanzan $20 \mathrm{~cm}$ de diámetro aunque en su mayoría están entre 2 y $4 \mathrm{~cm}$.

5. Ignimbrita rojiza de bajo grado, con un espesor aflorante máximo de 2-3 m, y cuya base no está expuesta (facies mLT(cc)). Los pómez son menores al centímetro generalmente, y los fragmentos líticos son de hasta pocos centímetros de diámetro. Los clastos de spatter son de tamaños variados, llegando hasta $30 \mathrm{~cm}$ de largo (Fig. $4.8 \mathrm{~b}$ ).

6. Muy similar a la anterior. En este sector los resaltos topográficos corresponden a coladas de basaltos pre-caldera, mientras que en las partes bajas se ubica la Ignimbrita Portezuelo, cubriendo a los basaltos parcialmente. El espesor de la ignimbrita es variable pero siempre escaso, menor a $1 \mathrm{~m}$ en donde puede observarse la base. Al igual que en el punto anterior, es de facies $\mathrm{mLT}$ (cc) con pómez violáceos hasta $0,5 \mathrm{~cm}$ de largo y líticos menores al centímetro. En un zona restringida fue observada la presencia de disyunción columnar en la ignimbrita, de formas hexagonales o polígonos más irregulares (Fig. $4.8 \mathrm{c}$ ).

7. Ignimbrita en facies mLT. En este sector, al norte de la Falla La Carbonilla, la ignimbrita se presenta como un manto continuo cubierto al sur por los Basaltos Post-caldera II.

8. La ignimbrita se encuentra cubriendo la parte superior de una colada traquítica precaldera, con techo plano y en facies emLT. Los fiammes son gris oscuro a rojizos y la matriz es gris levemente más oscura. Es rica en cristales, muy similar a la descripta posteriormente en el punto 10. 
9. Afloramiento de la ignimbrita en una quebrada importante, en el lado sudoeste de la cual se ubica una loma compuesta por lavas de los Traquitoides Pre-caldera, mientras que del lado opuesto (noreste), se encuentran afloramientos de la Ignimbrita Portezuelo que alcanzan aproximadamente $12 \mathrm{~m}$ de espesor. La mayor parte del perfil está constituido por una ignimbrita de alto grado, mientras que en la parte superior pasa transicionalmente, a una ignimbrita aparentemente de menor grado (no pudo observarse en el campo la parte superior del perfil) (Fig. $4.8 \mathrm{~d}$ ). El perfil comienza con una facies emLT color gris oscuro, con fiammes que generalmente no superan $l o s 10 \mathrm{~cm}$ de largo (Fig. 4.8 f). Esta pasa transicionalmente a una ignimbrita también en facies emLT color gris medio-oscuro, pero en este caso los fiammes poseen un tamaño marcadamente mayor. Estos son de varias decenas de centímetros de largo y hasta 5-7 cm de ancho (Fig. 4.8 e).

10. En este sector la ignimbrita está cubriendo casi por completo a una lava pre-caldera que fluye hacia el SE. Dada la naturaleza de los afloramientos no pudo determinarse su espesor. Presenta una parte inferior color negro en facies emLT, con fiammes hasta 10-15 cm de largo y $3 \mathrm{~cm}$ de ancho. En contacto neto, le sigue una ignimbrita rojiza en facies emLT(cc). Los clastos de spatter alcanzan hasta algunos centímetros de diámetro. En el sector proximal de la colada cubierta por la ignimbrita se observa una superficie muy sinuosa, con canales cavados paralelamente, no muy profundos, y con una superficie lisa. La orientación que presentan es transversal respecto de la que presentan los yardangs ubicados en el "Portezuelo de los Payunes", y a su vez parecen seguir la pendiente. Estas características descartan que sean rasgos de erosión eólica (podría especularse que se deben a un pequeño glaciar, sin embargo no han sido observados depósitos glaciales en la zona).

11. Si bien este sector se encuentra muy próximo al punto 10, las características de la ignimbrita son diferentes. Este punto se ubica fuera de la loma formada por la lava pre-caldera del punto 10, en un sector que presenta relativamente con poco relieve, entre los volcanes Payún Matrú y Payún Liso. Sus afloramientos están erosionados formando yardangs con un espesor entre 3 y $6 \mathrm{~m}$, donde pueden observarse dos facies distintas, en contacto neto (Fig. 4.9 a). En la parte inferior se encuentra una ignimbrita en facies mLT, que constituye la mayor parte del perfil. En la parte superior del mismo, se encuentra una ignimbrita en facies $\mathrm{mT}$, con pocos pómez rojizos de $2 \mathrm{~mm}$ de largo aproximadamente, y pocos líticos de 1-2 mm de largo.

12. En este punto se ubican afloramientos de la Ignimbrita Portezuelo sobre la ladera del Payún Liso, en el punto más alto que alcanzan sobre el volcán, aproximadamente 300 $\mathrm{m}$ por sobre la cota más baja del "Portezuelo de los Payunes". Es una ignimbrita de facies emLT(v), la cual cambia a facies mLT en la base del volcán. 


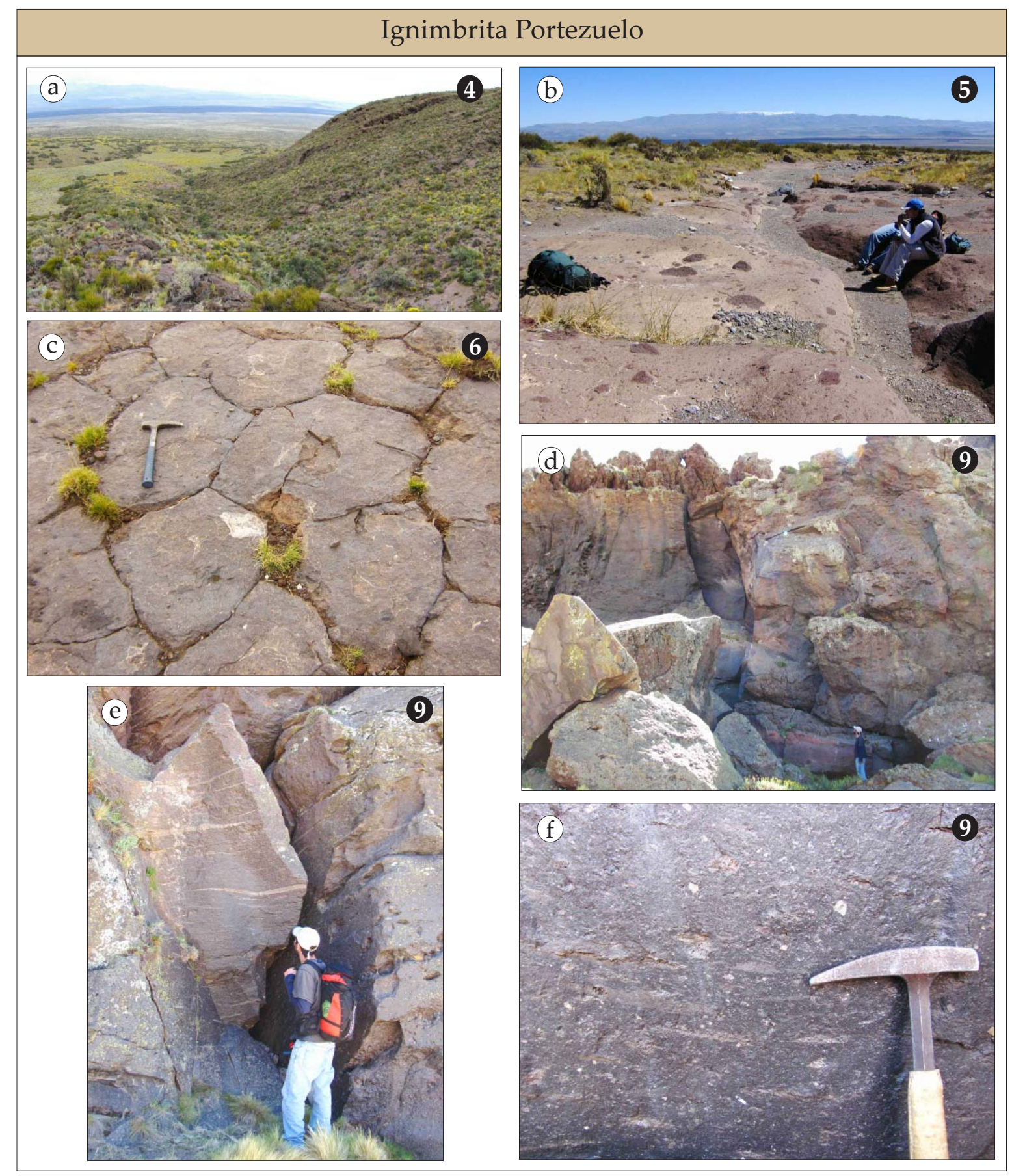

Figura 4.8: Fotos de campo de la Ignimbrita Portezuelo en los sitios numerados a la izquierda de cada foto. a) Ignimbrita reflejando la topografía previa. b) Ignimbrita en facies mLT(cc). c) Disyuncción columnar en la ignimbrita. d) Perfil con ignimbrita de alto grado mayormente. e) Ignimbrita en facies emLT, sector medio del perfil. f) Ignimbrita en facies emLT, sector basal del perfil. 
13. Es el lugar en donde se encuentra la loma de Traquitoides Pre-caldera cubierta casi por completo por la Ignimbrita Portezuelo mostrada en la Figura 4.4 b. Como ocurre en otros sectores en donde la ignimbrita sortea obstáculos y copia la topografía previa, la facies presente mayormente es emLT, con fiammes de hasta varias decenas de centímetros de largo y menos de $5 \mathrm{~cm}$ de ancho. En el sector más alto de la loma presenta una capa superior delgada (de algunos centímetros) en donde la facies es emLT(cc).

En un sector muy restringido aflora, por encima de la ignimbrita de alto grado, otra de características muy disímilies, en facies sT, y de aproximadamente $50 \mathrm{~cm}$ de espesor (Figs. $4.9 \mathrm{~b}$ y c).

14. En el sector izquierdo del rectángulo se encuentra una pequeña loma cubierta casi por completo por la Ignimbrita Portezuelo. Presenta en la base emLT(v) con fiammes gris medio que alcanzan $6 \mathrm{~cm}$ de largo y pocos milímetros de ancho, pocos líticos menores al centímetro y cristales de hasta pocos milímetros de largo. Por encima la ignimbrita en facies mLT, con fragmentos pumíceos mayores al centímetro, y el porcentaje de líticos es un poco mayor. Esta presenta un espesor que oscila entre 1 y $2 \mathrm{~m}$. A pocos metros de la loma cubierta por la ignimbrita, se encuentra una ignimbrita de facies $\mathrm{mT}$, con escasos fragmentos pumíceos globosos que no superan el centímetro (Fig. 4.9 d). Esta está en contacto neto con la inferior.

15. Zona relativamente plana en donde la mayor parte de la ignimbrita es de facies mLT, y donde afloran unos pequeños domos parcialmente cubiertos por la ignimbrita. La ignimbrita está remontando las pequeñas lomas formadas por los domos que tiene en la base un espesor reducido, de alrededor de $1 \mathrm{~m}$ (facies emLT(v)). Esta pasa hacia arriba a una ignimbrita en facies emLT. En los últimos $5 \mathrm{~cm}$, puede observarse una facies emLT(cc) con numerosos clastos de spatter de tamaños variados hasta algunos centímetros de diámetro (Fig. 4.9 e).

16. Muy similar al punto anterior. Se encuentran afloramientos de la Ignimbrita Portezuelo cubriendo el lado este de un cono de escoria pre-caldera, que a su vez están cubiertas por una colada de basaltos post-caldera. En la base del cono de escoria la ignimbrita alcanza aproximadamente $2 \mathrm{~m}$ de espesor, y se adelgaza hacia el tope del cono. La ignimbrita es de facies emLT con fiammes elongados hasta $10 \mathrm{~cm}$ de largo y 1 $\mathrm{cm}$ de ancho. Presenta una facies emLT(cc) en la parte superior del perfil, con clastos de spatter en general menores a los $10 \mathrm{~cm}$ de diámetro, aunque hay unos pocos mayores que alcanzan $35 \mathrm{~cm}$ de diámetro. Se han encontrado en contacto dos de estos clastos, y la forma redondeada de los mismos se aplana exactamente en la zona de contacto, similarmente a dos gotas de liquido (Fig. 4.9 f).

17. En este sector los afloramientos se encuentran muy cubiertos por sedimentos arenosos modernos y vegetación, aunque aflora la Ignimbrita Portezuelo de manera reducida 


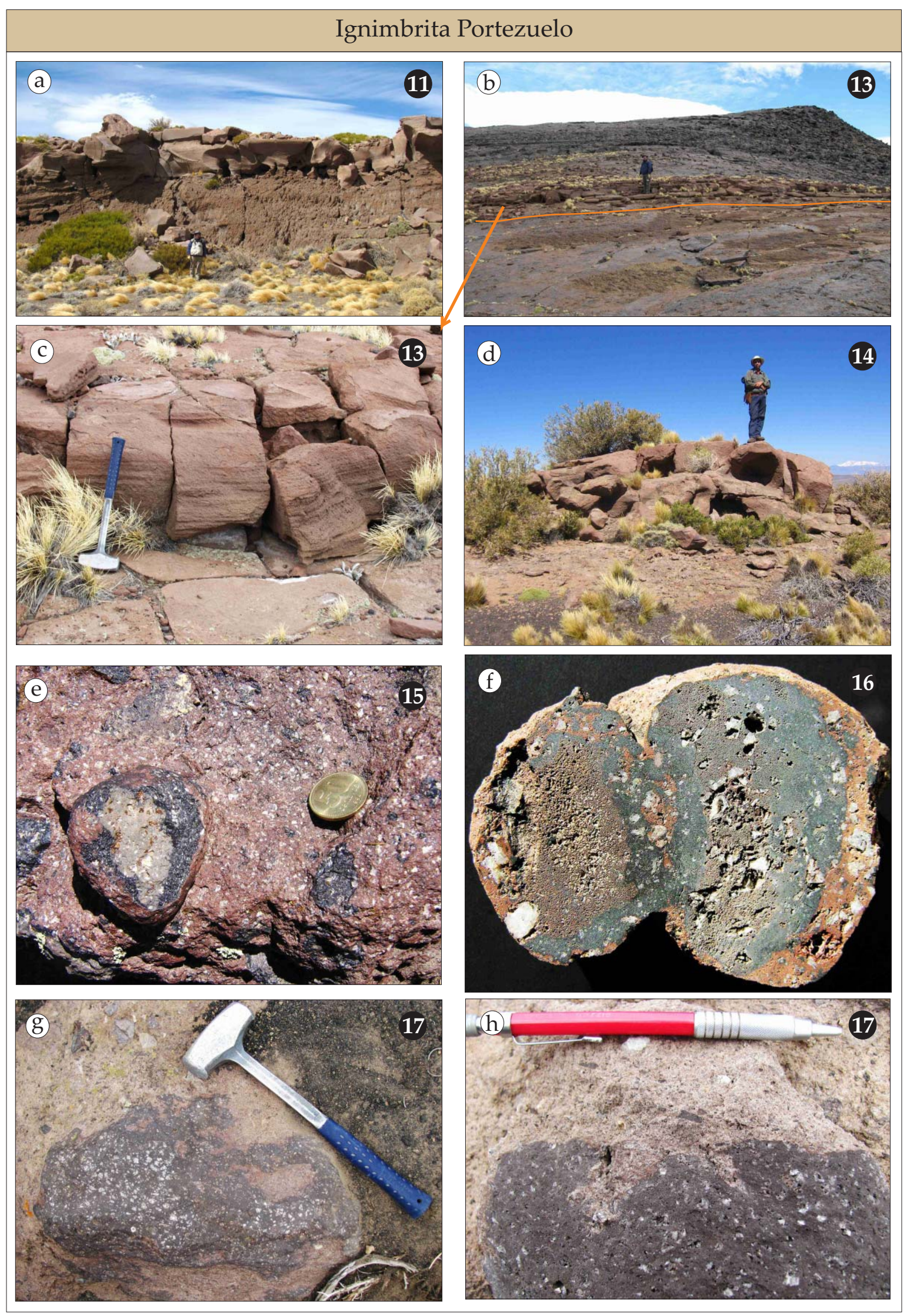

Figura 4.9: Fotos de la Ignimbrita Portezuelo. Los números a la izquierda se corresponden con la Figura 4.5. a) Facies mLT abajo y $\mathrm{mT}$ arriba. b) Ignimbrita reflejando el relieve. c) Facies sT. d) Facies mT. e) Facies emLT(cc). f), g) y h) clastos de spatter. 
en quebradas muy poco profundas. La ignimbrita es de facies mLT(cc) con pómez de hasta pocos centímetros de largo. Los clastos de spatter negros son de formas muy irregulares, de tamaños variables, alcanzando $50 \mathrm{~cm}$ de largo/diámetro (Figs. $4.9 \mathrm{~g}$ y h).

\subsubsection{Interpretación de las facies ignimbríticas}

Es sabido que la topografía ejerce un control sobre la depositación de corrientes piroclásticas y por lo tanto de los depósitos resultantes (Branney y Kokelaar, 2002; Woods et al., 1998; Sulpizio et al., 2008; Branney y Kokelaar, 1997). En aquellos sitios donde la ignimbrita trepa un relieve pre-existente (conos de escoria, lavas pre-caldera, Payún Liso), o también cuando existe un cambio hacia una pendiente menor, o sea, con un relieve cóncavo hacia arriba, la ignimbrita es de alto grado, masiva y eutaxítica (facies emLT, emLT(v) y emLT(cc)). La facies emLT(v), si está presente, aparece en la parte inferior del depósito, o bien es la única presente.

En las laderas del Payún Matrú, en aquellos sitios sin obstáculos prominentes para los flujos piroclásticos, las facies de la Ignimbrita Portezuelo son variadas, mayormente masivas aunque con y sin desarrollo de texturas eutaxíticas (mLT, emLT, emLT(v), sLT). En las zonas más bajas, al pie del Payún Matrú, no se observan facies emLT, y la ignimbrita es básicamente de bajo grado y masiva (facies mLT y $\mathrm{mLT}(\mathrm{cc})$ ). En algunos sectores de la parte superior de los depósitos de ignimbrita, ya sea en zonas bajas, en la ladera más proximal del volcán, o en aquellos sitios con obstáculos topográficos, se encuentran diferentes facies de la ignimbrita con estructuras tractivas (facies sLT, dsLT, sT), en contacto neto con las facies subyacentes. También pueden encontrarse facies masivas, pero de grano menor que el resto del perfil (facies mT).

Cabe destacar que las facies de ignimbritas de alto grado tienen espesores de poca potencia, por lo que se infiere que no es necesaria una columna espesa de rocas suprayacentes para el desarrollo de las texturas eutaxíticas. El aplastamiento y la soldadura de los clastos puede deberse a la alta temperatura y/o fluidez de los mismos (Branney y Kokelaar, 2002), lo cual también se favorece si la tasa de depositación es alta.

En cuanto a las facies con clastos de spatter traquíticos (facies emLT(cc) y mLT(cc)), el primer caso se encuentra donde la ignimbrita fue depositada sobre un obstáculo topográfico, y el segundo caso se encuentra en zonas bajas al pie del Payún Matrú. La forma y contactos de estos clastos sugieren que eran fluidos y que tenían un comportamiento plástico, a veces con el desarrollo de un borde enfriado, y además no presentan una diferencia composicional significativa con la Ignimbrita Portezuelo (ver Capítulo 6). En cuanto al transporte y sedimentación de los clastos de spatter, estos se comportan de la misma manera que los fragmentos líticos (Branney y Kokelaar, 2002).

Las ignimbritas masivas y mal seleccionadas indican que fueron depositadas rápida- 
mente por una corriente piroclástica con alta concentración de clastos y baja tasa de cizalla en su base (zona del límite del flujo dominada por escape de fluidos), sin poder hacerse inferencias sobre las características de la corriente más arriba (Branney y Kokelaar, 2002). Por otra parte, la estratificación paralela (facies sT y sLT) y una relativamente buena selección, indican que la zona límite del flujo estaba dominada por procesos tractivos, con una alta tasa de cizalla y baja concentración de clastos (Branney y Kokelaar, 2002). La facies dsLT pueden ser depositadas si las características del límite inferior del flujo son intermedias entre los dos casos mencionados, en cuanto a la concentración de partículas y la tasa de cizalla (Branney y Kokelaar, 2002). La presencia de cuerpos de ignimbritas masivas apilados, tal como ocurre en el perfil del borde norte de la caldera, podría indicar un carácter pulsatorio de las corrientes piroclásticas, con la depositación rápida (o inclusive en masa) de los diferentes pulsos, dando como resultado una agradación por pulsos (Sulpizio y Dellino, 2008).

\subsubsection{Traquiandesitas Post-caldera (TA pos)}

Las lavas de esta unidad corresponden a las primeras efusiones lávicas luego de la erupción explosiva que depositó a la Ignimbrita Portezuelo y que condujo al colapso de la caldera. Son todas lavas de composición intermedia variando entre traquiandesitas basálticas a traquiandesitas.

Las lavas nacen en su mayoría del borde sur y oeste de la caldera. Una excepción podría ser una colada ubicada al noroeste de la misma (Fig. 3.5) que, aunque es imposible observar su centro emisor por estar cubierto por lavas posteriores, parecería nacer en el faldeo noroccidental del Payún Matrú, al igual que otras Traquitas Post-caldera (colada "El Choique", Fig. 4.1). La única colada intra-caldera nace de su borde oeste, aunque el centro de emisión no se observa por estar cubierto por las Traquitas Post-caldera. Las coladas de esta unidad son fácilmente reconocibles, aunque se encuentran cubiertas parcialmente por sedimentos arenosos y vegetación en un grado variable (Fig. 4.10 a y b).

La morfología de las lavas de esta unidad es similar a las morfologías observadas en lavas basálticas. Son flujos compuestos, la mayoría son de tipo pahoehoe, con superficies no escoriáceas, desarrollo de algunos túmulis, lavas cordadas y canales angostos (Fig. $4.10 \mathrm{~b}$ y c). Los canales son sinuosos y presentan un albardón de superficie lisa, limitando al centro del flujo más rico en bloques (Fig. 4.10 d). La lava cordada se observa por sectores en las lavas ubicadas en el flanco sur del Payún Matrú (Fig. 4.10 e). A modo de ejemplo, en una colada en el flanco sur del Payún Matrú, se observa un túmuli donde la pendiente abrupta del flanco del volcán cambia hacia una más suave al pie del mismo. Este es elongado perpendicularmente a la pendiente, con aproximadamente $50 \mathrm{~m}$ de longitud.

Las coladas intra-caldera y extra-caldera del sureste (colada de "La Cueva") pertenecientes a esta unidad, son de morfología diferente. Si bien la superficie de estas dos lavas no es escoriácea como en las lavas $a$ a, tampoco presentan los rasgos mencionados de lavas 

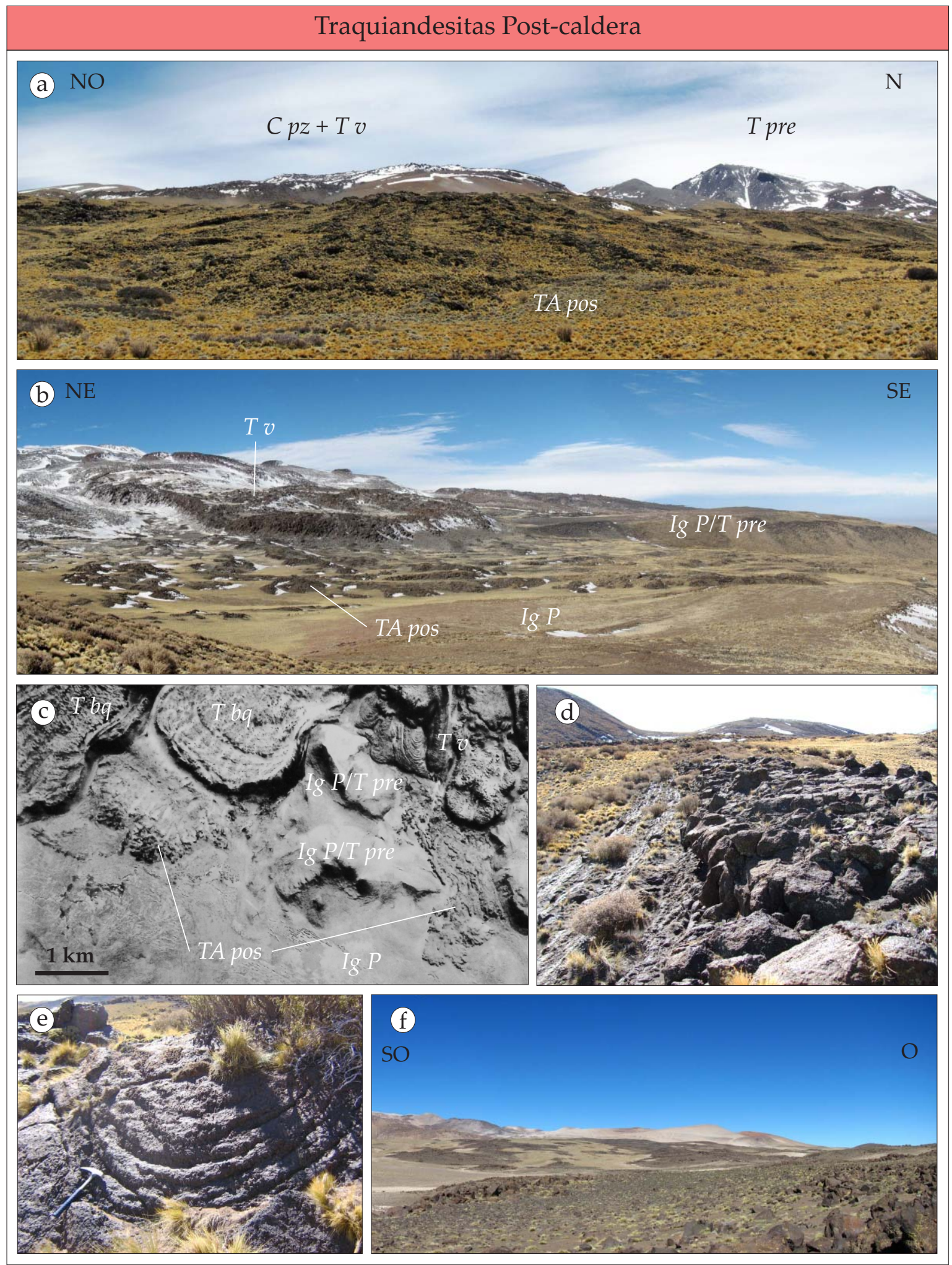

Figura 4.10: a) Flanco SE del Payún Matrú con una colada de TA pos en primer plano. b) Flanco SO del volcán, con una lava de TA pos apoyando sobre la $\operatorname{Ig} \mathrm{P}$. Ig P/T pre $=\operatorname{Ig} \mathrm{P}$ cubriendo a $T$ pre. c) Foto aérea de la misma colada de $b$, y otra de menor extensión más hacia el O (Colada del Caballo Muerto). d) Centro y borde de un canal en la colada de la foto b. La parte central blocosa sobresale por sobre los albardones. e) superficie cordada en la Colada del Caballo Muerto. f) Colada intra-caldera en primer plano. 
pahoehoe. La superficie es de aspecto blocoso, con bloques de superficies relativamente lisas, como son las lavas en bloque, pero presentan espesores menores y extensiones mayores que estas últimas (Fig. 4.10 f). También se observa que la superficie es monticular, especialmente en los sectores más distales de las lavas y donde la pendiente es menor que en sus sectores proximales. Por lo tanto, se puede decir que estas dos coladas lávicas comparten características de tanto los flujos a como los pahoehoe.

Debido a que en ningún caso se observa el centro emisor de estas lavas, sus dimensiones son difíciles de determinar con exactitud. La longitud de estas coladas varía aproximadamente entre 3 y $15 \mathrm{~km}$. La colada más extensa está en la ladera sureste del Payún Matrú, fluyendo también hacia el sudeste (colada de "La Cueva"), con el sector proximal de la misma cubierto por completo por un pavimento de gravas y bloques. Los espesores observados en el campo y mediante el Modelo Digital de Elevaciones son relativamente reducidos, varían desde escasos metros hasta algunas decenas de metros, y no son constantes debido a la irregularidad del techo de las lavas.

\subsubsection{Traquitas Post-caldera ( $T$ pos)}

Aunque las tres litofacies que conforman esta unidad se describan separadamente, estas se encuentran estrechamente relacionadas entre si, como se analizará posteriormente.

\subsubsection{Traquitas en bloque $(T b q)$}

Esta litofacies se compone de ocho flujos lávicos de morfología de lava en bloque y de composición traquítica relativamente homogénea, con escasa dispersión en el diagrama TAS (ver capítulo 7). Afloran principalmente en el sector extra-caldera del Payún Matrú, con un solo flujo intra-caldera. Los centros de emisión se ubican mayormente en el borde de caldera, aunque en algunos casos más alejadamente (Fig. 3.5). Un ejemplo es la denominada colada "Escorial del Toro" en el flanco NO del volcán, la cual presenta un canal principal y otros tres menores, cuyos centros de emisión se alinean perfectamente con una orientación ENEOSO (Fig. 3.5 y 4.11 a). Otras son la colada denominada "Farellones de la Portada" en la ladera SE (Fig. 4.11 c), y la denominada "Traquita La Calle", así como otra colada que se ubica inmediatamente al sur de esta última. 

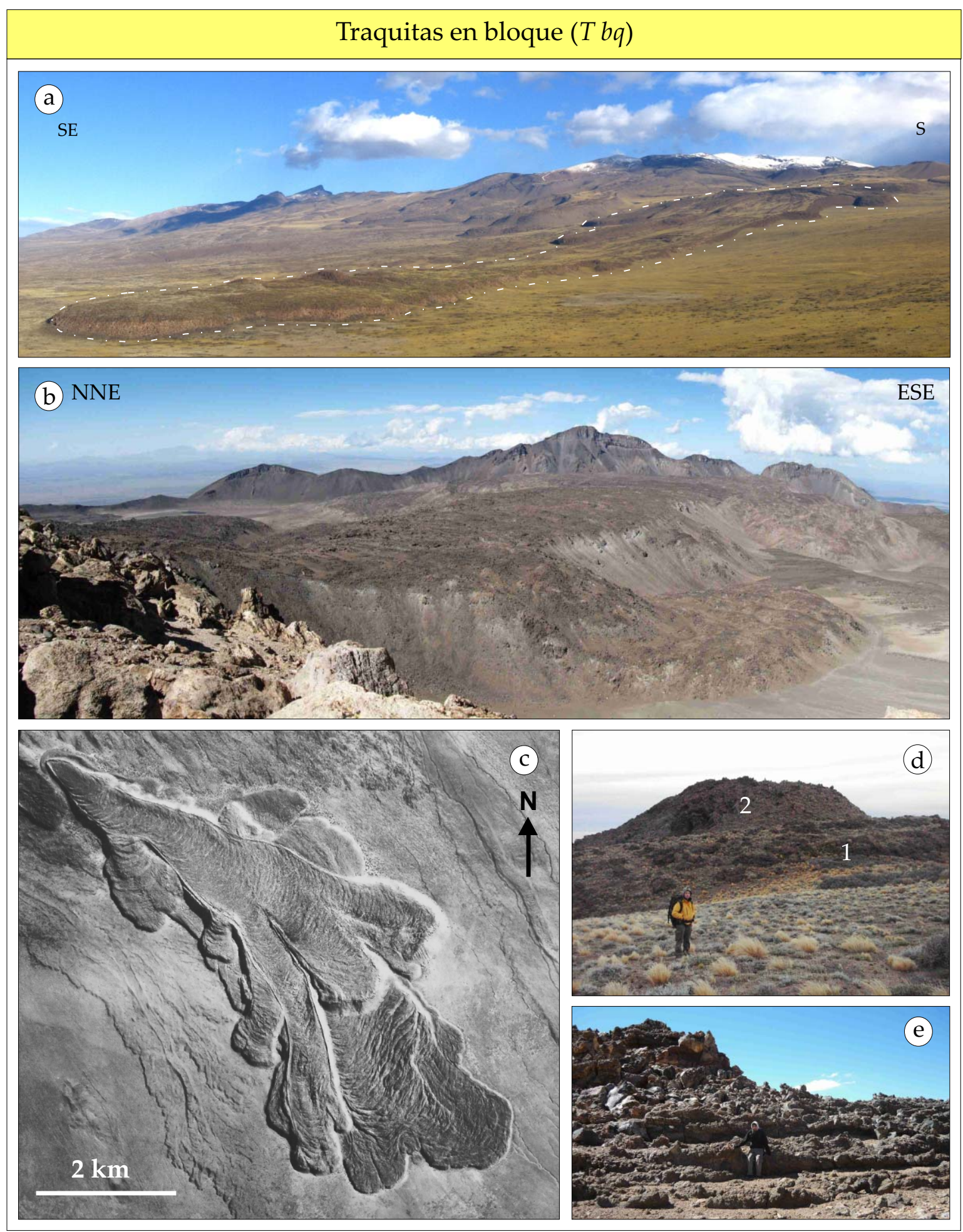

Figura 4.11: a) Colada del "Escorial del Toro", flanco NO del Payún Matrú. b) Colada intracaldera vista justo al sur de su nacimiento. Pared topográfica de la caldera de fondo. c) Foto aérea rectificada de la colada "Farellones de la Portada", en el flanco SSE del Payún Matrú. d) Nacimiento de la colada "Farellones de la Portada". 1: fase vítrea; 2: fase holocristalina (ver c). e) crestas de presión en la fase vítrea en el nacimiento de la colada intra-caldera. 
La morfología, como ya fue mencionado, es de lavas en bloque, con presencia de canales limitados por albardones, lóbulos frontales y crestas de presión perpendiculares a la dirección de flujo (Fig. 4.11 b y c). La superficie de las lavas está constituida por bloques sueltos, angulosos y lisos de muy diversos tamaños, y los frentes son abruptos. Los centros de emisión son puntuales, expandiéndose lateralmente el flujo en muchos casos hacia los sectores más distales, con lóbulos secundarios que sobrepasan el canal principal (Fig. 4.11 b y c).

Los flujos alcanzan pocos kilómetros de extensión, entre 2,5 km y 9 km, y los espesores varían desde pocas decenas de metros hasta $250 \mathrm{~m}$ de espesor. El volumen de cada flujo individual varía entre $0,2 \mathrm{~km}^{3}$ y $2 \mathrm{~km}^{3}$. El volumen fue calculado a partir de espesores indicados por un Modelo Digital de Elevaciones, mientras que las áreas fueron calculadas con una aplicación GIS a partir de los polígonos dibujados en el mapa geológico.

Un rasgo destacable de algunas de las lavas pertenecientes a esta litofacies, es que en el centro de emisión o sector principal de la colada la lava es un vitrófíro negro (idénticas a las de la litofacies de Traquitas vítreas) (Fig. $4.11 \mathrm{~d}$ y e). Este rasgo se observa en la colada intracaldera y en la colada de "Farellones de la Portada". La colada intra-caldera, en el centro de emisión, se compone de un vitrófiro negro dispuesto en forma de herradura, con crestas de presión de menor espaciamiento y magnitud (como son en la litofacies $T$ v, Fig. 4.11 e). Este sector conforma una fase vítrea de la misma colada, la cual es fundamentalmente holocristalina. Algo muy similar ocurre en la colada de "Farellones de la Portada", aunque en este caso la fase vítrea de la colada es de mayor extensión. En ambos casos, parecería que la fase vítrea fue la iniciadora del flujo lávico, seguida de la fase con mayor grado de cristalización. Además de estos dos ejemplos, en el borde NO de la caldera se halla una colada de Traquitas en bloque que se apoya sobre Traquitas vítreas (Fig. 3.5), y en ningún caso se observan los sitios de emisión, por estar cubiertos por lavas. Es probable (aunque difícil de corroborar) que las lavas vítreas que se observan debajo de las lavas en bloque, correspondan a una fase vítrea inicial de un mismo evento eruptivo. Además de la presencia de vidrio en el sector proximal de estas lavas, también se encontró, en el lóbulo frontal de un flujo ubicado en el flanco sur del Payún Matrú, la presencia de sectores vítreos negros reducidos, intercalados en la lava gris holocristalina.

\subsubsection{Conos Pumíceos (C pz)}

Esta litofacies se compone de depósitos mayormente clásticos de formas monticulares, generalmente equidimensionales aunque algunos depósitos son elongados. Poseen dimensiones que varían desde $0,35 \mathrm{~km}$ a $1,1 \mathrm{~km}$ de diámetro (aquellos equidimensionales), a 0,5-0,6 $\mathrm{km}$ de ancho por 1,1-1,5 km de largo (los conos elongados) (Fig. $4.12 \mathrm{a} \mathrm{y} \mathrm{b).} \mathrm{Afloran} \mathrm{a} \mathrm{lo} \mathrm{largo}$ del borde de la caldera, desde el sureste al norte, siendo más abundantes en el sector NO de la misma (Fig. 3.5). Presentan un excelente grado de preservación y no están disectados, imposibilitando en muchos casos la observación de perfiles verticales en los mismos. Sin 
embargo, existen algunos casos con cortes de pocos metros de espesor, en donde pueden observarse sus características internas (Fig. 4.12 b).

El color de los conos pumíceos varía desde un gris claro hasta amarillento, anaranjado y rojizo, inclusive en un mismo cono. La consolidación de los depósitos es ampliamente variable, en general suelen tener una superficie inconsolidada, aflorando por sectores depósitos bien consolidados.

La superficie de estos conos pumíceos está cubierta mayormente por clastos de pómez con un tamaño de grano muy variable, junto a bombas vítreas negras, abundantes en algunos sectores (Fig. 4.12 c). Las bombas de traquita son ecuantes, de formas a veces globosas $\mathrm{y}$ frecuentemente, aunque no siempre, poseen caras planas, ligeramente curvas, con aristas bien desarrolladas (Fig. $4.12 \mathrm{~d}$, e). Las bombas de mayor tamaño alcanzan hasta $1 \mathrm{~m}$ de diámetro. El centro de la bomba suele estar hueco, con una estructura fluidal conspicua en su interior, y en aquellas bombas no poligonales la superficie externa también es fluidal, con alternancia de bandas milimétricas y centrimétricas de lava color gris y negro (Fig. 4.12 f). En las bombas poligonales, las caras planas externas suelen tener una textura de corteza de pan, formadas durante el enfriamiento de la misma (Fig. 4.12 e).

En el borde NO de la caldera, entre las coladas de "La Víbora" y "El Pulpo" (Fig. 4.1), se encuentra una colada lávica naciendo a partir de un cono de pómez. En los bordes de la colada, y también dispersos en el cono, se encontraron clastos con sectores pumíceos y sectores de vidrio compacto negro, en contacto neto entre si e intercalados (a escala de milímetros a varios centímetros). Esta observación, junto con la abundancia en los conos pumíceos de bombas vítreas negras, sugiere una estrecha vinculación entre las litofacies de Traquitas vítreas y Conos pumíceos.

En el borde NNO de la caldera (Fig. 3.5) se encuentra un cono pumíceo el cual resume las propiedades texturales observadas en otros conos. Este es un cono rojizo en el cual se observan cortes del mismo, de los cuales el mayor posee aproximadamente $6 \mathrm{~m}$ de espesor (Fig. 4.13 a). En ellos, los depósitos son masivos a groseramente estratificados, teniendo a veces bancos de $0,5 \mathrm{~m}$ de espesor internamente masivos (Fig. 4.13 a y f). Otras veces la estratificación difusa se marca también en cambios de la coloración de los pómez, desde gris claro a rojizo (Fig. $4.13 \mathrm{f}$ ), que inclusive puede observarse dentro de un mismo clasto. La textura es clasto sostén y poseen una selección mala a muy mala. Están compuestos principalmente por clastos de pómez, y en menor medida por clastos de traquita negra vítrea, idénticos petrográficamente a las traquitas pertenecientes a la litofacies de Traquitas vítreas (Fig. 4.13 b y c). El tamaño de los clastos de pómez varía enormemente, desde pocos milímetros hasta algunas decenas de centímetros (generalmente hasta 20-30 cm). La redondez de estos clastos pumíceos también varía, siendo algunos angulosos y otros redondeados. Los clastos de traquita vítrea negra tienen generalmente desde menos de $1 \mathrm{~cm}$ hasta pocas decenas de centímetros de diámetro, son angulosos con caras planas y aristas marcadas, similares a las bombas poligonales. En abundancia variable, se encuentran bombas poligonales de hasta 1 


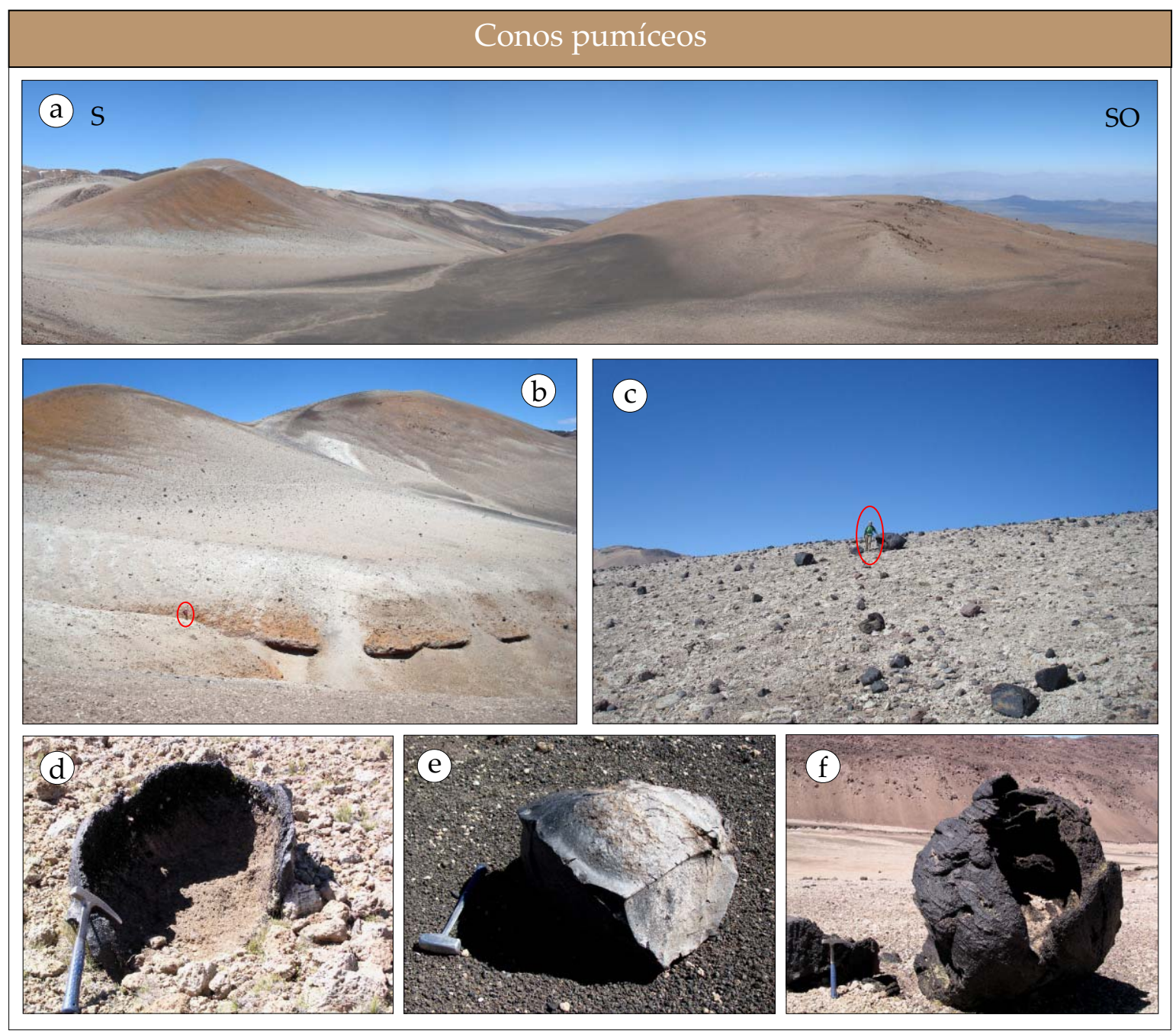

Figura 4.12: Fotos de los Conos pumíceos (unidad $T$ pos). a) Conos pumíceos en el borde $\mathrm{O}$ de la caldera (cono del fondo de $700 \mathrm{~m}$ de base). b) Conos en el borde $\mathrm{O}$ de la caldera. Ver persona en el círculo para la escala. c) Superficie de un cono pumíceo, borde NO de la caldera. d, e y f) Diferentes formas de bombas vítreas. 


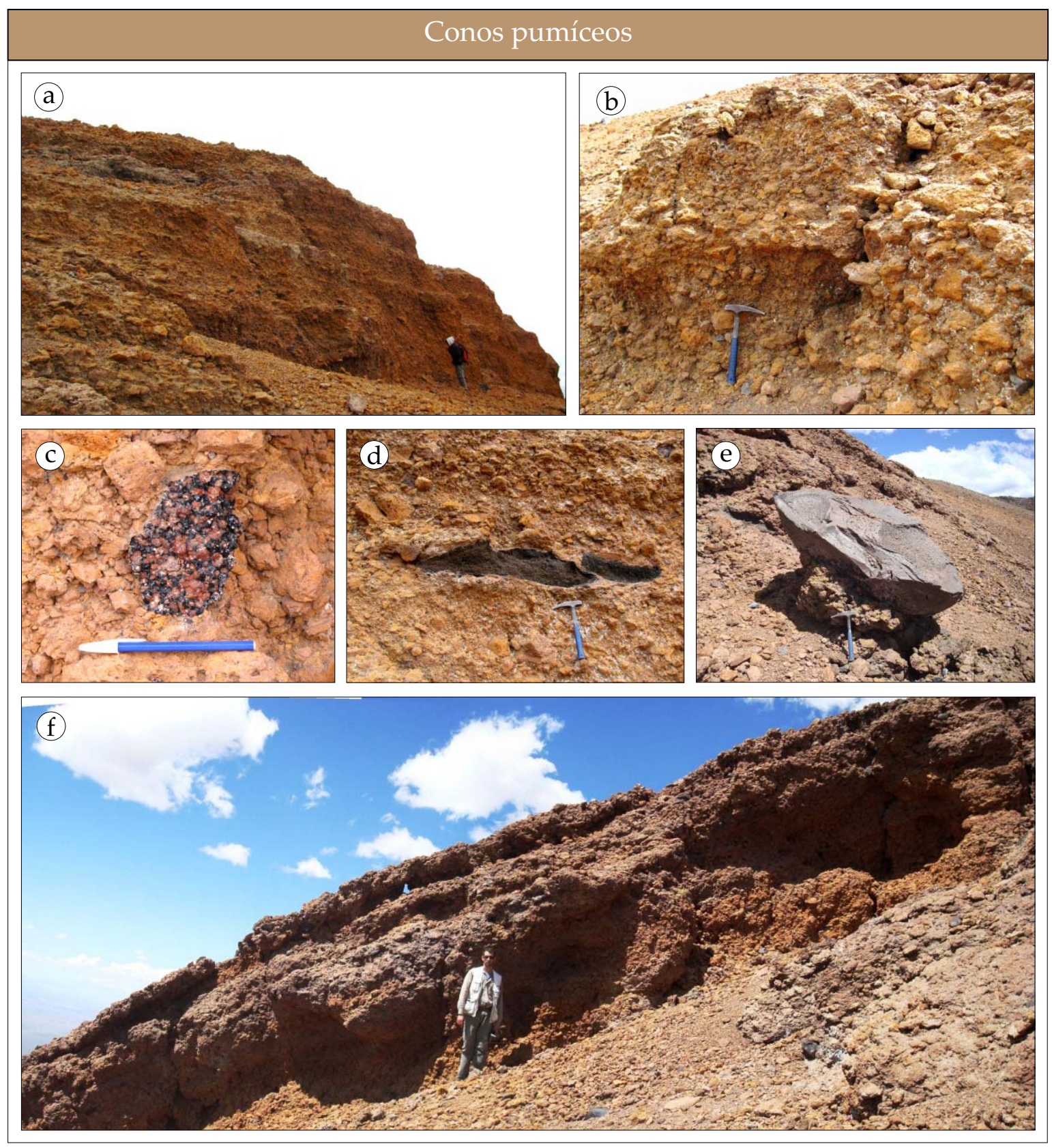

Figura 4.13: Cono pumíceo en el borde NO de la caldera. a) Corte expuesto del cono. b) Detalle del depósito pumíceo, clasto sostén. c) Clasto vitrofírico negro en el depósito pumíceo. d) Clastos de vidrio elongados. e) Bomba vitrofírica poligonal. f) Depósito de pómez estratificado. Ver discusión en el texto. 
$\mathrm{m}$ de diámetro, las cuales son escasas en los pocos perfiles observados, y más abundantes en la superficie de los conos (Fig. 4.13 e). En algunos casos los clastos vítreos negros poseen abundantes esferulitas rojizas, con una estructura interna concéntrica, y del orden del centímetro de diámetro (Fig. 4.13 c). Tanto los clastos de pómez como los clastos/bombas de traquita vítrea, son porfíricos con fenocristales de feldespato alcalino, euhedrales e incoloros aunque en algunos casos están teñidos al rojizo al igual que los clastos, y de 2-4 $\mathrm{mm}$ de largo. Aisladamente se han observado clastos de vidrio negro marcadamente elongados, siendo estos probablemente clastos que conservaban su fluidez al momento de la depositación (Fig. 4.13 d). Dentro de este mismo cono pumíceo, en su cara NO, se encuentra un resalto compuesto por traquitas vítreas exclusivamente, sin ser un depósito clástico (en apariencia).

Ligeramente más al sur que el cono pumíceo descripto anteriormente, en el borde ONO de la caldera, se encuentra otro cono rojizo de esta litofacies con un perfil expuesto de $4 \mathrm{~m}$ de espesor y con características peculiares. El perfil observable varía tanto verticalmente como lateralmente, por lo cual se realizaron descripciones en dos sectores, junto con un tercero al que no pudo accederse dada la naturaleza del afloramiento (Fig. 4.14 a).

En el punto 1 (Fig. 4.14 a), el perfil comienza con $2 \mathrm{~m}$ de lava traquítica vítrea, negra, con un bandeado discontinuo de la misma lava de color gris, por desvitrificación, de milímetros a centímetros (Fig. 4.14 b). Posee escasos clastos de pómez $(<5 \%)$ dentro de la lava, de hasta 5-6 cm de diámetro. La lava presenta una marcada estructura fluidal, deformándose al contorno de los clastos de pómez. Por encima y en contacto neto, le siguen 1-1,5 m de un depósito compuesto por una intercalación de pómez con lava traquítica vítrea. Presenta bandas de traquita poco vesiculada con bandas pumíceas, muy irregulares y discontinuas, ambas partes contienen fenocristales de feldespato alcalino (Fig. 4.14 c). Contiene clastos pumíceos de hasta 5-10 cm de diámetro, además de escasos líticos volcánicos, redondeados, de hasta $5 \mathrm{~cm}$ de largo. Por último, y en pasaje transicional, se encuentra un depósito clástico masivo a difusamente estratificado, bien consolidado, formado por clastos de pómez en su gran mayoría (> 95\%) (Fig. 4.14 d). La textura es clasto sostén, casi sin matriz, y con una muy mala selección. Los clastos de pómez varían desde pocos milímetros hasta 30-40 cm de diámetro. También se hallan escasos clastos de traquita vítrea, menores a $5 \mathrm{~cm}$ de diámetro, en un porcentaje bajo (3-5\%).

En el punto 2 (Fig. 4.14 a), el perfil no presenta variación vertical en el corte, y consiste en 5-6 m de lava traquítica negra, vítrea, similar al sector inferior del punto 1, aunque con mayor abundancia de clastos de pómez (Fig. 4.14 e y f). El tamaño de los clastos de pómez varía desde pocos centímetros hasta $30 \mathrm{~cm}$, en un porcentaje de $10 \%$ aproximadamente.

En el punto 3 (Fig. 4.14 a) se observa un depósito pumíceo clástico con las mismas características que la sección superior del punto 1. En la Figura $4.14 \mathrm{~g}$ ) se esquematiza las variaciones en las características de los depósitos en este cono pumíceo.

La naturaleza clástica de estos depósitos, junto con su morfología monticular y caracte- 


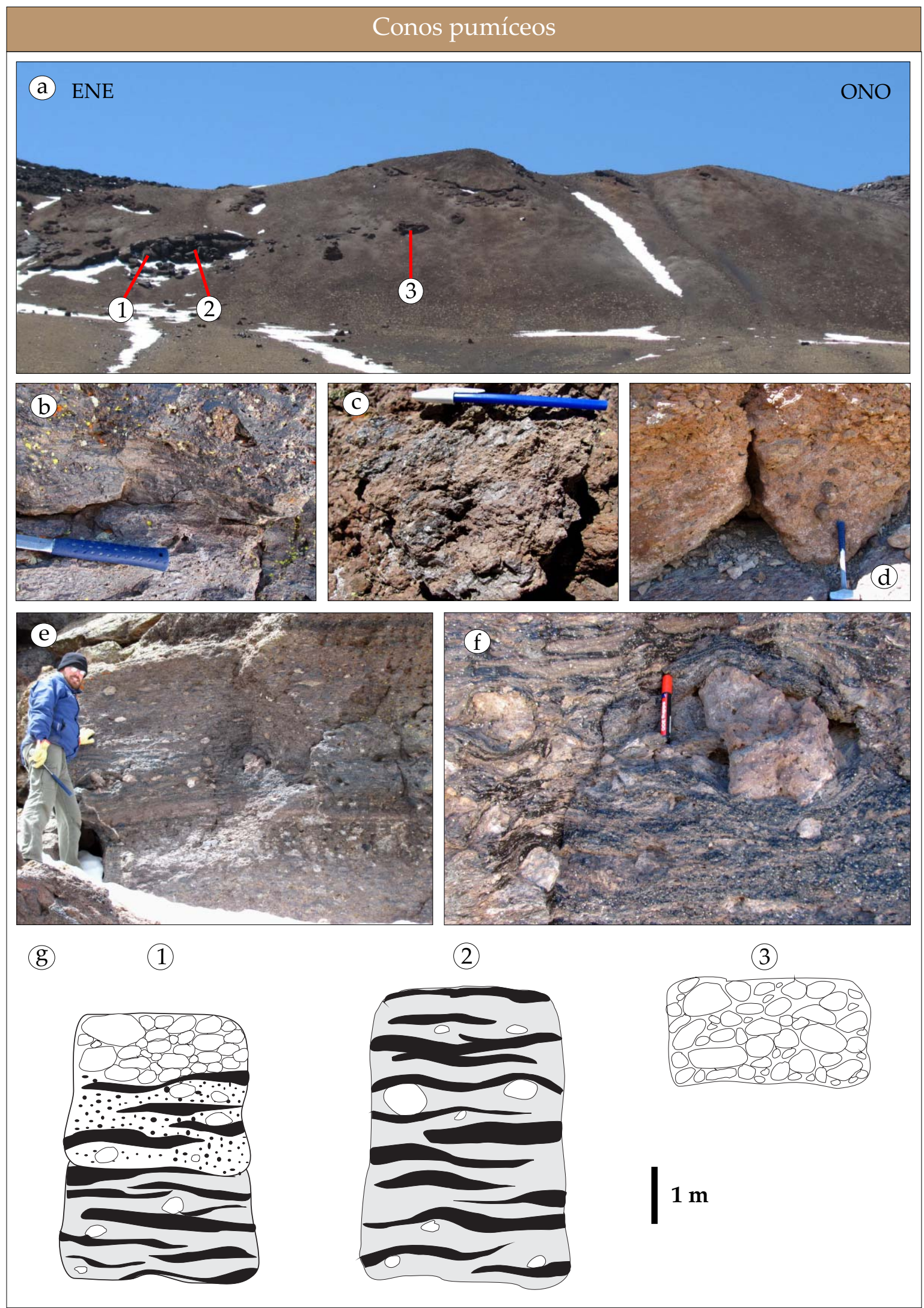

Figura 4.14: Cono pumíceo en el borde ONO de la caldera. a) Vista general del cono. b) vitrófiro negro en la base del perfil 1. c) Intercalación de pómez con el vitrófiro, sector medio del perfil 1. d) Depósito clástico en el tope del perfil 1. e) y f) Fotos del perfil 2. g) Dibujo de los tres perfiles en el cono pumíceo. 
rísticas texturales (clasto sostén, mala a muy mala selección, masivos a estratificados, etc) indican que se trata de depósitos de caída muy proximales, depositados directamente encima del conducto emisor (similarmente a los conos de escoria). La forma ecuante o elongada de los mismos podría deberse a la naturaleza del conducto emisor, dependiendo de si este era puntual o, por el contrario, si la erupción fue a través de una fisura.

El hecho de que se hayan encontrado sectores en algunos conos donde el depósito se asemeja a una lava, estaría indicando que los clastos de spatter eran lo suficientemente fluidos y calientes como para soldarse, dándole el aspecto lávico al depósito. La presencia de clastos de pómez vesiculares, no aplastados y con límites bien reconocibles, sugeriría que no todos los clastos depositados en un mismo sitio, y contemporáneamente, poseían estas características de alta fluidez.

\subsubsection{Traquitas vítreas $(T v)$}

Esta litofacies está compuesta por lavas vitrofíricas negras, de composición traquítica similar a las Traquitas en bloque (ver el Capítulo 7). Conforman principalmente domos, y en menor proporción coladas dómicas y coladas. Estas lavas fueron emitidas fundamentalmente a lo largo del borde occidental y sur de la caldera (Fig. 3.5). Existen pocas excepciones a esta regla, habiendo solamente dos coladas dómicas en el flanco oeste del Payún Matrú alejadas del borde de caldera, y otra colada pequeña en la ladera sudeste, inmediatamente al norte del "Farellón de la Portada" (Fig. 4.1).

Se encuentran escasas coladas lávicas de extensión reducida, entre 2 y hasta $4 \mathrm{~km}$ de largo, las cuales fueron emitidas, con una sola excepción, en un quiebre de pendiente entre la parte alta de la caldera y la ladera extra-caldera (Fig. 4.15 a, a esta colada corresponde la muestra PMB 12, la cual fue datada en $20 \mathrm{ka}$ ). En estos sitios el cambio de pendiente es brusco, produciendo que las lavas presenten cicatrices de deslizamiento cóncavas hacia la dirección de flujo, y un canal central que baja la ladera (Fig. 4.15 c). Hacia los bordes del canal central, se observan crestas de presión más o menos disfusas. En el sector de la colada que se encuentra desde el punto de emisión hacia el centro de la caldera (de extensión relativamente reducida), la morfología es claramente diferente, con crestas de presión bien desarrolladas en muchos casos (Fig. 4.15 b y c). La superficie de estas lavas suele tener plegamientos de lava muy marcados, y discontinuos (Fig. 4.15 e).

Los espesores de estas lavas, al igual que las coladas dómicas, son visiblemente inferiores a los espesores de las Traquitas en bloque, desde pocos metros hasta pocas decenas de metros (Fig. 4.15 e y f).

Las coladas dómicas se encuentran en sitios de pendiente relativamente menor, respecto de las otras coladas, o bien en zonas de altas pendientes pero como flujos poco extensos debido al escaso volumen de la efusión, como ocurre en en la ladera sur de la caldera (Fig. 4.16 a y c). El centro de emisión está marcado por un pequeño domo, el cual suele tener el 


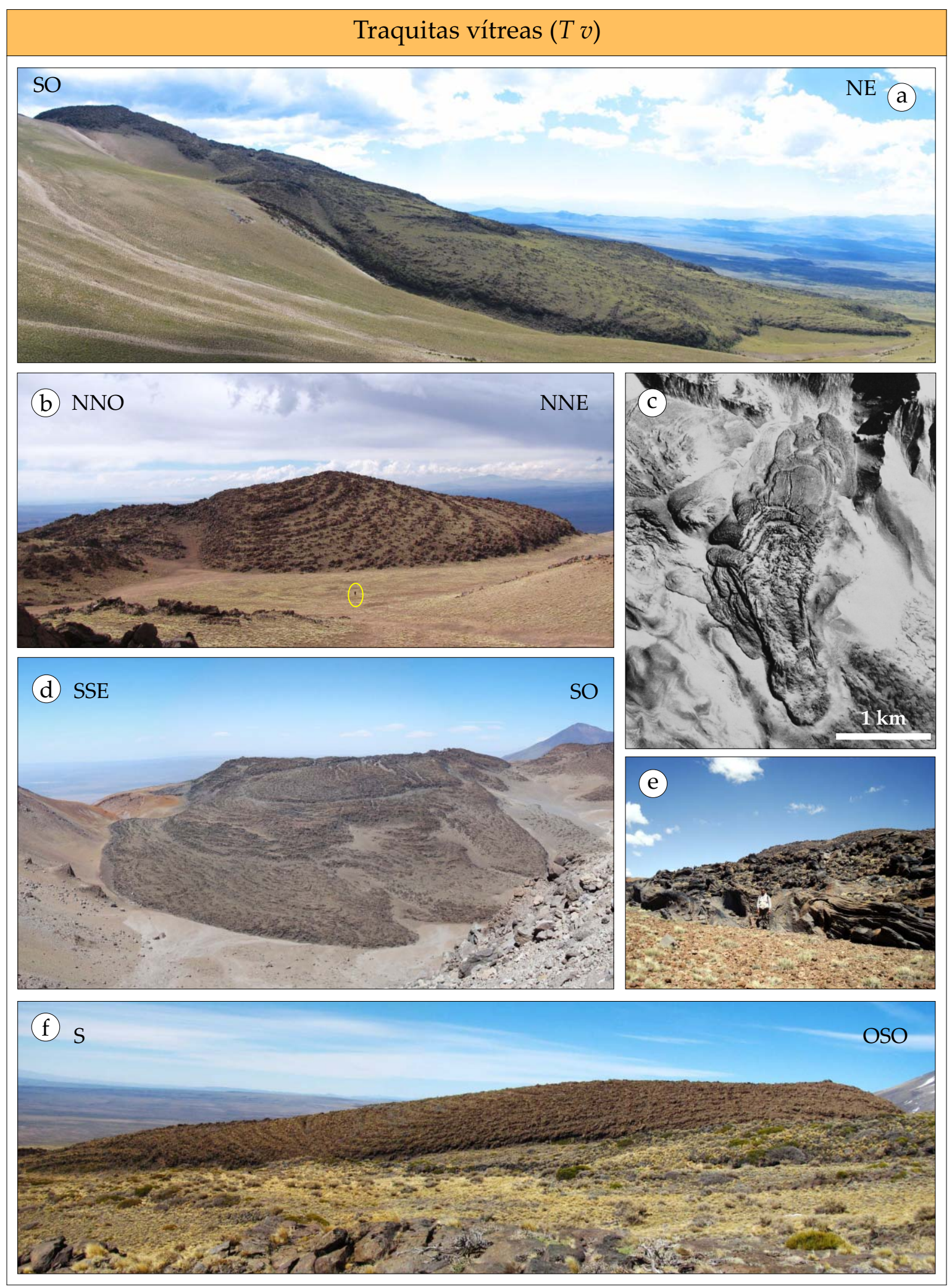

Figura 4.15: a) Colada denominada "El Pulpo" en el borde N de la caldera, de 2,9 km de longitud. b) Misma colada, vista desde el interior de la caldera. Persona encerrada en el circulo para escala. $c$, d y e) pertenecen a una colada en el flanco SE de la caldera, que nace justo al S del fin de la pared topográfica. f) Pequeña colada en el flanco sur, de 1,4 km de longitud. 


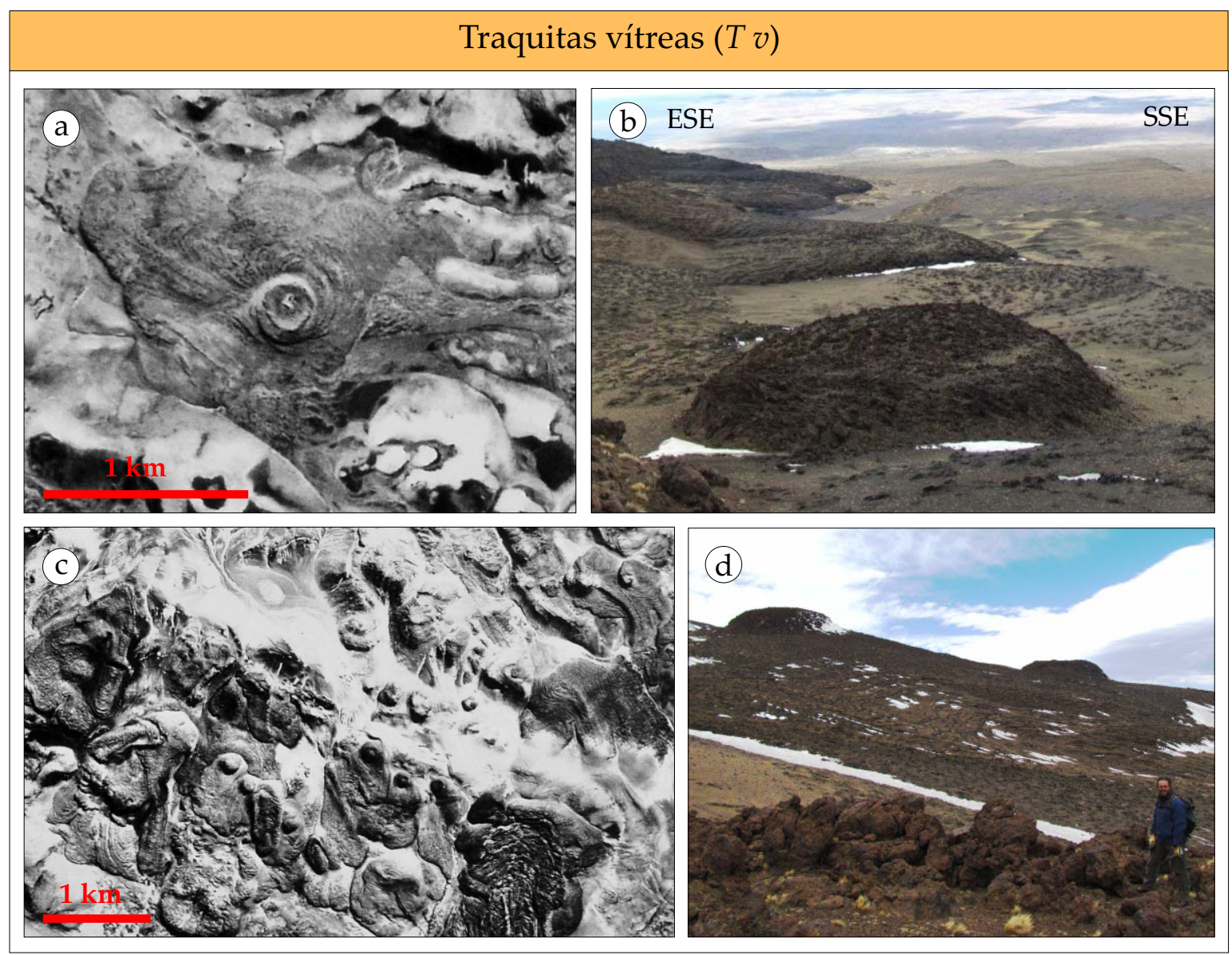

Figura 4.16: Fotos aéreas y de campo de domos y coladas dómicas de la litofacies $T v$. a) Foto aérea de una colada dómica al pie $\mathrm{O}$ de la caldera. b) Domo de $150 \mathrm{~m}$ de diámetro, ladera $\mathrm{S}$, mirando hacia el SO. c) Foto aérea rectificada del borde $\mathrm{S}$ de la caldera, con numerosos domos y coladas dómicas. d) Domos en el borde S de la caldera.

techo hundido. Las crestas de presión indicando la dirección de flujo son marcadas. Estas presentan una amplitud y "longitud de onda" menor en las Traquitas vítreas que aquellas de las Traquitas en bloque.

Los domos son abundantes en el borde SE a SO de la caldera (Fig. 4.16 c). En ocasiones dan lugar a un reducido flujo lávico, haciendo que el límite entre domo y colada dómica sea transicional y arbitrario. Se encuentran ocupando una franja anular relativamente ancha, y el alineamiento de estos domos, a veces también junto con las coladas, en rumbos variables y definiendo la estructura anular de la caldera, es notorio. Los domos son de dimensiones reducidas, entre $100 \mathrm{~m}$ y $1 \mathrm{~km}$ de diámetro, y generalmente de pocas decenas de metros de altura.

Si bien es difícil calcular el volumen con precisión, puede observarse que el volumen de cada domo o flujo particular es notoriamente menor a las lavas de las Traquitas en bloque. Con el área obtenida en el GIS y un espesor estimado, se obtienen volúmenes que oscilan 
entre 0,2 y 0,008 $\mathrm{km}^{3}$ para cada cuerpo. Si bien este no es un cálculo preciso, puede observarse que, en promedio, estos volúmenes resultan ser de al menos dos órdenes de magnitud menor que en el caso de las coladas de Traquitas en bloque.

\subsubsection{Relación y comparación entre las litofacies de Traquitas Post-caldera}

La diferencia entre las diferentes morfologías lávicas observadas entre las Traquitas en bloque y las Traquitas vítreas puede deberse, no sólo a las características reológicas de las lavas, sino al volumen de material eruptado y a la pendiente del terreno. Los domos son generalmente de menor volumen que las coladas, aunque hay algunos domos en la parte más alta del borde sur de la caldera de mayor magnitud que el resto de lavas y coladas dómicas.

Las crestas de presión se forman debido a una compresión paralela al flujo durante el avance de lavas silícicas. Para esto, se requiere de un techo o caparazón con una viscosidad mayor que en el núcleo, pero que al mismo tiempo la viscosidad del techo no sea lo suficientemente alta como para permitir que la caparazón se deforme fragilmente (Fink y Anderson, 2000). La longitud de onda de las corrugaciones son groseramente proporcionales al espesor de la caparazón enfriada del flujo (Fink y Anderson, 2000). Esta constante de proporcionalidad es mayor en las rocas más silícicas que en las menos silícicas. Dado que la longitud de onda en las Traquitas en bloque es visiblemente mayor que en las Traquitas vítreas, y ambas litofacies no presentan diferencias significativas composicionalmente, se infiere que las primeras poseen una costra enfriada de mayor espesor que las Traquitas vítreas.

La presencia de un vitrófiro negro en el nacimiento de algunas Traquitas en bloque, con una morfología similar a las Traquitas vítreas, junto con la intercalación en el tiempo de ambas litofacies, y las similitudes de composición y petrográficas (Capítulos 6 y 7) indican una estrecha relación entre las Traquitas vítreas y las Traquitas en bloque. Esto podría deberse a diferencias en el grado de cristalización y/o temperatura, y por lo tanto viscosidad, de los magmas alojados en una misma cámara magmática. La presencia de depósitos de pómez con clastos y bombas de Traquitas vítreas, junto con la presencia de una colada de esta litofacies naciendo de un cono pumíceo, y clastos compuestos por pómez y vidrio compacto, indica que los conos pumíceos representan una fase más vesicular de estos magmas traquíticos.

En resumen, si bien no se dispone de análisis químicos de fragmentos pumíceos, la relación entre estos y las Traquitas vítreas, junto con su idéntica petrografía (Capítulo 6), sugiere que se trata de una misma composición pero con un diferente grado de vesiculación y por lo tanto estilo eruptivo distinto. La similitud en la composición química de las dos litofacies de coladas traquíticas indica que una misma composición traquítica presenta tres tipos contrastantes de productos volcánicos.

En ciertos casos reportados en la literatura, existen transiciones entre una actividad explosiva temprana que luego cambia a efusiva (Fink y Anderson, 2000). En un principio se ex- 
plicaba este comportamiento por una diferencia en el contenido de volátiles de los magmas, pero luego se comprobó que esta condición no es necesaria. Esto sugirió que la diferencia en estilo eruptivo puede deberse a una variación en la pérdida de gases durante el ascenso, lo cual depende básicamente de la velocidad de ascenso y la permeabilidad del conducto (Fink y Anderson, 2000).

La gran parte de coladas y domos de Traquitas vítreas son posteriores a los conos pumíceos, aunque no se sabe con certeza si corresponden a eventos eruptivos separados, o una misma erupción que cambió su comportamiento, como suele ocurrir en erupciones basálticas (Vergniolle y Mangan, 2000). Al pie oeste de la caldera se encuentra una colada dómica ("Mousse", Fig. 4.1), en la cual se observan depósitos clásticos de pómez con intercalaciones de vidrio negro subyacentes en el borde SO de la colada. Esta relación sugeriría que la erupción comenzó con una fase explosiva (aunque de baja explosividad) con clastos lo suficientemente calientes y/o con una tasa de erupción lo suficientemente alta como para formar los clastos de spatter traquíticos, y luego evolucionó a una erupción efusiva.

\subsection{Campos basálticos este y oeste}

En el CVPM se encuentran más de 200 conos de escoria situados en una amplia franja de sentido E-O, la cual se interrumpe por la presencia de la caldera (Fig. 1.3 y 3.5). En las cercanías a la caldera, la franja con conos de escoria se hace más angosta que en los sectores más alejados, en los cuales se hallan más dispersos los conos basálticos (Fig. 4.17 a). No sólo es notable la falta de erupciones basálticas en la caldera, sino también su interrupción al norte y sur de la misma. El cono "Santa María" que da origen al "Escorial de la Media Luna" al NO del Payún Matrú, es una excepción en este sentido, aunque se encuentra relativamente alejado de la caldera (Fig. 4.1). Las coladas lávicas que nacen de estos conos se derraman hacia el sur o el norte, habiendo una divisoria en sentido E-O a la latitud del centro de la caldera, coincidente con la mayor densidad de conos de escoria. La composición de las lavas es basáltica a traquibasáltica (Capítulo 7).

Existen diferencias entre el campo basáltico este y oeste, en cuanto a las proporciones relativas de basaltos pre- y post-caldera que presenta cada uno. Al este del Payún Matrú, las lavas pre-caldera son abundantes, aflorando sobre todo al norte de la falla La Carbonilla (Fig. 4.1). Las lavas post-caldera se derraman hacia el sur, siendo un poco más abundantes los Basaltos Post-caldera I que los Basaltos Post-caldera II, restringida las nacientes de estos últimos a la falla La Carbonilla.

Por el contrario, al oeste de la caldera los afloramientos de Basaltos Pre-caldera son reducidos debido al intenso volcanismo basáltico posterior que los cubren. Esta unidad precaldera está representada por algunos conos de escoria que no fueron cubiertos por los derrames posteriores (Fig. 4.17 b). No se infiere que el volcanismo basáltico pre-caldera fuera más intenso en el campo este que en el oeste, ya que esto no puede afirmarse solamente con 


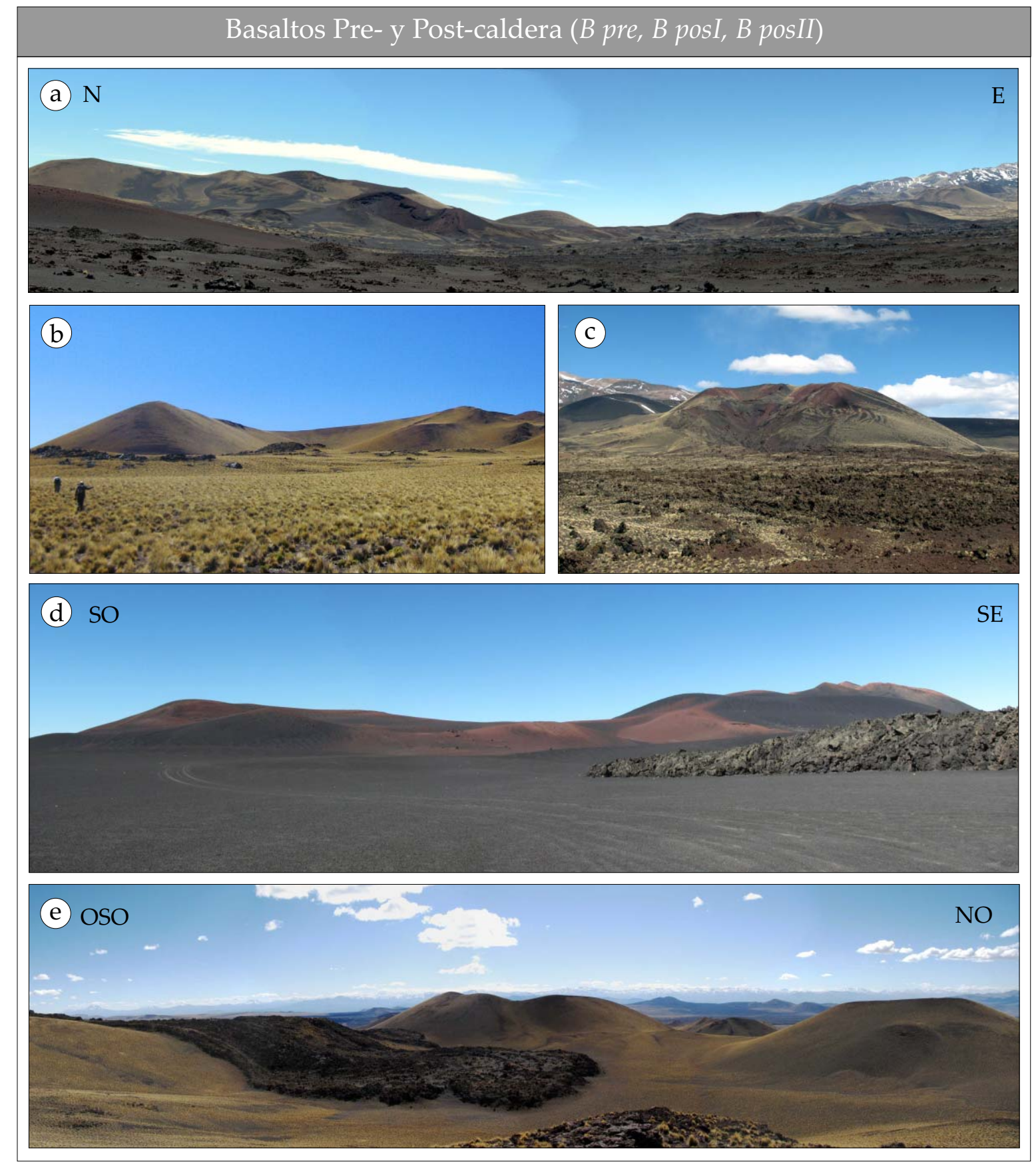

Figura 4.17: a) Campo basáltico al oeste del Payún Matrú, y la ladera oeste del volcán de fondo. b) Cono de escoria pre-caldera al oeste de la caldera, aportillado. c) Cono de escoria que da origen a la colada de La Tranquera, perteneciente a la unidad de Basaltos Post-caldera II. d) Cubierta de escoria lapillitica, cono de escoria y colada a $a$ La Araña, sin ninguna cobertura vegetal, en el campo basáltico oeste. Ver la huella de la camioneta para la escala. e) Conos de escoria de la unidad Basaltos Post-caldera I, y un lóbulo de la colada de La Tranquera derramándose entre ellos. 
un estudio de la superficie. El relieve general de todo el CVPM, el cual es de forma abovedada, y el hecho de que los basaltos post-caldera parecen acomodarse a un relieve previo de esa forma, sugieren que el volcanismo basáltico pre-caldera fue intenso a ambos lados del Payún Matrú.

En el campo basáltico oeste, las erupciones basálticas post-caldera fueron mucho más importantes que en el campo este, con coladas lávicas naciendo de conos de escoria ubicados esencialmente en un angosta franja E-O a la altura de la caldera. En este campo se encuentran cuatro coladas de Basaltos Post-caldera II principales ("Escorial de la Media Luna", "La Tranquera”, “Colada de Los Molles” y “La Araña”, Fig. 4.1), con otras pocas de menor magnitud. La actividad volcánica basáltica más moderna, y la post-caldera en general, se concentró hacia el oeste de la caldera.

Las lavas y conos de escoria pertenecientes a la unidad de Basaltos Post-caldera II presentan un grado de preservación variable. Hay lavas y conos que se encuentran perfectamente preservados, sin una mínima cubierta vegetal, como es el caso de "La Araña" (Fig. $4.17 \mathrm{~d}$ ). Otros, si bien preservan campos de bombas y morfología de lavas y conos intactos, sí presentan una leve cubierta vegetal (Fig. 4.17 c). Por otro lado, los Basaltos Post-caldera I presentan siempre una cobertura vegetal y también una delgada capa de sedimentos arenosos modernos, sin cubrirlos por completo (Fig. 4.17 e). Los conos de escoria, tanto los precomo los post-caldera, presentan a veces una coloración rojiza oscura por oxidación, que puede presentarse en todo el cono, o como sectores rojizos junto con otros negros.

Existe un control estructural sobre el volcanismo, observado tanto en el campo como en el mapa geológico, no sólo en los campos basálticos sino también en el Payún Matrú. Numerosos lineamentos, definidos por la alineación de conos de escoria y también por erupciones fisurales, se encuentran en los campos basálticos (Fig. 3.5). Este punto será tratado con más detalle en el capítulo siguiente.

En el campo basáltico oeste se encuentran zonas más o menos amplias con una cubierta de escoria tamaño lapilli, suavizando el terreno (Fig. 3.1 y 4.17 d). Esta cubierta puede presentar o no una incipiente cubierta vegetal parcial (coirones). Estos sectores con la cubierta lapillitica, que se observan como manchones oscuros en la imagen satelital (Fig. 1.3) se distribuyen en las cercanías de los conos de escoria más modernos (cono de "La Araña", "La Tranquera" y "Los Molles", Fig. 4.1). Esta cubierta posee una tendencia a dispersarse desde los conos modernos hacia el este, indicando la influencia de los fuertes vientos de la zona que provienen mayormente del oeste o noroeste (al menos actualmente). La presencia de los conos de escoria, así como de la cubierta de lapilli escoriáceo, indicarían que las erupciones fueron del tipo estromboliano (Vergniolle y Mangan, 2000). En algunos casos se observa una erupción fisural, la cual presenta un cono de escoria principal, y la traza de la fisura definida simplemente por la emisión de lava o por alineamiento de rampas pequeñas de spatter. Esto sugiere que en ciertos casos, y como está reportado en la literatura, la erupción comienza con un estilo fisural hawaiano tipo "cortinas de fuego" y finaliza con un estilo estrombo- 
liano (Vergniolle y Mangan, 2000). La dispersión de los productos eyectados en estos estilos eruptivos es relativamente reducida (generalmente en un radio menor a los $500 \mathrm{~m}$ desde la fuente) debido a la poca altura de la columna eruptiva y al tamaño relativamente grueso de los eyectos (Vergniolle y Mangan, 2000), aunque sin embargo es suficiente como para dispersar la escoria en tamaño lapilli y formar el paisaje observado.

Muchos conos de escoria son aportillados, naciendo un flujo lávico a partir del mismo. Se encontraron dos lavas, una proveniente del cono Morado Grande del oeste y la colada de La Tranquera (Fig. 4.1), las cuales presentan en la parte proximal del flujo una topografía tipo hummocky. Esta irregularidad en el tope del flujo se debe a que poseen grandes bloques compuestos por escoria y/o spatter estratificados, los cuales pertenecían al cono del cual nace la colada. El aportillamiento del cono de escoria se produjo, por lo tanto, por la ruptura del cono por efecto de la lava, luego de su formación.

En cuanto a la morfología de las lavas, se encuentran los dos tipos básicos de lavas basálticas: las lavas pahoehoe y las aa. En los Basaltos Pre-caldera y en los Basaltos Post-caldera I los flujos son compuestos y presentan rasgos característicos de las lavas pahoehoe, como ser superficies relativamente lisas, lavas cordadas, túmulis y también tubos pequeños con costras delgadas que dejan ver el interior con una superficie cordada (Figs. 4.18 a y b). De estos rasgos nombrados, el más habitual consiste simplemente en una lava con una superficie lisa y no escoriácea, mientras que los otros rasgos, si bien se observan en numerosos sitios, son menos frecuentes. En el campo basáltico este, al NE del mismo (inmediatamente por fuera de la esquina superior derecha del recuadro en la Figura 1.3), se encuentra las nacientes de un flujo basáltico pahoehoe que es considerado el más largo del planeta (Pasquerè et al., 2008). Presenta $181 \mathrm{~km}$ de longitud y fluye hacia el sudeste llegando hasta la provincia de La Pampa.

En un claro contraste, todas las lavas de los Basaltos Post-caldera II presentan una morfología aa. Se observan superficies escoriáceas, con un canal principal el cual puede bifurcarse o no, y albardones de ancho variable (Figs. 4.18 c y d). La longitud de estas coladas varía entre 9 km (Colada del "Morado Grande" del oeste) y 27 km (colada de "La Tranquera"). Se encuentran también dos flujos menores en el campo oeste, de $2 \mathrm{~km}$ de longitud.

Las diferencias en la morfología de las lavas basálticas puede deberse a diversos factores, como son la viscosidad, la tasa de efusión y la tasa de cizalla, las cuales dependen a su vez de otras variables, como la composición, la temperatura, el grado de cristalinidad, la pendiente, etc (Németh y Martin, 2007). Las lavas pahoehoe suelen formarse en lavas muy poco viscosas, con una tasa de efusión baja, mientras que ambos factores son un poco mayores en el caso de lavas aa. Debido a que en el CVPM se observan tanto lavas aa como pahoehoe adyacentes y en pendientes similares, es de suponer que la tasa de cizalla (reflejada por la pendiente) no es un factor determinante en la morfología lávica. Como se verá más adelante, los Basaltos Post-caldera II son de composición algo más evolucionada que los Basaltos Post-caldera I y Basaltos Pre-caldera, aunque la diferencia es leve y hay cierta superposición. El hecho de 


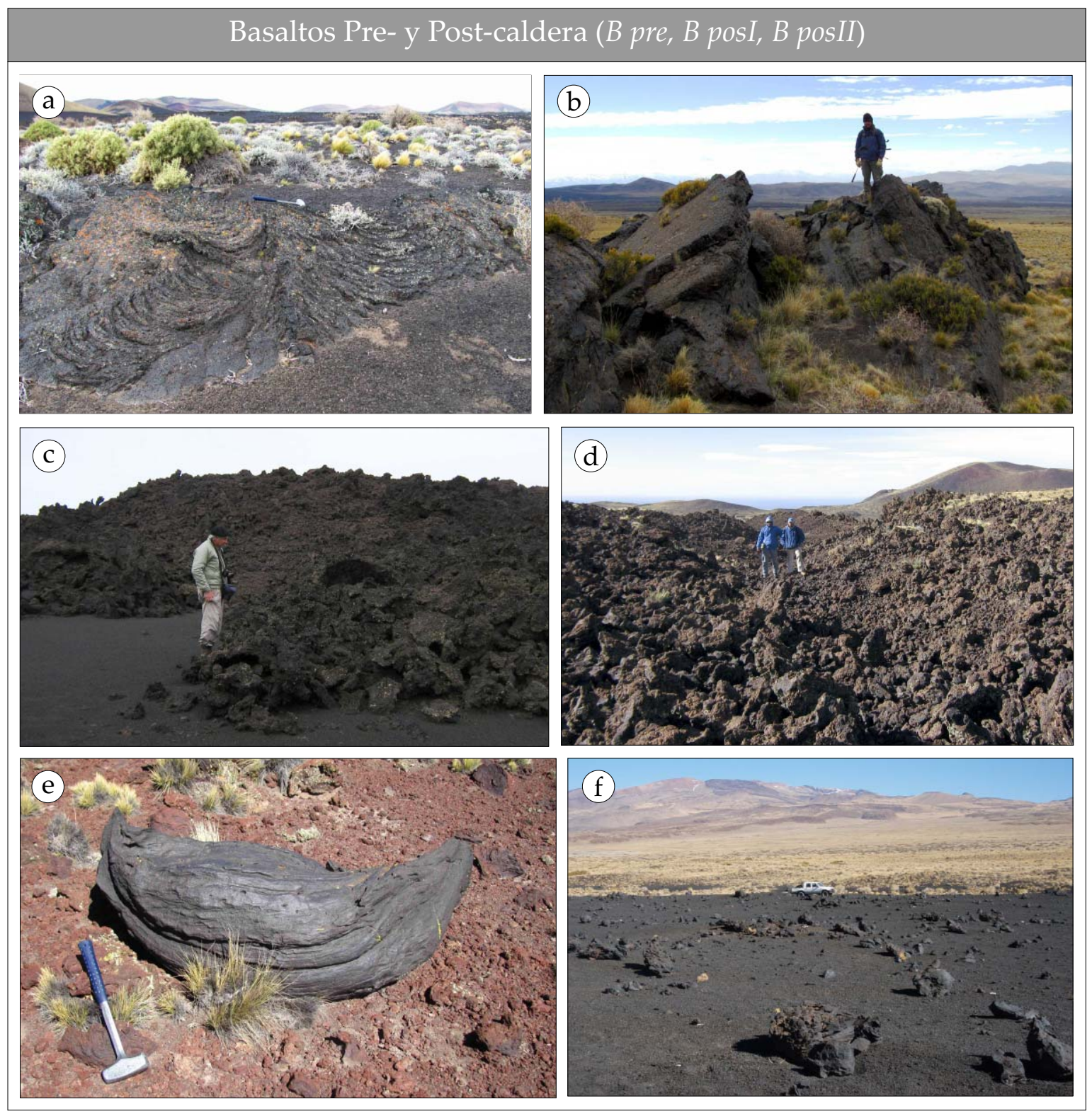

Figura 4.18: a) Lava cordada en una lava post-caldera I. b) Túmuli desarrollado en una lava post-caldera I, con el techo quebrado y superficies bien lisas. c y d) Superficies escoriáceas en lavas a a de los Basaltos Post-caldera II, en la colada de "La Araña"y otra en el campo basáltico este, respectivamente. e) Bomba basáltica de forma ahusada y considerable tamaño. f) Campo de bombas al pie del cono "Santa María". Fotografía tomada por Gerardo "Tito" Paez. 
que las lavas más modernas presenten una morfología de tipo aa podría deberse en parte a este factor, aunque en parte puede deberse a otros factores como la tasa de efusión, y/o temperatura, grado de cristalinidad, etc.

Es común la presencia de conos de escoria con abundantes bombas en su superficie, tanto en los conos pertenecientes a los Basaltos Post-caldera I como en los II (Fig. 4.18 f). Las bombas son de tamaño diverso, desde pocos centímetros hasta decenas de centímetros de largo. En cuanto a las formas de las mismas, abundan aquellas ahusadas (Fig. 4.18 e), y también otras más globosas o más irregulares y retorcidas. En muchas bombas quebradas se observa una costra de lava con pocas vesículas, y un interior más vesiculado, aumentando el tamaño de las vesículas hacia el centro de la bomba. También es frecuente la superficie de corteza de pan, formada por la contracción de la costra de la bomba durante el enfriamiento.

El volumen de los basaltos es difícil de determinar, debido a que no se conoce el espesor total de las lavas que conforman los campos basálticos. Se podría calcular un volumen de manera similar al estimado para el Payún Matrú, calculando primero un volumen de todo el campo volcánico, y luego restándole los volúmenes del Payún Matrú y Payún Liso. Sin embargo, se considero que puede cometerse un error significativo debido a que la cota inferior necesaria para el cálculo no es fácil de definir. Por un lado, es probable que la base del campo volcánico no sea plana, y por otro, en el límite de los basaltos donde aflora el basamento, este presenta cotas muy disímiles, lo cual invalida el cálculo.

\subsection{Volcán Payún Liso}

El Payún Liso, al no ser el objeto de estudio del presente trabajo, fue observado someramente. El objetivo principal de los escasos estudios fue conocer si su volcanismo era similar a la del Payún Matrú, en cuanto a la composición de los magmas y pertenencia a series magmáticas, cuestiones que serán tratadas en los capítulos 6 y 7 . El hecho de pertenecer al CVPM, junto con la contemporaneidad del Payún Liso con la etapa temprana y media del Payún Matrú y campos volcánicos, sugieren que este es el caso.

Como es típico para un estratovolcán, el Payún Liso se compone de lavas, ignimbritas y otras rocas volcaniclásticas. Los productos lávicos abundan por sobre los piroclásticos, al menos en su superficie. La composición de las lavas estudiadas es variable desde traquiandesitas basálticas a traquitas, siendo de naturaleza alcalina al igual que el resto del campo volcánico. La única ignimbrita observada se encuentra sobre el faldeo sur del cráter, por lo que no caben dudas de su proveniencia. Es una ignimbrita rojiza a anaranjada, con un espesor expuesto de 5-6 m. Presenta fiammes estirados, típicos de una ignimbrita de alto grado.

En el Payún Liso nacen tres abanicos aluviales, dos de los cuales se ubican en su ladera sur y uno en el flanco noreste del mismo. El perfil que presenta el volcán es cónico, como suele ser en volcanes jóvenes sin erosión (Davidson y Da Silva, 2000). Sin embargo, la presencia 


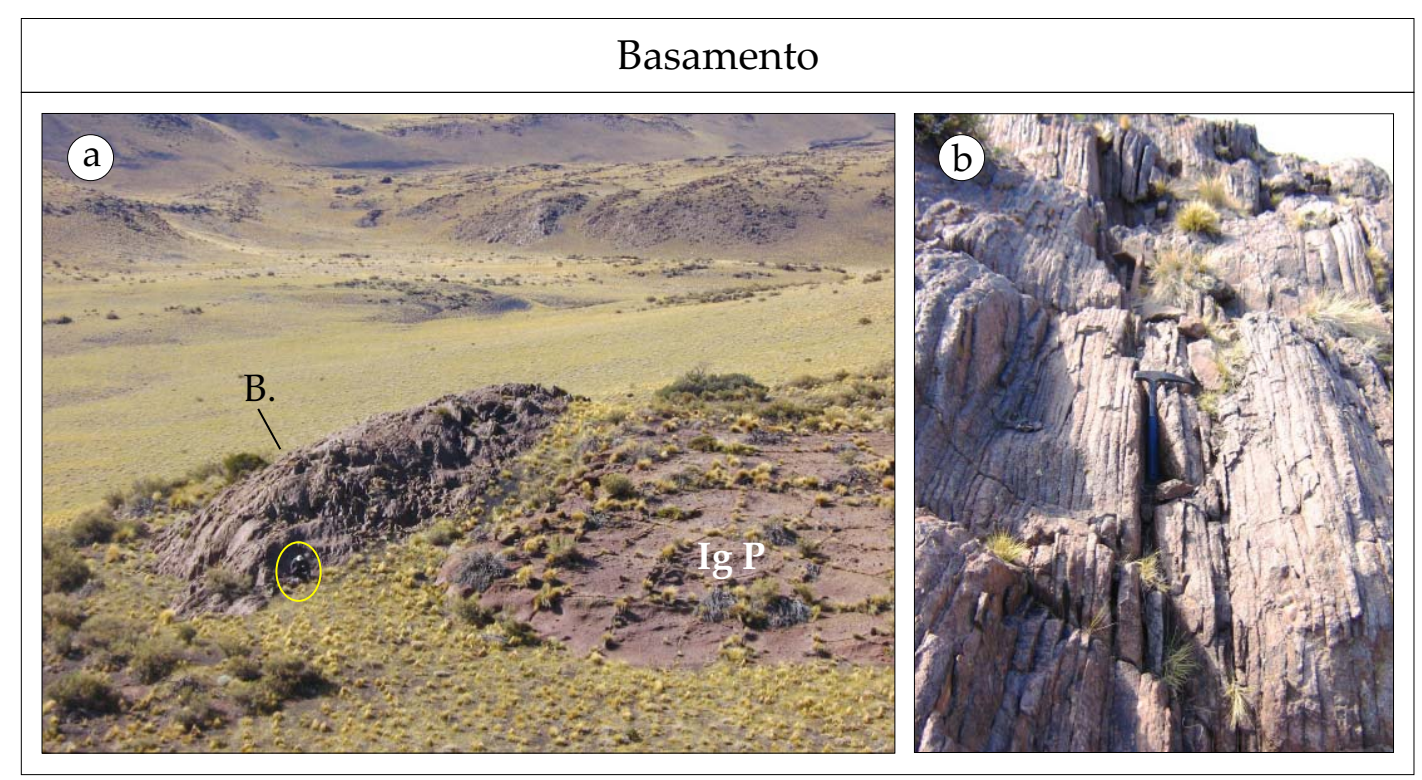

Figura 4.19: Fotos de los reducidos afloramientos de lavas cubiertas por la Ignimbrita Portezuelo, de naturaleza completamente diferente al resto de rocas del CVPM. a) cresta de aproximadamente $150 \mathrm{~m}$ de longitud (persona encerrada en el círculo). Ig P: Ignimbrita Portezuelo; B.: basamento. b) foliación por flujo en lavas.

de los abanicos aluviales junto con las incisiones no muy pronunciadas del mismo, indican una incipiente erosión, la cual no es lo suficientemente importante como para modificar el perfil general del volcán.

La localización de este volcán en el CVPM es ligeramente más al sur de la franja E-O con mayor densidad de conos basálticos y por el Payún Matrú. La evolución del mismo ocurrió en la etapa pre-caldera del campo volcánico y, aunque sea probable que haya tenido actividad en la etapa post-caldera, es claro por sus morfologías que su actividad cesó mucho antes de las últimas erupciones del Payún Matrú. Es probable que esta falta de actividad en la etapa post-caldera del CVPM se deba a su localización alejada de la franja E-O que concentra al volcanismo moderno.

\subsection{Basamento}

En el CVPM se hallan escasos afloramientos de unidades litoestratigráficas del sustrato del Payún Matrú, y no vinculadas con la evolución de este campo volcánico. Al SO de la caldera se hallan afloramientos reducidos, cubiertos parcialmente por la Ignimbrita Portezuelo (Fig. 4.19 a, mapeado solamente como Ignimbrita Portezuelo en el mapa resumido de la Figura 3.5, y mapeado con más detalle en el mapa completo del Anexo I). Estos afloramientos son lavas que corresponden químicamente a traquitas y dacitas (en el límite entre ambos campos del TAS). En estas lavas se observa una foliación paralela muy marcada, con 
filetes de flujo de varios centímetros de espesor, característica que sugiere que corresponden a un antiguo domo (Fig. 4.19 b). Se realizaron dos análisis químicos de estas rocas, y uno isotópico de $\mathrm{Sr}$, los cuales muestran una gran diferencia con las rocas del CVPM, por lo cual no parecen estar vinculadas con la evolución del mismo.

Dada la variabilidad litológica de las volcanitas Terciarias de la región y la escasez de afloramientos de las mismas en el CVPM, no es posible afirmar con seguridad a que unidad estratigráfica pertenecen. Aunque los estudios realizados son escasos, se infiere que estas rocas podrían pertenecer al Grupo Molle, o Ciclo Eruptivo Molle, de edad Mioceno medio-superior, el cual está compuesto fundamentalmente por basaltos (Basalto Molle, Basalto Puntilla del Huincan y Basalto Palaoco), pero que también presenta andesitas y dacitas (Nullo et al., 2002; Narciso et al., 2001). El Grupo Molle posee afloramientos al oeste y noroeste del CVPM, en la zona de Puntilla del Huincán y Sierra de Palauco. Otra posibilidad, es que pertenezcan a la Formación Huincán del Ciclo Eruptivo Huincán (Groeber, 1946; Nullo et al., 2002), la cual es tanto efusiva como extrusiva y de composiciones predominantemente andesíticas. Aflora también en la zona de Puntilla del Huincán, aunque restringidamente y con mayores afloramientos al norte de los $36^{\circ} \mathrm{S}$ y hacia el oeste de $\operatorname{los} 70^{\circ} 30^{\prime} \mathrm{O}$, y es de edad Miocena medio (Nullo et al., 2002). 


\section{Capítulo 5}

\section{Control estructural sobre el volcanismo}

\subsection{Estructuras regionales y el CVPM}

El primer aspecto para resaltar en cuanto a las estructuras del CVPM, es la concentración de las erupciones en una franja E-O. En esta franja se encuentra la mayor cantidad de conos de escoria y la caldera del Payún Matrú se ubica en una posición central en la misma, mientras que por fuera de esta franja los conos de escoria son relativamente escasos. Esta disposición de los centros de emisión sugiere una estructura de primer orden, ya que afectaría a todo el espesor de la corteza y no solamente su sector superior, considerando la proveniencia profunda de los magmas basálticos.

La orientación E-O de la franja definida por la caldera y los centros eruptivos basálticos no solamente puede deberse al campo de esfuerzos reciente, sino que también podría responder a antiguas estructuras, las cuales han facilitado y al mismo tiempo restringido a una franja el ascenso de los magmas. Dentro de la franja E-O que representa el CVPM se encuentran, a su vez, variaciones en las estructuras inferidas que podrían responder a los esfuerzos actuantes durante el volcanismo Pleistoceno-Holoceno del CVPM, como se verá en las secciones subsiguientes.

Una característica sobresaliente, es el hecho de que al norte del CVPM se encuentra un relleno sedimentario Terciario de aproximadamente $1000 \mathrm{~m}$ de espesor (Ostera y Dapeña, 2003), el cual desaparece al sur del campo volcánico (Llambías et al., 2010). Al oeste del Payún Matrú, en la salina de "El Cortaderal" (36 39' 9" S - 68 30' 43" O) se encuentran basaltos Pleistocenos sobreyaciendo a rocas sedimentarias de la Fm Malargüe (Cretácico Superior), lo cual indica que a esta latitud la cuenca sedimentaria del Terciario no se encuentra, encontrándose su borde austral a la latitud de la salina o hacia el norte de la misma.

La orientación de esta franja en sentido E-O, si bien es altamente oblicua a los Andes, no resulta extraña en la cordillera andina ni en el retroarco andino. Diversos autores han 
propuesto la existencia de estructuras antiguas que segmentan a la cadena andina y el antepaís, tanto al sur como al norte del CVPM. En la Cuenca Neuquina, que forma en parte el basamento del CVPM, se encuentran estructuras que constituyen líneas de debilidad de la corteza formadas en el basamento de la cuenca, y que a su vez, se ven reflejadas en el relleno de la misma (Ramos, 1978). Algunos ejemplos lo constituyen la dorsal de Huincul en el sector sur de la Cuenca Neuquina (Ramos, 1978) y el lineamiento Las Coloradas-Villarica (Chotin, 1976), entre otras. Además de estas estructuras E-O, se encuentran otras en sentido NO en la cuenca Neuquina (como el lineamiento Pino Hachado), siendo estas más abundantes que las primeras (Ramos, 1978). En la provincia de Mendoza, también se encuentran estructuras oblicuas a los Andes, como el lineamiento del río Salado marcado por lavas de basaltos alcalinos Holocenos con una orientación NO, y el lineamiento $\mathrm{NO}$ formado por los volcanes Tromen y Domuyo (Llambías et al., 2010). Otras estructuras oblicuas a los Andes en Mendoza se encuentran en el piedemonte del cordón del Carrizalito de la Cordillera Frontal, en donde se encuentran las zonas de fractura de Papagayos y Diamante, de rumbo NO-SE (Cortés y Sruoga, 1998; Sruoga et al., 2005). Estas zonas de fractura tuvieron actividad durante el Pleistoceno y también Holoceno (Cortés y Sruoga, 1998). En la misma zona pedemontana se ha identificado la zona de fracturas del arroyo El Carrizalito, de rumbo E-O, similarmente al CVPM (Cortés y Sruoga, 1998; Sruoga et al., 2005).

En síntesis, el volcanismo del CVPM tiene un fuerte control estructural en sus emisiones, canalizadas a través de lineamientos y restringidas a una faja E-O.

\subsection{Las erupciones como indicadoras de esfuerzos}

Con frecuencia se observa que las erupciones volcánicas indican estructuras, ya sea por alineamiento de conos de escoria, erupciones fisurales, o por alineamiento de volcanes poligenéticos (Alaniz-Alvarez et al., 1998; Cole, 1990; Takada, 1994). Estos lineamientos son importantes ya que con ellos se pueden hacer inferencias sobre el campo de esfuerzos actuante en una determinada región para los tiempos en que ocurría el volcanismo. Los lineamientos formados por conos de escoria son particularmente útiles en este caso, y abundantes en los campos basálticos al este y oeste del Payún Matrú.

Las inferencias sobre los esfuerzos regionales pueden realizarse si los conos de escoria no muestran un patrón radial a partir de un volcán poligenético, o si no están controlados por otros factores locales, como puede ser la topografía de un volcán o la presencia de una cámara magmática en profundidad (Paulsen y Wilson, 2010). La presencia de una cámara magmática en la corteza produce la desviación de los esfuerzos regionales a su alrededor, aunque este efecto local desaparece a relativamente poca distancia de la misma (Gudmundsson, 2006). Este autor demostró mediante modelos analíticos y numéricos, que en zonas alejadas de la cámara a una distancia de aproximadamente igual al diámetro de la misma, los esfuerzos presentan las direcciones regionales, como si la cámara magmática no 
estuviera presente. En el CVPM, la presencia de la cámara magmática del Payún Matrú y la topografía del mismo pudieron haber influido en la disposición de los conos de escoria. Sin embargo, teniendo en cuenta las consideraciones de Gudmundsson (2006), la mayor parte de los conos de escoria se encuentra por fuera del área de influencia del Payún Matrú (Fig. $5.3)$.

Los conos de escoria pueden tener una forma en planta variable, desde circulares a alargados, y también pueden encontrarse crestas elongadas sin un cráter definido (las cuales pueden continuarse desde un cono más equidimensional o no, Fig. 5.5 a). Los conos elongados y crestas lineales o fisurales (fisure ridges, Paulsen y Wilson, 2010) son comunes en los campos basálticos en general, y también en el CVPM. Las erupciones fisurales pueden iniciarse como una "cortina de fuego" (fire fountain) y luego la erupción puede restringirse a uno o más sectores, por enfriamiento diferencial del conducto planar (Vergniolle y Mangan, 2000). Así, se pueden formar conos de escoria alineados, cuya forma va a depender de si el conducto alimentador es puntual o planar.

Los conos se consideran elongados cuando la razón entre los ejes mayor y menor (conos representados como una elipse) es mayor a 1,2 (Paulsen y Wilson, 2010), lo cual equivale a una excentricidad de la elipse mayor a 0,55 (siendo 0 un círculo y 1 una línea o elipse extremadamente elongada). Los conos elongados y crestas lineales sirven como indicadores confiables de la ubicación y orientación de los diques alimentadores subsuperficiales, e inclusive pueden ser más confiables que los alineamientos de conos (Paulsen y Wilson, 2010). Por este motivo, se pueden usar las formas de conos elongados y crestas fisurales para inferir las direcciones de los esfuerzos, tal como se hace con los diques y lineamientos de conos de escoria (Paulsen y Wilson, 2010).

\subsection{Distribución y morfología de centros eruptivos}

En los campos basálticos y en el Payún Matrú, los centros eruptivos, ya sean conos de escoria, conos pumíceos o los nacimientos de coladas, se ubican frecuentemente a lo largo de lineamientos. Para definir los lineamientos de conos de escoria se tuvieron en cuenta la ubicación de los centros de emisión, sus formas y las orientaciones de erupciones fisurales y crestas lineales. La morfología de los conos de escoria varía desde conos circulares (Figs. 4.17 c y e), a conos elongados con diferente relación axial (Figs. 4.17 d). Además, se encuentran crestas lineales y otros depósitos de spatter y escoria, los cuales también indican el rumbo de la fisura, aunque su expresión topográfica es mínima. Esto último se observa, por ejemplo, en la erupción fisural de $1650 \mathrm{~m}$ de longitud en el campo basáltico oeste (inmediatamente al oeste de los conos que dan origen a la colada de Los Molles, Fig. 3.5, 4.1 y 5.1 a). En este lugar, se encuentran en el sector oeste de la fisura siete acumulaciones de spatter de formas aproximadamente circulares y de pocos metros de diámetro (Fig. 5.1 c y d), dos conos de escoria pequeños (menos de $100 \mathrm{~m}$ de largo) en el medio (Fig. 5.1 a y b), y hacia el lado este 


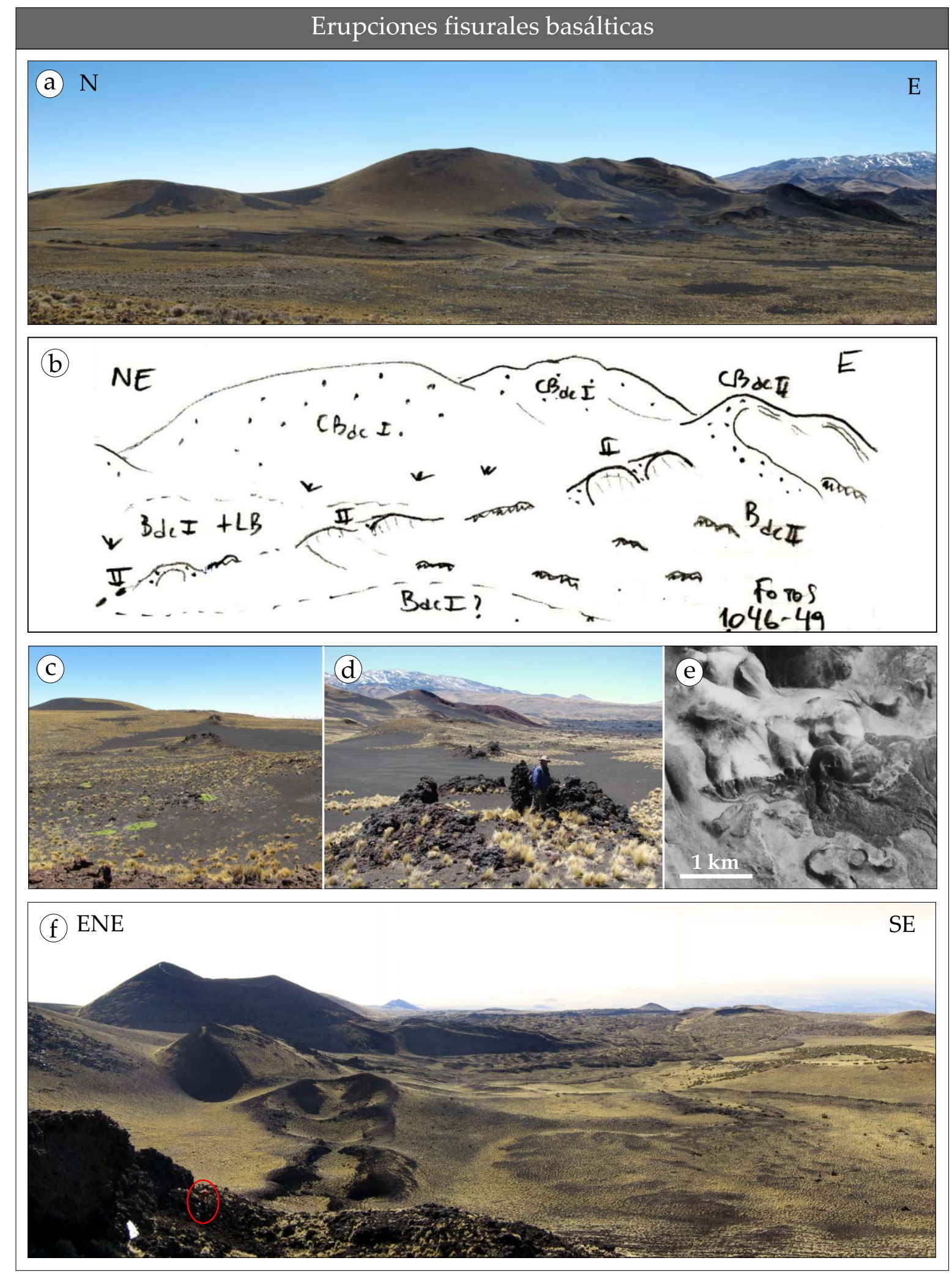

Figura 5.1: a) Foto de una erupción fisural en el campo oeste (1650 m de largo). b) Dibujo extraido de la libreta, del medio y derecha de la foto anterior, para distinguir mejor la foto. c) Desde una acumulación de spatter hacia el oeste, donde se ven dos acumulaciones anulares de pocos metros de diámetro alineadas. d) Desde el mismo lugar hacia el este, con el cono de escoria principal de fondo. e) Foto aérea de la falla La Carbonilla. f) Foto hacia el oeste, desde el extremo este de la falla La Carbonilla. Persona dentro del círculo para la escala. 
de la fisura, un cono de escoria aportillado (Fig. 5.1 a, b y d). Otro sitio en donde ocurre algo similar, notorio en las imágenes satelitales, es en la falla La Carbonilla, al oeste del Payún Matrú (Figs. 3.5 y 5.1 e). Aquí, la erupción fisural está marcada por una simple fisura, que se transforma en una cresta lineal y finalmente un cono de escoria (Cerro La Carbonilla) hacia el este (Fig. 5.1 e y f).

Para definir los lineamientos de las erupciones basálticas se realizó un mapa con la ubicación y forma de los conos de escoria, los cráteres de los conos (ya que, al igual que los conos elongados, la forma del cráter también es indicativa de la orientación de la fisura) y los ejes de las crestas lineales (Fig. 5.2). Además, en la Figura 5.2 se exhiben las erupciones fisurales que producen crestas lineales solamente, o que son simplemente una fractura a través de la cual se emitió lava (estas últimas son menos comunes que el resto). En la misma figura se exhiben también, los centros de emisión visibles de las lavas y los domos del Payún Matrú, así como la ubicación y forma de los conos pumíceos, de manera similar a los conos de escoria (Fig. 5.2).

Los lineamientos, tanto en los campos basálticos como en el Payún Matrú, fueron marcados con dos trazas diferentes: i) con línea llena se marcan los lineamientos con un grado de confianza relativamente alto (lineamientos clase A), y ii) con línea punteada se marcan aquellos lineamientos de existencia más dudosa (clase B). Para determinar la confiabilidad de un lineamiento se tuvieron en cuenta diversos factores, como la presencia de fisuras y crestas lineales, el número de conos de escoria (total y de conos elongados) y el espaciamiento entre conos. Si bien no se hizo un estudio detallado cuantificando cada uno de estos parámetros, sí se tuvieron en cuenta cualitativamente para definir los lineamientos. Así, por ejemplo, aquellos lineamientos con crestas lineales y conos de escoria con pocos cientos de metros de espaciamiento se trazaron con línea llena, mientras que otros lineamientos con pocos conos de escoria (3) no muy elongados, o con más conos pero más espaciados entre si, se trazaron con línea punteada.

Se identificaron 29 lineamientos para el campo basáltico este, 30 en el campo basáltico oeste (Fig. 5.3), y se determinó la longitud, el azimut y la clase (A o B) de cada uno. En el anexo I se muestra sobre una imagen satelital, los mapas de las Figuras 5.2 y 5.3 juntos. Como puede observarse en las Figuras 5.3 y 5.4, aunque los campos este y oeste muestran orientaciones similares de los lineamientos, se reconocen algunas diferencias en los rumbos de los mismos. En el campo basáltico este, la Figura 5.4b muestra que la orientación predominante es ENE (azimut entre $\mathrm{N} 70^{\circ}$ y N 80 ), aunque la media es $\mathrm{N} 86^{\circ}$ (orientaciones que no tienen en cuenta la clase y longitud de los lineamientos). Las otras direcciones con menor representación en cuanto a cantidad de lineamientos son aproximadamente E-O, y en mucha menor proporción se encuentran lineamientos NO-SE (Fig. 5.4 b). También puede observarse que las orientaciones más confiables (lineamientos clase A) más frecuentes poseen un azimut entre $\mathrm{N} 80^{\circ}$ y N $90^{\circ}$, mientras que en el caso de los lineamientos clase B, las orientaciones más frecuentes cambian ligeramente hacia el intervalo $\mathrm{N} 70^{\circ}-\mathrm{N} \mathrm{80^{ \circ }}$ (Fig. 5.4 


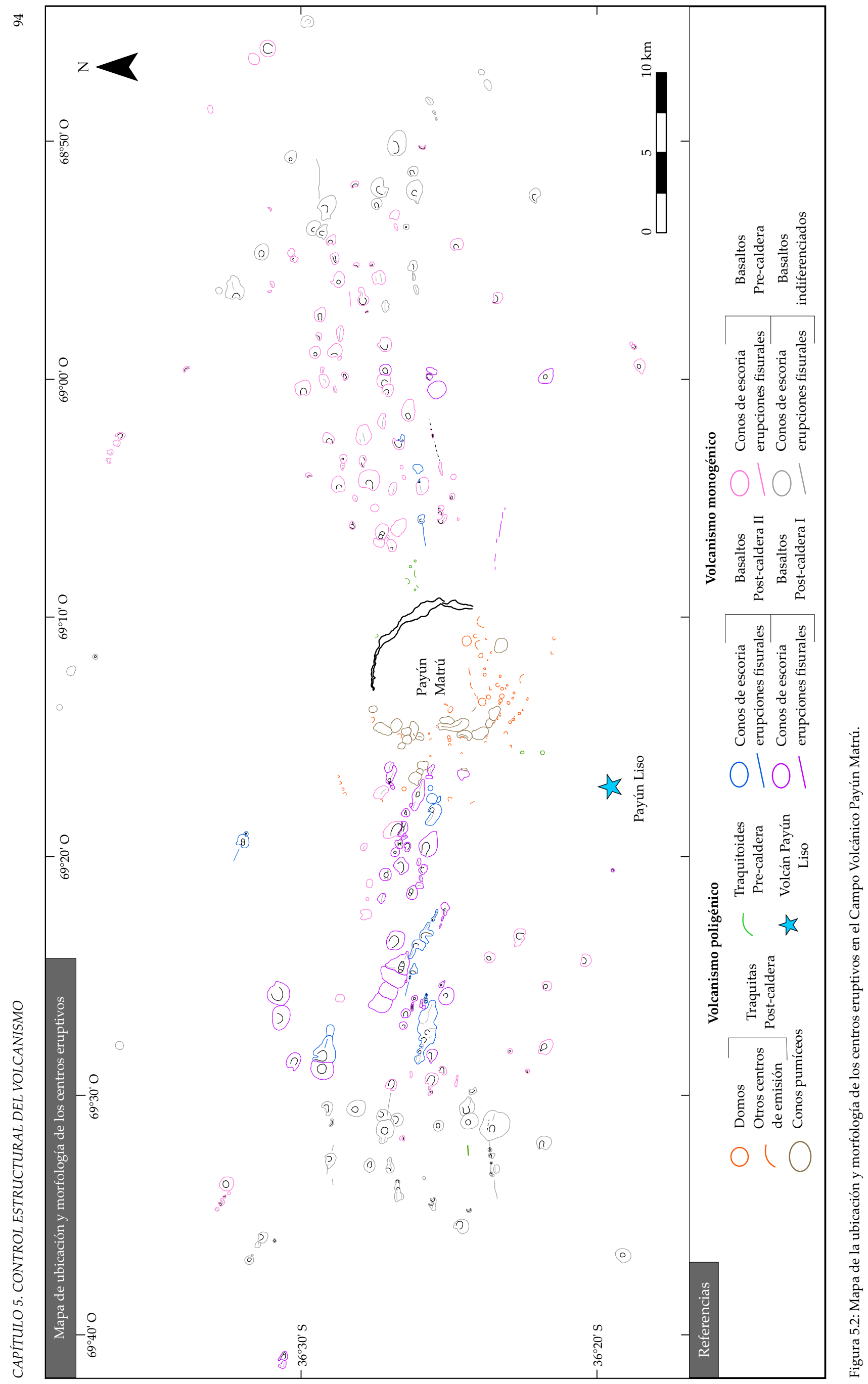




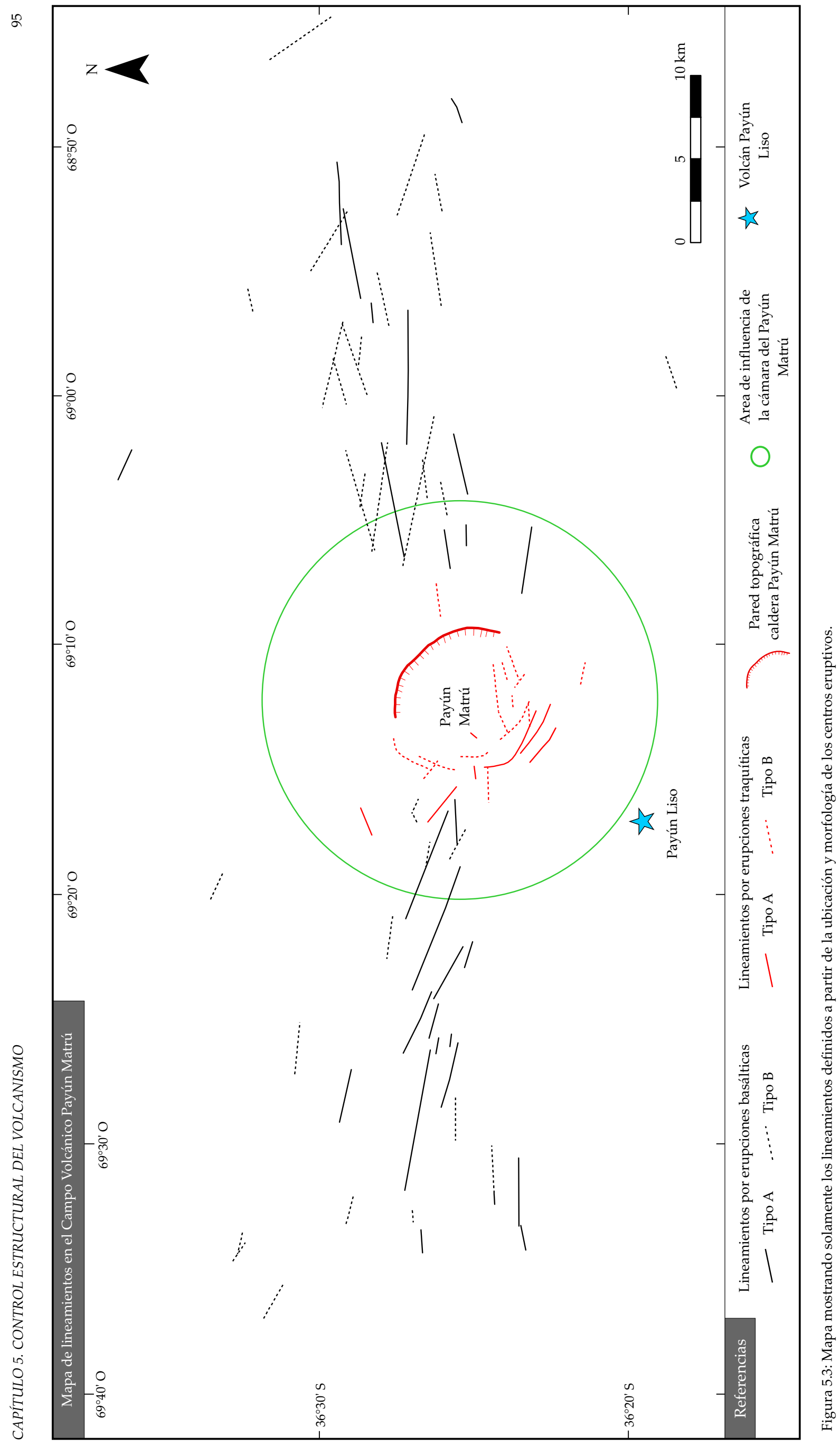


b).

En el caso del campo basáltico oeste, las orientaciones preferenciales se corren hacia el cuadrante NO. Sin tener en cuenta las dos clases de lineamientos ni la longitud de los mismos, las orientaciones preferenciales son ESE en primer lugar (azimut entre $\mathrm{N} 100^{\circ}$ y N $110^{\circ}$ la máxima frecuencia), y en segundo lugar E-O (Fig. 5.4 a). También existen ciertas diferencias menores entre los lineamientos clasificados como clase A y clase B, aunque siguen predominando estas dos direcciones principales (Fig. 5.4 a).

Las longitudes de los lineamientos varían entre ambos campos basálticos, siendo en general mayores en el campo este. En el campo oeste presentan longitudes entre $650 \mathrm{~m}$ y 6918 m, mientras que en el campo este tienen entre $1252 \mathrm{~m}$ y $9290 \mathrm{~m}$ de largo. Considerando la longitud de los lineamientos, en el campo basáltico oeste, aquellos con las mayores longitudes (mayores a los $2000 \mathrm{~m}$ ) presentan las mismas direcciones preferenciales que el total de lineamientos. Existe, sin embargo, una separación en las direcciones preferenciales con dos modas principales con azimut $\mathrm{N} 110^{\circ}-120^{\circ}$ y $\mathrm{N} 90^{\circ}-100^{\circ}$ respectivamente, separación que no es obvia si se incluyen a todos los lineamientos. Para el caso del campo basáltico este y teniendo solamente en cuenta los lineamientos mayores (mayores a los $3000 \mathrm{~m}$, más que en campo oeste debido a las mayores longitudes de lineamientos en general), se encuentra un patrón de orientaciones similar a los lineamientos de clase B. Esto puede explicarse porque, en general, se definieron más lineamientos de la clase B en el campo este y, además, entre los lineamientos de mayor longitud predominan los de esta clase.

Las diferencias en cuanto a la orientación de las fisuras al este y oeste de la caldera no son sólo espaciales sino también temporales. Es decir, en el campo basáltico este predominan los basaltos pre-caldera, con una participación relativamente restringida de los basaltos postcaldera. Por el contrario, en el campo basáltico oeste, si bien se encuentran conos de escoria pre-caldera, el volcanismo aflorante predominante es post-caldera.

\subsubsection{Influencia de la caldera}

La presencia de un volcán o de una cámara magmática en profundidad puede modificar la orientación de los esfuerzos regionales y, por lo tanto, el patrón de ubicación de los conos de escoria a su alrededor (Paulsen y Wilson, 2010; Gudmundsson, 2006). Se asume que el diámetro de la cámara magmática del Payún Matrú es similar al diámetro de la caldera, debido a la geometría de las fallas inversas y normales subverticales que se habrían formado durante el colapso (teniendo en cuenta modelos análogos que así lo indican, Acocella, 2007). En la Figura 5.3 el círculo verde indica cual sería teóricamente el área de influencia de la cámara magmática del Payún Matrú en la distribución de las fracturas que drenan las erupciones basálticas (Gudmundsson, 2006).

Las cámaras magmáticas desvían los esfuerzos en sus cercanías, debido a que si la cámara contiene a un magma con relativa escasa cantidad de cristales y no adquiere resistencia, 


\section{Lineamientos en los campos basálticos}

a Campo Basáltico Oeste
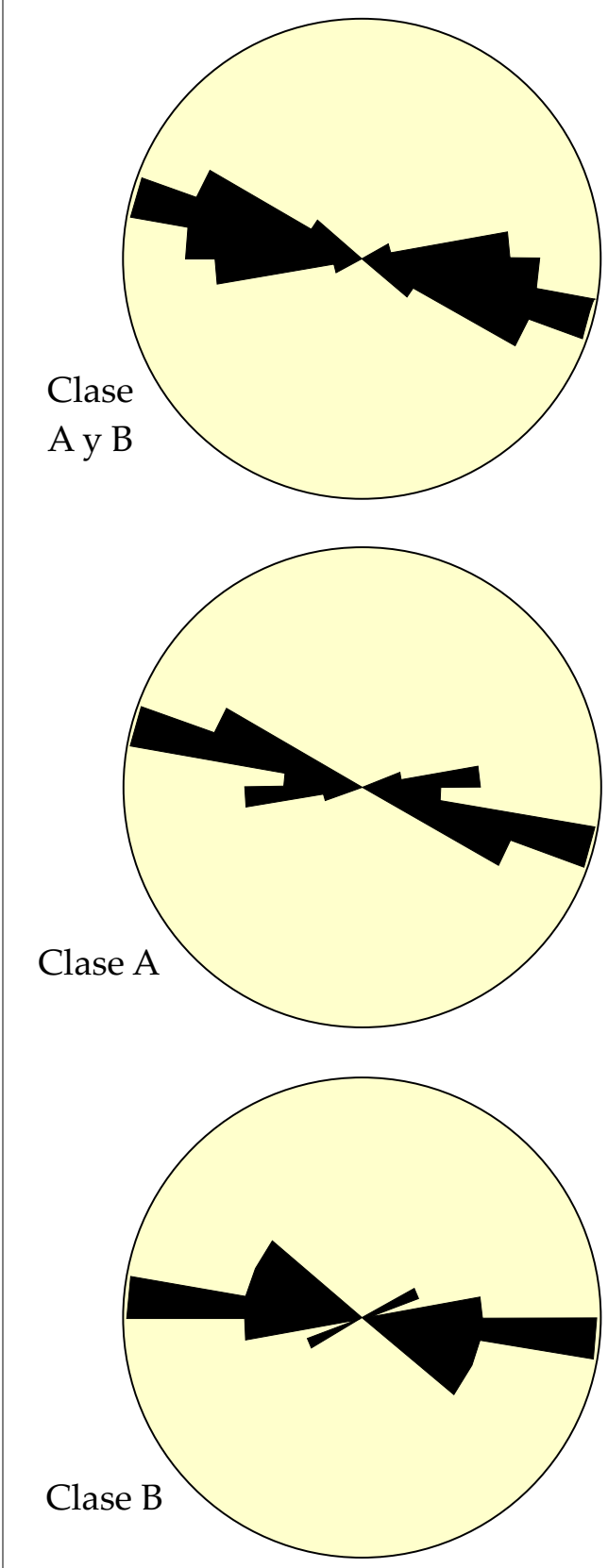

(b)

Campo Basáltico Este
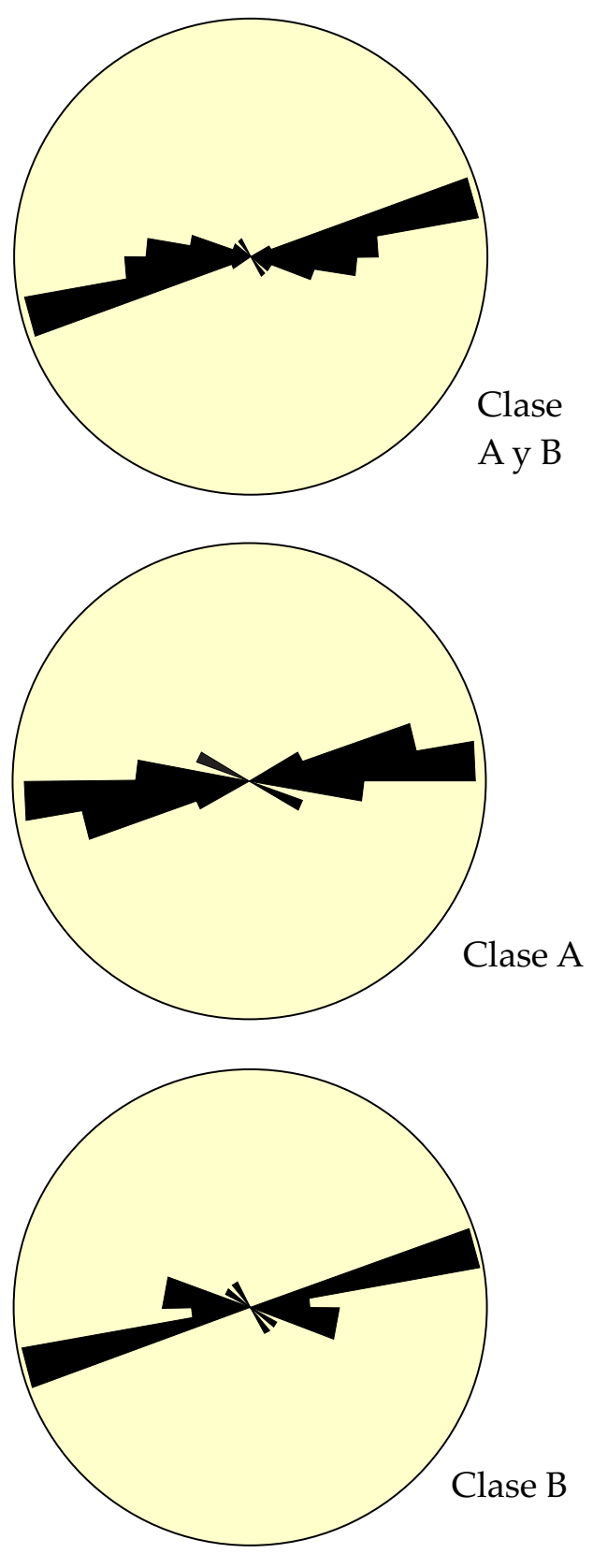

Figura 5.4: Diagrama de rosas de los lineamientos formados por erupciones basálticas en los campos oeste y este del CVPM (dentro y fuera del área de influencia del Payún Matrú). 
entonces el plano de contacto entre la cámara y la roca de caja no soporta cizalla y, por lo tanto, dos de los tres esfuerzos normales principales se ubican en ese plano (Gudmundsson, 2006). En consecuencia, las fracturas producidas por la presión de la cámara misma, u otras ajenas a la misma, tienden a orientarse perpendicularmente a la cámara magmática.

En primer lugar, se observa que la mayoría de los lineamientos quedan por fuera de esta área de influencia, algunos totalmente y otros en parte. Se realizaron diagramas de rosas utilizando solamente los lineamientos completamente por fuera del área de influencia del Payún Matrú, y no se observaron cambios significativos entre estos y los que tienen en cuenta la totalidad de los lineamientos. Esto puede deberse a que los rumbos de las fracturas debido a los esfuerzos regionales y el rumbo que tendrían que tener por estar influenciados por la cámara magmática del Payún Matrú, son coincidentes, probablemente por la configuración particular de la caldera dentro de la franja de conos basálticos.

Es interesante constatar la menor dispersión de los conos de escoria en las cercanías de la caldera. Esto se aprecia bien en el campo basáltico oeste, donde la franja con conos de escoria se adelgaza notoriamente dentro del área de influencia de la cámara magmática del Payún Matrú (Figs. 5.2 y 5.3). Algo similar ocurre en el campo basáltico este, donde los conos más alejados de la caldera se encuentran más dispersos en la franja E-O. Si bien en los diagramas de rosas de la totalidad de los lineamientos y de aquellos lineamientos por fuera del área de influencia de la caldera no muestran diferencias, queda claro al observar la ubicación de los conos de escoria que el Payún Matrú restringe de alguna manera la ubicación de los mismos. Este podría ser el motivo por el cual los lineamientos basálticos, que estarían representando el rumbo de los diques en profundidad, podrían concentrarse en una franja E-O más angosta que en zonas más alejadas del Payún Matrú.

\subsection{Orientación del campo de esfuerzos en el CVPM}

Las orientaciones con máximas frecuencias de los lineamientos en el campo basáltico este están en el intervalo $\mathrm{N} 70^{\circ}-80^{\circ}$, mientras que al oeste de la caldera están en el intervalo $\mathrm{N}$ $100^{\circ}-110^{\circ}$. Esta diferencia sugiere que el campo de esfuerzos no fue el mismo en las etapas pre- y post-caldera, teniendo en cuenta la variación temporal de los productos emitidos a un lado y otro del Payún Matrú.

El campo basáltico este presenta lineamientos conjugados, los cuales poseen ángulos agudos de menos de $30^{\circ}$, y con la bisectriz en sentido E-O. Este ángulo resulta bajo como para tratarse de fallas conjugadas con el esfuerzo máximo horizontal E-O, las cuales forman ángulos de alrededor de $60^{\circ}$ (Davis y Reynolds, 1996). Además, esta configuración de fallas y esfuerzos conlleva a una deformación por deslizamiento en los planos de falla, lo cual no se observa en esta zona. Si bien se espera que el ascenso de los magmas sea favorecido por fracturas tensionales sin cizalla, también existen casos en donde el ascenso del magmas se produce en zonas de cizalla, especialmente si se ocurre transtensión debido a la sinuosidad 
de las fallas, como ocurre por ejemplo con cuerpos de pegmatitas en las sierras de Córdoba (Demartis et al., 2011). Además de las fracturas con cizalla conjugadas y las fracturas de apertura sin cizalla, pueden ocurrir fracturas híbridas, en las cuales se produce tanto apertura como cizalla (Ramsey y Chester, 2004). Estas fracturas híbridas pueden formar juegos conjugados con ángulos agudos menores que las fallas de cizalla, y bajo un campo de esfuerzos mixto con extensión y compresión (Ramsey y Chester, 2004). En la bisectriz de las fracturas híbridas conjugadas se ubicaría el esfuerzo máximo horizontal, que en este caso sería E-O. Además, junto con estas fracturas híbridas se pueden formar otras tensionales paralelamente al esfuerzo máximo horizontal. Las orientaciones de los lineamientos en el campo basáltico este podrían, por lo tanto, explicarse mediante un esfuerzo máximo horizontal E-O durante la etapa pre-caldera, el cual produce fracturas tensionales en la misma dirección y fracturas híbridas conjugadas con un bajo ángulo.

$\mathrm{Al}$ oeste de la caldera, las orientaciones predominantes ESE de las erupciones fisurales sugieren un campo de esfuerzos para la etapa post-caldera con el esfuerzo máximo horizontal en la misma dirección ( $100^{\circ}-110^{\circ}$ ). A diferencia del campo este, no se observan en general lineamientos conjugados. Las fracturas que se forman paralelamente al esfuerzo compresivo máximo son de apertura, sin cizalla en las mismas (Davis y Reynolds, 1996), por lo cual resultan favorables para el ascenso de los magmas.

Esta tendencia general hacia la orientación E-O del esfuerzo normal máximo horizontal sugerido por los lineamientos en los campos basálticos, es coherente con la dirección del esfuerzo máximo horizontal medido actualmente mediante el breakout de pozos petroleros (Guzmán et al., 2005, 2007). En los trabajos realizados en la Cuenca Neuquina en el retroarco andino entre $34^{\circ}$ y $39^{\circ} \mathrm{S}$, el esfuerzo horizontal máximo tiene una orientación preferencial con un azimut de $\mathrm{N} 89^{\circ} \mathrm{y}$, aunque la tendencia general se mantiene, no es uniforme en toda la cuenca (Guzmán et al., 2005, 2007). Esta tendencia cambia ligeramente al norte y sur del río Colorado. Para la zona de interés (al norte del río Colorado), los esfuerzos horizontales máximos tienen una tendencia al ESE, con un azimut medio de $100^{\circ}$ (Guzmán et al., 2007).

Los resultados obtenidos por Guzmán et al. (2005) y Guzmán et al. (2007) están en concordancia con el campo de esfuerzos esperado para el margen occidental de este sector de Sudamérica. El campo de esfuerzos estaría controlado por dos factores principales: por las fuerzas de borde de placa (esfuerzo máximo horizontal con azimut $\mathrm{N} 80^{\circ}$ ) y por las fuerzas debidas a la topografía de la cordillera (esfuerzo máximo horizontal en sentido E-O) (Meijer, 1997; Guzmán et al., 2007).

En síntesis, tanto las consideraciones de las fuerzas actuantes sobre la placa Sudamericana en la región, como el estudio de esfuerzos actuales a partir de breakout de pozos petroleros y los lineamientos más modernos en el CVPM, apuntan a un esfuerzo máximo horizontal reciente en un sentido ESE (azimut aproximado N 100 ${ }^{\circ}$ ) al sur de Mendoza. En la etapa pre-caldera este esfuerzo máximo horizontal pudo ser levemente distinto, en sentido E-O. 


\subsection{Caldera del Payún Matrú}

La caldera es de forma aproximadamente circular y de $8 \mathrm{~km}$ de diámetro, presentando una clara asimetría. El borde $\mathrm{N}$ a SE de la misma está definido por una escarpa de altura variable, como ya se ha mencionado. El resto del borde de caldera no muestra una pared topográfica y está evidenciado por numerosas erupciones post-caldera. Los centros de emisión de las unidades post-caldera del Payún Matrú se ubican mayormente en una franja anular de ancho variable. Esta franja incrementa su ancho hacia el sur, lo cual sugiere un sistema de fracturas anulares y no una sola fractura anular como en el borde $\mathrm{N}$ a SE de la caldera. La altura máxima de la pared interna de la caldera es de $500 \mathrm{~m}$, en el sector denominado "La Nariz" (Fig. 4.1), indicando un colapso de por lo menos $500 \mathrm{~m}$, al menos en ese sector.

La estructura interna de la caldera no se conoce, y por lo tanto las inferencias sobre la misma expuestas a continuación se basarán en los rasgos morfológicos y estructurales superficiales. Numerosos modelos análogos de formación de calderas de colapso (Martin et al., 1994; Roche et al., 2000; Acocella, 2001; Walter y Troll, 2001; Kennedy et al., 2004) indican que las mismas presentan cuatro estadios evolutivos continuos, de acuerdo al grado de subsidencia (Acocella, 2007, y referencias incluidas). La cantidad de subsidencia requerida para alcanzar cada uno de estos estadios dependen del diámetro de la caldera y del espesor de la capa frágil por encima de la cámara magmática (Acocella, 2007). Los cinco tipos de caldera clásicos (downsag, pistón, piecemeal, trapdoor y funnel) se pueden corresponder a uno o más de estos cuatro estadios evolutivos (Acocella, 2007, 2008).

Una manera de identificar el estadio de una caldera con observaciones de superficie es mediante la razón $d / s$, donde $d$ es el diámetro de la caldera y $s$ es la subsidencia que tuvo lugar durante el colapso del edificio volcánico. Dado que el diámetro de la caldera es $8 \mathrm{~km}$ y, suponiendo en primera instancia que la subsidencia es de $500 \mathrm{~m}$ (el máximo observable, y el cual probablemente sea mayor que el promedio general, considerando la asimetría de la caldera), la razón $d / s$ es de 16 . Si se considera una subsidencia promedio menor, por ejemplo de $300 \mathrm{~m}$, el valor de $d / \mathrm{s}$ es de 26,6 . Teniendo en cuenta los valores de $d / s$ para cada uno de los cuatro estadios evolutivos $(d / s>40$ para el estadio $1, d / s$ entre $18 \mathrm{y}$ 40 para el estadio $2, d / s$ entre 14 y 18 para el estadio 3 y $d / s<14$ para el estadio 4 , Acocella, 2007), se puede inferir que la caldera del Payún Matrú se encuentra entre los estadios 2 y 3 , probablemente un estadio 2 y cercano al 3. En el estadio 2, las fallas inversas en forma de campana (verticales en profundidad y con inclinación hacia afuera de la caldera más cerca de la superficie) nucleadas en el borde de la cámara magmática, alcanzan la superficie y forman una escarpa visible (Acocella, 2007, 2008). El estadio 3 se caracteriza por presentar una zona anular externa a las fracturas anulares inversas con una inclinación hacia el centro de la caldera (Acocella, 2007, 2008), lo cual no se observa en el Payún Matrú.

Considerando la asimetría del borde de la caldera, y que las lavas intra-caldera posteriores a la misma fluyeron hacia su borde este, posiblemente el colapso de la caldera no ocurrió 


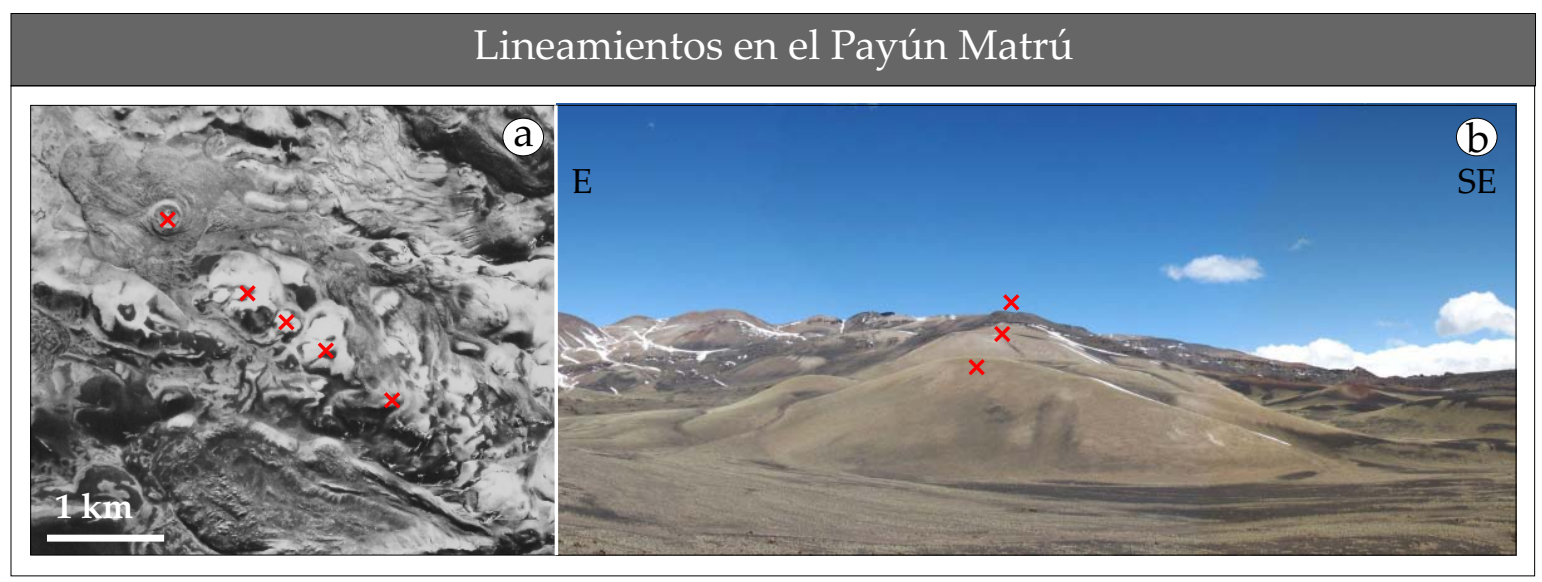

Figura 5.5: a) Foto aérea del flanco O del Payún Matrú, en donde se ve al NO a la colada dómica "El Mousse" (Fig. 4.1). Se observa un alineamiento de coladas y conos pumíceos (marcados con una cruz) en una dirección NO. Justo al sur de esta colada dómica se encuentra un cono de escoria post-caldera, con una elongación marcada y marcando un azimut similar. b) Foto de campo desde el centro de la colada "El Mousse" hacia el SE, marcando con una cruz los centros de emisión (uno de los cuales no se observa por ser de menor altura que el primero visible).

como un pistón simétrico, sino como una caldera del tipo trapdoor. La falta absoluta de erupciones emitidas en el sector de la pared topográfica de la caldera indicaría de alguna manera que esa estructura permaneció sellada posteriormente a su formación. Al mismo tiempo, las numerosas erupciones observadas en el borde SE a $\mathrm{N}$ de la caldera, sugeriría que estas se emitieron aprovechando las fracturas anulares no selladas formadas durante el colapso de la misma.

Cabe resaltar que las caldera de tipo trapdoor no se corresponden con un estadio en particular, sino que se pueden formar en los estadios 2 a 4 (Acocella, 2007). La asimetría en el colapso se puede deber a factores diversos, como una asimetría en la forma de la cámara magmática con un techo con forma dómica asimétrica (Acocella, 2001) o por la topografía del edificio previo al colapso (Kennedy et al., 2004). También, en algunos experimentos que emulan el colapso de una caldera, se produjeron asimetrías sin ninguna causa aparente (Roche et al., 2000). En el caso del Payún Matrú, es probable que la topografía previa a la formación de la caldera haya contribuido al colapso asimétrico, considerando que la altura del antiguo edificio es mayor en el sector de "La Nariz", de acuerdo con la actual topografía. Sin embargo, no se puede descartar que haya tenido influencia la morfología de la cámara magmática, ya que no se tiene información para concluir al respecto.

De manera similar a lo realizado para los campos basálticos, en el área del Payún Matrú se ubicaron en un mapa todos los centros de emisión de lavas visibles (mayormente postcaldera), y los contornos de los conos pumíceos. Las Figuras 5.2 y 5.3, muestran que los lineamientos de los centros de emisión del Payún Matrú difieren significativamente con 
aquellos inferidos en los campos basálticos. En la Figura 5.3 se observa la variación en el rumbo de los lineamientos definidos a partir de las erupciones traquíticas post-caldera, y la presencia de fracturas con rumbo variable, formando una geometría anular.

En algunos lugares del faldeo del Payún Matrú las erupciones traquíticas están orientadas con las mismas direcciones, o muy similares, que las erupciones basálticas. Esto puede observarse, por ejemplo, en la ladera oeste del Payún Matrú, en donde se distinguen una colada dómica, tres conos pumíceos y otra colada alineados perfectamente en una línea en dirección NO (Figs. 5.5 a y b y Fig. 5.3). Otro ejemplo lo constituye el agrupamiento de centros traquíticos en la ladera este del Payún Matrú que, si bien no se alinean perfectamente como en el caso anterior, sí puede observarse una tendencia de los mismos en sentido E-O (Figs. 3.5, 5.2 y 5.3). Esta orientación es similar a la que presenta la falla La Carbonilla, ubicada un poco más abajo en la ladera del Payún Matrú. Un último ejemplo es la fisura marcada por la colada de Traquitas en bloque del "Escorial del Toro" (Fig. 4.1), la cual presenta cuatro centros de emisión perfectamente alineados en sentido ENE. Además, el extremo oeste de la fisura se continúa con un resalto topográfico de aproximadamente $50 \mathrm{~m}$ de altura y con la misma orientación (longitud total de 2000 m). La orientación de esta fisura no es habitual en el campo basáltico oeste, aunque sí en el campo este. El hecho de que esta orientación no sea habitual en el lugar donde se encuentra puede deberse a que la fractura corresponda a estructuras anulares formadas durante el colapso de la caldera, y respondan por lo tanto a un evento local y no a un campo de esfuerzos regional. 


\section{Capítulo 6}

\section{Análisis petrográfico}

El presente capítulo trata el análisis mineralógico y textural detallado del CVPM. Previamente a la caracterización del CVPM, se realizará una síntesis sobre las diferentes texturas que pueden presentar internamente los minerales, y en especial los feldespatos. Esta revisión no intenta ser completamente abarcativa, sino que se centra en aquellas texturas encontradas en el CVPM, con especial énfasis en las texturas que indican o sugieren la mezcla de magmas. El capítulo es principalmente descriptivo, y se discutirá en detalle en el Capítulo 9 .

\subsection{Texturas mineralógicas en el CVPM}

Las diversas texturas o cambios composicionales que quedan registradas en los minerales son importantes para poder interpretar los procesos petrogenéticos de las rocas. En este aspecto, han sido esclarecedores los experimentos de laboratorio realizados por Tsuchiyama (1985), Nelson y Montana (1992), Stimac y Pearce (1992) y Nakamura y Shimakita (1998), entre otros. Cabe destacar que si bien un experimento en determinadas condiciones puede resultar en un tipo particular de textura mineralógica, no queda demostrado que esa misma textura pueda ser producida de otras maneras.

Las causas que determinan las diferentes texturas internas en los minerales se deben generalmente a procesos de disolución o crecimiento. Tsuchiyama (1985) realizó experimentos con plagioclasas, y reconoció dos tipos de disolución: por un lado, el cristal puede disolverse en un líquido que está subsaturado respecto a esa fase (disolución simple), causando el redondeamiento de los cristales y, por otro lado, puede producirse la disolución parcial del mineral debido a reacciones entre la plagioclasa y el fundido, las cuales producen una plagioclasa parcialmente disuelta con cribado en la misma.

La Tabla 6.1 muestra una síntesis de las principales texturas mineralógicas de las rocas del CVPM. Esta tabla presenta fundamentalmente texturas en los feldespatos, los cuales suelen registrar las variaciones fisico-químicas de su entorno. 


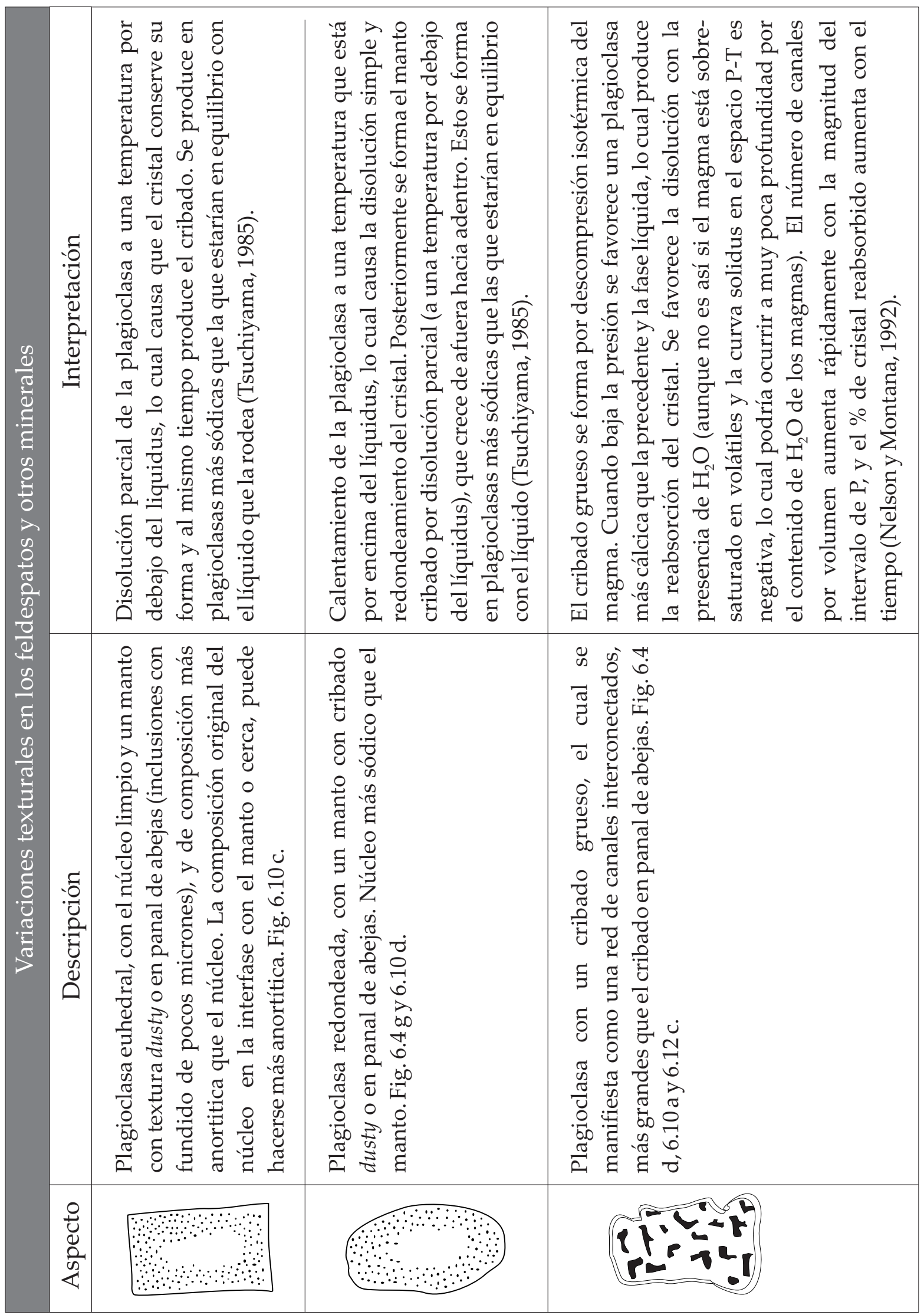

Tabla 6.1: Descripción e interpretación de las principales texturas intra-cristalinas de los feldespatos y otros minerales del CVPM. 


\begin{tabular}{|c|c|c|}
\hline Aspecto & Descripción & Interpretación \\
\hline & $\begin{array}{l}\text { Plagioclasa euhedral, con un anillo de } \\
\text { inclusiones de fundido de contornos mas o } \\
\text { menos rectangulares, formando canales, con un } \\
\text { borde fino de otra composición que rodea al } \\
\text { cribado, y otro borde externo limpio que puede } \\
\text { faltar. Cribado de } 20-50 \mu \text { m aproximadamente, o } \\
5-20 \mu \text { m, según la temperatura. Se pueden unir } \\
\text { variasinclusiones en una. Fig. } 6.2 \mathrm{e}, 6.10 \text { e, } 6.18 \mathrm{c} \text {. }\end{array}$ & $\begin{array}{l}\text { Disolución parcial congruente de una plagioclasa que es más } \\
\text { sódica que la que estaría en equilibrio con el liquido. Reacción que } \\
\text { avanza desde la superficie hacia el centro. Mientras se disuelve, } \\
\text { precipita una plagioclasa más cálcica en los bordes de los canales. } \\
\text { El espaciado de los canales con fundido y el tamaño máximo de } \\
\text { inclusiones decrecen cuando aumenta la temperatura, siendo esta } \\
\text { textura transicional al cribado dusty. El ancho de la reacción } \\
\text { depende del tiempo de reacción. Si el sistema está subsaturado en } \\
\text { plagioclasa de cualquier composición, no se forma el borde } \\
\text { externo limpio. Este borde tiene un \% An un poco menor que la } \\
\text { plagioclasa de la matriz. Si tiene núcleo limpio o no depende del } \\
\text { grado de reacción, si tiene borde limpio depende de la } \\
\text { temperatura. Esta disolución parcial tienelugar durantela mezcla } \\
\text { de magmas, es frecuente encontrar juntos cristales limpios y } \\
\text { cribados (Nakamuray Shimakita, 1998). }\end{array}$ \\
\hline & $\begin{array}{l}\text { Plagioclasa redondeada y con una interfase } \\
\text { rugosa con el fundido. Interfase un poco más } \\
\text { cálcica que la composición original de la } \\
\text { plagioclasa (que en el resto del cristal no cambia). }\end{array}$ & $\begin{array}{l}\text { Disolución parcial, en los bordes y fracturas del cristal, que causa } \\
\text { que la interfase sea rugosa. Ocurre en plagioclasas más sódicas } \\
\text { que las que estarían en equilibrio con el líquido. Posteriormente se } \\
\text { puede formar un manto con cribado en panal de abejas } \\
\text { (Tsuchiyama, 1985). }\end{array}$ \\
\hline & $\begin{array}{l}\text { Plagioclasa limpia de bordes redondeados. Con } \\
\text { la interfase lisa con el fundido. }\end{array}$ & $\begin{array}{l}\text { La plagioclasa de cualquier composición se vuelve redondeada y } \\
\text { más pequeña a temperaturas por encima del liquidus, por } \\
\text { disolución simple. Si el cristal es más cálcico que la plagioclasa en } \\
\text { equilibrio, la interfase es lisa (Tsuchiyama, 1985). }\end{array}$ \\
\hline
\end{tabular}




\begin{tabular}{|c|c|c|}
\hline Aspecto & Descripción & Interpretación \\
\hline & $\begin{array}{l}\text { Plagioclasa euhedral y limpia. Tiene un borde de } \\
\text { composición más sódica que el núcleo, en } \\
\text { contacto neto, como un sobrecrecimiento. La } \\
\text { interfase con el fundido es lisa. }\end{array}$ & $\begin{array}{l}\text { Cristalización de una plagioclasa más sódica sobre una más } \\
\text { cálcica. La plagioclasa cálcica no está en equilibrio con el fundido } \\
\text { pero no puede disolverse ya que este núcleo cristalizó a mayor } \\
\text { temperatura que la plagioclasa que estaría en equilibrio con el } \\
\text { liquido (Tsuchiyama, 1985). }\end{array}$ \\
\hline & $\begin{array}{l}\text { Plagioclasa con zonación en parches, la cual } \\
\text { consiste en parches irregulares corroidos } \\
\text { rellenos con una plagioclasa más cálcica en } \\
\text { continuidad cristalográfica, en una plagioclasa } \\
\text { más sódica. Fig. } 6.13 \mathrm{e} \text {. }\end{array}$ & $\begin{array}{l}\text { Reabsorción de una plagioclasa relativamente cálcica por un } \\
\text { decrecimiento en la presión confinante (baja el punto de fusión } \\
\text { cuando cae la presión en sistemas deficientes en agua), seguida } \\
\text { de la cristalización de una plagioclasa más sódica estable en las } \\
\text { nuevas condiciones (Vernon, 2004). }\end{array}$ \\
\hline & $\begin{array}{l}\text { Feldespatos alcalinos redondeados, de formas } \\
\text { ovoidales, los cuales pueden tener o no un manto } \\
\text { de plagioclasa obiotita. Fig. } 6.1 \mathrm{a} \text {. }\end{array}$ & $\begin{array}{l}\text { En el contexto de mezcla de magmas, esta textura es compatible } \\
\text { con la disolución de feldespatos alcalinos pre-existentes en el } \\
\text { magma félsico, por calentamiento debido al magma máfico de } \\
\text { mayor temperatura (Hibbard, } 1981 \text { y Hibbard, 1995). }\end{array}$ \\
\hline & $\begin{array}{l}\text { Manteado antirapakivi: plagioclasa con un } \\
\text { manto de feldespato alcalino. Fig. } 6.13 \mathrm{f} \text {. }\end{array}$ & $\begin{array}{l}\text { Se puede formar por mezcla de magmas, como resultado de la } \\
\text { juxtaposición de un liquido rico en los componentes del } \\
\text { feldespato alcalino y cercano al liquidus, y un magma más } \\
\text { primitivo en el cual ya cristalizó la plagioclasa. El magma félsico } \\
\text { se vuelve supercalentado, por encima del liquidus, y cristaliza } \\
\text { feldespato alcalino luego de que se produce la perdida de calor } \\
\text { post-mezcla, utilizando a la plagioclasa como superficie para la } \\
\text { nucleación (Hibbard, 1981 y Hibbard, 1995). }\end{array}$ \\
\hline
\end{tabular}




\begin{tabular}{|c|c|c|}
\hline Aspecto & Descripción & Interpretación \\
\hline & $\begin{array}{l}\text { Cualquier mineral, con "engolfamientos" o } \\
\text { huecos controlados cristalográficamente (planos } \\
\text { relativamente rectos, ángulos rectos), sin bordes } \\
\text { redondeados. La morfología depende de cada } \\
\text { especie mineral. Fig. } 6.15 \text { d y } 6.17 \text { c. }\end{array}$ & $\begin{array}{l}\text { Crecimiento esqueletal rápido, atrapando líquido, no es corrosión } \\
\text { porque el cristal no está redondeado y por la forma de las } \\
\text { inclusiones (Vernon, 2004). La progresión de morfologías } \\
\text { (euhedral, esqueletal, dendríticas y esferulitas) depende del } \\
\text { grado de sobre-enfriamiento que varía la razón entre las tasas de } \\
\text { difusión y crecimiento(Lofgren, 1974). }\end{array}$ \\
\hline & $\begin{array}{l}\text { Los fenocristales (especialmente cuarzo y } \\
\text { olivinas) pueden tener engolfamientos } \\
\text { típicamente redondeados (algunos pueden ser } \\
\text { relativamente planos y controlados } \\
\text { cristalográficamente). Fig. } 6.17 \mathrm{e} \text {. }\end{array}$ & $\begin{array}{l}\text { Se atribuye generalmente a corrosión del cristal por cambios en el } \\
\text { sistema (P, composición, etc), especialmente cuando las esquinas } \\
\text { del cristal están redondeadas o se trunca la zonación. Puede ser } \\
\text { por crecimiento, si las esquinas no están redondeadas y los } \\
\text { engolfamientos están controlados cristalográficamente, } \\
\text { sugiriendo un crecimiento esqueletal (Vernon, 2004) o en } \\
\text { equilibrio (Faure y Schiano, 2005). }\end{array}$ \\
\hline & $\begin{array}{l}\text { Anfíbol con borde redondeados y un anillo con } \\
\text { minerales anhidros en el borde, como opacos, y } \\
\text { de espesor variable. Fig. } 6.5 \mathrm{~d} \text {. }\end{array}$ & $\begin{array}{l}\text { El anfíbol se vuelve inestable cuando el magma asciende y el } \\
\text { contenido de volátiles en el fundido disminuye a menores } \\
\text { presiones. El crecimiento y espesor del anillo depende de una } \\
\text { manera compleja de la tasa de ascenso del magma. No se forma a } \\
\text { altas presiones ( }>80-90 \mathrm{Mpa} \text { ) o a bajas presiones }(<10 \mathrm{Mpa}) \\
\text { (Rutherford y Hill, 1993; Browne y Gardner, 2006). }\end{array}$ \\
\hline 80 & $\begin{array}{l}\text { Biotita con texturas de reabsorción (bordes } \\
\text { redondeados) y reacción con el liquido. Se forma } \\
\text { un anillo de minerales mayormente anhidros, } \\
\text { con plagioclasa, magnetita, anfíbol y piroxenos. } \\
\text { Fig. } 6.5 \text { b. }\end{array}$ & $\begin{array}{l}\text { Deshidrogenación in situ de la biotita, por calentamiento del } \\
\text { magma por otro de mayor temperatura hasta el punto de } \\
\text { desestabilizar la biotita. Si hay anfíbol en el anillo de reacción, es } \\
\text { porque este anillo se produjo inmediatamente antes de la } \\
\text { erupción, pero en profundidad. Bordes redondeados indican } \\
\text { una reabsorción incipiente (Feeley y Sharp, 1996). }\end{array}$ \\
\hline
\end{tabular}




\subsection{Traquitoides Pre-caldera}

Esta unidad es la que mayor variabilidad presenta petrográficamente (y también químicamente). Por este motivo, y con el fin de simplificar las descripciones, fue dividida en cinco subunidades, en base solamente a las características petrográficas y sin asignarle un orden estratigráfico. Las subunidades fueron definidas en base a los fenocristales de feldespatos presentes y a la textura de la pasta. Estas son:

- Subunidad 1: lavas con fenocristales de feldespatos alcalinos y pasta pilotáxica.

- Subunidad 2: lavas con fenocristales de feldespatos alcalinos y plagioclasas, pasta pilotáxica.

- Subunidad 3: lavas con fenocristales de plagioclasa solamente, pasta pilotáxica.

- Subunidad 4: lavas con fenocristales de plagioclasa solamente, pero con pasta intergranular predominante.

- Subunidad 5: ignimbritas pre-caldera.

La subunidad con mayor representatividad es la 3, abarcando casi la mitad de las muestras observadas. La menos frecuente es la subunidad 5, ya que solamente fueron encontradas rocas piroclásticas pre-caldera en el sector ENE de la pared topográfica de la caldera. El resto de las subunidades presentan abundancias similares entre si.

Las lavas de la subunidad 1 corresponden químicamente a traquitas, conformando estas un grupo más silícico que la mayor parte de las traquitas (ver capítulo 7). La subunidad 2 corresponden también a lavas traquíticas, pero con un contenido en sílice menor que la subunidad 1. La subunidad 3 corresponden principalmente a traquitas, aunque con menor abundancia de traquiandesitas y traquiandesitas basálticas. No se disponen de análisis químicos disponibles para las otras dos subunidades.

\subsubsection{Subunidad 1}

Este conjunto de lavas presentan colores variables, desde rosado hasta gris verdoso. Se caracterizan por presentar fenocristales de feldespato alcalino, clinopiroxeno como el mafito más abundante y presente en todas las lavas, olivina en escasas lavas y raramente biotita o anfíbol, además de minerales opacos y apatita. La pasta es pilotáxica, aunque contiene un bajo porcentaje de mafitos, y frecuentemente es traquítica por orientación de los microlitos. En una sola muestra fue encontrado cuarzo intersticial en la pasta.

Los feldespatos alcalinos (5-18\%) son seriados, variando en tamaño desde los microlitos en la pasta hasta fenocristales de $1 \mathrm{~cm}$ de largo. En gran parte de los casos están limpios sin cribados, aunque en algunos pocos casos se encuentran, además, cristales anhedrales 


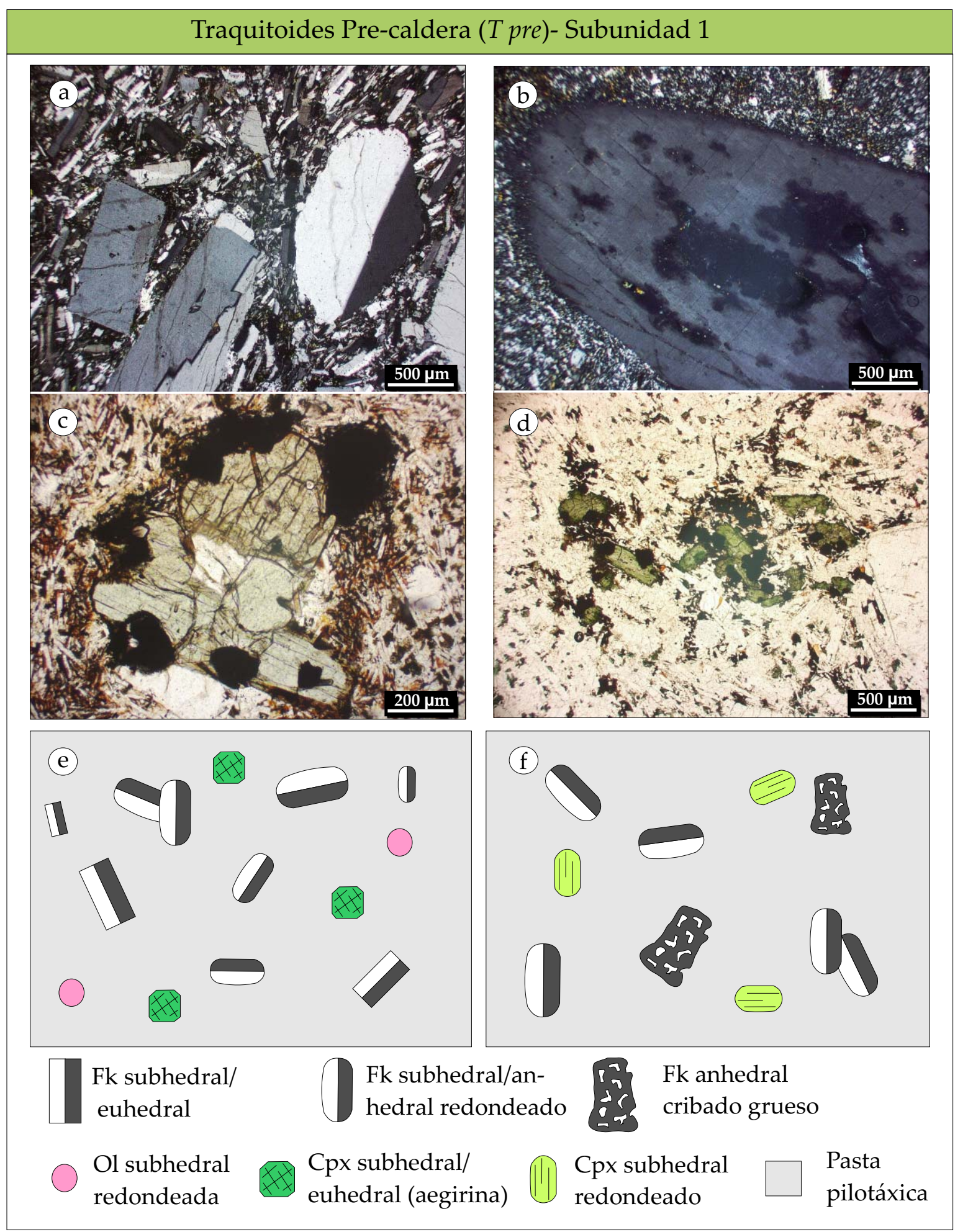

Figura 6.1: a) Feldespatos alcalinos euhedrales junto con otros redondeados. b) Feldespato alcalino con cribado grueso. c) Glomérulo de clinopiroxenos con bordes redondeados. d) Clinopiroxenos con un verde anómalo, posiblemente sean aegirina. e y f) Dibujos esquemáticos de las asociaciones minerales de dos lavas de esta subunidad. Fk: feldespato alcalino; Ol: olivina y Cpx: clinopiroxeno. 
con cribado grueso. Entre los fenocristales limpios, se encuentran cristales subhedrales euhedrales y otros subhedrales - anhedrales con las esquinas redondeadas, y generalmente ambos tipos juntos, y suelen agruparse en glomérulos (Fig. 6.1 a). Los fenocristales cribados poseen muchas veces un borde fino de sobrecrecimiento que sigue al borde externo del cristal y a los huecos producidos por el cribado (los cuales no son muy abundantes) (Fig. $6.1 \mathrm{~b}$ ). Los fenocristales limpios y cribados se encuentran juntos en la misma muestra. En un solo caso se encontraron escasos feldespatos manteados, con un núcleo de plagioclasa limpia, y un manto de espesor variable de feldespato alcalino (textura anti-rapakivi).

El clinopiroxeno es siempre escaso, desde $<1 \%$ hasta $2 \%$. Es seriado, alcanzando un largo máximo de 1,2 mm. Se encuentran dos tipos de clinopiroxeno, con un contraste marcado en la coloración (separadamente en diferentes lavas). Por un lado, los clinopiroxenos verde muy claro, como aquellos encontrados en el resto de las subunidades y en las otras unidades del CVPM (Fig. 6.1 c). Por otro lado, se encuentran unos clinopiroxenos verde medio-fuerte, con un pleocroísmo de verde a verde amarillento, similar a las aegirinas (probablemente sean aegirina-augita, por el mayor ángulo de extinción) (Fig. 6.1 d). El primer caso presenta los bordes con un redondeamiento visible, ocasionalmente además con un borde opaco fino. El cuarzo intersticial en la pasta se presenta en una lava con aegirinaaugita. La aegirina-augita es típica de magmas alcalinos, y puede coexistir tanto con cuarzo o con nefelina (Deer et al., 2001).

Los fenocristales de olivina, si bien se encuentran en varias muestras de esta subunidad, presentan un porcentaje muy escaso, menor al $1 \%$, y son seriadas de hasta $1 \mathrm{~mm}$ de largo. En todos los casos son redondeadas, ocasionalmente con un borde opaco fino.

La escasa biotita que se observa (1-2\%) está reemplazada por minerales opacos, por lo cual su presencia es dudosa. Son cristales seriados hasta $1 \mathrm{~mm}$ de largo. El anfíbol, también muy escaso $(<1 \%)$ es de pequeño tamaño $(<0,5 \mathrm{~mm}$ de largo), y se lo encuentra de dos maneras: i) anhedral y con un pleocroísmo del castaño claro-amarillento al castaño oscurorojizo, presente junto con aegirina; ii) euhedral aunque totalmente reemplazado por minerales opacos, reconociéndose solamente por su forma, junto con clinopiroxeno verde claro y redondeado.

En las figuras $6.1 \mathrm{e} \mathrm{y} \mathrm{f}$ se esquematizan, a modo de ejemplo, las asociaciones minerales junto con las características principales de los minerales presentes, de dos lavas pertenecientes a esta subunidad. A esta subunidad pertenece la muestra PMC 60, datada por el método ${ }^{39} \mathrm{Ar}-{ }^{40} \mathrm{Ar}$ en $700 \mathrm{ka}$.

\subsubsection{Subunidad 2}

Son lavas de colores variados, gris claro a medio, anaranjados y rojizos. Son porfíricas con fenocristales de plagioclasas, feldespatos alcalinos, clinopiroxeno, a veces olivinas y raramente biotita o anfíbol, además de minerales opacos y apatita. 
Los fenocristales de feldespatos (8-22\%) son seriados de hasta $5 \mathrm{~mm}$ de largo. En ocasiones es más frecuente la plagioclasa que el feldespatos alcalino, y otras veces se verifica la situación inversa.

La plagioclasa (2-14\%) puede estar limpia o presentar algún tipo de cribado, habiendo de los dos tipos en algunas lavas. Las plagioclasas limpias son mayormente subhedrales euhedrales (Fig. 6.2 a), aunque en ocasiones se encuentran también otras anhedrales y/o redondeadas, y en ciertos casos estas últimas son las únicas plagioclasas limpias presentes (Fig. 6.2 b). Pueden agruparse formando glomérulos, en donde los bordes cristalinos internos al glomérulo son anhedrales, y los externos sub- euhedrales. Son frecuentes los bordes finos como un sobrecrecimiento, y aquellas anhedrales/redondeadas pueden presentar bordes difusos con la pasta. Las plagioclasas cribadas son variadas, habiendo subhedrales euhedrales con cribado en panal de abejas dejando un núcleo limpio (Fig. 6.2 a), o fenocristales con cribado medio y dejando un borde limpio y zonado. Otras plagioclasas son anhedrales con cribado grueso, y un borde fino de otra composición que sigue al cribado y contorno externo del cristal (Fig. 6.2 c).

Los fenocristales de feldespatos alcalinos (3-12\%) también se presentan con y sin cribado, estando juntos o no estos dos tipos, y junto a plagioclasas limpias y/o cribadas. Los fenocristales sin cribado son por lo general anhedrales o redondeados, comúnmente agrupándose en glomérulos. Entre los fenocristales cribados son frecuentes los cristales anhedrales o redondeados y con un cribado grueso (Fig. 6.2 d) (en un solo caso se encontraron también con cristales subhedrales - euhedrales y con cribado grueso).

En una considerable menor proporción, se encuentran fenocristales de feldespatos alcalinos anhedrales/redondeados con un cribado medio en todo el cristal (Fig. 6.2 e), los cuales se encuentran junto a plagioclasas también anhedrales, aunque sin cribar. El cribado fino es típico de fenocristales de plagioclasas, pero algunas pocas lavas muestran relativamente abundantes cristales de un posible feldespato alcalino, sin macla ni zonación, con este tipo de cribado. Estos fenocristales son totalmente anhedrales o redondeados, con un anillo con cribado fino cerca del borde y dejando un núcleo y borde limpios (Fig. 6.2 f).

Los fenocristales de olivina (2-3\%), seriados hasta $1 \mathrm{~mm}$ de largo, a veces están frescos y otras veces presentan un borde opaco fino y/o una notoria alteración a iddingsita (en ciertos casos se torna tan opaca que su presencia está en duda). Son subhedrales, con las esquinas redondeadas (Fig. 6.3 a).

El clinopiroxeno (hasta $3 \%$ ) es mayoritariamente subhedral con los bordes de los cristales claramente redondeados (Fig. 6.3 b), presentando en ocasiones un borde opaco fino. Con mucha menor frecuencia, se encuentran cristales subhedrales - euhedrales sin redondear, pudiendo tener también, un borde opaco fino (Fig. $6.3 \mathrm{c}$ ).

Los fenocristales de biotita ( $2-3 \%$, seriada hasta $0,8 \mathrm{~mm}$ de largo), se encontraron en una sola lava de esta subunidad, casi por completo reemplazada por minerales anhidros como opacos, feldespatos y clinopiroxeno (Fig. 6.3 d). El anfíbol, presente en una sola muestra, está 


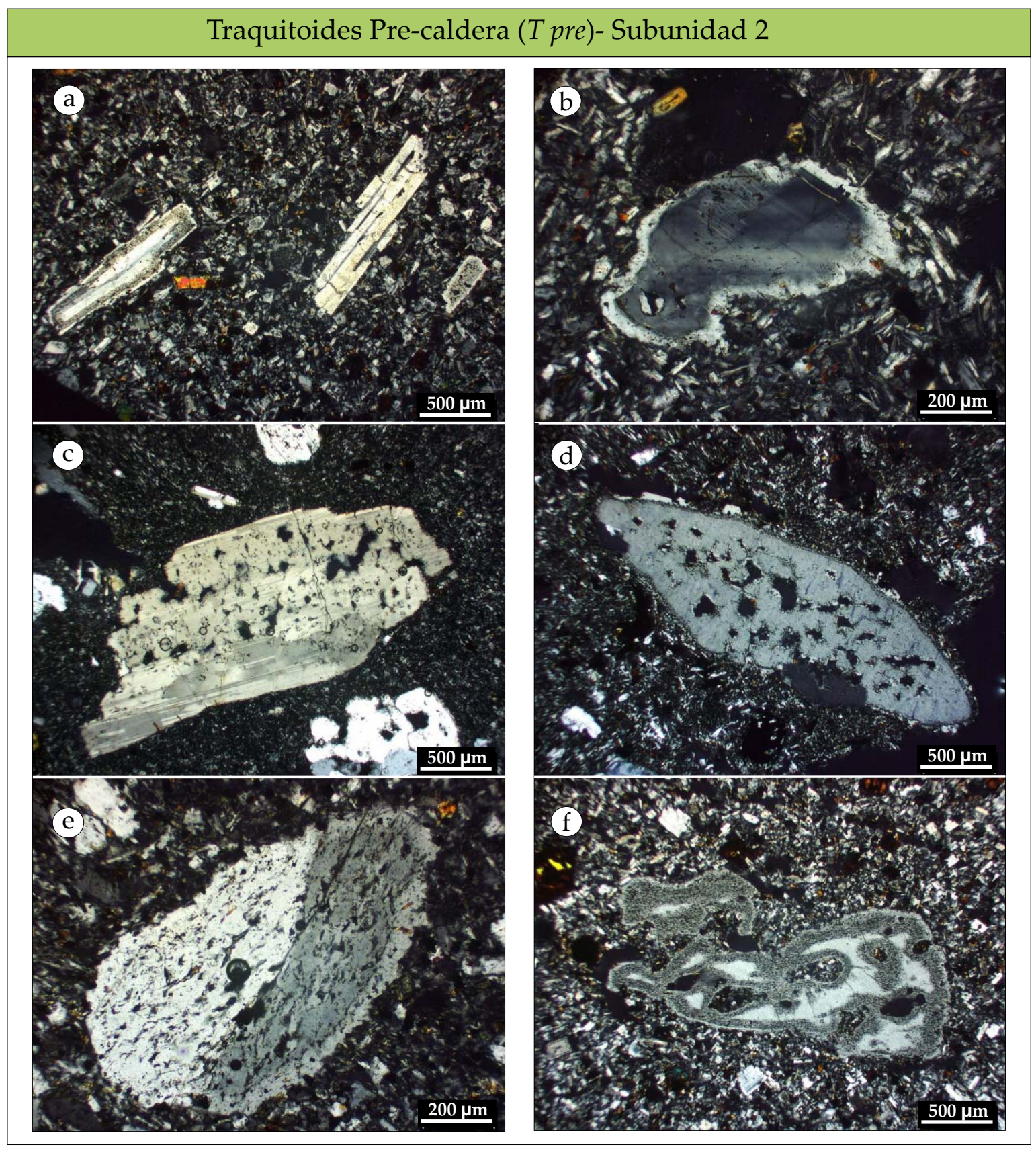

Figura 6.2: Fotos al microscopio de diferentes feldespatos de la subunidad 2 de los Traquitoides Pre-caldera. a) Plagioclasas euhedrales limpias y con un anillo de panal de abejas. b) Plagioclasa anhedral con un sobrecrecimiento fino. c) Plagioclasa con cribado grueso. d) Feldespato alcalino con cribado grueso. e) Feldespato alcalino con cribado medio. f) Feldespato alcalino totalmente anhedral y con un anillo de panal de abejas. 


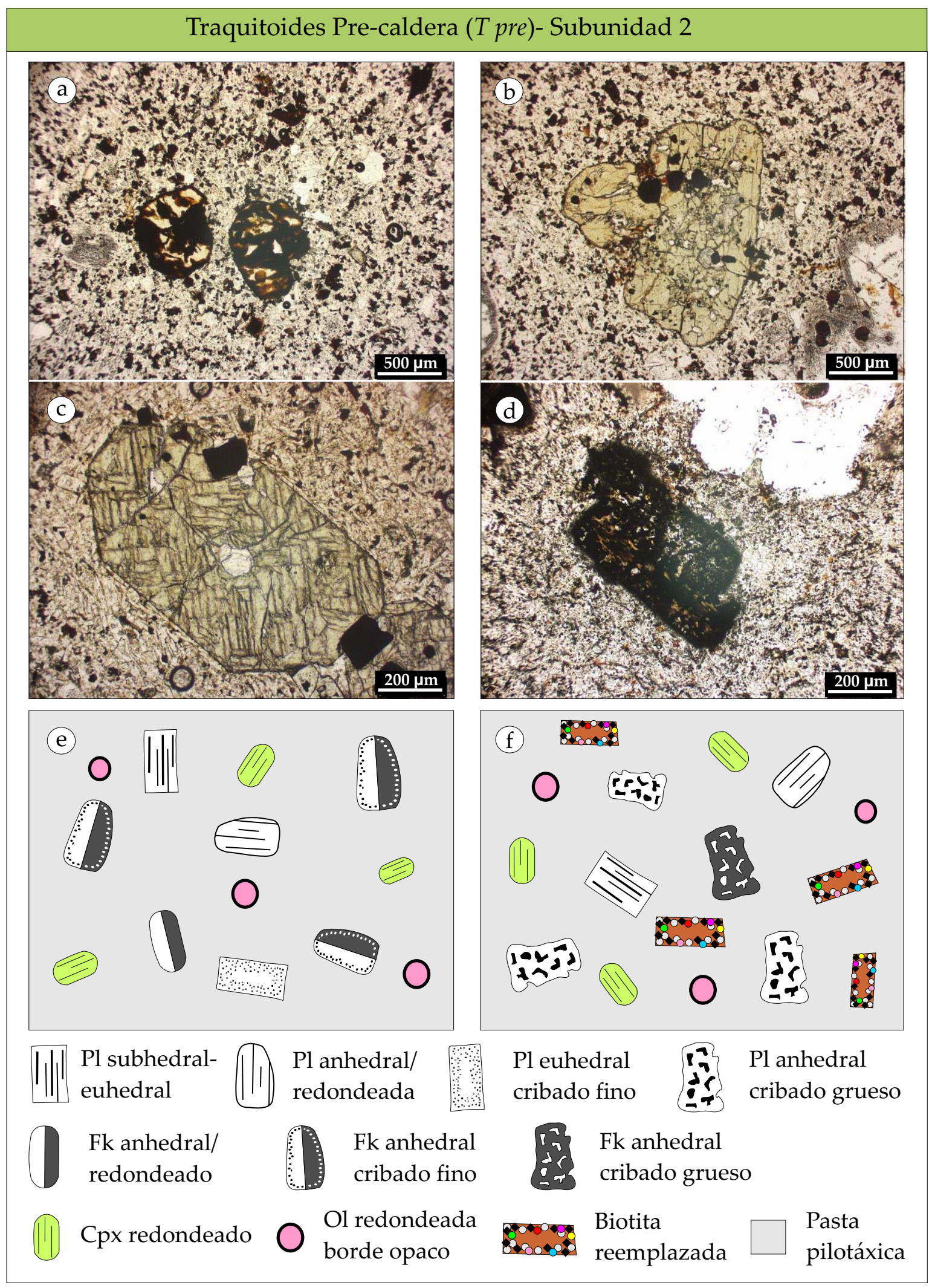

Figura 6.3: a-d) Fotomicrografías de minerales máficos de la subunidad 2 de los Traquitoides Pre-caldera. Ver explicación en el texto. e y f) Dibujos esquemáticos de dos lavas con diferente asociación mineral y texturas mineralógicas. Pl: plagioclasa; Fk: feldespato alcalino; Ol: olivina; Cpx: clinopiroxeno; Bt: biotita (el remplazo es por minerales anhidros). 
totalmente reemplazado por minerales opacos, distinguiéndose solamente por su forma.

En las Figuras 6.3 e y f se muestran esquemas de las asociaciones minerales y características mineralógicas de dos lavas pertenecientes a esta subunidad. El esquema de la Figura 6.3e corresponde a un afloramiento en la pared noreste de la caldera, mientras que el esquema de la Figura $6.3 \mathrm{f}$ corresponde a una lava aflorante en el sector nor-noreste de la pared baja de la caldera.

\subsubsection{Subunidad 3}

Esta subunidad es variada en cuanto a las texturas y minerales presentes. Si bien todas las lavas son porfíricas con fenocristales de plagioclasa (además de minerales opacos y apatita como accesorio frecuente), los fenocristales de minerales máficos son variados. El más común es la olivina, seguido del clinopiroxeno, biotita y anfíbol, este último presente en pocas oportunidades. Las asociaciones de minerales máficos que más se repiten son olivina + clinopiroxeno + biotita , olivina + clinopiroxeno, y olivina sola. Las pastas son pilotáxicas, aunque ciertas lavas presentan un contenido muy bajo de mafitos.

En cinco lavas fueron observadas pastas con dos dominios de diferente textura, claramente diferenciables, con un contacto neto entre ambas e irregular o sinuoso, como es una interfase entre dos líquidos inmiscibles. El dominio menos abundante está compuesto por una pasta también pilotáxica pero más oscura, respecto del dominio predominante, y se encuentra en lentes o bandas deformadas o simplemente en zonas globosas o irregulares (Figs. $6.4 \mathrm{a} \mathrm{y} \mathrm{b).}$

Los fenocristales de plagioclasa poseen una abundancia variable, desde $3 \%$ a $18 \%$. Son seriados, desde los microlitos presentes en la pasta hasta fenocristales de 4,5 mm de largo y es común que se agrupen formando glomérulos. Como es de esperar, también es variable el tipo de texturas mineralógicas de las plagioclasas presentes. Todas las muestras de esta subunidad poseen plagioclasas limpias (aunque con morfología variable) y en gran parte aunque no todas, poseen también fenocristales con algún tipo de cribado. La abundancia relativa entre fenocristales con y sin cribado es variable, generalmente predominan las plagioclasas limpias, aunque en numerosos casos se observa la situación inversa.

Las plagioclasas sin cribado más abundantes son aquellas subhedrales - euhedrales, habiendo también (muchas veces se las encuentra juntas) otras subhedrales con las esquinas redondeadas (Fig. 6.4 c). De los tres tipos de cribado (fino o en panal de abejas, medio y grueso), el más repetitivo es el cribado grueso. Las plagioclasas que presentan cribado grueso son generalmente anhedrales (Fig. $6.4 \mathrm{~d}$ ), aunque existen muchas excepciones, con fenocristales subhedrales - euhedrales y un cribado grueso (Fig. 6.4 e). En una significativa menor proporción se encuentran plagioclasas subhedrales - euhedrales o anhedrales/redondeadas con un cribado medio en todo el cristal, dejando un borde limpio (Fig. 6.4 f, del tipo euhedral). Estos dos tipos de cribado suelen tener un borde muy fino como un sobrecrecimiento, siguiendo 


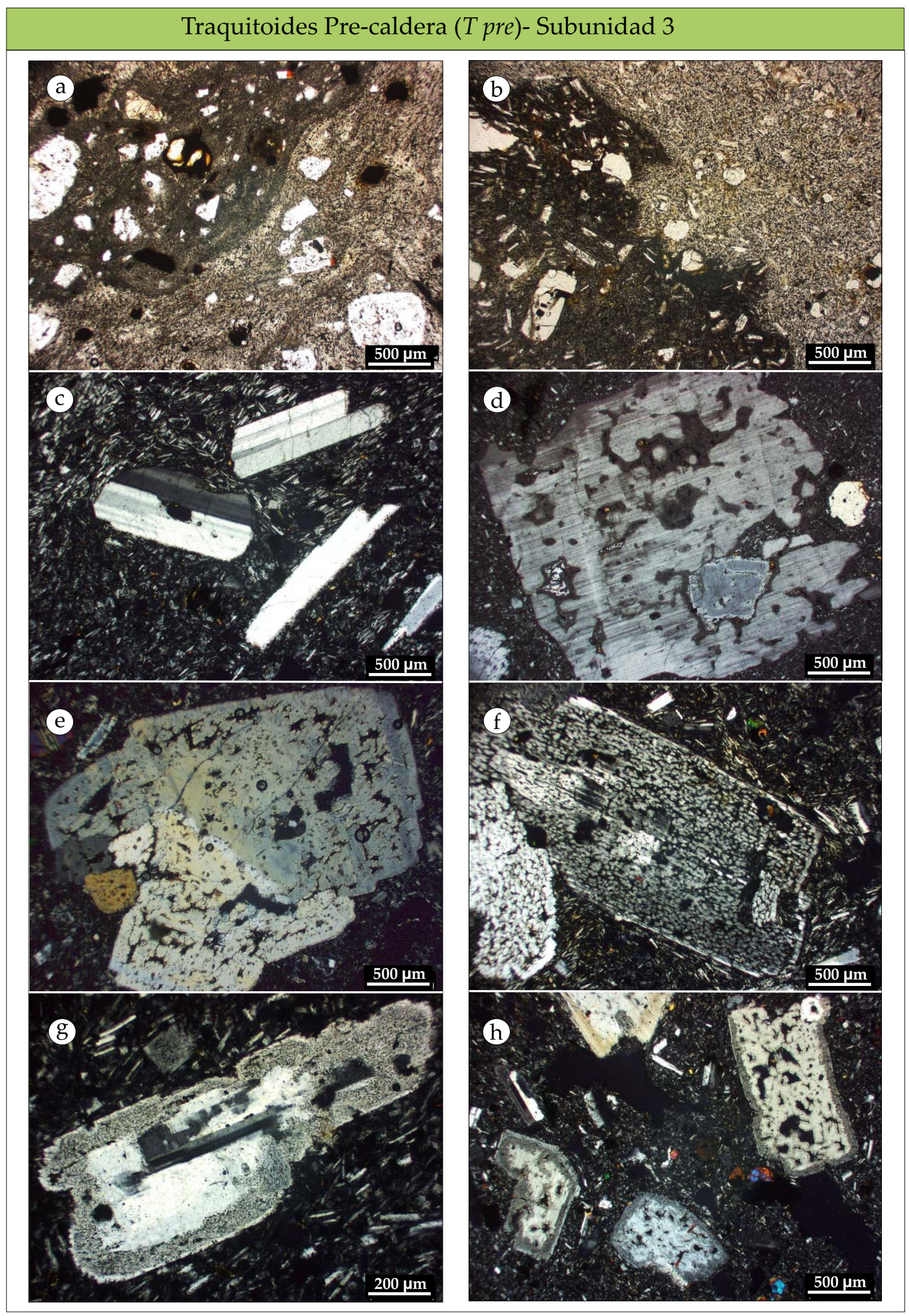

Figura 6.4: a) y b) Dos pastas diferentes en contacto neto. c) Plagioclasas limpias (euhedrales y otras redondeadas). d) y e) Plagioclasas con cribado grueso. f) Plagioclasas con cribado medio. g) Plagioclasa con cribado fino. h) Plagioclasas con cribado fino y grueso. 


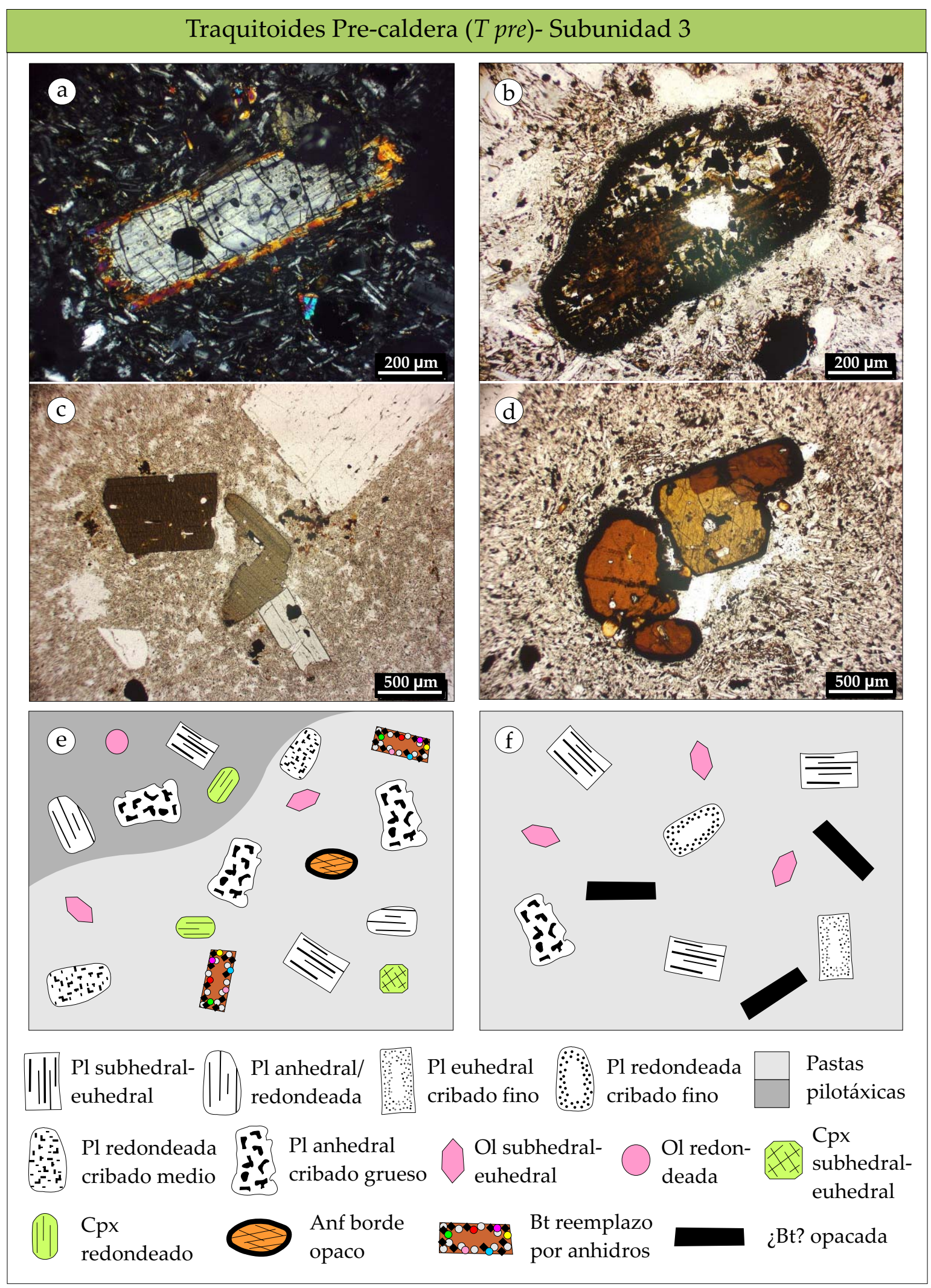

Figura 6.5: a) ortopiroxeno con un manto de clinopiroxeno. b) biotita parcialmente reemplazada por minerales anhidros. c) biotitas sin reemplazar, euhedrales y otras redondeadas. $d$ ) anfíbol con borde opaco. e y f) esquemas de asociaciones minerales con sus características de dos lavas de esta subunidad. Pl: plagioclasa; Ol: olivina; Cpx: clinopiroxeno; Bt: biotita; Anf: anfíbol. 
al contorno del cristal y del cribado. Las plagioclasas con cribado en panal de abejas son generalmente anhedrales o subhedrales redondeadas (Fig. $6.4 \mathrm{~g}$ ), siendo menos frecuentes las subhedrales - euhedrales. Estas plagioclasas suelen dejar un núcleo y borde fino limpio y zonado. El cribado en panal de abejas también aparece en pocas ocasiones junto al cribado grueso, en fenocristales anhedrales o redondeados, pudiendo tener partes del cristal sin cribar (Fig. $6.4 \mathrm{~h}$ ).

La olivina ( $\leq 3 \%$ ) se encuentra en pequeños fenocristales de hasta $0,8 \mathrm{~mm}$ de largo máximo. En numerosos casos se encuentra con el contorno redondeado, y en otros es subhedral - euhedral sin signos de redondeamiento. A veces presenta un borde opaco, tanto en los cristales con y sin redondeamiento, y más raramente, la olivina se encuentra totalmente reemplazada por minerales opacos o alterada a iddingsita, reconociéndose solamente por el contorno externo.

El clinopiroxeno $(\leq 4 \%)$, de color verde claro, es seriado llegando hasta $2,5 \mathrm{~mm}$ de largo (muchos menores a 1,5 mm). Lo más frecuente es que se encuentren tanto cristales subeuhedrales sin signos de redondeamiento como aquellos que si presentan las esquinas redondeadas. En escasas lavas se encuentran uno solo de estos dos tipos.

En sólo dos muestras analizadas se encontró una pequeña proporción de piroxenos manteados, con un núcleo relativamente grande de ortopiroxeno, rodeado por un manto de espesor variable pero relativamente fino de clinopiroxeno (Fig. 6.5 a). En una sola lava precaldera fueron encontrados fenocristales de ortopiroxeno $(<1 \%$, hasta $0,6 \mathrm{~mm}$ de largo), sin manto de clinopiroxeno pero con un borde opaco fino, y en pequeños glomérulos generalmente. Estos se encuentran junto a otros mafitos como el clinopiroxeno, anfíbol y biotita.

Los fenocristales de biotita $(\leq 4 \%$ ) son seriados, alcanzando hasta $3 \mathrm{~mm}$ de largo, aunque no suelen superar los $2 \mathrm{~mm}$. En la mayoría de los casos, se encuentra reemplazada por minerales opacos y otros félsicos y máficos (posiblemente feldespatos y clinopiroxeno, como es de esperar en los reemplazos de biotita por minerales anhidros, aunque su pequeño tamaño de grano no permite determinarlos con exactitud) (Fig. 6.5 b). También se pueden encontrar, o no, junto con las previamente descriptas, biotitas con el borde opaco. En pocas ocasiones se encuentran totalmente reemplazadas por minerales opacos, dejando en duda su presencia. En menor proporción que las biotitas reemplazadas, y en diferentes muestras, se encuentran otros fenocristales euhedrales sin reemplazar, aunque se exhibe en ciertos casos un redondeamiento de las esquinas (Fig. 6.5 c).

En las pocas lavas donde se encuentran fenocristales de anfíbol $(\leq 3 \%$, hasta $2,2 \mathrm{~mm}$ de largo), este presenta una coloración castaña, con el mismo pleocroísmo descripto en la subunidad 1, y a veces se encuentra en pequeños glomérulos. Se encuentra anhedral y con un borde opaco relativamente grueso (Fig. $6.5 \mathrm{~d}$ ), aunque en un solo caso no presenta borde opaco pero si un redondeamiento visible. En las lavas en las cuales el anfíbol está en pequeños glomérulos, el sector del cristal que está en contacto con otros minerales no presenta el borde opaco, mientras que el sector que limita con la pasta sí. 
Los enclaves son poco frecuentes, siendo estas de una textura microgranuda y de similar composición que la lava que lo hospeda. En las Figuras 6.5e y f se esquematizan dos lavas pertenecientes a esta subunidad. En el primer caso, corresponde a una lava expuesta en la pared noreste de la caldera, en la cual se encontraron evidencias microscópicas de mingling, con la presencia de dos pastas diferentes. En el segundo caso, corresponde a una lava extracaldera, ubicada en el flanco sureste del Payún Matrú.

\subsubsection{Subunidad 4}

Se compone de lavas de color gris medio a oscuro, todas porfíricas con plagioclasa y olivina, clinopiroxeno en casi todos los casos, además de minerales opacos y apatita solo en algunos pocas lavas. La pasta es intergranular, aunque en algunos casos el contenido de mafitos es escaso, asimilándose a una textura pilotáxica.

Los fenocristales de plagioclasa presentan porcentajes variables, desde $1 \%$ hasta $20 \%$, siendo en general menor al $10 \%$. El tamaño es seriado, desde los microlitos en la pasta hasta fenocristales de $1 \mathrm{~cm}$ de largo, aunque en general son menores a 3-4 $\mathrm{mm}$. Todas las lavas pertenecientes a esta subunidad poseen tanto fenocristales de plagioclasa limpios como cribados, con alguna excepción (sin plagioclasas cribadas o sin plagioclasas limpias) (Fig. 6.6 a). Las plagioclasas limpias son en la mayoría de los casos subhedrales - euhedrales, ocasionalmente junto a otras con las esquinas redondeadas. En marcada minoría, se encuentran solamente fenocristales redondeados $\mathrm{u}$ anhedrales.

Entre las plagioclasas cribadas, el tipo de cribado que predomina ampliamente es el panal de abejas, presentándose tanto en cristales subhedrales - euhedrales (Fig. 6.6 b) como en otros redondeados $u$ anhedrales (ambos tipos juntos) (Fig. 6.6 a). En estos casos los fenocristales suelen presentar un núcleo y un borde fino limpio. Ocasionalmente, se encuentran plagioclasas con cribado medio, las cuales no están junto a otro tipo de plagioclasas cribadas, y pueden ser tanto subhedrales - euhedrales (Fig. 6.6 c) como anhedrales/redondeadas. Raramente, se encuentran fenocristales anhedrales y con un anillo con cribado grueso y fino, dejando un borde fino y limpio. Este último tipo de cristales se las puede encontrar junto a plagioclasas limpias o con cribado fino solamente.

Los fenocristales de olivina $(\leq 5 \%)$ son seriados desde los microlitos de la pasta hasta fenocristales de 2,5 mm de largo, generalmente menores a 1,5 $\mathrm{mm}$. Son de diversas morfologías, habiendo cristales subhedrales - euhedrales (Fig. $6.6 \mathrm{~d}$ ), subhedrales/anhedrales redondeados, levemente esqueletales (Fig. 6.6 e) y con engolfamientos (con las esquinas redondeadas, Figura 6.6 d). Ningún tipo es marcadamente predominante sobre los otros. Las olivinas levemente más abundantes son aquellas redondeadas $\mathrm{u}$ anhedrales, y le siguen los fenocristales subhedrales - euhedrales y esqueletales. Los cristales con engolfamientos marcados y esquinas redondeadas son un poco menos abundantes. Las olivinas euhedrales se presentan junto a otras redondeadas o esqueletales. 


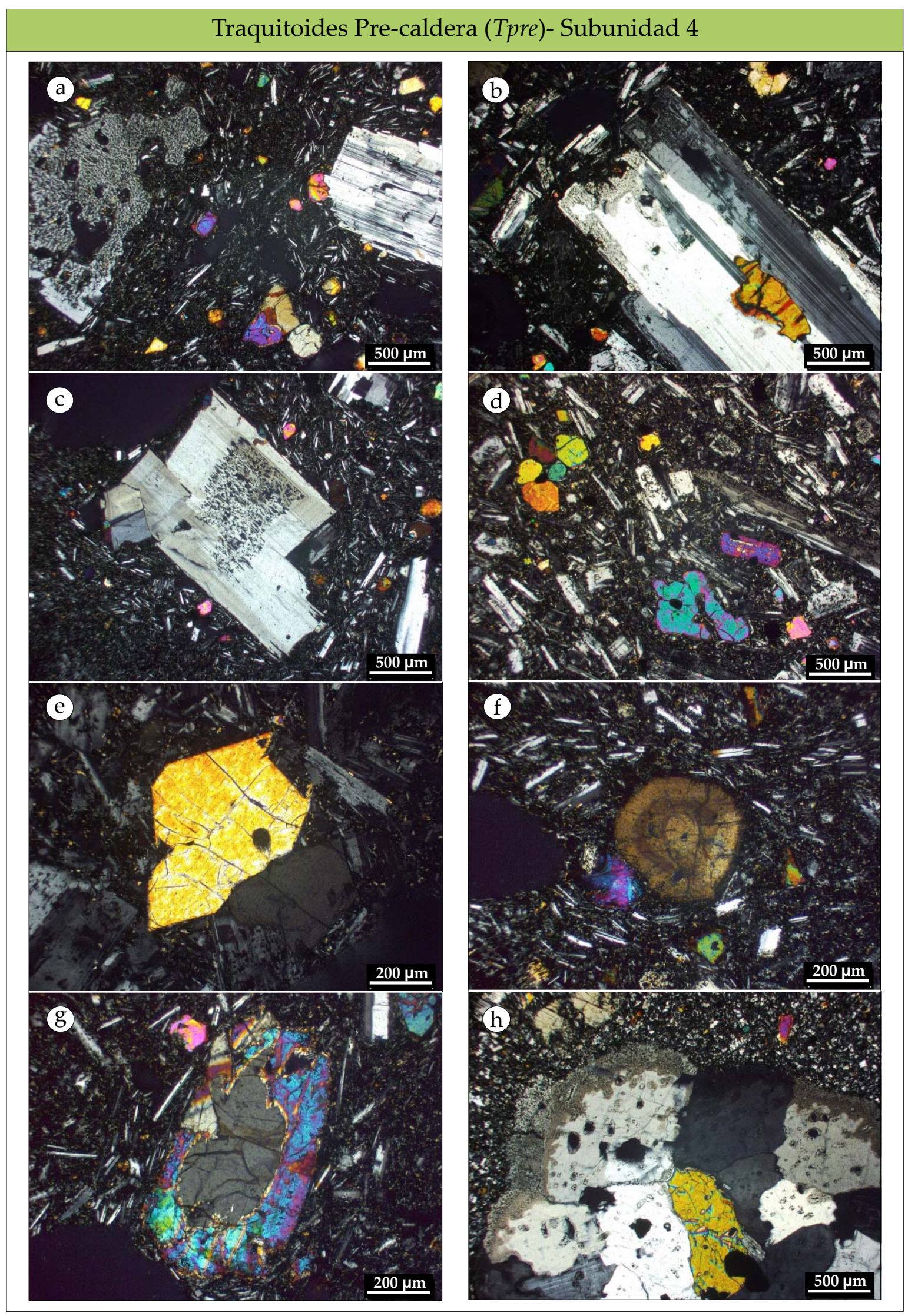

Figura 6.6: a) Plagioclasas limpias y cribadas. b) Plagioclasa euhedral con cribado fino. c) Plagioclasa euhedral con cribado medio. d) Olivinas euhedrales y otra con engolfamientos. e) Olivina levemnte esqueletal. f) Clinopiroxeno con zonación concéntrica. g) Clinopiroxeno sobre un núcleo posiblemente de olivina. h) Enclave con borde cribado fino. 


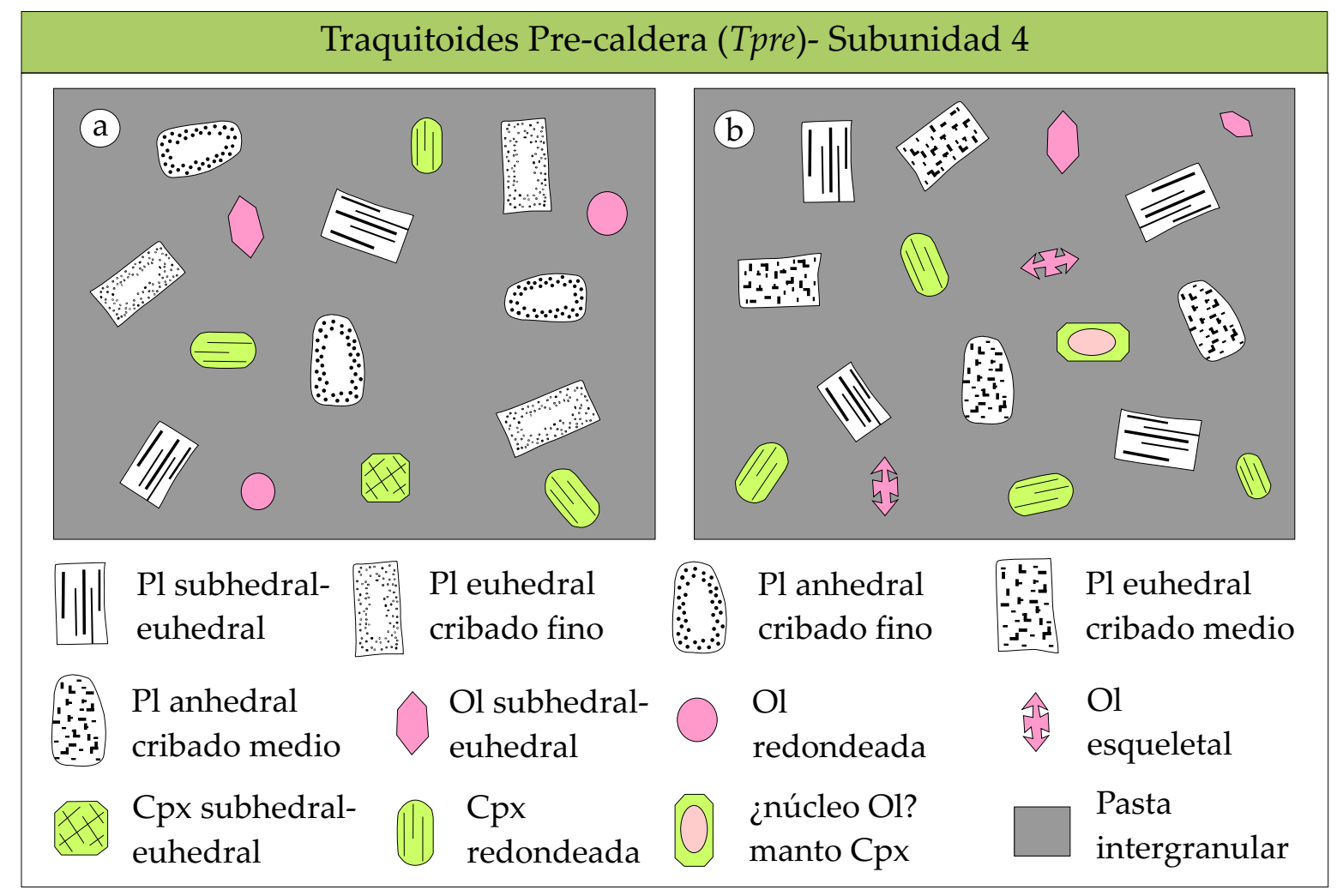

Figura 6.7: Dibujos esquemáticos de asociaciones minerales y sus texturas en dos lavas precaldera de la subunidad 4. Pl: plagioclasa; Ol: olivina; Cpx: clinopiroxeno.

El clinopiroxeno (1-4\%) es seriado de hasta 1,5 mm de largo. Es común que presenten zonación concéntrica o en reloj de arena (Fig. 6.6 f). En la amplia mayoría de las muestras con fenocristales de clinopiroxeno se encuentran dos tipos diferentes, juntos. Por un lado están aquellos fenocristales subhedrales - euhedrales, y por el otro los subhedrales con un marcado redondeamiento de las esquinas. En un solo caso aislado se encontraron solamente clinopiroxenos redondeados.

En dos lavas fueron encontrados mafitos manteados, con un manto de clinopiroxeno y un núcleo que posiblemente sea de olivina (Fig. 6.6 g). En una de estas lavas los mafitos manteados es sólo un cristal aislado, mientras que en la otra lava se encontraron en repetidas ocasiones.

Las Figuras 6.7 a y b ilustran las paragénesis mineral junto con sus características texturales en dos lavas diferentes, en la pared noreste de la caldera y en el flanco sureste del Payún Matrú, respectivamente. En esta última lava, se encuentran enclaves microgranulares anhedrales con plagioclasa, feldespatos alcalinos, clinopiroxeno y olivina, con un cribado fino en un anillo en el borde del enclave (Fig. $6.6 \mathrm{~h}$ ). 


\subsubsection{Subunidad 5}

A esta subunidad pertenecen las escasas ignimbritas pre-caldera encontradas en dos sitios mencionados del perfil de "La Nariz". En el primer caso, la ignimbrita corresponde a una de alto grado, similar a las ignimbritas lava-like, con un grado de soldadura muy alto aunque sin presentar signos de reomorfismo. La matriz es vítrea, color rojizo oscuro a castaño, en donde ya no se reconocen las trizas vítreas debido al alto grado de aplastamiento y soldadura (Fig. 6.8 a). Se observan esferulitas que no perturban la pseudofluidalidad del vidrio, indicando un origen post-deposicional (Fig. 6.8 b). Los cristales presentes, en porcentajes muy escasos, son plagioclasas ( $2 \%)$, feldespatos alcalinos, olivina y clinopiroxeno (en porcentajes $<1 \%$ cada uno de ellos). Los feldespatos son mayormente sub- euhedrales, limpios, aunque hay algunos fracturados. Alcanzan hasta $3 \mathrm{~mm}$ de largo. Las olivinas $(<0,6 \mathrm{~mm}$ de largo) son subhedrales - euhedrales y los clinopiroxenos $(<0,8 \mathrm{~mm}$ de largo $)$ presentan esquinas redondeadas. Los líticos son escasos, subangulosos y de lavas traquíticas/traquiandesíticas.

En el segundo caso, la ignimbrita presenta una textura eutaxítica, con fiammes bien elongados y densos, con el vidrio recristalizado en un arreglo desordenado de fibras de feldespatos. La matriz, con trizas deformadas, se encuentra oscurecida con un punteado fino de minerales opacos (Figs. 6.8 c y d). Presenta cristales de plagioclasas $(15 \%)$, olivina $(<1 \%)$, clinopiroxeno (1-2\%), biotita (2-3\%) y anfíbol $(<1 \%)$, además de opacos y apatita. Las plagioclasas (seriadas hasta $3 \mathrm{~mm}$ de largo) se encuentran limpias, a veces fracturadas. Las olivinas (hasta $0,7 \mathrm{~mm}$ de largo) presentan bordes redondeados y con un borde opaco fino (Fig. 6.8 c). El clinopiroxeno (hasta 1,3 mm de largo) es mayormente subhedral - euhedral, aunque unos pocos poseen signos de redondeamientos en las esquinas. La biotita $(<2 \mathrm{~mm}$ de largo, Figura 6.8 d) es subhedral - euhedral, y en varias oportunidades se distingue un redondeamientos de sus bordes. El anfíbol (hasta $0,8 \mathrm{~mm}$ de largo) presenta un pleocroísmo de castaño rojizo a castaño amarillento como en el resto de las lavas en donde está presente, y también posee esquinas redondeadas (Fig. 6.8 d).

\subsection{Ignimbrita Portezuelo}

Las características petrográficas de la Ignimbrita Portezuelo varían de acuerdo con las diferencias en sus facies presentadas en el Capítulo 4. Una característica constante o poco variable son los minerales presentes, y es por este motivo que se describirán conjuntamente. Otra característica que comparten las diferentes facies, es que los componentes vítreos predominan siempre por sobre los cristales y fragmentos líticos. 


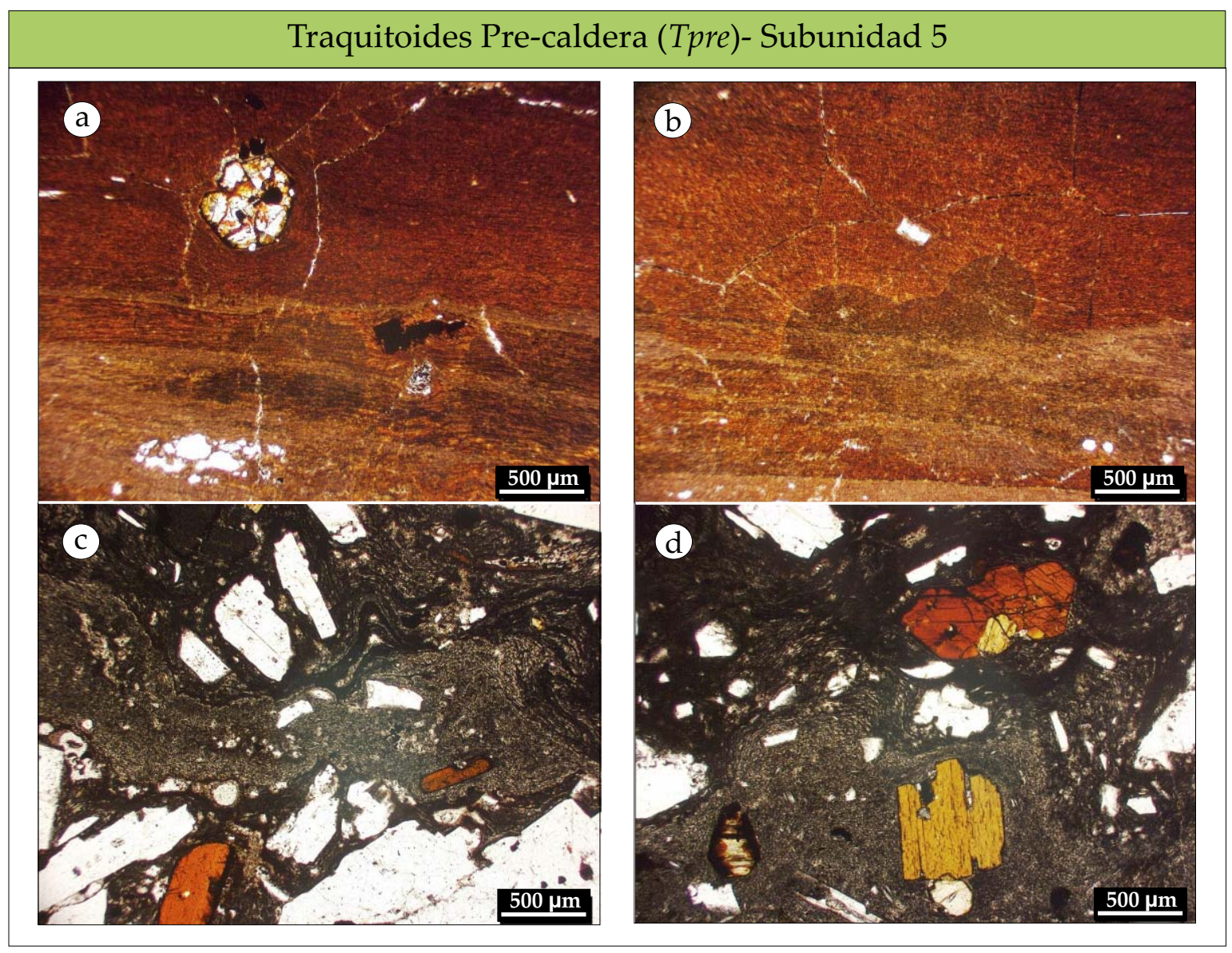

Figura 6.8: Fotomicrografías de ignimbritas pre-caldera. a y b) Ignimbrita de muy alto grado con a) cristal de olivina, y b) esferulitas. c y d) Ignimbrita en el perfil superior de "La Nariz", con fiamme (color gris más claro) y cristales de plagioclasas, biotita, anfíbol y olivina.

\subsubsection{Cristaloclastos}

Los cristales que presenta, tanto en la matriz como en los fiammes o pómez, son plagioclasas, feldespatos alcalinos, olivina, clinopiroxeno y biotita, además de opacos y apatita como mineral accesorio. El anfíbol se encuentra en escasas ocasiones con un porcentaje ínfimo, y no se lo ha encontrado dentro de pómez, por lo cual queda la duda de si se trata de un mineral presente en el magma fragmentado o no.

Las plagioclasas (4-16\%) predominan sobre los feldespatos alcalinos $(\leq 5 \%)$. Son limpias, aunque la forma cristalina es variable y pueden presentar maclas de albita o periclino muy finas (siendo probablemente anortoclasa, Fig. 6.9 b). Son frecuentes los cristales rotos y también, aunque en menor proporción, se encuentran cristales subhedrales con huecos o entradas controlados cristalográficamente y de bordes redondeados a rectos. Las esquinas de los cristales se conservan sin redondear, por lo cual se infiere que no es un rasgo de reabsorción, aunque en general el crecimiento esqueletal produce entradas o huecos rectos 
(Fig. 6.9 b). Minoritariamente, se encuentran cristales limpios sub- euhedrales y otros subanhedrales con un cribado medio en todo el cristal.

El feldespato alcalino es principalmente de dos tipos: por un lado se encuentran los cristales limpios subhedrales - anhedrales y/o fracturados, y por otro lado se encuentran cristales subhedrales - anhedrales y con cribado medio en todo el cristal (Fig. 6.9 a). Ambos tipos son comunes aunque no siempre se encuentran juntos. En muy raras ocasiones han sido encontrados cristales de plagioclasas o feldespatos alcalinos con una zonación patchy.

Los cristales de olivina $(\leq 3 \%)$ pueden ser tanto subhedrales - euhedrales como subhedrales con los bordes redondeados (Fig. 6.9 c). A veces (ambos tipos) presentan un borde opaco fino. Algunas veces los cristales redondeados y no redondeados se encuentran juntos en la misma muestra.

El clinopiroxeno $(\leq 3 \%)$ puede ser tanto subhedral - euhedral sin bordes redondeados (Fig. 6.9 g), o bien presentar un redondeamiento notorio. A veces estos dos tipos de cristales se encuentran juntos y en ocasiones no. Raramente presentan un borde opaco fino.

Los cristales de biotita ( $\leq 3 \%$ ) son en la mayoría de los casos subhedrales - euhedrales, sin remplazos de ningún tipo. A veces, en escasa proporción, pueden presentar las esquinas redondeadas (junto o no con otros cristales sin redondear, Figura 6.9 d y e). También se encuentran en ocasiones biotitas con un borde opaco, y en estos casos todas los cristales de la muestra presentan esta característica. Raramente fueron encontradas biotitas reemplazadas por un mosaico de minerales anhidros.

Los escasos cristales de anfíbol presentes (hasta 0,5 mm de largo) son subhedrales - euhedrales o bien presentan un remplazo por minerales opacos pervasivo, y en esos casos se lo reconoce por su forma cristalina. Poseen un pleocroísmo idéntico al descripto para los anfíboles presentes en los Traquitoides Pre-caldera.

\subsubsection{Vitroclastos y cristaloclastos}

Estos componentes serán descriptos en cada una de las facies ignimbríticas propuestas, debido a que sus características varían con los cambios faciales del depósito piroclástico.

\subsubsection{Facies de alto grado (emLT y emLT(v))}

Presentan una textura eutaxítica, con fiammes elongados y trizas deformadas de vidrio casi incoloro a castaño medio (Fig. 6.9 a y e). En reiteradas oportunidades (especialmente en las facies emLT), el vidrio se encuentra opacado con un punteado criptocristalino pervasivo (Fig. 6.9 d y e), dificultando o impidiendo la observación de las trizas, probablemente debido a una cristalización en fase vapor rellenando los poros (McPhie et al., 1993), o debido a recristalización del vidrio. Es común que los fiammes estén recristalizados en un mosaico desarreglado de fibras de feldespatos, a veces con el desarrollo de esferulitas o axiolitas. La matriz también ocasionalmente puede estar recristalizada. Los fiammes son porfíricos, 


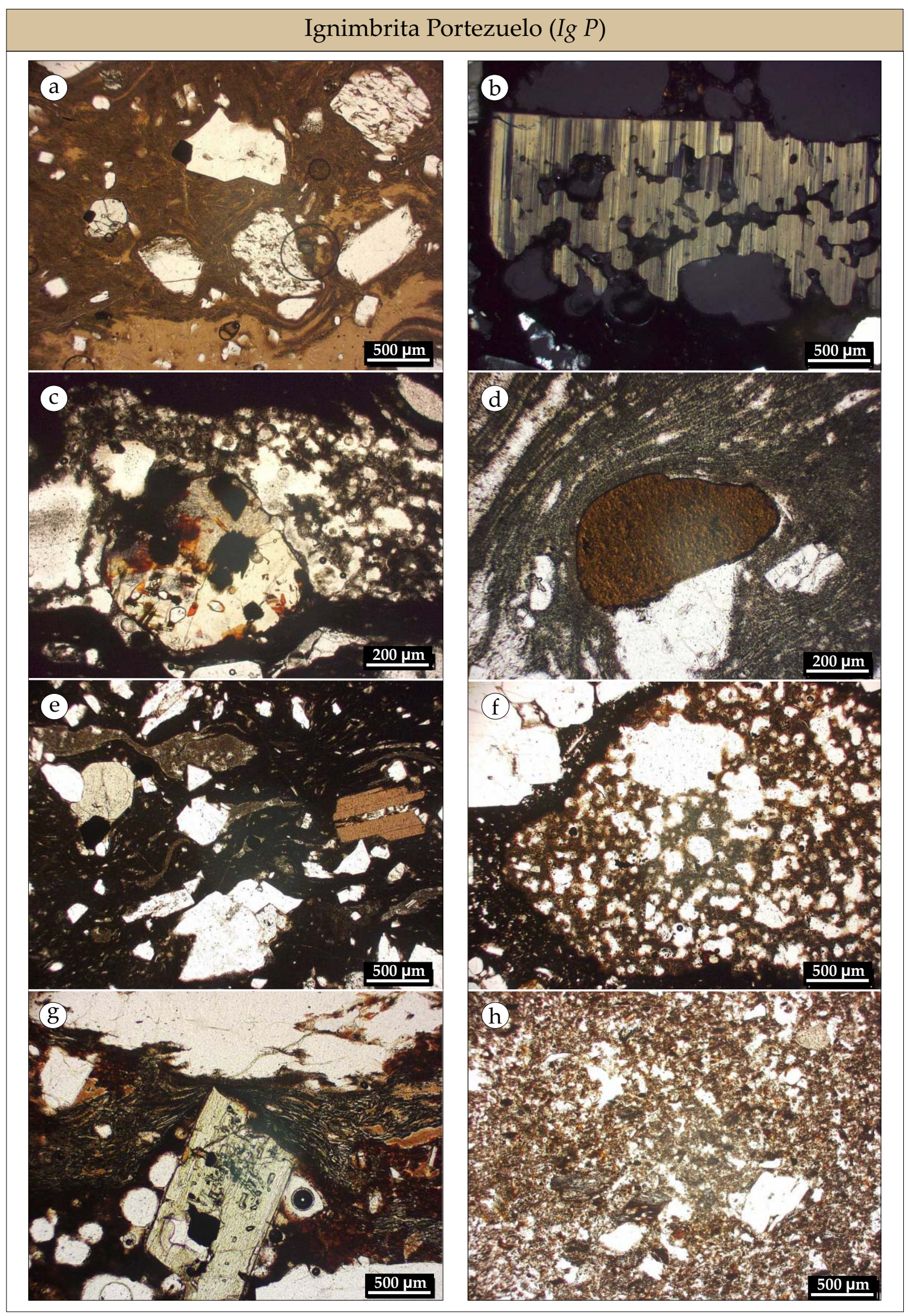

Figura 6.9: a) Textura eutaxítica, con cristales de feldespatos limpios y cribados. b) Anortoclasa con huecos o engolfamientos y esquinas sin redondear. c) Olivina dentro de un fiamme con inclusiones de apatita y opacos, redondeada. d) Biotita de contornos redondeados. e) Textura eutaxítica, con feldespatos, biotita y clinopiroxeno. f) Pómez globoso no colapsado. g) Clinopiroxeno saliendo y englobado por un clasto de spatter. h) Escasos pómez en una matriz con abundantes vesículas. 
con los mismos minerales que se encuentran en la matriz (con la excepción del anfíbol), aunque en un porcentaje menor. También pueden conservar cierto grado de vesiculación, especialmente en las facies emLT.

El porcentaje de cristales varía entre 10 y $23 \%$, similarmente al porcentaje de las lavas, mientras que el porcentaje de líticos (todos volcánicos) varía más restringidamente, entre $1-8 \%$.

\subsubsection{Facies de grado medio a bajo (mLT)}

Estas facies no presentan textura eutaxítica microscópicamente, salvo alguna excepción (muestras del punto 1 del capítulo 4). Los pómez son lensoidales a globosos, no colapsados, gris oscuro a claro o rojizos, y porfíricos con la misma mineralogía que la matriz (Fig. $6.9 \mathrm{f}$ ). La matriz posee trizas vítreas no deformadas, que varían desde incoloras a castañas o rojizas, las cuales en ocasiones no se distinguen debido a la presencia de un punteado criptocristalino castaño oscuro a opaco. Generalmente, y cuando la matriz no presenta el punteado oscuro, se observa que la misma está recristalizada en un mosaico de fibras cortas y desordenadas de feldespatos. La matriz puede poseer vesículas finas.

El porcentaje de cristales varía entre 6 y $26 \%$ (también contiene microlitos en abundancia variable), y el porcentaje de líticos volcánicos es escaso, variando entre 1 y $5 \%$.

\subsubsection{Facies con clastos de spatter traquíticos (emLT(cc) y mLT(cc))}

Se describirán en esta sección solamente a los clastos de spatter, en ignimbritas de alto y bajo grado, debido a que el resto de las características son similares a las facies ya descriptas emLT y mLT. Los clastos de spatter son porfíricos, con cristales de plagioclasa, feldespatos alcalinos, olivina, clinopiroxeno y biotita. La plagioclasa predomina ampliamente sobre los feldespatos alcalinos (seriados hasta 2,5 $\mathrm{mm}$ de largo) y los minerales máficos. La plagioclasa (7-15\%) es limpia y frecuentemente fragmentada, y a veces los cristales presentan huecos relativamente grandes, controlados cristalográficamente y con bordes redondeados, aunque las esquinas del cristal permanecen sin redondear. El feldespato alcalino es anhedral y con un cribado medio en todo el cristal.

La olivina ( $1 \%$, hasta $1 \mathrm{~mm}$ ) puede presentar o no signos de redondeamiento, y ocasionalmente un borde fino opaco. El clinopiroxeno (1\%, hasta 1,5 mm de largo) puede presentarse claramente redondeado, o subhedral - euhedral sin redondear (aunque no han sido observados estos dos tipos en la misma muestra). La biotita ( $1 \%$, hasta 2,5 $\mathrm{mm}$ de largo) es subhedral -euhedral sin ningún tipo de reemplazos.

En el caso de la facies emLT(cc), si bien se distingue un contacto neto entre los clastos de spatter y la matriz, estos clastos poseen formas redondeadas y el borde de los mismos es sinuoso, a veces con fenocristales que deforman y amoldan el borde del clasto (Fig. 6.9 g). Además, se observa a la matriz deformándose y adaptándose al contorno de los clastos de 
spatter (Fig. 6.9 g). Algunos clastos de spatter contienen abundantes vesículas, sin una zonación aparente en cuanto al grado de vesicularidad dentro del mismo, y están conformados por un vidrio castaño medio a oscuro, el cual está cristalizado por sectores. Otros clastos presentan una zonación marcada en cuanto al grado de vesículas dentro del mismo. Estos poseen un núcleo con abundantes vesículas equidimensionales, cristales (tamaño fenocristal a microlitos) y un vidrio castaño rojizo recristalizado con fibras de feldespatos desarregladas y esferulitas. El borde del clasto es significativamente menos vesicular y más oscuro, pudiendo variar en color de rojizo a negro. La estructura que poseen es similar a las bombas volcánicas, con un núcleo más vesicular que el borde. En algunos casos las vesículas se encuentran rellenas parcialmente con carbonatos.

En el caso de la facies $\mathrm{mLT}(\mathrm{cc})$, la forma de los clastos de spatter es altamente irregular, como ya fue mencionado en el capítulo 4 , y el contacto entre estos y la matriz, aunque sea irregular y con entradas, es neto. No se observa una variación marcada en la abundancia de vesículas desde el borde al núcleo, sino que los clastos de spatter son altamente vesiculados homogéneamente.

\subsubsection{Otras facies (dsLT, sLT, sT y mT)}

Las facies sLT y dsLT presentan, microscópicamente, características muy similares. La mayor diferencia está dada en la abundancia de pómez, que en estos casos puede llegar a ser muy escasa. El contenido de cristales está entre el 12-18\%, siendo los feldespatos menores a los $3 \mathrm{~mm}$ de largo, y los mafitos menores a 1,5 mm de largo.

La facies sT y $\mathrm{mT}$ son ricas en matriz, y casi no tienen pómez (que alcanzan $2 \mathrm{~mm}$ de largo) ni líticos (menores al milímetro). La matriz es rojiza fuerte y posee vesículas muy finas. Presentan un contenido de cristales que varía entre 6 y $15 \%$, menores al milímetro.

\subsection{Traquiandesitas Post-caldera}

Las lavas de esta unidad son de color gris medio a oscuro y porfíricas. Todas tienen fenocristales de plagioclasa (10-22\%), olivina (a excepción de una colada en el flanco SE del Payún Matrú, "Colada de La Cueva", Fig. 4.1) y clinopiroxeno (ambos minerales con porcentajes entre 2 y $5 \%$ ), junto con minerales opacos. Además, como excepción, la colada extra-caldera ubicada en el flanco noroeste del Payún Matrú (colada "El Choique", Fig. 3.5) presenta un muy bajo porcentaje $(<1 \%)$ de fenocristales de anfíbol. Como mineral accesorio puede aparecer ocasionalmente la apatita. Las texturas de la pasta varían entre intergranular, con la misma mineralogía que presentan como fenocristales, y pilotáxica, ambos tipos texturales pasando frecuentemente a una textura traquítica por orientación de los microlitos.

En las Traquiandesitas Post-caldera es común la existencia de texturas que indican desequilibrios mineralógicos, sobre todo en las plagioclasas. La colada intra-caldera de esta uni- 
dad será tratada separadamente al resto, a modo de ejemplo de la complejidad textural que puede presentar esta unidad y, además, porque presenta ciertas características particulares. En primera instancia se describirán las lavas de Traquiandesitas Post-caldera a excepción de la colada intra-caldera.

\subsubsection{Plagioclasas}

Los fenocristales de plagioclasa son seriados, variando desde los microlitos presentes en la pasta hasta fenocristales de $5 \mathrm{~mm}$ de largo. Presentan amplia variedad en cuanto a morfologías cristalinas y texturas internas, habiendo dos o más tipos diferentes presentes en la misma muestra (Fig. 6.10 a). Esta variabilidad dificulta hacer mayores generalizaciones, aunque sin embargo, en general la gran mayoría de las muestras presentan plagioclasas limpias (aunque la forma de los cristales varía) y que todas las lavas, a excepción de la "Colada de La Cueva" (Fig. 4.1), presentan también fenocristales de plagioclasa con uno o más tipos de cribados distintos.

En cuanto a las plagioclasas limpias, la mayoría son subhedrales - euhedrales (Fig. 6.10 a), habiendo menor proporción de cristales subhedrales con esquinas redondeadas (Fig. 6.10 b), y escasas anhedrales. Estos fenocristales no suelen ser los de mayor tamaño, muchas veces no superando el milímetro de largo.

El grupo de plagioclasas cribadas es más abundante y variado que el de las plagioclasas limpias. De los diferentes tipos de cribado descriptos en la primera sección del capítulo, se observan los tres, y en muchas lavas estos se encuentran juntos, inclusive en el mismo corte delgado. Es frecuente que los fenocristales cribados se encuentren en glomérulos. El cribado fino o en panal de abejas se observa tanto en cristales subhedrales - euhedrales (Fig. $6.10 \mathrm{a}$ y c) como en otros redondeados o anhedrales (Fig. 6.10 d), en ocasiones estos dos tipos se encuentran juntos, en otros no. Por lo general tienen un borde limpio y zonado, y las zonas cribadas varían desde un anillo fino cerca del borde dejando un núcleo relativamente grande y limpio, hasta todo el interior del cristal cribado.

El denominado cribado medio es menos frecuente en cuanto a lavas que lo presentan y, al igual que el cribado fino, se puede encontrar tanto en fenocristales euhedrales (Fig. 6.10 e) como anhedrales. También es usual que los fenocristales con este tipo de cribado presenten un borde limpio y zonado.

El cribado grueso es frecuente, tanto en la cantidad de lavas que lo presentan como en su abundancia. Es levemente más común en cristales subhedrales - euhedrales (Fig. 6.10 a) que en aquellos redondeados $u$ anhedrales (Fig. $6.10 \mathrm{f}$ ), aunque se encuentran los dos casos. Alrededor del borde del cristal y del cribado grueso hay generalmente un sobrecrecimiento fino.

En algunas lavas se encuentran fenocristales con cribado fino y grueso juntos, siendo estos cristales a veces subhedrales - euhedrales y otras veces con bordes redondeados $u$ 


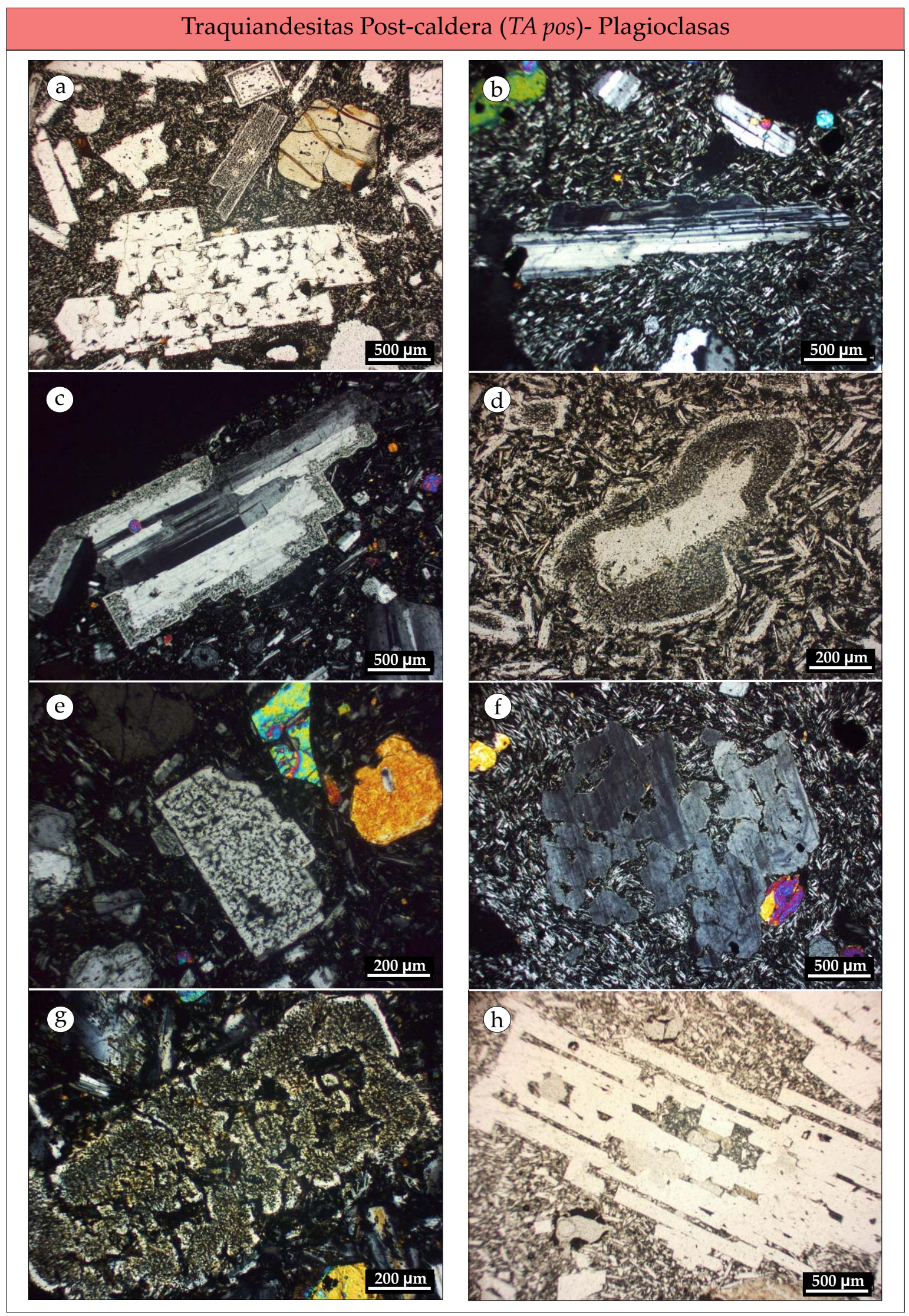

Figura 6.10: a) Plagioclasas limpias y cribadas. b) Plagioclasa limpia y redondeada. c) Plagioclasa euhedral con cribado fino. d) Plagioclasa anhedral con cribado fino. e) Plagioclasa con cribado medio. f) Plagioclasa con cribado grueso. g) Plagioclasa con cribado grueso y fino. h) Plagioclasa esqueletal. 
anhedrales (Fig. 6.10 g). En la única colada lávica sin plagioclasas cribadas, se encuentran fenocristales subhedrales - euhedrales y otros con huecos internos relativamente grandes y rellenos con pasta, controlados cristalográficamente y con esquinas bien rectas, sugiriendo que es un rasgo del crecimiento, posiblemente esqueletal (Fig. $6.10 \mathrm{~h}$ ).

\subsubsection{Minerales máficos}

Las olivinas son seriadas, desde los microlitos en la pasta cuando la textura es intergranular, o desde microfenocristales de $0,2 \mathrm{~mm}$ de largo cuando la pasta es pilotáxica, hasta fenocristales de 1,5 mm de largo. Es común que las olivinas se encuentren con inclusiones de opacos y apatita, o que simplemente formen pequeños glomérulos con estos minerales ( \pm clinopiroxeno). Todas las lavas presentan más de un tipo morfológico de olivinas. La mayoría de las muestras presentan olivinas subhedrales aunque con esquinas redondeadas en mayor proporción que el resto de las olivinas (Fig. 6.11 a). En pocos casos se encuentran además, olivinas subhedrales - euhedrales sin signos de redondeamientos (en solo un caso hay de este tipo de olivinas sin presentar también otras redondeadas) (Fig. 6.11 b). Además, algunas lavas presentan olivinas con engolfamientos frecuentemente pronunciados, y conservando las esquinas de los cristales sin redondear (Fig. 6.11 c). En una sola lava con olivinas engolfadas, estas no preservaban las esquinas cristalinas nítidas.

El clinopiroxeno también es seriado, llegando hasta $2 \mathrm{~mm}$ de largo y raramente hasta los $4 \mathrm{~mm}$. Al igual que las olivinas, es frecuente que se encuentren junto a microfenocristales de opacos y apatita, cuando está presente. La mayoría de estas lavas presentan fenocristales subhedrales, con las esquinas notoriamente redondeadas (Fig. $6.11 \mathrm{~d}$ ). Unas pocas de estas lavas poseen, además de los clinopiroxenos redondeados, fenocristales euhedrales sin redondear y generalmente en menor proporción que los primeros. Una minoría presenta solamente cristales subhedrales - euhedrales sin signos de redondeamiento (Fig. 6.11 e).

El anfíbol, presente en una solamente en la colada "El Choique" (Fig. 4.1), tiene entre 0,2 y $1 \mathrm{~mm}$ de largo. Presenta un pleocroísmo entre castaño claro y oscuro, idéntico al de los fenocristales de anfíbol presentes en los Traquitoides Pre-caldera. Los cristales son anhedrales y con un borde opaco relativamente grueso.

En algunas lavas, como por ejemplo la colada "El Choique" ubicada al NO de la caldera, se observan enclaves con la misma mineralogía que la lava hospedante, y con una textura interna granuda pero con las caras cristalinas externas al glomérulo subhedrales - euhedrales, como si hubieran crecido libremente (Fig. $6.11 \mathrm{f}$ ).

\subsubsection{Colada intra-caldera}

La colada intra-caldera de las Traquiandesitas Post-caldera se destaca entre las demás lavas de esta unidad porque presenta evidencias de mingling. Este proceso es visible de dos maneras: algunas muestras presentan microscópicamente dos pastas diferentes en contacto 


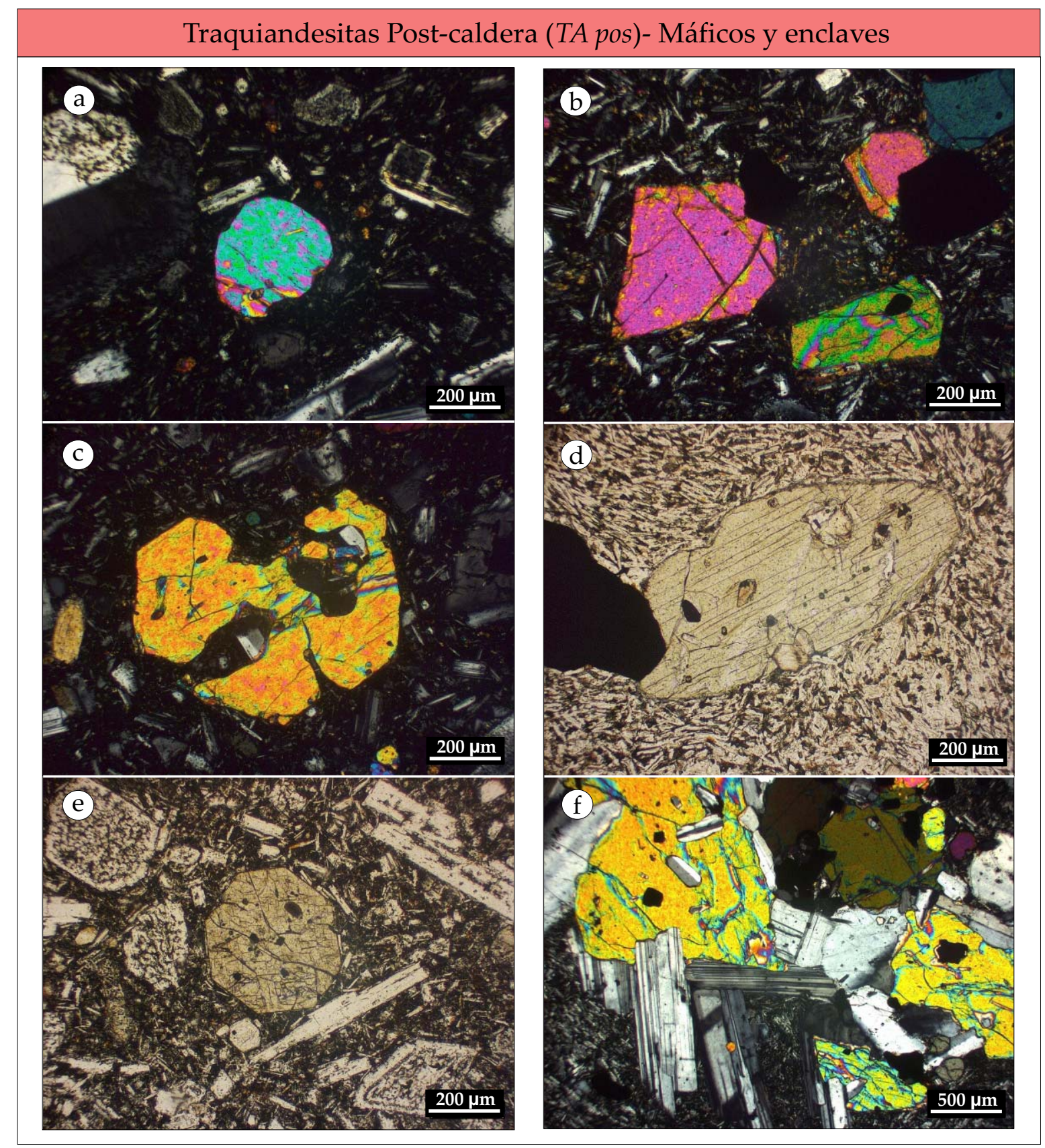

Figura 6.11: Fotos al microscopio de minerales máficos y enclaves. a) Olivinas redondeadas. b) Olivinas euhedrales. c) Olivina con engolfamientos pronunciados, sin redondear las esquinas del cristal. d) Clinopiroxeno marcadamente redondeado. e) Clinopiroxeno euhedral sin redondear. f) Enclave con textura interna granuda. 
neto entre si, aunque muy irregular y sinuoso, como la interfase entre dos líquidos que no se homogeneizan por completo (Fig. 6.12 a). Por otro lado, en el campo se distinguió un sector de la colada gris levemente más claro del que representa la mayoría de la colada. Este sector presenta no solo texturas diferentes al resto, sino también una geoquímica marcadamente disímil, como se verá en el capítulo siguiente (la lava oscura predominante es traquiandesita basáltica, mientras que el sector más claro es traquítico).

Los dos sectores de la colada son porfíricos con los mismos minerales, con plagioclasa, olivina y clinopiroxeno, además de los minerales opacos y apatita como accesorio. El sector gris claro presenta una pasta pilotáxica, con fenocristales de plagioclasa $(15 \%)$ que son de dos tipos básicamente, presentes en abundancias similares: unas plagioclasas subhedrales con los bordes redondeados, limpias y con un sobrecrecimiento fino, y otras plagioclasas anhedrales o redondeadas y con cribado grueso (Fig. 6.12 c). También se encuentran otras plagioclasas limpias las cuales no muestran signos de redondeamiento (Fig. 6.12 b). Los fenocristales de olivina (2-3\%) y clinopiroxeno (2-3\%) son subhedrales, con las esquinas cristalinas redondeadas, y se pueden encontrar en glomérulos junto a plagioclasas.

Las muestras que presentan evidencias microscópicas de mingling tienen dos texturas pilotáxicas aunque contrastantes, a veces con una pasta más oscura formando lentes o formas irregulares. Los fenocristales de plagioclasa son también subhedrales - euhedrales limpios, aunque algunos con las esquinas visiblemente redondeadas, y con menor proporción de fenocristales anhedrales o redondeados con cribado grueso. Los fenocristales de olivinas y clinopiroxenos también presentan características similares, siendo subhedrales con los bordes marcadamente redondeados.

El sector gris oscuro que compone la mayor parte de la colada, presenta un pasta intergranular y ligeramente más gruesa que el sector gris claro. Los fenocristales de plagioclasa (15-20\%) están mayoritariamente cribados, abundando el cribado en panal de abejas sobre el cribado medio y grueso. Los relativamente escasos fenocristales de plagioclasas limpias son subhedrales - euhedrales y presentan en el borde una zonación marcada, como un borde de otra composición. La mayor parte de los fenocristales con cribado en panal de abejas son subhedrales - euhedrales, aunque también presentan menor cantidad de plagioclasas redondeadas a anhedrales. Este cribado puede estar en todo el cristal menos en un borde relativamente fino y zonado, o en anillos y dejando partes del núcleo limpios. Estos fenocristales también coexisten con escasas plagioclasas sub- euhedrales con cribado medio en todo el cristal, menos el borde limpio. Es común que haya plagioclasas que presenten dos tipos de cribado, siendo frecuentes las plagioclasas subhedrales - euhedrales (mucho menos frecuentes las redondeadas a anhedrales) con un cribado grueso y fino superpuestos, también con un borde limpio, y dejando frecuentemente una parte del núcleo limpio (Fig. 6.12 d).

Los fenocristales de minerales máficos también presentan diferencias. Entre las olivinas, si bien hay muchas con los bordes redondeados, también son frecuentes aquellas sub- 


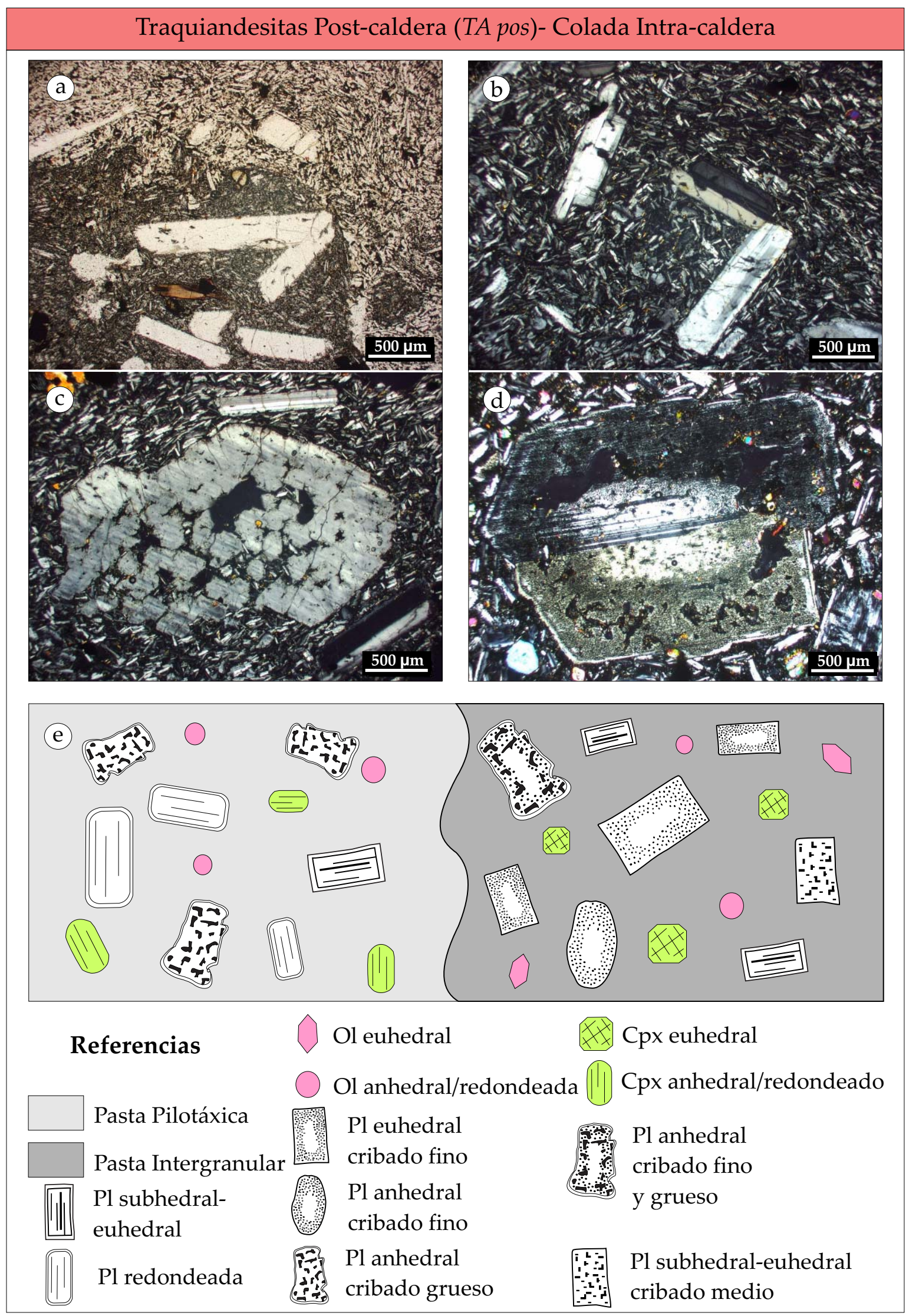

Figura 6.12: a) Dos pastas diferentes en contacto neto. b) Plagioclasas limpias. c) Plagioclasa con cribado grueso. d) Plagioclasa con cribado grueso y fino. e) Esquema de las texturas encontradas en el sector claro (izquierda) y oscuro (derecha) de la colada. Pl: Plagioclasa; Ol: Olivina; Cpx: Clinopiroxeno. 
euhedrales sin redondeamiento. Los clinopiroxenos son subhedrales - euhedrales con las esquinas preservadas, aunque en algunos casos se observan engolfamientos.

En la Figura 6.12 e, se ilustra las diferencias texturales entre los dos dominios descriptos.

\subsection{Traquitas Post-caldera}

Las tres litofacies de esta unidad presentan algunas características petrográficas similares, en cuanto a mineralogía y texturas presentes en los feldespatos, aunque con diferencias que justifican que sean tratadas separadamente.

\subsubsection{Traquitas en bloque}

Las lavas son gris claro, predominantemente holocristalinas y porfíricas con fenocristales de feldespatos alcalinos, clinopiroxenos, en algunos casos olivina y biotita, y muy raramente anfíbol. Como mineral accesorio es común la apatita. La pasta es pilotáxica variando a veces a traquítica, y es frecuente que presenten sectores irregulares con una coloración rojiza, en la mayoría de los casos rodeando a los fenocristales, aunque sin cambiar la textura de la misma (Fig. 6.13 b).

En algunas coladas lávicas, como la intra-caldera y la denominada "Farellones de la Portada" (Fig. 4.1), presentan en su parte proximal una textura vitrofírica al igual que las Traquitas vítreas (Fig. 6.13 g). El vidrio es negro, castaño medio al microscopio.

Si bien existe cierta variación en los tipos texturales de feldespatos alcalinos, en términos generales que estos se encuentran limpios y sin ningún tipo de cribado. El porcentaje de los fenocristales de feldespatos alcalinos varía entre 8 y $20 \%$, y son seriados desde los microlitos de la pasta hasta fenocristales de $5 \mathrm{~mm}$ de largo. Abundan los fenocristales subhedrales a euhedrales (Fig. 6.13 a) y también feldespatos subhedrales pero con las esquinas redondeadas y en ocasiones con los bordes difusos con la pasta (Fig. $6.13 \mathrm{~d}$ ). También es común que formen glomérulos, con una textura interna consertal entre los feldespatos alcalinos (típico de cristalización plutónica), mientras que externamente al glomérulo, los bordes de los cristales son euhedrales a subhedrales (Fig. 6.13 c).

Solamente dos lavas estudiadas presentan feldespatos alcalinos con huecos internos o entradas controladas cristalográficamente y rellenas con pasta o con vidrio (Fig. $6.13 \mathrm{~h}$ ). Este rasgo es común en la litofacies de Traquitas vítreas, como se verá más adelante, pero no en estas lavas. Como rareza, se encuentran casos aislados de feldespatos manteados con textura anti-rapakivi, con un núcleo de plagioclasa y un manto relativamente grueso de feldespato alcalino (Fig. $6.13 \mathrm{f}$ ). También muy escasamente, se encuentran feldespatos alcalinos que muestran una zonación en parches o patchy (Fig. 6.13 e).

El clinopiroxeno es el mafito más común y abundante, aunque en porcentajes menores al $4 \%$. Presentan tamaño seriado, desde 0,1 a $1 \mathrm{~mm}$ de largo. Son en la mayoría de los 


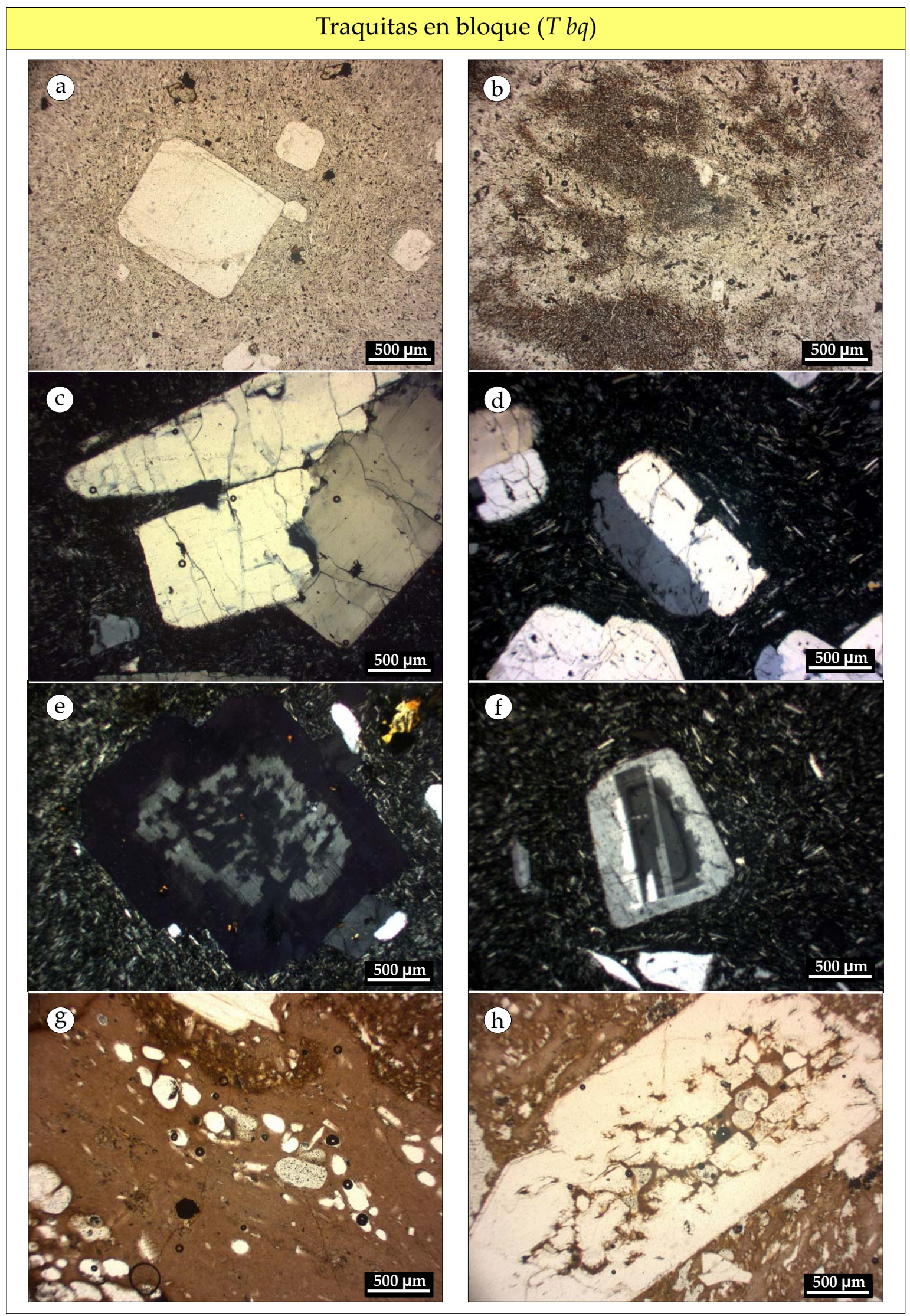

Figura 6.13: a) Feldespatos alcalinos euhedrales. b) pasta pilotáxica con sectores rojizos. c) Glomérulo de feldespatos alcalinos. d) Feldespatos alcalinos redondeados. e) Zonación en parches en feldespato alcalino. f) Textura anti-rapakivi. g) Textura vitrofírica. h) Feldespato con entradas siguiendo al clivaje. 


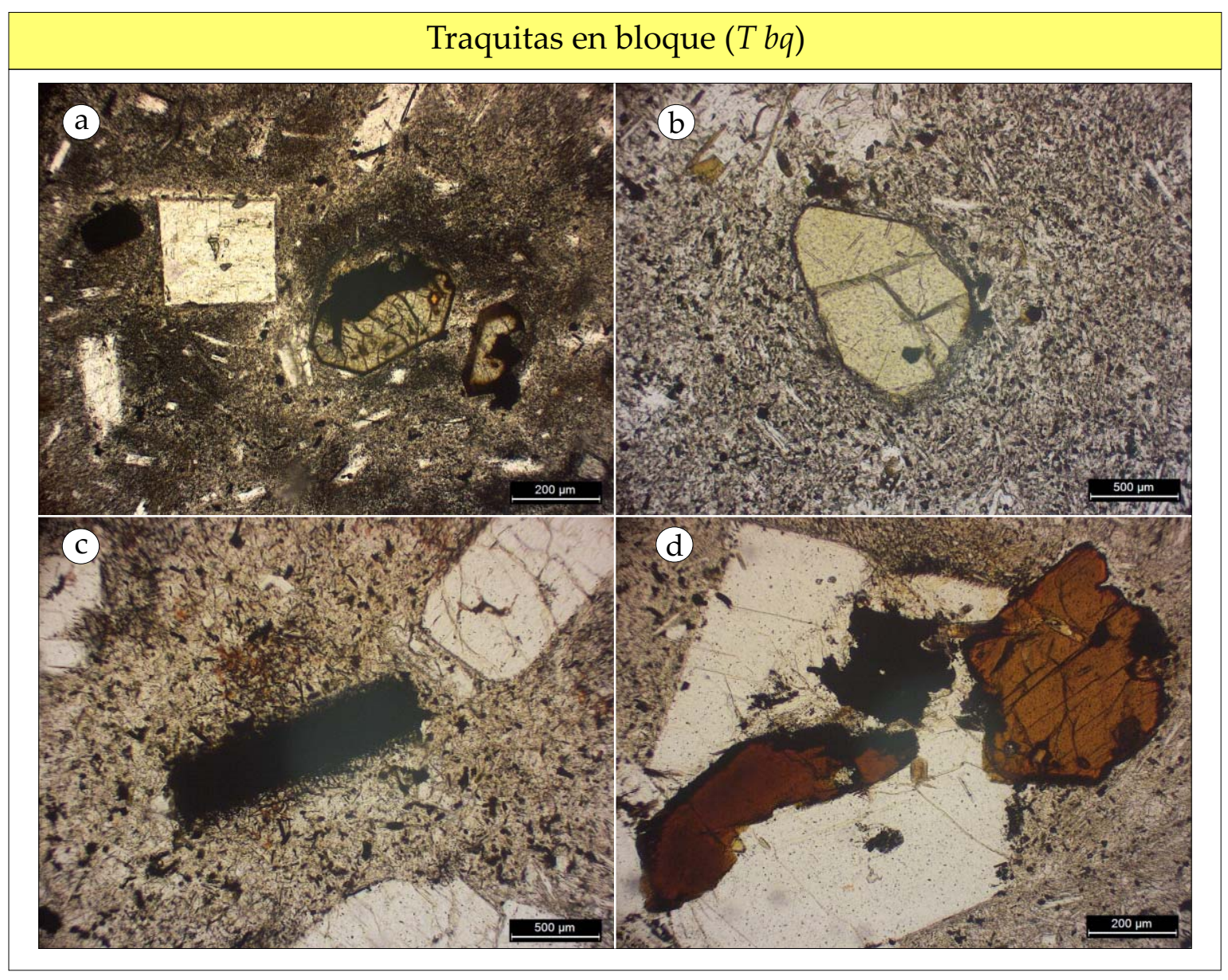

Figura 6.14: a) Clinopiroxeno euhedral con borde opaco fino. b) Olivina subhedral. c) Posible cristal de biotita, totalmente opacado. d) Anfíbol, muy escaso en estas lavas.

casos subhedrales a euhedrales sin redondeamiento, aunque es frecuente que presenten un borde opaco fino (Fig. 6.14 a). En algunos casos y subordinadamente, hay fenocristales de clinopiroxeno con los bordes redondeados y con bordes opacos.

La olivina está presente en un poco menos de la mitad de las lavas. Son fenocristales seriados y de pequeño tamaño, menores a $0,5 \mathrm{~mm}$ de largo. El porcentaje en que se encuentran es escaso, llegando hasta el $1 \%$. Algunos presentan una forma cristalina subhedral a euhedral (Fig. 6.14 b), mientras que en otros casos (en muestras separadas) se encuentran con los bordes redondeados. En ocasiones presentan un borde opaco fino y también una leve alteración a iddingsita.

Los fenocristales de biotita, presentes solo en algunas muestras de esta litofacies, son dificilmente reconocibles debido al reemplazo de la misma por minerales opacos (Fig. 6.14 c). La presencia de biotita en estos casos está en duda, sugerida por minerales opacos con un hábito acicular/laminar, además de la presencia de biotita parcialmente reemplazada en otras lavas. El porcentaje es escaso, hasta el $1 \%$ aproximadamente, y poseen un tamaño 
seriado que llega hasta $1 \mathrm{~mm}$ de largo.

El anfíbol aparece excepcionalmente, en solo dos lavas y en cantidades ínfimas, menores al $1 \%$. Los escasos cristales son todos menores al milímetro, y presentan pleocroísmo idéntico al ya mencionado, variando desde castaño amarillento a castaño rojizo oscuro. Presentan un borde opaco delgado a ausente, y algunos se encuentran en glomérulos junto a feldespatos alcalinos (Fig. $6.14 \mathrm{~d}$ ).

\subsubsection{Traquitas vítreas}

Esta litofacies consiste en vitrófiros negros, en los cuales frecuentemente se intercalan franjas o bandas discontinuas y de espesores variables (desde milimétricas hasta decenas de centímetros) de una lava gris medio, la cual está constituida por el vidrio recristalizado (Fig. 6.15 a). El vidrio, si bien se fractura fácilmente, no presenta signos de hidratación al no poseer fracturas perlíticas. Al microscopio el vidrio es castaño claro a castaño medio, y raramente casi incoloro. Es común el bandeamiento del vidrio dado por la presencia de bandas muy delgadas de un vidrio más claro, que se repliegan y también rodean a los fenocristales, amoldándose a los mismos (Figs. 6.15 b y g). En algunas muestras, el vidrio posee sectores de forma irregular más oscuros con un punteado castaño, posiblemente por alteración a arcillas.

También, en algunas lavas, suele haber sectores dentro de las mismas con alta vesicularidad, con textura pumícea aunque no clástica sino formando sectores mas vesiculados de la misma lava.

El vidrio contiene microlitos de abundancia variable, desde casi ausentes hasta abundantes, y generalmente estos dos dominios con diferente abundancia de microlitos se distribuyen en bandas alternadas. Los microlitos suelen tener una terminación en swallow tail, dado por el rápido crecimiento esqueletal de los mismos en condiciones de alta sobresaturación (Vernon, 2004). Es frecuente que los microlitos se orienten dando una textura traquítica. Raramente el contenido de microlitos de feldespatos es alto, dando una textura intersertal. Todas las lavas son porfíricas con fenocristales de feldespatos alcalinos, clinopiroxenos, olivinas y opacos, junto con apatita como mineral accesorio, habiendo en la mitad de los casos biotita.

Los fenocristales de feldespato potásico están en general entre el 5 y $17 \%$, y son seriados hasta $5 \mathrm{~mm}$ de largo, aunque generalmente no superan los $3 \mathrm{~mm}$. La mayoría de los fenocristales son subhedrales a euhedrales (Fig. 6.15 b). Frecuentemente se hallan agrupados formando glomérulos, y los cristales poseen limites internos al glomérulo anhedrales y externos al mismo euhedrales a subhedrales (Fig. 6.15 c). También es frecuente que haya una cantidad minoritaria de cristales fracturados. En la mayoría de las muestras, y en un porcentaje menor al de los feldespatos euhedrales, hay fenocristales que presentan entradas pronunciadas o huecos en su interior, de formas irregulares y rellenos con vidrio, los cuales 


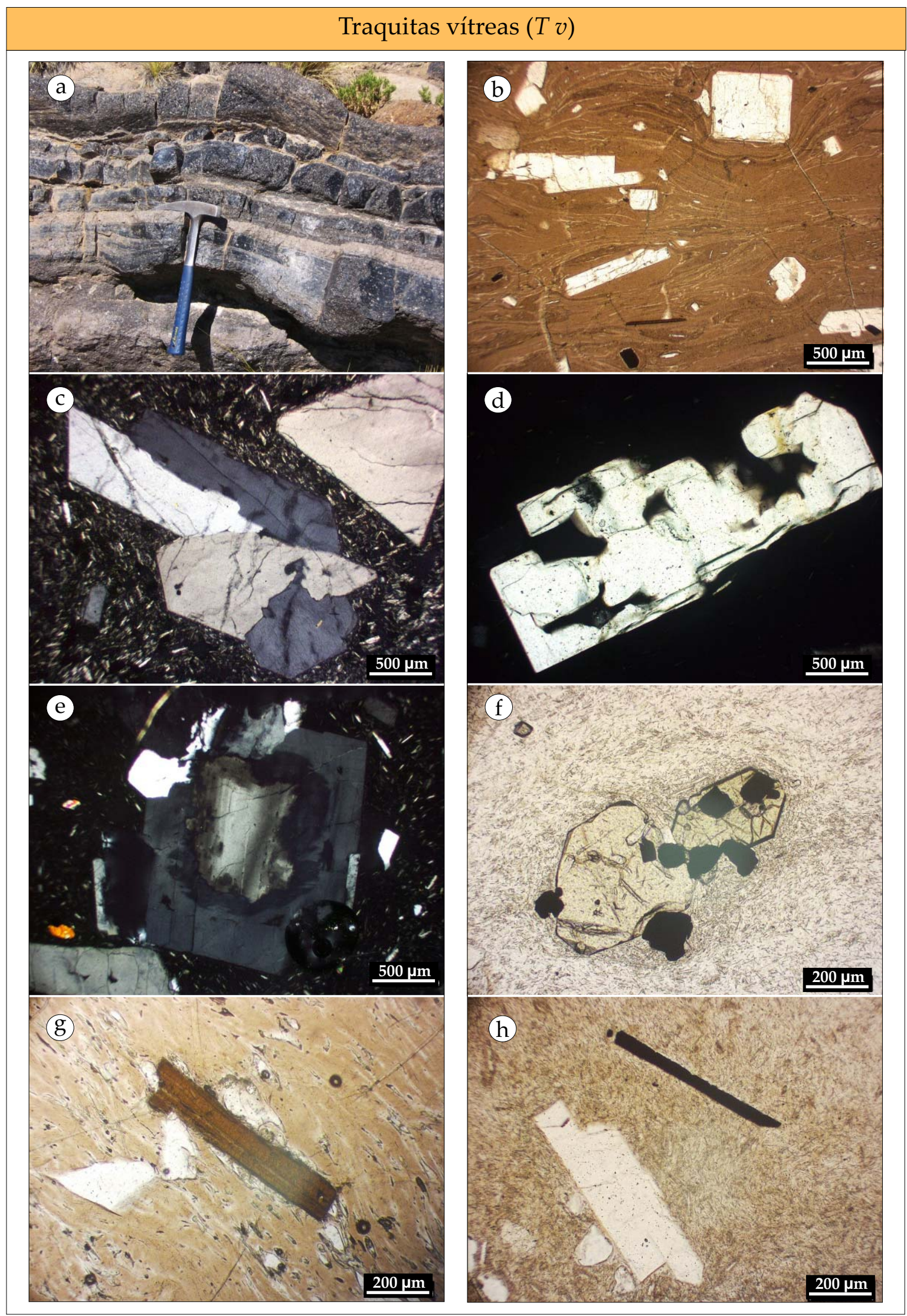

Figura 6.15: a) Lava bandeada de $T v$. b) Feldespatos alcalinos en vidrio castaño. c) Glomérulo de feldespatos alcalinos. d) Feldespato alcalino con huecos controlados cristalográficamente. e) Textura anti-rapakivi. f) Olivina y clinopiroxeno. g) Biotita euhedral. h) Posible biotita opacada. 
se encuentran controlados cristalográficamente (siguiendo las líneas de clivaje) (Fig. 6.15 d). Los cristales que presentan estos rasgos no poseen signos de redondeamiento, por lo que es un indicio de que estos huecos no se formaron por disolución sino por crecimiento (Vernon, 2004). Como rarezas, solamente en dos lavas se observaron casos aislados de feldespatos manteados, con una textura anti-rapakivi. Consisten en un núcleo de plagioclasa, anhedral, y un manto relativamente grueso de feldespato potásico euhedral (Fig. 6.15 e).

El clinopiroxeno ( $\leq 3 \%$ ) es el mafito mas abundante, aunque igualmente se encuentra en porcentajes marcadamente menores que los feldespatos alcalinos. El tamaño de los cristales es seriado, variando desde microfenocristales hasta (raramente) fenocristales de 2,5 $\mathrm{mm}$ de largo, siendo en su mayoría menores a 1,5 mm. Son verde muy claro, en los cuales se distingue a veces un leve tinte rosado. Los cristales son todos euhedrales a subhedrales y sin presentar bordes opacos ni redondeados (Fig. 6.15 f). Es frecuente que se encuentren en glomérulos junto a feldespatos alcalinos, y también que estén junto con minerales opacos y apatita.

La olivina es el mafito que le sigue en abundancia, está presente en todas las muestras aunque escasamente, desde menos de $1 \%$ hasta $3 \%$. Son fenocristales de pequeño tamaño y seriados, hasta $0,7 \mathrm{~mm}$ de largo. Los cristales son subhedrales y con redondeamiento visible, aunque no siempre, habiendo en algunos casos cristales de olivina sin redondear (Fig. 6.15 f), e inclusive en la misma muestra se encuentran unos fenocristales redondeados y otros no. Generalmente se encuentran frescas sin ninguna alteración, aunque en ciertos casos muestran una leve alteración a iddingsita. En un solo caso la olivina posee un borde opaco relativamente grueso. Al igual que el clinopiroxeno, pueden estar junto a feldespatos potásicos en glomérulos, y también está asociada a opacos y apatita.

La biotita, no siempre presente, es escasa, alcanzando $2 \%$ como máximo. También es seriada, hasta $1 \mathrm{~mm}$ de largo. En la mayoría de los casos es euhedral y sin reemplazos (Fig. $6.15 \mathrm{~g}$ ), aunque existen casos en que la presencia de biotita está en duda, por estar totalmente reemplazados por minerales opacos. En los casos que la biotita está opacada, se reconocen inclusiones no opacadas de la misma en los feldespatos alcalinos, además de opacos de forma alargada en la base vítrea (Fig. $6.15 \mathrm{~h}$ ).

\subsubsection{Conos pumíceos}

En esta sección se describirá la petrografía de los fragmentos pumíceos de los depósitos clásticos descriptos previamente. Como ya fue mencionado, los clastos de pómez son gris claro o amarillento-naranja (Fig. 6.16 a). El pómez está formado por un vidrio incoloro a castaño (en los pómez gris), a amarillo fuerte (en los pómez anaranjados), sin recristalizar. En algunos sectores presentan esferulitas, las cuales no alteran la textura vesicular y por lo tanto se formaron posteriormente al depósito (Fig. 6.16 b). Las vesículas en los clastos de pómez son de formas variadas, desde equidimensionales a alargadas, en el segundo caso 


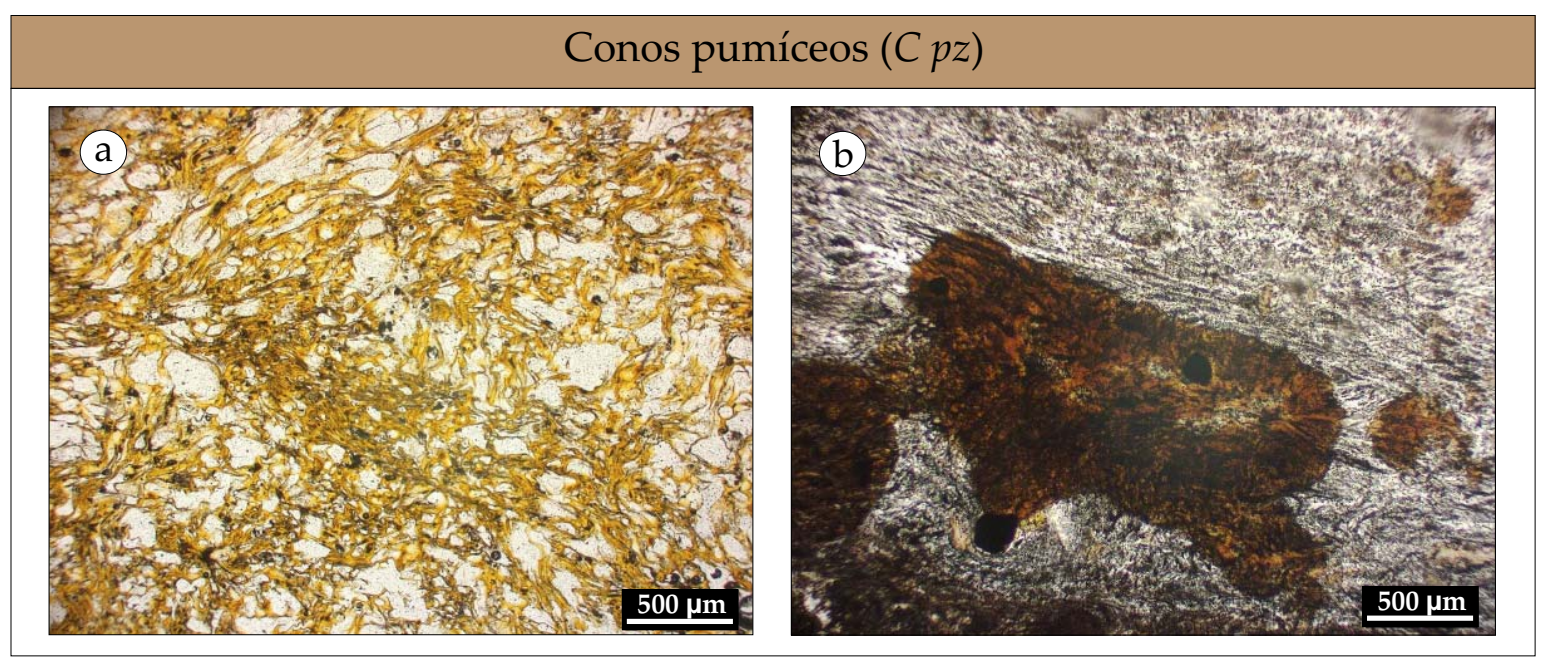

Figura 6.16: Fotomicrografías de fragmentos de pómez. a) Vidrio vesiculado de color amarillento. b) Esferulitas en un clasto de pómez.

el pómez presenta ocasionalmente un aspecto fibroso. El porcentaje de vesículas también varía ampliamente, estando éste generalmente entre 35 y $60 \%$. El tamaño de las vesículas se encuentra entre 50 um y $1 \mathrm{~cm}$ de diámetro/largo. La mayor parte de las vesículas son submilimétricas, aunque también se encuentran otras de mayor tamaño.

Los pómez son pórfíricos con la misma mineralogía que se encuentra en las Traquitas vítreas, aunque el porcentaje de fenocristales en general es menor. Las características y asociaciones de los feldespatos y mafitos son idénticas también a la litofacies de Traquitas vítreas.

\subsection{Basaltos Pre- y Post-caldera}

Las tres unidades que componen los campos basálticos poseen similitudes petrográficas, como es de esperar, aunque también algunas diferencias. Son todas lavas gris medio a oscuro, en su gran mayoría porfíricas, aunque existen escasas lavas casi afíricas. La pasta es intergranular mayoritariamente (Fig. 6.17 a), y solamente se encuentra vidrio en escasas lavas con textura intersertal, pertenecientes a los Basaltos Post-caldera II.

Los fenocristales que presentan son olivina, plagioclasa y clinopiroxeno, aunque no siempre se encuentran los tres juntos. La olivina es un mineral siempre presente, como fenocristales (salvo alguna rara excepción) y también como microlitos en la pasta. Los fenocristales de plagioclasa también se encuentran siempre en estas lavas, salvo en pocas excepciones en donde la plagioclasa está presente sólo en la pasta. El clinopiroxeno, si bien es muy frecuente y se observa en la mayoría de las lavas, es un mineral que falta en varias ocasiones.

El porcentaje de fenocristales en general, tiene una tendencia a ser mayor en las coladas más modernas de los Basaltos Post-caldera II que en las antiguas pre-caldera. Esta tendencia se ve reflejada en la química también, como se verá en el capítulo siguiente. 
Tanto en los basaltos pre- como en los post-caldera, se encuentran algunas lavas con evidencias de mingling. Estas lavas poseen dos pastas diferentes (ambas intergranulares). En estos casos, una pasta más oscura se encuentra generalmente en contacto neto con otra pasta más clara, y escasas veces con contacto difuso, la cual constituye la mayor proporción de la muestra. El contacto entre ambas pastas es irregular, sinuoso y con entradas pronunciadas, como es una interfase entre dos fundidos (Fig. 6.17 b).

\subsubsection{Olivinas}

El porcentaje de fenocristales de olivina es variable, siendo en algunos casos muy escasa y menor al $1 \%$, y en otros casos alcanza el $5 \%$. Son siempre seriadas, desde los microlitos que se encuentran en la pasta hasta fenocristales que pueden alcanzar 2,5 mm de largo. Son en general prácticamente incoloras a verde claro. Las morfologías cristalinas son variadas, con cristales subhedrales a euhedrales, esqueletales, subhedrales con las esquinas redondeadas y otros con engolfamientos pronunciados aunque sin redondear las esquinas.

En los Basaltos Pre-caldera predominan los cristales esqueletales, presentes tanto como fenocristales como microlitos en la pasta (Fig. 6.17 c). También es común que haya olivinas euhedrales (Fig. 6.17 d) junto con las esqueletales, aunque en menor cantidad. En considerable menor proporción, se encuentran también olivinas con engolfamientos (Fig. 6.17 e), conjuntamente con las esqueletales.

En los Basaltos Post-caldera I y II cambian levemente las abundancias relativas de cada uno de estos cuatro tipos de fenocristales. En las unidades post-caldera son abundantes las olivinas subhedrales - euhedrales y las esqueletales (tanto como fenocristales como microlitos). Estos dos tipos suelen aparecer juntos, a veces predominando los euhedrales sobre los esqueletales, y otras veces de manera inversa. En menor abundancia, pero siendo aún frecuente, se encuentran fenocristales con engolfamientos, y estos se hallan junto con fenocristales euhedrales y/o esqueletales. Raramente se encuentran olivinas con las esquinas redondeadas (Fig. 6.17 f), también junto con olivinas euhedrales y/o esqueletales, y en ocasiones las cuatro morfologías cristalinas se encuentran en el mismo corte delgado.

\subsubsection{Clinopiroxenos}

Los fenocristales de clinopiroxeno son verde claro y varían su abundancia desde menos de $1 \%$ hasta $5 \%$ en los basaltos post-caldera, y en aquellos pre-caldera alcanzan solamente el $2 \%$. El clinopiroxeno es seriado, desde microlitos hasta fenocristales con tamaños máximos variables entre 1,2 $\mathrm{mm}$ de largo (Basaltos Pre-caldera) y 2,5 $\mathrm{mm}$ de largo (Basaltos Post-caldera I y II). Los fenocristales son básicamente de dos tipos: por un lado cristales subhedrales - euhedrales sin redondeamiento, y por otra parte cristales marcadamente redondeados (Figs. $6.17 \mathrm{~g} \mathrm{y} \mathrm{h,} \mathrm{respectivamente).} \mathrm{La} \mathrm{zonación} \mathrm{composicional,} \mathrm{ya} \mathrm{sea} \mathrm{concén-}$ trica o en reloj de arena, es común y notoria tanto en los basaltos más antiguos como en los 


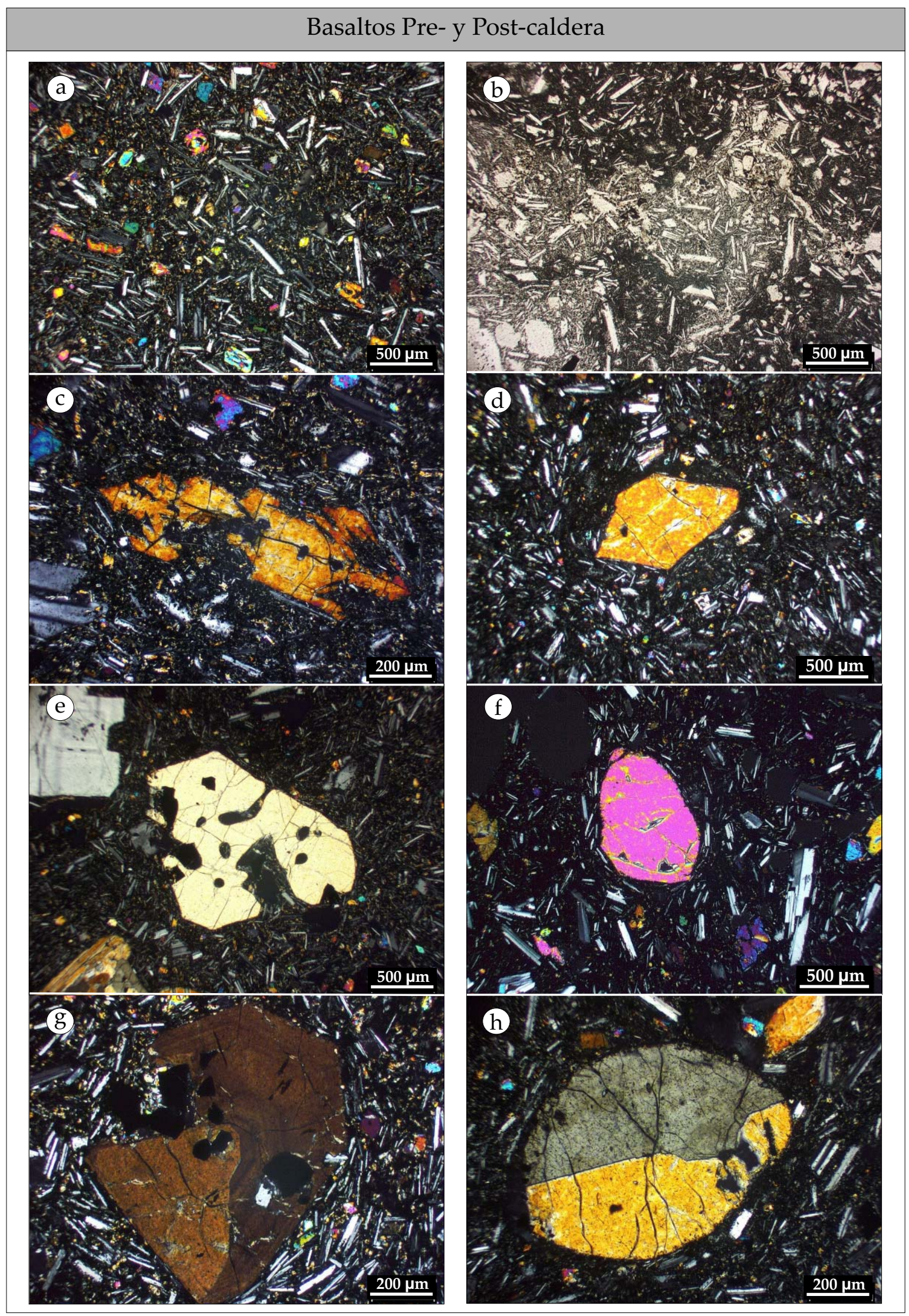

Figura 6.17: a) Pasta intergranular. b) Dos pastas diferentes en contacto neto. c) Olivina esqueletal. d) Olivina euhedral. e) Olivina con engolfamientos. f) Olivina redondeada. g) Clinopiroxeno euhedral. h) Clinopiroxeno redondeado. 
más modernos.

En los Basaltos Pre-caldera los fenocristales de clinopiroxeno presentan redondeamiento de las esquinas marcado. Raramente se hallan fenocristales euhedrales sin redondear, los cuales no están junto con otros redondeados.

En los Basaltos Post-caldera I son comunes tanto los cristales subhedrales - euhedrales como los redondeados, y es frecuente que estos dos tipos se encuentren juntos, aunque a veces no, y predomina levemente el clinopiroxeno redondeado sobre el que no lo está.

En los Basaltos Post-caldera II sigue la tendencia a aumentar la proporción de los fenocristales subhedrales - euhedrales sobre los redondeados, ya que muchos presentan solamente cristales sin redondear. Algunos presentan ambos tipos de fenocristales, mientras que en pocos casos se encuentran solamente cristales redondeados. Como rareza, se encontraron en la colada lávica de "La Tranquera" (Fig. 4.1) fenocristales con engolfamientos pronunciados y con los bordes bien conservados, sin redondeamiento (Fig. 6.18 a).

\subsubsection{Plagioclasas}

Las plagioclasas son las más variables en cuanto a proporción modal de fenocristales. Varían desde menos del 1\%, hasta 10-12\% en los Basaltos Post-caldera I. Los Basaltos Precaldera y los Post-caldera II no alcanzan porcentajes tan altos, llegando hasta el 4-5\% como máximo. Los cristales de plagioclasa son seriados, desde los microlitos en la pasta hasta los fenocristales. Es también en la unidad de Basaltos Post-caldera I en donde los cristales de plagioclasa alcanzan los mayores tamaños, con una longitud máxima de 3,5 $\mathrm{mm}$, aunque en general no superan los $2 \mathrm{~mm}$. En cambio, en los Basaltos Pre-caldera y Post-caldera II los fenocristales son menores a los $2 \mathrm{~mm}$ y frecuentemente son menores al milímetro.

Las plagioclasas que abundan son subhedrales - euhedrales y limpias, las cuales están presentes en todas las lavas con fenocristales de plagioclasa (Fig. 6.18 b), aunque también se encuentran una variedad de tipos diferentes de fenocristales en menor proporción. Son frecuentes los fenocristales subhedrales - euhedrales con cribado medio en el interior y un borde limpio y zonado (Fig. 6.18 c). Este cribado en ocasiones está en duda, confundiéndose con la presencia de abundantes inclusiones de opacos en las plagioclasas, aunque por las formas de las inclusiones, se asemeja al cribado. También presentan, minoritariamente, fenocristales con este tipo de cribado pero anhedrales. Además de estos dos tipos principales de fenocristales de plagioclasa (euhedrales y limpias, y con cribado medio), se encuentran varios tipos diferentes pero como casos aislados, sin repetirse con frecuencia.

También pueden observarse tanto en los basaltos pre- como post-caldera, la presencia de cristales de características notoriamente diferentes al resto. En los Basaltos Pre-caldera, una sola colada lávica muestra fenocristales limpios y con crecimiento esqueletal en el borde (Fig. 6.18 d). Otras coladas presentan un solo fenocristal anhedral, y con un cribado fino en panal de abejas ya sea en todo el cristal o en un anillo cerca del borde, siendo claramente de 


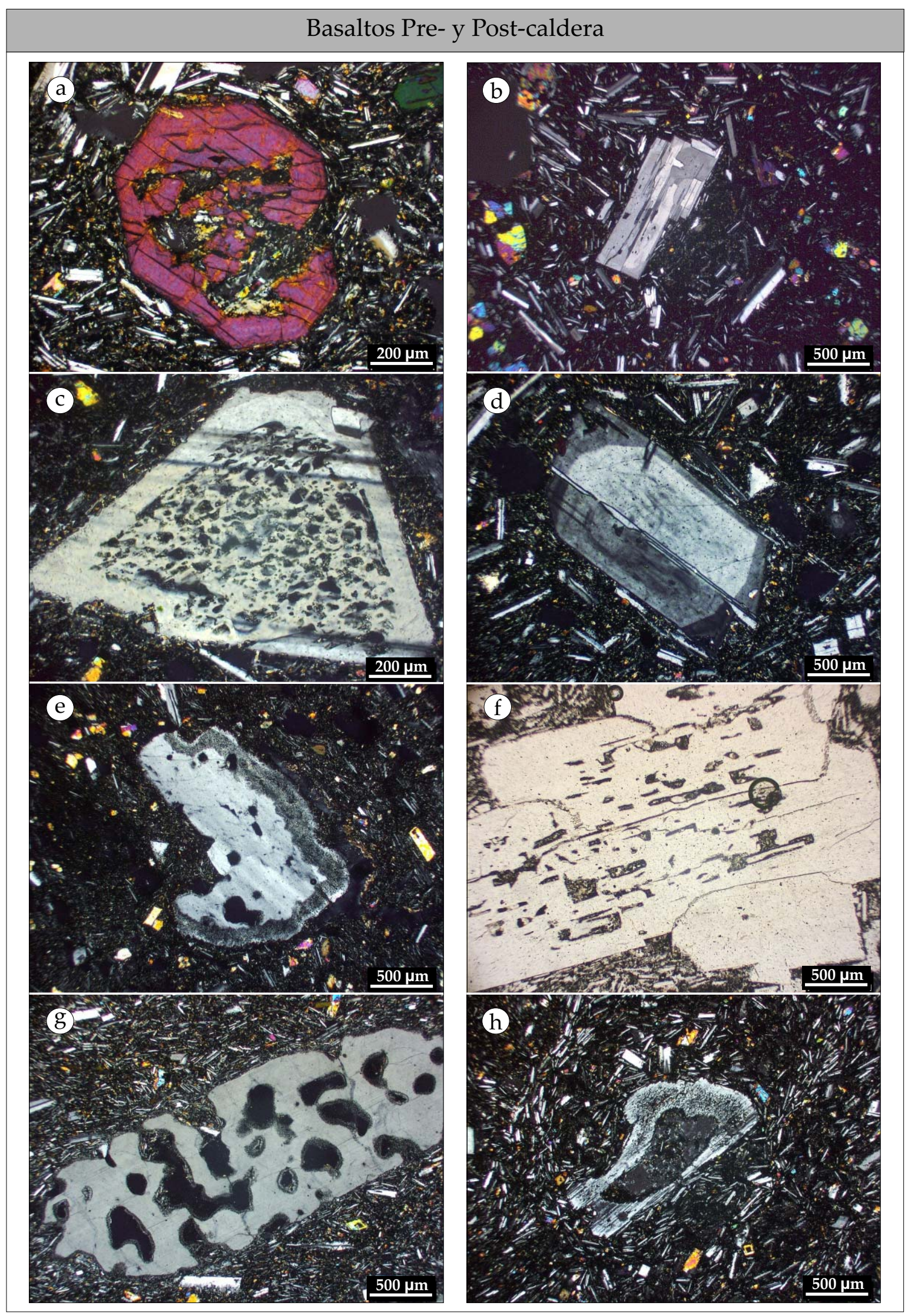

Figura 6.18: a) Clinopiroxeno con engolfamientos. b) Plagioclasa limpia y euhedral. c) Plagioclasa con cribado medio. d) Plagioclasa levemente esqueletal. e) Plagioclasa anhedral con cribado fino. f) Plagioclasa esqueletal. g) Xenocristal de feldespato alcalino. h) Plagioclasa anhedral y con cribado fino. 
otro origen distinto al de los fenocristales euhedrales y limpios (Fig. 6.18 e).

En solamente dos lavas de los Basaltos Post-caldera I, se encuentran fenocristales con huecos relativamente grandes, rellenos con pasta, controlados cristalográficamente y con esquinas angulosas. Estas características indicarían que se trata de un rasgo del crecimiento (esqueletal) y no de disolución (Fig. 6.18 f) (Vernon, 2004). También cabe destacar el caso de un basalto el cual posee dos xenocristales posiblemente de feldespato alcalino (macla de albita muy fina y difusa), de tamaño marcadamente mayor al resto de los fenocristales (el mayor es de $1 \mathrm{~cm}$ de largo), totalmente anhedrales y redondeados y que, además, poseen un cribado grueso y un cribado en panal de abejas que bordea al contorno del cristal y del cribado grueso (Fig. 6.18 g). En cuanto a los Basaltos Post-caldera II, como fenocristal claramente distinto al resto, se destaca una plagioclasa anhedral y redondeada, con cribado en panal de abejas en su interior, menos en un borde limpio, la cual se encuentra junto con otras plagioclasas euhedrales y limpias (Fig. $6.18 \mathrm{~h}$ ).

\subsection{Payún Liso}

Se describirá brevemente la petrografía de rocas del Payún Liso, dado que no es el objeto del presente trabajo. Las descripciones son orientativas y no completamente abarcativas y representativas de la petrografía de todo el volcán, debido a la escasez de muestras estudiadas. Además, no existen al momento estudios específicos sobre el Payún Liso, por lo cual se desconoce el grado de variabilidad que puede presentar. Se estudiaron solamente seis muestras, de las cuales una corresponde a la ignimbrita ubicada en las cercanías del cráter, y las otras cinco a lavas del flanco norte del volcán.

\subsubsection{Lavas}

Son todas holocristalinas y porfíricas, con fenocristales de plagioclasa, junto a olivina y clinopiroxeno en la mayoría, y minerales opacos y apatita frecuente como accesorio. Se encontraron lavas sin clinopiroxeno y otra sin olivina. La pasta es generalmente pilotáxica, aunque en un caso es intergranular, y en otro se encuentran lentes o sectores de una pasta pilotáxica oscura dentro de una pasta pilotáxica clara (Fig. 6.19 a).

Las plagioclasas (5-20\%) son seriadas desde los microlitos en la pasta hasta fenocristales de $5 \mathrm{~mm}$ de largo. En todas las lavas se encuentran mayoritariamente fenocristales subhedrales - euhedrales y limpios, estando junto a otros subhedrales y redondeados en la mayoría de los casos (Fig. 6.19 b). En algunas lavas se hallan plagioclasas cribadas junto con las plagioclasas limpias, siendo las primeras subhedrlaes - euhedrales con cribado medio generalmente (Fig. 6.19 c), o con cribado grueso (Fig. 6.19 d).

Los fenocristales de olivina (1-3\%) son seriados hasta 1,2 $\mathrm{mm}$ de largo, pueden ser tanto sub- euhedrales como tener las esquinas redondeadas (Fig. 6.19 e), siendo frecuente que es- 


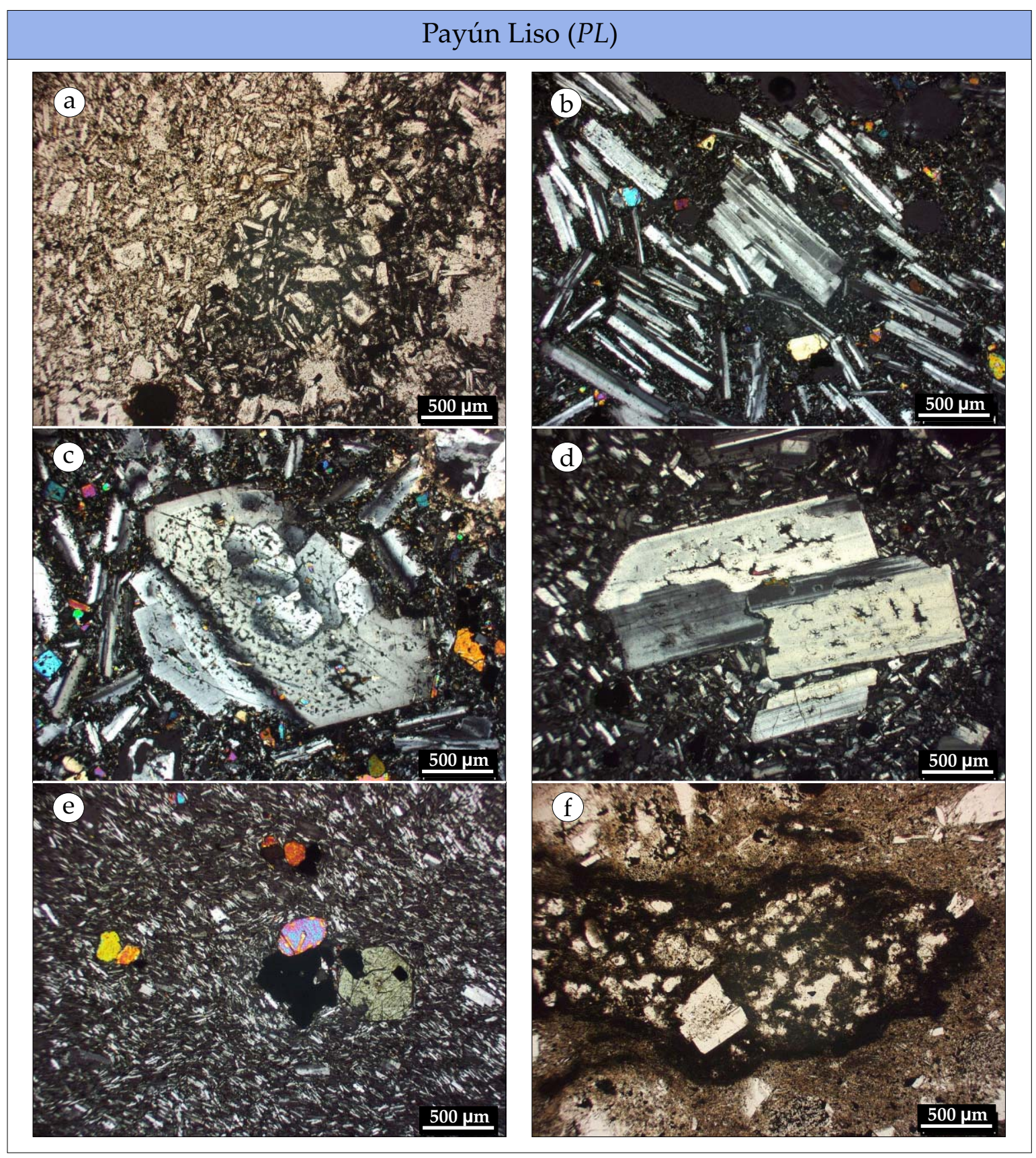

Figura 6.19: a) lava con dos pastas pilotáxicas diferentes. b) plagioclasas euhedrales seriadas y limpias. c) plagioclasa con cribado medio en todo el cristal menos en el borde limpio. d) plagioclasa euhedral con cribado grueso en el interior. e) olivinas redondeadas y clinopiroxeno euhedral en pasta pilotáxica. f) Ignimbrita del Payún Liso. 
tos dos tipos se encuentren juntos. El clinopiroxeno ( $\leq 4 \%$ ), seriado hasta $1,5 \mathrm{~mm}$ de largo máximo, también es de dos tipos. Los más abundante son los fenocristales subhedrales y redondeados, y en menor proporción (generalmente juntos) se encuentran otros fenocristales subhedrales - euhedrales sin redondeamiento (Fig. 6.19 e).

\subsubsection{Ignimbrita Payún Liso}

La ignimbrita del Payún Liso es rojiza-anaranjada y bien soldada. Presenta fiammes elongados, de menos del centímetro de largo, y no han perdido del todo su vesicularidad. Los fiammes se encuentran opacados, siendo más oscuros que la matriz (Fig. 6.19 f). La matriz está conformada por vidrio casi incoloro con un punteado criptocristalino castaño mediooscuro, y en la cual no se logran distinguir trizas vítreas.

La ignimbrita presenta cristales de plagioclasas, feldespatos alcalinos, clinopiroxeno, opacos y apatita como accesorio. Los feldespatos alcanzan un porcentaje de $14 \%$, predominando la plagioclasa, y son seriados alcanzando 2,5 mm de largo. Predominan los cristales de plagioclasas limpias subhedrales - euhedrales y los cristales fracturados, y considerable menor proporción se encuentran cristales anhedrales con cribado medio o grueso. Los cristales de feldespatos alcalinos son escasos, estando muchos fracturados. El clinopiroxeno (< $1 \%$ ) alcanza $0,7 \mathrm{~mm}$ de largo y se encuentra anhedral o redondeado, y con un borde opaco fino. Los fragmentos líticos no son abundantes (3-5\%), siendo todos volcánicos y de pastas pilotáxicas claras y oscuras, y unos pocos porfíricos con plagioclasa.

\subsection{Síntesis de la petrografía del Payún Matrú}

En las tablas 6.20 y 6.21 se muestra un resúmen con las principales características petrográficas de las rocas del Payún Matrú y campos basálticos.

Las rocas de la etapa pre-caldera del Payún Matrú son altamente variables, y presentan lavas con y sin texturas indicativas de desequilibrios mineralógicos. En las subunidades 2, 3 y 4 abundan los feldespatos con rasgos de disolución simple (redondeamiento) o parcial (cribados), junto con otros limpios. Los mafitos de estas subunidades también presentan características como redondeamiento o reemplazo (biotita), en concordancia con lo observado en los feldespatos. Además, se hallaron lavas con dos pastas interdigitadas indicando mingling entre ambas. La gran parte de las texturas mencionadas, aunque no todas, indicarían que en numerosas lavas de esta unidad tuvieron lugar procesos de mezcla de magmas. Estas características no se observan en la subunidad 5, mientras que en la subunidad 1 solamente se encuentran cristales con disolución simple y otros feldespatos con cribado grueso. En el primer caso, el redondeamiento podría deberse a aumentos locales en la temperatura del magma (probablemente por la inyección de un magma más máfico en la cámara), mientras que en el segundo caso, el cribado sería por el efecto de la disminución en la presión, sin 


\begin{tabular}{|c|c|c|c|c|c|}
\hline & \multicolumn{5}{|c|}{ Traquitoides Pre-caldera } \\
\hline & Subunidad 1 & Subunidad 2 & Subunidad 3 & Subunidad 4 & Subunidad 5 \\
\hline $\begin{array}{l}\text { Feldespato } \\
\text { alcalino }\end{array}$ & $\begin{array}{l}\text { 5-18 \%. Limpios, } \\
\text { euhedrales y } \\
\text { redondeados. } \\
\text { Pocos con cribado } \\
\text { grueso. }\end{array}$ & $\begin{array}{l}\text { 3-12\%. Limpios y } \\
\text { redondeados } \pm \\
\text { cribado grueso. }\end{array}$ & & & $\begin{array}{l}<1 \% \text {. Limpios, a } \\
\text { veces fracturados. }\end{array}$ \\
\hline Plagioclasa & & $\begin{array}{l}\text { 2-14 \%. Limpias } \\
\text { (euhedrales o } \\
\text { redondeadas) }+ \\
\text { con cribado (fino } \\
\text { a grueso). }\end{array}$ & $\begin{array}{l}\text { 3-18 \%. Limpias } \\
\text { (euhedrales y } \\
\text { redondeadas) + } \\
\text { con cribado (fino } \\
\text { a grueso). }\end{array}$ & $\begin{array}{l}\text { 1-20\%. Limpias } \\
\text { (euhedrales } \pm \\
\text { redondeadas) + } \\
\text { con cribado (fino, } \\
\text { a veces medio a } \\
\text { grueso). }\end{array}$ & $\begin{array}{l}2-15 \% . \text { limpias, a } \\
\text { veces fracturadas. }\end{array}$ \\
\hline Olivina & $\begin{array}{l}<1 \% . \text { En escasas } \\
\text { lavas. Subhedral } \\
\text { redondeada. }\end{array}$ & $\begin{array}{l}\text { 2-3\%. En algunas } \\
\text { lavas. Subhedral } \\
\text { redondeada. }\end{array}$ & $\begin{array}{l}<3 \% . \text { Euhedral y } \\
\text { subhedral } \\
\text { redondeada. }\end{array}$ & $\begin{array}{l}<5 \% \text {. Euhedral, } \\
\text { redondeada, } \\
\text { esqueletal, } \\
\text { engolfada. }\end{array}$ & $\begin{array}{l}<1 \% . \text { Euhedral o } \\
\text { subhedral } \\
\text { redondeada. }\end{array}$ \\
\hline $\begin{array}{l}\text { Clino- } \\
\text { piroxeno }\end{array}$ & $\begin{array}{l}<2 \% . \text { A veces } \\
\text { redondeados. } \\
\text { Algunos son } \\
\text { aegirina/augita. }\end{array}$ & $\begin{array}{l}<3 \% . \text { Subhedral } \\
\text { redondeado, a } \\
\text { veces euhedral. }\end{array}$ & $\begin{array}{l}<4 \% . \text { Euhedral y } \\
\text { subhedral } \\
\text { redondeado. } \\
\text { Generalmente } \\
\text { presente. } \\
\text { Piroxenos } \\
\text { manteados raros. }\end{array}$ & $\begin{array}{l}\text { 1-4 \%. Euhedral y } \\
\text { subhedral } \\
\text { redondeado. } \\
\text { Generalmente } \\
\text { presente. } \\
\text { Piroxenos } \\
\text { manteados raros. }\end{array}$ & $\begin{array}{l}<2 \% . \text { Euhedral o } \\
\text { subhedral } \\
\text { redondeado. }\end{array}$ \\
\hline Anfíbol & < 1\%. Raro. & $\begin{array}{l}\text { En una sola lava. } \\
\text { Reemplazado por } \\
\text { opacos. }\end{array}$ & $\begin{array}{l}<3 \% \text {. Anhedral } \\
\text { con borde opaco. } \\
\text { Raro. }\end{array}$ & & $\begin{array}{l}<1 \% . \\
\text { Redondeado. }\end{array}$ \\
\hline Biotita & $\begin{array}{l}<2 \% . \text { En duda, } \\
\text { por reemplazo } \\
\text { por minerales } \\
\text { opacos. }\end{array}$ & $\begin{array}{l}\text { 2-3\%. Reemplazo } \\
\text { por minerales } \\
\text { anhidros. Muy } \\
\text { rara. }\end{array}$ & $\begin{array}{l}<4 \% \text {. Reemplazo } \\
\text { por minerales } \\
\text { anhidros } \mathrm{u} \\
\text { opacos. A veces } \\
\text { sin reemplazo. A } \\
\text { veces ausente. }\end{array}$ & & $\begin{array}{l}<3 \% \text {. Euhedral o } \\
\text { subhedral } \\
\text { redondeada. }\end{array}$ \\
\hline $\begin{array}{l}\text { Pasta/ } \\
\text { matriz }\end{array}$ & Pilotáxica. & Pilotáxica. & $\begin{array}{l}\text { Pilotáxica. A veces } \\
\text { con mingling entre } \\
\text { dos pastas. }\end{array}$ & Intergranular. & $\begin{array}{l}\text { Eutaxítica. Alto } \\
\text { grado de } \\
\text { soldadura. }\end{array}$ \\
\hline
\end{tabular}

Figura 6.20: Tabla de síntesis de las características petrográficas de los Traquitoides Precaldera. Las subunidades 1 a 4 son lávicas, mientras que la subunidad 5 corresponde a ignimbritas. 


\begin{tabular}{|c|c|c|c|c|c|}
\hline & \multirow{2}{*}{$\begin{array}{l}\text { Ignimbrita } \\
\text { Portezuelo }\end{array}$} & \multirow{2}{*}{$\begin{array}{c}\text { Traquiandesitas } \\
\text { Post-caldera }\end{array}$} & \multicolumn{2}{|c|}{ Traquitas Post-caldera } & \multirow{2}{*}{\begin{tabular}{|l} 
Basaltos Pre-, \\
Post-caldera IyI
\end{tabular}} \\
\hline & & & $T b q$ & $T v+C p z$ & \\
\hline $\begin{array}{l}\text { Feldespato } \\
\text { alcalino }\end{array}$ & $\begin{array}{l}<5 \% \text {. Limpios } \\
\text { (subhedrales, } \\
\text { anhedrales o } \\
\text { fracturados) + con } \\
\text { cribado medio. }\end{array}$ & & $\begin{array}{l}\text { 8-20\%. Limpios, } \\
\text { euhedrales y } \\
\text { subhedrales } \\
\text { redondeados. }\end{array}$ & $\begin{array}{l}\text { 5-17 \%. } \\
\text { Euhedrales, } \\
\text { algunos con } \\
\text { huecos siguiendo } \\
\text { el clivaje. }\end{array}$ & $\begin{array}{l}\text { Escasos } \\
\text { xenocristales. }\end{array}$ \\
\hline Plagioclasa & $\begin{array}{l}\text { 4-16 \%. Limpias } \\
\text { (euhedrales, } \\
\text { fracturadas, con } \\
\text { huecos siguiendo } \\
\text { el clivaje) + pocas } \\
\text { cribado medio. }\end{array}$ & $\begin{array}{l}\text { 10-22 \%. Limpias } \\
\text { (euhedrales, } \\
\text { redondeadas) + } \\
\text { con cribado (fino } \\
\text { a grueso). }\end{array}$ & & & $\begin{array}{l}1-10 \% . \\
\text { Euhedrales y } \\
\text { limpias, algunas } \\
\text { con cribado } \\
\text { medio. }\end{array}$ \\
\hline Olivina & $\begin{array}{l}<3 \% . \text { Euhedral } \pm \\
\text { redondeada. }\end{array}$ & $\begin{array}{l}\text { 2-5\%. subhedral } \\
\text { redondeada, } \\
\text { pocas euhedrales } \\
\text { o engolfadas. }\end{array}$ & $\begin{array}{l}<1 \% . \text { Euhedral o } \\
\text { redondeada. No } \\
\text { siempre presente. }\end{array}$ & $\begin{array}{l}\text { 1-3\%. Euhedral o } \\
\text { subhedral } \\
\text { redondeada. }\end{array}$ & $\begin{array}{l}<5 \% \text {. Euhedral, o } \\
\text { esqueletal, o } \\
\text { redondeada, o } \\
\text { engolfada. }\end{array}$ \\
\hline $\begin{array}{l}\text { Clino- } \\
\text { piroxeno }\end{array}$ & $\begin{array}{l}<3 \% . \text { Euhedral } \pm \\
\text { subhedral } \\
\text { redondeado. }\end{array}$ & $\begin{array}{l}\text { 2-5\%. Subhedral } \\
\text { redondeado + } \\
\text { euhedral } \\
\text { ocasionalmente. }\end{array}$ & $\begin{array}{l}<4 \% . \text { Euhedral, a } \\
\text { veces subhedral } \\
\text { redondeado. }\end{array}$ & $<3 \%$. Euhedral. & $\begin{array}{l}\text { 1-5\%. A veces } \\
\text { ausente. Euhedral } \\
\text { o redondeado } \\
\text { (estos más } \\
\text { abundantes en } \\
\text { Basaltos Pre- } \\
\text { caldera. }\end{array}$ \\
\hline Anfíbol & $\begin{array}{l}\text { Raro, algunos con } \\
\text { reemplazo por } \\
\text { opacos. }\end{array}$ & $\begin{array}{l}<1 \% \text {. En colada } \\
\text { El Choique. Con } \\
\text { borde opaco. }\end{array}$ & $\begin{array}{l}<1 \% \text {. Raro. Borde } \\
\text { opaco delgado o } \\
\text { ausente. }\end{array}$ & & \\
\hline Biotita & $\begin{array}{l}<3 \% \text {. Euhedrales, } \\
\text { pocas } \\
\text { redondeadas, } \\
\text { remplazo por } \\
\text { minerales } \\
\text { anhidros raro. }\end{array}$ & & \begin{tabular}{|l|}
$<1 \%$. En duda \\
por estar \\
reemplazada por \\
minerales opacos. \\
No siempre \\
presente.
\end{tabular} & $\begin{array}{l}<2 \% \text {. Con y sin } \\
\text { reemplazo por } \\
\text { opacos. No } \\
\text { siempre presente. }\end{array}$ & \\
\hline $\begin{array}{l}\text { Pasta/ } \\
\text { matriz }\end{array}$ & \begin{tabular}{|l|} 
Matriz muy \\
variable \\
(ignimbrita de \\
grado bajo a alto).
\end{tabular} & $\begin{array}{l}\text { Pilotáxica e } \\
\text { intergranular. } \\
\text { Mingling en } \\
\text { colada intra- } \\
\text { caldera. }\end{array}$ & $\begin{array}{l}\text { Pilotáxica. } \\
\text { Ocasionalmente } \\
\text { vitrofírica. }\end{array}$ & Vitrofírica. & $\begin{array}{l}\text { Intergranular. } \\
\text { Ocasionalmente } \\
\text { con mingling. }\end{array}$ \\
\hline
\end{tabular}

Figura 6.21: Tabla de síntesis de las rocas sin- y post-caldera del Payún Matrú, y de Basaltos Pre- y Post-caldera I y II. 
necesidad de una mezcla entre magmas diferentes.

La Ignimbrita Portezuelo presenta mayoritariamente cristales que no indican desequilibrios, aunque sí presenta minoritariamente cristales con texturas como cribados en feldespatos y redondeamientos o reemplazos en minerales máficos, los cuales sugieren historias diferentes para los cristales presentes. Estas texturas indican desequilibrio entre los cristales y el magma, el cual puede deberse a un incremento en la temperatura del mismo (Feeley y Sharp, 1996), o a que la composición de algunos feldespatos era más sódica que la de aquellos en equilibrio con el liquido, produciendo como consecuencia la disolución parcial de los mismos (cribado medio) (Nakamura y Shimakita, 1998).

Las Traquiandesitas Post-caldera, por otra parte, posee en todas las lavas, a excepción de una sola, desequilibrios mineralógicos y también evidencias de mingling (colada intracaldera). Estas características sugieren que durante la etapa post-caldera temprana ocurrieron procesos de mezcla de magmas en el Payún Matrú.

Por otra parte, la unidad de Traquitas Post-caldera es notoriamente diferente a las lavas precedentes de la etapa post-caldera. No se exhiben feldespatos con cribados ni tampoco se encuentran evidencias de mingling. Esto sugiere que la mezcla de magmas no tuvo lugar durante esta etapa. Sin embargo, se observan rasgos como redondeamiento en algunos cristales, indicando una disolución posiblemente por un aumento en la temperatura del magma, lo cual puede deberse aun magma máfico más caliente situado en la base de la cámara magmática. Esto será discutido con más detalle en el capítulo 9. 


\section{Capítulo 7}

\section{Geoquímica y análisis isotópico de roca total}

\subsection{Clasificación de las rocas del CVPM}

En el diagrama TAS de clasificación de rocas volcánicas (Total Alcali Silica, Le Maitre, 2002), las rocas del Campo Volcánico Payún Matrú se ubican entre los campos de basaltos hasta el de las traquitas, con una tendencia lineal entre ambos extremos. Esta tendencia indica que las rocas pertenecen a la serie alcalina, y en particular, a la denominada serie transicional (o suavemente alcalina) (Baker, 1987; Fitton, 1987). Una sola lava (PM 38, Fig. 7.1) perteneciente a las Traquitas vítreas, plotea en el campo de las riolitas (Fig. 7.2).

La Figura 7.1 muestra la ubicación de las 58 muestras analizadas químicamente. Con respecto a las muestras analizadas de la Ignimbrita Portezuelo, cuatro de las seis muestras son de roca total, las cuales poseen un contenido de clastos líticos relativamente bajo (menor a $8 \%$ ). De las dos muestras restantes analizadas, una corresponde a fiammes, el cual es el dato más confiable para reflejar la composición del magma, y la otra corresponde a clastos de spatter.

Los análisis químicos de las Traquitas Post-caldera fueron hechos solamente sobre las litofacies de Traquitas vítreas y Traquitas en bloque, y no sobre los Conos pumíceos. Esto se debe a la estrecha relación entre las Traquitas vítreas y los Conos pumíceos, a la gran vesicularidad que poseen los pómez, y a que gran parte de ellos se encuentran oxidados.

Las volcanitas del sustrato previo al Payún Matrú aflorantes al pie SO del volcán se clasifican como dacitas y traquitas, y están claramente separadas de la tendencia general del CVPM (Fig. 7.2). Debido a que tanto en el TAS como en todo el resto de los diagramas químicos poseen una tendencia marcadamente diferente al resto (diagramas de Harker, de discriminación tectónica, etc.), no se consideran parte del Payún Matrú y no se mostrarán en gran parte de los diagramas subsiguientes.

Los basaltos fisurales tanto pre- como post-caldera se ubican en los campos de basaltos 


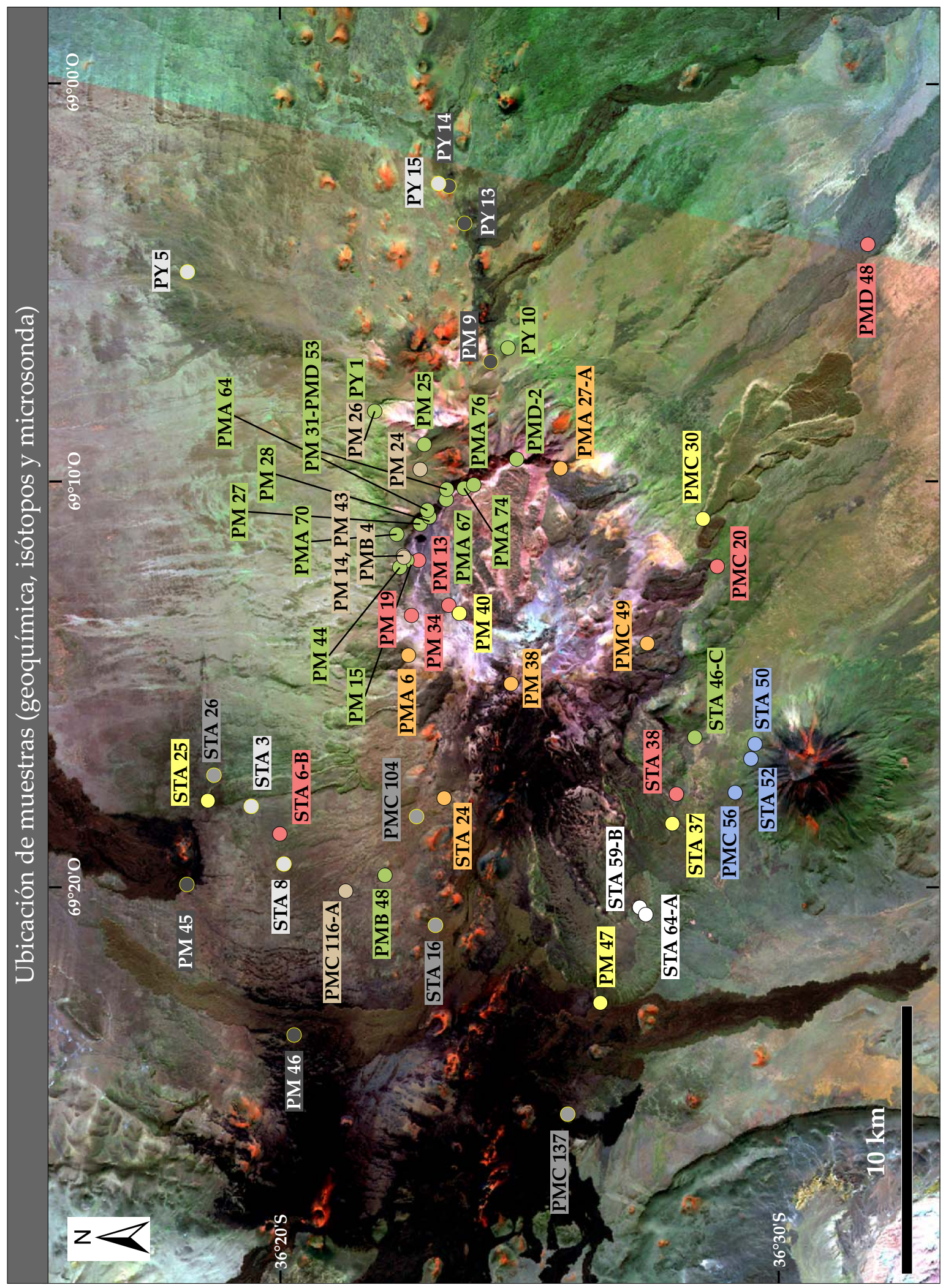

Figura 7.1: Imagen satelital LANDSAT 7 con la ubicación de las muestras con análisis geoquímicos e isotópicos. Los colores corresponden a los de cada unidad, ver referencias en el diagrama TAS. 


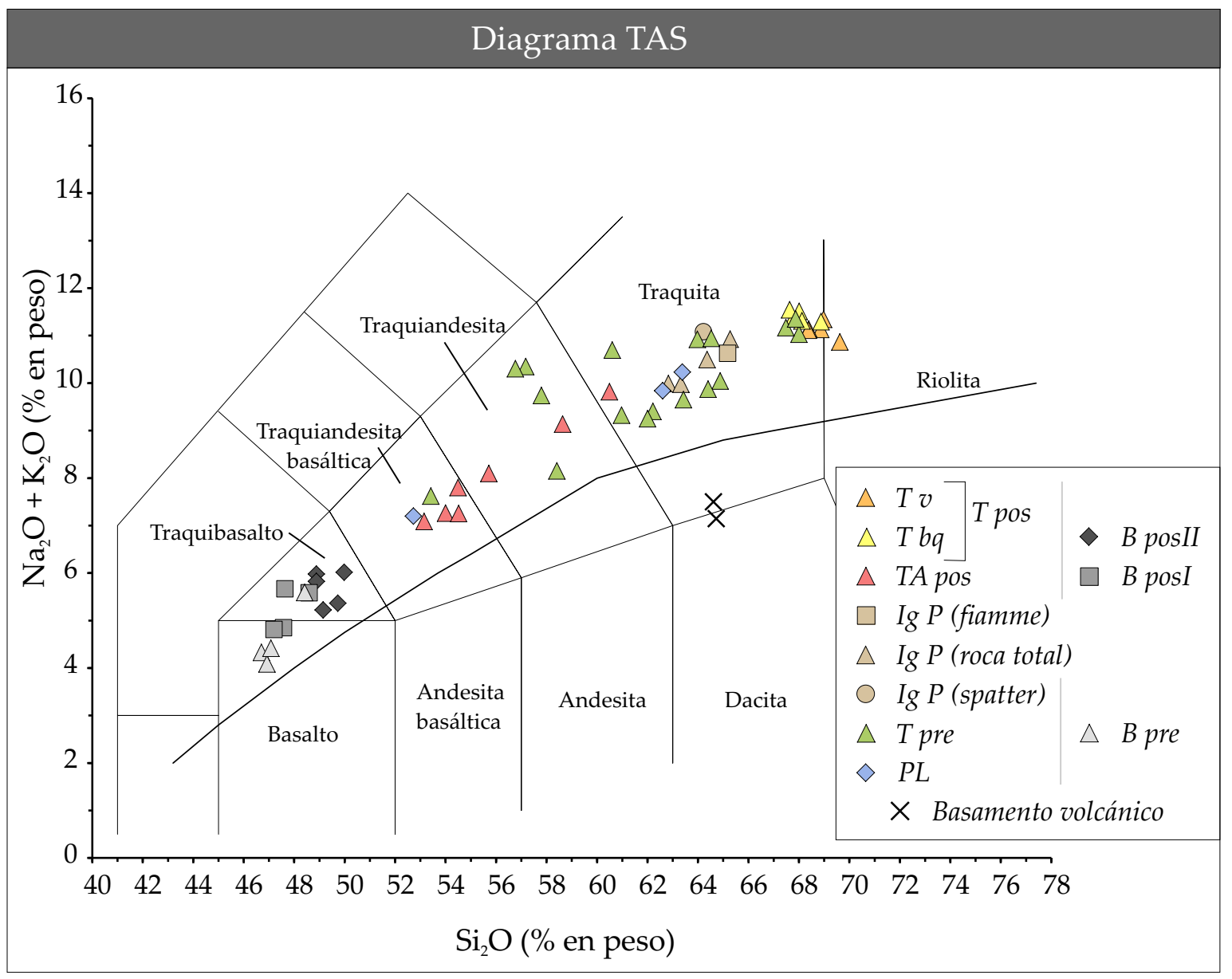

Figura 7.2: Diagrama de clasificación TAS para rocas volcánicas (Le Maitre, 2002).

y traquibasaltos (Fig. 7.2), con un porcentaje en $\mathrm{SiO}_{2}$ entre 46,7 y $50 \%$ y un porcentaje de alcalis $\left(\mathrm{Na}_{2} \mathrm{O}+\mathrm{K}_{2} \mathrm{O}\right)$ entre 4,1 y $6 \%$ (tanto los álcalis como la sílice recalculados en base anhidra). Todas las lavas de los Basaltos Post-caldera II plotean dentro del campo de los traquibasaltos, en tanto que la mayoría de las muestras de la unidad Basaltos Pre-caldera plotean dentro del campo de basaltos. Por lo tanto, se registra una evolución química con el tiempo desde el campo de basaltos al de traquibasaltos, aunque existen superposiciones entre las tres unidades de los basaltos fisurales.

Los Traquitoides Pre-caldera presentan una amplia dispersión en el TAS, siendo la gran parte de las muestras traquitas y con menor participación de traquiandesitas, con una sola muestra ploteando en el campo de las traquiandesitas basálticas (Fig. 7.2). El porcentaje de $\mathrm{SiO}_{2}$ varía de 53,4 a $68 \%$ y el de álcalis está entre 7,6 y 11,3\%. Los fiammes, los clastos de spatter y la roca total de la Ignimbrita Portezuelo, indican una composición traquítica (Fig. 7.2), con un contenido de $\mathrm{SiO}_{2}$ entre 62,8 y 65,3\% y de álcalis entre el 9,9 y 11,1\%.

La unidad de Traquiandesitas Post-caldera presenta también una relativamente amplia 
dispersión composicional, entre traquiandesitas basálticas y traquiandesitas, con una sola muestra (PM 13, Fig. 7.1) ploteando en el campo de las traquitas (Fig. 7.2). Esta muestra más evolucionada pertenece a un sector de la colada intra-caldera, la cual es principalmente de composición traquiandesita basáltica (muestras PM 19 y PM 34, Fig. 7.1). En comparación con otras unidades del CVPM, esta unidad posee relativamente pocas coladas lávicas. Teniendo en cuenta el número de coladas analizadas y las existentes, la representatividad en los análisis químicos de las Traquiandesitas Post-caldera es mayor que en las otras unidades. Considerando la muestra traquítica de la colada intra-caldera, el contenido de $\mathrm{SiO}_{2}$ varía entre 53,1 y 60,5\%, mientras que el de los álcalis varía entre 7,1 y 9,8\%.

Las litofacies de Traquitas en bloque y Traquitas vítreas pertenecientes a la unidad de Traquitas Post-caldera plotean en un sector restringido del TAS, en el campo de las traquitas, y transicional al campo de las riolitas (Fig. 7.2). Estas dos litofacies, si bien son fácilmente reconocibles en el campo debido a sus morfologías, son prácticamente indistinguibles químicamente. Tienen en conjunto un porcentaje de $\mathrm{SiO}_{2}$ entre 69,6 y 67,6\%, y de álcalis entre 10,9 y $11,5 \%$.

Las escasas muestras del volcán Payún Liso presentan una tendencia alcalina similar a las rocas del Payún Matrú. Dos de las tres muestras se plotean en el campo de las traquitas, mientras que una es una traquiandesita basáltica (Fig. 7.2).

Los campos de traquibasaltos, traquiandesitas basálticas y traquiandesitas pueden ser a su vez divididos en base a los contenidos de $\mathrm{Na}_{2} \mathrm{O}$ y $\mathrm{K}_{2} \mathrm{O}$. Si se cumple que $\mathrm{Na}_{2} \mathrm{O}-2>\mathrm{K}_{2} \mathrm{O}$, entonces los tres campos mencionados se denominan hawaiitas, mugearitas y benmoreitas, respectivamente (Best y Christiansen, 2001; Winter, 2010). Las muestras del CVPM que caen en los tres campos mencionados presentan contenidos de sodio relativamente altos, correspondiendo a las hawaiitas, mugearitas y benmoreitas.

Los basaltos alcalinos continentales (que incluyen a basaltos y traquibasaltos) se dividen en dos grupos en base a las proporciones de álcalis: i) basaltos sódicos, si se cumple que el cociente $\mathrm{K}_{2} \mathrm{O} / \mathrm{Na}_{2} \mathrm{O}<1$ y, ii) basaltos potásicos, en el caso contrario (Farmer, 2003). Para los basaltos y traquibasaltos del CVPM, esta relación se encuentra entre 0,28 y 0,44, perteneciendo claramente al grupo sódico.

El diagrama TAS muestra un hiato de un poco más de $3 \%$ de $\mathrm{SiO}_{2}$, entre 49,98 y 53,15\%, en donde no se encuentran muestras de los basaltos fisurales ni del Payún Matrú. También se observa un intervalo sin muestras aunque de menor magnitud (de aproximadamente $2 \%$ de $\mathrm{SiO}_{2}$ ) en el campo de las traquitas, entre 65,3 y $67,5 \%$ de $\mathrm{SiO}_{2}$. Este ultimo hiato se encuentra entre las traquitas más silícicas (Traquitas Post-caldera y subunidad 1 de los Traquitoides Pre-caldera), y el resto de las traquitas (Fig. 7.2). Las muestras más silícicas de la subunidad 1 de los Traquitoides Pre-caldera corresponden al denominado "Filo Blanco" (Fig. 4.1) y una lava en el perfil de "La Nariz" (muestras PM 25, PY 1 y PMA 76, Fig. 7.1).

El hiato en composiciones intermedias, en conjunto con la escasez relativa de rocas intermedias, no parece ser un accidente del muestreo, ya que las lavas de las Traquiandesitas 


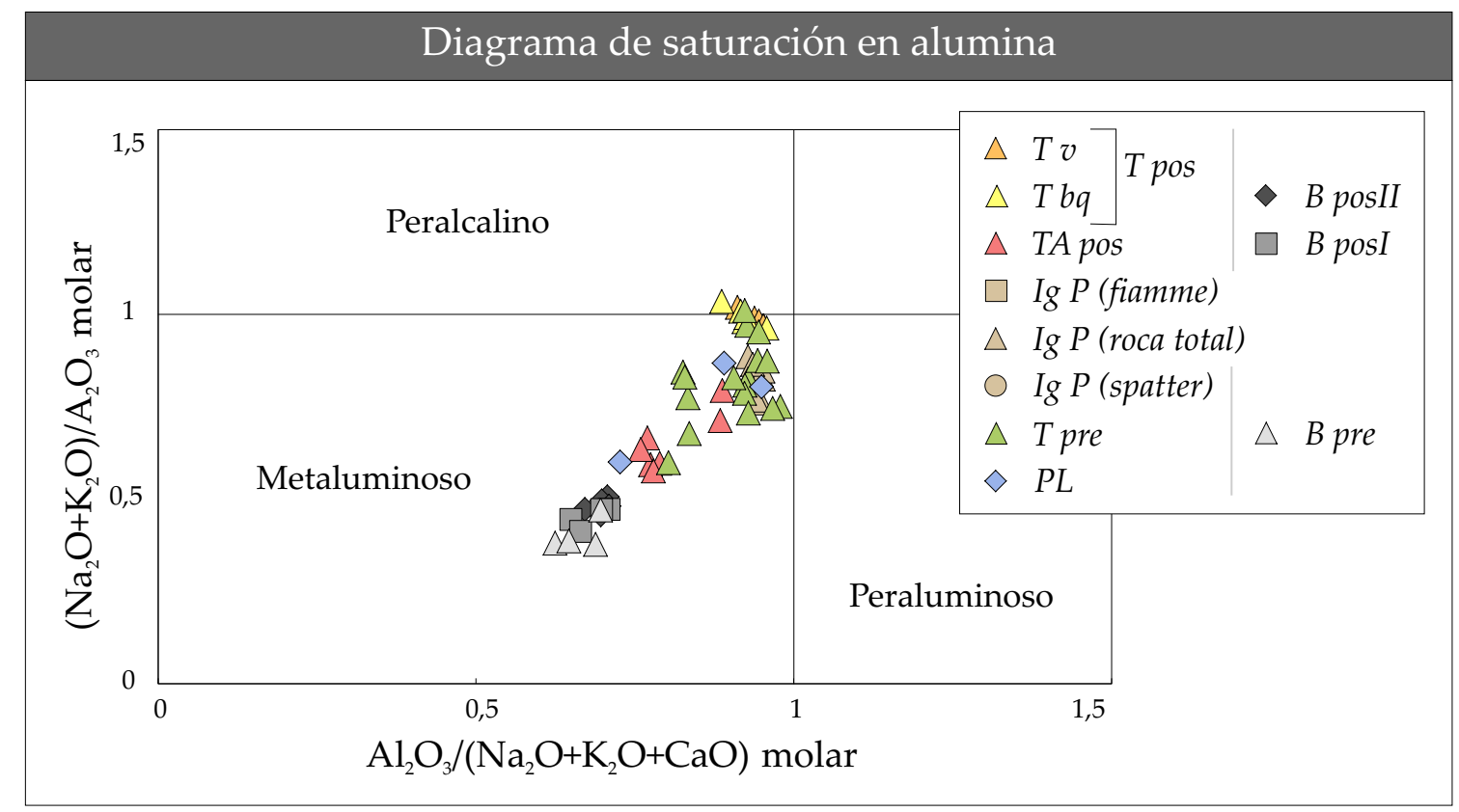

Figura 7.3: Diagrama de clasificación según el índice de saturación en alúmina.

Post-caldera están sobre-representadas con respecto a otras unidades. En numerosos volcanes las rocas intermedias son menos abundantes que los basaltos y las riolitas o traquitas (Peccerillo et al., 2003; Fitton, 1987), y presentan un hiato entre las rocas básicas y ácidas, el cual fue denominado Daly gap (Winter, 2010). Este gap fue explicado originalmente suponiendo un origen distinto de los magmas básicos y félsicos, aunque luego se comprobó que también puede deberse a la dinámica de la cristalización fraccionada (Winter, 2010; Peccerillo et al., 2007). Durante el fraccionamiento a bajas presiones, la transición de los fundidos residuales desde composiciones básicas a ácidas es un proceso rápido, debido a la abundancia de fases cristalizantes al mismo tiempo en el estadio intermedio (Peccerillo et al., 2007). La composición del liquido cambia abruptamente en el estadio intermedio, por lo cual la proporción de fundidos de esta composición es relativamente escasa (Peccerillo et al., 2007). Por otro lado, si se producen rocas intermedias como consecuencia de la mezcla de magmas entre magmas ácidos y básicos, es de esperar que las rocas más cercanas a ambos extremos sean más comunes que las intermedias, y variando de acuerdo a las proporciones de cada extremo composicional (Winter, 2010).

Con respecto a los índices de saturación en alúmina, la gran parte de las muestras del CVPM son metaluminosas, siendo solamente las traquitas más evolucionadas peralcalinas (Fig. 7.3). Este es el caso de tres muestras de Traquitas vítreas y Traquitas en bloque, mientras que el resto de las muestras de estas litofacies se encuentran cercanas a ser peralcalinas. 


\subsubsection{Norma CPIW}

$\mathrm{Al}$ calcular la norma CPIW es necesario tener en cuenta la proporción de $\mathrm{Fe}_{2} \mathrm{O}_{3} / \mathrm{Fe}$ total, ya que la norma es sensible al estado de oxidación del hierro. Debido a que los análisis químicos de roca total solamente proveen el contenido de hierro como $\mathrm{Fe}_{2} \mathrm{O}_{3}$, fue necesario calcular esta proporción en base al coeficiente de Le Maitre (1976). En dicho cálculo, no solo se tiene en cuenta los contenidos de $\mathrm{Fe}_{2} \mathrm{O}_{3}$, sino que también se involucran los porcentajes de $\mathrm{SiO}_{2}, \mathrm{Na}_{2} \mathrm{O}$ y $\mathrm{K}_{2} \mathrm{O}$.

Las Traquitas Post-caldera y la Ignimbrita Portezuelo presentan todas cuarzo normativo, con valores entre 6 y $15 \%$. El cuarzo normativo es mayor en la litofacies de Traquitas vítreas y menor en la Ignimbrita Portezuelo. Esta característica también se exhibe en el diagrama TAS, en donde las rocas más diferenciadas del Payún Matrú tienden al campo de las riolitas (sobresaturadas en sílice) y no al de fonolitas (subsaturadas en sílice). En las Traquitas Pre-caldera la proporción de cuarzo normativo varía ampliamente, en concordancia con la variabilidad química de la unidad, alcanzando un máximo de $12 \%$, y $<1 \%$ en las rocas menos silíceas. Con las Traquiandesitas Post-caldera ocurre algo similar, las rocas más silíceas presentan cuarzo normativo con un valor máximo de $4 \%$ (parte traquítica de la colada intracaldera), mientras que las rocas menos silícicas no tienen cuarzo normativo.

Thompson (1984) propuso una clasificación de los basaltos sobre la base de las proporciones de nefelina, olivina, diópsido, hipersteno y cuarzo normativos. Estos minerales son aquellos representados en el tetraedro basáltico propuesto originalmente por Yoder y Tilley (1962). Los basaltos y traquibasaltos fisurales presentan todos nefelina $(<5 \%)$, olivina (entre el 5 y $10 \%$ ) y diópsido normativos, sin hipersteno ni cuarzo normativos. Los contenidos de nefelina normativa son menores al $10 \%$, por lo tanto se clasifican como Basaltos olivínicos alcalinos, los cuales son subsaturados en sílice (Thompson, 1984).

En el sistema residual sílice-nefelina-kalsilita normativos, las rocas del Payún Matrú presentan una tendencia desde el alto térmico entre la albita y ortosa, hacia el mínimo térmico entre la albita y la sílice (Fig. 7.4 a). Esto está en concordancia con la tendencia hacia la sobresaturación en sílice que se observa en el diagrama TAS. Aunque este diagrama es usado para las rocas diferenciadas, también se graficaron las lavas de los campos basálticos. Existe una aparente falta de coherencia en las unidades basálticas, debido a que estas estarían pasando por encima del alto térmico cercano a la albita. Sin embargo, debe tenerse en cuenta que los basaltos poseen componentes máficos que son necesarios utilizar para su correcta representación, los cuales no se encuentran en este diagrama. La proyección de los basaltos en este sistema desde un mineral normativo máfico, como el diópsido o la forsterita, produciría el efecto aparente de que se está atravesando un alto térmico.

En los sistemas $\mathrm{SiO}_{2}-\mathrm{Ne}-\mathrm{Fo}$ y $\mathrm{SiO}_{2}-\mathrm{Ne}-\mathrm{Di}$ (sílice, nefelina y forsterita o diópsido normativos, respectivamente) existe un alto térmico entre la forsterita o diópsido y la albita (Morse, 1980). En el sistema $\mathrm{SiO}_{2}-\mathrm{Ne}-\mathrm{Di}$, las unidades basálticas del CVPM se distribuyen desde el 


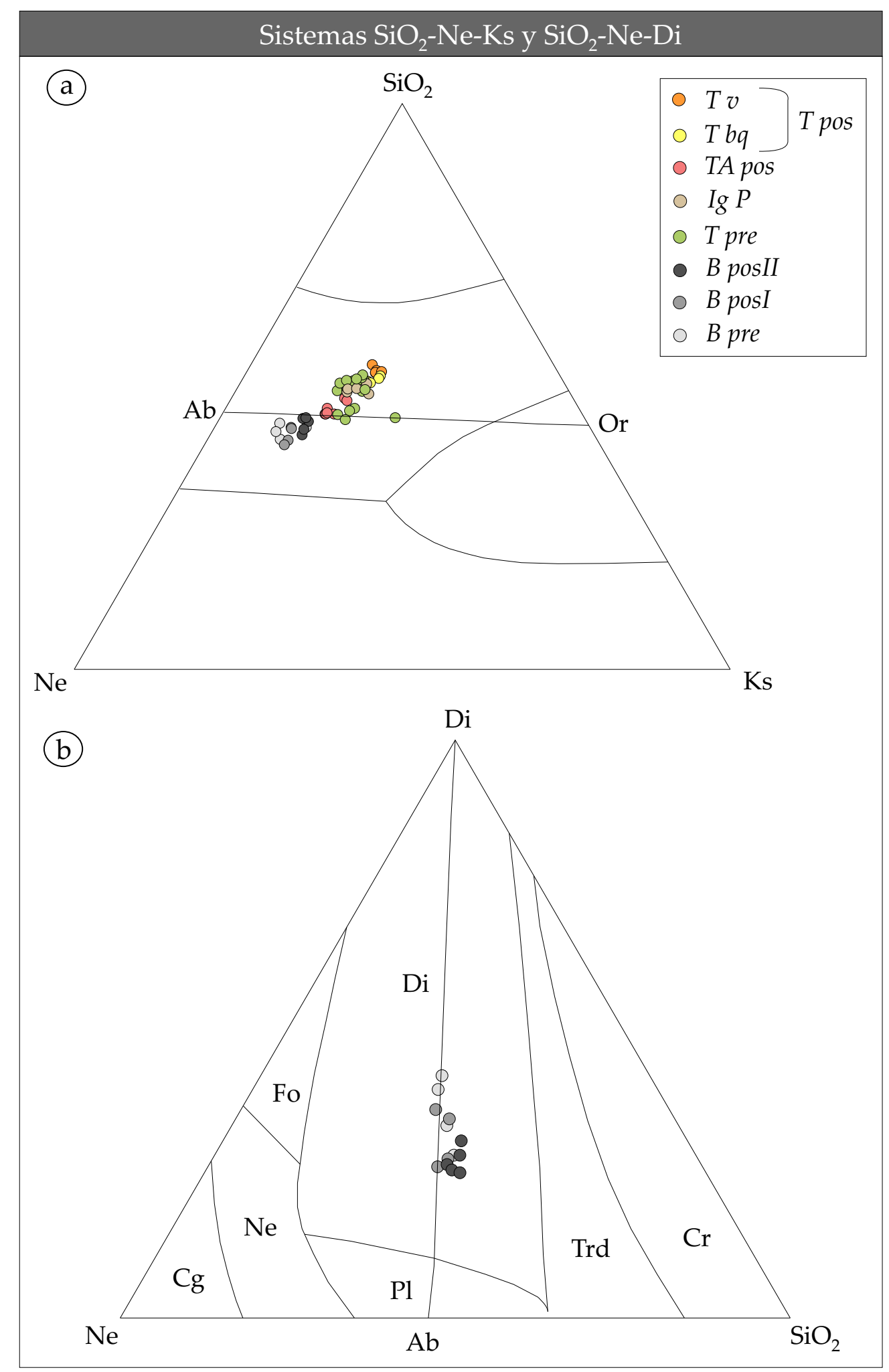

Figura 7.4: a) Sistema residual cuarzo-nefelina-kalsilita (normativos), a 1 kbar de presión, para todas las rocas del CVPM. Límite de los campos según Hamilton y MacKenzie (1965). b) Sistema sílice-nefelina-diópsido para basaltos (Schairer y Yoder, 1960). Di: diópsido; Ne: nefelina, Ab: albita; Fo: forsterita; Pl: plagioclasa, $\mathrm{Cg}$ : carnegieita (no se conoce en la naturaleza); Trd: tridimita; Cr: cristobalita. 
alto térmico entre el diópsido y albita hacia el extremo de la sílice y no de nefelina (Fig. 7.4 b). De esta manera, la aparente incoherencia de los basaltos en el sistema $\mathrm{SiO}_{2}-\mathrm{Ne}-\mathrm{Ks}$ se explica por la no consideración de los minerales máficos, los cuales son de suma importancia en los basaltos.

\subsection{Diagramas de variación}

En la Figura 7.5 se muestran los diagramas de Harker para elementos mayoritarios. El $\mathrm{Al}_{2} \mathrm{O}_{3}$ se mantiene constante hasta un valor de $65 \% \mathrm{SiO}_{2}$, y luego del pequeño hiato dentro de las traquitas mencionado previamente, disminuye en las Traquitas Post-caldera y en las muestras mas silíceas de los Traquitoides Pre-caldera. La alúmina se encuentra entre 16,2 y $18,3 \%$ para contenidos de $\mathrm{SiO}_{2}$ menores al $65,5 \%$, y entre 14,9 y $16,1 \%$ para valores de $\mathrm{SiO}_{2}$ mayores al 65,5\%.

$\mathrm{El} \mathrm{Fe}_{2} \mathrm{O}_{3}(\mathrm{~T})$ presenta una tendencia lineal decreciente con el aumento de $\mathrm{SiO}_{2}$, con valores máximos en 12,4\% y mínimos en 2,9\%. Las Traquitas Post-caldera poseen valores casi constantes de $\mathrm{Fe}_{2} \mathrm{O}_{3}(\mathrm{~T})$. $\mathrm{El} \mathrm{MgO}$ y $\mathrm{CaO}$ presentan una tendencia similar, aunque el $\mathrm{MgO}$ tiene mayor dispersión, sobre todo en las rocas básicas, y alcanza valores menores, entre 7,3 y $0,12 \%$. Los valores de CaO están entre 11,1 y 0,6\%.

Tanto el $\mathrm{Na}_{2} \mathrm{O}$ como el $\mathrm{K}_{2} \mathrm{O}$ poseen una tendencia lineal a aumentar con el contenido de $\mathrm{SiO}_{2}$. Presentan valores entre 3,2 y 6,3\% en el primer caso, y entre 0,9 y 5,6 \% en el segundo.

En la Figura 7.6 se muestran algunos diagramas de variación de elementos minoritarios y traza. Tanto el $\mathrm{TiO}_{2}$ como el $\mathrm{Sr}$, muestran un decrecimiento con el aumento de $\mathrm{SiO}_{2}$, aunque el Sr con mayor dispersión. $\mathrm{El}_{2} \mathrm{O}_{5}$ presenta una alta dispersión en los basaltos y traquibasaltos, mientras que en las unidades pertenecientes al Payún Matrú y Payún Liso decrece linealmente, estando las muestras de los campos basálticos y de los volcanes poligenéticos separadas. Algo similar, aunque con una tendencia diferente, ocurre con el $\mathrm{Ba}$, el cual aumenta con la $\mathrm{SiO}_{2}$ a excepción de las traquitas más silíceas, las cuales poseen contenidos marcadamente menores de $\mathrm{Ba}$. $\mathrm{El} \mathrm{Zr}, \mathrm{Nb}$ y $\mathrm{U}$ muestran comportamientos similares, con un aumento de los mismos al incrementarse el contenido de $\mathrm{SiO}_{2}$, aunque con una mayor dispersión en las rocas más silícicas. Las dos muestras de Traquitoides Pre-caldera que presentan una mayor abundancia de $\mathrm{Zr}, \mathrm{Nb}$ y $\mathrm{U}$, alejándose de la tendencia general, corresponden a una lava en el borde NE de la caldera (muestras PM 31 y PMD 53, Fig. 7.1). Estas dos muestras también presentan un mayor contenido de álcalis, y se ubican levemente por encima de la tendencia general del CVPM (Fig. 7.2).

El Cr y Ni muestran un comportamiento similar (Fig. 7.6, no se muestra el Cr), con un rango de valores relativamente alto y variable en los basaltos y traquibasaltos. El resto de las rocas analizadas poseen valores de $\mathrm{Ni}$ y $\mathrm{Cr}$ por debajo del límite de detección, el cual es de 20 ppm (a excepción de escasas Traquiandesitas Post-caldera y Traquitoides Pre-caldera). En la Figura 7.6 se muestran solamente las muestras con contenidos de Ni por encima del 


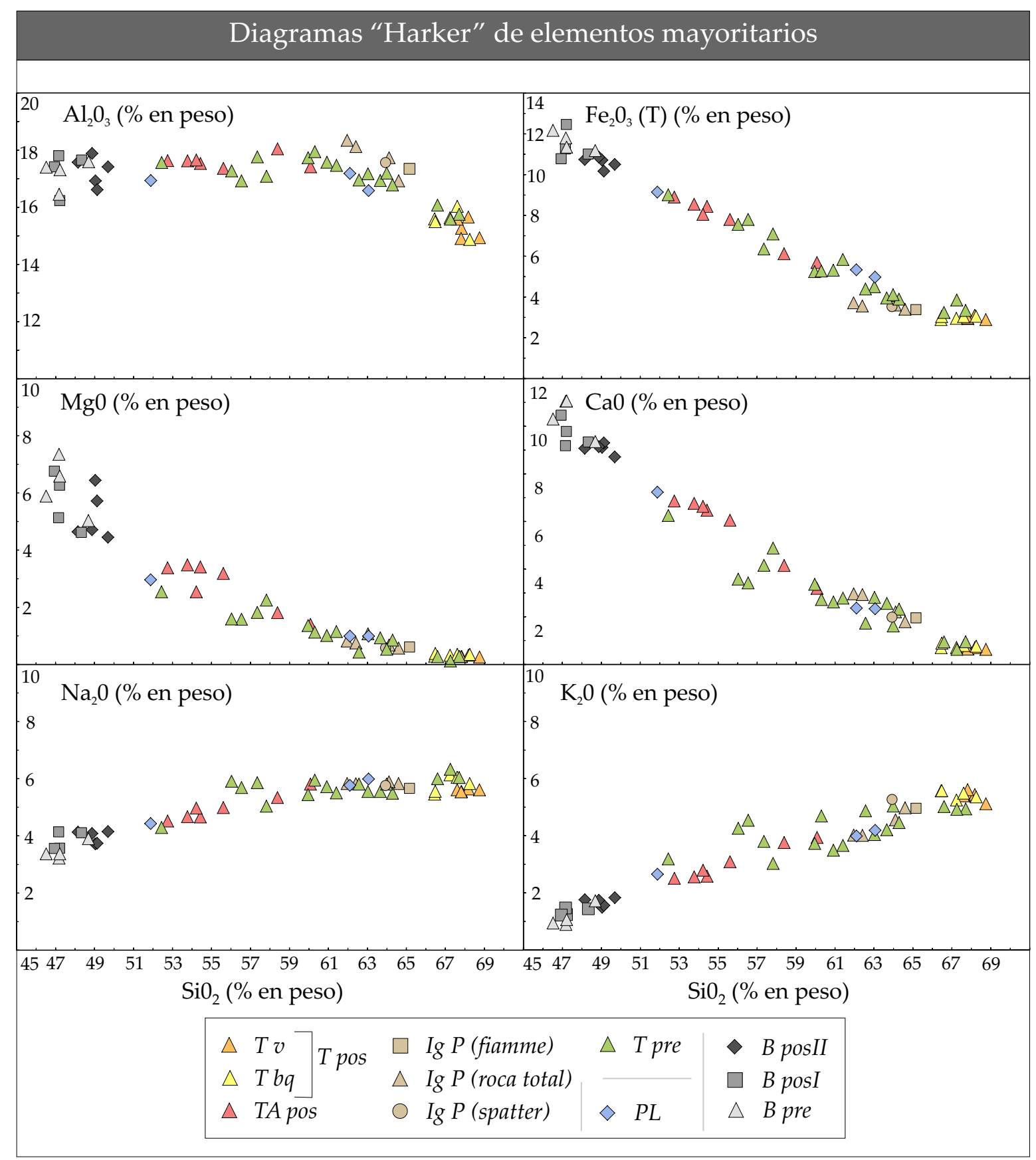

Figura 7.5: Diagramas de variación tipo Harker para elementos mayoritarios. 


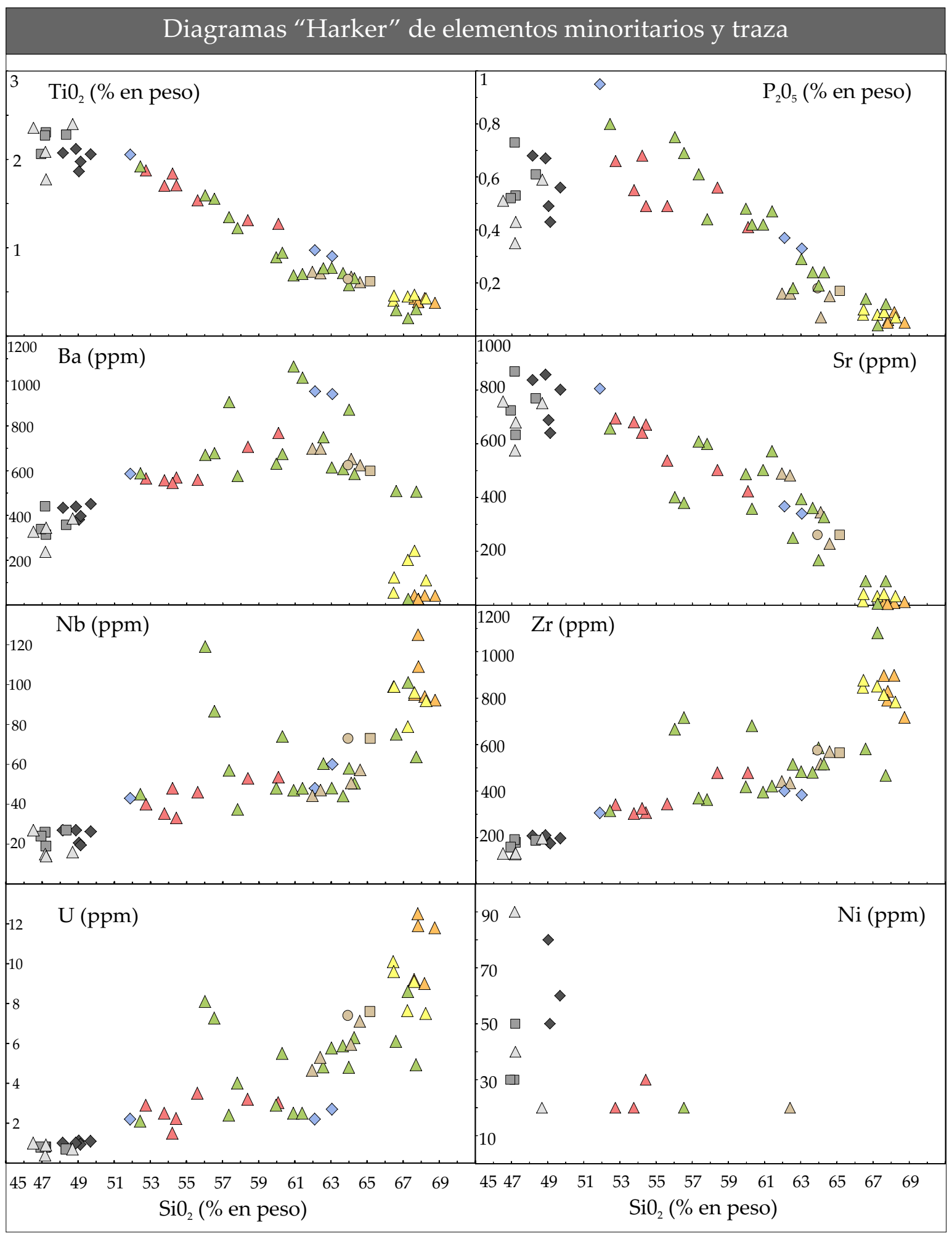

Figura 7.6: Diagramas de variación para algunos elementos minoritarios y traza. Ver diagrama anterior para las referencias. 
límite de detección.

Las tendencias observadas en los diagramas tipo Harker sugieren que las rocas del CVPM están genéticamente relacionadas y son comagmáticas. Las inflexiones en los diagramas de variación marcan la aparición de una fase durante la cristalización fraccionada, o la desaparición de un mineral particular durante la fusión parcial. Estas inflexiones pueden ocurrir en un diagrama de un determinado elemento y estar ausentes en otro, dependiendo de la naturaleza de los minerales involucrados (Riddle, 1993; Rollinson, 1993).

Si bien la cristalización fraccionada es un proceso petrogenético que causa frecuentemente las tendencias observadas en los diagramas de Harker, estas tendencias también pueden deberse a otros procesos (Rollinson, 1993; Winter, 2010). La contaminación por asimilación es frecuente aunque no suele ser demostrable en este tipo de diagramas con elementos mayoritarios. También puede ocurrir que algunas tendencias se deban a la mezcla entre dos magmas de diferente composición (Rollinson, 1993).

El decrecimiento de $\mathrm{Mg}$, Fe y $\mathrm{Ca}$ al aumentar la $\mathrm{SiO}_{2}$ es consistente con la remoción de minerales que cristalizan tempranamente, como pueden ser la olivina, piroxenos y plagioclasas (Winter, 2010). La disminución abrupta del Ni en los basaltos y traquibasaltos sugiere el fraccionamiento de olivinas, ya que el Ni es compatible en este mineral (Winter, 2010). El Ti y el V (este último elemento no mostrado) presentan un comportamiento similar, decreciendo en las rocas más silíceas, lo cual es típicamente un indicador del fraccionamiento de óxidos de Fe-Ti (ilmenita o titanomagnetita) (Riddle, 1993; Best y Christiansen, 2001). Si el Ti y V mostraran un comportamiento divergente, entonces estarían indicando una sustitución con Ti en fases accesorias como rutilo o titanita (Riddle, 1993), comportamiento que no se observa en las rocas del CVPM.

El $\mathrm{P}_{2} \mathrm{O}_{5}$ es incompatible en magmas máficos, aunque compatible en magmas intermedios a silícicos, cuando la apatita comienza a cristalizar (Best y Christiansen, 2001). Las inflexiones en el diagrama de variación del $\mathrm{P}_{2} \mathrm{O}_{5}$ en valores intermedios de $\mathrm{SiO}_{2}$ puede indicar la remoción de apatita durante la cristalización fraccionada (Riddle, 1993). Esto se observa entre los basaltos/traquibasaltos fisurales y el resto de las rocas del Payún Matrú y Payún Liso. Por lo tanto, la tendencia decreciente del $\mathrm{P}_{2} \mathrm{O}_{5}$ a partir de composiciones intermedias señalan un control por parte de la apatita.

El Ba sustituye al $\mathrm{K}$ en los feldespatos alcalinos, en la biotita, y también en menor medida en la hornblenda (Riddle, 1993; Best y Christiansen, 2001). La tendencia creciente del Ba se revierte claramente para las Traquiandesitas Post-caldera y las muestras más silícicas de los Traquitoides Pre-caldera, y también, aunque más levemente, en la Ignimbrita Portezuelo y otras traquitas pre-caldera. Este cambio es coherente con la presencia de abundante feldespato alcalino en las Traquitas Post-caldera y las lavas más silícicas de los Traquitoides Pre-caldera, así como también con la presencia de biotita en algunos casos. El anfíbol no parece tener un control sobre el $\mathrm{Ba}$, debido a que se encuentra en porcentajes escasos, $\mathrm{y}$ a que éste es más frecuente en los Traquitoides Pre-caldera y no en las lavas con menores 
contenidos de Ba.

$\mathrm{El} \mathrm{Sr}$, al igual que el Eu divalente, sustituye al Ca en las plagioclasas (aunque no en piroxenos), y también al K en los feldespatos alcalinos (Riddle, 1993; Best y Christiansen, 2001; Winter, 2010). El decrecimiento constante que muestra el diagrama tipo Harker de Sr, desde los basaltos hasta las traquitas (con mayor dispersión en los basaltos), está de acuerdo con un control por parte de las plagioclasas. La plagioclasa es una fase frecuente en todas las unidades volcánicas, a excepción de las últimas erupciones de Traquitas Post-caldera.

El Zr, al igual que el Hf, son elementos incompatibles que pueden sustituir al Ti en minerales accesorios como el rutilo y titanita (ninguno de estos minerales están presentes en el CVPM), y es un constituyente mayor del circón (Riddle, 1993). El aumento del Zr, sin ningún cambio mayor en la pendiente del diagrama bivariante, indicaría que este elemento es incompatible para las fases cristalizantes, y por lo tanto se concentra en las rocas más silíceas.

\subsection{Diagramas multielementos}

\subsubsection{Diagrama de Tierras Raras}

En los diagramas multielementos, los elementos de las Tierras Raras (REE) son normalizados a valores de referencia estándar, siendo estos valores comúnmente de meteoritos condriticos. Estos meteoritos se piensa que poseen una composición química similar a la de la Tierra entera primitiva (Best y Christiansen, 2001). Un inconveniente que se presenta al utilizar a los meteoritos condriticos, es que estos no son composicionalmente homogéneos, y han dado lugar a una serie de valores distintos para la normalización. Una normalización ampliamente usada en la literatura y la elegida para este trabajo, es la presentada por Nakamura (1974).

En las Figuras 7.7 y 7.8 se muestran los diagramas multielementos de Tierras Raras para las diferentes unidades del CVPM. El patrón de las REE de las rocas ígneas depende de la composición de la fuente de los magmas, y también de los equilibrios cristal-fundido que tuvieron lugar durante la evolución magmática (Rollinson, 1993). Los basaltos fisurales fueron agrupados en un solo diagrama, dada la similitud de los patrones observados. Los basaltos pre- y post-caldera muestran una pendiente negativa, con un mayor enriquecimiento de las Tierras Raras livianas (LREE) respecto a las pesadas (HREE). Este patrón es típico en los basaltos de islas oceánicas (OIB), y se explica como producto de la fusión parcial de una peridotita o cristalización fraccionada de un fundido derivado de la peridotita, en donde los elementos más incompatibles se concentran en la fracción liquida (Winter, 2010). La pendiente negativa se mantiene en el resto de las unidades del CVPM, aunque se exhibe un aumento gradual en la abundancia de REE desde los basaltos/traquibasaltos hacia las rocas más silícicas, junto con la aparición de anomalías en el Eu en estas últimas (Figs. 7.7 y 7.8). 


\section{Diagramas Spider de Tierras Raras (Normalización Nakamura, 1974)}

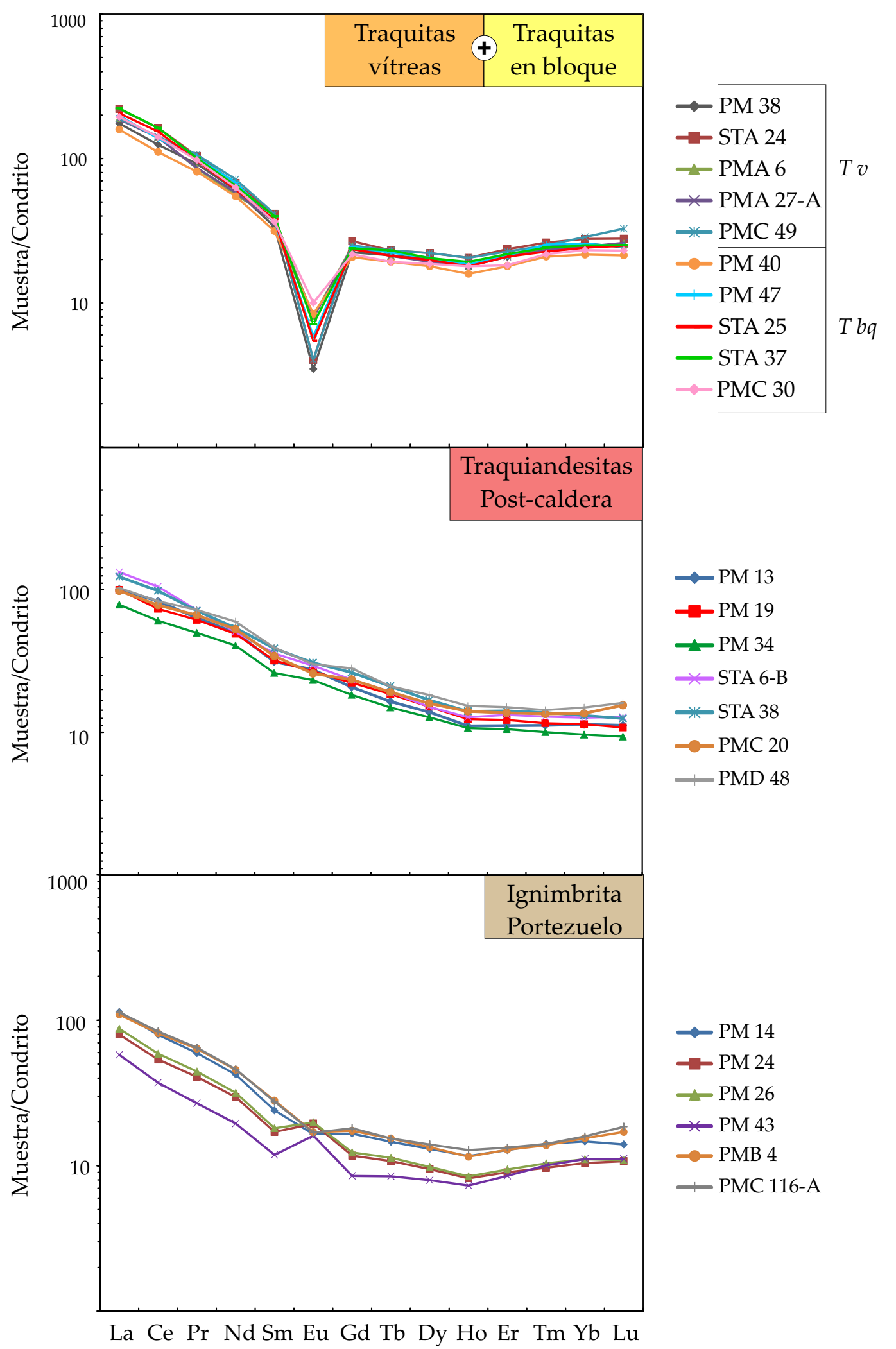

Figura 7.7: Diagrama de REE para la etapa sin- y post-caldera del Payún Matrú. 


\section{Diagramas Spider de Tierras Raras (Normalización Nakamura, 1974)}

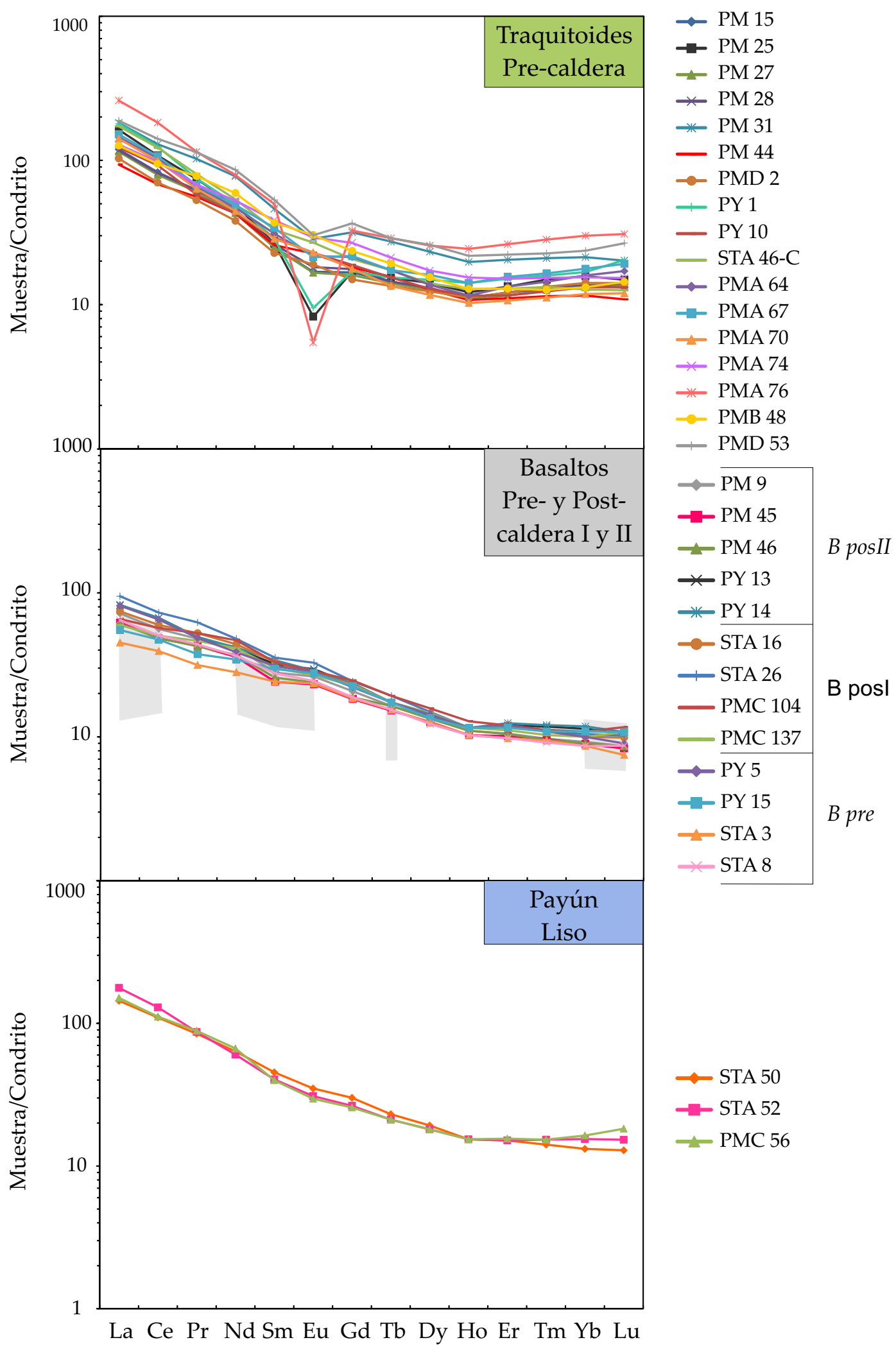

Figura 7.8: Diagrama de REE para la etapa pre-caldera del Payún Matrú, el Payún Liso y los basaltos fisurales (en gris basaltos del arco contemporáneo según Hickey-Vargas et al., 1989 y Tormey et al., 1991). 
En la Figura 7.8 se grafican en gris claro las composiciones de basaltos del arco Andino Pleistoceno-Reciente, para su comparación directa con los basaltos de retroarco. Los basaltos ploteados pertenecen a diferentes centros volcánicos ubicados entre $35^{\circ} \mathrm{S}$ y $39^{\circ} 30^{\prime} \mathrm{S}$, siendo estos los volcanes Planchón, San Pedro, Cerro Azul, Antuco, Llaima (datos según Tormey et al., 1991), y los volcanes Villarica y Lanin, junto con otros conos basálticos cercanos como Cerro Redondo, Caburga, Pichares, Huelemolle y Huililco (Hickey-Vargas et al., 1989). Si bien existen diferencias químicas en las lavas del arco al norte y sur de los $37^{\circ} \mathrm{S}$ (Tormey et al., 1991), las tendencias generales se mantienen y por lo tanto se han utilizado volcanes al sur de los $37^{\circ} \mathrm{S}$ para su comparación con los basaltos del CVPM. A pesar de que en la Figura 7.8 una parte considerable de las REE no están graficadas (por no estar disponibles los datos), se observa en los basaltos del arco actual una pendiente negativa, aunque con menores valores de REE en general y una pendiente menor, en comparación con los basaltos de retroarco del CVPM.

El grado de fraccionamiento de las LREE con respecto a las HREE (una medida de la pendiente en los diagramas) se puede medir con la razón $\mathrm{La} / \mathrm{Yb}$, con ambos elementos normalizados (Fig. 7.9 b). El diagrama de Yb vs. La/Yb muestra que las Traquitas Post-caldera, la Ignimbrita Portezuelo y la mayoría de las muestras de las Traquiandesitas Post-caldera y Traquitoides Pre-caldera presentan pendientes comparables a las de los basaltos fisurales (B posII, B posI y B pre). Estos valores de $\mathrm{La} / \mathrm{Yb}$ normalizados están entre 5 y 10 aproximadamente. El $\mathrm{Yb}$ aumenta desde los basaltos fisurales a las Traquitas Post-caldera, reflejando el hecho de que estas últimas presentan mayor abundancia en general de Tierras Raras con respecto a los primeros. También se grafican a los basaltos del arco contemporáneo mencionados, los cuales presentan menores pendientes representadas por el cociente $(\mathrm{La} / \mathrm{Yb})_{n}$, para valores similares o levemente menores de $\mathrm{Yb}$ (Fig. 7.9).

El Eu puede presentar anomalías tanto negativas como positivas, las cuales están controladas principalmente por los feldespatos, ya que el Eu en estado divalente es compatible en las plagioclasas y feldespatos alcalinos (Rollinson, 1993). La remoción de feldespatos desde un fundido por cristalización fraccionada, o la retención de este mineral en la fuente, va a dar lugar a una anomalía negativa de Eu. Otros minerales también contribuyen con anomalías de Eu, como la hornblenda, titanita, clino- y ortopiroxeno, aunque en estos casos las anomalías son positivas y de menor magnitud (Rollinson, 1993). De estos minerales mencionados, sólo el clinopiroxeno está presente en las rocas del CVPM.

La anomalía de Eu se mide comparando la concentración en la muestra analizada con la concentración que tendría interpolando entre los valores normalizados de Sm y Gd (denominada $\mathrm{Eu}^{*}$ ). En la Figura 7.9 a, se grafica el contenido en $\mathrm{SiO}_{2}$ vs. $\mathrm{Eu} / \mathrm{Eu}^{*}$, y al diagrama se lo divide en tres zonas diferentes. Dado que un valor de exactamente $\mathrm{Eu} / \mathrm{Eu}^{*}=1$ no es habitual por más que no se encuentren anomalías de Eu en los diagramas de REE, se estableció arbitrariamente un rango de $1 \pm 0,1$ para diferenciar a las muestras con y sin anomalías de $\mathrm{Eu}$. 

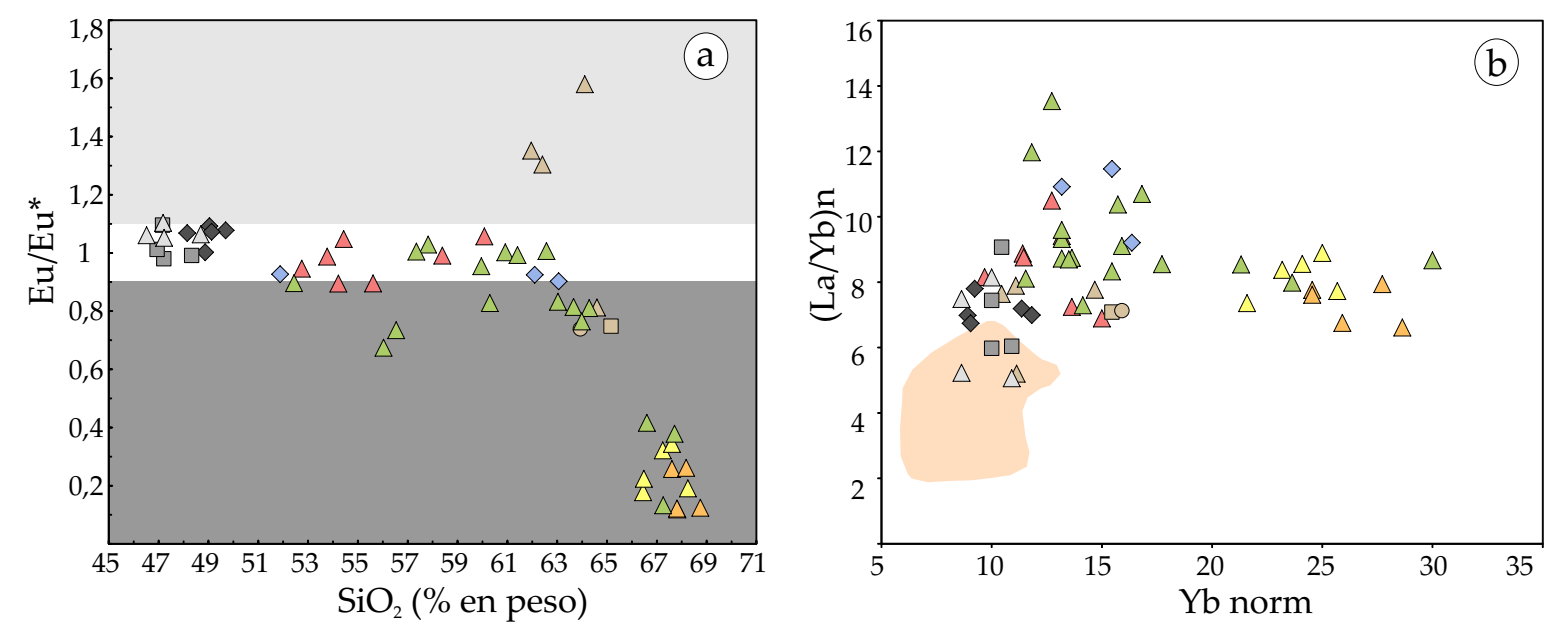

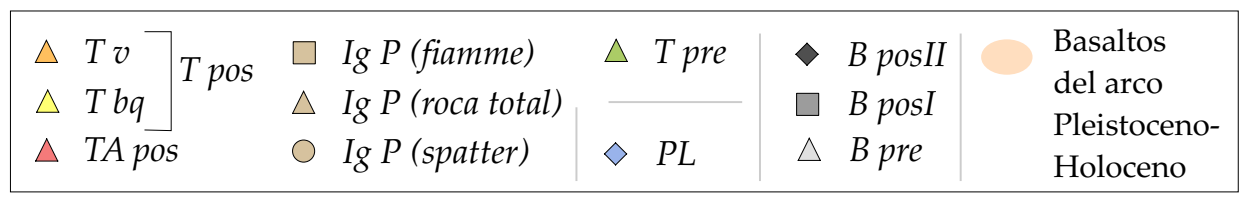

Figura 7.9: a) Anomalías de Eu. En gris oscuro se muestran las rocas con anomalías negativas, y en gris claro las que poseen anomalías positivas. b) Fraccionamiento de LREE respecto a las HREE $(\mathrm{La} / \mathrm{Yb})_{\mathrm{n}}$ vs. $\mathrm{Yb}_{\mathrm{n}}$. En rosa claro se muestra el campo de los basaltos del arco contemporáneo con el CVPM (Hickey-Vargas et al., 1989; Tormey et al., 1991).

Como se muestra en las Figuras 7.8 y 7.9 a, los basaltos fisurales no poseen anomalías significativas de $\mathrm{Eu}$ y, en general, presentan una tendencia a tener una leve anomalía positiva. Por el contrario, las Traquitas en bloque y Traquitas vítreas, junto con las escasas traquitas pre-caldera más silícicas son las lavas con mayores anomalías, en este caso negativas. El resto de los Traquitoides Pre-caldera no presentan o presentan una relativamente leve anomalía negativa de Eu. La Ignimbrita Portezuelo muestra un comportamiento contradictorio, con muestras con una leve anomalía negativa (fiammes, clastos de spatter y algunas de roca total), y otras con una marcada anomalía positiva de Eu (roca total, muestras PM 24, PM 26 y PM 43, Fig. 7.1). Tanto las Traquiandesitas Post-caldera como las lavas analizadas del Payún Liso no presentan anomalías de Eu, tendiendo en algunos casos a una leve anomalía negativa (Figs. 7.7, 7.8 y 7.9 a).

\subsubsection{Diagrama Spider de elementos incompatibles}

Para estos diagramas multielementos existen diferentes opciones para el orden y lista de elementos graficados, y también diferentes maneras de normalizar a los elementos. Una normalización frecuente es utilizando una estimación de la composición primitiva de la Tierra no diferenciada, ya sea mediante la composición de meteoritos condriticos o del manto primitivo. Otra normalización diferente de los elementos incompatibles es mediante la composición promedio de los basaltos más abundantes en la Tierra: los MORB. En el presente 
trabajo se eligió utilizar la normalización con respecto al MORB, según Pearce (1983).

En el diagrama spider de elementos incompatibles se ordenan a los elementos de acuerdo con dos parámetros: el potencial iónico y el coeficiente de distribución del elemento entre una lerzolita granatífera y el fundido (Rollinson, 1993). Los elementos móviles (Sr, K, Rb y Ba) se sitúan a la izquierda del diagrama en orden de incompatibilidad creciente hacia la derecha. Los elementos inmóviles (Th, Ta, Nb, Ce, P, Zr, Hf, Sm, Ti, Y, Yb) se ubican a continuación, con el grado de incompatibilidad que crece hacia la izquierda (Rollinson, 1993). En las Figuras 7.10 y 7.11 se muestra el patrón de elementos incompatibles normalizados a los MORB de las rocas del CVPM.

Dejando de lado al Sr, el cual es compatible en las plagioclasas, todos los elementos representados en el diagrama spider de elementos incompatibles, tienen coeficientes de partición bajos entre un magma basáltico y una asociación cristalizante con olivina, plagioclasa y clinopiroxeno. Mientras procede la cristalización fraccionada, y también durante la fusión parcial del manto, no se afecta significativamente la razón entre los elementos incompatibles, con la excepción del Sr. Esto produce que la curva se desplace hacia arriba por un aumento de la abundancia de los elementos, aunque no cambia significativamente la forma de la curva (Figs. 7.10 y 7.11) (Pearce, 1982).

El patrón de concentración de elementos incompatibles va a depender de las fases que se adicionen o se remuevan del magma, y de las fases retenidas en la fuente. La retención de granate en el manto durante la fusión parcial del mismo produce líquidos con un bajo contenido en Y y HREE (Riddle, 1993). La plagioclasa adicionada o sustraída del fundido durante la cristalización fraccionada a baja presión puede producir anomalías positivas o negativas de Sr, respectivamente. Existen otros procesos que también pueden producir anomalías, como la contaminación cortical, cuyo efecto es variable dependiendo de la naturaleza de las rocas asimiladas, y la retención de $\mathrm{Nb}$ y Ta en zonas de subducción (Riddle, 1993).

Considerando a los ejemplos presentados por Pearce (1982), los basaltos y traquibasaltos fisurales del CVPM son similares a una curva tipo Azores (basaltos alcalinos de intraplaca), con un enriquecimiento de los elementos más incompatibles ( $\mathrm{Ba}$, $\mathrm{Th}$, Ta y $\mathrm{Nb}$ ) y un enriquecimiento en Ti respecto a Y e Yb (Fig. 7.11). No presentan evidencias de pertenecer a una zona de subducción, como son las anomalías negativas de $\mathrm{Nb}$ y Ta. Para su comparación, se grafican en la Figura 7.11b, a los basaltos del arco Andino entre $35-39,5^{\circ} \mathrm{S}$ ya mencionados. En este caso, la anomalía negativa en $\mathrm{Ta}$ y $\mathrm{Nb}$ es notoria y, al igual que en el diagrama de $\mathrm{REE}$, los contenidos en elementos incompatibles es en general menor que en los basaltos del CVPM.

Las Figuras 7.10 y 7.11 indican que, si bien existen picos marcados en ciertos elementos y la abundancia de los elementos varía, la forma general de la curva (sin tener en cuenta los picos) no cambia para las distintas unidades del CVPM. Las anomalías negativas se producen en el $\mathrm{Ba}, \mathrm{P}_{2} \mathrm{O}_{5}$ y $\mathrm{TiO}_{2}$, indicando un control por parte de los feldespatos alcalinos, apatita y óxidos de Fe-Ti. Estos picos son marcados en las litofacies de las Traquitas Post-caldera 


\section{Diagramas Spider de elementos incompatibles (Normalización Pearce, 1983)}

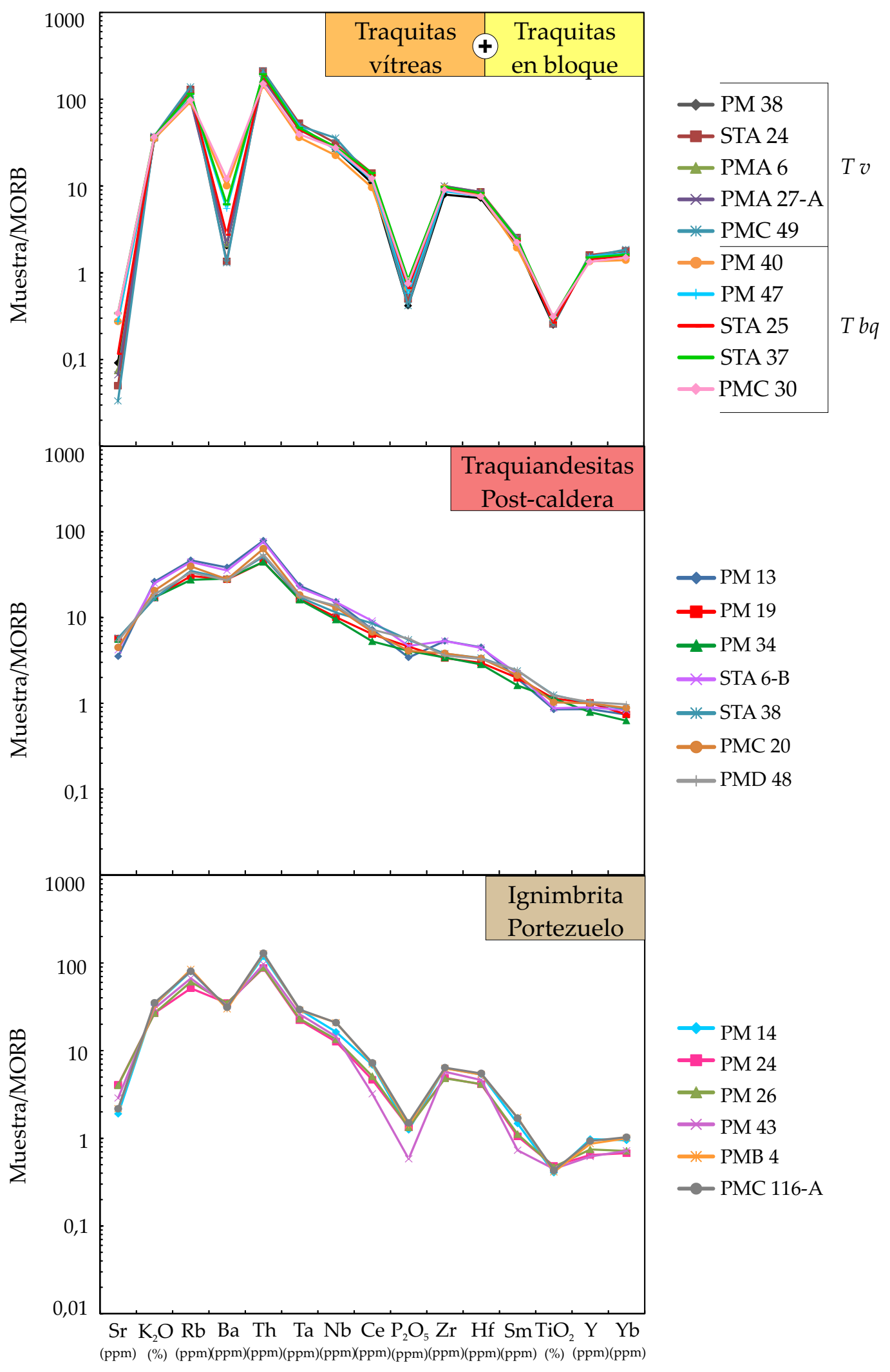

Figura 7.10: Diagrama spider de elementos incompatibles para rocas del Payún Matrú de la etapa sin- $\mathrm{y}$ post-caldera. 
Diagramas Spider de elementos incompatibles (Normalización Pearce, 1983)

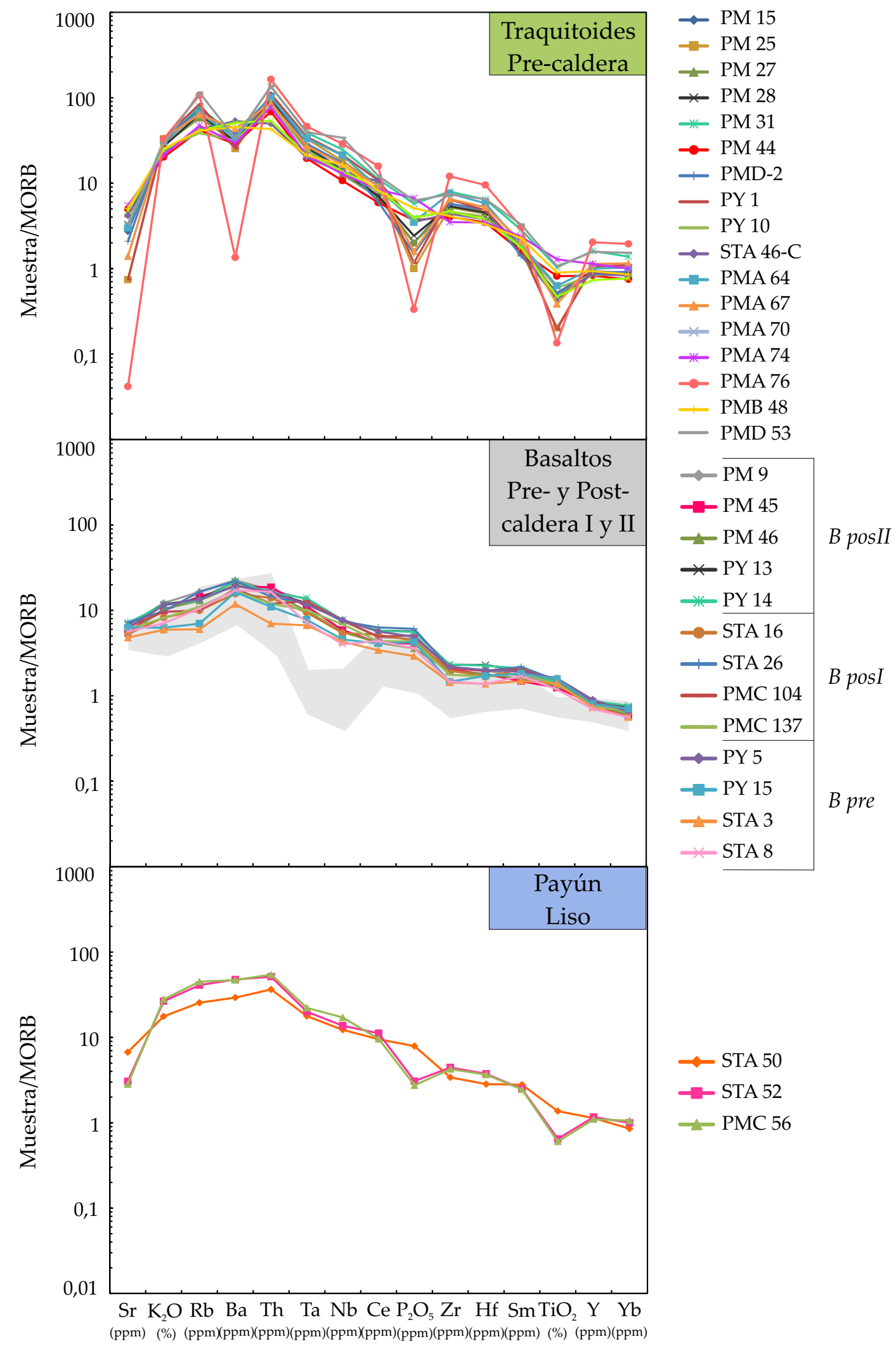

Figura 7.11: Diagrama spider de elementos incompatibles para la etapa Pre-caldera del Payún Matrú, para el Payún Liso y los basaltos fisurales (en gris basaltos del arco según HickeyVargas et al., 1989 y Tormey et al., 1991). 
y escasas Traquitoides Pre-caldera, y menores en la Ignimbrita Portezuelo y en el resto de Traquitoides Pre-caldera. En las Traquiandesitas Post-caldera las anomalías negativas en Ba, $\mathrm{P}_{2} \mathrm{O}_{5}$ y TiO${ }_{2}$ son leves a ausentes, al igual que algunos Traquitoides Pre-caldera. Se distingue una disminución en el contenido de Sr en las unidades del Payún Matrú en comparación con los basaltos fisurales, similarmente al $\mathrm{Ba}$, lo cual indica un control principalmente por parte de las plagioclasas, y también feldespato potásico.

Las Figuras 7.10 y 7.11 indican que la abundancia de los elementos incompatibles, dejando a un lado los picos negativos, aumenta progresivamente desde los basaltos hacia las rocas más evolucionadas (Traquitas Post-caldera), lo cual es la tendencia esperada en procesos de cristalización fraccionada (Pearce, 1982).

Con respecto al volcán Payún Liso, la forma de la curva es similar al de algunas lavas de Traquitoides Pre-caldera, con una posible anomalía negativa en el $\mathrm{Sr}$, y picos negativos en el $\mathrm{P}_{2} \mathrm{O}_{5}$ y TiO$_{2}$, pero no en el $\mathrm{Ba}$ (Fig. 7.11). Esto sugiere que el Payún Liso pudo haber sido el producto de la diferenciación de los magmas basálticos, al igual que el Payún Matrú.

La falta de una anomalía de $\mathrm{Nb}$ y $\mathrm{Ta}$ es indicativa de la falta de una componente de subducción en los magmas, ya que esta anomalía es probablemente un rasgo diagnostico de trasporte de elementos traza por fluidos acuosos a presiones relativamente bajas (1-2 GPa) en las partes relativamente someras de una zona de subducción (Baier et al., 2007). A mayores presiones ( $5 \mathrm{GPa}$ ), estos elementos se vuelven más solubles en los fluidos acuosos, lo cual produce la desaparición de la anomalía de $\mathrm{Nb}$ y Ta (Baier et al., 2007). Esto se debe a que el contenido de aluminio en el clinopiroxeno disminuye a mayores presiones, y a que el particionamiento del $\mathrm{Nb}$ y Ta en el clinopiroxeno aluminoso es esencial para el empobrecimiento de estos elementos en fluidos acuosos (Baier et al., 2007). No es necesaria la presencia de rutilo (que retiene al $\mathrm{Nb}$ y Ta) en la placa oceánica que subducta, aunque ayuda en esta característica.

En resumen, los diagramas spiders de elementos incompatibles indican que la fuente de los basaltos/traquibasaltos es un manto fértil (como en los basaltos tipo OIB) y no un manto deprimido (como en los MORB), y que las traquitas tanto pre- como post-caldera parecen ser consecuencia del fraccionamiento de los basaltos fisurales. Con respecto a las Traquiandesitas Post-caldera, y a gran parte de las Traquitas Pre-caldera, no se puede afirmar con la geoquímica solamente si las tendencias observadas son producto de la cristalización fraccionada de los basaltos, o si son producto de la mezcla entre estos últimos con magmas traquíticos.

\subsection{Discriminación tectónica}

El CVPM se encuentra en el retroarco Andino Cuaternario y, aunque su ambiente tectónico es conocido, se realizaron algunos diagramas de discriminación tectónica para comparar su ubicación tectónica con su afinidad geoquímica. 
El diagrama de Pearce et al. (1984) modificado por Förster et al. (1997), el cual plotea al $\mathrm{Y}+\mathrm{Nb}$ vs. $\mathrm{Rb}$, es un diagrama que fue originalmente realizado para rocas graníticas, pero que igualmente se puede aplicar a rocas volcánicas. Este diagrama está diseñado para discriminar tectónicamente a rocas intermedias a ácidas, con contenidos de $\mathrm{SiO}_{2}$ mayores al 60 \% (Förster et al., 1997). Por este motivo, en este diagrama fueron ploteadas solamente las Traquitas Post-caldera, una sola muestra de las Traquiandesitas Post-caldera (PM 13 de la colada intracaldera), la Ignimbrita Portezuelo, la gran parte de las lavas de los Traquitoides Pre-caldera, y dos lavas del volcán Payún Liso. Todas las muestras se ubican dentro del campo de WPG (granitos de intraplaca) (Fig. 7.12 a). La tendencia que muestra la Figura 7.12 a, estaría causada por diferenciación, debido a que este proceso produce que las rocas ploteen paralelamente a las lineas que dividen los campos de WPG con COLG y ORG (Förster et al., 1997). Las dos lavas pertenecientes al basamento del CVPM (STA 59-B y STA 64-A, Fig. 7.1) caen en el campo VAG, de granitos de arco volcánico (Fig. 7.12).

El campo de WPG incluye una variedad de ambientes tectónicos, además de intraplaca continental y oceánica (Förster et al., 1997). Este campo también abarca a rocas formadas en cuencas de trasarco oceánicas, cuencas de retroarco continentales, rocas formadas en un estadio post-colisión continente-continente y, ocasionalmente, a rocas evolucionadas de márgenes continentales, o un estadio terminal de un magmatismo de arco continental (Förster et al., 1997).

Gorton y Shandl (2000) realizaron una modificación de un diagrama de discriminación tectónica diagramado por Pearce (1983), el cual plotea a Ta/Yb vs. Th/Yb. Este diagrama, junto con el de $\mathrm{Yb}$ vs. Th/Ta utilizado por los mismos autores, está indicado para rocas intermedias a ácidas, con un contenido de $\mathrm{SiO}_{2}>54 \%$. Sin embargo, en los diagramas correspondientes se grafican áreas en donde se ubicarían los basaltos de intraplaca y dorsales oceánicas. Es por este motivo que se han confeccionado estos gráficos para todas las muestras, no solo para las intermedias a ácidas.

Pearce y Peate (1995) definieron elementos conservativos y no conservativos. Los elementos conservativos son aquellos que no tienen una contribución detectable de la placa subductada a la fuente del volcanismo de arco, mientras que los no-conservativos si la poseen. En un ambiente de subducción, los elementos no-conservativos son incorporados al magma generado por fusión o por fluidos acuosos. Los elementos conservativos permanecen en la placa subductada debido a que están contenidos en fases accesorias, o porque los fluidos acuosos no los movilizan (Pearce y Peate, 1995). Los elementos típicamente conservativos son los elementos de alto potencial iónico (HFSE) y HREE, mientras que los noconservativos son las LREE y los elementos litófilos de radio iónico grande (LILE). El Th, si bien pertenece al grupo de HFSE, se comporta como no-conservativo en ambientes de arco, ya que la solubilidad del Th en fluidos de zonas de subducción es extremadamente baja y se considera que este elemento es derivado de los sedimentos de la placa subductada (Gorton y Shandl, 2000). Esto explicaría el aumento del Th con respecto al Ta en los magmas de arco 


\section{Diagramas de discriminación tectónica}
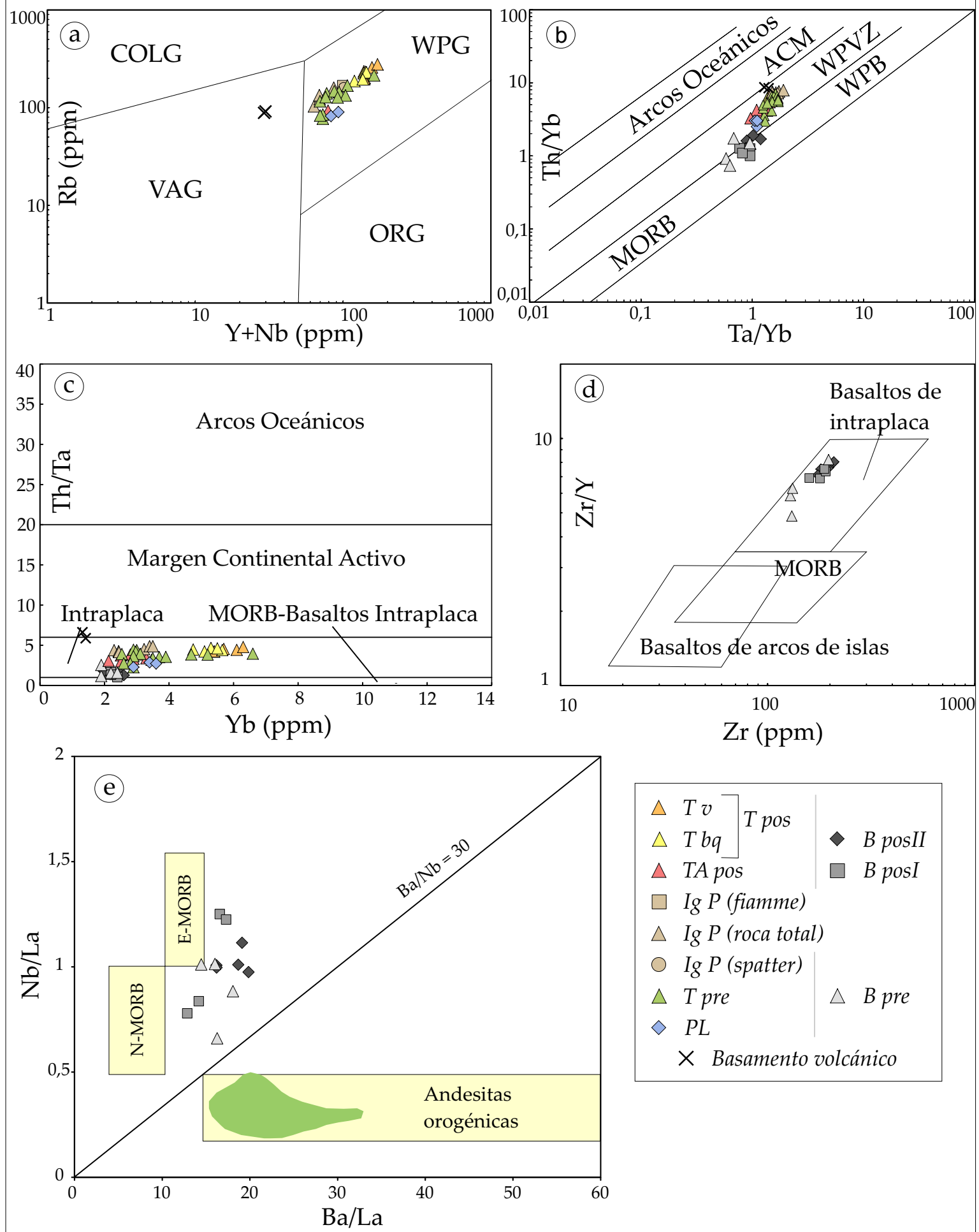

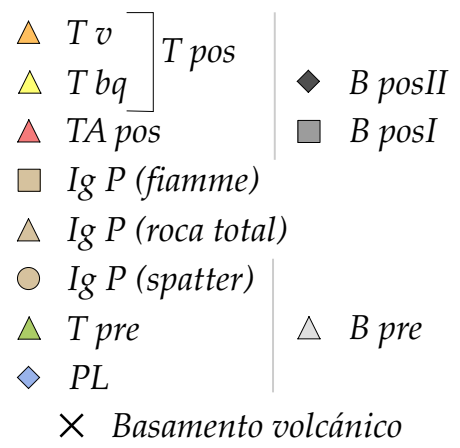

Figura 7.12: Diagramas de discriminación tectónica según: a) Pearce et al. (1984) modificado por Förster et al. (1997); COLG: granitoides colisionales. VAG: granitoides de arco volcánico. WPG: granitoides de intraplaca. ORG: granitoides de dorsal oceánica. b y c) Gorton y Shandl (2000). ACM: margen continental activo. WPVZ: zonas volcánicas de intraplaca. WPB: basaltos de intraplaca. d) Pearce y Norry (1979). e) Comparación entre los contenidos de Ba y Nb, campos de acuerdo a Hawkesworth et al. (1995). En verde se grafican los basaltos del arco Andino Cuaternario de diferentes centro volcánicos entre $35^{\circ} \mathrm{S}$ y $39,5^{\circ} \mathrm{S}$ (datos de Hickey-Vargas et al., 1989 y Tormey et al., 1991). 
(Gorton y Shandl, 2000).

Dentro de una suite, un aumento en $\mathrm{Th} / \mathrm{Yb}$ es acompañado por un aumento similar en $\mathrm{Ta} / \mathrm{Yb}$ en rocas intermedias a ácidas, ya que el Th y Ta son similares en cuanto a su grado de incompatibilidad en las mismas, mientras que el $\mathrm{Yb}$ es significativamente menos compatible (Gorton y Shandl, 2000). El Yb es utilizado como normalizador para minimizar los efectos de fusión parcial y cristalización fraccionada (Pearce y Peate, 1995). En el diagrama de Ta/Yb vs. $\mathrm{Th} / \mathrm{Yb}$, una misma suite tiene una pendiente de 1 ya que el Th y Ta están enriquecidos a un grado similar con respecto al $\mathrm{Yb}$ (Gorton y Shandl, 2000). El mismo autor dividió ambientes tectónicos en un diagrama de $\mathrm{Yb}$ vs. Th/Ta, representando a arcos oceánicos con los mayores valores de Th/Ta, seguido de margenes continentales activos, intraplaca y MORB-basaltos de intraplaca en un único campo. En la Figura 7.12 b y c, se observa que las muestras del CVPM caen en los campos de intraplaca, en concordancia con la Figura 7.12 a.

Otro diagrama discriminatorio utilizado para basaltos plotea al contenido de $\mathrm{Zr}$ vs. $\mathrm{Zr} / \mathrm{Y}$ (Pearce y Norry, 1979). En concordancia con los gráficos anteriores, los basaltos fisurales del CVPM se ubican sin dudas en el campo de los basaltos de intraplaca (WPB) (Fig. $7.12 \mathrm{~d}$ ).

Por último, es útil comparar los contenidos de $\mathrm{Ba} \mathrm{y} \mathrm{Nb}$ en los basaltos, mediante los cuales se puede distinguir si estos tienen una componente de subducción y contaminación cortical, o si son químicamente similares a los basaltos OIB (Fitton et al., 1991). La Figura 7.16b muestra que los basaltos y traquibasaltos del CVPM se ubican lejos de las lavas orogénicas, con contenidos de $\mathrm{Nb}$ relativamente altos en comparación con el Ba. En verde se indican los basaltos del arco Andino Cuaternario previamente graficados en los diagramas spiders (Hickey-Vargas et al., 1989; Tormey et al., 1991), en donde los basaltos presentan contenidos de $\mathrm{Nb}$ bajos, típico de zonas de subducción. La diferencia entre el CVPM y el arco volcánico es clara y, además, es lo esperable para ambos ambientes tectónicos. Por lo tanto, los diagramas comparativos de $\mathrm{Nb}$ y $\mathrm{Ba}$ indican una afinidad geoquímica de los basaltos del CVPM con los OIB, sin una componente de subducción.

Todos los diagramas de discriminación tectónica mostrados (junto con otros no mostrados) indican una afinidad a un ambiente de intraplaca y no a un ambiente de subducción. Esto es coherente con la similitud en las características geoquímicas entre el CVPM y basaltos tipo OIB.

\subsection{Fraccionamiento y magmas primarios}

Los magmas primarios se definen como aquellos formados por fusión parcial en profundidad y no fueron subsecuentemente modificados por procesos de diferenciación magmática durante su ascenso a la superficie (Winter, 2010). Algunos criterios para reconocer magmas primarios son químicos. Uno de ellos se basa en que la olivina residual que permanece en el manto luego de la fusión parcial, posee una composición de Fo ${ }_{86}$ a Fo91, y otro criterio es que los líquidos basálticos en equilibrio con esa composición de olivina, tendrían que 
tener un \#Mg entre 66 y 75 (Aldanmaz et al., 2006; Best y Christiansen, 2001; Winter, 2010). Otras características de magmas primarios son los altos contenidos de $\mathrm{Cr}$ (>1000 ppm) y Ni (> 300-500 ppm) (Aldanmaz et al., 2006; Best y Christiansen, 2001; Winter, 2010).

Los contenidos de Ni y Cr para los basaltos fisurales del CVPM oscilan entre $<20$ y 80 ppm, y 30-180 ppm, respectivamente. Estos contenidos resultan muy bajos en comparación con lo esperado para un magma primario.

\subsection{1. $\quad$ \# $\mathrm{Mg}$}

El número de $\mathrm{Mg}$ se calcula en base a los contenidos de $\mathrm{Mg}$ y Fe en la roca: \#Mg = $\mathrm{Mg} /\left(\mathrm{Mg}+\mathrm{Fe}^{+2 *}\right)$. El Fe total se expresa como $\mathrm{Fe}^{+2}$, y dado que los análisis químicos de roca total proveen el hierro como $\mathrm{Fe}_{2} \mathrm{O}_{3}$, es necesario hacer una conversión. Para ello se utilizaron los cálculos de Le Maitre (1976), en donde el porcentaje de FeO que tendría la roca se calcula no solo en base al porcentaje $\mathrm{Fe}_{2} \mathrm{O}_{3}$, sino también con los porcentajes de $\mathrm{SiO}_{2}$ y álcalis. A partir del porcentaje de $\mathrm{FeO}$ que estaría presente en las rocas, se puede conocer el porcentaje $\mathrm{Fe}_{2} \mathrm{O}_{3}$ y este, a su vez, fue convertido a $\mathrm{FeO}$ y sumado al $\mathrm{FeO}$ calculado previamente.

En la Figura 7.13 se muestra un diagrama de variación de la $\mathrm{SiO}_{2} v s$. \# $\mathrm{Mg}$, en el cual se observa una correlación negativa. El \# Mg para los basaltos varía entre 45 y 55, siendo estos valores bajos como para tratarse de magmas primarios.

El fraccionamiento de plagioclasas puede estar indicado por el decrecimiento de $\mathrm{Sr}$ con el decrecimiento de \#Mg, además de las anomalías negativas de Sr y Eu en los diagramas spiders (Xia et al., 2004). En los basaltos y traquibasaltos del CVPM no se observa esta tendencia entre el Sr y \#Mg, sino al revés, con una correlación negativa con pendiente suave (diagrama no mostrado). Además, no existe una anomalía negativa de Sr ni Eu en los diagramas multielementos. Estas dos tendencias observadas no están de acuerdo con el fraccionamiento de plagioclasas en los basaltos fisurales del CVPM.

\subsubsection{Covariaciones $\mathrm{Cr}-\mathrm{Y}$}

Pearce (1982) ideó un gráfico el cual plotea al Y (elemento incompatible en los magmas basálticos) vs. Cr (o Ni, utilizado como índice del fraccionamiento). Si bien este gráfico discrimina tectónicamente a diferentes tipos de basaltos (entre MORB, basaltos de intraplaca y de arco volcánico), también es un indicador de si hubo o no fraccionamiento en los basaltos previamente a su erupción, por lo cual este diagrama se presenta en esta sección.

Los elementos $\mathrm{Y}$ y $\mathrm{Cr}$ no participan de los procesos que dan lugar a la heterogeneidad del manto, debido posiblemente a que los procesos de empobrecimiento y enriquecimiento del mismo involucran la transferencia de elementos incompatibles con una lerzolita granatífera (Pearce, 1982). El diagrama de $\mathrm{Y} v$ s. Cr es indicativo de si hubo fraccionamiento en los basaltos, ya que el $\mathrm{Cr}$ es un elemento que está fuertemente particionado en las fases máficas 


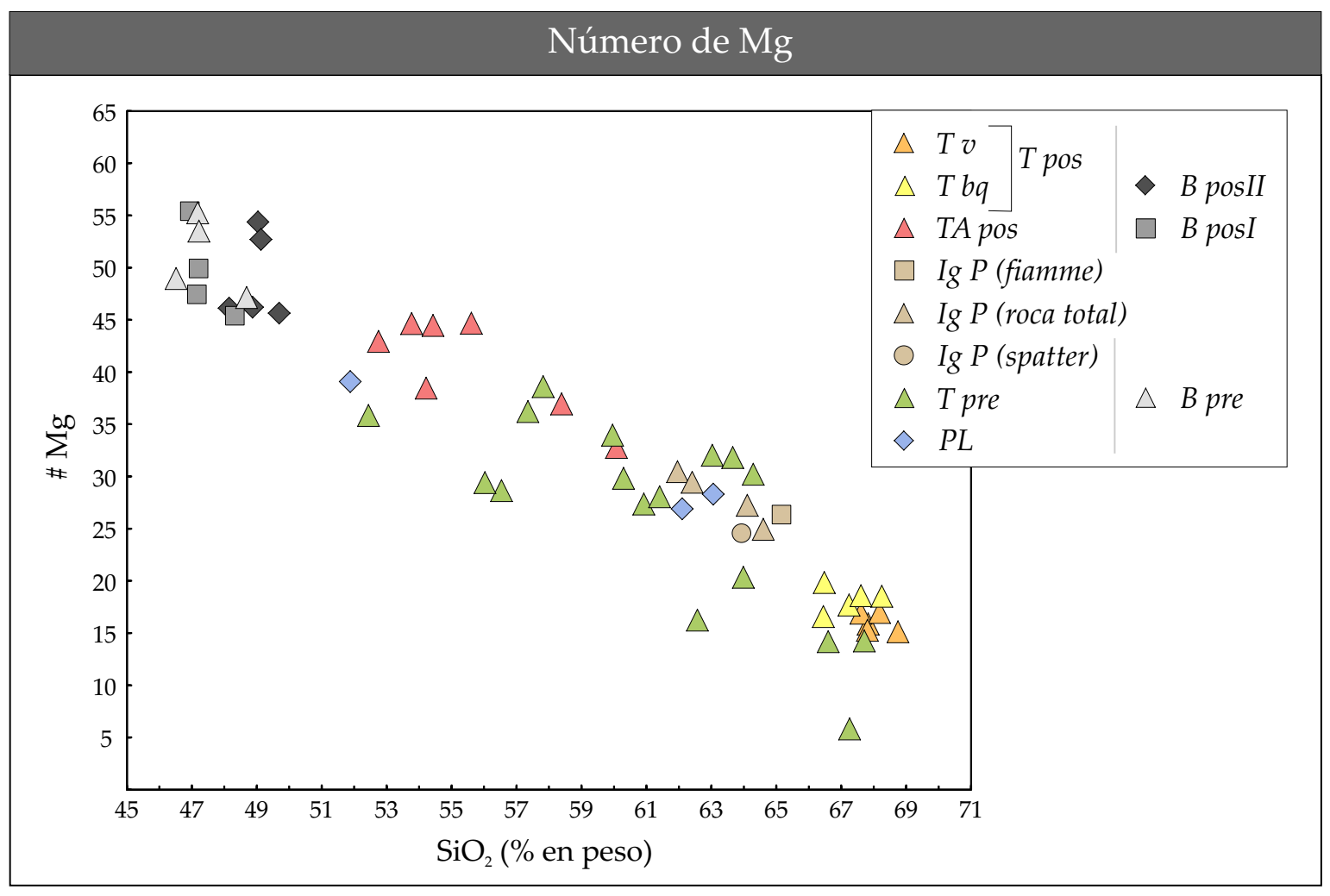

Figura 7.13: Diagrama de $\mathrm{SiO}_{2}$ vs. \# Mg.

que cristalizan tempranamente, como la olivina, piroxeno y espinela de cromo. Como consecuencia, la tendencia inicial cuando estas fases se fraccionan es vertical, paralela al eje del Cr. Cuando la plagioclasa empieza a cristalizar y fraccionarse, la tendencia en el diagrama se curva haciéndose más horizontal, debido a que la plagioclasa no incorpora al Cr (Pearce, 1982). El Y, al ser un elemento incompatible, su abundancia depende no sólo del grado de fusión parcial, sino también de la presencia o no de fases que retengan a dicho elemento en el manto (como es el caso del granate).

En la Figura 7.14 se pueden distinguir tres campos, con superposición parcial entre ellos, en donde se diferencian los basaltos MORB, de intraplaca y de arcos volcánicos (Pearce, 1982). La tendencia que presentan los basaltos/traquibasaltos es claramente subvertical, sugiriendo que tuvo lugar el fraccionamiento de fases máficas, aunque no de plagioclasa. Extrapolando esta tendencia subvertical hacia la curva que representa la fusión parcial del manto, se sugeriría que el grado de fusión parcial fue de aproximadamente $20 \%$. Sin embargo, no es conveniente afirmarlo ya que la curva de fusión parcial representada en la Figura 7.14 depende de como sea modelado el manto (lerzolita con plagioclasa en este caso), y existe una alta probabilidad de que no coincida con las características de la fuente de los basaltos de CVPM. Si la fuente mantélica contiene fases que retienen el Y, entonces el grado de fusión parcial sería menor. 


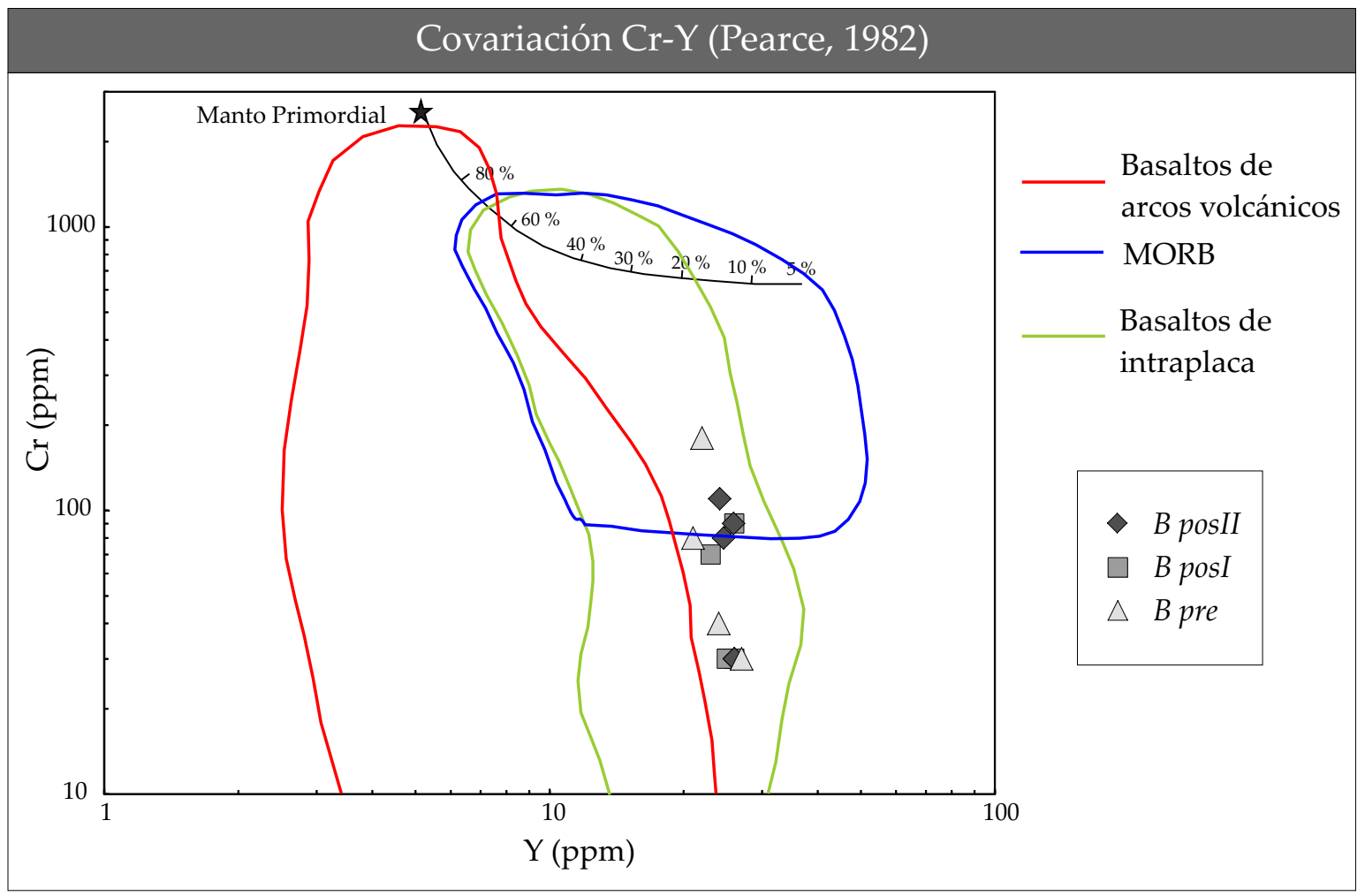

Figura 7.14: Covariación Cr-Y (Pearce, 1982).

Los basaltos y traquibasaltos plotean dentro del campo de basaltos de intraplaca, lo cual es acorde a los diagramas de discriminación tectónica mostrados anteriormente. Algunas lavas plotean en la zona en donde los campos de basaltos de intraplaca y MORB se superponen, aunque es fácilmente distinguible que estos no pertenecen a una dorsal oceánica.

\subsubsection{Otras evidencias de fraccionamiento en basaltos}

Otras evidencias químicas, además de las mencionadas, pueden utilizarse para identificar si los basaltos son magmas primarios, y que minerales estarían involucrados en su fraccionamiento. Una de ellas es la correlación positiva entre los contenidos de $\mathrm{MgO}$ y Sc, lo cual indica el fraccionamiento del clinopiroxeno, debido a que el Sc es un elemento compatible en este mineral (Feeley y Winer, 1999). En los basaltos fisurales del CVPM (así como también en el resto de las rocas, figura no mostrada) se observa una clara correlación positiva, sugiriendo que tuvo lugar el fraccionamiento de clinopiroxenos, no solo en los basaltos, sino también en las rocas del Payún Matrú (y probablemente en el Payún Liso también).

El fraccionamiento de clinopiroxeno también es sugerido por correlaciones positivas entre $\mathrm{MgO}$ y CaO$/ \mathrm{Al}_{2} \mathrm{O}_{3}$, en conjunto con una correlación positiva entre $\mathrm{MgO}$ y Sc/Y (Mattsson y Oskarsson, 2005). El clinopiroxeno es el único mineral presente en basaltos que puede causar la disminución del $\mathrm{CaO}$ sobre el $\mathrm{Al}_{2} \mathrm{O}_{3}$, y generalmente se asocia con una cristaliza- 
ción a altas presiones. Esta misma tendencia puede ocurrir por acumulación de plagioclasa o una variación en el grado y profundidad de fusión (Mattsson y Oskarsson, 2005). El fraccionamiento de clinopiroxeno se confirma al observar la correlación positiva entre el $\mathrm{MgO}$ y la razón Sc/Y. Se eligen al Sc e Y por tener ambos un coeficiente de distribución similar en olivinas y plagioclasas, pero no en clinopiroxenos, ya que el Sc es compatible en este mineral y no así el Y (Mattsson y Oskarsson, 2005). La Figura 7.15 muestra correlaciones positivas entre el $\mathrm{MgO}$ y $\mathrm{CaO} / \mathrm{Al}_{2} \mathrm{O}_{3}$, así como entre $\mathrm{MgO}$ y Sc/Y, lo cual indica que tuvo lugar el fraccionamiento de clinopiroxeno, al ser el único mineral capaz de producir las tendencias observadas en ambos gráficos (Mattsson y Oskarsson, 2005).

El fuerte decrecimiento del Ni en relación a la $\mathrm{SiO}_{2}$ (Fig. 7.6) es coherente con el fraccionamiento de olivinas en los basaltos y traquibasaltos fisurales (Winter, 2010; Riddle, 1993). No se encuentran evidencias de un fraccionamiento significativo de plagioclasas en las unidades basálticas, por varios motivos: i) no se hallan anomalías negativas de Sr en el diagrama spider de elementos incompatibles (Fig. 7.11); ii) no poseen anomalías negativas de Eu en el diagrama multielementos de REE (Fig. 7.8); iii) existe una correlación negativa con pendiente suave entre el \#Mg y el Sr (Xia et al., 2004) y, iv) debido a la tendencia vertical en el diagrama de $\mathrm{Y}$ vs. Cr (Fig. 7.14) (Pearce, 1982). El hecho de que los diagramas químicos indiquen el fraccionamiento de olivinas y clinopiroxenos pero no significativamente de plagioclasas en las lavas de los campos basálticos, sugiere un fraccionamiento en profundidad.

\subsection{Fuente mantélica}

Sobre la base de los datos geoquímicos, pueden realizarse inferencias sobre la fuente mantélica y las condiciones de fusión de la misma, como son la profundidad y el grado de fusión. Un cociente frecuentemente utilizado para inferir la composición mineralógica y profundidad del manto es $\mathrm{La} / \mathrm{Yb}$ normalizado a los meteoritos condriticos. El La es altamente incompatible en los minerales de peridotita con espinela y granate, mientras que el $\mathrm{Yb}$ es incompatible en espinela pero no en granate Farmer (2003). Una razón ( $\mathrm{La} / \mathrm{Yb})_{\mathrm{n}}$ alta (aproximadamente $>5$ ) en basaltos primarios es un indicador de granate en la fuente (Farmer, 2003). En los basaltos fisurales este cociente es relativamente alto, con valores entre 5 y 9 (Fig. 7.9), lo cual indicaría la presencia de granate en la fuente reteniendo a los HREE. Sin embargo, hay que considerar que no se trata de fundidos primarios sino que los magmas basálticos fueron modificados por procesos de cristalización fraccionada, por lo cual habría que analizar cómo modifican estos procesos a la pendiente de las REE.

Los elementos de las Tierras Raras pueden ser utilizados para discernir entre la fusión de una fuente a alta presión y una a baja presión. A profundidades mayores a $70 \mathrm{~km}$, el granate y clinopiroxeno son fases importantes en el manto, y permanecen como fases residuales cuando se produce hasta 15-20 \% de fusión parcial (Winter, 2010). El empobreciminto extremo de las HREE con respecto a las LREE en el patrón del diagrama spider de las rocas 


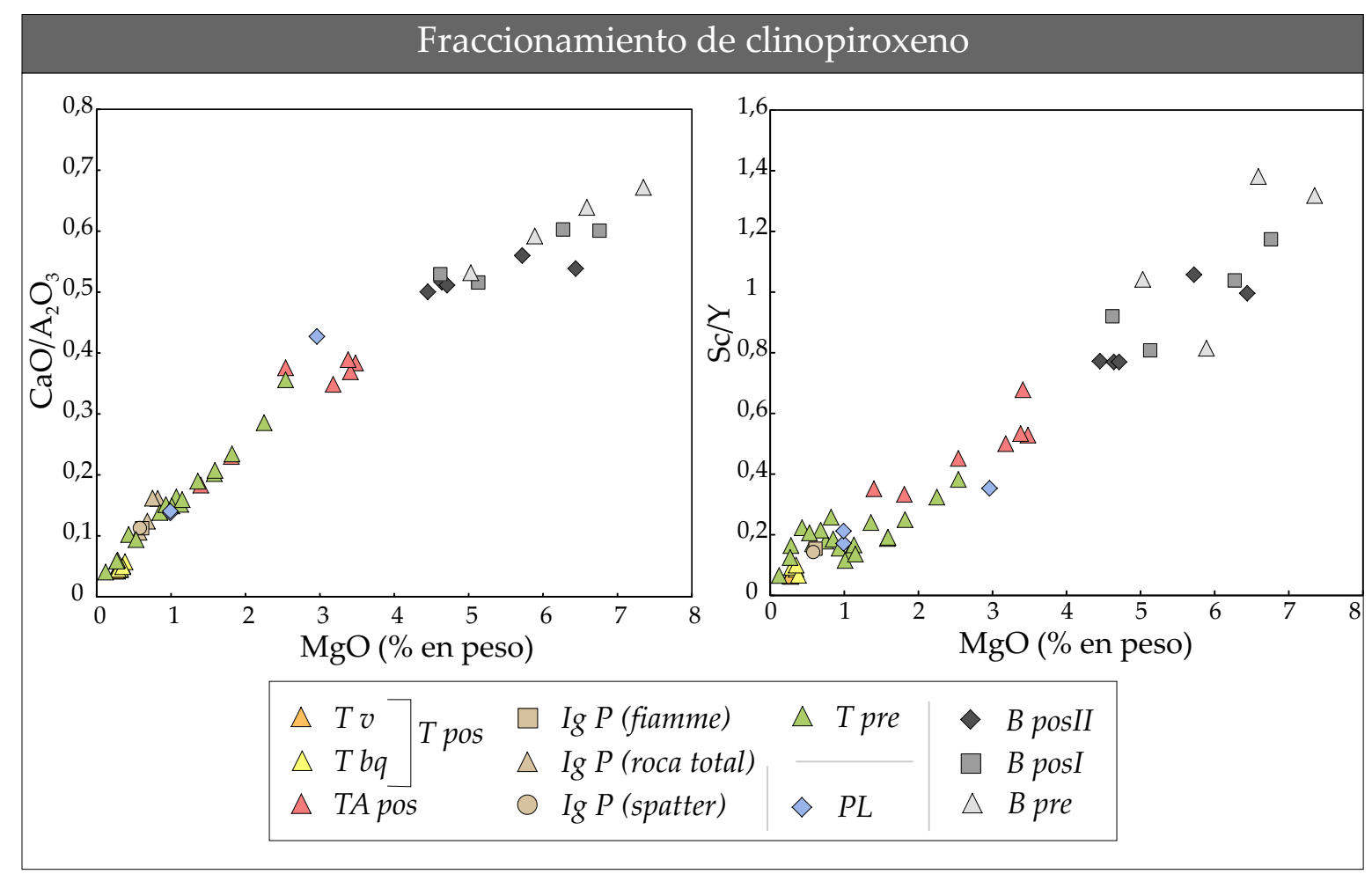

Figura 7.15: Diagramas bivariantes que sugieren el fraccionamiento de clinopiroxeno, debido a las correlaciones positivas exhibidas.

básicas puede indicar la presencia de granate en la fuente (Rollinson, 1993; Winter, 2010). Tanto el bajo grado de fusión parcial como la retención de granate en la fuente producen pendientes negativas fuertes, aunque la presencia de granate en la fuente genera típicamente una pendiente negativa dentro de las HREE, mientras que el enriquecimiento de LREE a bajos grados de fusión parcial produce cambios menores dentro de las HREE (Winter, 2010).

El granate cambia notoriamente el coeficiente de partición para las REE en líquidos basálticos a partir del Dy (Rollinson, 1993), y por este motivo se eligió la relación Dy/Lu como medida de la pendiente de las HREE. En los basaltos y traquibasaltos existe una pendiente negativa leve dentro de las HREE, dado que el cociente Dy/Lu se encuentra entre 1,24 y 1,67 . Desde las unidades basálticas a las traquíticas, existe un cambio en la pendiente dentro de las HREE, en donde la pendiente negativa en los basaltos disminuye, e inclusive se vuelve positiva, en las Traquitas Post-caldera (Figs. 7.7 y 7.11). Los minerales que pueden ser responsables del cambio de pendiente en las HREE son la plagioclasa y el anfíbol, los cuales poseen coeficientes de partición tales como para producir la tendencia observada (Rollinson, 1993). Debido a que no se evidencia el fraccionamiento de estos minerales en los basaltos, no parece factible que los basaltos primarios hayan tenido una pendiente negativa mayor dentro de las HREE.

Diversos diagramas químicos se han utilizado para inferir la fuente de los magmas y 


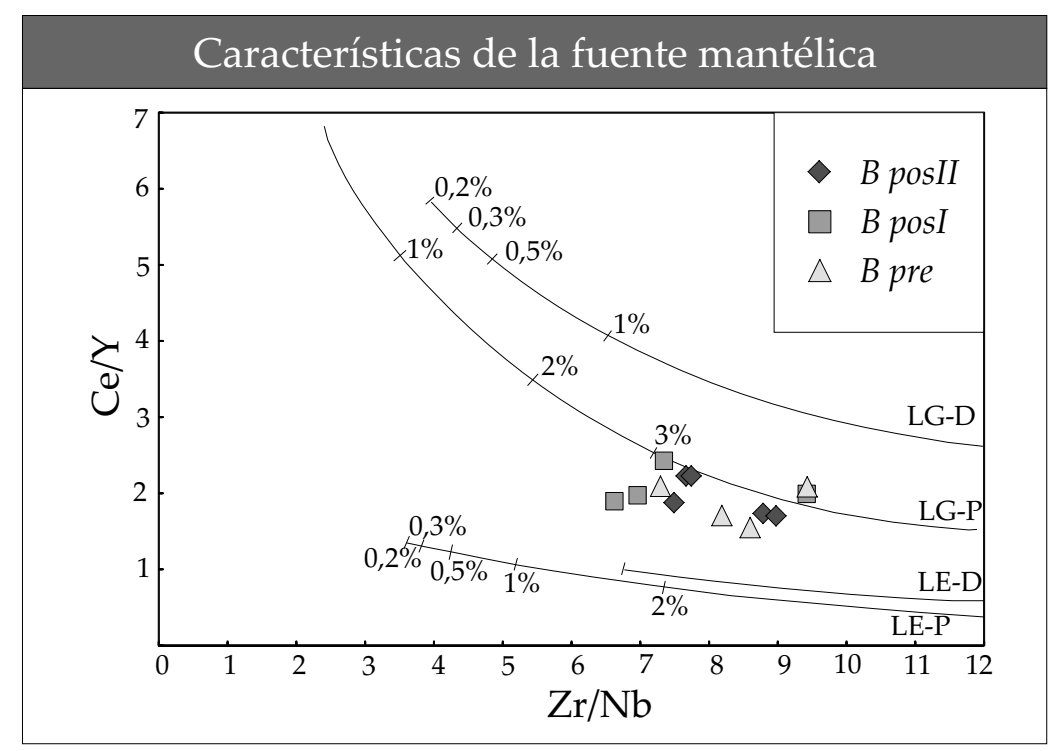

Figura 7.16: Dos diagramas químicos que ilustran las características de la fuente mantélica de los magmas basálticos. a) Según Hardarson y Fitton (1991). LG: Lerzolita con granate, LE: Lerzolita con espinela. D: Deprimida, P: Primitiva.

el grado de fusión, aunque las curvas de fusión representadas en los mismos dependen de cómo sea modelado el manto. Uno de estos diagramas es el que compara al cociente $\mathrm{Zr} / \mathrm{Nb}$ vs. Ce/Y (Hardarson y Fitton, 1991). En este gráfico, se dibujan curvas de fusión para cuatro composiciones mantélicas: lerzolitas con granate deprimidas y primitivas (fértiles), y lerzolitas con espinela deprimidas y primitivas. En la Figura 7.16 a, se muestra que los basaltos y traquibasaltos fisurales del CVPM se ubicarían en el campo de estabilidad del granate (manto fértil, no deprimido) pasando al de espinela. Esto indicaría que los magmas son generados a profundidades de entre 60 y $80 \mathrm{~km}$, o inclusive más considerando las lavas ubicadas dentro del campo de estabilidad del granate (Xia et al., 2004).

Otros diagramas útiles para diferenciar entre una fuente mantélica con granate o con espinela están dados por las relaciones de LREE/HREE vs. MREE/HREE, como por ejemplo $\mathrm{La} / \mathrm{Yb}$ vs. Dy/Yb (Baker et al., 1997). La fusión en el campo de la espinela produce pocos cambios en el cociente $\mathrm{Dy} / \mathrm{Yb}$ de los fundidos en comparación con el de su fuente, y también pocos cambios en $\mathrm{Dy} / \mathrm{Yb}$ con la fracción de fundido producido. En cambio, la fusión en el campo de estabilidad del granate produce grandes cambios en $\mathrm{Dy} / \mathrm{Yb}$ con la fracción de fundido y, además, esta relación en el fundido es distinta a la de su fuente (Baker et al., 1997). Otro diagrama similar compara a la relación $\mathrm{La} / \mathrm{Yb}$ con el $\mathrm{Yb}$, en donde la fusión de una lerzolita con espinela produce una correlación positiva fuerte entre $\mathrm{La} / \mathrm{Yb}$ y $\mathrm{Yb}$. Por otra parte, la fusión de una lerzolita con granate produce fundidos sin una corrivación entre $\mathrm{La} / \mathrm{Yb}$ y $\mathrm{Yb}$, ya que el $\mathrm{Yb}$ es retenido por el granate (Baker et al., 1997).

Los diagramas $\mathrm{La} / \mathrm{Yb}$ vs. $\mathrm{Dy} / \mathrm{Yb}$ para los basaltos y traquibasaltos (no mostrado) mues- 
tran una tendencia casi vertical al igual que la curva de fusión del granate (para los valores bajos de $\mathrm{La} / \mathrm{Yb}$ ), aunque las muestras se ubican entre las curvas de fusión de una lerzolita con granate y una con espinela. En cuanto al diagrama de $\mathrm{La} / \mathrm{Yb} v s$. $\mathrm{Yb}$ (no mostrado), también exhibe una tendencia casi vertical con valores relativamente bajos de $\mathrm{La} / \mathrm{Yb}$, en este caso coincidiría con la curva de fusión de una lerzolita con espinela. Si bien las tendencias observadas en ambos gráficos son aparentemente contrarias, hay que considerar que estos modelos semicuantitativos dependen de qué manera es modelado el manto. Por ejemplo, el grado de fusión inferido depende de las proporciones de clinopiroxeno/granate. La contaminación cortical y la extensiva cristalización fraccionada pueden producir dispersión (Baker et al., 1997). Una opción viable que explicaría ambos gráficos es que los basaltos sean fundidos formados en parte por una lerzolita con granate, y en parte por una lerzolita con espinela.

A profundidades menores a los 30-40 km la plagioclasa es una fase importante en el manto, y puede ser detectada por una anomalía de Eu en el fundido (Winter, 2010). Esta anomalía no se observa en los basaltos fisurales, por lo cual podría descartarse que la fuente mantélica contenga plagioclasa (además de que la profundidad cortical para este sector es de unos $35 \mathrm{~km}$, Yuan et al., 2006).

También queda descartada una fuente mantélica litosférica con flogopita o anfíbol. El $\mathrm{K}$, $\mathrm{Rb}$ y Ba se particionan preferentemente en la flogopita, y empobrecimientos relativos de estos elementos en diagramas spider normalizados al manto primitivo indican la presencia de flogopita en la fuente. El anfíbol también retiene al $\mathrm{K}$ y Ba, así como al Sr y las MREE (Farmer, 2003). No se encuentran evidencias de empobrecimiento en estos elementos en el diagrama spider normalizado al manto primitivo en el CVPM (no mostrado), por lo cual no parece probable la opción de un manto litosférico con flogopita o anfíbol.

En síntesis, si bien las lavas de los campos basálticos muestran características que indican una fuente mantélica con granate, también presentan otras más afines con una fuente con espinela o no definitorias para uno $u$ otro caso (como las muy leves pendientes negativas en las HREE). Es probable, por lo tanto, que los magmas se hayan originado en parte por fusión de un manto con granate, y en parte por fusión de un manto con espinela, a profundidades entre 60-80 km (pudiendo estar la fuente a más profundidad).

\subsection{Isótopos de $\mathrm{Sr}$ y $\mathrm{Nd}$}

Las relaciones isotópicas de $\mathrm{Sr}$ y $\mathrm{Nd}$ son importantes para caracterizar la fuente de los magmas, ya que el magma hereda las relaciones isotópicas de su fuente y, además, esta no se modifica por eventos posteriores de fraccionamiento (Rollinson, 1993; Winter, 2010). Las rocas ígneas jóvenes reflejan directamente la composición isotópica de la fuente. Esto es debido a que los isótopos padre ( $\mathrm{Rb}$ para el $\mathrm{Sr}$ y $\mathrm{Sm}$ para el $\mathrm{Nd}$ ) no tienen el suficiente tiempo para decaer en sus hijos radigénicos, y que se agreguen a los heredados por la fuente 
(Rollinson, 1993). Todas las rocas datadas pertenecientes al CVPM son menores a $1 \mathrm{Ma}$, por lo cual no es necesario realizar ninguna corrección por la edad.

Las rocas ígneas en general plotean en el ${ }^{143} \mathrm{Nd} /{ }^{144} \mathrm{Nd} v s .{ }^{87} \mathrm{Sr} /{ }^{86} \mathrm{Sr}$ dentro de lo que se conoce como el arreglo del manto (mantle array, Fig. 7.17). Zindler y Hart (1986) reconocieron cinco reservorios mantélicos isotópicamente diferentes, los cuales son: DM (manto deprimido), HIMU (enriquecido en $\mathrm{U}$ y Th con respecto al $\mathrm{Pb}$, y sin un aumento de $\mathrm{Rb} / \mathrm{Sr}$ ), PREMA (composición del manto prevalente), BSE (Bulk Silicate Earth), EMI y EMII (mantos enriquecidos I y II). El manto deprimido está representado por los basaltos de dorsales oceánicas, mientras que el punto que marca la Tierra primitiva (BSE, las relaciones isotópicas que tendría el material meteórico del reservorio uniforme después de $4550 \mathrm{Ma}$ ), no es ni deprimido ni enriquecido (Krauskopt y Bird, 1995).

Las rocas del CVPM se ubican dentro de la tendencia del manto, entre los reservorios PREMA-HIMU y BSE (Fig. 7.17 a). Para las muestras analizadas del CVPM, los valores de ${ }^{87} \mathrm{Sr} /{ }^{86} \mathrm{Sr}$ son relativamente acotados y se encuentran entre 0,703813 y 0,704841 , habiendo una clara distinción en dos grupos. Tres de las cuatro muestras de las Traquitas Postcaldera presentan mayores valores de ${ }^{87} \mathrm{Sr} /{ }^{86} \mathrm{Sr}$ que el resto, aunque con valores similares de ${ }^{143} \mathrm{Nd} /{ }^{144} \mathrm{Nd}$. El grupo de menores valores de ${ }^{87} \mathrm{Sr} /{ }^{86} \mathrm{Sr}$, el cual es la amplia mayoría, tiene valores entre 0,703813 y 0,704132 .

El rango de ${ }^{87} \mathrm{Sr} /{ }^{86} \mathrm{Sr}$ para los basaltos de islas oceánicas (OIB) se encuentra entre 0,7032 y 0,7050 , y poseen una relación de ${ }^{143} \mathrm{Nd} /{ }^{144} \mathrm{Nd}$ alrededor de 0,5128 (Allègre, 2008). Los rangos de valores de la relación isotópica del Sr y $\mathrm{Nd}$ del CVPM se encuentran dentro de lo que sería típico para los basaltos de islas oceánicas y, a excepción de las tres muestras mencionadas, no se observa una clara distinción entre los basaltos fisurales y las rocas del Payún Matrú. Esto refuerza la proveniencia mantélica de los magmas, debido a que los valores isotópicos están dentro de lo que es el promedio mantélico $\left(0,704\right.$ para ${ }^{87} \mathrm{Sr} /{ }^{86} \mathrm{Sr}$ ) (Krauskopt y Bird, 1995), siendo estos de valores demasiado bajos para tener una proveniencia cortical.

El hecho de que sean similares los valores entre los basaltos fisurales y los traquitoides del Payún Matrú (con las excepciones previamente mencionadas) es una evidencia importante de la cosanguineidad entre los magmas. La clara separación de las tres Traquitas Postcaldera hacia mayores valores de ${ }^{87} \mathrm{Sr} /{ }^{86} \mathrm{Sr}$ (pero que sin embargo no supera el 0,705 , y se encuentran todavía dentro del rango de los OIB) estaría indicando una moderada contaminación cortical para esas lavas.

En la Figura 7.17b se grafica la variación de la relación isotópica del Sr con el contenido en $\mathrm{SiO}_{2}$, en donde se distinguen claramente los dos grupos, con las tres muestras de Traquitas Post-caldera con mayores contenidos de ${ }^{87} \mathrm{Sr} /{ }^{86} \mathrm{Sr}$ que el resto. Dejando de lado las muestras traquíticas mencionadas, los valores de ${ }^{87} \mathrm{Sr} /{ }^{86} \mathrm{Sr}$ son similares para los basaltos/traquibasaltos fisurales y los traquitoides del Payún Matrú, aunque se observa una tendencia a que estos últimos tengan un valor levemente mayor. En general, la adición de material cortical a magmas basálticos o su región fuente se espera que resulte en una co- 


\section{Isótopos de $\mathrm{Sr}$ y $\mathrm{Nd}$}

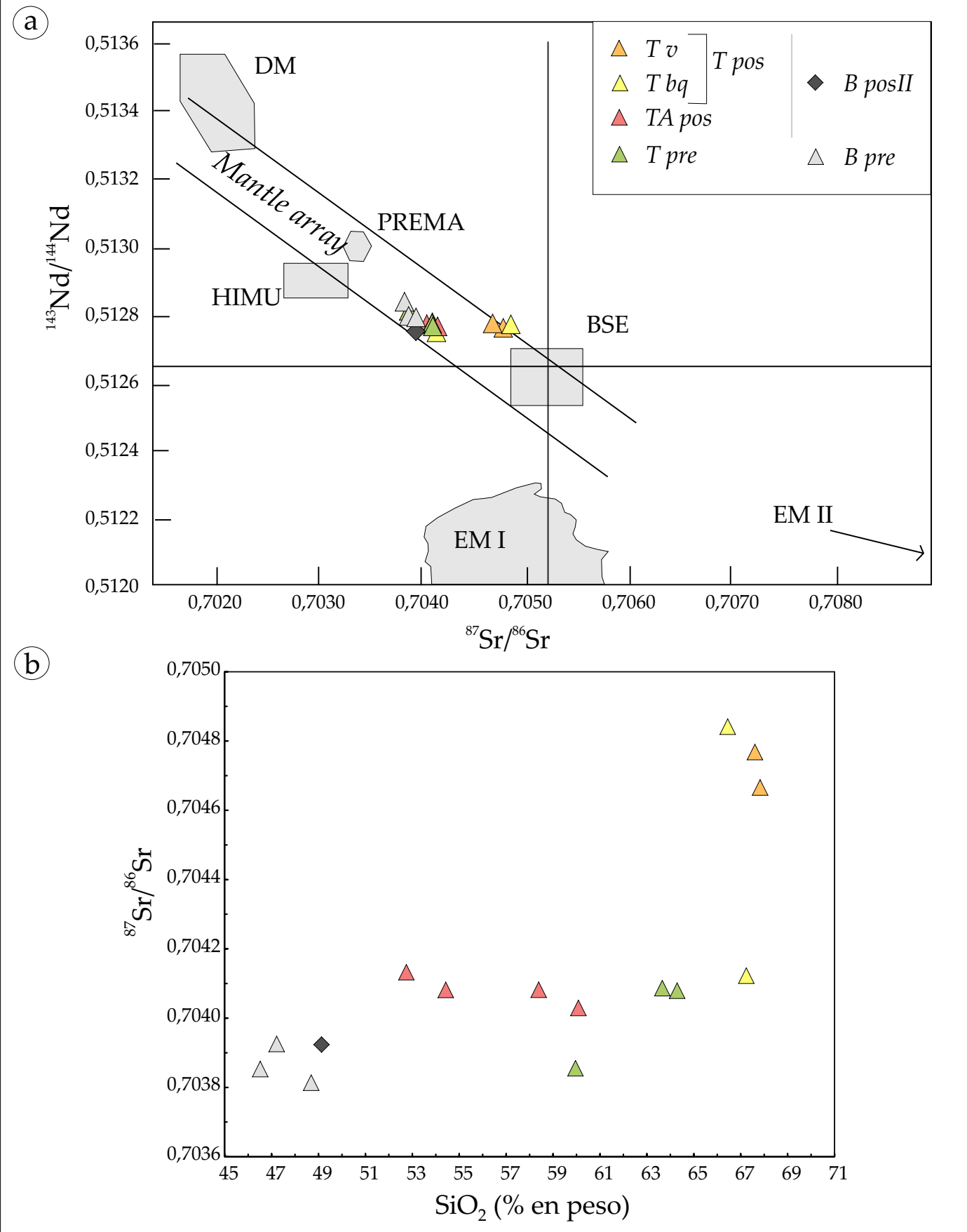

Figura 7.17: a) Relaciones isotópicas del $\mathrm{Sr}$ y $\mathrm{Nd}$, con los distintos reservorios mantélicos según Zindler y Hart (1986). DM: manto deprimido; HIMU: manto enriquecido en U y Th con respecto al $\mathrm{Pb}$; PREMA: composición del manto prevalente; BSE: composición global de la tierra silicática; EM I y II: mantos enriquecidos isotópicamente. b) Covariación $\mathrm{SiO}_{2}$ ${ }^{87} \mathrm{Sr} /{ }^{86} \mathrm{Sr}$. 
varianza positiva entre ${ }^{87} \mathrm{Sr} /{ }^{86} \mathrm{Sr}$ con parámetros como $\mathrm{SiO}_{2}, \mathrm{Rb} / \mathrm{Sr}$ y $\mathrm{K}_{2} \mathrm{O} / \mathrm{P}_{2} \mathrm{O}_{5}$ (Hoang y Uto, 2003; Aldanmaz et al., 2006). El leve aumento de ${ }^{87} \mathrm{Sr} /{ }^{86} \mathrm{Sr}$ en los traquitoides del Payún Matrú con respecto a los basaltos fisurales sugiere una leve contaminación cortical para la mayoría aunque no todas de estas rocas.

Con respecto a la fuente de los magmas, existen dos fuentes mantélicas fértiles para la generación de basaltos continentales: el manto litosférico y el sublitosférico (Farmer, 2003). Los basaltos continentales que derivan del manto sublitosferico y que no han asimilado litosfera, se espera que tengan relaciones isotópicos de $\mathrm{Sr}$ y $\mathrm{Nd}$ idénticas a los de los basaltos oceánicos (estos basaltos presentan una variedad de fuentes mantélicas, como las fuentes de los MORB y fuentes variables de OIB). El manto litosférico tiene una relación isotópica de $\mathrm{Nd}$ más baja $\left(\xi_{\mathrm{Nd}}<0\right)$ y una de Sr más alta $(>0,7045)$ en comparación con el manto sublitosferico (Farmer, 2003). Los basaltos alcalinos continentales de tipo sódico poseen un amplio rango de composiciones isotópicas, aunque típicamente tienen alta relación inicial de $\mathrm{Nd}\left(\xi_{\mathrm{Nd}}>0\right)$ y baja de $\operatorname{Sr}(<0,705)$. Nuevamente, los valores obtenidos para el CVPM coinciden con este tipo basáltico, provenientes del manto sublitosférico o astenosférico.

\subsection{Porcentajes de magmas básicos en la mezcla}

En la presente sección se muestran cálculos de porcentajes de magmas máficos involucrados en la de mezcla de magmas básicos y félsicos. Aunque todavía no fue discutida en detalle la existencia de mezcla de magmas en las rocas del Payún Matrú (ver Capítulo 9), si se han mencionado desequilibrios texturales al respecto. Los cálculos se presentan en este capítulo debido a que para los mismos se utiliza las composiciones de roca total, y con el objetivo de no presentar información nueva en las discusiones.

En aquellas lavas con fuertes evidencias de mezcla de magmas, y que además se disponían de análisis químicos de roca total, se realizó un cálculo de los porcentajes de magmas básicos y félsicos involucrados en la mezcla. Los cálculos fueron realizados en base al método descripto por Bryan et al. (1969), el cual estima a través del método de cuadrados mínimos las respectivas proporciones involucradas de magmas básicos y félsicos/intermedios. Cabe destacar que en este mismo método se basa el software IgPet para los mismos cálculos. Se utilizó una versión modificada del método descripto por Bryan et al. (1969) (para asegurar que los porcentajes de mezcla estimados sean valores positivos, debido a que el método original puede resultar en porcentajes negativos).

Los porcentajes de magmas máficos y félsicos involucrados en la mezcla calculados de esta manera, son similares a los visualmente inferidos de acuerdo a la ubicación en el diagrama TAS de los extremos composicionales y el magma híbrido. En este diagrama, así como en cualquier otro diagrama bivariante, la composición del magma intermedio se encuentra en una línea recta que une ambos extremos mezclados, y los porcentajes de estos últimos pueden calcularse mediante la regla de la palanca. La regla de la palanca es un método grá- 
fico de estimar mediante mínimos cuadrados los porcentajes de magmas básicos y silícicos, aunque presenta la desventaja de que se utilizan solamente dos óxidos. La ventaja del método descripto por Bryan et al. (1969), radica en que se pueden utilizar todos los elementos mayoritarios y minoritarios al mismo tiempo para la estimación porcentual.

Para representar al extremo máfico de la mezcla, se eligieron de una a tres composiciones de basaltos para un mismo cálculo. Para representar el extremo silícico de la mezcla, se eligieron la misma cantidad de composiciones que el extremo máfico, y se procuró elegir composiciones de traquitas con contenidos de sílice intermedios, es decir, intermedios dentro del campo de traquitas en el diagrama TAS. Esto es debido a que el extremo silícico de la mezcla no es probable que sea de una composición similar a las Traquitas Post-caldera (las cuales son las traquitas más silícicas). Es probable que el extremo silícico de la mezcla sea similar a composiciones traquíticas de los Traquitoides Pre-caldera o Ignimbrita Portezuelo, con contenidos de sílice menores (ver explicación en el Capítulo 9). En el caso especial de la colada intra-caldera de las Traquiandesitas Post-caldera, y debido a que fue encontrada lava de composición traquítica dentro de la misma (muestra PM 13, Anexo II), se utilizó la composición de esta lava como representante del extremo silícico.

El cálculo fue realizado para algunas Traquitas Pre-caldera y Traquiandesitas Post-caldera con evidencias petrológicas y de química mineral que sugieren la mezcla de magmas. Las muestras elegidas fueron: PM 27, PM 28, PY 10, PMA 74 y PMD-2 (Traquitoides Pre-caldera) y PM 34, STA 6-B y PMC 20 (Traquiandesitas Post-caldera). Los resultados de los cálculos, así como los extremos composicionales utilizados, se muestran en el Anexo V.

Los porcentajes de magmas basálticos involucrados en la mezcla es altamente variable. Estos varían desde 55-56 \% para la lava intra-caldera y la colada del Escorial del Piche (Fig. 4.1) de las Traquiandesitas Post-caldera y la muestra PMA 74 de las Traquitas Pre-caldera, hasta solamente un 3-7\% para el dique de la muestra PM 27 de las Traquitas Pre-caldera. En porcentajes intermedios, se encuentran la lava PMD-2 (T pre) con 5\%, la PM 28 (T pre) con 9-12\%, la PY 10 (T pre) con 17-22\%, y la colada STA 6-B (TA pos) con 23-30\% de magma máfico.

Cabe aclarar que el ajuste no es bueno en todos los casos, y algunos cálculos fueron desechados por el gran error presentado. Las muestras PY 10 y PMA 74 no arrojaron resultados confiables, ya que el error porcentual del ajuste es alto, por lo que se realizaron otros cálculos variando los extremos composicionales. A pesar de los errores del ajuste, el resultado final no cambia significativamente al variar los extremos composicionales, por lo cual es probable que aunque los extremos máficos y silícicos no coincidan con los reales, los porcentajes finales de magmas basálticos y traquíticos no estén tan errados. 


\subsection{Síntesis}

El CVPM es de naturaleza alcalina, con una evolución desde basaltos hasta traquitas. Los basaltos contienen nefelina normativa mientras que las traquitas poseen cuarzo normativo, lo cual se refleja en el TAS en la tendencia de las traquitas hacia el campo de las riolitas (sobresaturación en sílice).

Los basaltos alcalinos son del tipo sódico $\left(\mathrm{K}_{2} \mathrm{O} / \mathrm{Na}_{2} \mathrm{O}<1\right)$, el grupo más común entre los basaltos alcalinos continentales de intraplaca (Farmer, 2003). Este tipo basáltico consiste no sólo en basaltos sino también en traquibasaltos, y presentan ciertas características geoquímicas en común, como contenidos de $\mathrm{TiO}_{2}$ relativamente altos $(\sim 1,5-4 \%)$, y de $\mathrm{Na}_{2} \mathrm{O}$ altos $(\sim 2-4 \%)$, patrones de elementos traza normalizados al manto primitivo similares a los basaltos de islas oceánicas (OIB), y una relativa alta relación isotópica de $\mathrm{Nd}\left(\xi_{\mathrm{Nd}}>0\right)$ y baja de $\mathrm{Sr}\left({ }^{87} \mathrm{Sr} /{ }^{86} \mathrm{Sr}<0,705\right)$ (Farmer, 2003). Estas composiciones de elementos traza e isotópicas se citan como evidencias de que los basaltos/traquibasaltos sódicos son producto de un bajo grado de fusión parcial $(<5 \%)$ de la astenósfera, ya sea por un ascenso del manto pasivo o por una pluma mantélica (Farmer, 2003).

Tanto los diagramas de variación como los diagramas spider de Tierras Raras e incompatibles, sugieren una relación comagmática entre los traquitoides del Payún Matrú y las lavas de los campos basálticos. Esta tendencia se afirma al tener en cuenta las relaciones isotópicas de Sr y Nd, ya que ambos grupos presentan valores acotados y similares (a excepción de las traquitas con una moderada contaminación cortical).

Los basaltos fisurales no son magmas primarios por sus características químicas, y presentan evidencias de fraccionamiento de fases máficas (olivinas y clinopiroxeno) y óxidos de $\mathrm{Fe}-\mathrm{Ti}$, pero no de un fraccionamiento significativo de plagioclasa. Los traquitoides presentan a su vez evidencias de fraccionamientos de plagioclasas (algunas T pre e Ig $P$ y todas las $T$ pos), de feldespatos potásicos (todos menos algunas pocas $T$ pre), clinopiroxenos, óxidos de Fe-Ti y apatita. Las lavas de composición intermedia pertenecientes a la unidad de Traquiandesitas Post-caldera y Traquitoides Pre-caldera que presentan texturas indicadoras de mezcla de magmas, no se pueden diferenciar del tren evolutivo por diferenciación de basaltos para dar traquitas, debido a que en diagramas de variación las rocas que son producto de mezcla se ubican en una línea que conecta a los extremos composicionales de la mezcla.

La afinidad tectónica mediante la geoquímica es de intraplaca, visible no solamente en los diagramas de discriminación tectónica, sino también en los diagramas spiders presentados. La fuente de los magmas basálticos correspondería a un manto sublitosférico, aunque quedan dudas de si se trata de un manto con granate o con espinela. Una opción probable de acuerdo a los datos geoquímicos sería una peridotita con granate fértil, aunque no hay que descartar la idea de que también esté involucrada una fuente con espinela. 


\section{Capítulo 8}

\section{Composición química mineral}

Los análisis químicos de minerales de las rocas del Payún Matrú y campos basálticos se realizaron para caracterizar la composición de los mismos, y también para identificar y corroborar desequilibrios mineralógicos vinculados con la mezcla de magmas. Además, los microanálisis químicos se utilizaron para obtener datos cuantitativos de termobarometría de los magmas. Todas las muestras analizadas poseen análisis geoquímico de roca total, con una sola excepción, y la ubicación de las muestras puede verse en la Figura 7.1. Los datos de la composición química mineral se exhiben en el Anexo IV.

Con respecto a los Traquitoides Pre-caldera, fueron analizadas tres lavas traquíticas, de las cuales dos se ubican en la pared NE de la caldera, siendo una un dique y otra una colada (muestras PM 27 y PM 28, respectivamente, Fig. 7.1), y una muestra ubicada en el faldeo oriental del Payún Matrú (muestra PY 10). Las tres muestras analizadas corresponden a la subunidad 3 de los Traquitoides Pre-caldera, con una asociación mineral de plagioclasa + olivina + clinopiroxeno + biotita (PM 27), plagioclasa + olivina + clinopiroxeno + anfíbol (PM 28) y plagioclasa + clinopiroxeno + ortopiroxeno + anfíbol + biotita (PY 10, única muestra del CVPM donde se encontró ortopiroxeno sin manto de clinopiroxeno). Las tres lavas muestran desequilibrios texturales, con plagioclasas limpias y cribadas. La muestra PM 28 corresponde a una colada lávica con evidencias de mingling, con dos pastas pilotáxicas distintas a veces en contacto neto y sinuoso y otras veces difuso.

En la Ignimbrita Portezuelo, fueron analizados feldespatos, olivina y clinopiroxeno de la facies emLT(v), de una muestra ubicada en la base del perfil de la ignimbrita en la pared norte de la caldera (muestra PM 14, Fig. 7.1). También se analizó la composición de feldespatos y clinopiroxeno en clastos de spatter de la ignimbrita aflorante sobre un cono de escoria precaldera, pertenecientes a la facies emLT(cc) (ubicación en el punto 16, Fig. 4.5 a, la muestra corresponde a los clastos de la Figura $4.9 \mathrm{f}$ ).

Las Traquiandesitas Post-caldera analizadas corresponden a la colada intra-caldera (muestra PM 34, Fig. 7.1), la "Colada del Caballo Muerto" (muestra STA 38, Fig. 7.1) y la colada "El Choique" en el faldeo noroeste del Payún Matrú (muestra STA 6-B, Fig. 7.1). En los tres casos 
se analizaron plagioclasas, olivinas, clinopiroxeno y, además, en la colada "El Choique" se analizó la composición del anfíbol (única lava en esta unidad que presenta este mineral, en muy escasa proporción).

Fueron analizadas dos coladas de las Traquitas Post-caldera, una de la colada intracaldera de la litofacies de Traquitas en bloque (muestra PM 40, Fig. 7.1), y otra de Traquitas vítreas ubicada en el borde SE de la caldera (muestra PMA 27-A, Fig. 7.1). En ambas coladas se analizaron feldespatos alcalinos y clinopiroxenos, y olivina solamente en las Traquitas vítreas, ya que no fue encontrada en la muestra de Traquitas en bloque.

Con respecto a las lavas de los campos basálticos, las muestras analizadas corresponden a los Basaltos Pre-caldera (colada de los "Morados grandes", muestra PY 5, Fig. 7.1), y a los Basaltos Post-caldera II, con las coladas de "La Tranquera" (muestra PM 46, Fig. 7.1) y otra que nace en la Falla La Carbonilla (muestra PY 13, Fig. 7.1). Los minerales analizados en los tres casos son plagioclasa, olivina y clinopiroxeno.

\subsection{Feldespatos}

\subsubsection{Traquitoides Pre-caldera}

En el dique de la muestra PM 27, se analizaron tres fenocristales de plagioclasa con diferentes características. Estos fenocristales corresponden a una plagioclasa subhedral - anhedral con cribado grueso ( $\mathrm{Pl}$ a, Fig. 8.1 a), una subhedral con bordes redondeados y limpia (Pl b, Fig. 8.1 a) y un glomérulo con plagioclasas manteadas, con un núcleo limpio y zonado y un manto con cribado medio (Pl c, Fig. 8.1 a). Por último, también se analizó un microlito de la pasta (Pl p, Fig. 8.1 a).

La plagioclasa con cribado grueso posee una composición poco variable de núcleo a borde, siendo esta oligoclasa $\left(\mathrm{An}_{26-30}-\mathrm{Ab}_{63-66}\right)$ (Fig. $\left.8.1 \mathrm{a}\right)$. La plagioclasa limpia y redondeada presenta zonación normal, variando desde andesina en el núcleo y medio del cristal, oligoclasa en el borde interno y finalmente un borde transicional al campo de la anortoclasa (variación desde $\mathrm{An}_{20-37}-\mathrm{Ab}_{57-68}-\mathrm{Or}_{5-13}$ ) (Fig. 8.1 a). La plagioclasa manteada presenta un núcleo y un manto de composiciones marcadamente diferentes y con un intervalo composicional amplio. El núcleo es bytownitico/labradorítico en el centro del mismo ( $\left.A n_{70-72}-\mathrm{Ab}_{27-29}\right)$ y labradoritico en su borde $\left(\mathrm{An}_{57}-\mathrm{Ab}_{41}\right)$. El manto cribado es de composición oligoclasa, con escasa dispersión ( $\left.\mathrm{An}_{26-30}-\mathrm{Ab}_{63-66}-\mathrm{Or}_{7-8}\right)$ (Fig. 8.1 a). La composición del microlito de la pasta es también de oligoclasa, idéntico al manto descripto $\left(\mathrm{An}_{28-29}-\mathrm{Ab}_{64}-\mathrm{Or}_{7-8}\right)$ y a la "Pl $\mathrm{a}$ ", y también dentro del rango de composiciones de "Pl b" (Fig. 8.1 a). Esto podría sugerir que, aunque la lava haya incorporado cristales marcadamente distintos (posiblemente por mezcla de magmas), la composición de la lava no varió significativamente, evidenciado por la similitud en composiciones del manto descripto y microlitos.

Con respecto a la lava PM 28, se analizaron tres fenocristales de plagioclasas diferentes 


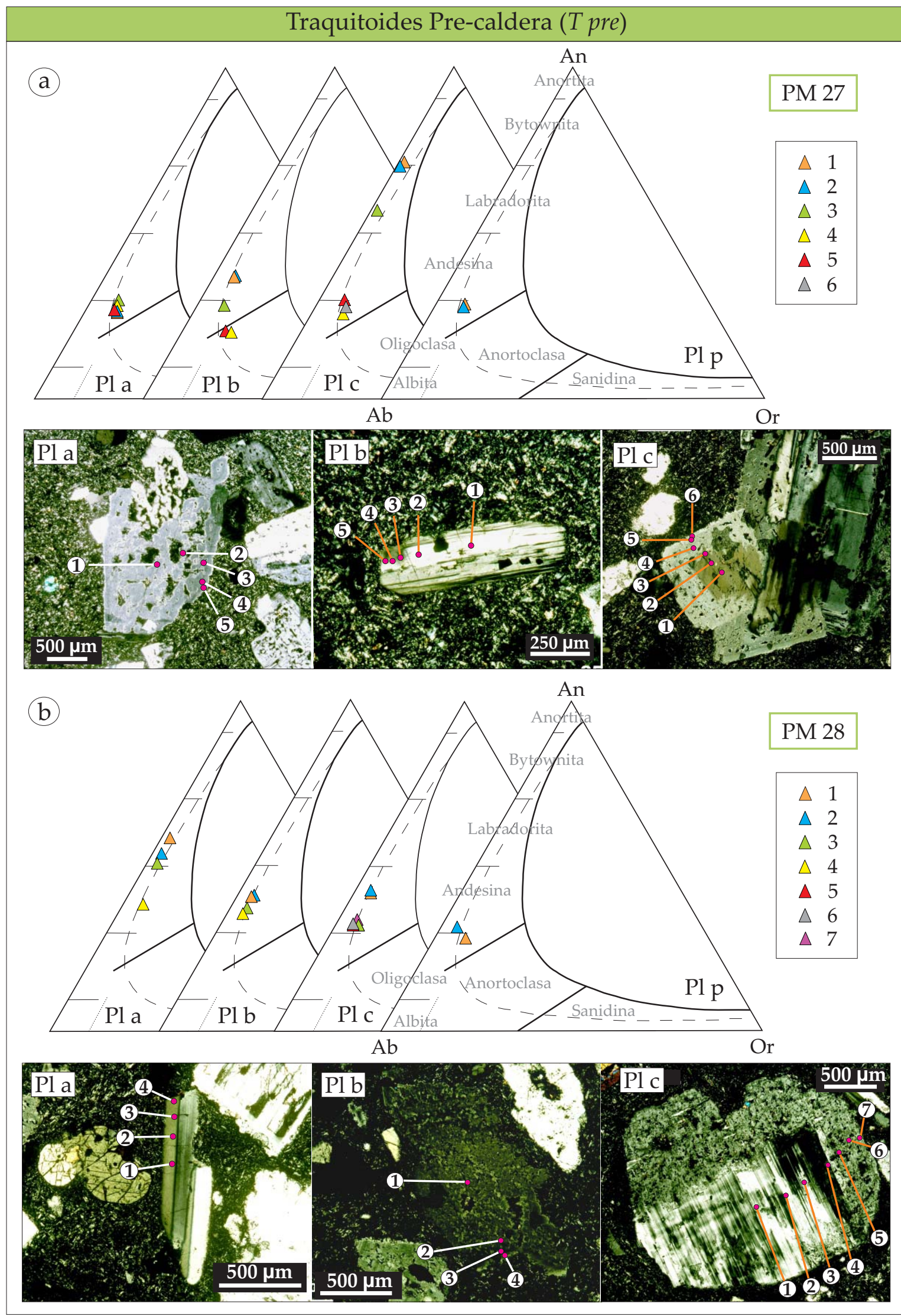

Figura 8.1: Diagramas composicionales de plagioclasas de la unidad T pre, junto a fotografías de los cristales y ubicación de los puntos analizados. a) Muestra PM 27. b) Muestra PM 28. Ver discusión en el texto. 


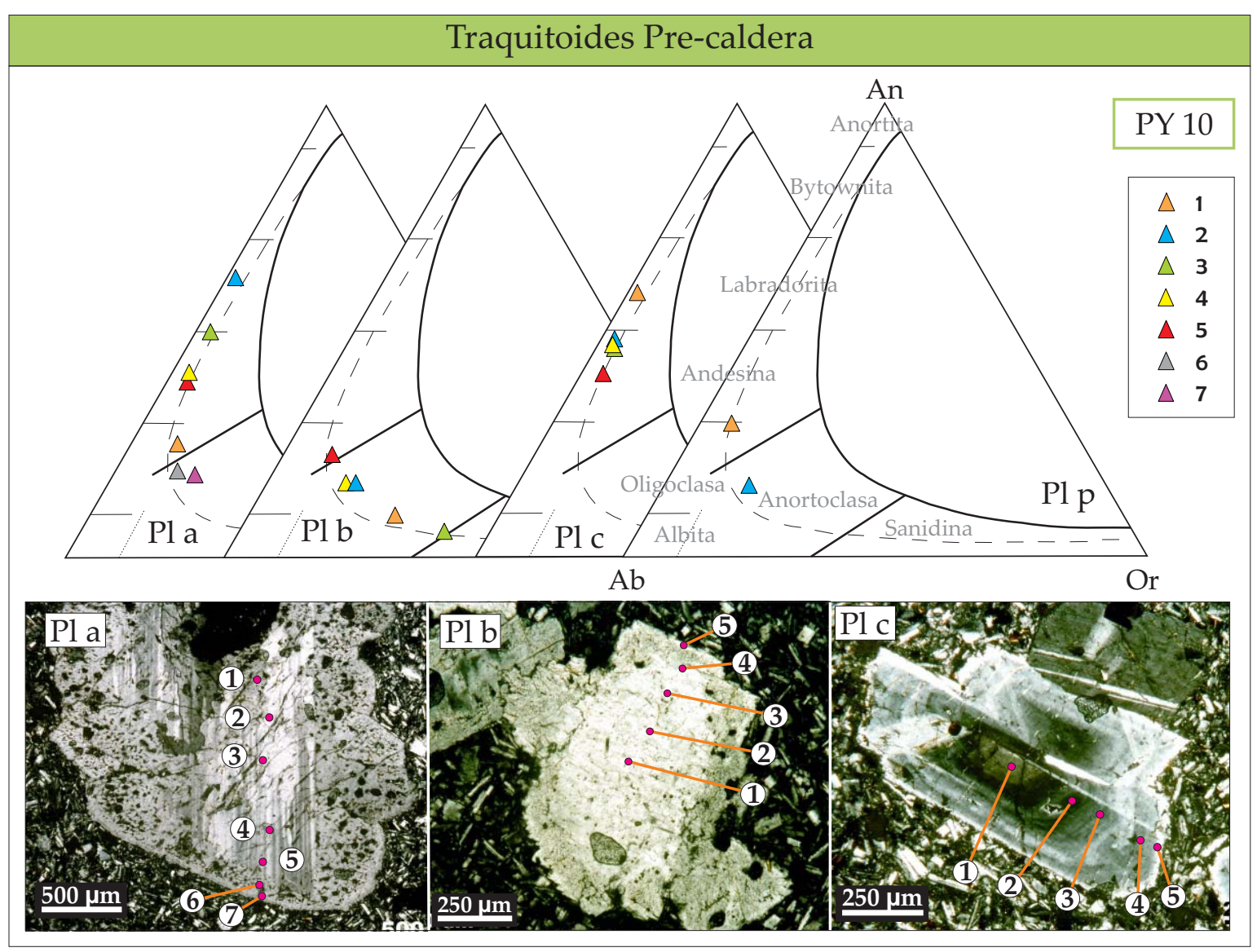

Figura 8.2: Diagramas composicionales de plagioclasas de la unidad T pre, junto a fotografías de los cristales y ubicación de los puntos analizados. Ver explicación en el texto.

y los microlitos de la pasta. En primer lugar se estudió una plagioclasa limpia y con bordes redondeados ( $\mathrm{Pl} \mathrm{a),} \mathrm{la} \mathrm{cual} \mathrm{presenta} \mathrm{una} \mathrm{composición} \mathrm{que} \mathrm{varía} \mathrm{desde} \mathrm{labradorita} \mathrm{en}$ el núcleo hasta andesina en el borde $\left(\mathrm{An}_{59-38}-\mathrm{Ab}_{39-56}-\mathrm{Or}_{2-5}\right)$ (Fig. $8.1 \mathrm{~b}$ ), evidenciando una zonación normal. La plagioclasa denominada " $\mathrm{Pl} \mathrm{b",} \mathrm{es} \mathrm{totalmente} \mathrm{anhedral} \mathrm{y} \mathrm{con} \mathrm{un} \mathrm{criba-}$ do medio a grueso, con una composición relativamente homogénea de núcleo a borde con una tendencia a la zonación normal, dentro del campo de la andesina $\left(\mathrm{An}_{36-41}-\mathrm{Ab}_{55-60}\right)$ (Fig. 8.1 b). La plagioclasa "Pl c" es de contornos redondeados, con macla de periclino fina y con un manto incompleto con cribado fino-medio con tabiques donde fue posible obtener una medición (Fig. 8.1 b). La composición de este cristal es andesinica, con la parte interna del núcleo limpio más anortítico que el resto del cristal $\left(\mathrm{An}_{42-32}-\mathrm{Ab}_{53-63}\right)$ (Fig. 8.1 b). No hay diferencias composicionales entre el manto cribado y el borde interno del sector limpio del cristal.

Por último, la muestra PY 10 no sólo presenta una asociación mineral fuera de lo común para el CVPM (por la presencia de ortopiroxeno), sino también es la que mayor variación composicional presenta en los feldespatos, con presencia de composiciones desde labrado- 
rita hasta anortoclasa pasando al campo de las sanidinas. Se analizó una plagioclasa subhedral con esquinas redondeadas ( $\mathrm{Pl}$ a), la cual presenta un núcleo limpio irregular, una zona relativamente gruesa con cribado medio y un borde fino limpio (Fig. 8.2). Los siete puntos analizados indican una zonación normal con un amplio espectro composicional, desde labradorita hasta anortoclasa, y con un salto composicional entre el centro limpio y el sector cribado ( $\mathrm{An}_{18-62}-\mathrm{Ab}_{36-69}-\mathrm{Or}_{2-16}$, el punto 1 no se encuentra en el centro limpio sino en una zona interna con cribado) (Fig. 8.2). También se analizó un feldespato que presenta un núcleo limpio con macla de periclino, un anillo de contornos redondeados con cribado en panal de abejas, y un borde fino limpio (Pl b, Fig. 8.2). El núcleo es de anortoclasa, con una composición variable entre $\mathrm{An}_{6-17}-\mathrm{Ab}_{55-68}-\mathrm{Or}_{15-39}$. El borde fino limpio es menos potásico y más cálcico, transicional a una oligoclasa de composición $\mathrm{An}_{23}-\mathrm{Ab}_{68}-\mathrm{Or}_{9}$ (Fig. 8.2). Finalmente, se analizó una plagioclasa euhedral y limpia, con un zonación concéntrica marcada y un sobrecrecimiento fino ( $\mathrm{Pl} \mathrm{c)}$. El núcleo es labradoritico, el medio y borde del cristal es andesinico, y el sobrecrecimiento fino levemente más sódico, y también andesinico (variación entre $\mathrm{An}_{40-58}-\mathrm{Ab}_{40-55}-\mathrm{Or}_{2-4}$ ) (Fig. 8.2). El microlito de la pasta analizado (Pl p) arrojó valores disímiles entre núcleo y borde, siendo de oligoclasa y anortoclasa, respectivamente (Fig. $8.2)$.

\subsubsection{Ignimbrita Portezuelo}

En el caso de la muestra de la ignimbrita en facies emLT(v) (PM 14), se analizaron tres feldespatos alcalinos los cuales arrojaron composiciones similares, con escasa dispersión en el diagrama de clasificación de los feldespatos. Estos cristales son: un feldespato limpio y fracturado (Fk a, ubicado en la matriz), otro subhedral que presenta engolfamientos y huecos controlados cristalográficamente, sin redondear las esquinas ( $F k b$, ubicado en un fiamme) y otro limpio y euhedral, con macla de albita muy fina (Fk c, ubicado en la matriz) (Fig. 8.3 a). Las composiciones son de anortoclasa y sin ninguna variación entre núcleo y borde $\left(\mathrm{An}_{10-12}-\mathrm{Ab}_{61-63}-\mathrm{Or}_{25-29}\right)$ (Fig. $\left.8.3 \mathrm{a}\right)$.

En el clasto de spatter se analizaron fenocristales y microfenocristales de plagioclasa, limpios y subhedrales - euhedrales ( $\mathrm{Pl} \mathrm{a}$, b c c y e), y también otro fenocristal euhedral con escasos huecos internos controlados cristalográficamente ( $\mathrm{Pl} \mathrm{g}$, figura $8.3 \mathrm{~b}$ ). En todos los casos, a excepción del fenocristal "Pl b", las composiciones plotean dentro del campo de la andesina, con un rango entre $\mathrm{An}_{32-36}-\mathrm{Ab}_{59-62}-\mathrm{Or}_{4-6}$ (Fig. 8.3 b). En el caso del fenocristal Pl $\mathrm{b}$, la composición es de anortoclasa, con un rango de $\mathrm{An}_{11-12}-\mathrm{Ab}_{65-66}-\mathrm{Or}_{22-23}$, idéntico a los cristales analizados en la muestra PM 14 (Fig. 8.3 b).

\subsubsection{Traquiandesitas Post-caldera}

En las tres coladas mencionadas (intra-caldera, "El Choique" y "Colada del Caballo Muerto", Fig. 4.1) fueron analizadas plagioclasas con diferentes texturas, unas limpias y 


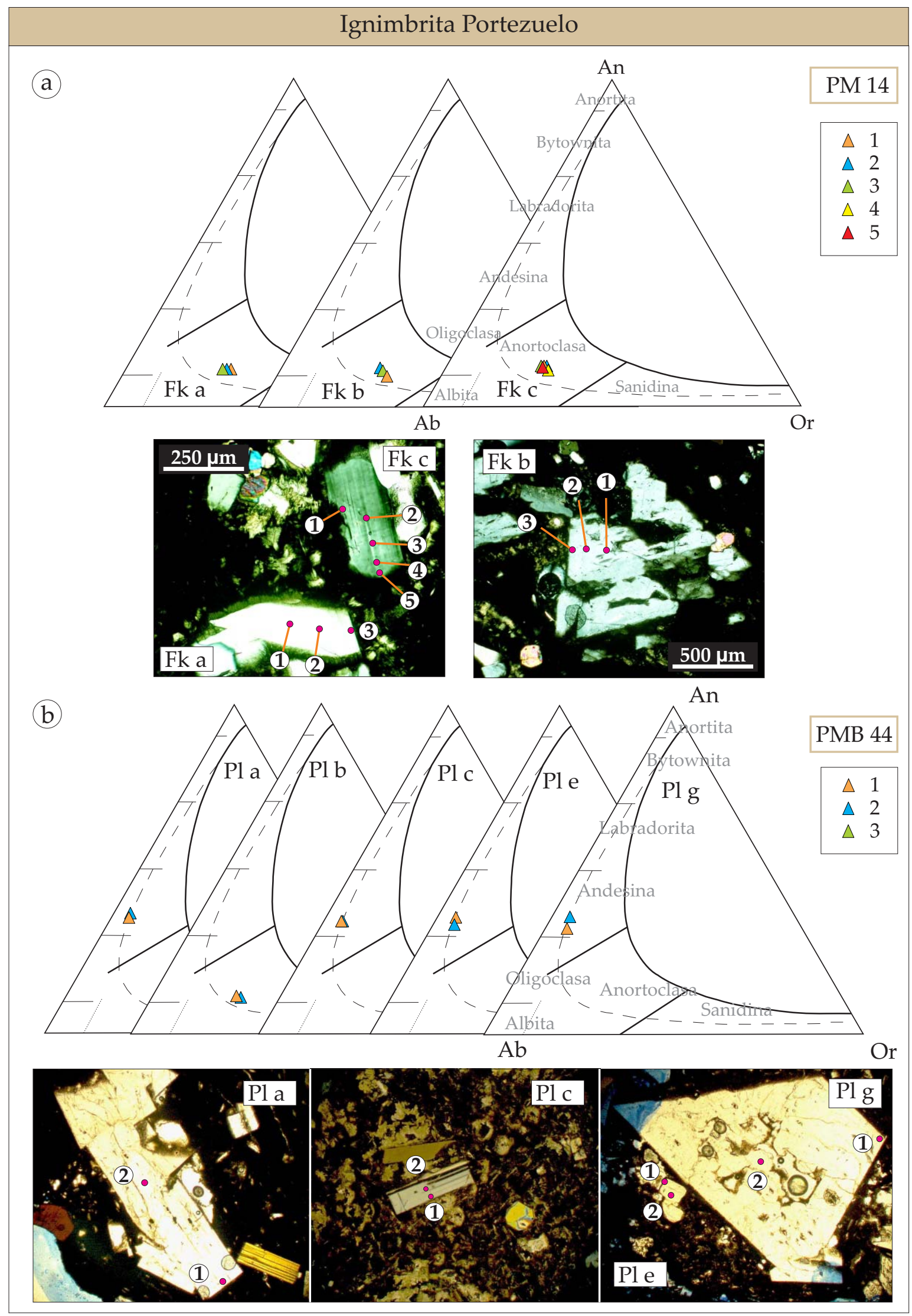

Figura 8.3: Diagramas composicionales de feldespatos de la unidad $\operatorname{Ig} P$, junto a fotografías de los cristales y ubicación de los puntos analizados. a) facies emLT(v) (muestra PM 14), y b) clasto de spatter (muestra PMB 44). 
otras con uno o más tipos de cribado. Esta unidad, al igual que las lavas analizadas de los Traquitoides Pre-caldera, presenta un rango amplio en las composiciones de las plagioclasas. En la colada intra-caldera, de composición traquiandesita basáltica, fueron analizadas cuatro plagioclasas texturalmente diferentes, además de un microlito de la pasta (Fig. 8.4): i) plagioclasa euhedral con un anillo grueso con cribado en panal de abejas y un borde fino limpio (Pl a); ii) plagioclasa euhedral y limpia, con un sobrecrecimiento fino (Pl b); iii) plagioclasa euhedral con cribado grueso en el interior, y cribado fino en un anillo cerca del borde y rodeando los huecos del cribado grueso (Pl c); y iv) plagioclasa euhedral con el núcleo con cribado grueso y un borde relativamente grueso y limpio (Pl d).

$\mathrm{La}$ "Pl a" presenta en el núcleo limpio una composición fundamentalmente labradorítica y más rica en sodio cerca del anillo cribado $\left(\mathrm{An}_{52-72}-\mathrm{Ab}_{27-45}\right)$, mientras que el borde limpio posee una composición labradorítica similar al sector medio del cristal (punto 6 idéntico al punto 3) (Fig. 8.4). La plagioclasa euhedral (Pl b) es bytownita en todo el cristal ( $\mathrm{An}_{71-83^{-}}$ $\left.A b_{16-27}\right)$, menos en el borde de sobrecrecimiento, el cual cambia abruptamente a andesina $\left(\mathrm{An}_{45}-\mathrm{Ab}_{50}\right)$ (Fig. 8.4). La "Pl c" es relativamente uniforme de centro a borde, siendo de composición andesina $\left(\mathrm{An}_{33-41}-\mathrm{Ab}_{\left.53-57-\mathrm{Or}_{6-10}\right)}\right.$ (Fig. 8.4). La "Pl d" es también andesinica aunque levemente más cálcica y con una relativa poca variación composicional de núcleo a borde $\left(\mathrm{An}_{42-46}-\mathrm{Ab}_{49-52}-\mathrm{Or}_{5-6}\right)$ (Fig. 8.4). El microlito de la pasta analizado es andesinico, de idéntica composición que la "Pl d" (An $\left.\mathrm{An}_{4-46}-\mathrm{Ab}_{49-52}-\mathrm{Or}_{5-6}\right)$ (Fig. 8.4). Las composiciones de las plagioclasas "Pl c", "Pl d" y el microlito, junto con los bordes de los cristales "Pl a" y "Pl b", son relativamente uniformes y andesínicos. En contraste, los núcleos de las plagioclasas "Pl a" y "Pl b" son más cálcicos (labradoríticos y bytowníticos, respectivamente). Esto sugiere que ambiente en el cual crecieron estas dos plagioclasas ( $\mathrm{Pl} \mathrm{a} \mathrm{y} \mathrm{b)} \mathrm{fue} \mathrm{diferente} \mathrm{al} \mathrm{ambiente} \mathrm{en}$ el cual crecieron el resto de las plagioclasas y el borde de las mismas, posiblemente causado por la mezcla de magmas.

La colada en el flanco NO del Payún Matrú, "El Choique”, presenta también fenocristales de plagioclasas con texturas diferentes. En primer lugar, la "Pl a" es subhedral con cribado grueso en el interior del cristal y un borde limpio relativamente grueso (Fig. 8.5). La composición de este cristal es homogénea de núcleo a borde, siendo esta andesina $\left(\mathrm{An}_{39-42-}\right.$ $\left.\mathrm{Ab}_{54-56}-\mathrm{Or}_{4-5}\right)$. La "Pl b", la cual es euhedral y limpia, presenta también una composición relativamente homogénea aunque un poco más cálcica $\left(\mathrm{An}_{45-51}-\mathrm{Ab}_{46-51}-\mathrm{Or}_{3-4}\right)$ (Fig. 8.5). La "Pl c" es subhedral con las esquinas levemente redondeadas y un anillo muy fino con cribado en panal de abejas cerca del borde. La composición del núcleo y medio del cristal es marcadamente diferente a la composición del borde, siendo andesina $\left(\mathrm{An}_{30-38}-\mathrm{Ab}_{57-62}-\mathrm{Or}_{5-8}\right)$ y anortoclasa $\left(\mathrm{An}_{5}-\mathrm{Ab}_{57}-\mathrm{Or}_{37}\right)$, respectivamente (Fig. 8.5). La "Pl d" es la que posee mayor variación composicional: presenta un núcleo limpio y zonado de labradorita, el cual se hace más sódico hacia el medio y borde (andesina). Le sigue en contacto neto un anillo con cribado medio y un borde limpio fino, de composición andesinica más sódica aún (variación del cristal entre $\mathrm{An}_{36-67}-\mathrm{Ab}_{32-58}-\mathrm{Or}_{2-6}$ ) (Fig. 8.5). El microlito de la pasta es andesina, similar 


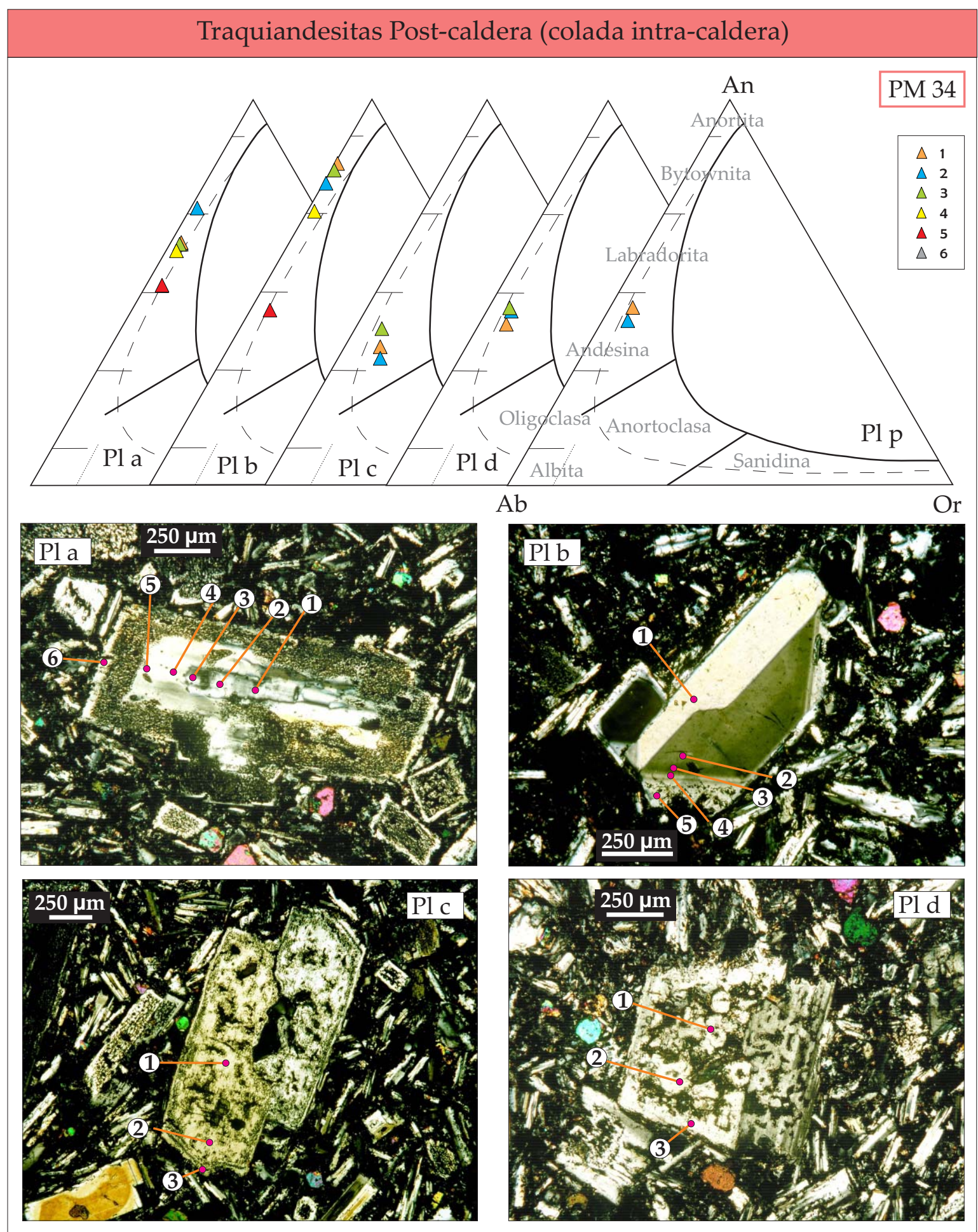

Figura 8.4: Diagramas composicionales y microfotografías con los puntos analizados de plagioclasas de la colada intra-caldera de las Traquiandesitas Post-caldera. Ver explicación en el texto. 


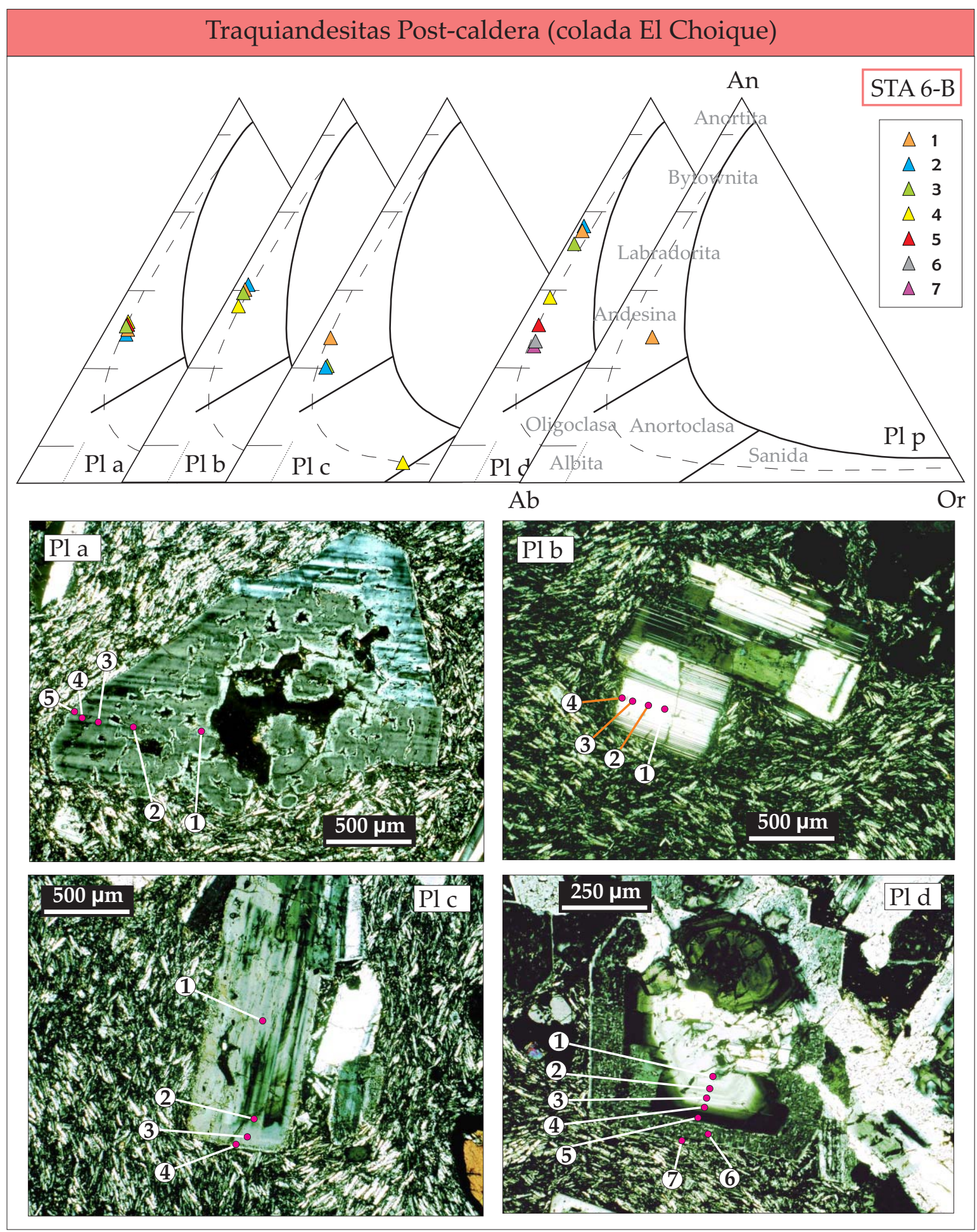

Figura 8.5: Diagramas composicionales y microfotografías con los puntos analizados de plagioclasas de la colada "El Choique". Ver explicación en el texto. 


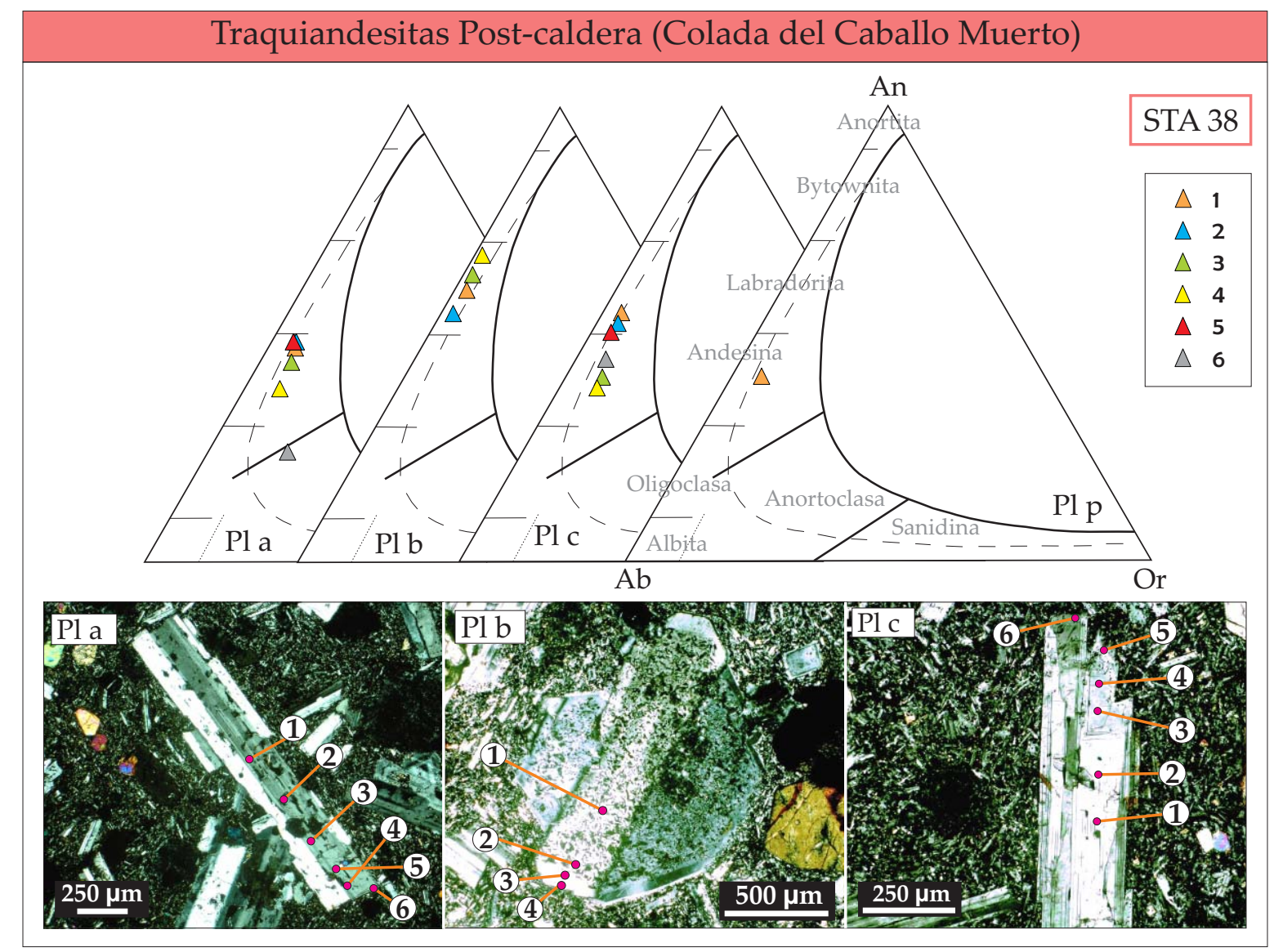

Figura 8.6: Diagramas composicionales y microfotografías con los puntos analizados de plagioclasas en la colada del Caballo Muerto. Ver explicación en el texto.

a la zona externa de la "Pl d", y a la composición de la "Pl a", aunque con un aumento del componente ortosa (Fig. 8.5).

En la Figura 8.6 se muestran los fenocristales de plagioclasa analizados de la "Colada del Caballo Muerto". Estos corresponden a fenocristales euhedrales con un leve cribado grueso (Pl a), otro subhedral con cribado medio en todo el cristal a excepción del borde limpio (Pl b) y, por último, una plagioclasa euhedral y limpia (Pl c) además de un microlito en la pasta (Fig. 8.6). En el primer caso, la plagioclasa es andesina $\left(\mathrm{An}_{38-48}-\mathrm{Ab}_{47-55}-\mathrm{Or}_{4-7}\right)$ con un borde más sódico y potásico de anortoclasa $\left(\mathrm{An}_{24}-\mathrm{Ab}_{61}-\mathrm{Or}_{15}\right)$ (Fig. 8.6). En el caso de la "Pl $\mathrm{b}^{\prime \prime}$, tanto el núcleo cribado como el borde limpio son de labradorita, siendo el borde limpio más cálcico que el resto del cristal (núcleo cribado de $\mathrm{An}_{55-63}-\mathrm{Ab}_{35-43}$, y borde de $\mathrm{An}_{67}-\mathrm{Ab}_{31}$ ) (Fig. 8.6). La "Pl c" presenta una composición entre labradorita y andesina, con una zonación compleja, posiblemente oscilatoria $\left(\mathrm{An}_{41-55}-\mathrm{Ab}_{42-54}-\mathrm{Or}_{3-7}\right)$ (Fig. 8.6). El microlito es andesina, de composición similar al núcleo y borde de la "Pl c" (Fig. 8.6). 


\subsubsection{Traquitas Post-caldera}

Los feldespatos alcalinos de las litofacies de Traquitas en bloque y Traquitas vítreas son de composición relativamente homogénea, con escasa dispersión en el diagrama composicional de feldespatos. En cada feldespato alcalino se analizaron tres puntos, distribuidos en centro, medio y borde del cristal.

En el caso de la muestra de las Traquitas en bloque, se analizaron tres feldespatos diferentes: i) uno con bordes difusos con la pasta y un ligero redondeamiento de sus esquinas (Fk a, Fig. 8.7 a); ii) un feldespato euhedral con bordes nítidos con la pasta y sin redondeamiento (Fk b, Fig. 8.7 a); y iii) un feldespato euhedral con macla de albita muy fina (Fk c, Fig. 8.7 a). En los tres casos, las composiciones no varían significativamente de núcleo a borde, siendo los feldespatos anortoclasas pasando al campo de las sanidinas $\left(\mathrm{Or}_{32-37}\right.$ y $\left.\mathrm{Ab}_{61-65}\right)$ (Fig. 8.7 a).

En el caso de las Traquitas vítreas, se analizaron dos feldespatos alcalinos morfológicamente distintos: i) un feldespato euhedral (Fig. 8.7 b) y ii) un feldespato con engolfamientos redondeados y esquinas sin redondear (Fig. 6.15 d). Ambos feldespatos alcalinos poseen también composiciones similares de núcleo a borde, con un contenido de potasio levemente mayor que en los feldespatos alcalinos de las Traquitas en bloque. Estos plotean entre los campos de anortoclasa y sanidina, levemente desplazados hacia esta última $\left(\mathrm{Or}_{37-41} \mathrm{y}\right.$ $\mathrm{Ab}_{56-59}$ ) (Fig. 8.7 b).

\subsubsection{Basaltos Pre- y Post-caldera}

Si bien las plagioclasas analizadas de los basaltos presentan algunas diferencias en cuanto a sus texturas internas, composicionalmente corresponden todas a bytownitas y labradoritas. En la colada de los "Morados Grandes" del este (PY 5) fueron analizadas cinco plagioclasas con diferentes texturas. La "Pl a" (Fig. 8.8) euhedral y con un núcleo con inclusiones de opacos o cribado medio en el primer caso (es difícil afirmarlo cuando la pasta es oscura), y la "Pl b", euhedral con un núcleo grande con cribado medio y un borde grueso y limpio, presentan ambas composiciones similares (bytownita/labradorita, $\mathrm{An}_{63-80}-\mathrm{Ab}_{19-35}$ ). $\mathrm{La}$ "Pl c", la cual es subhedral y redondeada con los bordes difusos con la pasta, es bytownita $\left(\mathrm{An}_{71-76}-\mathrm{Ab}_{23-27}\right)$ (Fig. 8.8), mientras que las "Pl d" y "Pl e" son más sódicas. La "Pl d" es anhedral y redondeada, con un cribado fino en todo el cristal, siendo el núcleo más cálcico que el borde $\left(\mathrm{An}_{62-72}-\mathrm{Ab}_{28-35}\right)$, mientras que la "Pl e" es euhedral con cribado fino solamente en un anillo cerca del borde (labradorita, $\mathrm{An}_{59-62}-\mathrm{Ab}_{37-39}$ ) (Fig. 8.8). El microlito en pasta es labradorítico y de similar composición que los sectores más sódicos de las plagioclasas analizadas (Fig. 8.8).

En la "Colada de La Tranquera" (Fig. 4.1), los fenocristales son básicamente bytowníticos, mientras que el borde de algunos cristales y los microlitos de la pasta son labradoríticos. $\mathrm{La}$ "Pl a" (Fig. 8.9 a) es euhedral con un borde con crecimiento esqueletal leve. El fenocristal, 


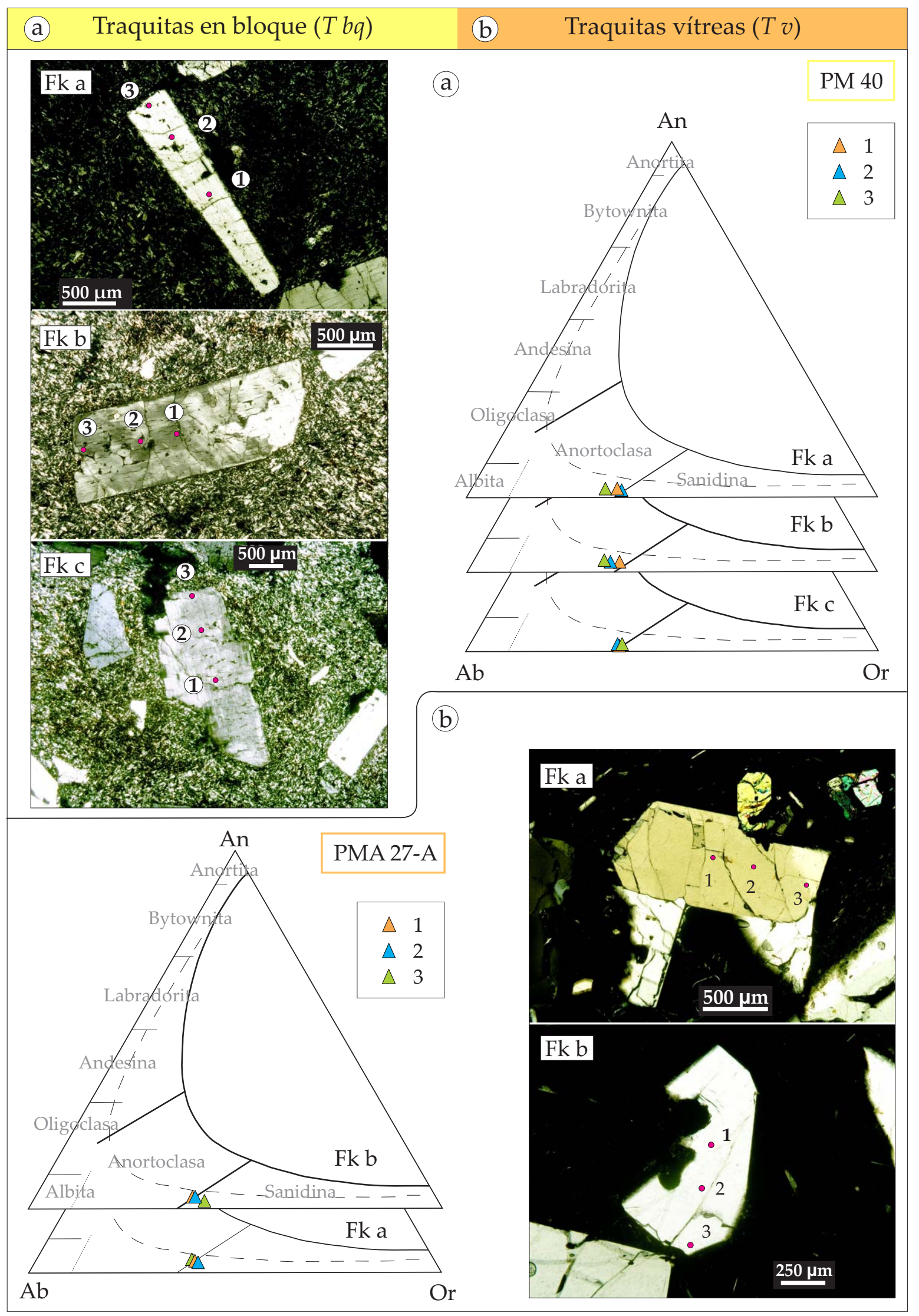

Figura 8.7: Diagramas composicionales y microfotografías con los puntos analizados de feldespatos alcalinos en las Traquitas Post-caldera. a) Muestra PM 40, de las Traquitas en bloque.b) Muestra PMA 27-A, de las Traquitas vítreas. Ver explicación en el texto. 


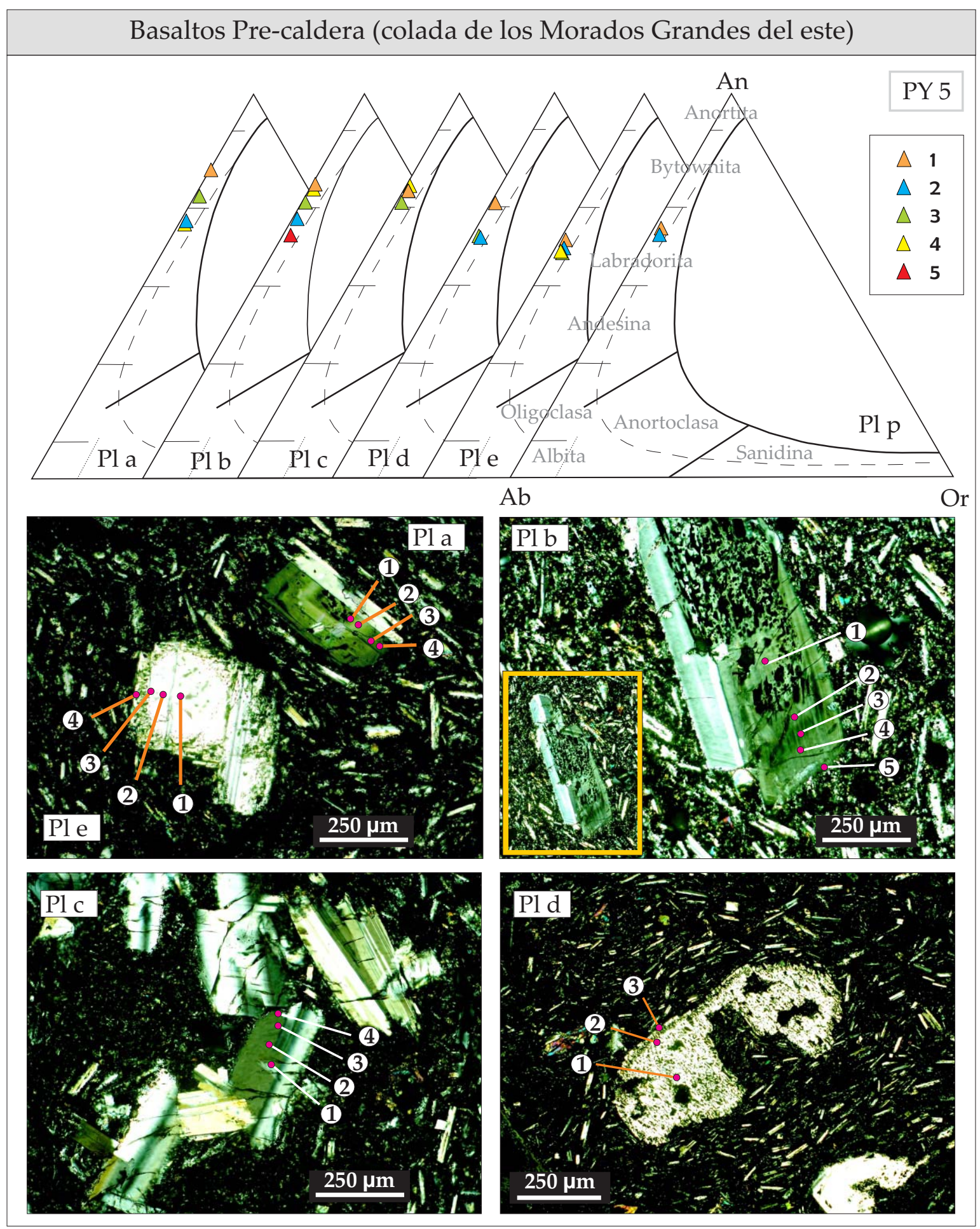

Figura 8.8: Diagramas composicionales y microfotografías con los puntos analizados de plagioclasas en la colada pre-caldera que nace al este del Payún Matrú (muestra PY 5). 


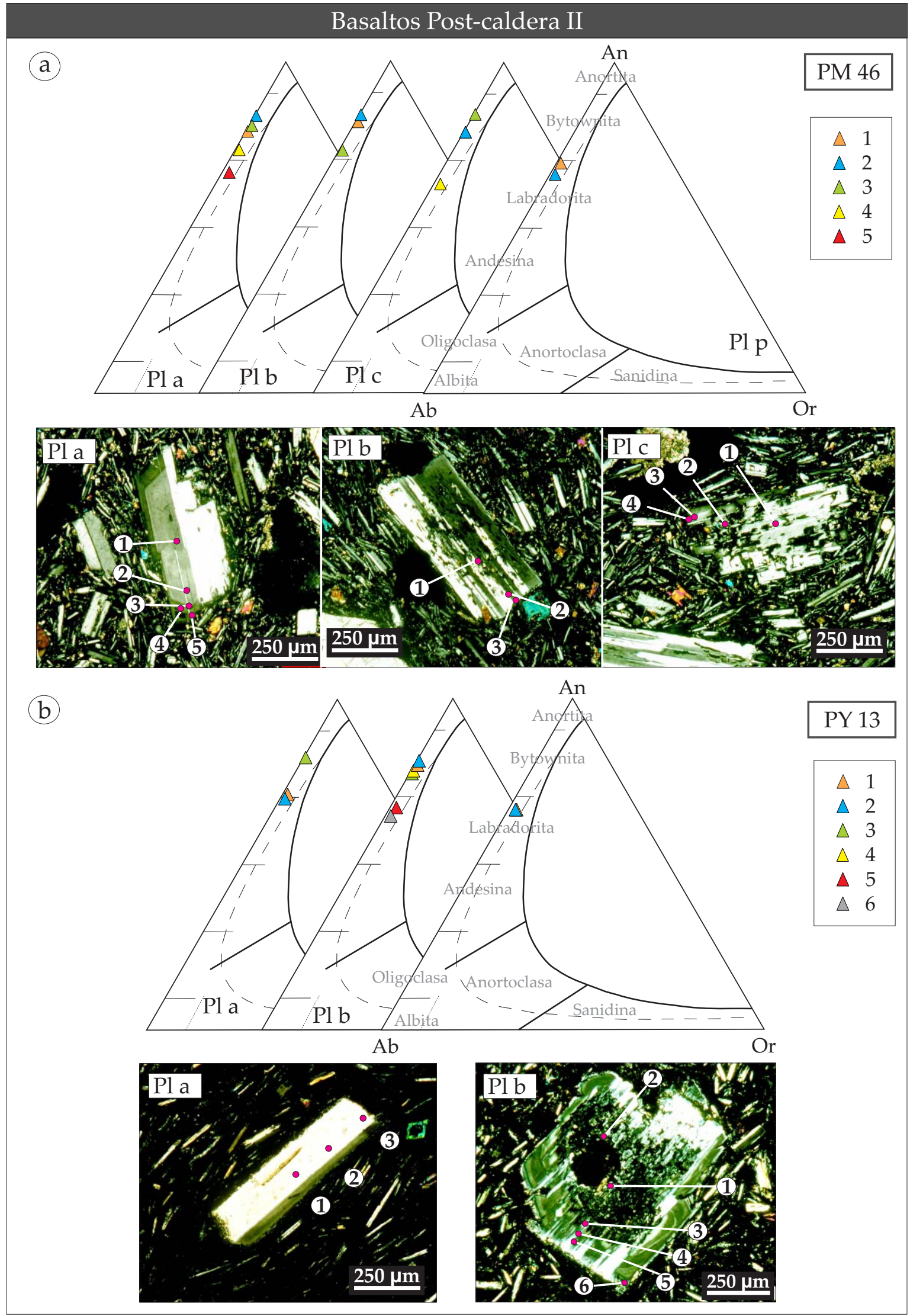

Figura 8.9: Diagramas composicionales y microfotografías con los puntos analizados de plagioclasas en: a) Colada de La Tranquera; y b) Colada al este del Payún Matrú (muestra PY 13). 


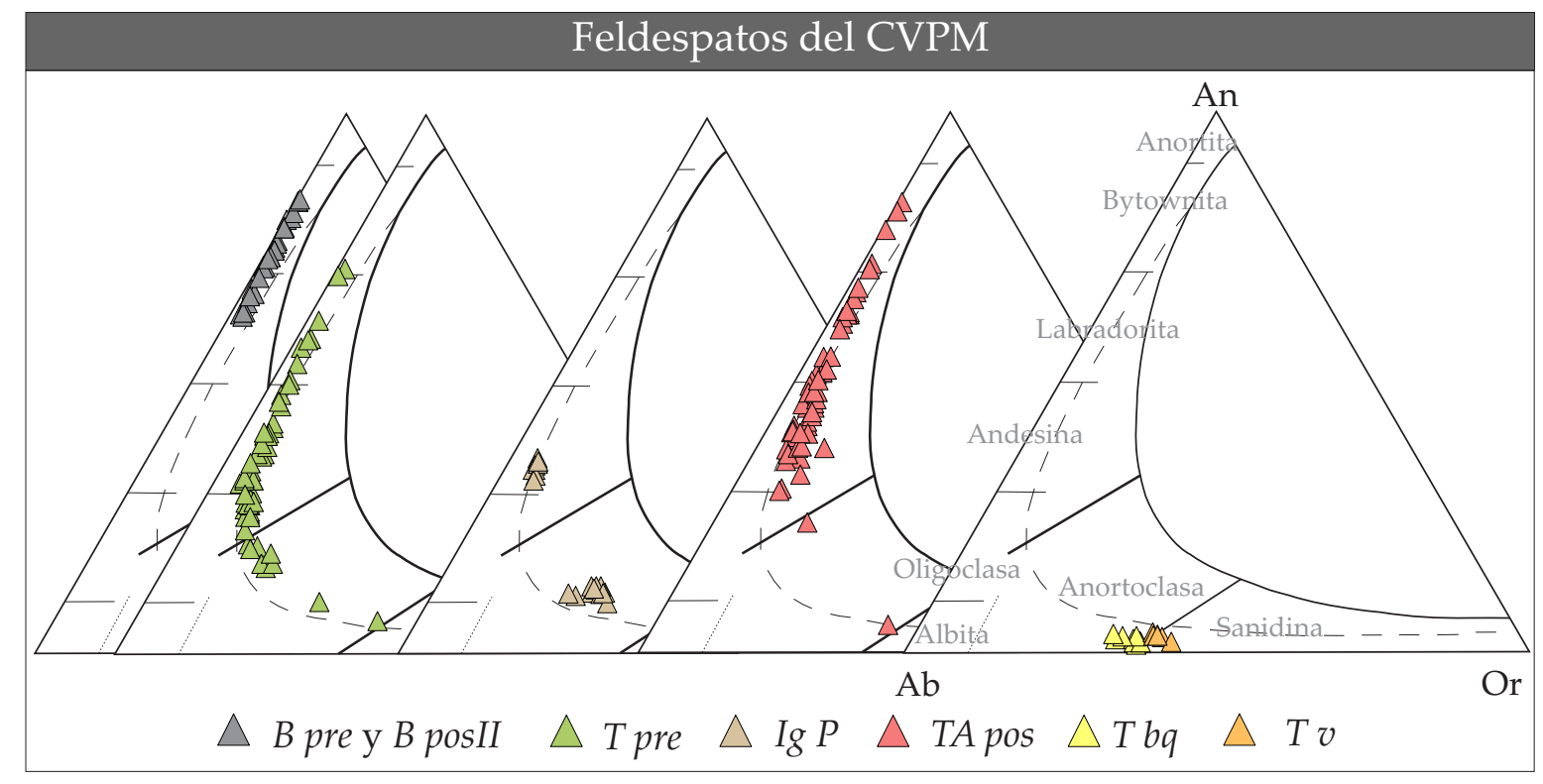

Figura 8.10: Composiciones de todos los feldespatos analizados, separados según unidad y litofacies (basaltos agrupados en un solo grupo dado la similitud de las composiciones).

a excepción del borde más externo, tiene una composición de $\mathrm{An}_{79-84}-\mathrm{Ab}_{16-21}$, mientras que el borde esqueletal es de $\mathrm{An}_{66-73}-\mathrm{Ab}_{25-32}$. La "Pl b" (Fig. 8.9 a) es euhedral con cribado medio en el interior, sin un limite marcado entre el centro cribado y el borde. Esta es enteramente bytownita $\left(\mathrm{An}_{73-84}-\mathrm{Ab}_{16-26}\right)$, siendo el borde menos cálcico que el núcleo. La "Pl c" presenta una composición bytownítica similar al centro y medio de la "Pl a" ( $\left.\mathrm{An}_{79-84}-\mathrm{Ab}_{15-21}\right)$, mientras que el borde es de labradorita $\left(\mathrm{An}_{63}-\mathrm{Ab}_{35}\right)$ (Fig. $\left.8.9 \mathrm{a}\right)$.

En la colada de Basaltos Post-caldera II al este del Payún Matrú (PY 13, Fig. 7.1), se analizó tanto un fenocristal de plagioclasa euhedral y limpio (Pl a), como otro también euhedral pero con el centro cribado medio (Pl b). Ambos abarcan un rango composicional similar, $\left(A n_{70-83}-A b_{17-29}\right.$ en el primer caso y $A n_{64-81}-A b_{18-34}$ en el segundo) (Fig. 8.9 b). El microlito en pasta medido es labradorítico composicionalmente similar al borde de la "Pl b" (Fig. 8.9 b).

Las composiciones de las plagioclasas en las tres lavas basálticas están acotadas al rango bytownita-labradorita, a pesar de existir diferencias texturales en las mismas. Un sólo cristal con cribado es levemente más albítico que el resto de las plagioclasas analizadas ("Pl e" de la colada pre-caldera).

\subsubsection{Comparación entre unidades}

En la Figura 8.10 se muestran en diferentes diagramas la composición de los feldespatos para cada unidad estudiada. La composición de las plagioclasas en las unidades basálticas está repartida homogéneamente en los campos de bytownita y labradorita, sin preponderar 
ninguna composición en especial, lo cual sugiere que no existió una variación composicional en el tiempo en el reservorio basáltico profundo. Además, los Traquitoides Pre-caldera presentan un amplio rango composicional entre labradorita y anortoclasa, siendo las primeras plagioclasas con composición similar a las plagioclasas presentes en los basaltos fisurales (este rango composicional podría ser mayor, si se tiene en cuenta que se han analizado solamente feldespatos de la subunidad 3). A pesar, de la amplitud composicional, las plagioclasas que predominan en esta unidad pre-caldera son andesina - oligoclasa.

La Ignimbrita Portezuelo presenta una marcada diferencia entre los feldespatos presentes en fiamme y matriz (anortoclasas) y aquellos presentes en el clasto de spatter (andesina, el cual también posee un cristal de anortoclasa). Sin embargo, no se descarta que no se encuentren andesinas en fiammes y matriz en otros sitios de la Ignimbrita Portezuelo. Esto se debe a que se existen plagioclasas en otros sectores no analizados de la ignimbrita, y al hecho de que las ignimbritas pueden presentar zonaciones composicionales, como se observa en numerosos ejemplos del mundo.

En las Traquiandesitas Post-caldera predomina la composición andesínicas, aunque también poseen abundantes plagioclasas labradoríticas y bytowníticas, de idéntica composición a las plagioclasas basálticas. Tanto en las Traquiandesitas Post-caldera como en las Traquitas Pre-caldera, se identificaron plagioclasas con composición bytownítica/labradorítica que cambia bruscamente hacia el borde a una composición más albítica, con un hiato composicional separando ambas partes.

Con respecto a las Traquitas Post-caldera, la composición de los feldespatos alcalinos es relativamente uniforme, en el límite entre los campos de la anortoclasa y sanidina. Sin embargo, los feldespatos alcalinos de la litofacies de Traquitas vítreas presentan una tendencia a ser más ricos en potasio respecto a aquellos en las Traquitas en bloque.

\subsection{Olivinas}

Los fenocristales de olivina analizados en los Traquitoides Pre-caldera son de contornos redondeados, y presentan un contenido de forsterita relativamente uniforme entre el $51 \mathrm{y}$ 56 \% (Fig. 8.11 a y b). En la Ignimbrita Portezuelo, se analizó una olivina euhedral alojada en un fiamme, la cual posee una composición de $\mathrm{Fo}_{53-54}$. Con respecto a las Traquiandesitas Post-caldera, la composición de olivinas en las tres lavas estudiadas de esta unidad varía en cada muestra analizada, con un contenido de forsterita variable entre 66 y 78 \% (Fig. 8.11 a). Las olivinas más forsteríticas corresponden a la "Colada del Caballo Muerto", mientras que las menos ricas en $\mathrm{Mg}$ se encuentran en la colada intra-caldera de esta unidad. En la colada intra-caldera de las Traquiandesitas Post-caldera, se analizaron dos olivinas de diferente morfología: un fenocristal euhedral (Fig. $8.11 \mathrm{~d}$ ) y otro con engolfamientos pronunciados (Fig. 8.11 c). No se detectaron diferencias composicionales a pesar de las diferencias texturales, y ambas olivinas poseen composición de $\mathrm{Fo}_{66-67}$ (Fig. 8.11 a). En las Traquitas Post-caldera 
se encontraron olivinas solamente en la litofacies de Traquitas vítreas, euhedrales y frescas (Fig. 8.11 e). La composición medida arrojó un valor de $\mathrm{Fo}_{44}$.

En las lavas de los campos basálticos se midió la composición de fenocristales de olivina en las tres coladas basálticas/traquibasálticas mencionadas (muestras PY 5, PM 46 y PY 13, Fig. 7.1). Las olivinas son casi todas euhedrales, con leve morfología esqueletal en el borde en uno de los casos (Fig. 8.11 g). La composición de estas olivinas es homogénea, de Fo76-79. También fue analizada una olivina con engolfamientos pronunciados en la colada de "La Tranquera" (Fig. 8.11 f), cuyo contenido de Mg es de Fo $83-85$ (Fig. 8.11 a), mayor al resto.

\subsection{Piroxenos}

Los clinopiroxenos del CVPM son del tipo Ca-Mg-Fe o "Quad", según la clasificación de Morimoto et al. (1989) (Fig. 8.12). Algunos piroxenos se ubican levemente por encima de la línea $\mathrm{Q}+\mathrm{J}=2$, aunque no así la mayoría. El grupo de piroxenos que plotean sobre el eje $\mathrm{Q}$ corresponden a ortopiroxenos, ya que los mismos no poseen $\mathrm{Na}$. Como se mencionó previamente, todos los piroxenos encontrados corresponden a clinopiroxenos, a excepción de dos lavas traquíticas pre-caldera que contienen ortopiroxenos, con y sin manto de clinopiroxeno.

En los Traquitoides Pre-caldera, los clinopiroxenos son augitas con un rango composicional entre $\mathrm{Wo}_{39-44}-\mathrm{En}_{34-43}-\mathrm{Fs}_{15-23}$ (Fig. 8.13 a). En general poseen un menor contenido en ferrosilita hacia el borde de los fenocristales, o un mayor \# $\mathrm{Mg}$, indicando una tendencia hacia la zonación inversa (Fig. 8.14). Los fenocristales analizados son euhedrales y sin redondear (Fig. 8.13 a), a excepción de los glomérulos presentes en la lava al este de la caldera (PY 10), los cuales presenta fenocristales redondeados. Los cristales de ortopiroxeno de la lava PY 10 se encuentran en pequeños glomérulos y plotean en el campo de la enstatita pasando al campo de la ferrosilita $\left(\mathrm{Wo}_{3}-\mathrm{En}_{48-52}-\mathrm{Fs}_{45-48}\right)$ (Fig. $\left.8.13 \mathrm{a}\right)$.

Los fenocristales de la Ignimbrita Portezuelo, ubicados en la matriz (facies emLT(v)) y en los clastos de spatter, son relativamente homogéneos aunque presentan un mayor contenido de diópsido y \# Mg en el segundo caso (Fig. 8.13 b y Fig. 8.14). Para el clinopiroxeno en la matriz, la composición es $\mathrm{Wo}_{43}-\mathrm{En}_{37-39}-\mathrm{Fs}_{18-20}$, mientras que el fenocristal en el clasto de spatter es de composición $\mathrm{Wo}_{44-46}-\mathrm{En}_{38-41}-\mathrm{Fs}_{15-16}$. Los cristales son subhedrales - euhedrales y sin bordes redondeados.

Los fenocristales de clinopiroxeno de las Traquiandesitas Post-caldera muestran una escasa dispersión en el diagrama "Quad" de piroxenos, y todos corresponden a augitas cálcicas (Fig. 8.13 c). La composición se encuentra dentro del rango $\mathrm{Wo}_{42-44}-\mathrm{En}_{40-45}-\mathrm{Fs}_{13-16}$ (Fig. $8.13 \mathrm{c}$ ). Si bien algunos cristales presentan una zonación concéntrica o en reloj de arena, no se ven reflejados en el cuadrilátero de los piroxenos, aunque si en el \# Mg (Fig. 8.14). Las variaciones en \# Mg presentan en general un aumento del mismo hacia el borde de los cristales, indicando una zonación inversa. La mayor variación en el \# Mg se presenta en el clinopiroxeno de la muestra STA 6-B ("colada "El Choique", Fig. 8.14). En esta lava, el núcleo del 


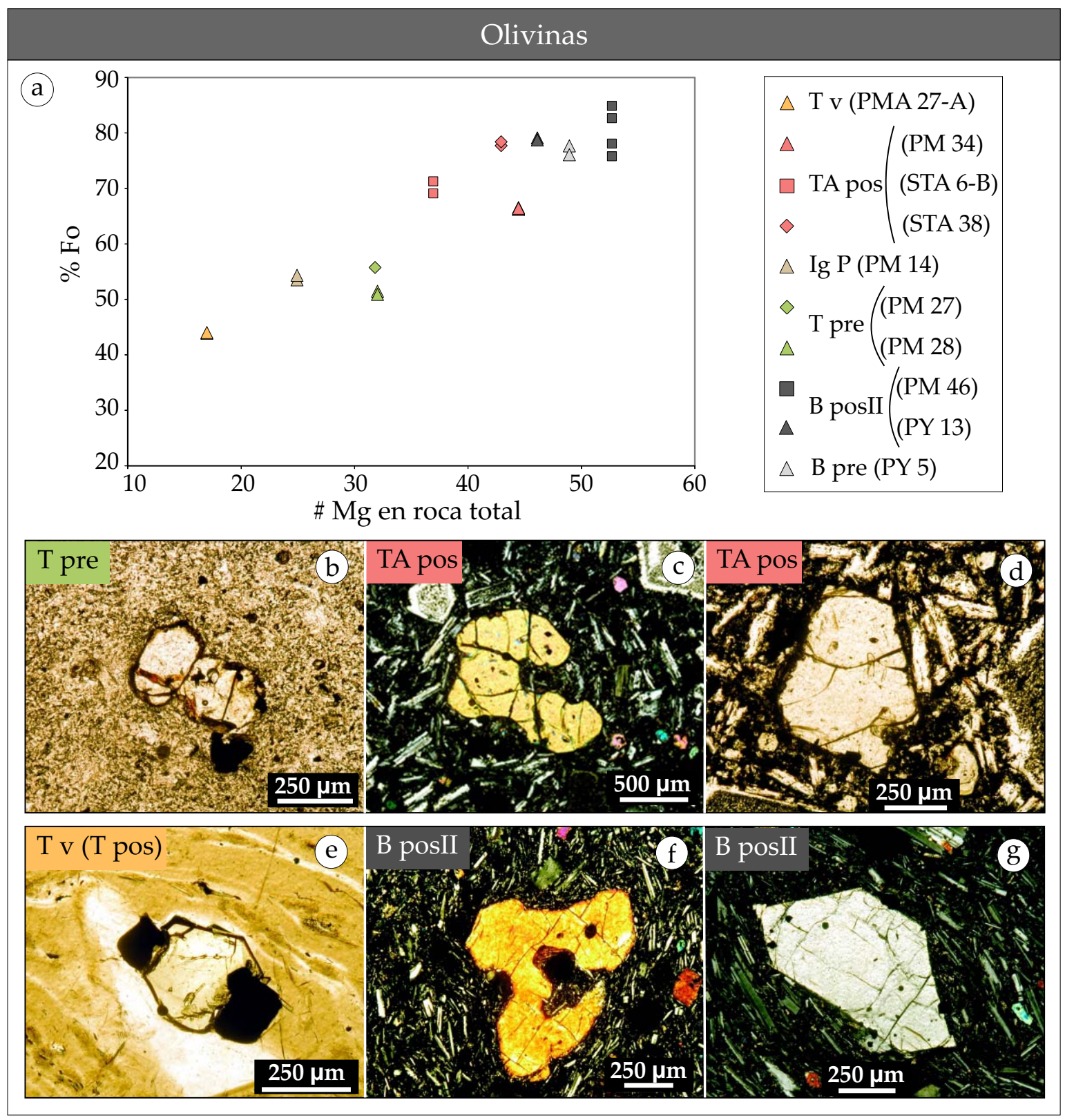

Figura 8.11: Análisis de olivinas del Payún Matrú y campos basálticos. a) Diagrama que muestra la variación composicional de las olivinas en función de la composición de la roca total (representada por el \# Mg). Entre paréntesis se indica la muestra a la que pertenece cada punto. b) Olivinas de Traquitoides Pre-caldera. c) y d) Olivinas de la unidad TA pos, pertenecientes a la colada intra-caldera. e) Olivina euhedral de Traquitas vítreas. f) Olivina engolfada en lava basáltica. g) Olivina euhedral en lava basáltica. 


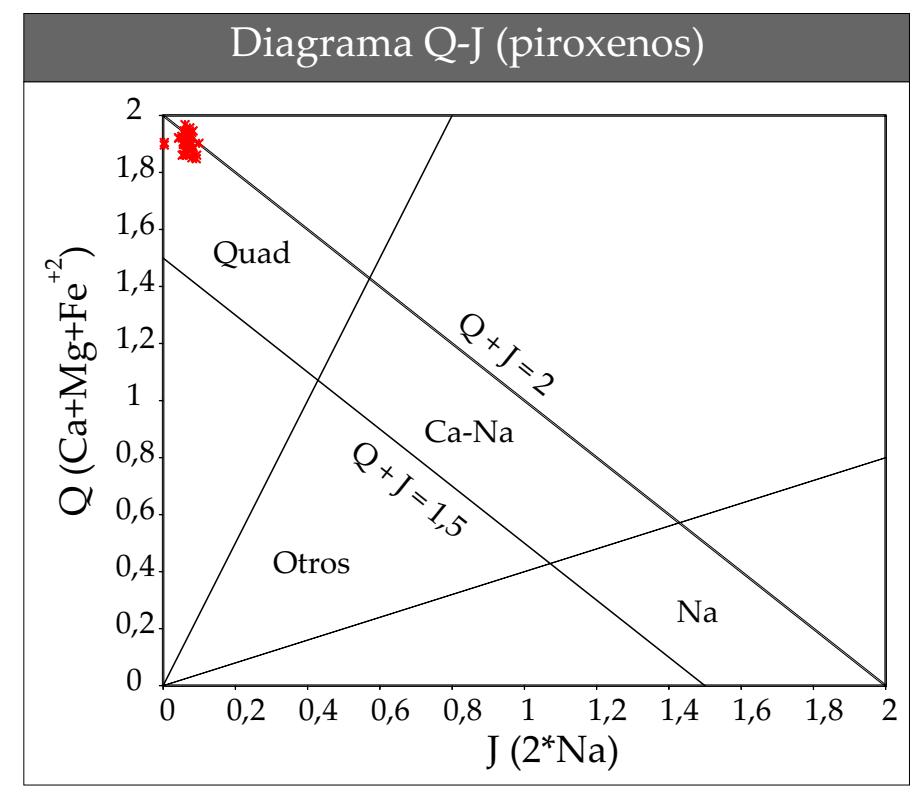

Figura 8.12: Diagrama Q-J para la clasificación de piroxenos, según Morimoto et al. (1989).

cristal posee \# Mg similar al resto de los clinopiroxenos de la unidad (entre 60 y 62), mientras que el medio y borde del cristal es más magnesiano con \# Mg similar a los clinopiroxenos de las lavas basálticas (entre 64 y 67). El contenido de Ti puede presentar variaciones importantes, correspondiéndose con las diferentes zonas en cristales con zonación en reloj de arena (ver Tabla en el Anexo IV).

En el caso de las Traquitas Post-caldera, los clinopiroxenos analizados tanto en la litofacies de Traquitas en bloque como Traquitas vítreas son similares composicionalmente, siendo estos augitas ( $\left.\mathrm{Wo}_{39-41}-\mathrm{En}_{37-38}-\mathrm{Fs}_{22-24}\right)$ (Fig. $8.13 \mathrm{~b}$ ). Los fenocristales son euhedrales en las Traquitas vítreas y levemente redondeados en las Traquitas en bloque (Fig. 8.13 b). El \# Mg se encuentra entre 49 y 52, con una pequeña variación en los cristales indicando una zonación normal (Fig. 8.14)

Los clinopiroxenos analizados en los basaltos fisurales (Basaltos Pre-caldera y Basaltos Post-caldera II) son más ricos en calcio que los fenocristales analizados del Payún Matrú. Plotean dentro del campo del diópsido y algunos son transicionales a augita, con composiciones de $\mathrm{Wo}_{45-48}-\mathrm{En}_{39-43}-\mathrm{Fs}_{11-14}$ (Fig. $8.13 \mathrm{~d}$ ). Los clinopiroxenos analizados son subhedrales - euhedrales, con una zonación concéntrica visible ópticamente en algunos casos, sin signos de redondeamiento en el caso de los fenocristales de Basaltos Post-caldera II (Fig. 8.13 d), y con las esquinas redondeadas en el caso de los Basaltos Pre-caldera. La zonación se ve reflejada en el \# Mg, el cual varía entre 62 y 69 (Fig. 8.14). En la colada de "La Tranquera" (muestra PM 46) se analizaron dos clinopiroxenos con diferencias relevantes: en el "Cpx a" el centro y borde presentan una diferencia significativa en el \# Mg, con una disminución del mismo hacia el borde; en el "Cpx b" se evidencia también una variación importante en el \# 


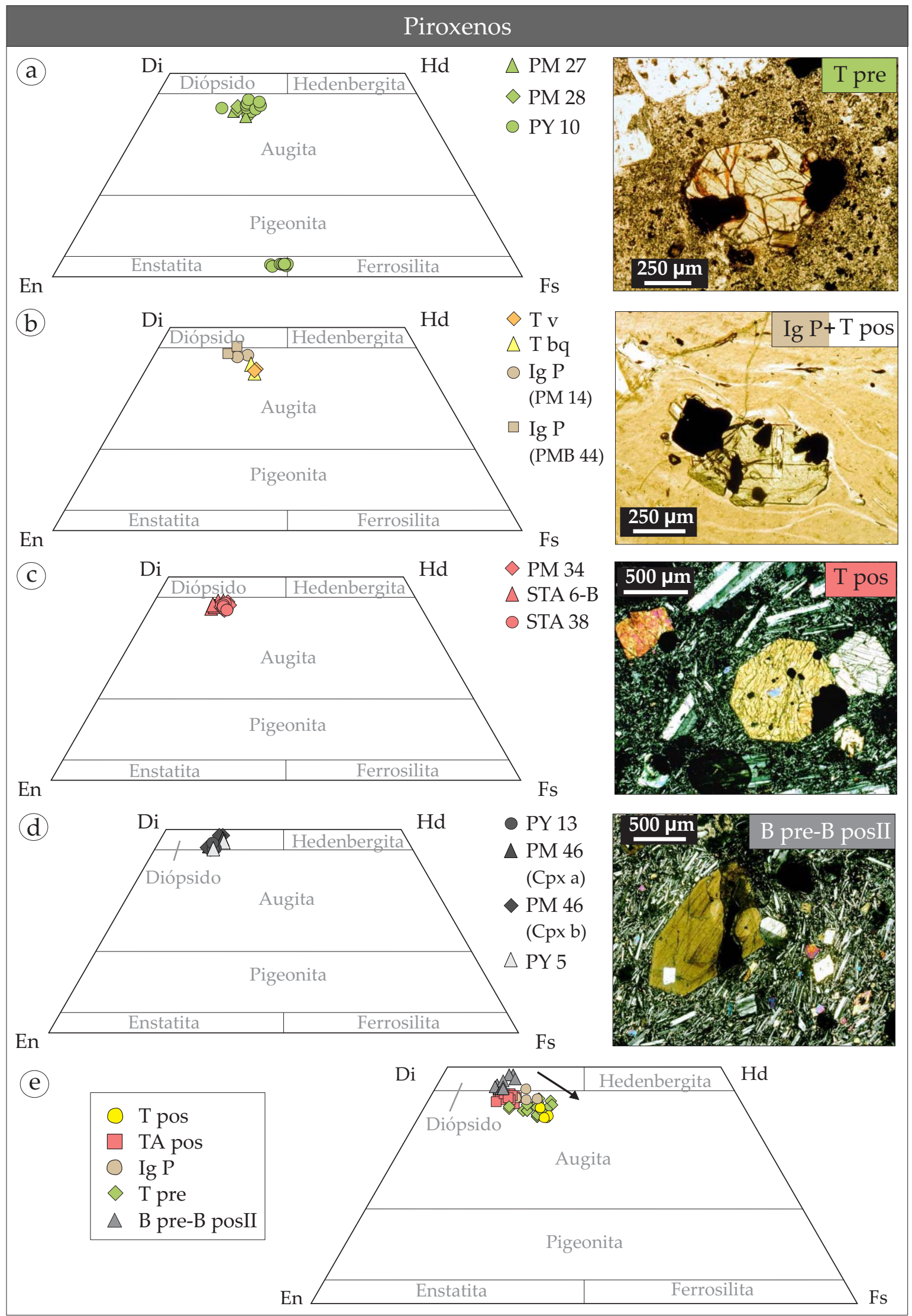

Figura 8.13: Diagramas de clasificación de piroxenos "Quad" de Morimoto et al., 1989. a) Piroxenos en Traquitoides Pre-caldera. b) Piroxenos en la Ignimbrita Portezuelo y Traquitas Post-caldera. c) Piroxenos en Traquiandesitas Post-caldera. d) Piroxenos en basaltos pre- y post-caldera. 


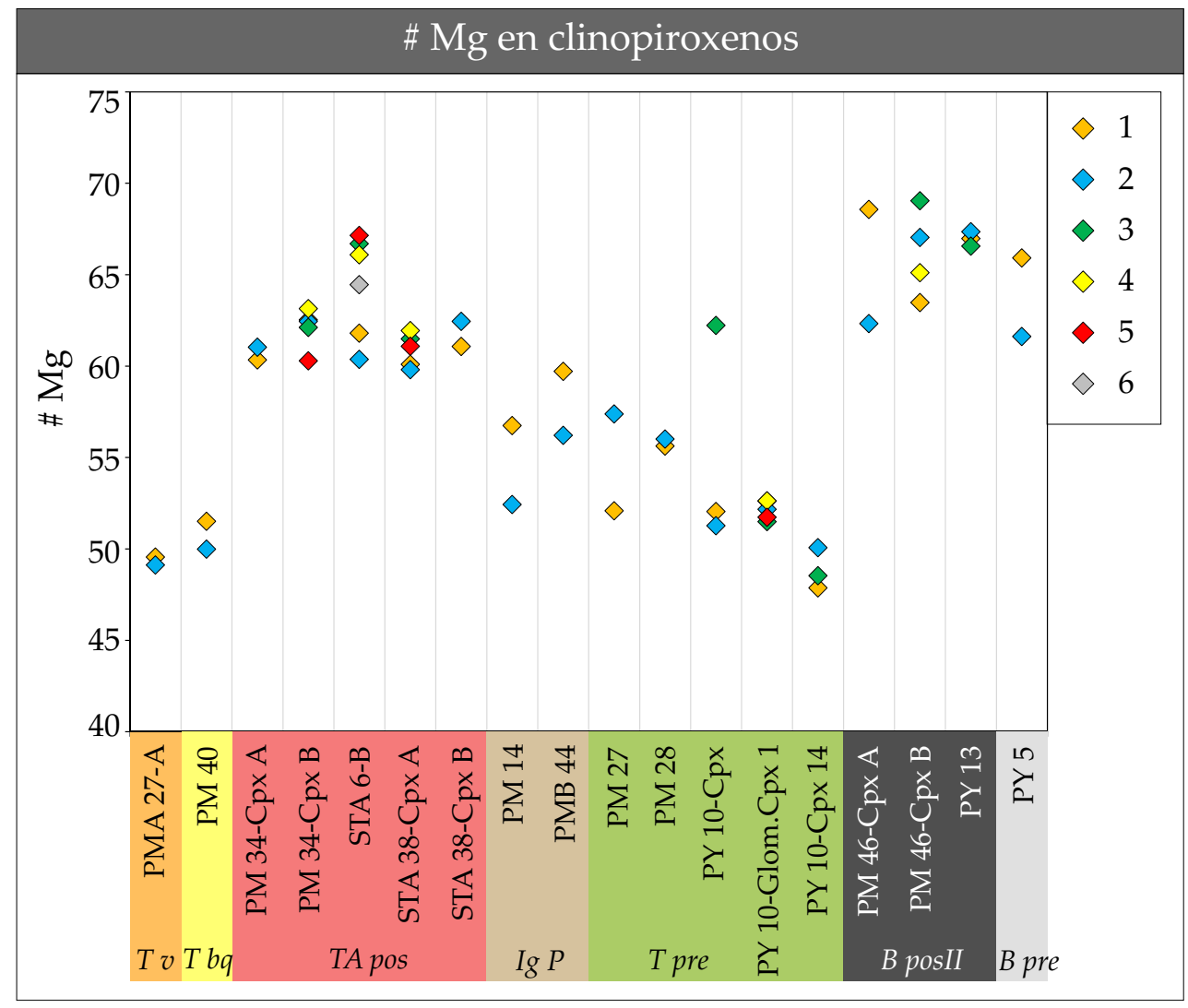

Figura 8.14: \# Mg en los clinopiroxenos del CVPM, por cristal analizado. Los números en las referencias corresponden a los puntos analizados en cada cristal, siendo 1 el centro y aumentando hacia el borde.

$\mathrm{Mg}$, pero esta vez con zonación inversa (Fig. 8.14).

Observando el diagrama de la Figura 8.13 e, puede verse que la tendencia en la composición de los clinopiroxenos, desde los basaltos fisurales a las Traquitas Post-caldera, evoluciona hacia el extremo de ferrosilita, aumentando el contenido de Fe y disminuyendo el de Ca junto con el incremento de la acidez de las rocas. La composición de los clinopiroxenos de las Traquiandesitas Post-caldera es cercana a la composición de los mismos en los basaltos fisurales, con solapamiento muy leve en el \# Mg de los núcleos de cristales en algunos casos (Fig. 8.14). En los Traquitoides Pre-caldera no se han detectado clinopiroxenos de composiciones similares a aquellos en los basaltos. Cabe destacar que el número de fenocristales analizados es reducido, por lo tanto la existencia de clinopiroxenos diopsídicos en las rocas del Payún Matrú y de procedencia de los magmas basálticos no queda descartada.

Los ortopiroxenos no manteados en una sola lava alcalina de Traquitoides Pre-caldera, sugeriría que los ortopiroxenos podrían ser xenocristales. Sin embargo, si se tiene en cuenta la tendencia de las traquitas hacia la sobresaturación en sílice, transicionales al campo de las riolitas en el diagrama TAS, junto con la presencia de cuarzo intersticial en una lava 


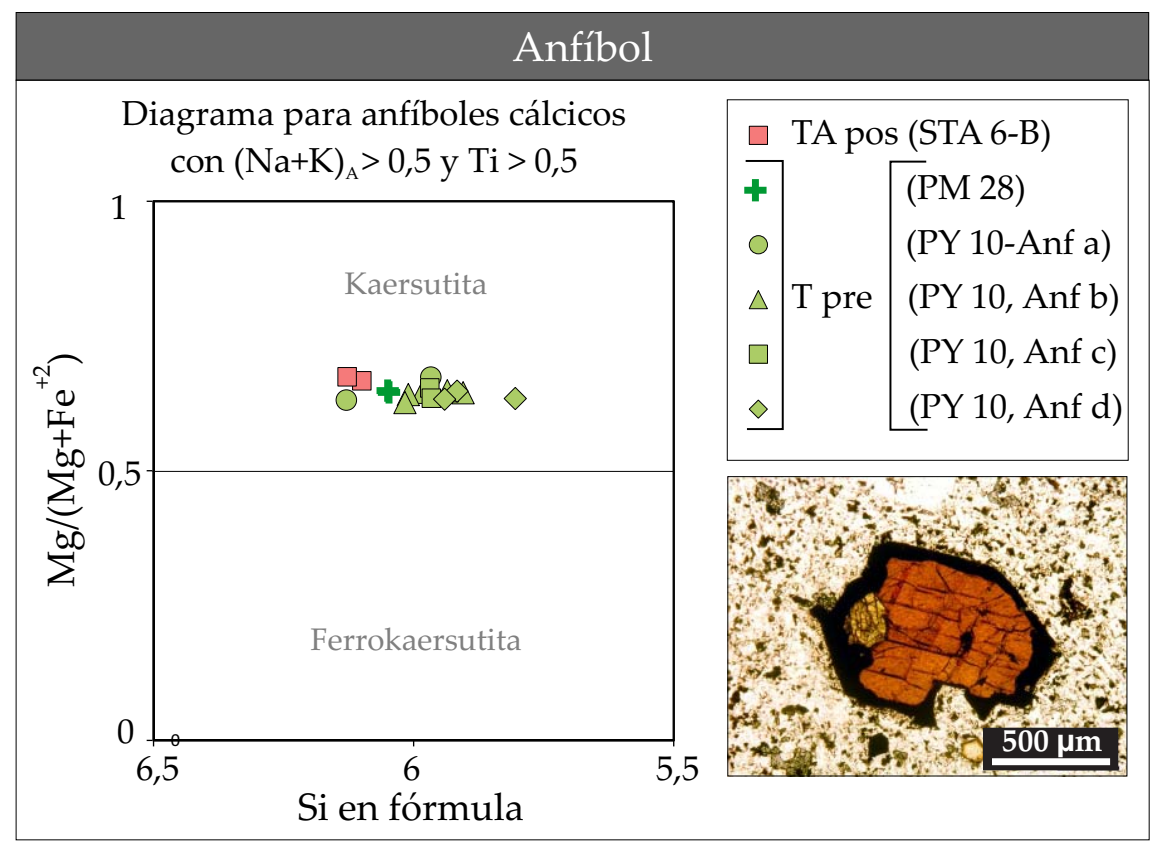

Figura 8.15: Clasificación de los anfíboles cálcicos, con contenidos mayores a 0,5 de Ti, según Leake et al. (1997). El anfíbol en la microfotografía pertenece a la muestra PY 10 de los Traquitoides Pre-caldera. La denominación $(\mathrm{Na}+\mathrm{K})_{\mathrm{A}}$ hace referencia al contenido de $\mathrm{Na}$ y $\mathrm{K}$ en el sitio estructural $A$ de la fórmula general de los anfíboles $\mathrm{A}_{0-1} \mathrm{~B}_{2} \mathrm{C}_{5} \mathrm{~T}_{8} \mathrm{O}_{22} \mathrm{OH}_{2}$ Leake et al. (2004).

pre-caldera, es probable que el ortopiroxeno sí haya cristalizado en el magma en el que se encuentra y no sea un xenocristal.

\subsection{Anfíboles}

La composición de los anfíboles fue analizada en dos lavas de Traquitas Pre-caldera (muestras PM 28 y PY 10), y en la única lava de Traquiandesitas Post-caldera en donde se encuentra anfíbol (muestra STA 6-B). En ambos casos el anfíbol es subhedral - anhedral y con un borde opaco relativamente grueso (Fig. 8.15).

Para clasificar a los anfíboles se siguió el criterio de Leake et al. (1997) y Leake et al. (2004), según el cual los anfíboles analizados del Payún Matrú pertenecen al grupo 2 o anfíboles cálcicos. El grupo 2 o cálcico posee un valor de la suma de cationes de Ca y Na en el sitio B mayor a 1, y un contenido de $\mathrm{Na}$ en el sitio B menor a 0,5. Dentro de este grupo, y teniendo en cuenta los contenidos de Ti, los cuales son relativamente altos (mayor a 0,5, exceptuando un sólo análisis con un valor menor aunque muy cercano), los anfíboles se clasifican como kaersutita (Fig. 8.15). Los contenidos de Si en fórmula varían entre 5,90 y 6,13, mientras que el \# $\mathrm{Mg}\left(\mathrm{Mg} /\left(\mathrm{Mg}+\mathrm{Fe}^{+2}\right)\right)$ es relativamente constante, entre 0,63 y 0,65. 


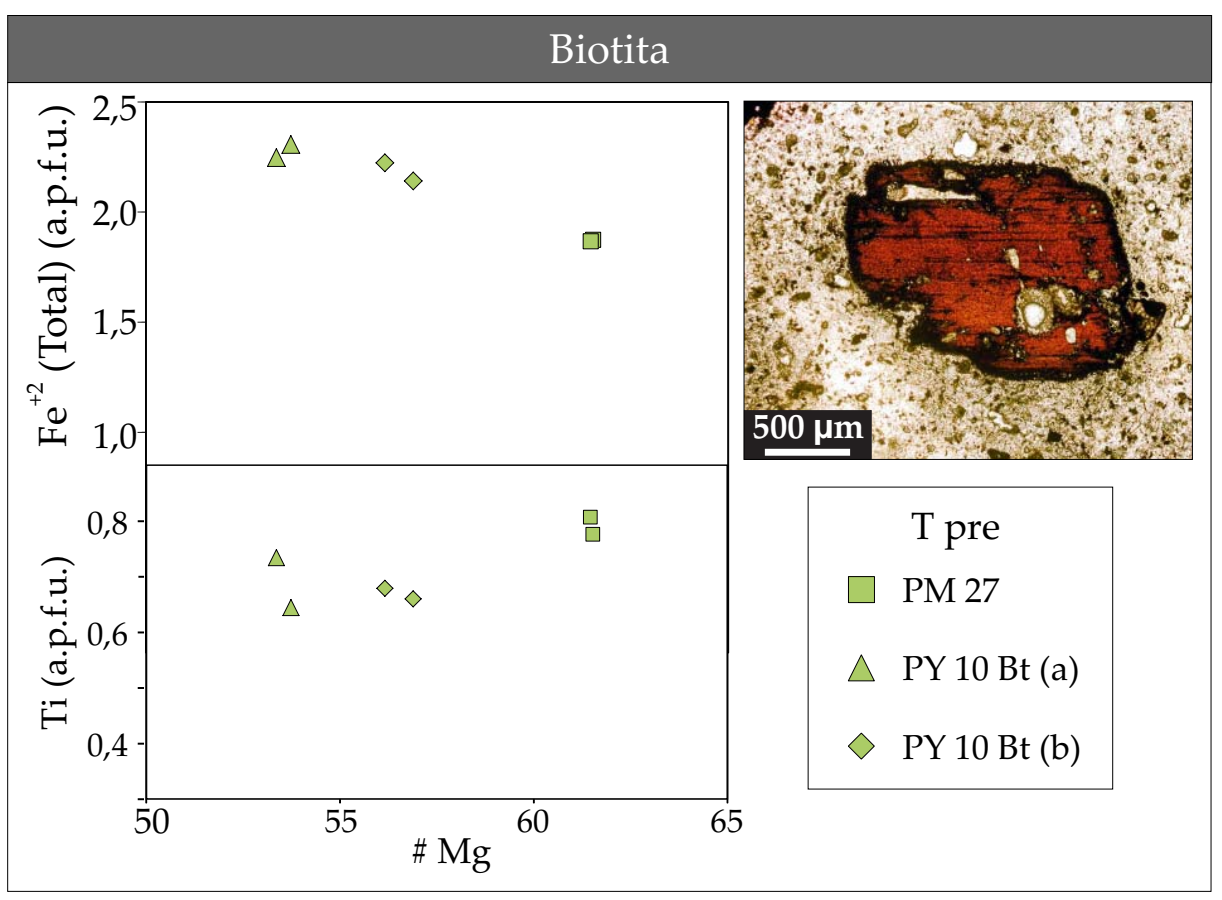

Figura 8.16: Composición química de las biotitas en los Traquitoides Pre-caldera. La microfotografía corresponde a la muestra PY 10 (Bt a).

\subsection{Micas}

Sobre la base de la clasificación de Rieder et al. (1998), las micas del CVPM son trioctaédricas correspondientes a biotita. Los análisis de este mineral provienen solamente de lavas de Traquitoides Pre-caldera, ya que no fue encontrada en los cortes delgados analizados de la Ignimbrita Portezuelo y Traquitas Post-caldera. La biotita en las lavas de los Traquitoides Pre-caldera, presenta un borde opaco no muy grueso (muestra PM 27), o bien un borde opaco relativamente fino junto con un incipiente reemplazo por minerales anhidros (muestra PY 10, Fig. 8.16).

El \# Mg (\# Mg = $100 \times \mathrm{Mg} /(\mathrm{Mg}+\mathrm{Fe}+\mathrm{Mn}))$ varía entre 53 y 62, siendo el fenocristal con valor más alto de la muestra PM 27 (\# Mg entre 61 y 62), y los menos magnesianos de la lava PY 10 (\# Mg igual a 53 y 56). El contenido de Ti a.p.f.u. (átomo por unidad de fórmula) es alto, entre 0,64 y 0,80. Esto puede deberse, no sólo al contenido de Ti en el magma (y a los óxidos que estén cristalizando conjuntamente con la biotita), sino también a la temperatura de cristalización, ya que a mayor temperatura aumenta la solubilidad del Ti en la biotita (Patiño Douce, 1993). En la Figura 8.16 se muestran diagramas que comparan el \# Mg con el contenido en $\mathrm{Fe}^{+2}$ (total) y el Ti a.p.f.u.. El Fe ${ }^{+2}$ y el Ti muestran una tendencia inversa con el aumento de \# Mg, siendo la muestra PM 27 (mayor \# Mg) la de menor contenido en $\mathrm{Fe}^{+2}$ y mayor contenido de Ti. 


\subsection{Vidrio volcánico}

Los análisis de vidrio volcánico provienen de fiammes de la Ignimbrita Portezuelo y de la base de Traquitas vítreas. En la Ignimbrita Portezuelo, el vidrio es traquítico, con una composición entre 65 y $67 \%$ de $\mathrm{SiO}_{2}$, y entre 9 y $10 \%$ de álcalis (el doble de $\mathrm{K}_{2} \mathrm{O}$ que de $\mathrm{Na}_{2} \mathrm{O}$, aproximadamente). El vidrio analizado de la litofacies Traquitas vítreas es riolítico, con un contenido de $68,8 \%$ de $\mathrm{SiO}_{2}$ y 9,3\% de álcalis (también más $\mathrm{K}_{2} \mathrm{O}$ que $\mathrm{Na}_{2} \mathrm{O}$, aunque no es tanta la diferencia).

En la Figura 8.17 se gráfica el diagrama TAS con la composición promedio de los feldespatos alcalinos en las Traquitas vítreas $\left(\mathrm{SiO}_{2}=66,2 \%\right.$ y $\left.\mathrm{Na}_{2} \mathrm{O}+\mathrm{K}_{2} \mathrm{O}=13,5 \%\right)$ y en la Ignimbrita Portezuelo (muestra PM 14, feldespatos en fiammes y matriz). Se puede observar que las líneas que conectan la composición de los feldespatos con las composiciones del vidrio pasa muy cerca de la composición de la roca total (encerrada en el círculo azul). Esto indicaría que la tendencia del vidrio a ser más silícico y con menos álcalis que la roca total se debe a la cristalización de los feldespatos alcalinos, los cuales constituyen mayormente la población de cristales presentes en estas lavas. La pequeña diferencia observada podría deberse a otra fase mineral minoritaria, como por ejemplo los clinopiroxenos (de menor contenido en $\mathrm{SiO}_{2}$ y álcalis que la roca total).

El pequeño hiato composicional que se observa alrededor del $66 \%$ de sílice en los análisis de roca total puede deberse a un salto en el contenido de fenocristales, pero no necesariamente a una discontinuidad en la composición de los vidrios (Bacon y Druitt, 1988).

\subsection{Cálculos geobarométricos}

Con el propósito de obtener datos cuantitativos de presión y temperatura de los magmas del CVPM, se realizaron cálculos geobarométricos con los análisis de la química mineral y aplicando diferentes metodologías. Los cálculos de temperatura de los magmas resultan importantes al evaluar los posibles procesos de mezcla entre magmas diferentes, y éste es el principal motivo por el cual se han realizado los cálculos. Los datos obtenidos, junto con los métodos aplicados, se exhiben a continuación.

\subsubsection{Termómetros con vidrios}

Se calculó la temperatura sobre la base de la composición de vidrios de las Traquitas vítreas y la Ignimbrita Portezuelo, de acuerdo con dos cálculos propuestos por Putirka (2008). El primero es una corrección a una fórmula sencilla propuesta por Helz y Thornber (1987), la cual tiene en cuenta solamente la composición de $\mathrm{MgO}$ en el liquido y posee un error estándar de $\pm 71^{\circ} \mathrm{C}$. El segundo cálculo es independiente de la presión, y tiene en cuenta no sólo el contenido de $\mathrm{MgO}$ en el liquido, sino también el FeO, álcalis y agua, con un error 


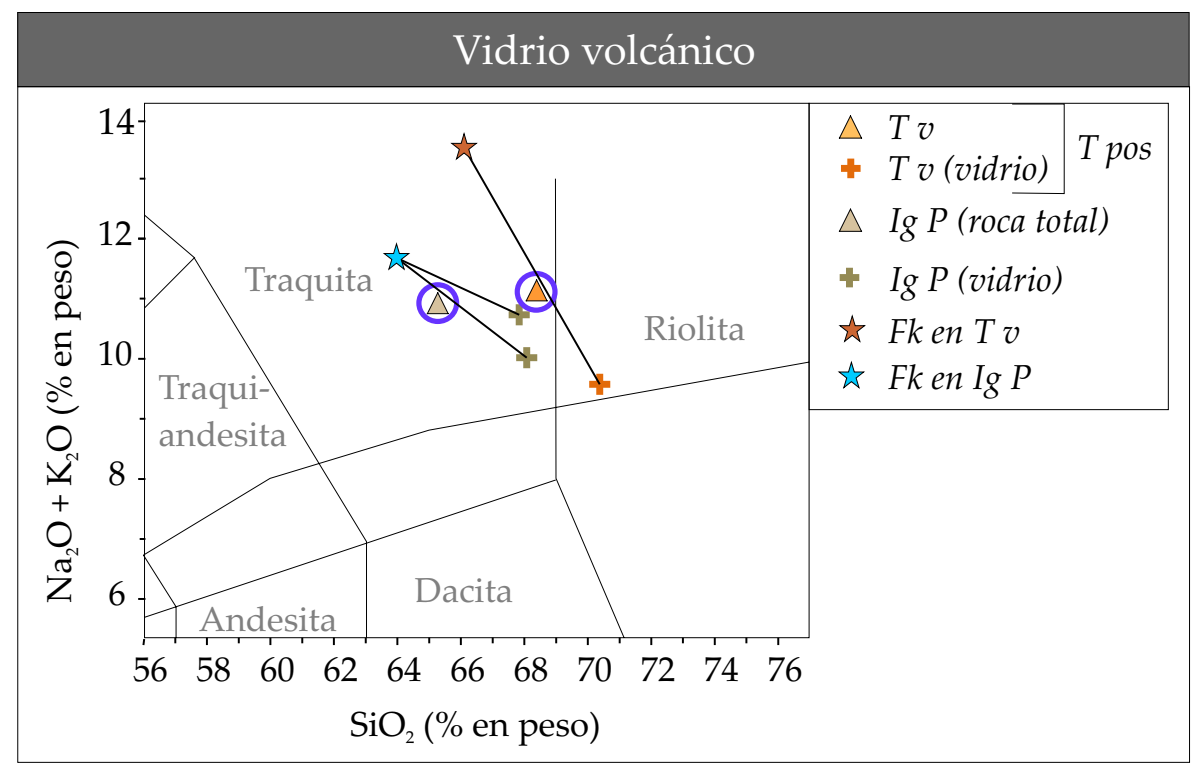

Figura 8.17: Diagrama de clasificación TAS (sector meso-silícico a ácido), en donde se indica no sólo la composición de roca total sino la composición del vidrio y la composición promedio de feldespatos alcalinos de la Ignimbrita Portezuelo y Traquitas vítreas. En círculos azules se encierran a las composiciones de roca total de las muestras con vidrio analizado.

estándar de $\pm 51^{\circ} \mathrm{C}$. En ambos casos las temperaturas obtenidas son similares, siendo para las Traquitas vítreas de $955^{\circ} \mathrm{C}$ (primer y segundo método) y para la Ignimbrita Portezuelo de $972-984{ }^{\circ} \mathrm{C}$ (primer método) y $980{ }^{\circ} \mathrm{C}$ (segundo método).

\subsubsection{Termómetro olivina-fundido}

Otros métodos termométricos utilizados se basan en el equilibrio entre la olivina y el fundido. Para el cálculo se tienen en cuenta preferentemente las composición de las olivinas y vidrio (aplicable solamente a las Traquitas vítreas e Ignimbrita Portezuelo) o, si no se dispone de composiciones de vidrio, por la roca total (aplicable en los Traquitoides Pre-caldera, Traquiandesitas Post-caldera y Basaltos Pre- y Post-caldera II). Este método fue desarrollado por varios autores, pero en el presente trabajo los cálculos se realizaron en base a los modelos de Beattie (1993) y Putirka et al. (2007), utilizando una planilla excel desarrollada por Putirka, disponible en el sitio web http://www . csufresno. edu/ees/Faculty\&Staff/Putirka/ Keith_Putirka.html.

El modelo de Beattie (1993) se ajusta mejor en sistemas anhidros, mientras que el de Putirka (2008) se ajusta mejor en sistemas hidratados. En los casos en que se utilizó la composición de roca total para aproximar la composición del liquido, los cálculos fueron hechos utilizando la composición del núcleo de la olivina. En los casos en que se utilizó la composición del vidrio, los cálculos fueron hechos con la composición del borde de la olivina. Esto es así debido a que los minerales que son soluciones sólidas pueden variar su composición de 
núcleo a borde, a medida que varía la composición del liquido. Por lo tanto, lo más probable es que la composición en equilibrio con el vidrio sea la composición del borde de la olivina, y no la del núcleo, el cual posiblemente cristalizó en un liquido de composición levemente diferente. En el otro caso, se supone que un liquido de composición igual a la roca total comenzó a cristalizar, y por lo tanto la composición de olivina que estaría en equilibrio con la del liquido sería la de su núcleo.

En las Traquitas vítreas, el resultado de estos cálculos fue de $929^{\circ} \mathrm{C}$ (Putirka et al., 2007) y $1021^{\circ} \mathrm{C}$ (Beattie, 1993), similar a las temperaturas de la Ignimbrita portezuelo con $928^{\circ} \mathrm{C}$ (Putirka et al., 2007) y $1030^{\circ} \mathrm{C}$ (Beattie, 1993). Para las tres lavas de Traquiandesitas Postcaldera, las temperaturas son mayores, variando entre $1023-1110{ }^{\circ} \mathrm{C}$ (Putirka et al., 2007) y 1062-1105 ${ }^{\circ} \mathrm{C}$ (Beattie, 1993) (Tabla 8.1). Cabe destacar que los resultados obtenidos deben interpretarse con precaución, tanto para las Traquiandesitas Post-caldera como los Traquitoides Pre-caldera. Se infiere de las texturas y composiciones mineralógicas estudiadas, que las lavas son posiblemente híbridas (ver Capítulo 9) por lo que la composición de la olivina y el líquido (roca total) pueden no corresponder a un equilibrio liquido-sólido, dando como resultado una temperatura que no refleja la temperatura de cristalización de la olivina. Las temperaturas de las dos lavas pre-caldera del Payún Matrú arrojaron un rango de temperaturas entre $999-1029{ }^{\circ} \mathrm{C}$ (Putirka et al., 2007) y 1029-1036 ${ }^{\circ} \mathrm{C}$ (Beattie, 1993) (Tabla 8.1). Por otro lado, las temperaturas calculadas para los basaltos fisurales son mayores, variando entre $1108-1159{ }^{\circ} \mathrm{C}$ (Putirka et al., 2007) y $1129-1158^{\circ} \mathrm{C}$ (Beattie, 1993) (Tabla 8.1). En la Figura 8.18 se esquematizan las temperaturas obtenidas mediante este método para las diferentes unidades.

\subsubsection{Termobarómetros feldespato alcalino/plagioclasa-fundido}

Del mismo modo que en el método anterior, se utilizó de preferencia la composición del vidrio (en las Traquitas vítreas e Ignimbrita Portezuelo), junto con la composición del borde de los feldespatos alcalinos. En el resto de las lavas se utilizó la composición de la roca total para aproximar la composición del fundido, junto con el núcleo de plagioclasas. También se tienen que tomar las mismas precauciones con los resultados obtenidos en las unidades Traquiandesitas Post-caldera y Traquitoides Pre-caldera, por el hecho de ser magmas posiblemente híbridos. Los cálculos se realizaron con el método de Putirka (2005) y Putirka (2008), utilizando la planilla de cálculo disponible en la página web: http://www.csufresno.edu/ees/Faculty\&Staff/Putirka/Keith_Putirka.html. El cálculo de presión por este método no es confiable y se ajusta solamente a composiciones similares a las estudiadas para este método (Putirka, 2008), lo cual está de acuerdo con los resultados inverosímiles hallados en algunos casos.

En las Traquitas vítreas, las temperaturas calculadas en base a feldespatos alcalinos y vidrio varían entre 860 y $865{ }^{\circ} \mathrm{C}$, las cuales son considerablemente menor que en los méto- 
dos anteriores. En las Traquitas en bloque (roca total-feldespato alcalino) las temperaturas calculadas varían entre $862-871{ }^{\circ} \mathrm{C}$. En la Ignimbrita Portezuelo, la temperatura en base al equilibrio feldespato alcalino-vidrio arrojó un resultado similar a los ya mencionados, entre 947-950 ${ }^{\circ} \mathrm{C}$. Los cálculos de presión son irreales, ya que en el caso de las dos litofacies de Traquitas Post-caldera, la presión resultó entre 33 y 40 kbar, mientras que en la Ignimbrita Portezuelo resultó alrededor de 15 kbar.

Las lavas de las Traquiandesitas Post-caldera presentan temperaturas en un rango de 1056-1163 ${ }^{\circ} \mathrm{C}$, similares a las temperaturas calculadas en base al equilibrio olivina-fundido (Tabla 8.1). Las temperaturas calculadas para las tres lavas de Traquitoides Pre-caldera dan valores entre $1014{ }^{\circ} \mathrm{C}$ y $1108^{\circ} \mathrm{C}$, un poco mayores que las previamente calculadas (Tabla 8.1). Para esta unidad, las presiones calculadas también arrojan valores de presión no confiables.

En cuanto a los basaltos fisurales, las temperaturas se encuentran en un rango de 1148$1215^{\circ} \mathrm{C}$, y las presiones entre 6,6 y 10,6 kbar (Tabla 8.1), que en este caso podrían ser datos confiables, aunque debido a la poca confiabilidad del método en las otras unidades del Payún Matrú, no se puede afirmar que sea así. Este rango de presiones se corresponde a una profundidad debida a carga litostática en corteza continental entre 23 y $36 \mathrm{~km}$, aproximadamente.

\subsubsection{Termobarómetros con clinopiroxeno-fundido}

Para calcular la temperatura y presión en base al equilibrio entre clinopiroxeno y el liquido, se utilizaron los métodos de Putirka et al. (1996) y Putirka et al. (2003), en una planilla de cálculo disponible en la página web mencionada de Putirka. El modelo propuesto por Putirka et al. (1996) es recomendado para sistemas anhidros, mientras que el de Putirka et al. (2003) es recomendable para sistemas hidratados. Debido a que los cálculos barométricos para las rocas del Payún Matrú no dieron resultados confiables (presiones inclusive negativas, aunque los datos de temperatura son similares a los ya calculados), no se utilizará este método para estas rocas, sino solamente para los basaltos fisurales.

Las temperaturas y presiones obtenidas para los Basaltos Pre-caldera y Basaltos Postcaldera II se encuentran entre $1149-1190{ }^{\circ} \mathrm{C}$ y 4,2-9 kbar (Putirka et al., 1996), y entre 1121$1164{ }^{\circ} \mathrm{C}$ y 4,8-5,8 kbar (Putirka et al., 2003). Estas presiones equivalen a una profundidad de alrededor de 17 a $32 \mathrm{~km}$, si se hace la equivalencia con la presión litostática. Debido a que los magmas suelen estar sobrepresionados en las cámaras magmáticas, la profundidad podría ser menor (Best y Christiansen, 2001).

\subsubsection{Termobarómetros que involucran al ortopiroxeno}

Estos métodos son solamente aplicables a la muestra PY 10 de los Traquitoides Precaldera, ya que es la única lava en donde se realizaron análisis de ortopiroxeno, la cual es una especie mineral rara en el CVPM. Esta lava no posee vidrio, y por lo tanto los cálculos 


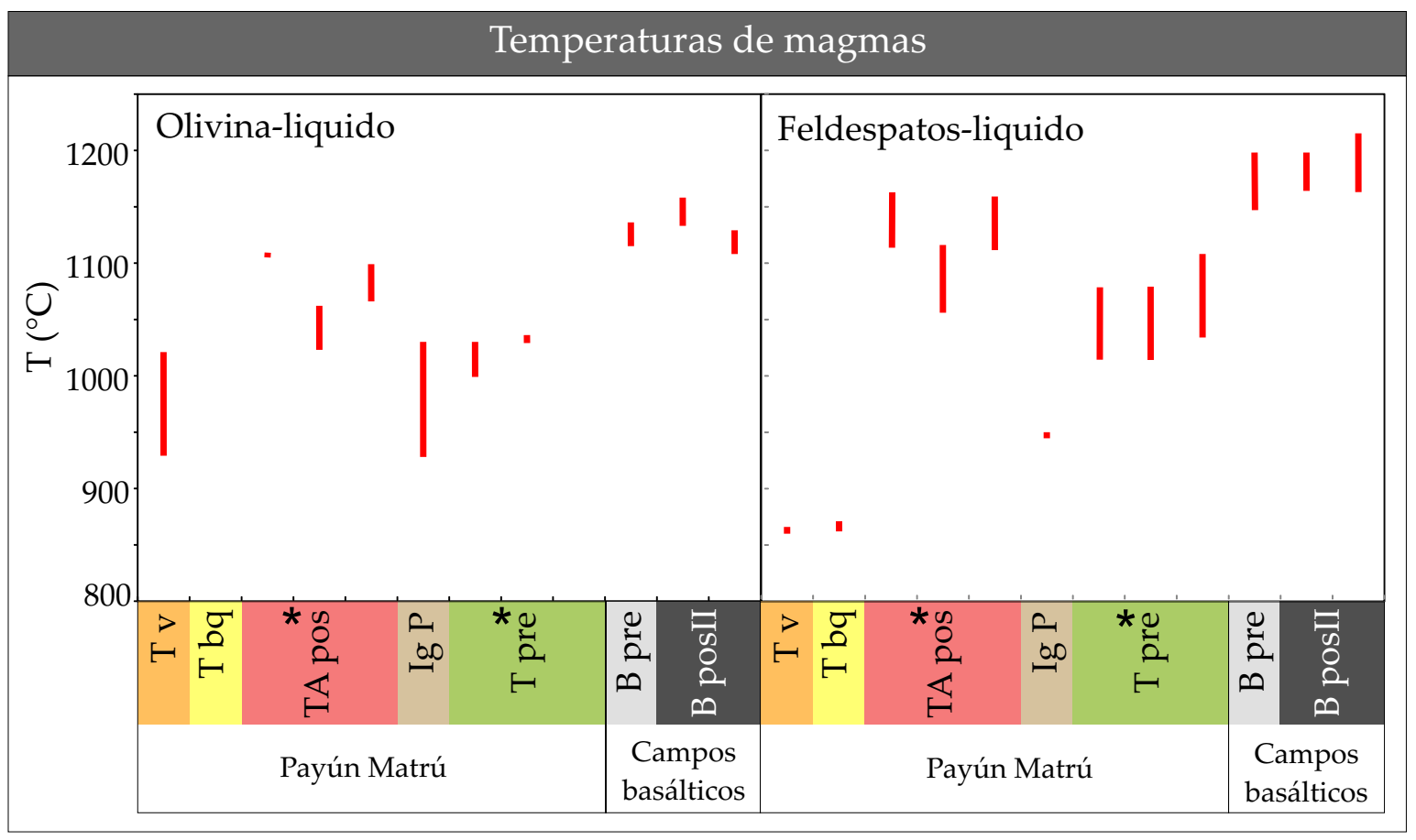

Figura 8.18: Diagrama comparativo de las temperaturas calculadas en base a los métodos que utilizan el equilibrio entre olivina y fundido, y a los métodos basados en el equilibrio feldespatos-fundido. El asterisco es para resaltar que en esos casos posiblemente la olivina o feldespato no estaba en equilibrio con un líquido de composición igual a la roca total, ya que si el magma es híbrido, puede no corresponderse la composición de la roca total con la composición del fundido en la cual cristalizó el fenocristal.

fueron hechos con la composición de roca total, junto con la composición del núcleo de los ortopiroxenos.

En primera instancia se realizaron cálculos de presión y temperatura con un método que involucra a la composición de ortopiroxeno y del liquido en equilibrio con él (métodos realizados por Beattie (1993) y Putirka (2008), mediante la hoja de cálculo disponible en el sitio web: http://www.csufresno.edu/ees/Faculty\&Staff/Putirka/Keith_Putirka.html). Estos métodos no resultaron buenos para los análisis disponibles, ya que el rango de presión y temperatura que arrojan son demasiado amplios, entre $976-1136{ }^{\circ} \mathrm{C}$ y 0,3-0,7 GPa.

Otros métodos para rocas volcánicas, involucran a las composiciones de clino- y ortopiroxeno. Los métodos aplicados fueron formulados por Brey y Köhler (1990) y Putirka (2008), y se realizaron mediante la planilla de cálculo disponible en el sitio web mencionado. Las temperaturas obtenidas para esta lava pre-caldera fueron de $828-887^{\circ} \mathrm{C}$ (Brey y Köhler, 1990) y 791-826 ${ }^{\circ} \mathrm{C}$ (Putirka, 2008), mientras que la presión resulta elevada, entre 7,9 y 10,6 kbar (equivalentes a profundidades debido a presión litostática en corteza continental entre 28 y $40 \mathrm{~km}$, aproximadamente). 


\subsubsection{Termobarómetros con anfíbol}

Los cálculos realizados se basaron en el método de Ridolfi et al. (2010), el cual calcula no sólo la temperatura y presión en base a la composición de anfíboles, sino también el contenido de agua en el magma y la $\mathrm{fO}_{2}$. El método es aplicable a anfíboles cálcicos (hornblendas de rocas calcoalcalinas en ambiente de subducción) con un \#Al $>0,21\left(\# \mathrm{Al}={ }^{[6]} \mathrm{Al} / \mathrm{Al}_{\mathrm{T}}\right)$. Los cálculos se realizaron mediante una planilla de cálculo (programa Amp-TB) confeccionada por Ridolfi et al. (2010). Los anfíboles del Payún Matrú, si bien no son hornblendas de magmas calcoalcalinos, sí pertenecen al grupo cálcico y también cumplen la condición de poseer un \# Al menor a 0,21 .

Las lavas pre-caldera con anfíbol dieron valores de temperatura y presión en rangos superpuestos, de $991-995^{\circ} \mathrm{C}$ y 4,22-4,28 kbar (muestra PM 28) y $971-1036{ }^{\circ} \mathrm{C}$ y 3,53-5,17 kbar (muestra PY 10, Tabla 8.1). El error en los valores de temperatura es de $22{ }^{\circ} \mathrm{C}$, mientras que en el caso de la presión es variable, entre 0,39 y 0,57 kbar. La única lava de Traquiandesitas Post-caldera con anfíbol (muestra STA 6-B) arrojó un resultado de $983^{\circ} \mathrm{C}$ y 3,59-3,78 kbar de presión (con un error de $22{ }^{\circ} \mathrm{C}$ para la temperatura y 0,39-0,42 kbar para la presión, Tabla 8.1). Los valores de presión son equivalentes a una profundidad debida a presión litostática en corteza continental entre 13 y $19 \mathrm{~km}$, siendo éstos valores de profundidad máximos si se considera la sobrepresión que puede existir en las cámaras magmáticas. Por otro lado, el contenido de $\mathrm{H}_{2} \mathrm{O}$ en los magmas según el método, da valores entre 3,7 y 5,2\%, con un error que varía entre $0,5-0,8 \%$.

\subsubsection{Termómetros con anfíbol-plagioclasa}

Por último, se calcularon temperaturas en base al método propuesto por Holland y Blundy (1994), con el programa Hb-Pl 1.2 desarrollado por los mismos autores (http:// www.esc.cam.ac.uk/research/research-groups/holland). Los autores proponen dos modelos, de los cuales uno se utiliza en rocas subsaturadas sin cuarzo, y se basa en el equilibrio Edenita + Albita $=$ Richterita + Anortita. Además, se puede usar en una amplia gama de composiciones, en un rango de temperaturas entre $400-1000{ }^{\circ} \mathrm{C}$ y presiones de $0-15 \mathrm{kbar}$. La temperatura es calculada para presiones fijas de 0, 5, 10 y $15 \mathrm{kbar}$.

Dada la heterogeneidad composicional de plagioclasas y anfíboles de las Traquitas Precaldera y Traquiandesitas Post-caldera debida posiblemente a la mezcla de magmas, este método debe aplicarse con precaución. Por este motivo, no se tiene certeza sobre los pares plagioclasa-anfíbol en equilibrio, y los datos obtenidos son sólo orientativos de las temperaturas de cristalización de los magmas.

En la muestra PY 10 de los Traquitoides Pre-caldera, la temperatura fue calculada para un rango composicional de las plagioclasas entre $\mathrm{Ab}_{36-49}$, y una composición de centro y borde de los cuatro anfíboles analizados en la muestra. El rango de temperaturas obtenido para una presión de 5 kbar es relativamente amplio, entre 962 y $1022{ }^{\circ} \mathrm{C}$, con un promedio 
de $991{ }^{\circ} \mathrm{C}$ (Tabla 8.1). La lava de la muestra PM 28 pre-caldera con análisis de anfíbol, arrojó temperaturas también en un rango amplio, entre 895 y $986{ }^{\circ} \mathrm{C}$, con un promedio de 947 ${ }^{\circ} \mathrm{C}$ (a 5 kbar de presión, Tabla 8.1). En este caso, las composiciones de plagioclasa son más variadas, y para los cálculos se utilizaron plagioclasas en en el intervalo $\mathrm{Ab}_{39-62}$, junto con la composición de centro y borde del anfíbol estudiado.

En el caso de la muestra de Traquiandesitas Post-caldera, se utilizaron las composiciones de plagioclasas en un rango de $\mathrm{Ab}_{46-62}$. Las temperaturas obtenidas promedian los $938^{\circ} \mathrm{C}$, con una variación considerable entre 895 y $981^{\circ} \mathrm{C}$ (a 5 kbar, Tabla 8.1).

\subsubsection{Interpretación de los datos termobarométricos}

La Tabla 8.1 muestra una síntesis de los cálculos realizados para las diferentes unidades y muestras. La heterogeneidad composicional hallada en los minerales sugiere que los datos cuantitativos de termobarometría, calculados con los análisis químicos de los mismos, deban ser interpretados con precaución sobre todo en los Traquitoides Pre-caldera y Traquiandesitas Post-caldera.

Como puede observarse, en algunos casos no varían considerablemente los valores de temperatura calculados mediante diferentes métodos, pero en otros casos sí. Los basaltos arrojaron temperaturas entre 1108 y $1215^{\circ} \mathrm{C}$, con diferencias de hasta $107^{\circ} \mathrm{C}$ para una misma lava. Las temperaturas de las lavas de los Traquitoides Pre-caldera son variables, inclusive en una misma lava. El rango de temperaturas calculado para la unidad es de $791-1108{ }^{\circ} \mathrm{C}$ (muestra PY 10), siendo un poco más restringidos los rangos para las otras lavas, que en general rondan los $1000^{\circ} \mathrm{C}$.

En la Ignimbrita Portezuelo y Traquitas Post-caldera, las temperaturas son menos variables que en las lavas pre-caldera. Las Traquitas vítreas e Ignimbrita Portezuelo presentan temperaturas similares, y en las Traquitas en bloque se obtuvieron menores temperaturas (aunque el único método utilizado en este caso arrojó las menores temperaturas obtenidas para las Traquitas vítreas e Ignimbrita Portezuelo). Las temperaturas de las Traquiandesitas Post-caldera vuelven a ser ampliamente variables, entre 895 y $1163^{\circ} \mathrm{C}$, siendo más coherentes las temperaturas obtenidas para la colada intra-caldera con un promedio de $1134{ }^{\circ} \mathrm{C}$.

Las presiones calculadas se muestran sólo para las unidades basálticas y Traquitoides Pre-caldera, debido a que en el resto de las unidades los valores obtenidos por diferentes métodos no eran confiables (presiones negativas y/o demasiado elevadas). Las presiones calculadas son variables en un rango considerable de entre 5,5 y 10,6 kbar. Este rango disminuye si se considera cada método de cálculo por separado, es decir, para cada lava basáltica las presiones obtenidas mediante los equilibrios plagioclasa-fundido o clinopiroxenofundido son similares. Las presiones obtenidas basadas en el equilibrio plagioclasa-fundido son mayores que aquellas obtenidas mediante el equilibrio clinopiroxeno-fundido.

Las variaciones observadas pueden deberse a diversos motivos, como por ejemplo la 


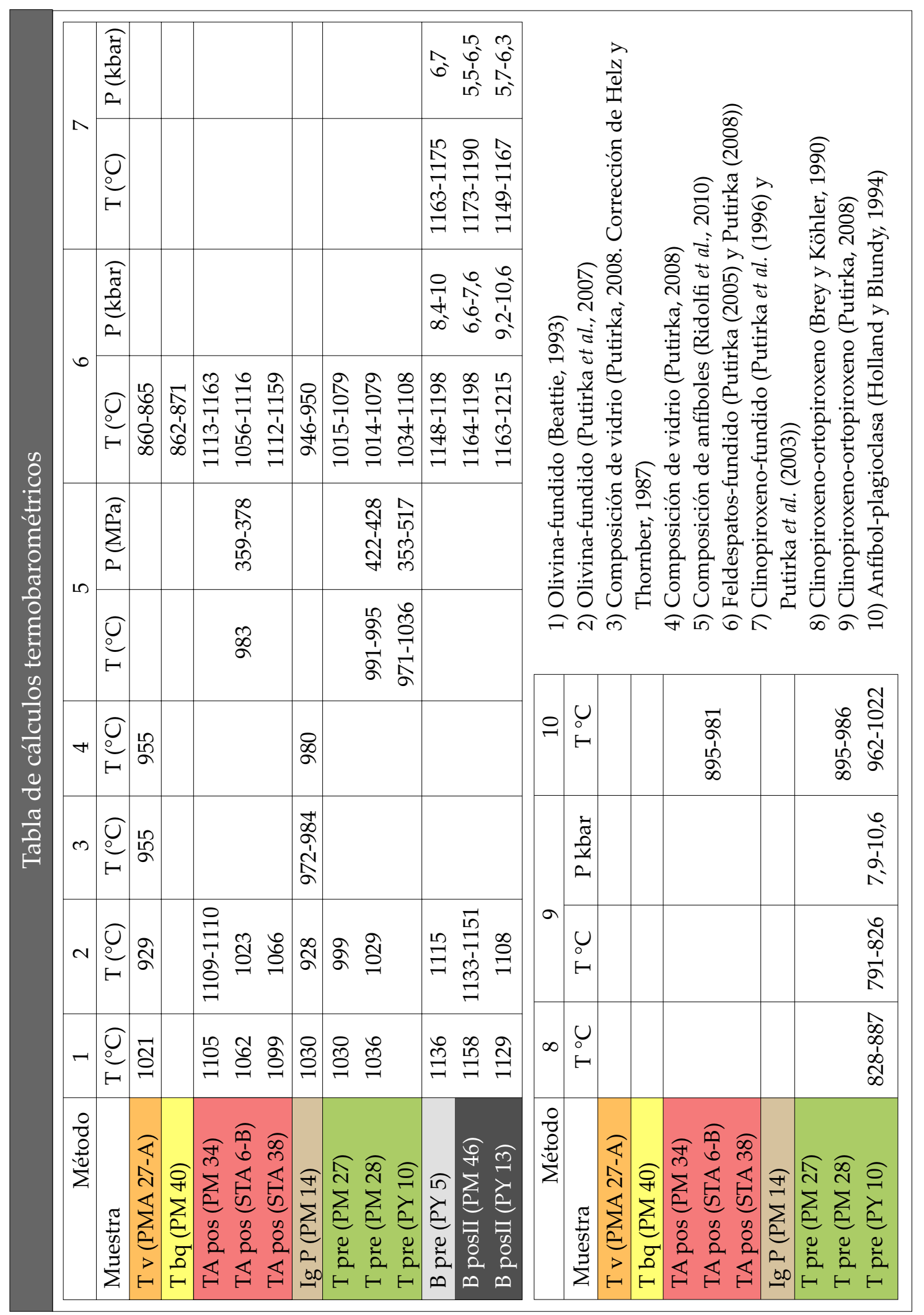

Tabla 8.1: Síntesis con los resultados de temperatura y presión calculados según diferentes métodos y autores. 


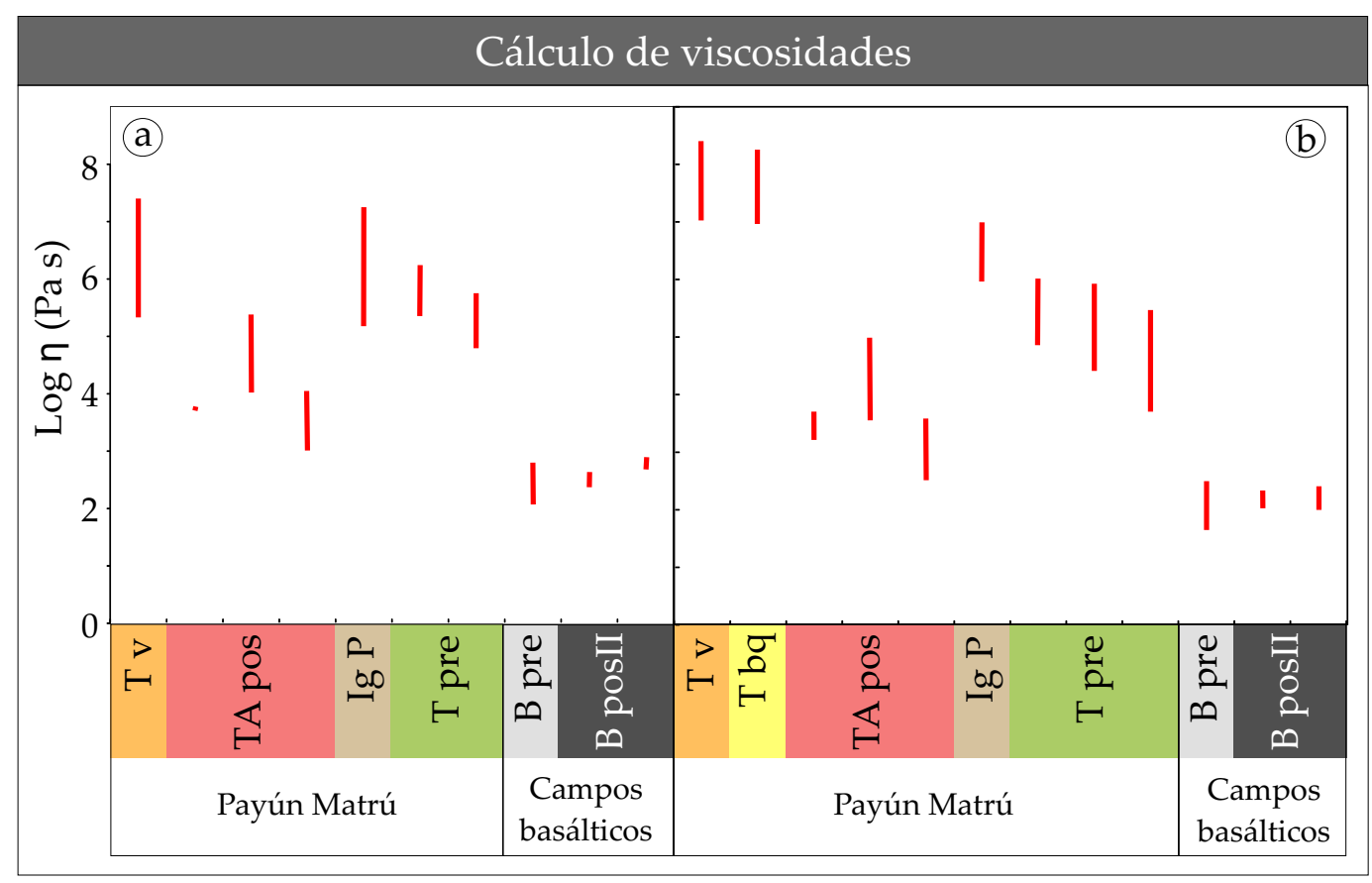

Figura 8.19: Diagramas comparativos de las viscosidades ( $\eta$, expresadas en Pa s) en diferentes lavas. La viscosidad de la Ignimbrita Portezuelo fue incluida, ya que se calcula la viscosidad a la temperatura en que teóricamente estaban cristalizando las olivinas o feldespatos en profundidad, previamente a la fragmentación del magma. a) Viscosidades a partir de las temperaturas calculadas con los métodos de olivina-fundido. b) Viscosidades calculadas a partir de los métodos de feldespato-fundido.

incertidumbre que surge al asumir que dos especies minerales se encuentran en equilibrio (sobre todo con las composiciones de plagioclasa), o por utilizar la composición de la roca total como equivalente a la del fundido que estaba en equilibrio con un determinado mineral (lo cual lleva a un error aún mayor si se trata de magmas híbridos).

\subsection{Cálculos de viscosidad}

Los cálculos de viscosidad fueron realizados con el propósito de comparar las viscosidades de los basaltos y traquibasaltos con las viscosidades de las traquitas del Payún Matrú. El motivo de estos cálculos se deben a que la viscosidad, al igual que la temperatura, es un parámetro importante en los procesos de mezcla de magmas. Las diferencias entre las viscosidades de dos magmas que se mezclan, influye en el grado de homogeneización de los mismos.

El método utilizado es el propuesto por Giordano et al. (2008), el cual calcula las viscosidades en base a la composición y temperatura de los magmas. Para los cálculos, se utilizaron las temperaturas ya calculadas, y en particular se tuvieron en cuenta las temperaturas ob- 
tenidas mediante los métodos de equilibrio olivina-fundido y feldespato-fundido, debido a que estos métodos son los que se aplican a más cantidad de unidades al mismo tiempo.

El contenido de volátiles es un factor influyente en las viscosidades de los magmas y, al mismo tiempo, es difícil de determinar. No fue utilizado el cálculo de contenido de $\mathrm{H}_{2} \mathrm{O}$ medido con la composición de los anfíboles, ya que se obtuvieron solamente para los Traquitoides Pre-caldera y Traquiandesitas Post-caldera. Debido a que los basaltos no poseen anfíbol, no se puede calcular el contenido de $\mathrm{H}_{2} \mathrm{O}$ para estas lavas. Por lo tanto, no se pueden realizar comparaciones de viscosidades entre traquitas y basaltos, lo cual constituye el objetivo del presente cálculo.

Teniendo en cuenta que las rocas no presentan alteración, se podría llegar a estimar el contenido de volátiles mediante el LOI de los análisis químicos. Sin embargo, hay que considerar que el contenido de volátiles puede ser mayor, lo cual puede disminuir significativamente la viscosidad de los magmas. Los cálculos de viscosidad fueron realizados para magmas anhidros y con un contenido de volátiles equivalente al LOI. Estos cálculos son estimativos, aunque sirven para comparar cualitativamente las diferencias de viscosidades entre los magmas (teniendo en cuenta las diferencias aproximadas en los órdenes de magnitud de las viscosidades).

En la Figura 8.19 a), se puede observar que las diferencias en viscosidades entre las unidades basálticas y las del Payún Matrú son menores entre las Traquiandesitas Post-caldera y los basaltos (1 a 3 órdenes de magnitud), mientras que es mayor entre los Traquitoides Pre-caldera, Ignimbrita Portezuelo y Traquitas vítreas (2 a 5 órdenes de magnitud). Una situación similar se observa en la Figura 8.19 b), en donde las diferencias entre las viscosidades de los basaltos y Traquiandesitas Post-caldera (1 a 3,5 órdenes de magnitud) son menores que entre los basaltos y el resto de las unidades del Payún Matrú (2 a 7,5 órdenes de magnitud, siendo las mayores diferencias con las Traquitas Post-caldera). 


\section{Capítulo 9}

\section{Discusión}

\subsection{Origen del volcanismo en el CVPM}

\subsubsection{Inicio de Payenia}

La Provincia Basáltica de Payenia, del retroarco andino mendocino, comienza su evolución luego de un período de subducción somera en el Mioceno, el cual se inició a los 19-17 Ma y finalizó a los 4-5 Ma (Kay et al., 2006; Folguera y Ramos, 2011). Posteriormente, la subducción cambió a un régimen normal, el cual se continúa hasta la actualidad. La placa de Nazca subductada presenta un ángulo de inclinación de aproximadamente $25^{\circ}$ hasta los $100 \mathrm{~km}$ de profundidad, y de $40^{\circ}$ hasta los $200 \mathrm{~km}$, proyectándose a unos $300 \mathrm{~km}$ por debajo del CVPM (Yuan et al., 2006). El cambio en el régimen de subducción estuvo acompañado de cambios en el campo de esfuerzos, pasando de una etapa contraccional en el Mioceno a una extensional en el Plioceno a Holoceno (Kay et al., 2006).

El magmatismo en el retroarco de Payenia, de naturaleza fundamentalmente basáltica alcalina y con afinidad geoquímica de intraplaca, es contemporáneo con el desarrollo del arco magmático Cuaternario en la zona del límite entre Argentina y Chile. La actividad volcánica en Payenia comenzó débilmente a los 5 Ma (Llambías et al., 2010), incrementando considerablemente su actividad a partir de los 1,8-2 Ma (Folguera et al., 2009; Llambías et al., 2010). La actividad Holocena de Payenia se restringe solamente al CVPM (también en el volcán Tromen, aunque no se lo incluye habitualmente como parte de Payenia). Al presente, no han sido encontradas en el CVPM lavas correspondientes al comienzo de la actividad en Payenia, ya que la lava más antigua datada posee una edad de $700 \mathrm{ka}$. Esta lava pertenece al volcán Payún Matrú y es coincidente con el comienzo de la época eruptiva puentelitense de Payenia (Bermúdez et al., 1993).

La distribución del volcanismo en el CVPM está controlada por una estructura mayor E$\mathrm{O}$, definida por la concentración de los centros de emisión en una franja de dicha orientación. El campo volcánico se sitúa en el límite de la cuenca sedimentaria Terciaria que se encuentra 
al norte del mismo, ya que a una latitud de esta cuenca no se encuentra, y los basaltos se apoyan directamente sobre los depósitos del Cretácico Superior.

\subsubsection{Fuente de los magmas y régimen de subducción}

Diversas líneas de información pueden utilizarse para tratar de conocer la fuente de los magmas. Los datos de la geoquímica de roca total e isotópicos de $\mathrm{Sr}$ y $\mathrm{Nd}$ de los basaltos y traquibasaltos del CVPM presentados en el presente trabajo, son de suma utilidad para tal fin. Por otro lado, para la región del arco y retroarco de Mendoza y sur de Neuquén se encuentra en la literatura información geofísica sobre las características actuales de la corteza y manto. Ambas fuentes de información indican fuertemente que el lugar de origen de los magmas en el CVPM es el manto, siendo más difícil de acotar las características del mismo.

Mediante estudios geofísicos, se determinó que a la latitud del CVPM se encuentran anomalías de conductividad eléctrica, de las que se infiere que existe una zona con fundidos parciales y/o volátiles por debajo de las erupciones basálticas (Burd et al., 2008). Estas anomalías de alta conductividad eléctrica empiezan a los $200 \mathrm{~km}$ de profundidad por debajo del CVPM (Burd et al., 2008). También se determinó que entre los 40 y $60 \mathrm{~km}$ de profundidad existe una zona con bajas velocidades sísmicas (Gilbert et al., 2006), debajo de una corteza de 30-35 km de espesor en el retroarco (Gilbert et al., 2006; Yuan et al., 2006), la que fue interpretada como la base posible de la litosfera en el retroarco (Gilbert et al., 2006). Esta interpretación implicaría la presencia de un manto litosférico notoriamente atenuado debajo del CVPM.

En la Figura 9.1 a) se muestra un perfil topográfico, basado en el modelo de elevación digital de la región a una latitud de $36^{\circ} 25^{\prime}$ S, desde el límite oeste de la placa Sudamericana hasta el antepaís, mostrando las diferentes regiones morfoestructurales. Además, se incluye en el gráfico un perfil mostrando la placa de Nazca subductada, y se indica también la zona de bajas velocidades sísmicas en el retroarco (Gilbert et al., 2006). La Figura 9.1 b) muestra las anomalías de conductividad eléctrica reportadas por Burd et al. (2008). En la base de la corteza, por debajo de la zona oeste del CVPM, se encuentra una anomalía de conductividad eléctrica, la cual se correlaciona con la mayor abundancia de actividad volcánica reciente en el campo basáltico oeste (además del Payún Matrú).

En base a las tomografías del manto presentadas por Aragón et al. (2011), puede distinguirse que el CVPM se encuentra en una zona de transición entre los regímenes de subducción somera y normal (sección a) de la Figura 9.2 con una subducción somera, y sección b) con subducción normal). Si bien diversos métodos geofísicos infieren una zona de subducción normal por debajo del CVPM, el límite entre esta zona y la de subducción somera se encontraría cercana al CVPM (Fig. 9.2), pudiendo estar influenciado el volcanismo del CVPM por la cercanía a la subducción somera. 


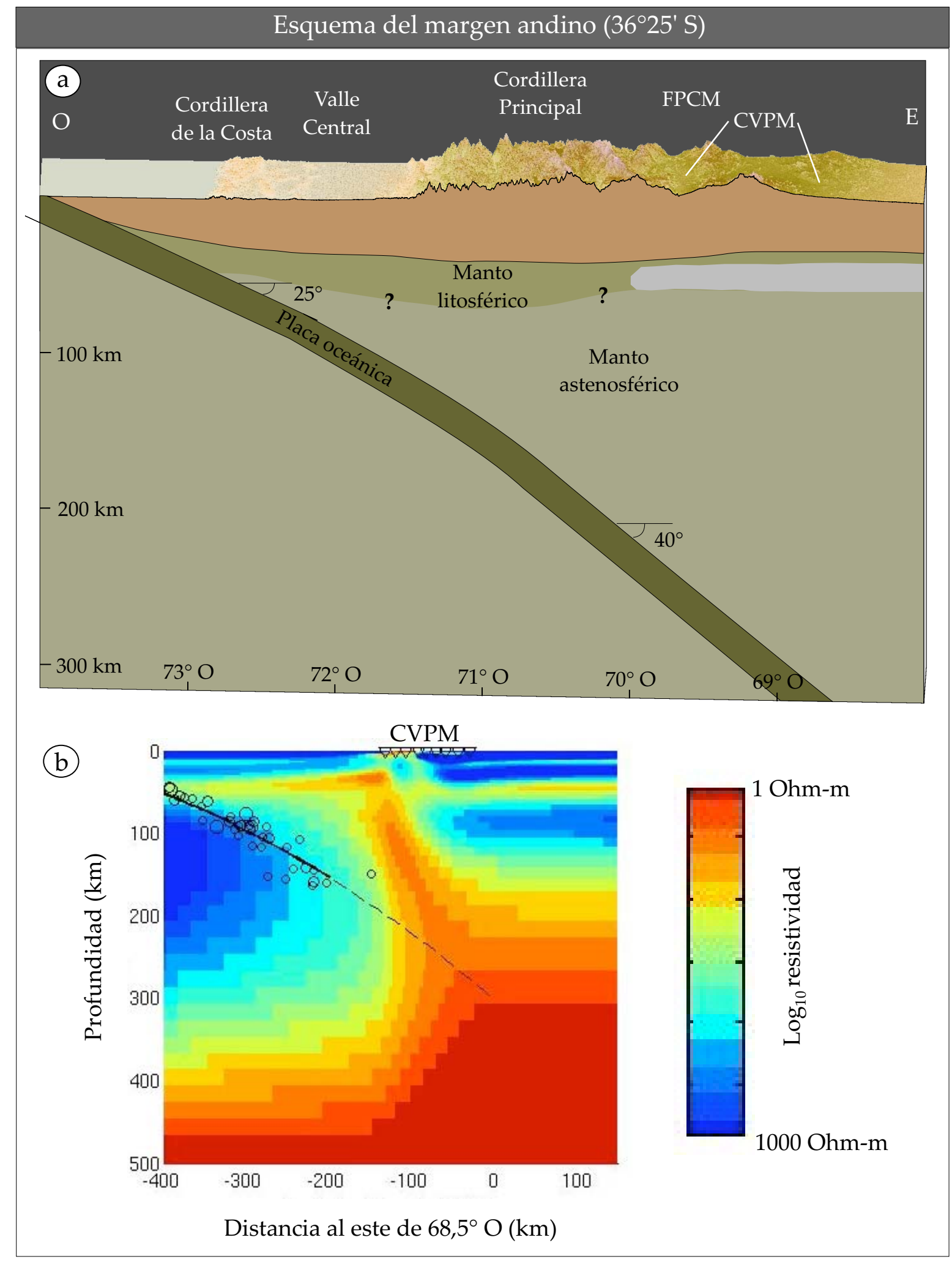

Figura 9.1: a) Esquema del margen andino a una latitud de $36^{\circ} 25^{\prime}$ S. FPCM: Faja plegada y corrida de Malargüe. Topografía según ASTER GDEM (2009) (exageración vertical $600 \%$ ). Profundidad de la base de la corteza basada en Gilbert et al. (2006) y Yuan et al. (2006). La zona gris claro indica la zona de baja velocidad sísmica, según Gilbert et al. (2006), la cual podría corresponder con la base de la litosfera. La inclinación de la placa de Nazca subductada según Yuan et al. (2006). b) Anomalías de conductividad eléctrica según Burd et al. (2008). 
Una característica significativa que se observa en el segmento de subducción normal de la Patagonia norte, es la interrupción de la placa subductada a una profundidad de entre 300 y 350 km (Fig. 9.2 a). Las tomografías del manto indicarían que la placa de Nazca se encuentra por debajo del CVPM a alrededor de $300 \mathrm{~km}$ (Fig. $9.2 \mathrm{~d}$ ), en coincidencia con Burd et al. (2008). Directamente al norte del CVPM se observa, tanto a los $120 \mathrm{~km}$ de profundidad como a los $300 \mathrm{~km}$, que las zonas de alta densidad interpretadas como placa oceánica subductada, se ensanchan hacia el este (Fig. 9.2 c y d). Esto sugiere que la zona de subducción somera se encuentra cercana al CVPM, y además al sur de los $33^{\circ} \mathrm{S}$, el cual es la latitud ampliamente citada como límite del segmento de subducción plana pampeano. De acuerdo con el rumbo de las fallas transformantes del océano Pacífico y las tomografías del manto, el límite entre los segmentos con alto y bajo ángulo de subducción presenta un rumbo NE a ENE.

La configuración interpretada de la zona de subducción, en donde el CVPM está en una zona transicional, sobre un régimen de subducción normal aunque cercano a un régimen de subducción somera, permite hacer inferencias sobre posibles formas de ascenso astenosférico. Si en el límite entre una zona de subducción somera y una normal se produce una ventana astenosférica, una posibilidad es que exista convección lateral de manto astenosférico desde esa ventana, ubicada al norte del CVPM, hacia el sur. Otra posibilidad es que, al igual en al norte de la Patagonia, la placa de Nazca se interrumpa a una profundidad de 300-350 km a la latitud del CVPM, aunque no es lo observado en las tomografías del manto (Fig. 9.2 d). También podría haber un ascenso astenosférico desde la cuña del manto por encima de la placa subductada, como se observa en las anomalías de conductividad eléctrica (Burd et al., 2008) (Fig. 9.1). Esta parece ser la opción más viable teniendo en cuenta estas anomalías mencionadas, aunque se tiene que considerar que no se conoce cómo varían las anomalías de conductividad eléctrica en un sentido N-S.

La geoquímica de las rocas basálticas del CVPM es una fuente de información importante para hacer inferencias sobre las características de la fuente de los magmas. Los diagramas spiders de REE y de elementos incompatibles sugieren que la fuente mantélica es una astenósfera fértil (no deprimida como en los basaltos MORB), ya que los patrones son similares a los de basaltos de islas oceánicas, sin evidencias de componentes de subducción. Esto se corrobora con otros diagramas químicos de elementos traza (por ejemplo La/ $\mathrm{Nb} v$ s. $\mathrm{La} / \mathrm{Ba}$ ), los cuales indican una similitud química con los basaltos OIB, sugiriendo la procedencia astenosférica de los magmas.

Una fuente mantélica con plagioclasa no es factible en este caso, debido a que no se observan anomalías negativas de Eu en el diagrama spider de REE. Considerando que la plagioclasa es estable hasta 30-40 km de profundidad (Winter, 2010), esta profundidad coincidiría aproximadamente con la base de la corteza $(30-35 \mathrm{~km})$ a la latitud del CVPM, determinada por estudios geofísicos (Yuan et al., 2006; Gilbert et al., 2006). Para discernir si el manto fuente de los magmas se encuentra dentro del campo de estabilidad del granate o espinela, además del diagrama spider de REE, varios autores han propuesto distintos dia- 


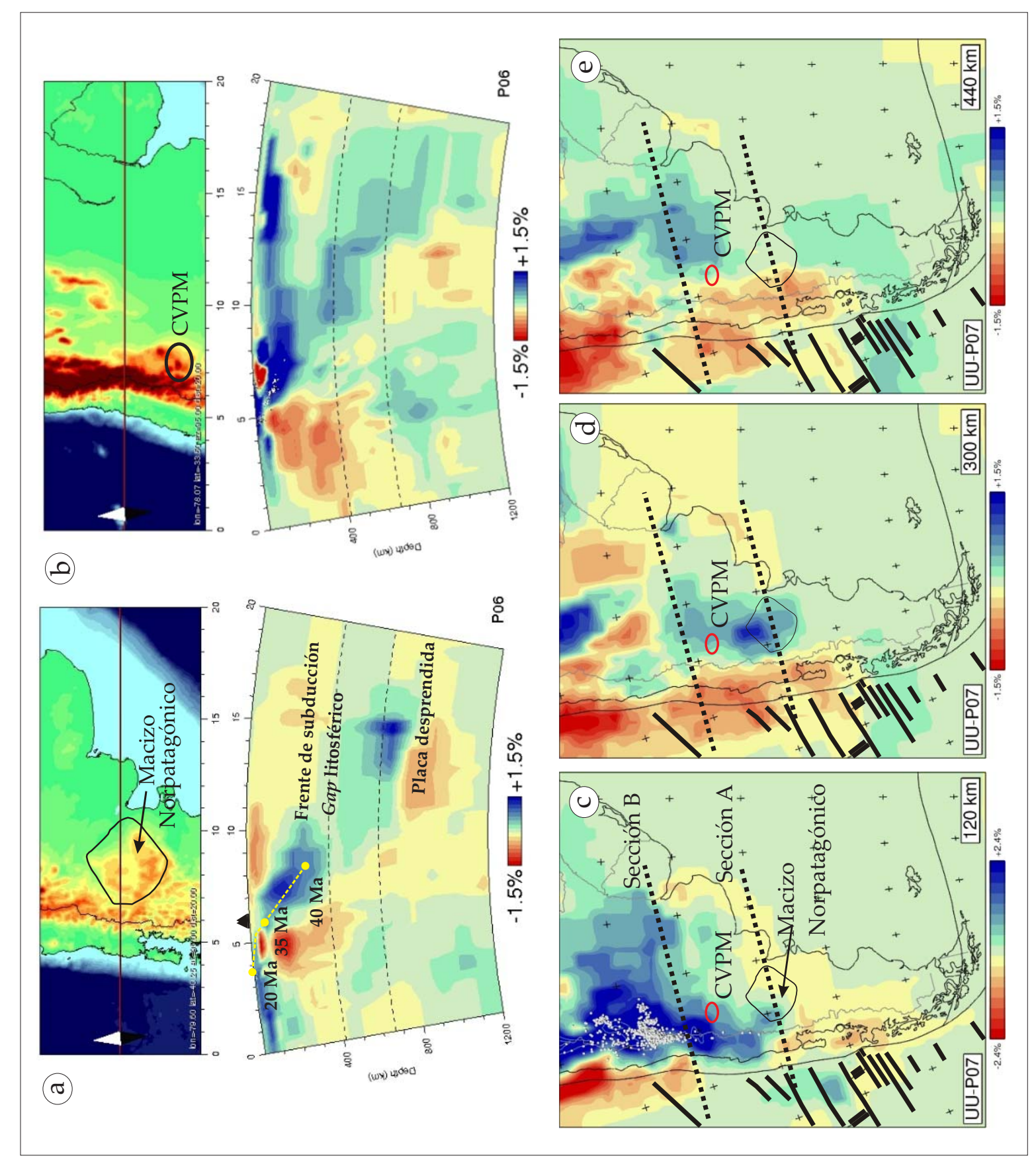

Figura 9.2: Tomografías del manto mediante el estudio de las ondas P, modificado de Aragón et al. (2011). El azul intenso representa las velocidades sísmicas mayores, interpretadas como litósfera fría y densa. En rojo se muestran las menores velocidades, representando un material menos denso. c), d) y e) mapas de las velocidades sísmicas a los 120 km, $300 \mathrm{~km} \mathrm{y}$ $440 \mathrm{~km}$ de profundidad, respectivamente. 
gramas químicos para identificar la fuente mantélica, mostrando adicionalmente los porcentajes de fusión hipotéticos. Estos diagramas presentan un cierto grado de incertidumbre al aplicarlos al CVPM, ya que dependen del modelado del manto en cada caso. Esto queda demostrado por la falta de coherencia entre algunos de estos diagramas al graficar a los basaltos/traquibasaltos fisurales. Para los basaltos del CVPM, los diagramas sugieren en general una fuente mantélica con granate, o en transición al campo de estabilidad de la espinela, aunque en un caso particular indican un manto con espinela. La pendiente en el diagrama spider de REE también sugiere una fuente mantélica con granate $(\mathrm{La} / \mathrm{Yb}>5)$ (Farmer, 2003).

Comparando esta pendiente con la de otras regiones con basaltos alcalinos y transicionales cuya fuente contiene granate, como por ejemplo Hawaii, se observa que los basaltos del CVPM poseen pendientes similares (aunque ligeramente menores) a los basaltos alcalinos y transicionales de Loihi (Hawaii) (Fig. 9.3) (Clague, 1987). Las profundidades a las cuales se encuentra el manto con espinela o granate varía entre 30 y $60-80 \mathrm{~km}$ en el primer caso y de 80-400 km en el segundo (Winter, 2010; Xia et al., 2004; Best y Christiansen, 2001).

La fuente mantélica no muestra señales de estar enriquecida en elementos incompatibles por metasomatismo, tal como propone Kay (2002) y Kay et al. (2004). El contenido de elementos incompatibles es coherente con un bajo grado de fusión parcial de peridotita no metasomatizada. El proceso de metasomatismo aumenta alrededor de un orden de magnitud el contenido de incompatibles, en comparación con fundidos formados por un muy bajo grado de fusión parcial (1\%) de un manto no metasomatizado (Best y Christiansen, 2001).

Otra similitud entre los basaltos del CVPM y aquellos de islas oceánicas es la firma isotópica de $\mathrm{Sr}$ y $\mathrm{Nd}$, la cual indica que la fuente es deprimida isotópicamente, aunque en un grado relativamente bajo. Además, estas relaciones isotópicas están en acuerdo con una procedencia astenosférica de los magmas, lo cual es típico para los basaltos alcalinos continentales de tipo sódico, como es el caso del CVPM (Farmer, 2003).

Si bien en la zona de estudio no fueron encontrados xenolitos mantélicos en los basaltos, Bertotto et al. (2009) encontraron xenolitos de peridotitas con espinela en tres localidades de Mendoza y La Pampa. Los autores propusieron una fuente mantélica con granate para el origen de los magmas, y explicaron la presencia de los xenolitos con espinela como no relacionados con la formación de los basaltos (Bertotto et al., 2009).

Por lo tanto, la geoquímica de los basaltos del CVPM sugiere que la fuente mantélica posee granate y probablemente pasando al campo de estabilidad de la espinela, a una profundidad mínima de entre 60 y $80 \mathrm{~km}$. Es probable que los basaltos no deriven de un manto homogéneo, sino que deriven en parte de un manto con espinela, y en parte de un manto con granate (Baker et al., 1997). Por otra parte, la profundidad estimada mediante la geoquímica de los basaltos es coincidente con la posible base de la litosfera estudiada mediante métodos geofísicos, los cuales indican que la base de la misma estaría a los $60 \mathrm{~km}$ de profundidad. 


\subsubsection{Mecanismos de fusión}

Un aspecto importante en relación al origen de los magmas, es el motivo por el cual se produce la fusión del manto. El origen de los magmas en Payenia se atribuye a la convección astenosférica activada al empinarse la placa oceánica subductada (Kay et al., 2006). Los tres mecanismos que pueden fundir una roca son disminución de la presión, aumento de la temperatura y cambio de la composición para disminuir la temperatura del solidus. La principal forma en que puede producirse fusión aumentando la temperatura es por calentamiento por conducción (Asimow, 2000). Esto suele ocurrir en lugares donde se producen magmas basálticos por descompresión, los cuales forman luego un subplacado generalmente en la base de la corteza, que a su vez aumenta la temperatura y funde a las rocas de la corteza (Asimow, 2000). Debido a que los basaltos del CVPM no tienen una firma cortical, no parece viable este mecanismo.

Considerando que durante el Mioceno medio y tardío existía en la región un régimen de subducción somera con generación de rocas calcoalcalinas a una distancia de $500 \mathrm{~km}$ de la fosa, Kay et al. (2006) proponen que el manto que genera los magmas en Payenia ya estaba previamente hidratado. Sin embargo, teniendo en cuenta los volúmenes de magma eruptados, es necesaria otra causa adicional para explicar la generación de los mismos (Kay et al., 2006). La zona de alto ángulo y alta conductividad debajo del CVPM podría ser una zona de fusión y/o ascenso de la astenosfera, produciendo la fusión por descompresión de la misma. Esta zona comienza a una profundidad de $200 \mathrm{~km}$ por encima de la placa de Nazca (Burd et al., 2008).

Los porcentajes de fusión parcial son bajos en general, como se propone habitualmente para este tipo de basaltos (Rogers y Hawkesworth, 2000). Los diagramas químicos realizados que indicarían grados de fusión, no resultan confiables ya que arrojan valores altamente variables. Kay (2002) modeló a los basaltos de Payenia como formados por un grado de fusión parcial entre el 2 y $8 \%$. De acuerdo a las características geoquímicas e isotópicas del grupo al que pertenecen los basaltos del CVPM (basaltos continentales alcalinos sódicos), su origen se atribuye a un bajo grado de fusión parcial del manto $(<5 \%)$, ya sea por un ascenso pasivo o activo (pluma) de la astenósfera (Farmer, 2003).

\subsection{Naturaleza del volcanismo en el CVPM}

\subsubsection{Dos estilos de volcanismo}

En el CVPM conviven dos estilos contrastantes y contemporáneos de volcanismo. Por un lado, se encuentran los basaltos y traquibasaltos conformando campos volcánicos adyacentes al Payún Matrú. Por otro lado, se encuentra el volcanismo poligenético fundamentalmente traquítico de los volcanes Payún Matrú y Payún Liso, formando un volcán compuesto en forma de escudo y un estratovolcán, respectivamente. 
La caldera del Payún Matrú es un fuerte indicio de la presencia de una cámara magmática superficial, a pocos kilómetros de profundidad bajo el volcán (Lipman, 2000; Parfitt y Wilson, 2008). Es altamente probable que la o las cámaras magmáticas que alimentaron al Payún Matrú durante la etapa pre-caldera no se hayan encontrado a la misma profundidad, pudiendo haber variado su localización y tamaño desde el origen del volcán hasta la formación de la caldera. Independientemente de su localización exacta, la presencia de una cámara magmática relativamente superficial contrasta con el origen profundo de los magmas basálticos, los cuales provendrían de zonas de almacenamiento en la discontinuidad de Mohorovicic o en la corteza inferior (ver sección siguiente).

Otro aspecto relevante al momento de definir la estratigrafía, es el único evento explosivo de importancia en el CVPM. Este evento está relacionado con la formación de la caldera y la depositación de la Ignimbrita Portezuelo, la cual constituye un horizonte guía. De esta manera, el CVPM fue dividido en tres etapas: pre-, sin-, y post-caldera. Los detalles restantes utilizados en la separación de las unidades ya han sido desarrollados en el Capítulo 3, por lo que no serán repetidos aquí.

\subsubsection{Magmas basálticos}

Los basaltos alcalinos continentales pueden dividirse en dos grupos, de acuerdo a la preponderancia de sodio o potasio. Las lavas basálticas del CVPM pertenecen al grupo sódico, el cual es el grupo más común y extendido en el mundo de basaltos alcalinos continentales (Farmer, 2003).

Teniendo en cuenta los análisis geoquímicos de roca total, queda claro que los basaltos fisurales no son primarios, sino que han sufrido procesos de cristalización fraccionada desde su génesis en el manto hasta su erupción. Los patrones de Tierras Raras en los diagramas spiders y otros diagramas químicos con elementos traza y mayoritarios, sugieren que las fases fraccionantes en los basaltos son olivina, clinopiroxeno y óxidos de Fe-Ti, pero no hubo un fraccionamiento significativo de plagioclasas.

Además, la escasez de xenolitos mantélicos sugiere la presencia de un sistema de almacenamiento de los magmas basálticos en profundidad, el cual actuaría como filtro para los xenolitos. Una situación similar ocurre, por ejemplo, en las islas de Hawaii, en donde los basaltos alcalinos de la etapa pre-escudo y post-caldera contienen xenolitos mantélicos, y no así los basaltos toleíticos de la etapa de construcción del escudo. Se infiere que esta diferencia es debida a que las zonas de almacenamiento de magmas basálticos formadas durante la etapa del escudo filtran a los xenolitos mantélicos, impidiendo su erupción, mientras que en las etapas pre-escudo y post-caldera estas zonas de almacenamiento no se encuentran, facilitando el ascenso de los xenolitos (Clague, 1987). La ausencia de xenolitos también puede deberse a un ascenso relativamente lento de los magmas, lo cual favorece el asentamiento de los mismos durante el recorrido del magma hacia la superficie. Dada las evidencias de 
fraccionamiento en los basaltos, es probable que los xenolitos que pudieran estar presentes en los magmas primarios hayan quedado retenidos en los sistemas de almacenamiento en profundidad.

Los cálculos barométricos para las unidades basálticas, junto con el espesor de la corteza debajo del CVPM (determinado por métodos geofísicos, Yuan et al., 2006), sugieren que los magmas basálticos formados en la astenósfera se han acumulado en el limite entre corteza y manto o en la corteza inferior. Las presiones obtenidas son variables, equivalentes a profundidades debidas a presión litostática en corteza continental de entre 20 y $37 \mathrm{~km}$ aproximadamente. Además, en la base de la corteza se encuentran anomalías de conductividad eléctrica, interpretadas como zonas con fundidos parciales y/o volátiles (Fig. 9.1) (Burd et al., 2008). Los subplacados máficos en la base de la corteza o corteza inferior son relativamente comunes en general, y están formados por acumulaciones progresivas de diferentes pulsos de magmas basálticos, formando cuerpos tabulares tipo sills (Annen, 2011).

Los basaltos no presentan signos de contaminación con materiales corticales, ya sea desde el punto de vista isotópico o a través de enclaves. No se han encontrado enclaves corticales en los mismos, a excepción del basalto post-caldera que nace de la falla La Carbonilla, el cual presenta escasos fragmentos de una roca traquítica. En este caso, los enclaves poseen una fina capa de vidrio recubriéndolos, indicando el rápido enfriamiento del magma en el contacto con el mismo, lo cual no favorece la asimilación de los enclaves traquíticos. Es probable que la traquita pertenezca al Payún Matrú y se haya incorporado al basalto durante su ascenso, a escasa profundidad. Sin embargo, el hecho de que no se encuentren fragmentos de otras rocas dentro de los basaltos no es indicador de la falta de contaminación cortical, siendo más confiables los datos isotópicos. La falta de contaminación cortical podría deberse a la extensa fusión de la corteza durante el Pérmico y Triásico, período en el cual la corteza se volvió más refractaria (Kay, 2002).

Considerando la variación composicional dentro de las unidades de Basaltos Pre- y Postcaldera I y II, no todas las lavas presentan el mismo grado de fraccionamiento desde su origen (considerando una misma fuente y grados similares de fusión). El diagrama TAS (Fig. 7.2) indica que las lavas de la unidad Basaltos Post-caldera II son más evolucionadas que aquellas de los Basaltos Pre-caldera. Sin embargo, al observar las variaciones en $\mathrm{Ni}, \mathrm{Cr}$ y \# Mg, esta tendencia desaparece, y los Basaltos Pre-caldera y los Basaltos Post-caldera I y II no presentan diferencias significativas entre ellos, aunque los últimos poseen un mayor contenido en sílice (Figs. 7.6 y 7.13). La lava analizada más primitiva, de acuerdo a los tres parámetros ya mencionados, corresponde a la etapa pre-caldera (muestra STA 3, ver Anexo II).

En la colada de "La Tranquera" (Fig. 4.1) perteneciente a los Basaltos Post-caldera II, se analizaron dos olivinas cuyas composiciones difieren, siendo una más magnesiana que la otra y que las olivinas de las otras lavas basálticas $\left(\mathrm{Fo}_{82-85}\right.$, mientras que el resto de las olivinas en basaltos/traquibasaltos posee un contenido de Fo75-79). La composición de esta 
olivina se aproxima mucho a la composición esperada teóricamente para un magma primario, y podría representar por lo tanto un fenocristal remanente cristalizado en el fundido primario.

\subsubsection{Series magmáticas}

Las rocas del CVPM pertenecen a la serie alcalina y a su vez, dentro de esta serie, se asemejan a las series denominadas suavemente alcalinas o transicionales (Fig. 7.2). Las series alcalinas transicionales se caracterizan por poseer una variación composicional desde basaltos olivínicos hasta traquitas, pudiendo finalizar la evolución de la serie en riolitas (sobresaturadas en sílice) o fonolitas (subsaturadas en sílice) (Baker, 1987; Clague, 1987; Fitton, 1987). Las tendencias de los extremos más silícicos hacia la sobresaturación o subsaturación puede darse inclusive dentro de un mismo volcán (Baker, 1987). El carácter transicional de la serie alcalina puede observarse en diferentes atributos de las rocas, geoquímicos y petrográficos. Las traquitas del Payún Matrú poseen una tendencia evolutiva hacia el campo de las riolitas, al igual que los análisis de vidrio de Traquitas vítreas e Ignimbrita Portezuelo, indicando que la evolución de los magmas en el CVPM es hacia la sobresaturación en sílice. Además, el contenido de nefelina normativa en los basaltos fisurales es menor al $5 \%$ (sin hipersteno normativo), lo cual también indica una alcalinidad moderada (Baker, 1987). En las rocas intermedias deja de haber nefelina normativa y comienza a aparecer el cuarzo normativo, el cual se incrementa en las traquitas más silícicas.

En otros diagramas geoquímicos, como los spider de REE, los valores de La normalizados al condrito (el elemento más incompatible de las REE) están aproximadamente entre 50 y 100, mientras que en otras regiones volcánicas del mundo con basaltos de las series alcalinas, por ejemplo Hawaii o el SE de China, los valores máximos de La normalizado son generalmente mayores a 100 (Clague, 1987; Zou et al., 2000). En la Figura 9.3 a), se muestran para su comparación el diagrama spider de REE de los basaltos del CVPM, junto con basaltos alcalinos a transicionales de Hawaii y SE de China. Las series transicionales poseen un solapamiento importante con las series alcalinas propiamente dichas, aunque poseen una tendencia a tener menores contenidos de REE. Por lo tanto, el diagrama de REE es afín a aquel de las series transicionales, aunque el solapamiento con las series alcalinas es importante.

La tendencia hacia la sobresaturación se evidencia también en el sistema residual $\mathrm{SiO}_{2}$ Ne-Ks (sílice, nefelina y kalsilita normativos), en donde los traquitoides del CVPM evolucionan desde el alto térmico ubicado sobre la línea que conecta a la albita con ortosa, hacia el mínimo térmico colindante con el cuarzo. Las composiciones de vidrios de Traquitas vítreas e Ignimbrita Portezuelo reflejan aún más esta tendencia.

Las tendencias geoquímicas están de acuerdo con la petrografía, ya que ni los basaltos ni las traquitas poseen nefelina $\mathrm{u}$ otro feldespatoide modal. Los basaltos están caracterizados 


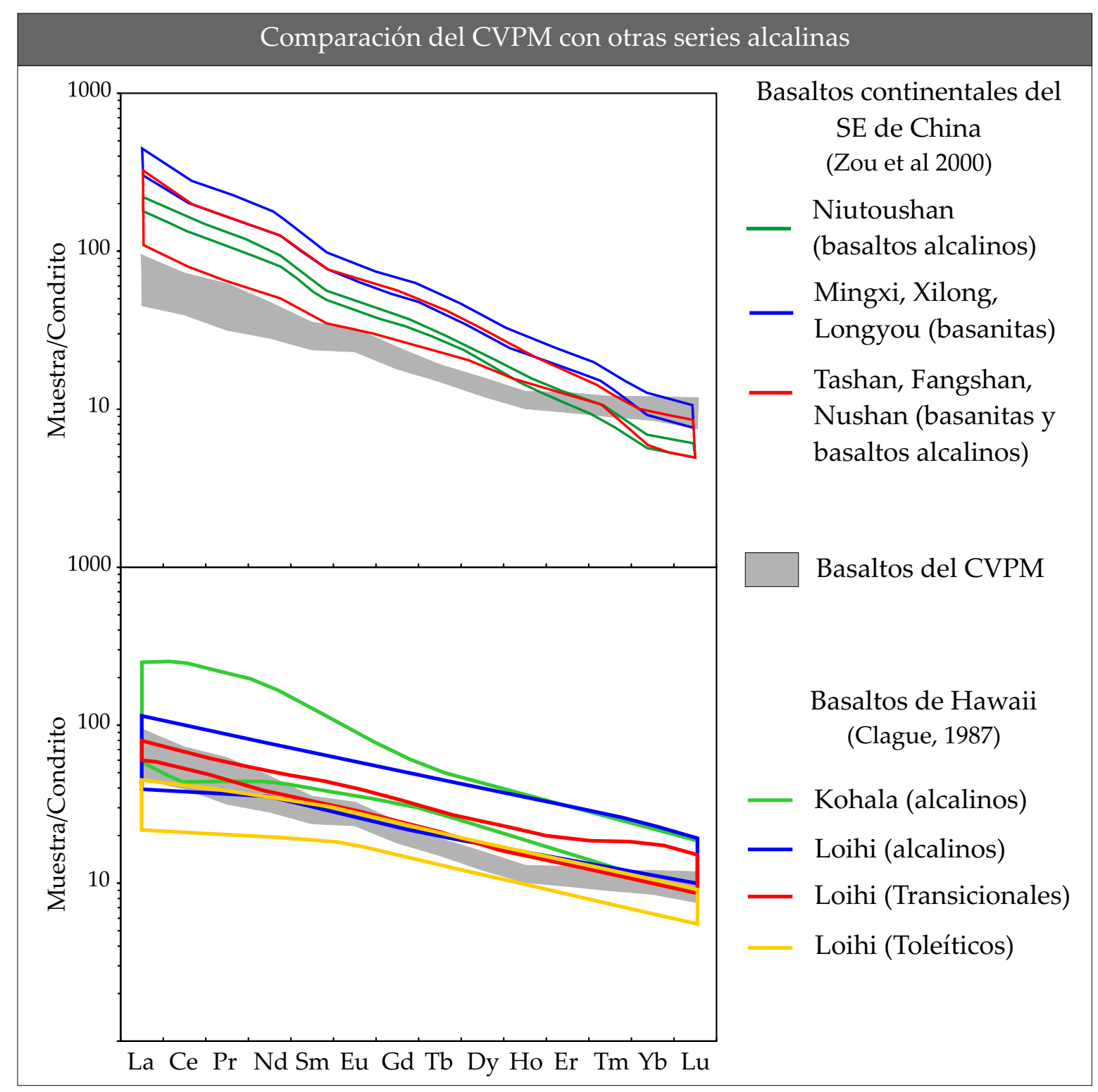

Figura 9.3: Diagramas spiders de REE comparando los basaltos y traquibasaltos del CVPM con otras rocas alcalinas, transicionales y toleíticas del SE de China y Hawaii. 
por fenocristales de olivina y clinopiroxeno (además de plagioclasa), lo cual es lo normal para este tipo basáltico (Baker, 1987). En la pasta de una lava traquítica perteneciente a la subunidad 1 de los Traquitoides Pre-caldera se encontró cuarzo intersticial, y en otra lava fue encontrado ortopiroxeno (el cual podría estar en equilibrio con el liquido, sin ser un xenocristal), en concordancia con la tendencia a la sobresaturación en sílice.

Otra característica importante de las series alcalinas transicionales es la bimodalidad basalto-traquita, con escasa participación de rocas intermedias con contenidos de $\mathrm{SiO}_{2}$ entre 48 y 58 \%, característica denominada Daly Gap (Winter, 2010; Baker, 1987). Este hiato composicional tiende a desaparecer a medida que se aumenta el grado de alcalinidad de las series (Baker, 1987). Las rocas del CVPM poseen una relativamente escasa proporción de rocas intermedias (de traquiandesitas basálticas y traquiandesitas, Fig. 7.2) y, además, muchas de estas lavas intermedias (junto con algunas traquitas) poseen texturas y composiciones minerales particulares las cuales sugieren mezcla de magmas, como se discutirá más adelante.

\subsubsection{Magmas traquíticos}

El volcán Payún Matrú se compone fundamentalmente de lavas traquíticas, con menor participación de rocas intermedias e ignimbritas, y junto a otros productos piroclásticos también traquíticos. Las emisiones de estas lavas y piroclastos evolucionados es contemporánea con el volcanismo basáltico/traquibasáltico adyacente al Payún Matrú. Estas observaciones conducen a pensar que el origen de los magmas traquíticos y la formación del Payún Matrú están ligados de alguna manera a los magmas basálticos.

Tanto el diagrama TAS de clasificación (Fig. 7.2) como los diagramas de variación (Figs. 7.5 y 7.6) sugieren una relación de comagmatividad entre basaltos y traquitas. Las variaciones de los elementos traza desde los basaltos hasta las traquitas (Figs. 7.8, 7.7, 7.11 y 7.10), así como los valores isotópicos de Sr y Nd para las unidades del Payún Matrú y los campos basálticos, indican que los productos evolucionados del Payún Matrú son formados por fraccionamiento de los basaltos. Asímismo, en la generación de lavas intermedias (traquiandesitas basálticas, traquiandesitas y también algunas traquitas) intervienen otros procesos (mezcla de magmas) que se discutirán en la sección siguiente.

Los isótopos de Sr indican que los magmas traquíticos no tuvieron contaminación cortical significativa, o que esta fue leve. La mayoría de las Traquitas Post-caldera presentan valores ligeramente mayores de ${ }^{87} \mathrm{Sr} /{ }^{86} \mathrm{Sr}$, sugiriendo algo de contaminación cortical en la etapa póstuma del Payún Matrú (Fig. 7.17 b). El magma traquítico no pudo haberse originado por fusión de corteza cortical o por fraccionamiento conjuntamente con una asimilación cortical considerable, teniendo en cuenta la geoquímica y la isotopía. Este último mecanismo ha sido invocado para algunos otros sitios con volcanismo bimodal, como por ejemplo el oeste Africano (línea Cameroon) (Fitton, 1987). Otro ejemplo es el rift de Etiopía, donde existe una marcada bimodalidad con basaltos transicionales y traquitas/riolitas. En este caso el 
origen de las rocas silícicas se atribuye a la cristalización fraccionada de los magmas basálticos en cámaras someras, con contaminación cortical escasa (Peccerillo et al., 2003, 2007) o en grado variable (Trua et al., 1999).

Los patrones de los elementos traza indican que la evolución del magma basáltico para producir magmas diferenciados se debió primeramente al fraccionamiento de plagioclasas y feldespatos alcalinos, clinopiroxenos, óxidos de Fe-Ti y apatita. El fraccionamiento de feldespatos alcalinos es mayor en las Traquitas Post-caldera y escasas Traquitas Pre-caldera, cuyas lavas poseen como principal fenocristal al feldespato alcalino. La disminución de la pendiente de HREE, desde las unidades basálticas a las traquíticas (Figs. 7.8 y 7.7), puede deberse al anfíbol y/o plagioclasas, considerando los coeficientes de partición de REE (Rollinson, 1993). Dada la significativa mayor abundancia de plagioclasas que de anfíbol en las rocas del Payún Matrú, se infiere que esta variación en las HREE se debe principalmente al fraccionamiento de plagioclasas, con un menor grado de fraccionamiento de anfíbol que contribuya a este efecto. Los fenocristales de olivina son comunes en todas las unidades del CVPM, aunque adquieren menor importancia en las lavas félsicas. El efecto del fraccionamiento de la olivina es claro en el caso de los basaltos, pero no así en los traquitoides, debido al rápido decaimiento en $\mathrm{Ni}$ desde los basaltos a los traquitoides. Sin embargo, y dada su persistencia a lo largo de la evolución de los magmas, es probable que también constituya una fase fraccionada en los traquitoides, aunque su efecto esté enmascarado por otros minerales en los diagramas spiders de elementos incompatibles y de REE.

Una cuestión importante al considerar comagmáticos a los basaltos y traquitas, tiene relación con el volumen relativo de ambos magmas en el CVPM. Es lógico que los magmas básicos posean un volumen significativamente mayor que los félsicos, considerando que los magmas félsicos se formaron a partir de los básicos. El volumen del Payún Matrú fue estimado en $170 \mathrm{~km}^{3}$, mientras que el volumen de lavas basálticas no se pudo estimar con precisión debido a que el cálculo es complejo en este caso, tal como se explicó en el Capítulo 3. De todas maneras, es reconocible la gran magnitud, en cuanto a volúmenes relativos, del volcanismo traquítico. Esto no contradice la derivación del magma traquítico a partir de los basaltos, sino que indica que se deberían considerar también los volúmenes no extruídos (o cubiertos) de ambos tipos de magmas. Considerando el volumen del Payún Matrú (más el del Payún Liso, si es que este se originó de la misma manera que el Payún Matrú), se infiere que, o bien el porcentaje de magma basáltico extruído es menor que el porcentaje de magma traquítico extruído, o que existe un volumen importante de lavas basálticas cubiertas por otras lavas.

La aparente incoherencia en los volúmenes relativos de basaltos y traquitas comagmáticos extruídos se repite también en otras regiones, como el rift de Etiopía. En este caso, se encuentran volcanes poligénicos con abundantes rocas silícicas (diferenciados de basaltos) y escasas rocas básicas, hecho explicado por una estratificación de la cámara magmática, donde las erupciones se producen preferentemente desde la parte silícica superior de la cámara 
y no desde el sector inferior basáltico (Peccerillo et al., 2007). A su vez, en el origen de lavas e ignimbritas riolíticas voluminosas en el mismo rift, sí estaría involucrada la corteza, por fusión de corteza inferior máfica y contaminación cortical, lo cual aumenta el volumen de magmas silícicos (Trua et al., 1999).

En síntesis, si bien hay casos en los cuales la abundancia de rocas silícicas es explicada por fusión cortical o cristalización fraccionada más asimilación cortical (AFC), también existen otros casos en donde la corteza no parece intervenir en la génesis de rocas evolucionadas, tal como sugieren la geoquímica e isotopía del CVPM. Las abundancias relativas de magmas básicos y félsicos puede deberse al sistema magmático del CVPM en particular, dando lugar a que estos magmas no se extruyan conservando las proporciones relativas que ambos tienen en todo el sistema volcánico (Peccerillo et al., 2003).

\subsubsection{El Daly Gap}

Como ya se ha mencionado, en el CVPM existe una preponderancia de las rocas basálticas/traquibasálticas y traquíticas, con una menor participación de rocas intermedias (Fig. 7.2). La escasez relativa de estas rocas parecería problemática considerando que los datos geoquímicos e isotópicos sugieren el fraccionamiento de los basaltos para generar las traquitas, con una escasa participación cortical. Además, gran parte de las rocas intermedias poseen evidencias de ser lavas híbridas, por lo cual no serían el producto del fraccionamiento de los basaltos.

Sin embargo, la escasez de rocas intermedias fue explicada por Peccerillo et al. (2003) para un volcán del rift de Etiopía (volcán Gedemsa) como consecuencia justamente de la cristalización fraccionada. Este volcán muestra una evolución desde basaltos transicionales a traquitas y riolitas peralcalinas. De acuerdo con modelados termodinámicos, la cantidad de liquido residual durante la cristalización fraccionada desde basaltos a riolitas no cambia linealmente, sino que decrece suavemente en las etapas tempranas y tardías del fraccionamiento, y decrece abruptamente en grados intermedios del mismo (Peccerillo et al., 2003). Por lo tanto, la cantidad de fundido residual durante el fraccionamiento decrece notoriamente para contenidos de $\mathrm{SiO}_{2}$ intermedios. Mientras baja la temperatura, los magmas que se fraccionan pasan relativamente rápido por la etapa intermedia, ya que la separación de diversos minerales ocurre en un intervalo estrecho de temperatura, produciendo en consecuencia una proporción menor de fundidos intermedios (Peccerillo et al., 2003). Además, la cristalización en profundidad de magmas basálticos genera fundidos residuales silícicos, los cuales poseen una diferencia composicional significativa con respecto a los magmas basálticos (Marsh, 2000, 2002).

Si se considera que gran parte de las rocas intermedias del CVPM no son producto del fraccionamiento de basaltos, sino que son consecuencia de mezcla de magmas, el Daly Gap que se observa en la Figura 7.2 es aún más marcado. Sin embargo, esto es explicable me- 
diante procesos de cristalización fraccionada que, al menos en el rango composicional de basaltos transicionales a traquitas/riolitas peralcalinas, son capaces de reducir notoriamente la cantidad de magmas intermedios (Peccerillo et al., 2003). Esto puede no ser aplicable, por ejemplo, en composiciones más alcalinas, como fue observado por Baker (1987).

\subsection{Mezcla de magmas}

La mezcla de magmas es un proceso frecuente y citado para numerosos volcanes del mundo (Gerbe y Thouret, 2004; Tepley III et al., 1999; Mandeville et al., 1996; Leonard et al., 2002; Arnosio, 2010, entre otras). Varios aspectos del CVPM indican que la mezcla de magmas entre magmas basálticos/traquibasálticos y traquíticos tuvo lugar reiteradas veces en el sistema volcánico del Payún Matrú, y que ha sido un proceso significativo en la evolución del mismo. Esta sección se centra en todas aquellas evidencias, desde la megaescala a la microescala, que indican o sugieren la mezcla de magmas.

\subsubsection{Evidencias a macroescala}

En primer lugar, y como se mencionó en la introducción, la distribución del volcanismo en el CVPM merece una mención especial (Fig. 1). El tipo de volcanismo en los volcanes Payún Matrú y Payún Liso contrastan fuertemente con los campos basálticos al este y oeste del Payún Matrú. Una característica importante es la ausencia de basaltos en el Payún Matrú, la cual contrasta con su abundancia adyacentemente (Fig. 3.5).

Teniendo en cuenta este escenario, y que el Payún Matrú se ubica en el centro de una franja grosera E-O con abundante volcanismo de basaltos fisurales, sería difícil explicar la distribución del volcanismo sin recurrir a la interacción entre ambos. Dado que no se han encontrado rocas basálticas ni traquibasálticas en el área de la caldera del Payún Matrú, y a que los magmas basálticos adyacentes provienen de una zona relativamente más profunda, es probable que la ausencia de erupciones basálticas en el Payún Matrú se deben a la intercepción de los magmas basálticos por la cámara magmática del mismo (Fig. 9.4). En consecuencia, en el volcán Payún Matrú no se encuentran emisiones de magmas basálticos o traquibasálticos puros, sino mezclas de estos con otros magmas más diferenciados alojados en la cámara del volcán.

\subsubsection{Evidencias a meso-escala: mixing vs. mingling}

Cuando dos o más magmas de diferentes composiciones, temperaturas y viscosidades se mezclan, o entran en contacto entre sí, el grado de homogeneización puede ser variable. En ocasiones, algunos magmas se mezclan completamente dando como resultado un magma híbrido homogéneo y de composición intermedia entre ambos extremos, proceso denominado mixing (Sparks y Marshall, 1986). En otros casos la mezcla es incompleta al momento de la 


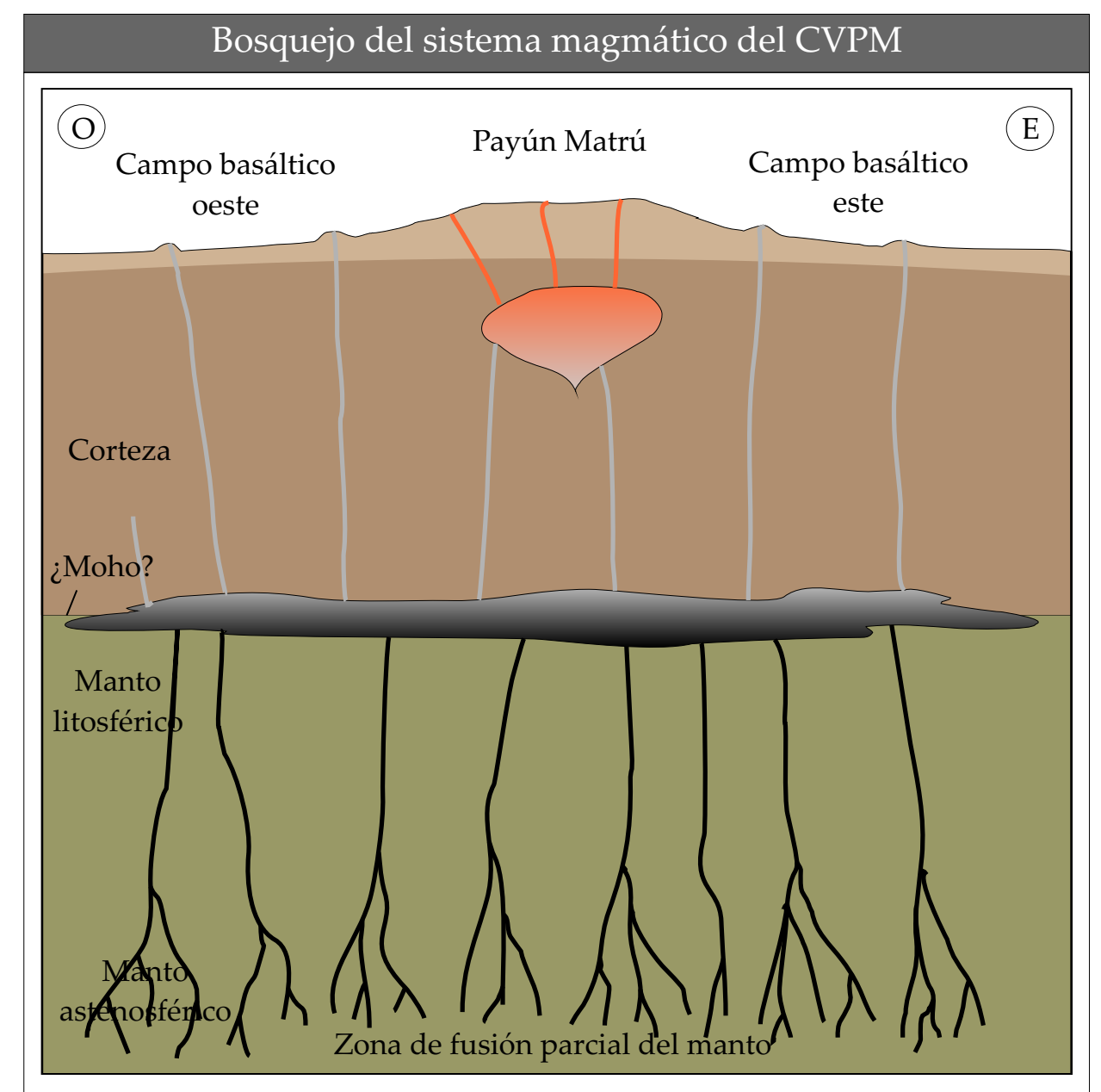

Figura 9.4: Esquema sin escala del sistema magmático del CVPM en sentido E-O, para ilustrar las interacción entre los magmas basálticos alojados posiblemente en la discontinuidad de Mohorovicic y el magma traquítico alojado en la cámara magmática del Payún Matrú.

solidificación y los dos magmas involucrados preservan su identidad, proceso denominado mingling (Sparks y Marshall, 1986).

Además de la composición y temperatura de ambos extremos, otros factores influencian el grado de homogeneización de la mezcla, como el contenido de volátiles, las proporciones relativas entre ambos, el contraste de viscosidades y el grado de cristalinidad. Luego de alcanzar un equilibrio termal entre los magmas, el magma máfico puede permanecer fluido, o comportarse como un sólido dado su alto grado de cristalización (Sparks y Marshall, 1986).

Cuando la proporción de cristales en un magma alcanza el $60 \%$ aproximadamente, se produce un cambio de fluido a prácticamente un sólido, ya que la viscosidad aumenta rápidamente en varios órdenes de magnitud (Sparks y Marshall, 1986). En el caso en que el magma máfico adquiera un comportamiento cercano al sólido, no se produce la hibridación, encontrándose inclusiones máficas dispersas en el magma huésped silícico (Sparks y 
Marshall, 1986). La diferencia en las viscosidades de ambos magmas influye en el grado en que se puedan mezclar los magmas. Según experimentos realizados por Campbell y Turner (1986), un magma de baja viscosidad inyectado en un reservorio con un magma de mayor viscosidad, no produce una homogeneización detectable entre ambos cuando la razón de viscosidades es mayor a 400, mientras que cuando las viscosidades son similares, ocurría una mezcla extensiva (hibridación).

La presencia de enclaves máficos de formas redondeadas o irregulares encontradas dentro de lavas intermedias a ácidas se interpreta frecuentemente como una clara evidencia de la mezcla de magmas (Coombs et al., 2002; Bacon, 1986; Eichelberger, 1980; Murphy et al., 2000). La formación de inclusiones se ve favorecida cuando las diferencias composicionales y de temperaturas son altas, y cuando la proporción del magma máfico es baja (Sparks y Marshall, 1986). Las inclusiones también pueden estar compuestas por un magma intermedio, no necesariamente máfico, o por un magma híbrido. Una característica en común es que estas inclusiones suelen ser más máficas que el extremo silícico de la mezcla (Bacon, 1986).

La hibridación puede producirse cuando luego de alcanzado el equilibrio térmico entre ambos magmas, el magma máfico permanece como un fundido. Esto requiere generalmente una gran proporción de magma máfico (alrededor del $50 \%$ ), especialmente si la diferencia composicional es grande (Sparks y Marshall, 1986). La difusión térmica es generalmente 3 a 5 órdenes de magnitud mayor que la difusión química, por lo cual, aunque las temperaturas en el contacto entre ambos magmas puede cambiar significativamente, las composiciones no (Sparks y Marshall, 1986). Otra manera de generar magmas híbridos es mediante la desintegración de las inclusiones previamente formadas (Clynne, 1999).

Las evidencias de mingling en el Payún Matrú son escasas en comparación con las evidencias de hibridación. Han sido encontrados escasos enclaves en los Traquitoides Precaldera, en una lava ubicada en el perfil de La Nariz (subunidad 3, muestras PM 31 y PMD 53, Fig. 7.1). Más frecuente se encuentran evidencias de mingling con dos líquidos diferentes, como bandas o zonas irregulares dentro del magma huésped, a veces con un límite difuso entre ambos líquidos. Esto sugiere que el grado de homogeneización es intermedio entre la formación de enclaves con bordes bien definidos y la hibridización completa. La colada intra-caldera de la unidad Traquiandesitas Post-caldera es un caso particular, dado que el mingling se observa a la escala de afloramiento. Además de encontrarse dos pastas diferentes, la misma colada es principalmente de traquiandesita basáltica, mientras que sectores minoritarios de la misma son traquíticos.

En el CVPM, la formación de magmas híbridos como consecuencia de la mezcla de magmas es más frecuente que la formación de enclaves o la homogeneización incompleta de los extremos composicionales. Las lavas con evidencias de mezcla de la etapa pre-caldera del Payún Matrú son, generalmente, de composición traquítica, por lo cual los porcentajes de magmas basálticos involucrados son relativamente bajos (hasta un $22 \%$ de acuerdo a los cálculos realizados). En estos casos, y dada la falta de inclusiones, es probable que el magma 
resultante sea la consecuencia de procesos múltiples de mezcla, resultando una mezcla de un magma traquítico con otro magma híbrido de composición intermedia. Esto favorecería la homogeneización de ambos, ya que disminuyen los contrastes térmicos, composicionales y de viscosidad, mientras que el porcentaje de magma intermedio involucrado aumentaría (respecto a los cálculos realizados con un extremo basáltico). Algo similar ocurre con la colada "El Choique" (muestra STA 6-B) de las Traquiandesitas Post-caldera, ya que aunque presenta un porcentaje de magma básico mayor (de hasta $30 \%$ ), resulta todavía bajo en comparación con el que en principio se requeriría para la homogeneización (Sparks y Marshall, 1986). El magma híbrido también podría formarse por desintegración de inclusiones híbridas de composición intermedia.

En otras lavas relativamente escasas de las Traquitas Pre-caldera, así como en las lavas de Traquiandesitas Post-caldera, la hibridación se habría favorecido por los altos porcentajes de magmas basálticos involucrados (alrededor del $55 \%$ ). También hay que considerar las diferencias en las temperaturas y viscosidades de los extremos composicionales. Es probable que los contrastes de temperatura no hayan sido elevados, ya que la diferencia máxima de temperatura entre traquitas y basaltos calculada es del orden de $150^{\circ}-200^{\circ} \mathrm{C}$ (método olivina-fundido), pudiendo ser menor esta diferencia en los magmas mezclados, facilitando así la hibridación. Los cálculos de temperatura y viscosidad realizados para las lavas híbridas pueden presentar errores considerables, ya que no reflejan exactamente al extremo félsico antes de la mezcla, ni tampoco al magma intermedio resultante.

En síntesis, la falta de enclaves máficos puede deberse o bien a la alta proporción de magma máfico en la mezcla, a la mezcla entre un magma traquítico con otro magma intermedio híbrido por procesos complejos de mezclas múltiples, o bien a la desintegración de inclusiones híbridas. El magma híbrido se habría formado en la interfase entre el magma traquítico y el basáltico inyectado en la cámara del Payún Matrú.

\subsubsection{Evidencias a microescala y geoquímicas}

Las evidencias que indican la mezcla de magmas con la información disponible, provienen de la petrografía, la geoquímica de roca total y la química mineral. Las texturas y composiciones mineralógicas son especialmente importantes, ya que los minerales reflejan el cambio en su entorno inmediato, debido a los cambios en composición y temperatura consecuente de la mezcla de magmas.

Las características mineralógicas que han sido interpretadas como consecuencia de la mezcla de magmas, y encontradas en las rocas del Payún Matrú son: i) plagioclasas euhedrales o redondeadas con un cribado fino o medio (Tsuchiyama, 1985; Nakamura y Shimakita, 1998); ii) diversos tipos de feldespatos manteados, como las texturas antirapakivi (Hibbard, 1981, 1995), núcleo de plagioclasa redondeada con un manto más cálcico (Stimac y Pearce, 1992) o núcleo sin redondeamiento y un manto más sódico (Tsuchiyama, 1985); iii) 
feldespatos redondeados, los cuales pueden presentar una interfase "difusa" con la pasta (Tsuchiyama, 1985; Hibbard, 1981, 1995); iv) plagioclasas u otros minerales con composiciones y texturas contrastantes en una misma roca, las cuales evidencian diferentes historias en su formación o en los procesos posteriores que la modificaron (Clynne, 1999; Murphy et al., 2000); v) biotitas reemplazadas por minerales anhidros, como feldespatos, óxidos y piroxenos (Feeley y Sharp, 1996); vi) zonaciones reversas en varios minerales, como plagioclasas y piroxenos (también puede explicarse por aumento en el contenido de volátiles, aunque en presencia de otras texturas de mezcla es más probable que ésta sea la causa) (Mandeville et al., 1996; Kusçu y Floyd, 2001; Andrews et al., 2008); vii) otros cristales con redondeamiento, común en clinopiroxenos (Vernon, 2004).

En las rocas del CVPM también se encuentran otras texturas que indican desequilibrios, pero no atribuibles a procesos de mezcla de magmas en un sistema abierto. Ejemplos de esto son el cribado grueso en las plagioclasas, atribuible a una descompresión (Nelson y Montana, 1992), anfíbol con un borde de minerales anhidros opacos y biotitas con bordes de opacos, formados por descompresión y pérdida de volátiles en el magma (Rutherford y Hill, 1993; Browne y Gardner, 2006), y feldespatos con zonación en parches, cuyo núcleo disuelto sería el producto de la descompresión, con un posterior relleno del mismo por crecimiento del feldespato en equilibrio en las nuevas condiciones (Vernon, 2004). Otras texturas mineralógicas comunes en el CVPM, que provienen de la cristalización del magma y no requieren de desequilibrios para su formación, son los engolfamientos en cristales sin esquinas redondeadas (Faure y Schiano, 2005), presentes en olivinas de las unidades basálticas, y los feldespatos con huecos relativamente grandes controlados cristalográficamente. Ambas texturas mineralógicas son atribuibles al crecimiento de los cristales en equilibrio, en el primer caso, y por crecimiento esqueletal en el segundo (Lofgren, 1974; Vernon, 2004).

La geoquímica de roca total resultó útil para caracterizar los extremos de la mezcla. Cuando dos magmas se mezclan para formar un magma híbrido de composición intermedia, las composiciones de ambos extremos y del magma híbrido resultante deben formar una línea recta en un diagrama de variación tipo Harker (Winter, 2010). Así, los diagramas de Harker en un sistema volcánico marcado por numerosos eventos de mezcla de magmas muestran tendencias rectilíneas y no ligeramente curvas, como generalmente sucede por procesos de diferenciación magmática (Winter, 2010).

En la Figura 9.5 se muestran dos diagramas de variación para el $\mathrm{Al}_{2} \mathrm{O}_{3}$ y $\mathrm{CaO}$, los cuales muestran tendencias diferentes. Las lavas de las unidades de campos basálticos fueron agrupadas en un círculo anaranjado, y las rocas del Payún Matrú fueron agrupadas en dos grupos (círculos amarillo y gris oscuro). En ambos casos se dibujaron líneas que conectan las composiciones basálticas con las del Payún Matrú. En algunos diagramas de variación, como el del $\mathrm{CaO}$, se observa que los basaltos, traquitoides dentro del círculo amarillo y traquitas dentro del círculo gris se encuentran aproximadamente alineadas (Fig. 9.5). Esta situación no se corrobora con el diagrama de variación de la alúmina. Las Traquitas Post- 
Diagramas "Harker" de elementos mayoritarios

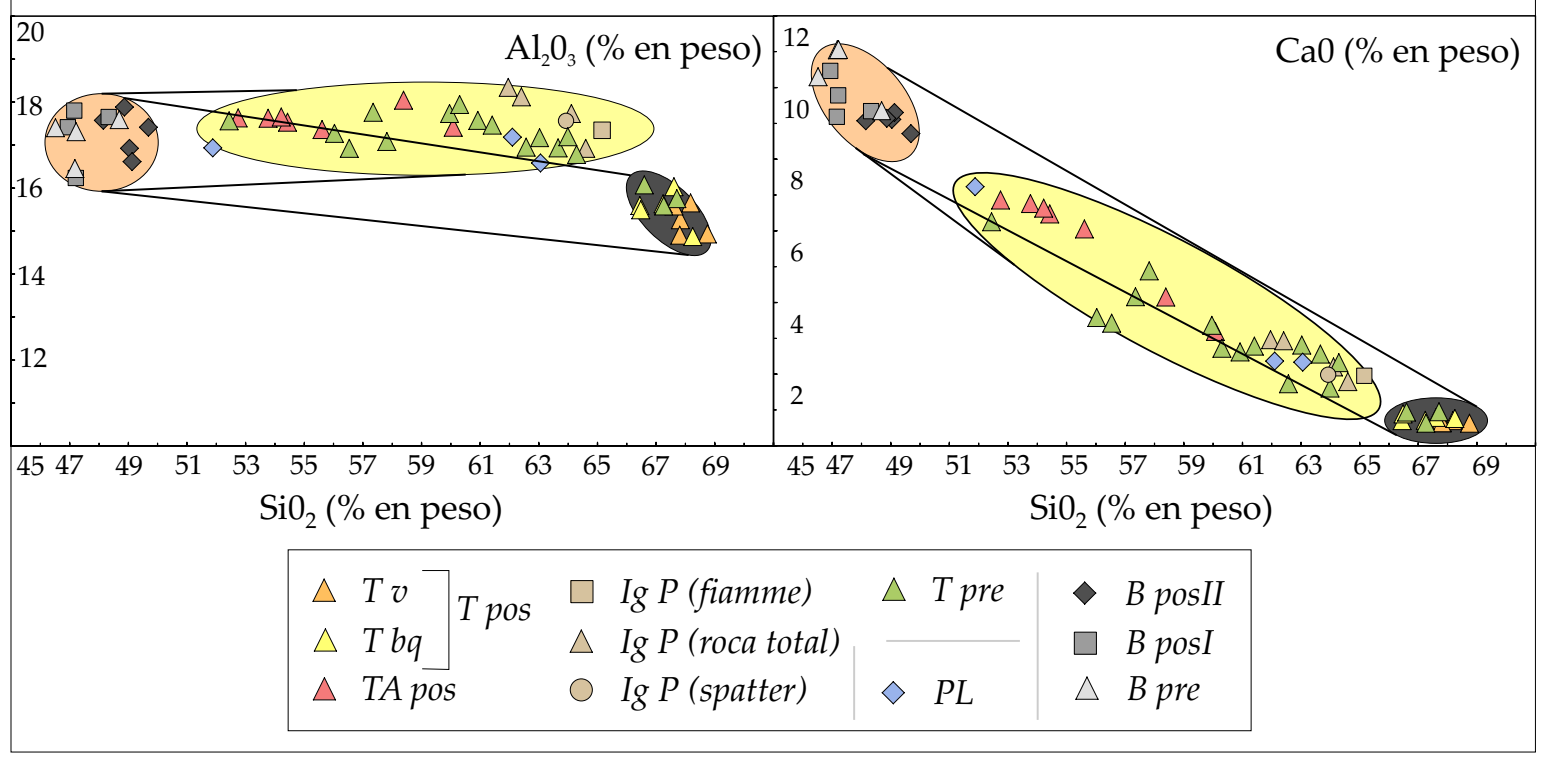

Figura 9.5: Diagramas de Harker para el $\mathrm{Al}_{2} \mathrm{O}_{3}$ y CaO. Detalles en el texto.

caldera y escasas lavas de Traquitoides Pre-caldera se encuentran por fuera de la tendencia lineal (Fig. 9.5). La gran mayoría del resto de rocas del Payún Matrú caen por fuera de la zona que conecta el círculo con basaltos y el círculo gris con traquitas.

En el diagrama de Harker del $\mathrm{P}_{2} \mathrm{O}_{5}$, algunas lavas de Traquitoides Pre-caldera y Traquiandesitas Post-caldera se desvían de la tendencia entre basaltos y traquitas. Sin embargo, estas escasas muestras se corresponden con aquellas lavas sin indicios de ser híbridas de las unidades mencionadas.

Por lo tanto, si muchas de las lavas del Payún Matrú dentro del círculo amarillo de la Figura 9.5 representan composiciones híbridas, el extremo silícico de la mezcla no es probable que haya sido de una composición traquítica como las Traquitas Post-caldera, sino que sea de composición traquítica como las encerradas en el círculo amarillo (hacia el lado derecho de la elipse dibujada).

\subsubsection{Etapa pre-caldera del Payún Matrú}

Los Traquitoides Pre-caldera, además de las evidencias de mingling ya mencionadas, presentan numerosas lavas con desequilibrios texturales que sugerirían fuertemente la mezcla de magmas. Los desequilibrios se expresan, por ejemplo (ver muestra PM 27, Capítulo 8), como plagioclasas manteadas con un núcleo de composición bytownítica-labradorítica, similar a las plagioclasas de los basaltos, y un manto con un salto composicional hacia la albita importante (salto de $30 \%$ An, de composición oligoclasa). Esto sugiere una procedencia del cristal de un magma basáltico (Izbekov et al., 2002), y un subsecuente sobrecrecimiento en el 
magma traquítico. Otras plagioclasas en la misma lava presentan redondeamiento o cribado grueso, con una composición similar al manto de la plagioclasa manteada. Los microlitos de la pasta poseen una composición idéntica a los fenocristales (oligoclasa), lo cual indica que si se trata de una lava híbrida, la composición del extremo traquítico de la mezcla no cambió significativamente, ya que fenocristales cristalizados antes de la mezcla y los microlitos que habrían cristalizado posteriormente a la misma, no muestran diferencias composicionales. Esto concuerda con el bajo porcentaje calculado de magma basáltico involucrado en la mezcla (3-7\%). Junto a esta población de plagioclasas existen clinopiroxenos redondeados y otros euhedrales que, además, poseen un borde con mayor \#Mg (zonación inversa, sugiriendo un aumento en la temperatura) y olivinas redondeadas.

Otras poblaciones de fenocristales en desequilibrio incluyen a biotitas reemplazadas por minerales anhidros junto con clinopiroxenos redondeados y no redondeados, y plagioclasas con cribado fino en un anillo y un borde más cálcico que el núcleo. Las olivinas analizadas químicamente poseen un contenido de Fo significativamente menor que las analizadas en las lavas basálticas, por lo cual habrían cristalizado en un magma traquítico. En estos casos, el redondeamiento de las esquinas es más factible que se produzca al aumentar la temperatura del magma, por ser una olivina cristalizada a menor temperatura que el magma basáltico.

Otras lavas de los Traquitoides Pre-caldera presentan texturas diversas que indican la mezcla de magmas, inclusive en una misma muestra. Estas texturas incluyen plagioclasas limpias (euhedrales y/o redondeadas) junto con otras con panal de abejas y/o con cribado medio (redondeadas o no), o feldespatos alcalinos redondeados y con cribado medio o bien anhedrales y con un anillo de cribado fino, reemplazo en las biotitas y redondeamiento de clinopiroxenos. Estos desequilibrios pueden encontrarse en las subunidades 2, 3 y 4 de las Traquiandesitas Pre-caldera.

Las rocas de las subunidades 1 y 5 no poseen estas texturas mencionadas indicadoras de mezcla de magmas, siendo simplemente el producto del fraccionamiento de los basaltos. El único rasgo a destacar en la subunidad 1 es el redondeamiento de feldespatos alcalinos, que aunque constituyen una minoría, es repetitivo en las lavas de esta subunidad. El redondeamiento de feldespatos alcalinos se produce por disolución debido a un aumento en la temperatura del magma que, en el contexto de mezcla de magmas, se interpreta que un magma máfico es el responsable del incremento en temperatura del magma silícico, aunque no es necesario que exista una hibridación o mingling entre ambos (Hibbard, 1981, 1995). Además, en esta subunidad, algunos clinopiroxenos y olivinas presentan redondeamiento. En la subunidad 1 también se encuentran algunos feldespatos alcalinos con cribado grueso, y muy raramente feldespatos manteados conformando una textura anti-rapakivi. La textura antirapakivi se interpreta como formada por la mezcla de magmas, y los escasos fenocristales con esta textura podrían ser antecristales (cristales formados dentro del sistema magmático, cristalizados en magmas progenitores del magma en que se encuentran y reincorporados al 
mismo) (Jerram y Martin, 2008). Estas características mencionadas sugieren que, al menos una parte de la población de cristales de las lavas de la subunidad 1, sufrieron un cambio en su entorno (aumento de temperatura y disminución de la presión), pero aún así, no parecen haber cambiado su composición significativamente, y por lo tanto no son lavas híbridas.

Las plagioclasas y feldespatos alcalinos con cribado grueso, los cuales son comunes en los Traquitoides Pre-caldera, no requieren de un sistema abierto para su formación. Mediante la convección dentro de una cámara, los fenocristales pueden experimentar cambios complejos en la temperatura, presión, presión de agua en su entorno inmediato, produciendo crecimientos o disoluciones (Zellmer et al., 2003). El hecho de que se encuentren junto a otros cristales limpios o con otros rasgos texturales es un problema aún no resuelto, y que probablemente tenga relación con la dinámica de la erupción y los sectores drenados de la cámara magmática.

\subsubsection{Etapa sin-caldera del Payún Matrú}

La Ignimbrita Portezuelo no muestra desequilibrios mineralógicos abundantes como algunas lavas pre-caldera. Sin embargo, se encuentran algunas texturas indicadoras de desequilibrios mineralógicos, las cuales se repiten en diversos afloramientos de la ignimbrita. En contraste con los abundantes feldespatos y mafitos limpios y no redondeados, se encuentran otros feldespatos anhedrales y con cribado medio, mafitos redondeados (olivinas, especialmente clinopiroxeno y menos frecuentemente biotita), además de muy escasas biotitas reemplazadas por minerales anhidros. El cribado medio en las plagioclasas se explica por la falta de equilibrio entre la misma y el fundido, el cual estaría en equilibrio con una plagioclasa más cálcica. En el caso de un simple aumento de la temperatura del magma sin cambio en su composición, la plagioclasa en equilibrio con el fundido también sería más cálcica que previamente al aumento en la temperatura. Por lo tanto, el efecto de un aumento de temperatura (por debajo del liquidus del feldespato) podría producir el cribado en los cristales (no el cribado grueso). Estos rasgos sugieren que al menos una parte del magma extruído sufrió cambios de temperatura, produciendo la disolución o reacción de los cristales.

Debido a que se encuentran diferencias en distintos sectores de la ignimbrita en cuanto a las proporciones relativas de feldespatos alcalinos y plagioclasas, es probable que la cámara magmática haya estado zonada, dentro de las composiciones traquíticas. Hasta el momento, no se han identificado cristales con composiciones "anómalas" que sugieran una procedencia de un magma más básico.

Los clastos de spatter analizados poseen una composición similar a la ignimbrita (tanto de fiammes como de roca total), aunque los feldespatos poseen una composición diferente a aquellos analizados en roca total. La composición de plagioclasas en estos clastos es de un contenido de anortita similar a otras plagioclasas encontradas en lavas traquíticas. Esto, junto al hecho de la ausencia de cribados en las mismas, indica que se encontraban en equi- 
librio en el magma traquítico de los clastos de spatter. Por lo tanto, los clastos de spatter no estarían representando a un magma más básico o híbrido enfriado al entrar en contacto con el magma más silícico.

Si bien en general no se observan desequilibrios mineralógicos-texturales abundantes como en algunas Traquitoides Pre-caldera y Traquiandesitas Post-caldera que sugieran la hibridación del magma, la Ignimbrita Portezuelo sí posee ciertos rasgos que indican desequilibrios. Todas las texturas encontradas se podrían explicar con un aumento en la temperatura del magma, sin necesidad de hibridación con un magma basáltico. El hecho de que la población de cristales con desequilibrios sea minoritaria en comparación con los cristales sin desequilibrios, podría deberse a que el aumento de temperatura no fue pervasivo y homogéneo en el magma, sino que se concentró en sectores, probablemente en la base de la cámara, y debido a una inyección de un magma básico. El mecanismo disparador de la erupción se discutirá en la sección siguiente.

\subsubsection{Etapa post-caldera del Payún Matrú}

Entre las lavas post-caldera del Payún Matrú, la unidad que presenta numerosas evidencias de mezcla es la de Traquiandesitas Post-caldera. No sólo por las evidencias de mingling en la colada intra-caldera, sino por desequilibrios mineralógicos que indican la hibridización en muchas lavas de esta unidad. El sector de composición intermedia de la colada intracaldera posee gran variedad de plagioclasas: limpias y euhedrales, junto a otras con cribado fino o medio, redondeadas y no, y con cribado grueso y fino. Además, se identificó un cristal euhedral bytownítico con un sobrecrecimiento fino de andesina, con un salto de $26 \%$ An entre núcleo y borde. Este cristal es el más cálcico analizado y podría representar una plagioclasa cristalizada en un magma basáltico, dada la similitud en las composiciones con las plagioclasas en los basaltos. También los mafitos muestran signos de reabsorción, siendo frecuentes los clinopiroxenos y olivinas con bordes redondeados. Estas texturas mineralógicas contrastan con el sector traquítico minoritario de la colada, en donde predominan las plagioclasas limpias. Las plagioclasas redondeadas minoritarias en este sector de la colada pueden deberse a un aumento en la temperatura del magma traquítico en contacto con el magma máfico.

Otras lavas de esta unidad post-caldera también poseen variaciones en las texturas y composiciones en las plagioclasas, además de mafitos redondeados y no redondeados y zonación inversa en clinopiroxenos (colada "El Choique", Fig. 4.1), las cuales sugieren que son magmas híbridos. Dos coladas en el flanco sur-suroeste del Payún Matrú poseen como únicos indicios de desequilibrio el redondeamiento de cristales (plagioclasas y mafitos) y cribado grueso en las plagioclasas, texturas que no requieren de procesos de hibridación, aunque si de un aumento en la temperatura en el caso de los redondeamientos. La colada del "La Cueva" (Fig. 4.1) en el flanco sudeste del Payún Matrú es la única lava de esta unidad 
que no posee ninguna evidencia de desequilibrios mineralógicos, ni en las plagioclasas ni en los mafitos.

\subsubsection{Basaltos Pre- y Post-caldera}

Las lavas basálticas y traquibasálticas tanto pre- como post-caldera presentan rasgos texturales, y en ocasiones de composición mineral, que indican una génesis compleja. Estas características sugieren que en el sistema de almacenamiento de los magmas basálticos pudieron ocurrir procesos de mezcla entre composiciones similares, por recarga del sistema con magmas también basálticos. Esto se infiere a partir de rasgos como la presencia de dos pastas intergranulares en una misma roca, con una interfase que indica que ambas partes estaban fundidas, en conjunto con otras características mineralógicas.

Dentro de las texturas mineralógicas, el redondeamiento de los fenocristales de clinopiroxeno es notorio. Los clinopiroxenos redondeados son frecuentes en los Basaltos Precaldera (son los únicos presentes en la mayoría de los casos), disminuyen su abundancia en los Basaltos Post-caldera I, en cuyas lavas se encuentra también clinopiroxenos sin redondear, y son aún más escasos en los Basaltos Post-caldera II, en donde los fenocristales que predominan no presentan redondeamientos. Con las composiciones de clinopiroxenos disponibles se pudieron identificar zonaciones reversas y núcleos de cristales con composiciones contrastantes (colada de "La Tranquera", Fig. 4.1). En esta misma colada se identificó una olivina con un contenido de Fo mayor al resto, lo cual indicaría que la población de cristales en la lava reflejan condiciones diferentes en su formación, pudiendo ser esta olivina parte de la población de cristales del magma primario.

Otros rasgos de la mineralogía en los basaltos/traquibasaltos son que, junto con los fenocristales de plagioclasas limpias y subhedrales - euhedrales, existe una menor proporción de cristales que muestran un cribado medio en el centro (los cuales podrían ser antecristales, según Jerram y Martin, 2008). También, en los basaltos pre- y post-caldera, se identificaron algunos fenocristales de feldespatos completamente diferentes al resto, sugiriendo que se trata de xenocristales o antecristales (fenocristales de plagioclasa de tamaño mayor al resto totalmente anhedrales con un anillo con cribado en panal de abejas, y otros feldespatos alcalinos también anhedrales y redondeados, con cribados gruesos y fino).

Las poblaciones cristalinas en las lavas basálticas, tanto las pre- como las post-caldera, podrían deberse a un sistema de almacenamiento longevo, en el cual se producen recargas del mismo con magmas basálticos, produciéndose como consecuencia desequilibrios en los cristales ya formados.

\subsubsection{Modelos de mezcla en el CVPM}

Debido al grado variable de hibridación en lavas pre- y post-caldera, y a los porcentajes variables de magmas máficos involucrados, es posible que hayan habido diferentes esce- 
narios en los cuales se produjo la mezcla de magmas. En la presente sección se presentan hipótesis de la formación de los magmas mezclados.

En primer lugar, la discusión se refiere a las lavas con evidencias de mezcla sin mingling y con una composición de roca total traquítica o traquiandesítica, y cuyos cálculos indican un bajo o muy bajo grado de participación de magmas basálticos/traquibasálticos (porcentaje de magma máfico menor al $25 \%$ ). Dados los bajos porcentajes de magmas máficos involucrados y la ausencia de enclaves, es probable que el proceso de mezcla haya sido más complejo que una simple mezcla de dos componentes de composiciones contrastantes. Algo similar ocurre por ejemplo, en el volcán Nevado Sabancaya (Perú), en donde los magmas híbridos se formaron por mingling-mixing en múltiples estadios (Gerbe y Thouret, 2004).

Un posible causa para explicar las poblaciones dispares de minerales y el bajo porcentaje de magma máfico, es por medio de la inyección de un magma basáltico en la cámara del Payún Matrú, en una primera instancia (Fig. 9.6 a). La inyección de magma máfico pudo ocurrir de manera no turbulenta, formando una capa de magma basáltico en la base de la cámara o, por el contrario, pudo ocurrir una inyección forzada y turbulenta. Como consecuencia, se forma una capa de magma híbrido en la base de la cámara (Fig. 9.6 a). En el primer caso esto puede ser por hibridación en una capa en el contacto entre los dos magmas, y en el segundo caso puede ser debido a la mezcla turbulenta y la consecuente hibridación, y un posterior asentamiento del magma híbrido en la base de la cámara por su mayor densidad que el magma traquítico (Campbell y Turner, 1986). Los cálculos termométricos indican que el contraste de temperatura entre el magma máfico y el traquítico podría no haber sido muy alto ( posiblemente menor a $150^{\circ} \mathrm{C}$ ), favoreciendo el proceso de hibridación. Debido a que no se observan procesos de mingling en estas rocas, si al comienzo de la mezcla se formaron enclaves híbridos, estos deben haber sido disgregadas durante la convección en la cámara (Clynne, 1999).

En la zona de la cámara con un magma híbrido, los feldespatos del magma traquítico se reabsorben de diferentes maneras, dependiendo de los contrastes de temperatura y composición, mientras que aquellos pertenecientes al magma basáltico pueden presentar sobrecrecimientos (Fig. 9.6 a). A su vez, pueden comenzar a cristalizar microlitos estables en el magma híbrido. El magma traquítico en contacto con la capa híbrida puede iniciar su convección en la cámara, debido a un aumento en la temperatura del mismo (Fig. 9.6 b). Al mismo tiempo, la cristalización y aumento de temperatura puede producir la exsolución en los volátiles, tanto de la capa híbrida como del magma máfico, especialmente a relativas bajas presiones (Fig. 9.6 b). El magma vesiculado puede eventualmente volverse menos denso que el magma traquítico, y por lo tanto pueden separarse parcelas del mismo y ascender hacia el magma suprayacente, promoviendo la mezcla entre el magma híbrido y el basáltico con el magma traquítico (Clynne, 1999) (Fig. 9.6 c). Se forma así un nuevo magma híbrido, con poblaciones de cristales altamente dispares, que evidencian historias y procesos diferentes (Fig. 9.6 d). Además, este nuevo magma híbrido posee un porcentaje de 


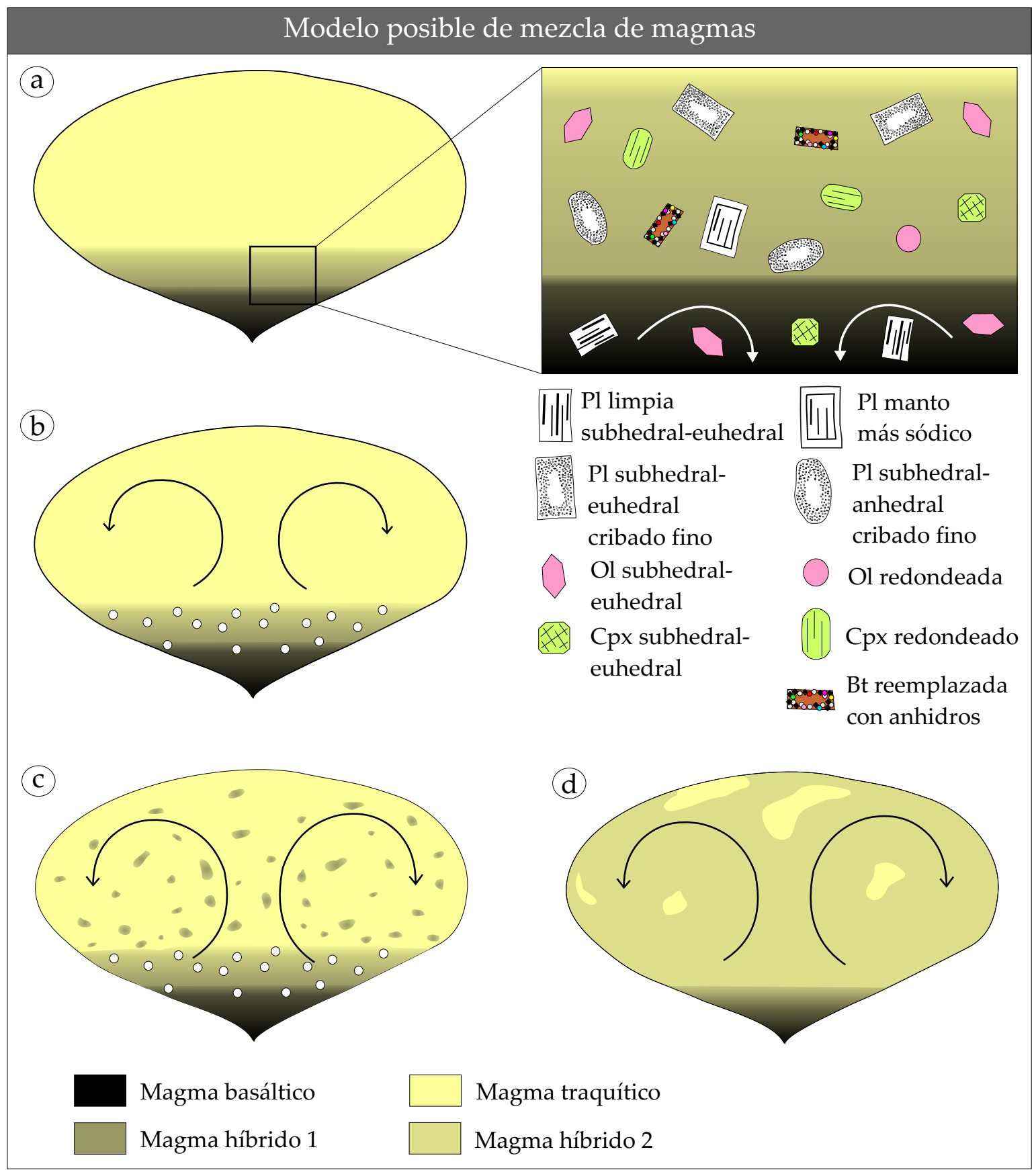

Figura 9.6: Esquema de un posible modelo de mezcla de magmas para lavas con un bajo porcentaje de magma basáltico involucrado. Pl: plagioclasa; Ol: olivina; Cpx: clinopiroxeno; Bt: biotita. a) Inyección de basaltos en la base de la cámara, formando una capa híbrida con las traquitas. Los fenocristales pertenecientes al magma traquítico se disuelven de manera simple o parcial, mientras que no es así para el caso de los fenocristales del magma basáltico (pueden presentar sobrecrecimientos). b) La exsolución de volátiles por la cristalización del magma híbrido y basáltico puede disminuir considerablemente la densidad de la capa híbrida, al mismo tiempo que habría convección dentro del magma traquítico, por un aumento en su temperatura. c) Enclaves híbridas son arrastrados por su menor densidad al magma traquítico, mezclándose con este. d) Nuevo magma híbrido formado por desintegración de enclaves híbridos y por mezcla entre la capa híbrida y traquítica. 
magma máfico significativamente menor que la primera capa de magma híbrido formada. A su vez, se favorece la homogeneización entre el primer magma híbrido formado y el resto del magma traquítico no híbrido alojado en la cámara, ya que se disminuyen los gradientes de temperatura y viscosidad entre ambos.

En el caso de las escasas lavas pre-caldera con evidencias de mingling, con la presencia de dos pastas fluidas interdigitadas, su formación podría ser similar a la anterior. El mecanismo propuesto podría haber sido como el explicado anteriormente, con la diferencia de que la formación y disgregación de enclaves híbridas habrían quedado preservadas en el magma extruído, también híbrido (Fig. 9.6 c). Diversos factores podrían haber contribuido a la falta de homogeneización total del magma, como las diferencias en temperatura y viscosidades de los magmas, o por una convección menos turbulenta y menos efectiva para la mezcla, o simplemente un menor tiempo transcurrido entre la inyección basáltica y la erupción.

Para el caso de lavas híbridas de composiciones traquiandesiticas basálticas o traquiandesíticas, y con un alto porcentaje de magma basáltico involucrado (alrededor de $55 \%$ ), la situación podría haber sido algo diferente. Estas lavas pertenecen mayormente a las Traquiandesitas Post-caldera, aunque también pueden encontrarse en los Traquitoides Precaldera. En estos casos, la inyección de abundante magma máfico en la cámara traquítica (y/o traquiandesitica), junto con una convección turbulenta, pueden haber favorecido la hibridación, resultando en composiciones intermedias. Además, si el extremo silícico de la mezcla no es demasiado diferenciado (traquita no muy silícica o traquiandesita), entonces no sólo se favorece la mezcla por un menor contraste composicional y de temperatura y viscosidad, sino que el magma híbrido resultante es menos silícico. Este es el caso de la colada intra-caldera de las Traquiandesitas Post-caldera, donde un sector de la colada es traquítico, aunque cercano al campo de traquiandesitas. Este sector de la colada posee signos de disolución por aumento de la temperatura del magma por encima del liquidus de las plagioclasas, pero no posee signos de una hibridación pervasiva. En esta colada, el sector traquítico podría representar parcelas de una cámara zonada, con abundante magma híbrido y que, sin embargo, conservó parcelas de magma sin mezclar. El efecto de la inyección basáltica en estos sectores no homogeneizados composicionalmente podrían restringirse simplemente a un aumento en la temperatura.

En síntesis, se encuentran lavas en el CVPM con diferentes grados de mezcla y homogeneización, entre magmas basálticos y magmas traquíticos derivados de los primeros. Algunas lavas presentan evidencias de hibridación aunque con escasa participación de magma máfico, pudiendo representar las parcelas de un magma mezclado "diluido", otras lavas similares pero con una homogeneizaron incompleta y, por último, otras lavas en donde la participación de magma máfico en la hibridación fue más importante. 


\subsubsection{Erupción de la Ignimbrita Portezuelo}

En numerosos casos el mecanismo desencadenante de una erupción explosiva se liga a la inyección de un magma basáltico en la cámara magmática más silícica de un volcán (Snyder, 2000; Mandeville et al., 1996; Leonard et al., 2002). En una primera instancia, teniendo en cuenta la distribución del volcanismo en el CVPM y las evidencias de mezcla de magmas en la etapa pre-caldera del volcán, sería esperable que la causa de la erupción explosiva sea la introducción de un magma basáltico en la cámara del Payún Matrú. Sin embargo, las texturas mineralógicas no sugieren la hibridación como en algunas lavas de Traquitoides Pre-caldera o Traquiandesitas Post-caldera.

Las texturas de disolución (cribado, redondeamiento) y reemplazo (en las biotitas) en la Ignimbrita Portezuelo, en franca minoría respecto a los cristales no disueltos ni reemplazados, pueden ser explicadas conjuntamente mediante un aumento de temperatura del magma (Feeley y Sharp, 1996; Nakamura y Shimakita, 1998; Tsuchiyama, 1985). Además, se tiene que considerar de qué manera pueden encontrarse juntos cristales que han sufrido modificaciones atribuibles a un aumento de la temperatura y otros que no. El modelo teórico realizado por Snyder (2000) es muy útil en este aspecto. Snyder (2000) modeló los efectos térmicos en los magmas cuando un magma basáltico se intruye en la base de una cámara más silícica, acumulándose en una capa en la base de la misma. Entre ambos magmas se produce un contraste térmico y composicional que provoca la convección interiormente en ambas capas. En la base del magma silícico, en el contacto con el magma basáltico, se produce una capa de borde (generalmente el espesor es de alrededor de 1-2 m) en donde el magma silícico aumenta su temperatura significativamente (Snyder, 2000; Couch et al., 2001). Este proceso de convección dentro de la cámara originado por un gradiente de temperatura a raíz de una intrusión basáltica en la misma, fue denominado self-mixing por Couch et al. (2001).

El tiempo transcurrido desde la inyección basáltica al comienzo de la convección en las zonas basálticas y silícicas de la cámara son generalmente de menos de una hora para la capa basáltica y variable para el caso de la capa silícica (desde pocas horas a pocas semanas, dependiendo de la viscosidad del magma) (Snyder, 2000; Couch et al., 2001). Los tiempos de homogeneización de la temperatura en el magma silícico son grandes, de aproximadamente pocos años a decenas de años por cada kilómetro de espesor de la cámara silícica. Teniendo en cuenta que esta intrusión ocurre días a semanas antes de la erupción (White, 1996), y los tiempos que se requieren para homogeneizar la cámara silícica, la homogeneización resulta inalcanzable antes de la erupción. Por lo tanto, el espesor de magma silícico que aumenta su temperatura antes de la erupción es básicamente la capa de borde.

Es probable que un escenario parecido sea el causante de la erupción explosiva de la Ignimbrita Portezuelo en el Payún Matrú, por inyección de un magma basáltico en la base de la cámara del volcán. La inyección de un pulso magmático máfico en la cámara silícica au- 


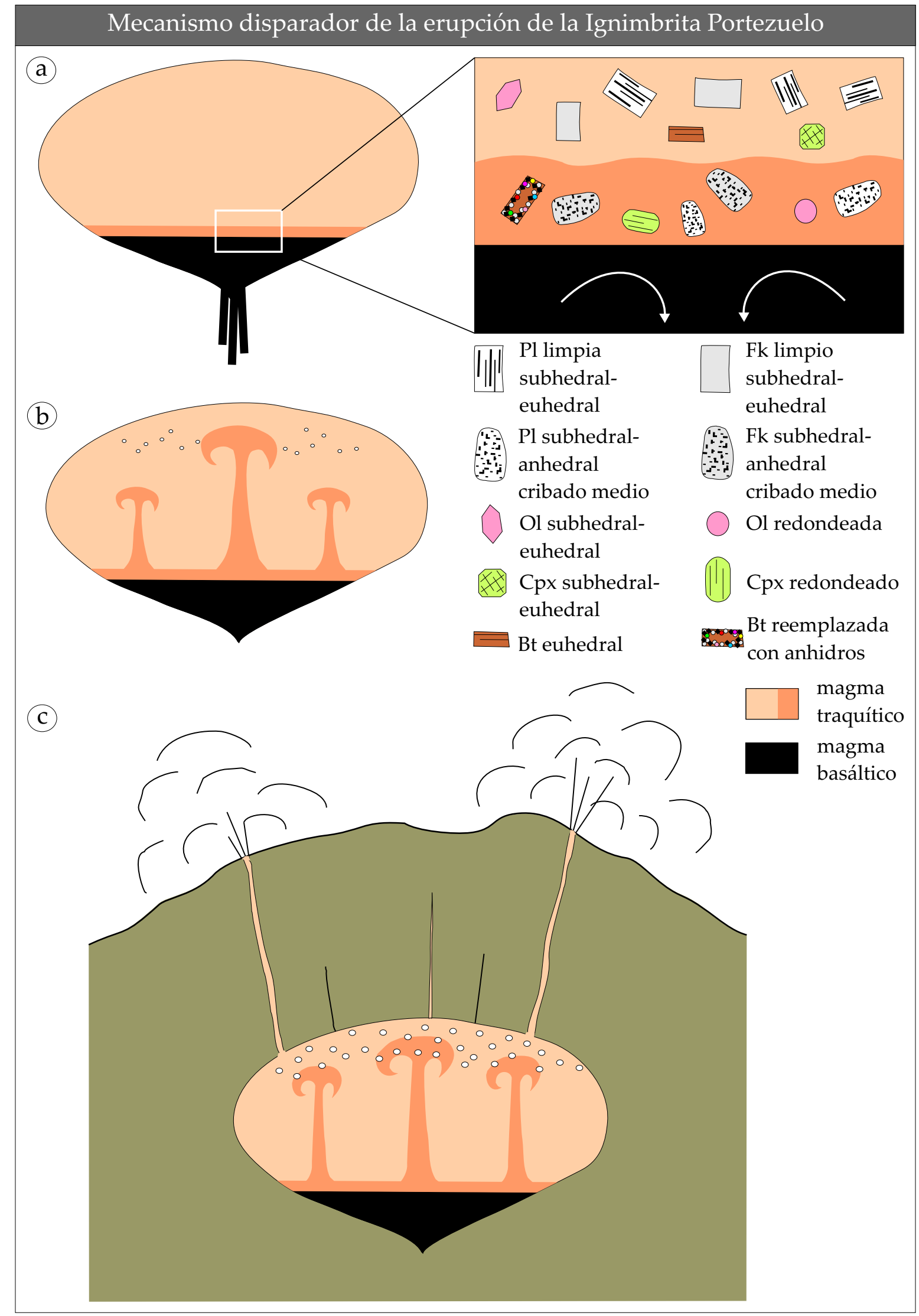

Figura 9.7: Esquemas del posible mecanismo disparador de la erupción explosiva de la Ignimbrita Portezuelo. Pl: plagioclasa; Fk: feldespatos alcalinos; Ol: olivina; Cpx: clinopiroxeno; Bt: biotita. Forma de las plumas ascendentes en base a Couch et al. (2001), el cual constituye un modelo alternativo a la convección clásica en una cámara magmática con celdas subcirculares ascendentes. 
menta la presión interna de la misma, debido a un aumento de volumen en la misma. Según modelos analíticos, este aumento de presión es insuficiente para causar la erupción, necesitándose otro mecanismo adicional dado por la exsolución de volátiles, tanto del magma silícico como del máfico (Folch y Martin, 1998).

En el contacto entre ambos magmas, el magma silícico aumenta su temperatura causando la convección y reabsorción de sus cristales, mientras que el magma máfico se enfría, favoreciendo la cristalización (Folch y Martin, 1998). Así, en la capa de borde del magma traquítico, el aumento de la temperatura debido al magma basáltico más caliente pudo haber producido el cribado en los feldespatos, el redondeamiento de clinopiroxenos, olivina y biotita, y el reemplazo de la biotita por minerales anhidros (Fig. 9.7 a). Las diferencias de viscosidades entre los magmas basálticos y el magma que originó a la Ignimbrita Portezuelo son relativamente amplias según los cálculos, de 2 a 3,5 órdenes de magnitud como mínimo. Este contraste en las viscosidades no favoreció la hibridación entre ambos magmas (Campbell y Turner, 1986) sino que cada uno conservó su identidad, produciéndose principalmente cambios térmicos en los mismos.

Una vez que comienza la convección en el sector traquítico de la cámara magmática, la zona de borde más caliente y con cristales reabsorbidos asciende y se mezcla o intercala con las zonas más frías y sin cristales reabsorbidos de la cámara (Fig. 9.7 b). A su vez, el calentamiento del magma traquítico puede producir la exsolución de los volátiles, lo cual contribuye al aumento de la presión interna de la cámara (Snyder, 2000). Según modelos analíticos de Folch y Martin (1998), el aumento en temperatura no es el factor principal en la exsolución de los volátiles, ya que el efecto de la temperatura es menor en comparación con el efecto de la composición y presión. Por lo tanto, la exsolución de volátiles en el magma traquítico se produciría a medida que el magma silícico aumenta su temperatura en el contacto con el magma máfico y asciende convectivamente, disminuyendo la presión respecto del magma basal y favoreciendo así la exsolución (Folch y Martin, 1998). Al mismo tiempo, la cristalización en el magma máfico incrementa el contenido de volátiles en el mismo, pudiendo alcanzar la sobresaturación y exsolviendo los volátiles. Este último proceso aumenta adicionalmente la presión de la cámara, siendo un mecanismo eficiente para producir la sobresaturación en la misma (Folch y Martin, 1998). Por lo tanto, tres factores contribuyen al aumento de la presión interna en la cámara: la exsolución de volátiles, tanto del magma silícico como máfico, y el mayor volumen de magma en la cámara, causado por la inyección del magma basáltico (Murphy et al., 2000; Snyder, 2000; Folch y Martin, 1998).

Por estos motivos, la erupción explosiva de la Ignimbrita Portezuelo podría haberse desencadenado por un calentamiento del magma traquítico en la base de la cámara (producto de la introducción del magma basáltico, sin necesidad de hibridizarse con el mismo), lo cual produjo la convección y exsolución de volátiles del magma traquítico. Además, se produce un aumento en la presión de la cámara por un incremento del magma alojado en la misma, y por la exsolución de volátiles del magma máfico debido a la cristalización del mismo. Es- 
tos procesos pudieron conducir a que la presión interna en la cámara aumente lo suficiente como fracturar el techo de la misma y causar la erupción explosiva (Fig. 9.7 c).

\subsubsection{La particularidad de la Ignimbrita Portezuelo en el CVPM}

Si la mezcla de magmas fue un proceso recurrente en la historia del Payún Matrú, surge el interrogante de por qué la Ignimbrita Portezuelo es el único depósito piroclástico de flujo importante. En la escarpa de La Nariz se encontraron ignimbritas pre-caldera, indicando que también hubo eventos explosivos en la etapa pre-caldera del volcán. Sin embargo, estas ignimbritas no poseen indicios mineralógico-texturales que indiquen hibridación entre magmas félsicos y básicos, o que simplemente haya ocurrido un aumento de temperatura del magma silícico. Por lo tanto, el origen de la explosividad en estos casos puede deberse a la exsolución de volátiles por un simple aumento en el contenido de los mismos a medida que avanzaba la cristalización, y la rápida vesiculación y ascenso del mismo (Cashman et al., 2000).

En los otros casos en que los productos emitidos poseen evidencias de mezcla, esta no provocó erupciones explosivas. Los magmas con una mezcla pervasiva y eruptados de forma efusiva indican que ni el aumento del volumen de la cámara por la inyección, ni la exsolución de los volátiles fueron suficientes como para aumentar considerablemente la presión interna de la cámara y disparar a la erupción (Folch y Martin, 1998).

\subsection{Evolución del CVPM}

\subsubsection{Etapa pre-caldera}

La etapa pre-caldera del CVPM es la más extendida temporalmente, con una duración de al menos $600 \mathrm{ka}$, aproximadamente. La lava más antigua datada es de $700 \mathrm{ka}$, siendo esta una edad mínima para el comienzo de la actividad volcánica en el CVPM. Esta etapa se extiende hasta la erupción explosiva que depositó a la Ignimbrita Portezuelo, hace aproximadamente $100 \mathrm{ka}$ (entre 148 y $82 \mathrm{ka}$ ). La actividad en los campos basálticos y el Payún Matrú fue contemporánea, de acuerdo a las relaciones de campo y dataciones radimétricas disponibles. Hasta el momento se desconoce de qué manera comenzó la actividad volcánica en el CVPM. Dado que los basaltos y las traquitas son cosanguíneos, es posible que previo al comienzo del Payún Matrú se hayan producido solamente efusiones basálticas. También es posible que ambos tipos de volcanismo hayan comenzado su actividad simultáneamente.

El volcán Payún Liso, al sudoeste del Payún Matrú, evolucionó durante la etapa precaldera. Las edades obtenidas por Germa et al. (2010) para este volcán indican una edad entre 285 y 261 ka. Posiblemente estas edades no sean las más antiguas del volcán, ya que fueron obtenidas a partir de lavas en la superficie del mismo, y el grado de erosión no expone el núcleo más antiguo del mismo. Una posibilidad, aunque no puede afirmarse al momento, 
es que el Payún Liso haya comenzado su crecimiento junto al Payún Matrú. Las pocas lavas e ignimbritas estudiadas de este volcán indican una composición similar al Payún Matrú, en cuanto a la geoquímica y petrografía. Dada la cercanía al Payún Matrú y contemporaneidad de ambos volcanes, es probable que ambos presenten un origen similar, es decir, que sus productos sean diferenciados de los magmas basálticos adyacentes y contemporáneos, con una escasa participación cortical. Esta hipótesis queda por ser investigada en futuros trabajos.

En cuanto a los campos basálticos, los basaltos pre-caldera son notoriamente más abundantes en el campo basáltico este que en el campo oeste. Esta diferencia no indica, sin embargo, que la actividad volcánica en el campo oeste de la etapa pre-caldera haya sido escasa, sino que los Basaltos Pre-caldera allí han sido mayormente cubiertos por las emisiones de los Basaltos Post-caldera I y II. La distribución y morfología de los conos de escoria en el campo basáltico este, sugieren para la etapa pre-caldera un campo de esfuerzos regionales con el esfuerzo máximo horizontal en sentido E-O.

El edificio antiguo pre-caldera del Payún Matrú es complejo, con una gran variedad de litologías y cuerpos volcánicos los cuales conformaban un volcán compuesto en forma de escudo. Todas las rocas de la etapa pre-caldera del Payún Matrú fueron agrupadas en una sola gran unidad: Traquitoides Pre-caldera. Debido a la complejidad en establecer las relaciones temporales entre las rocas de esta unidad, y a la escasez de dataciones radimétricas, no es posible al momento definir una estratigrafía de mayor detalle para esta etapa. Se han realizado subdivisiones de la misma, pero con criterios exclusivamente petrográficos y con el fin de simplificar su caracterización.

Los Traquitoides Pre-caldera presentan afloramientos extensos sobre todo en el flanco NE a SE del Payún Matrú, en donde no fueron cubiertas por la actividad post-caldera del mismo, y en donde están parcialmente cubiertas por la Ignimbrita Portezuelo. En esta etapa pre-caldera del Payún Matrú, los productos emitidos son esencialmente lavas, conformando coladas, domos y escasos diques. En considerable menor proporción, se encuentran ignimbritas con un grado de soldadura alto a muy alto, y rocas volcaniclásticas aún no estudiadas. En consecuencia, en esta etapa predominaron las efusiones tranquilas de lavas, con episodios aislados y escasos de erupciones explosivas.

Con respecto al sistema magmático profundo del CVPM, se pueden realizar algunas inferencias con la información disponible. Los magmas basálticos generados en el manto astenosférico fueron acumulándose progresivamente como cuerpos tabulares en la corteza inferior y/o discontinuidad de Mohorovicic, formando posiblemente un subplacado máfico. A medida que se intruyen estos cuerpos tabulares, y cristaliza el magma en los bordes del mismo, se forma un frente de solidificación que posee un aumento progresivo en la cristalinidad desde el centro al borde del cuerpo (Marsh, 2000, 2002). En estas zonas con alto contenido de cristales, se producen fundidos intersticiales diferenciados a partir de magmas basálticos, con contenidos de sílice que pueden alcanzar el 60-70 \% (Marsh, 2000). A medida 
que crece el frente de solidificación y que el porcentaje de cristales en el borde del cuerpo alcanza aproximadamente un $65 \%$, el frente de solidificación superior puede volverse gravitacionalmente inestable y fracturarse. De esta manera, se libera parte del fundido intersticial silícico, el cual se acumula en parcelas dentro del cuerpo mayormente basáltico (Marsh, 2000, 2002). Una situación similar ocurre en filones capas toleíticos, en donde se forman lentes silícicos de plagiogranitos de 2-3 m de espesor y 40-50 m de longitud (Marsh, 2000). Este proceso puede ocurrir reiteradas veces, formando una asociación de magmas marcadamente bimodal, y de esta manera acumularse un volumen considerable de magmas silícicos a partir de filones capa basálticos (Marsh, 2000).

Es probable, por lo tanto, que las sucesivas acumulaciones de magmas basálticos en la base de la corteza hayan originado por cristalización fraccionada un volumen menor de magmas traquíticos. Estos magmas diferenciados pueden haberse segregado, comenzado así la formación de la cámara magmática traquítica del Payún Matrú. Mientras los procesos que generan a los magmas basálticos en el manto sigan actuando, y se sigan acumulando estos en un sistema de almacenamiento, se continúa así la alimentación de la/s cámara/s magmática/s del Payún Matrú. Al mismo tiempo, dicha cámara puede evolucionar no sólo por cristalización fraccionada y recarga con magmas diferenciados de los basaltos, sino también por inyecciones de magmas basálticos en la misma.

En los Traquitoides Pre-caldera se han identificado lavas que poseen signos de hibridación, así como una cantidad considerablemente menor de rocas con evidencias de mingling, junto con otras lavas e ignimbritas que no poseen evidencias de mezcla de magmas. Durante el crecimiento del Payún Matrú, hubo reiterados episodios de mezcla de magmas, junto con otros períodos en que las inyecciones basálticas en la cámara no fueron importantes, permitiendo así la evolución de los magmas por cristalización fraccionada.

Las composiciones las rocas mezcladas y las no mezcladas son principalmente traquíticas (la mayoría con $\% \mathrm{SiO}_{2}$ menor al $65 \%$ ), con algunas traquitas con porcentaje de sílice mayor al $67 \%$ y junto a una proporción menor de traquiandesitas y traquiandesitas basálticas, dando como resultado un amplio rango composicional. Las lavas traquíticas híbridas poseen proporciones de magmas máficos involucrados en la mezcla generalmente bajo o muy bajo. Estos cálculos, junto con el hecho de que las composiciones son traquíticas, indican que los procesos de mezcla pudieron haber sido complejos, involucrando probablemente varios estadios de mezcla para formar un magma híbrido traquítico. Por el contrario, las pocas lavas intermedias que también presentan evidencias de ser híbridas involucrarían mayores porcentajes de magmas máficos, por lo cual podrían estar representando una mayor inyección de basaltos en la cámara y, a su vez, podrían mezclarse con otras lavas traquíticas para formar un híbrido también traquítico.

En la Figura 9.8 se esquematiza una evolución posible del sistema magmático del CVPM (Figs. 9.8 a) y b) representando la etapa pre-caldera). Esta etapa pre-caldera del CVPM se identificaron variaciones composicionales y texturales que sugieren que la historia del vol- 
cán estuvo caracterizada por períodos de mezcla extensiva con otros en los que la cámara magmática parece haber evolucionado como un sistema cerrado. Los basaltos adyacentes al Payún Matrú son relativamente homogéneos en sus características, y contemporáneos con la evolución del mismo.

\subsubsection{Etapa sin-caldera}

La etapa sin-caldera del CVPM está representada por un evento puntual: la erupción de la Ignimbrita Portezuelo y formación de la caldera del Payún Matrú. De acuerdo a dataciones de lavas pre- y post-caldera, la erupción explosiva ocurrió en el Pleistoceno tardío, entre 148 y 82 ka. La Ignimbrita Portezuelo no pudo ser datada, dado los bajos contenidos de Ar en los feldespatos alcalinos.

El Índice de Explosividad Volcánica (VEI) de esta erupción se puede estimar en base a los cálculos volumétricos de la ignimbrita, cuyos valores están entre 25 y $33 \mathrm{~km}^{3}$ (Germa et al., 2010; Llambías et al., 2010). De acuerdo a estos valores, el VEI es de 6, valor que corresponde a erupciones de grandes proporciones, pero no de las mayores registradas.

Los afloramientos de la Ignimbrita Portezuelo tienen una distribución radial a partir de la caldera, los cuales alcanzan los $40 \mathrm{~km}$ aproximadamente desde la misma. Fue depositada tanto en las partes bajas del relieve previo como en zonas relativamente altas, como la ladera del Payún Liso, el cerro "El Sombrero" en el "Portezuelo de los Payunes" y sobre abundantes conos de escoria pre-caldera.

Las composiciones de fiammes, roca total y clastos de spatter analizados son todos traquíticos y con una dispersión moderada en el diagrama TAS. Una diferencia química significativa se exhibe en los elementos de REE. Las anomalías de Eu son tanto levemente negativas (análisis de fiammes, clastos de spatter y una roca total), como marcadamente positiva en otros casos (análisis de roca total) (Fig. 7.9 a). Esta diferencia se refleja moderadamente en los cristales presentes en estos dos grupos, con una menor participación de feldespatos alcalinos, en general, en las rocas con anomalía de Eu positiva. Las anomalías positivas en Eu se explican en ocasiones como debidas a una acumulación de plagioclasas, aunque en estos casos el contenido de cristales no varía significativamente, por lo cual no parece ser la causa. Las anomalías negativas serían por el fraccionamiento de plagioclasas y feldespatos alcalinos del magma.

Se definieron ocho facies ignimbríticas, en base a descripciones someras de sus características. Tanto en sectores proximales como distales, la ignimbrita es masiva, con variaciones en el grado de soldadura, en la presencia de clastos de spatter y aspecto vitrofírico, entre otros. Las estructuras tractivas son relativamente escasas, indicando que los flujos piroclásticos que la depositaron fueron densos en general, al menos en sus sectores basales. En aquellos lugares en donde la ignimbrita sorteó obstáculos, se depositaron facies de alto grado, masivas y eutaxíticas. La compactación y soldadura de los clastos en estos casos y en 


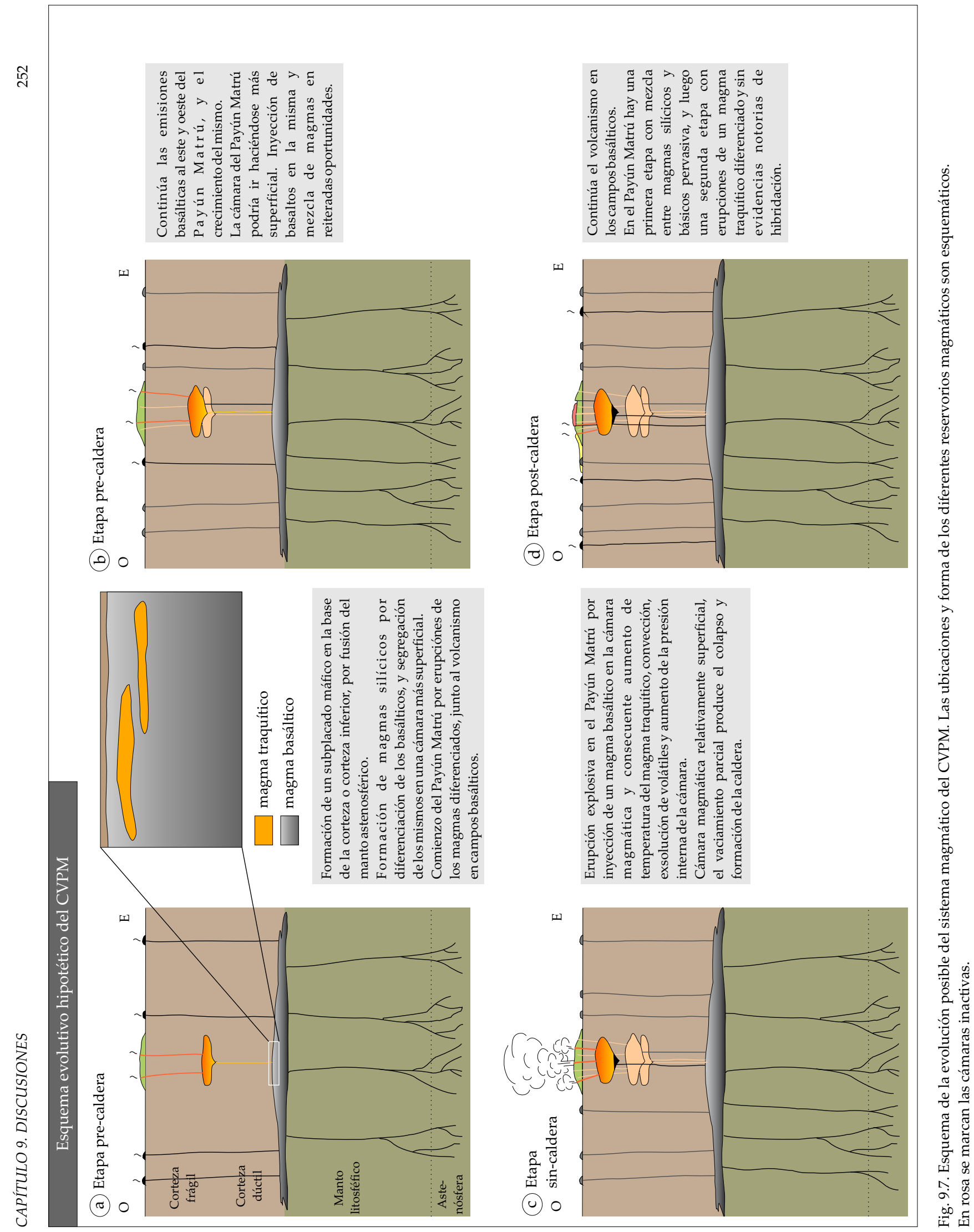


otros casos en donde la ignimbrita es de alto grado, no se debe al peso de la roca suprayacente, debido a los escasos espesores de ignimbrita suprayacente, o su ausencia. La soldadura puede deberse a la conservación de la temperatura y fluidez de los clastos, favorecida no sólo por la temperatura del magma, sino también por altas tasas de acumulación.

La caldera se habría formado como consecuencia de esta erupción explosiva que vació en parte a la cámara magmática, produciéndose así el colapso gravitacional del techo de la misma. Debido a las diferencias en la morfología del borde de la misma (pared topográfica marcada de $\mathrm{N}$ a SE y resto del borde definido por erupciones post-caldera en una franja relativamente ancha), el colapso no parece haber sido simétrico. La morfología de la caldera es de tipo trapdoor, con un colapso de al menos 500 m en la escarpa del sector de "La Nariz", y pudiendo ser menor en otros sectores. El estadio evolutivo al que pertenece la caldera, teniendo en cuenta su diámetro y subsidencia, es probablemente el estadio 2 (cercano al 3) (Acocella, 2007). La asimetría presente en la caldera puede ser causada por diversos factores, considerando la topografía actual de las rocas pre-caldera del Payún Matrú, donde las mayores alturas se encuentran en el sector ESE del volcán ("La Nariz"), es probable que una asimetría en la topografía haya contribuido a la asimetría en el colapso.

Sobre la base de la distribución del volcanismo basáltico y la morfología de la caldera, se pueden hacer inferencias sobre el diámetro de la cámara magmática (al menos para las etapas sin- y post-caldera). Considerando que las fallas anulares que se forman al colapsar una caldera son subverticales, el diámetro de la cámara magmática sería similar al diámetro de la caldera (Gudmundsson, 2008). Además, si se considera la presencia de conos de escoria y erupciones fisurales basálticas cerca de la caldera, y que el ascenso de los magmas basálticos es desde zonas relativamente profundas y a través de diques subverticales, entonces estos basaltos son un límite lateral para la extensión de la cámara magmática del Payún Matrú.

La Figura 9.8 c) esquematiza esta etapa en el marco de la evolución probable del sistema magmático del CVPM. La etapa sin-caldera del CVPM es la más acotada temporalmente de todas, afectando solamente al volcán Payún Matrú. Sin embargo, dada su particularidad e importancia en la estratigrafía del campo volcánico, es que esta etapa adquiere una gran significancia para el mismo.

\subsubsection{Etapa post-caldera}

La etapa post-caldera del Payún Matrú comienza con la efusión de lavas intermedias de las Traquiandesitas Post-caldera. Estas emisiones ocurrieron principalmente en el borde SE a O de la caldera, probablemente aprovechando estructuras formadas durante el colapso del edificio y formación de la caldera. Las lavas de esta unidad denotan un cambio marcado en la composición de los productos emitidos, desde la erupción explosiva de un magma traquítico (Ignimbrita Portezuelo) hacia la efusión de lavas intermedias (traquiandesitas basálticas a traquiandesitas). 
Los procesos de mezcla de magmas son notorios en esta unidad, aunque están ausentes en escasas coladas. Es probable que luego de la erupción explosiva, haya quedado como remanente en la cámara magmática, una gran proporción de magma máfico. Si, además, luego se producen nuevas inyecciones basálticas, y si la presión interna de la cámara no se sobrepasa y por lo tanto no hay erupciones por un tiempo relativamente prolongado, se podría producir la mezcla extensiva entre remanente de magma traquítico y los pulsos sucesivos de magmas basálticos (Fig. 9.8 d). Esto produciría una mezcla con un alto porcentaje de magma máfico. Si bien en un principio los contrastes de temperatura y viscosidad podrían haber sido lo suficientemente grandes como para prevenir la homogeneización de los magmas, la erupción de la Ignimbrita Portezuelo puede haber favorecido la convección vigorosa dentro de la cámara. Con las sucesivas inyecciones basálticas en la misma, la proporción de magma máfico pudo aumentar considerablemente, favoreciendo la mezcla. Además, la previa inyección de magmas basálticos desencadenando la erupción explosiva, en conjunto con un tiempo prolongado dentro de la cámara, pudieron haber actuado para disminuir los contrastes de temperatura y viscosidad entre ambos extremos, ayudando a la homogeneización de los magmas. En la colada intra-caldera de esta unidad, se preservan parcelas de magma traquítico no homogeneizado con el magma máfico, lo cual indica que no siempre ocurrió la homogeneización completa. La presencia de lavas con poblaciones de cristales que no denotan desequilibrios (colada de "La Cueva", Fig. 4.1), podrían corresponder a la cristalización en equilibrio, luego de la mezcla y homogeneización.

Posteriormente a las emisiones de lavas intermedias, se produce un cambio abrupto en la composición, con la erupción de lavas y piroclastos de las Traquitas Post-caldera. Esta unidad es de composición traquítica relativamente homogénea y con una tendencia hacia la sobresaturación en sílice. Es probable que, para producir este cambio composicional significativo, el volcán haya pasado por un periodo de reposo en donde se producía el fraccionamiento de los magmas en una cámara somera, como se ha reportado para otros volcanes (Ej. Soufriere Hills, Zellmer et al., 2003). Al igual que las Traquiandesitas post-caldera, la emisión de lavas y piroclastos de las Traquitas Post-caldera se produjo principalmente en una franja anular del borde SE a N de la caldera, y en menor proporción en el faldeo del Payún Matrú. Esta distribución de las emisiones evidencia estructuras anulares, probablemente heredadas de la formación de la caldera.

En este período de la etapa post-caldera del Payún Matrú se producen una serie de erupciones que, si bien la composición magmática y mineralógica es relativamente homogénea, la morfología y estilo eruptivo de sus productos presentan un claro contraste. Así, se pueden identificar las tres litofacies de las Traquitas Post-caldera: Traquitas en bloque, Conos pumíceos y Traquitas vítreas. Estas litofacies están ligadas genéticamente entre sí, debido a que las nacientes de algunas coladas de Traquitas en bloque son vitrofíricas, a que una lava de Traquitas vítreas nace de un cono pumíceo, y a que los Conos pumíceos presentan en sus depósitos bombas idénticas a las Traquitas vítreas y, en ocasiones, el grado de soldadura de 
los mismos los asemejan a lavas vítreas. La sucesión temporal de estas tres litofacies no es perfectamente ordenada, sino que se suceden intercaladamente en el tiempo.

Las lavas traquíticas post-caldera no poseen signos de hibridación, siendo las composiciones mineralógicas homogéneas y las más evolucionadas del CVPM (junto a otras escasas Traquitas Pre-caldera). Los feldespatos presentes en esta unidad no presentan texturas de reabsorción, aunque sí tienen rasgos atribuíbles al crecimiento (como los engolfamientos controlados cristalográficamente, sobre todo en la litofacies de Traquitas vítreas). Además poseen muy escasos fenocristales con textura anti-rapakivi, textura atribuida a la mezcla de magmas (Hibbard, 1981, 1995), los cuales podrían representar antecristales (Jerram y Martin, 2008).

Aunque las Traquitas vítreas y Traquitas en bloque presenten composiciones homogéneas, poseen algunas diferencias menores entre ambas. Estas diferencias se observan en la composición de roca total y en las composiciones mineralógicas analizadas. Se distingue una tendencia a mayores contenidos en sílice de las Traquitas vítreas, aunque existe una gran superposición entre ambas litofacies. Tanto la composición de los feldespatos alcalinos como de clinopiroxenos analizados son ligeramente diferentes, siendo los feldespatos alcalinos más ricos en potasio y los clinopiroxenos con menor \# Mg en el caso de las Traquitas vítreas.

Las lavas basálticas de los Basaltos Post-caldera I y II, contemporáneas a las unidades post-caldera del Payún Matrú, se concentran mayormente en el campo basáltico oeste, marcando una migración de la actividad basáltica hacia ese sector. Esto coincide con las anomalías de conductividad eléctrica observadas en el manto y base de la corteza, las cuales se encuentran por debajo del campo basáltico oeste en la actualidad (Burd et al., 2008). Las últimas efusiones basálticas de los Basaltos Post-caldera II, reconocidas por su excelente preservación y la ausencia de cobertura vegetal, se encuentran al oeste del Payún Matrú. Si bien la colada del $\mathrm{C}^{\circ}$ La Carbonilla se atribuyó a la unidad de Basaltos Post-caldera II, esta presenta una cobertura vegetal incipiente, al igual que otras de la misma unidad ubicadas en el campo basáltico oeste.

De acuerdo a los análisis disponibles, existe una tendencia en el tiempo a una evolución en la composición de las lavas de unidades basálticas hacia composiciones traquibasálticas. Los Basaltos Post-caldera II son en su totalidad traquibasálticos, mientras que los Basaltos Post-caldera I son tanto basaltos como traquibasaltos. También se diferencian en la morfología de lavas, siendo las coladas de Basaltos Post-caldera I mayormente tipo pahoehoe, mientras que las coladas de Basaltos Post-caldera II son todas aa. Probablemente esta diferencia tenga relación con la mayor tasa de efusión de las últimas lavas, ya que no hay diferencias en las pendientes y tampoco parecen haber diferencias en viscosidad y temperatura de los magmas, teniendo en cuenta los cálculos realizados para lavas post- y pre-caldera.

A partir de los lineamientos definidos en base a la ubicación y forma de los conos de escoria y las erupciones fisurales, se puede inferir el rumbo de los diques alimentadores. 
Estos indican que durante la etapa post-caldera del CVPM el esfuerzo principal máximo horizontal presenta un rumbo ESE, con un azimut de $\mathrm{N} 100^{\circ}$, levemente diferente al de la etapa pre-caldera. Esta dirección es coincidente con las mediciones del campo de esfuerzos actual mediante el breakout de pozos petroleros (Guzmán et al., 2005, 2007). Este campo de esfuerzos es el esperable, considerando los esfuerzos que se producirían por la convergencia de la Placa de Nazca y la cadena montañosa andina.

Por último, queda el interrogante de si el CVPM está todavía activo o no. Las edades radimétricas disponibles de las lavas más modernas son de algunos miles de años y, además, se observan conos de escoria y coladas basálticas en un grado de preservación aún mayor. Pobladores de la zona de la familia Moya, han comentado que en la década del 70 observaron "humo negro" que salía de la ladera sureste del Payún Matrú. También hay tradiciones orales que no se pueden remontar a más de algunos cientos de años, afirmando la existencia de actividad volcánica en el área en tiempos históricos (Inbar y Risso, 2001b). Durante las tareas de campo no se han observado signos de actividad. Si bien no hay signos evidentes de actividad en la actualidad, es perfectamente factible que el sistema volcánico del CVPM esté aún activo, dada la poca antigüedad de las últimas lavas, las anomalías geofísicas observadas actualmente debajo del mismo, y las tradiciones orales. 


\section{Conclusiones}

Sobre la base de los datos presentados en los capítulos precedentes, se enumeran a continuación las principales conclusiones del presente trabajo.

- El CVPM es de edad Pleistocena-Holocena, siendo la lava datada más antigua de 700 ka, perteneciente al núcleo expuesto del Payún Matrú. Esta edad coincide con el comienzo de la época eruptiva puentelitense de Payenia (Bermúdez et al., 1993).

- El CVPM presenta dos tipos de volcanismo diferente y contemporáneos: por una parte se encuentran volcanes poligenéticos como el Payún Matrú (volcán compuesto en forma de escudo con una caldera en su cúspide) y el Payún Liso (estratovolcán), y por otra parte se encuentran los campos basálticos al este y oeste del Payún Matrú, con más de 200 conos de escoria e innumerables coladas.

- El Payún Matrú y los campos basálticos se distribuyen en una franja E-O, con el Payún Matrú en una posición central en la misma. El Payún Liso se encuentra levemente al sur de dicha franja. La distribución de los centros eruptivos está controlada por una estructura E-O. El CVPM se ubica en el límite de la cuenca sedimentaria Terciaria al norte del mismo.

- El volcán Payún Matrú es de composición principalmente traquítica, aunque también posee lavas intermedias en menor proporción (traquiandesitas y traquiandesitas basálticas). No se encontraron lavas basálticas o traquibasálticas en el mismo. El estudio somero del Payún Liso indica que también podría ser un volcán traquítico con menor participación de lavas intermedias. Las lavas de los campos basálticos son basaltos y traquibasaltos, preponderando los primeros en la etapa pre-caldera, y los segundos en la etapa post-caldera.

- Se mejoró y actualizó el esquema estratigráfico previo principalmente mediante observaciones de campo. Esta nueva estratigrafía fue confirmada y acotada temporalmente en base a dataciones radimétricas propias y de Germa et al. (2010). En primer lugar, se distinguieron las unidades de los campos basálticos de aquellas correspondientes al Payún Matrú. Esta discriminación se realizó en base a aspectos descriptivos (composicionales y morfológicos), los cuales resultan corresponderse directamente con las 
diferencias en el origen y almacenamiento de los magmas basálticos y traquíticos. En segundo lugar, y en base a la Ignimbrita Portezuelo, se definieron tres etapas evolutivas del CVPM, las etapas pre-, sin-, y post-caldera.

- La etapa pre-caldera del CVPM está representada por el volcán Payún Liso, por los Traquitoides Pre-caldera en el Payún Matrú, y por los Basaltos Pre-caldera en los campos basálticos. Los Traquitoides Pre-caldera se componen fundamentalmente por lavas, con considerable menor participación de ignimbritas y rocas volcaniclásticas. Las composiciones son variadas, desde traquiandesitas basálticas a traquitas, predominando ampliamente estas últimas. Los Basaltos Pre-caldera se encuentran tanto al este como al oeste del Payún Matrú, aflorando principalmente al este del volcán al no haber sido cubiertos completamente por erupciones posteriores.

- La Ignimbrita Portezuelo y la caldera del Payún Matrú representan la etapa sin-caldera, la etapa de menor duración del campo volcánico. La ignimbrita es traquítica, y presenta cambios faciales verticales y laterales, predominando las facies masivas con características variables. Presenta clastos de spatter traquíticos, sin una aparente diferencia composicional con el magma fragmentado. La erupción de la Ignimbrita Portezuelo, y la formación de la caldera, quedan acotadas entre los 148 y $82 \mathrm{ka}$, en base a dataciones de lavas previas y posteriores a la misma.

- La caldera del Payún Matrú es asimétrica, con una pared topográfica de altura variable (500 m máximo) formando el borde $\mathrm{N}$ a SE de la caldera. A lo largo de la misma no se han emitido lavas en la etapa post-caldera. El borde restante de la caldera puede inferirse a través de los numerosos centros eruptivos posteriores, los cuales se localizan sobre una franja anular relativamente ancha. El colapso del edificio volcánico fue asimétrico, posiblemente de tipo trapdoor, resultando una caldera en estadio evolutivo entre 2 y 3.

- La etapa post-caldera comienza en el Payún Matrú con la emisión de lavas correspondientes a la unidad Traquiandesitas Post-caldera (la edad de la colada intra-caldera es de $82 \mathrm{ka}$, Germa et al., 2010). Las lavas de esta unidad son intermedias (traquiandesitas basálticas y traquiandesitas). Luego se inicia la última etapa, con lavas y depósitos piroclásticos de caída de composición traquítica marcadamente diferente a las Traquiandesitas Post-caldera, conformando la unidad de Traquitas Post-caldera. Esta fue dividida en tres litofacies: Traquitas en bloque (lavas con morfología en bloque), Conos pumíceos (depósitos de caída de forma monticulares), y Traquitas vítreas (coladas dómicas, domos, escasas coladas). Las tres litofacies se intercalan en el tiempo, como se evidencia en el campo y por dataciones radimétricas (37 a $7 \mathrm{ka}$, dataciones propias y de Germa et al., 2010, aunque existen evidencias del inicio más temprano de esta unidad). 
- La actividad post-caldera en los campos basálticos está representada por las unidades de Basaltos Post-caldera I y II. La actividad durante esta etapa fue más intensa en el lado oeste de la caldera. Las morfologías lávicas son diferentes en ambas unidades, siendo en los Basaltos Post-caldera I lavas tipo pahoehoe, y en los Basaltos Post-caldera II lavas tipo aa. Los conos de escoria y lavas más modernos se encuentran en excelente estado de preservación, sin siquiera una leve cobertura vegetal.

- Se identificaron numerosas erupciones fisurales y alineamientos de conos de escoria, tanto al este como al oeste del Payún Matrú. A partir de ellos, se infirieron las direcciones preferenciales de los esfuerzos horizontales regionales (para las etapas pre- y post-caldera). En el campo basáltico del este (mayormente pre-caldera), se identificaron lineamientos $\mathrm{E}-\mathrm{O}$ y también otros conjugados de bajo ángulo con la bisectriz en sentido E-O, lo que sugiere un esfuerzo máximo horizontal E-O durante la etapa precaldera. En el campo basáltico oeste, con predominio de conos de escoria post-caldera, los lineamientos identificados sugieren un campo de esfuerzos levemente distinto. El esfuerzo máximo horizontal para esta etapa sería en sentido ESE-ONO (azimut N 100$110^{\circ}$ ), lo cual coincide con las mediciones de esfuerzos actuales determinadas para el sur de Mendoza (azimut N 100, Guzmán et al., 2007).

- Las rocas del CVPM pertenecen a la serie alcalina transicional o suavemente alcalina, con variación composicional entre basaltos y traquitas transicionales a riolitas, con tendencia a la sobresaturación en sílice de las rocas más evolucionadas.

- Los magmas basálticos se originaron en el manto astenosférico fértil, probablemente en un manto con granate, o en transición al campo de la espinela. La profundidad mínima de fusión del manto, estimada mediante la geoquímica y corroborada por métodos geofísicos, sería de aproximadamente $60 \mathrm{~km}$. De acuerdo a los isótopos de Sr y $\mathrm{Nd}$, la fuente mantélica de los magmas es isotópicamente deprimida, aunque en un grado moderado, y se ubica dentro del arreglo del manto entre los reservorios BSE y PREMA-HIMU.

- Los basaltos y traquibasaltos del CVPM pertenecen al grupo sódico de los basaltos alcalinos continentales, de acuerdo a sus características químicas e isotópicas.

- Los basaltos y traquibasaltos ubicados en el retroarco, en el CVPM, son químicamente diferentes a los basaltos contemporáneos ubicados en el arco volcánico a latitudes semejantes, mientras que resultan ser similares a basaltos tipo OIB. Presentan una afinidad geoquímica a intraplaca, sin evidencias de una componente de subducción, como la anomalía de $\mathrm{Nb}$ y Ta, la cual sí se observa en los basaltos del arco.

- Las lavas de los campos basálticos no representan magmas primarios, debido a que se han fraccionado previamente a su erupción. Las fases fraccionantes estarían dadas 
por olivina, clinopiroxeno y óxidos de $\mathrm{Fe}-\mathrm{Ti}$, sin fraccionamiento significativo de plagioclasa.

- Los cálculos barométricos sugieren que los magmas basálticos se habrían acumulado en la base de la corteza o discontinuidad de Moho (profundidades entre 20 y $37 \mathrm{~km}$ aproximadamente), lo cual se corresponde con estudios geofísicos de conductividad eléctrica (Burd et al., 2008).

- Los magmas traquíticos del Payún Matrú y los basálticos adyacentes son comagmáticos. Las traquitas se originaron por fraccionamiento de los basaltos, en base a los patrones de elementos mayoritarios y traza, y a los datos isotópicos.

- Las rocas traquíticas del Payún Matrú muestran evidencias de fraccionamiento, en grado variable, de feldespatos alcalinos, plagioclasas, clinopiroxeno, óxidos de Fe-Ti y apatita. El fraccionamiento de feldespatos alcalinos y plagioclasas es más significativo en las traquitas más silícicas, pertenecientes a las Traquitas Post-caldera y también a algunas lavas de los Traquitoides Pre-caldera.

- En el CVPM existe una menor proporción de rocas intermedias, en comparación con la abundancia de rocas basálticas/traquibasálticas y traquíticas. Esto se debe a que el fraccionamiento de basaltos alcalinos produce, al menos en las series alcalinas transicionales, magmas silícicos con una escasa proporción de magmas intermedios (Daly Gap).

- Algunas lavas traquíticas post-caldera presentan una moderada contaminación cortical, mientras que en el resto de las rocas del Payún Matrú la contaminación es muy leve a ausente. Los basaltos y traquibasaltos no presentan evidencias de contaminación.

- En el Payún Matrú han sido encontradas numerosas evidencias de mezcla entre magmas basálticos y traquíticos. Estas evidencias incluyen tanto la ausencia de basaltos y traquibasaltos en el Payún Matrú (en contraste con su abundancia en los campos basálticos adyacentes), como el mingling entre dos pastas diferentes y diversas texturas mineralógicas como por ejemplo: plagioclasas con cribado en panal de abejas junto con otras limpias, feldespatos con textura anti-rapakivi, plagioclasas con sobrecrecimientos marcadamente distintos, zonaciones reversas en mafitos y biotita reemplazada por minerales anhidros. Las evidencias de hibridación completa entre estos magmas son más comunes que las de mingling.

- Los extremos silícicos en la mezcla de magmas serían magmas diferenciados de los basaltos, de composición traquítica (aunque no de composición similar a las traquitas más silícicas de las Traquitas Post-caldera y subunidad 1 de Traquitoides Pre-caldera). 
El extremo máfico puede ser tanto basáltico como traquibasáltico, e inclusive, puede ser un magma intermedio híbrido formado en procesos de mezcla previos, dando lugar a mezclas complejas en múltiples estadios.

- En los Traquitoides Pre-caldera, las lavas con evidencias de mezcla de magmas son principalmente traquitas, y los porcentajes de magma basáltico involucrado son bajos, menores al $22 \%$. Por este motivo, es probable que la hibridación se haya producido por estadios múltiples de mezcla y/o desintegración de inclusiones híbridas. Los Traquitoides Pre-caldera también presentan minoritariamente lavas intermedias híbridas, con un porcentaje alto de magma basáltico involucrado ( $55 \%$ según los cálculos). En la etapa pre-caldera del Payún Matrú hubo reiterados episodios de mezcla de magmas, junto con otros períodos en los cuales la cámara magmática parece haber evolucionado como un sistema cerrado.

- La Ignimbrita Portezuelo no muestra evidencias de ser un magma híbrido, aunque sí presenta algunos desequilibrios minerales explicables mediante un aumento en la temperatura del magma. La erupción explosiva pudo haberse desencadenado por la inyección de un magma basáltico en la cámara traquítica, lo cual aumentó la temperatura del magma traquítico en contacto con el magma basáltico. Debido a esta inyección se inicia la convección del magma traquítico, se produce exsolución de volátiles tanto en el magma traquítico como en el basáltico, y como consecuencia de esto aumenta la presión interna de la cámara, desencadenando la erupción.

- La mayoría de las Traquiandesitas Post-caldera presentan evidencias de mezcla (por hibridación y/o mingling), con un alto porcentaje de magma basáltico involucrado, de alrededor del $55 \%$. La inyección de magmas basálticos en la cámara del Payún Matrú pudo haber continuado luego de la erupción explosiva, generando en consecuencia estas lavas.

- Las lavas y piroclastos de Traquitas Post-caldera son de composición traquítica uniforme, y junto con las lavas de la subunidad 1 de los Traquitoides Pre-caldera, son las lavas más silícicas del Payún Matrú. No presentan rasgos que indiquen mezcla de magmas, y son el producto de la cristalización fraccionada probablemente de los magmas intermedios previamente eruptados. 


\section{Bibliografía}

Acocella, A. (2001). Formation of nonintersecting nested calderas: insights from analogue models. Terra Nova, 13:58-63.

Acocella, A. (2007). Understanding caldera structure and development: An overview of analogue models compared to natural calderas. Earth-Science Reviews, 85:125-160.

Acocella, A. (2008). Structural Development of Calderas: A Synthesis from Analogue Experiments. En Gottsmann, J. y Martí, J., editores, Caldera Volcanism: Analysis, Modelling and Responce, pág. 285-312. Elsevier. ISBN 978-0-444-53165-0.

Alaniz-Alvarez, S. A., Nieto-Samaniego, A. F., y Ferrari, L. (1998). Effect of strain rate in the distribution of monogenic and polygenic volcanism in the Transmexican volcanic belt. Geology, 26(7):591-594.

Aldanmaz, E., Köprübaşi, N., Gürer, O. F., Kaymaksci, N., y Gourgaud, A. (2006). Geochemical constraints on the Cenozoic, OIB-type alkaline volcanic rocks of NW Turkey: Implications for mantle sources and melting processes. Lithos, 86:50-76.

Allègre, C. J. (2008). Isotope Geology. Cambridge University Press, 512 pág.

Andrews, B. J., Gardner, J. E., y Housh, T. B. (2008). Repeated recharge, assimilation, and hybridization in magmas erupted from El Chichón as recorded by plagioclase and amphibole phenocrysts. Journal of Volcanology and Geothermal Research, 175:415-426.

Annen, C. (2011). Implications of incremental emplacement of magma bodies for magma differentiation, thermal aureole dimensions and plutonism-volcanism relationships. Tectonophysics, 500:3-10.

Aragón, E., D’Eramo, F., Castro, A., Pinotti, L., Brunelli, D., Rabbia, O., Rivalenti, G., Varela, R., Spakman, W., Demartis, M., Cavarozzi, C. E., Aguilera, Y. E., Mazzucchelli, M., y Ribot, A. (2011). Tectono-magmatic response to major convergence changes in the North Patagonian suprasubduction system; the Paleogene subduction-transcurrent plate margin transition. Tectonophysics, 509(3-4):218-237. 
Arnosio, M. (2010). Evidencia textural y geoquímica de mezcla de magmas en el volcán Chimpa, Puña Salteña. Revista de la Asociación Geológica Argentina, 66:253-270.

Asimow, P. D. (2000). Melting the mantle. En Sigurdsson, H., editor, Encyclopedia of Volcanoes, pág. 55-68. Academic Press.

ASTER GDEM (2009). ASTER Global Digital Elevation Model. http:/ /www.ersdac.or.jp/GDEM/E/index.html.

Bacon, C. R. (1986). Magmatic inclusions in silicic and intermediate volcanic rocks. Journal of Geophysical Research, 91:6091-6112.

Bacon, C. R. y Druitt, T. H. (1988). Compositional evolution of the zoned calcalkaline magma chamber of Mount Mazama, Crater Lake, Oregon. Contributions to Mineralogy and Petrology, 98:224-256.

Baier, J., Audétat, A., y Keppler, H. (2007). The origin of the negative niobium tantalum anomaly in subduction zone magmas. Earth and Planetary Science Letters, 267:290-300.

Baker, B. H. (1987). Outline of the petrology of the Kenya rift alkaline province. En Fitton, J. G. y Upton, B. G. J., editores, Alkaline Igneous Rocks, número 30 en Geological Society Special Publication, pág. 293-311. Geological Society o.

Baker, J. A., Menzies, M. A., Thirlwall, M. F., y Macpherson, C. G. (1997). Petrogenesis of Quaternary Intraplate Volcanism, Sana'a, Yemen: Implications for Plume-Lithosphere Interaction and Polybaric Melt Hybridization. Journal of Petrology, 38(10):1359-1390.

Beattie, P. (1993). Olivine-melt and orthopyroxene-melt equilibria. Contributions to Mineralogy and Petrology, 115:103-111.

Bermúdez, A. y Delpino, D. (1989). La provincia basáltica andino cuyana. Revista de la Asociación Geológica Argentina, 44(1-4):35-55.

Bermúdez, A., Delpino, D., Frey, F., y Saal, A. (1993). Los basaltos de retroarco extraandinos. En Ramos, V. A., editor, Geología y Recursos Naturales de Mendoza, volumen 13 de Relatorio I, pág. 161-172. Congreso Geológico Argentino Nro. 12 y Congreso de Exploración de Hidrocarburos Nro. 2.

Bertotto, G. W. (2000). Cerro Agua Poca, un cono basáltico cuaternario portador de xenolitos ultramáficos, en el oeste de la provincia de La Pampa, Argentina. Revista de la Asociación Geológica Argentina, 55:59-71.

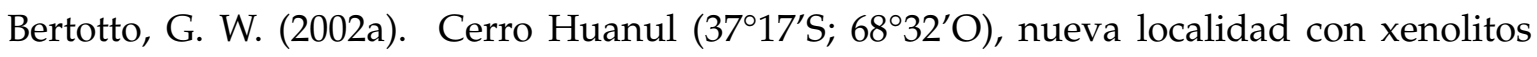
ultramáficos en basanitas cenozoicas del sur de Mendoza. En XV Congreso Geológico Argentino, volumen 3, pág. 66-70. 
Bertotto, G. W. (2002b). Xenolitos ultramáficos en el cerro de La Laguna, volcanismo basáltico de retroarco en el sureste de la provincia de Mendoza, Argentina. Revista de la Asociación Geológica Argentina, 57:445-450.

Bertotto, G. W., Cingolani, C. A., y Bjerg, E. A. (2009). Geochemical variations in Cenozoic back-arc basalts at the border of La Pampa and Mendoza provinces, Argentina. Journal of South American Earth Sciences, 28:360-373.

Best, M. G. y Christiansen, E. H. (2001). Igneous Petrology. Blackwell Science, 458 pág.

Branney, M. J. y Kokelaar, P. (1997). Giant bed from a sustained catastrophic density current flowing over topography: Acatlan ignimbrite, Mexico. Geology, 25(2):115-118.

Branney, M. J. y Kokelaar, P. (2002). Pyroclastic Density Currents and the Sedimentation of Ignimbrites, volumen 27 de Momoirs. The Geological Society of London, 130 pág., London.

Brey, G. P. y Köhler, T. (1990). Geothermobarometry in Four-phase Lherzolites II. New Thermobarometers, and Practical Assessment of Existing Thermobarometers. Journal of Petro$\log y, 31(6): 1353-1378$.

Browne, B. L. y Gardner, J. E. (2006). The influence of magma ascent path on the texture, mineralogy and formation of Hornblende reaction rims. Earth and Planetary Science Letters, 246:161-176.

Bryan, W. B., Finger, L. W., y Chayes, F. (1969). Estimating Proportions in Petrographic Mixing Equations by Least-Squares Approximation. Science, 163(3870):926-927.

Burd, A., Booker, J. R., Pomposiello, M., Favetto, A. Larsen, J., Giordanengo, G., y Orozco Bernal, L. (2008). Electrical conductivity beneath the Payún Matrú Volcanic Field in the Andean back-arc of Argentina near 36,5 S: Insights into the magma source. En Extended Abstracts, pág. 90-93, Nice. 7th International Symposium on Andean Geodynamics.

Campbell, I. H. y Turner, J. S. (1986). The influence of viscosity on fountains in magma chambers. Journal of Petrology, 27:1-30.

Carrasco-Núñez, G., Siebert, L., Díaz-Catellón, R., Vázquez-Selem, L., y Capra, L. (2010). Evolution and hazards of a long-quiescent compound shield-like volcano: Cofre de Perote, Eastern Trans-Mexican Volcanic Belt. Journal of South American Earth Sciences, 197:209-224.

Cas, R. y Wright, J. V. (1987). Volcanic Sucessions: Modern and Ancient. Allen and Unwin, 528 pág., London.

Cashman, K. V., Sturtevant, B., Papale, P., y Navon, O. (2000). Magmatic fragmentation. En Sigurdsson, H., editor, Encyclopedia of volcanoes, pág. 421-430. Academic Press, California. 
Chotin, P. (1976). Essai d'interpretation du Bassin Andin chileno-argentin en tant que bassin marginal. Ann. Soc. Geol. Nord.

Cingolani, C. A., Llambías, E. J., Tickyj, H., Manassero, M., y Abre, P. (2001). El PreCarbonífero del Bloque San Rafael, Mendoza (Argentina): Evolución y correlaciones en el margen proto-andino de Gondwana. En 11 Congreso Latinoamericano de Geología, 3 Congreso Uruguayo de Geología, número 250.

Clague, D. A. (1987). Hawaiian alkaline volcanism. En Fitton, J. G. y Upton, B. G. J., editores, Alkaline Igneous Rocks, número 30 en Geological Society Special Publications, pág. 227-252. Geological Society of America.

Clynne, M. A. (1999). A complex magma origin for rocks erupted in 1915, Lassen Peak, California. Jounal of Petrology, 40:105-132.

Cole, J. W. (1990). Structural control and origin of volcanism in the Taupo volcanic zone, New Zeland. Bulletin of Volcanology, 52:445-459.

Coombs, M. L., Eichelberger, J. C., y Rutherford, M. J. (2002). Experimental and textural constrains on mafic enclave formation in volcanic rocks. Journal of Volcanology and Geothermal Research, 119:125-144.

Cortés, J. M. y Sruoga, P. (1998). Zonas de fractura cuaternarias y volcanismo asociado en el piedemonte de la Cordillera Frontal (34०10' S, Argentina. En Actas X Congreso Latinoamericano de Geología y VI Congreso Nacional de Geología Económica, volumen 2, pág. 116-121.

Couch, S., Sparks, R. S. J., y Carroll, M. R. (2001). Mineral disequilibrium in lavas explained by convective self-mixing in open magma chambers. Nature, 411:1037-1039.

Davidson, J. P. y Da Silva, S. (2000). Composite Volcanoes. En Sigurdsson, H., editor, Encyclopedia of Volcanoes, pág. 663-681. Academic Press.

Davis, G. H. y Reynolds, S. J. (1996). Structural Geology of Rocks and Regions. Wiley, 800 pág., 2da edición edición. ISBN: 978-0-471-52621-6.

Deer, W. A., Howie, R. A., y Zussman, J. (1992). An Introduction to the Rock-Forming Minerals. Pearson Education Limited, 712 pág., London, 2da edición.

Deer, W. A., Howie, R. A., y Zussman, J. (2001). Rock-Forming Minerals, Framework Silicates: Feldspars, volumen 4A. The Geological Society, 972 pág., London, 2da edición. ISBN 186239-081-9.

Demartis, M., Pinotti, L. P., Coniglio, J. E., D’Eramo, F. J., Tubía, J. M., Aragón, E., y Insúa, L. A. A. (2011). Ascent and emplacement of pegmatitic melts in a major reverse shear zone (Sierras de Córdoba, Argentina). Journal of Structural Geology, 33:1334-1346. 
Eichelberger, J. C. (1980). Vesiculation of mafic magma during replenishment of silicic magma reservoirs. Nature, 288:446-450.

Farmer, G. L. (2003). Continental Basaltic Rocks. En Holland, H. D. y Turekian, K. K., editores, Treatise on Geochemistry, pág. 1 - 39. Pergamon, Oxford.

Faure, F. y Schiano, P. (2005). Experimental investigation of equilibration conditions during forsterite growth and melt inclusion formation. Earth and Planetary Science Letters, 236(34):882-898.

Feeley, T. C. y Sharp, Z. D. (1996). Chemical and hydrogen isotopic evidence for in situ dehydrogenation of biotite in silicic magma chamber. Geology, 24:1021-1024.

Feeley, T. C. y Winer, G. S. (1999). Evidence for fractionation of quaternary basalts on St. Paul Island, Alaska, with implications for the development of swallow magma chambers beneth Bearing Sea. Lithos, 46:661-676.

Fink, J. H. y Anderson, S. W. (2000). Lava Domes and Coulees . En Sigurdsson, H., editor, Encyclopedia of Volcanoes, pág. 307-319. Academic Press.

Fitton, J. G. (1987). The Cameroon line, West Africa: a comparison between oceanic and continental alkaline volcanism. En Fitton, J. G. y Upton, B. G. J., editores, Alkaline igneous rocks, número 30, pág. 273-291. Geological Society of America.

Fitton, J. G., James, D., y Leeman, P. W. (1991). Basic Magmatism Associated With Late Cenozoic Extension in the Western United States: Compositional Variations in Sapce and Time. Journal of Geophysical Research, 96(B8):13693-13711.

Folch, A. y Martin, J. M. (1998). The generation of overpressure in felsic magma chambers by replenishment. Earth and Planetary Science Letters, 163:301-314.

Folguera, A., Naranjo, J. A., Orihashi, Y., Sumino, H., y Nagao, K. (2009). Retroarc volcanism in the northern San Rafael Block ( $34^{\circ}-35^{\circ} 30^{\prime}$ S), southern Central Andes: Occurrence, age, and tectonic setting. Journal of Volcanology and Geothermal Research, 186:169-185.

Folguera, A. y Ramos, V. A. (2011). Repeated eastward shifts of arc magmatism in the Southern Andes: A revision to the long-term pattern of Andean uplift and magmatism. Journal of South American Earth Sciences. (en prensa).

Förster, H.-J., Tischendorf, G., y Trumbull, R. B. (1997). An evaluation of the Rb vs. (Y $+\mathrm{Nb}$ ) discrimination diagram to infer tectonic setting of silicic igneous rocks. Lithos, 40:261-293.

Galland, O., Hallot, E., Cobbold, P. R., y Buffet, G. (2007). Volcanism in a compressional Andean setting: A structural and geochronological study of Tromen volcano (Neuquén province, Argentina). Tectonics, 26(TC4010):1-24. 
Gerbe, M. y Thouret, J. (2004). Role of magma mixing in the petrogenesis of tephra erupted during the 1990-98 explosive activity of Nevado Sabancaya, southern Peru. Bulletin of Volcanology, 66:541-561.

Germa, A., Quidelleur, X., Gillot, P. Y., y Tchilinguirian, P. (2010). Volcanic evolution of the back-arc Pleistocene Payun Matru volcanic field (Argentina). Journal of South American Earth Sciences, 29:717-730.

Geyer, A., Folch, A., y Martí, J. (2006). Relationship between caldera collapse and magma chamber withdrawal: An experimental approach. Journal of Volcanology and Geothermal Research, 157:375-386.

Gilbert, H., Beck, S., y Zandt, G. (2006). Lithospheric and upper mantle structure of central Chile and Argentina. Geophysical Journal International, 165:383-398.

Giordano, D., Russel, J. K., y Dingwell, D. (2008). Viscosity of magmatic liquids: A model. Earth and Planetary Science Letters, 271:123-134.

González Díaz, E. (1970). Rasgos morfológicos del área volcánica del cerro-volcán Payún Matrú. Opera Lilloana, 20.

González Díaz, E. F. (1972). Descripción geológica de la Hoja 30d Payún Matrú. Informe Técnico Boletín 130, Dirección Nacional de Geología y Minería.

González Díaz, E. F. (1979). Descripción geológica de la Hoja 31d La Matancilla, provincia de Mendoza . Informe Técnico Boletín 173, Dirección Nacional de Geología y Minería.

Gorton, M. P. y Shandl, E. S. (2000). From Continents to Island Arcs: A Geochemical Index of Tectonic Setting for Arc-related and Within-Plate Felsic to Intermediate Volcanic Rocks. The Canadian Mineralogist, 38:1065-1073.

Groeber, P. (1937). Descripción geológica de la Hoja 30c, Puntilla de Huincán, provincia de Mendoza. Informe técnico, Diracción Nacional de Geología y Minería, Buenos Aires.

Groeber, P. (1946). Observaciones Geológicas a lo Largo del Meridiano 70: 1. Hoja Chos Malal. Revista de la Asociación Geológica Argentina, 1(3):5-36. Asociación Geológica Argentina, Serie C Reimpreciones, ISSN 0325-4135.

Gudmundsson, A. (2006). How local stresses control magma-chamber ruptures, dyke injections, and eruptions in composite volcanoes. Earth-Science Reviews, 79:1-31.

Gudmundsson, A. (2008). Magma-Chamber Geometry, Fluid Transport, Local Stresses and Rock Behaviour During Collapse Caldera Formation. En Gottsmann, J. y Martí, J., editores, Caldera Volcanism: Analysis, Modelling and Response, pág. 313-350. Elsevier. 
Guzmán, C. G., Cristallini, E. O., y Bottesi, G. L. (2007). Contemporary stress orientations in the Andean retroarc between $34^{\circ} \mathrm{S}$ and $39^{\circ} \mathrm{S}$ from borehole breakout analysis. Tectonics, 26:1-13. TC3016.

Guzmán, C. G., Cristallini, E. O., Bottesi, G. L., y Cómeron, R. E. (2005). Horizontal stress orientation from breakout analysis in the Neuquén Basin. En Extended Abstracts, pág. 354357, Barcelona. 6th International Symposium on Andean Geodynamics.

Hamilton, D. L. y MacKenzie, W. S. (1965). Phase equilibria studies in the system NaAlSiO4 (nepheline)-KAl SiO4 (kalsilita)-SiO2-H2O. Mineralogical Magazine, 34:214-231.

Hardarson, B. S. y Fitton, J. G. (1991). Increased mantle melting beneath Snaefellsjökull volcano during Late Pleistocene deglaciation. Nature, 353:62-64.

Hawkesworth, C., Turner, S., Gallagher, K., Hunter, A. Bradshaw, T., y Rogers, N. (1995). Calc-alkaline magmatism, lithospheric thinning and extension in the Basin and Range. Journal of Geophysical Research, 100:10271-10286.

Helz, R. T. y Thornber, C. R. (1987). Geothermometry of Kilauea Iki lava lake, Hawaii. Bulletin of Volcanology, 49:651-668. 10.1007/BF01080357.

Hibbard, M. J. (1981). The Magma Mixing Origin of Mantled Feldspars. Contributions to Mineralogy and Petrology, 76:158-170.

Hibbard, M. J. (1995). Petrography to Petrogenesis. Prentice Hall, 587 pág., New Jersey.

Hickey-Vargas, R., Moreno Roa, H., Lopez Escobar, L., y Frey, F. A. (1989). Geochemical variations in Andean basaltic and silicic lavas from the Villarica-Lanin volcanic chain $\left(39.5^{\circ}\right.$ S): an evaluation of source heterogeneity, fractional crystallization and crustal assimilation. Contributions to Mineralogy and Petrology, 103:361-386.

Hildreth, W., Grunder, A., y Drake, R. (1984). The Loma Seca Tuff and the Calabozos Caldera: a major ash-flow and caldera complex in southern Andes of central Chile. Geological Society of America Bulletin, 95:45-54.

Hoang, N. y Uto, K. (2003). Geochemistry of Cenozoic basalts in the Fukuoka district (northern Kyushu, Japan): implications for asthenosphere and lithospheric mantle interaction. Chemical Geology, 198:249-268.

Holland, T. y Blundy, J. (1994). Non-ideal interactions in calcic amphiboles and their bearing on amphibole-plagioclase thermometry. Contributions to Mineralogy and Petrology, 116:433-447. 
Inbar, M. y Risso, C. (2001a). A morphological and morphometric análisis of a high density cinder cone volcanic field - Payun Matru, south-central Andes, Argentina. Zeitschrift für Geomorfologie, 45(3):321-343.

Inbar, M. y Risso, C. (2001b). Holocene yardangs in volcanic terrains in the southern Andes. Earth Surface Processes and Landforms, 26:657-666.

Izbekov, P. E., Eichelberger, J. C., Patino, L. C., Vogel, T. A., y Ivanov, B. V. (2002). Calcic cores of plagioclase phenocrysts in andesite from Karymsky volcano: Evidence for rapid introduction by basaltic replenishment. Geology, 30:799-802.

Jerram, D. A. y Martin, V. M. (2008). Understanding crystal populations and their significance through the magma plumbing system. Geological Society, London, Special Publications, 304:133-148.

Kalsbeek, F. y Frei, R. (2006). The Mezoproterozoic Midsommerso dolerites and associated high-silica intrusions, North Greendland: crustal melting, contamination and hydrothermal alteration. Contributions to Mineralogy and Petrology, 152:89-110.

Kay, S. M. (2002). Magmatic sources, tectonic setting and causes of tertiary to recent Patagonian plateau magmatism ( $36^{\circ} \mathrm{S}$ to $52^{\circ} \mathrm{S}$ latitude). Número 3, pág. 95-100, Calafate. Congreso Geológico Argentino.

Kay, S. M., Burns, W. M., Copeland, P., y Mancilla, O. (2006). Upper Cretaceous to Holocene magmatism and evidence for transient Miocene shallowing of the Andean subduction zone under the northern Neuquén Basin. En Evolution of an Andean margin: A tectonic and magmatic view from the Andes to the Neuquén Basin ( $35^{\circ}-39^{\circ}$ S latitude) - Geological Society of America Special Paper, volumen 407, pág. 19-60. Geological Society of America, Colorado, Kay, S. M. and Ramos, V. A. edición.

Kay, S. M., Gorring, M., y Ramos, V. A. (2004). Magmatic sources, setting and causes of Eocene to recent Patagonian plateau magmatism ( $36^{\circ} \mathrm{S}$ to $52^{\circ} \mathrm{S}$ latitude). Revista de la Asociación Geológica Argentina, 59(4):556-568.

Kennedy, B., Styx, J., Vallance, J. W., Lavallèe, Y., y Longprè, M. A. (2004). Controls on caldera structure: results from analogue sandbox modelling. GSA Bulletin, 106:515-524.

Koppers, A. A. P. (2002). ArArCALC-software for 40Ar/39Ar age calculations. Computational Geosciences, 28:605-619.

Krauskopt, K. B. y Bird, D. K. (1995). Introduction to Geochemistry. McGraw-Hill, 647 pág., New York.

Kuiper, K. F., Deino, A., Hilgen, F. J., Krijgsman, W., Renne, P. R., y Wijbrans, J. R. (2008). Synchronizing rock clocks of Earth history. Science, 320:500-504. 
Kusçu, G. G. y Floyd, P. A. (2001). Mineral compositional and textural evidence for magma mingling in the Saraykent volcanics. Lithos, 56:207-230.

Le Maitre, R. W. (1976). Some problems of the proyection of chemical data into mineralogical classifications. Contributions to Mineralogy and Petrology, 56:181-189.

Le Maitre, R. W., editor (2002). Igneous Rocks, a Clasification and Glosary of Terms. Cambridge University Press, 236 pág., 2 edición.

Leake, B. E., Woolley, A. R., Arps, C. E. S., Birch, W. D., Gilbert, M. C., Grice, J. D., Hawthorn, F. C., Kato, A., Kisch, H. J., Krivovichev, V. G., Linthout, K., Laird, J., Mandarino, J. A., Maresh, W. V., Nickel, E. H., Schumacher, J. C., Smith, D. C., Stephenson, N. C. N., Ungaretti, L., Whittaker, E. J. W., y Youzhi, G. (1997). Nomenclature of amphiboles:Report of the Subcommittee on Amphiboles of the International Mineralogical Association, Commission on New Minerals and Mineral Names. The Canadian Mineralogist, 35:219-246.

Leake, B. E., Woolley, A. R., Birch, W. D., Burke, E. A. J., Ferraris, G., Grice, J. D., Hawthorn, F. C., Kisch, H. J., Krivovichev, V. G., Schumacher, J. C., Stephenson, N. C. N., y Whittaker, E. J. W. (2004). Nomenclature of amphiboles: Additions and revisions to the International Mineralogical Association's amphibole nomenclature. American Mineralogist, 89:883-887.

Leonard, G. S., Cole, J. W., Nairn, I. A., y Self, S. (2002). Basalt triggering of the c. AD 1305 Kaharoa rhyolite eruption, Tarawera Volcanic Complex, New Zealand. Journal of Volcanology and Geothermal Research, 115(3-4):461-486.

Lipman, P. W. (2000). Calderas. En Sigurdsson, H., editor, Encyclopedia of Volcanoes, pág. 643-662. Academic Press, California.

Llambías, E. J. (1966). Geología y petrología del volcán Payún Matrú. Acta Geológica Lilloana, 8:265-315.

Llambías, E. J., Bertotto, G. W., Risso, C., y Hernando, I. R. (2010). El volcanismo cuaternario en el retroarco de Payenia: una revisión. Revista de la Asociación Geológica Argentina, 67(2):278-300.

Lofgren, G. (1974). An Experimental Study of Plagioclase Crystal Morphology: Isotermal Crystallization. American Journal of Science, 274:243-273.

Mandeville, C. W., Carey, S., y Sigurdsson, H. (1996). Magma mixing, fractional crystallization and volatile degassing during the 1883 eruption of Krakatau volcano, Indonesia. Journal of Volcanology and Geothermal Research, 74:243-274.

Marchetti, D. W., Cerling, T. E., Everson, E. B., Gosse, J. C., y Martínez, O. (2006). Cosmogenic exposures ages of lava flows that temporarily dammed the Río Grande and Río 
Salado, Mendoza province. En Backbone of the Americas - Patagonia to Alaska, volumen 5-39. Geological Society of America - Asociación Geológica Argentina.

Marsh, B. D. (2000). Magma chambers. En Sigurdsson, H., editor, Encyclopedia of volcanoes, pág. 191-206. Academic Press.

Marsh, B. D. (2002). On bimodal differentiation by solidification front instability in basaltic magmas, part 1: Basic mechanics. Geochimica et Cosmochimica Acta, 66:2211-2229.

Martin, J. M., Ablay, G. J., Redshaw, L. T., y Sparks, R. S. J. (1994). Experimental studies of collapse calderas. Journal of the Geological Society of London, 151:919-929.

Mattsson, H. y Oskarsson, N. (2005). Petrogenesis of alkaline basalts at the tip of a propagating rift: Evidence from the Heimaey volcanic centre, south Iceland. Journal of Volcanology and Geothermal Research, 147(3-4):245-267.

McPhie, J., Doyle, M., y Allen, R. (1993). Volcanic textures: A guide to the interpretation of textures in volcanic rocks. CODES University of Tasmania, 198 pág. 085901522X.

Meijer, P. (1997). Forces controlling the present day state of stress in the Andes. World stress map rel. 1997-1, Heidelberg Academy of Sciences and Humanities.

Min, K., Mundil, R., Renne, P. R., y Ludwing, K. R. (2000). A test for systematic errors in 40Ar/39Ar geochronology through comparison with $\mathrm{U} / \mathrm{Pb}$ analysis of a 1.1-Ga rhyolite. Geochimica et Cosmochimica Acta, 64:73-98.

Morimoto, N., Fabries, J., Ferguson, A. K., Ginsburg, I. V., Ross, M., Seifert, F. A., Zussman, J., Aoki, A., y Gottardi, G. (1988). Nomenclature of Pyroxenes. Canadian Mineralogist, 73:1123-1133.

Morimoto, N., Fabries, J., Ferguson, A. K., Ginsburg, I. V., Ross, M., Seifert, F. A., Zussman, J., Aoki, A., y Gottardi, G. (1989). Nomenclature of Pyroxenes. Canadian Mineralogist, 27:143-156.

Morse, S. A. (1980). Basalts and phase diagrams: An introduction to the quantitative use of phase diagrams in igneous petrology. Springer-Verlag, 493 pág., New York.

Muñoz Bravo, J., Stern, C. R., Bermúdez, A., Delpino, D., Dobbs, M. F., y Frey, F. A. (1989). El volcanismo Plio-Cuaternario a través de los $34^{\circ}-39^{\circ} \mathrm{S}$ de los Andes. Revista de la Asociación Geológica Argentina, 44:270-286.

Murphy, M. D., Sparks, R. S. J., Barclay, J., Carroll, M. R., y Brewer, T. S. (2000). Removilization of andesite magma by intrusion of mafic magma alt the Soufriere Hills volcano, Montserrat, West Indies. Jounal of Petrology, 41:21-42. 
Nakamura, M. (1974). Determination of REE, Ba, $\mathrm{Fe}, \mathrm{Mg}$, $\mathrm{Na}$ and $\mathrm{K}$ in carbonaceous and ordinary chondrites. Geochimica et Cosmochimica Acta, 38:757-775.

Nakamura, M. y Shimakita, S. (1998). Dissolution origin and syn-entrapment compositional change of melt inclusion in plagioclase. Earth and Planetary Science Letters, 161:119-133.

Narciso, V., Santamaría, G., y Zanettini, J. (2001). Hoja Geológica 3769-I, Barrancas. Provincias de Mendoza y Neuquen. Informe Técnico Boletín 253, Instituto de Geología y Recursos Minerales, Servicio Geológico Minero Argentino.

Nelson, S. T. y Montana, A. (1992). Sieve-textured plagioclase in volcanic rocks produced by rapid decompression. American Mineralogist, 77:1242-1249.

Németh, K. y Martin, U. (2007). Practical Volcanology, volumen 207. Occasional Papers of the Geological Institute of Hungary, 220 pág., Budapest. 978-963-671-259-4.

Nullo, F. E., Stephens, G. C., Otamendi, J., y Baldauf, P. E. (2002). El volcanismo del Terciario superior del sur de Mendoza. Revista de la Asociación Geológica Argentina, 57:119-132.

Ostera, A. H. y Dapeña, C. (2003). Environmental Isotopes and Geochemistry of Bañado Carilauquén, Mendoza, Argentina. En Short Papers - IV South American Symposium on Isotope Geology, pág. 461-464.

Parfitt, E. y Wilson, L. (2008). Fundamentals of Physical Volcanology. Blackwell, 256 pág., Oxford. ISBN 9780632054435.

Pasquerè, G., Bistacchi, A., Francalanci, L., Bertotto, G. W., Boari, E., Massironi, M., y Rossotti, A. (2008). Very long pahoehoe inflated basaltic lava flows in the Payenia Volcanic Province (Mendoza and La Pampa, Argentina). Revista de la Asociación Geológica Argentina, 63(1):131-149.

Patiño Douce, A. E. (1993). Titanium substitution in biotite: an empirical model with applications to thermometry, $\mathrm{O}_{2}$ and $\mathrm{H}_{2} \mathrm{O}$ barometries, and consequences for biotite stability. Geochemical Geology, 108:133-162.

Paulsen, T. S. y Wilson, T. J. (2010). New criteria for systematic mapping and reliability assessment of monogenetic volcanic vent alignments and elongate volcanic vents for crustal stress analyses. Tectonophysics, 482:16-28.

Pearce, J. A. (1982). Trace element characteristics of lavas from destructive plate boundaries. En Thorpe, R. S., editor, Andesites, pág. 525-548. John Wiley \& Sons.

Pearce, J. A. (1983). Role of the sub-continental lithosphere in magma genesis at active continental margins. En Hawkesworth, C. J. y Norry, M. J., editores, Continental basalts and mantle xenoliths, pág. 230-249. Shiva Nantwich. 
Pearce, J. A., Harris, N. B. W., y Tindle, A. G. (1984). Trace Element Discrimination Diagrams for the Tectonic Interpretation of Granitic Rocks. Journal of Petrology, 25:956-983.

Pearce, J. A. y Norry, M. J. (1979). Petrogenetic implications of Ti, Zr, Y, and Nb variations in volcanic rocks. Contributions to Mineralogy and Petrology, 69:33-47.

Pearce, J. A. y Peate, D. W. (1995). Tectonic Implications of the Composition of Volcanic Arc Magmas. Annual Review of Earth and Planetary Sciences, 23:251-285.

Peccerillo, A., Barberio, M. R., Yirgu, G., Ayalew, D., Barbieri, M., y Wu, T. W. (2003). Relationships between mafic and peralkaline silicic magmatism in continental rift settings: a petrological, geochemical and isotopic study of the Gedemsa volcano, Central Ethiopian Rift. Jounal of Petrology, 44:2003-2032.

Peccerillo, A., Donati, C., Santo, A. P., Orlando, A., Yirgu, A., y Ayalew, D. (2007). Petrogenesis of silicic peralkaline rocks in the Ethiopian rift: Geochemical evidence and volcanological implications. Journal of African Earth Sciencies, 48:161-173.

Polanski, J. (1954). Rasgos geomorfológicos del territorio de la provincia de Mendoza. En Cuadernos de Estudio e Investigación, número 4. Instituto de Investigaciones Económicas y Tecnológicas.

Putirka, K. D. (2005). Igneous thermometers and barometers based on plagioclase + liquid equilibria: Test of some existing models and new calibrations. American Mineralogist, 90:336-346.

Putirka, K. D. (2008). Thermometers and Barometers for Volcanic Systems. Reviews in Mineralogy and Geochemistry, 69(1):61-120.

Putirka, K. D., Johnson, M., Kinzler, R., Longhi, J., y Walker, D. (1996). Thermobarometry of mafic igneous rocks based on clinopyroxene-liquid equilibria, 0-30 knar. Contributions to Mineralogy and Petrology, 123:92-108.

Putirka, K. D., Mikaelian, H., Ryerson, F. J., y Shaw, H. (2003). New clinopyroxene-liquid thermobarometers for mafic, evolved, and volatile-bearing lava compositions, with applications to lavas from Tibet and the Snake River Plain, Idaho. American Mineralogist, 88:1542-1554.

Putirka, K. D., Perfit, M., Ryerson, F. J., y Jackson, M. G. (2007). Ambient and excess mantle temperatures, olivine thermometry, and active vs. passive upwelling. Chemical Geology, 241:177-206.

Pyle, D. M. (2000). Sizes of volcanic eruptions. En Sigurdsson, H., editor, Encyclopedia of volcanoes, pág. 263-269. Academic Press. 
Ramos, V. A. (1978). Estructura. En Geología y Recursos Naturales del Neuquén, número 7 en Relatorio, pág. 99-118, Neuquén. Congreso Geológico Argentino.

Ramos, V. A. (2009). Anatomy and global context of the Andes: Main geologic features and the Andean orogenic cycle. En Kay, S. M., Ramos, V. A., y Dickinson, W. R., editores, Backbone of the Americas: Shallow Subduction, Plateau Uplift, and Ridge and Terrane Collision, volumen 204 de Memoir, pág. 31-65. The Geological Society of America.

Ramos, V. A. y Folguera, A. (2005). Tectonic evolution of the Andes of Neuquén: constraints derived from the magmatic arc and foreland deformation. En Veiga, G. D., Spalletti, L. A., Howell, J. A., y Schwarz, E., editores, Special Publications, volumen 252, pág. 15-35. The Geological Society of London, London.

Ramos, V. A. y Folguera, A. (2010). Payenia volcanic province in the Southern Andes: An appraisal of an exceptional Quaternary tectonic setting. Journal of Volcanology and Geothermal Research.

Ramos, V. A. y Kay, S. M. (2006). Overview of the tectonic evolution of the southern Central Andes of Mendoza and Neuquén ( $35^{\circ}-39^{\circ} \mathrm{S}$ latitude). Número 407 en Geological Society of America Special Paper, pág. 1-17. Colorado.

Ramsey, J. M. y Chester, F. M. (2004). Hybrid fracture and the transition from extension fracture to shear fracture. Nature, 428:63-66.

Riddle, C. (1993). Analysis of geological materials. Marcel Dekker Inc., 463 pág., New York. ISBN 0-8247-9132-0.

Ridolfi, F., Renzulli, A., y Puerini, M. (2010). Stability and chemical equilibrium of amphibole in calc-alkaline magmas: an overview, new thermobarometric formulations and application to subduction-related volcanoes. Contributions to Mineralogy and Petrology, 160:45-66.

Rieder, M., Cavazzini, G., D’Yaconov, Y. S., Frank-Kamenetskii, V. A., Gottardi, G., Guggenheim, S. Koval, P. V., Müller, G., Neiva, A. M. R., Radoslovich, E. W., Robert, J.-L., Sassi, F. P., Takeda, H., Weiss, Z., y Wones, D. R. (1998). Nomenclature of the Micas. The Canadian Mineralogist, 36:41-48.

Risso, C., Németh, K., Combina, A. M., Nullo, F., y Drosina, M. (2008). The role of phreatomagmatism in a Plio-Pleistocene high-density scoria cone field: Llancanelo Volcanic Field (Mendoza), Argentina. Journal of Volcanology and Geothermal Research, 169:61-86.

Roche, O., Druitt, T. H., y Merle, O. (2000). Experimental study of caldera formation. Journal of Geophysical Research, 105(B1):395-416. 
Rodríguez, E., Morris, C. S., Belz, J. E., Chapin, E. C., Martin, J. M., Daffer, W., y Hensley, S. (2005). An Assessment of the SRTM Topographic Products. Technical report, JPL, NASA. Jet Propulsion Laboratory D-31639.

Rogers, N. y Hawkesworth, C. (2000). Composition of magmas. En Sigurdsson, H., editor, Encyclopedia of volcanoes, pág. 115-131. Academic Press, California.

Rollinson, H. R. (1993). Using Geochemical Data: Evaluation, Presentation, Interpretation. Longman Group United Kingdom, 352 pág. ISBN 0582067014.

Rutherford, M. J. y Hill, P. M. (1993). Magma ascent rates from amphibole breakdown: An experimental study applied to the 1980-1986 Mount St. Helens eruptions. Journal of Geophysical Research, 98(11):667-685.

Schairer, J. F. y Yoder, H. S. (1960). The nature of residual liquids from crystallization, with data on the system nepheline-diópside-silica. American Journal of Science, 258-A:273-283.

Shane, P., Martin, S. B., Smith, V. C., Beggs, K. F., Darragh, M. B., Cole, J. W., y Nairn, I. A. (2007). Multiple rhyolite magmas and basalt injection in the 17.7 ka Rerewhakaaitu eruption episode from Tarawera Volcanic Complex, New Zealand. Journal of Volcanology and Geothermal Research, 164:1-26.

Silvestro, J. y Atencio, M. (2009). La cuenca Cenozoica del Río Grande y Palauco: Edad, evolución y control estructural, Faja Plegada de Malargüe ( $\left.36^{\circ} \mathrm{S}\right)$. Revista de la Asociación Geológica Argentina, 65:154-169.

Smith, M. E., Carroll, A. R., y Singer, B. S. (2008). Synoptic reconstruction of a major ancient lake system: Eocene Green River Formation, Western United States. Geological Society of America Bulletin, 12:54-84.

Snyder, D. (2000). Thermal effects of the intrusion of basaltic magma into a more silicic magma chamber and implications for eruption triggering. Earth and Planetary Science Letters, 175:257-273.

Sparks, R. S. J. y Marshall, L. A. (1986). Thermal and mechanical constraints on mixing between mafic and silicic magmas. Journal of Volcanology and Geothermal Research, 29(14):99-124.

Sruoga, P., Etcheverría, M. P., Folguera, A., Repol, D., Cortes, J. M., y Zanettini, J. C. (2005). Hoja Geológica 3569-I, Volcán Maipo, Provincia de Mendoza. Informe Técnico Boletín 290, Instituto de Geología y Recursos Minerales, Servicio Geológico Minero Argentino.

Sruoga, P., Petrinovic, I. A., Lara, L., Wright, E. M., y Asato, G. (ined). Mapa de volcanes activos. SEGEMAR. 
Steiger, R. H. y Jaeger, E. (1977). Subcommission on geochronology: convention on the use of decay constants in geo- and cosmochronology. Earth and Planetary Science Letters, 36:359362.

Stern, C. R., Frey, F. A., Futa, K., Zartman, R. E., Peng, Z., y Kyser, T. K. (1990). Trace-element and $\mathrm{Sr}, \mathrm{Nd}, \mathrm{Pb}$, and $\mathrm{O}$ isotopic composition of Pliocene and Quaternary alkali basalts of the Patagonian Plateau lavas of southernmost South America. Contributions to Mineralogy and Petrology, 104:294-308.

Stimac, J. A. y Pearce, T. H. (1992). Textural evidence of mafic-felsic magma interaction in dacite lavas, Clear Lake, California. American Mineralogist, 77:795-809.

Sulpizio, R., De Rosa, R., y Donato, P. (2008). The influence of variable topography on the depositional behaviour of pyroclastic density currents: The examples of the Upper Pollara eruption (Salina Island, southern Italy). Journal of Volcanology and Geothermal Research, 175(3):367-385. ISSN 0377-0273.

Sulpizio, R. y Dellino, P. (2008). Sedimentology, Depositional Mechanisms and Pulsating Behaviour of Pyroclastic Density Currents. En Gottsmann, J. y Martí, J., editores, Caldera Volcanism: Analysis, Modelling and Response, pág. 57-96. Elsevier.

Takada, A. (1994). The influence of regional stress and magmatic input on styles of monogenetic and polygenetic volcanism. Journal of Geophysical Research, 99(B7):13563-13573.

Tepley III, F. J., Davidson, J. P., y Clynne, M. A. (1999). Magmatic interactions as recorded in plagioclase phenocrysts of Chaos Crag, Lassen Volcanic Center, California. Journal of Petrology, 40(5):787-806.

Thompson, R. N. (1984). Dispatches from the basalt front. 1. Experiments. Proceedings of the Geologists' Association, 95:249-262.

Tormey, D. R., Hickey-Vargas, R., Frey, F. A., y López-Escobar, L. (1991). Recent lavas from the Andean volcanic front (33 to $42^{\circ} \mathrm{S}$ ); Interpretations of along-arc compositional variations. En Harmon, R. S. y Rapela, C. W., editores, Andean magmatism and its tectonic setting, pág. 57-77. Geological Society of America Special Paper 265, Boulder, Colorado.

Trua, T., Deniel, C., y Mazzuoli, R. (1999). Crustal control in the genesis of Plio-Quaternary bimodal magmatism of the Main Ethiopian Rift (MER): geochemical and isotopic ( $\mathrm{Sr}, \mathrm{Nd}$, $\mathrm{Pb}$ ) evidence. Chemical Geology, 155:201-231.

Tsuchiyama, A. (1985). Dissolution kinetics of plagioclase in the melt of the system diopsidealbite-anorthite, and origin of dusty plagioclase in andesites. Contributions to Mineralogy and Petrology, 89:1-16. 
Varela, R., Roverano, D., y Sato, A. M. (2000). Granito El Peñón, Sierra de Umango: descripción, edad $\mathrm{Rb} / \mathrm{Sr}$ e implicancias geotectónica. Revista de la Asociación Geológica Argentina, 55(4):407-413.

Vergniolle, S. y Mangan, M. (2000). Hawaiian and Strombolian Eruptions. En Sigurdsson, H., editor, Encyclopedia of Volcanoes, pág. 447-461. Academic Press, California.

Vernon, R. H. (2004). A Practical Guide To Rock Microstructure. Cambridge University Press, 606 pág. ISBN-10: 0521891337.

Violante, R., Osella, A., de la Vega, M., Rovere, E., y Osterrieth, M. (2010). Paleoenvironmental reconstruction in the western lacustrine plain of Llancanelo Lake, Mendoza, Argentina. Journal of South American Earth Sciences, 29:650-664.

Wagner, L. S., Beck, S., y Zandt, G. (2005). Upper mantle structure in the south central Chilean subduction zone ( $30^{\circ}$ to $36^{\circ}$ S). Journal of Geophysical Research, 110:B01308.

Walter, T. R. y Troll, V. R. (2001). Formation of caldera periphery faults: an experimental study. Bulletin of Volcanology, 63(2-3):191-203.

Wessel, P. y Smith, W. H. F. (1995). New Version of the Generic Mapping Tools Released. http://www . agu.org/eos_elec. American Geophysical Union.

White, R. A. (1996). Precursory Deep Long-Period Earthquakes at Mount Pinatubo: SpatioTemporal Link to a Basalt Trigger. En Newhall, C. G. y Punongbayan, R. S., editores, Fire and Mud: Eruptions and Lahars of Mount Pinatubo, Philippines. U.S. Geological Survey.

Winter, J. D. (2010). An introduction to igneous and metamorphic petrology. Pearson Prentice Hall, 699 pág. ISBN-10: 0132403420.

Woods, A. W., Bursik, M. I., y Kurbatov, A. V. (1998). The interaction of ash flows with ridges. Bulletin of Volcanology, 60:38-51. 10.1007/s004450050215.

Xia, L.-Q., Xu, X.-Y., Xia, Z.-C., Li, X.-M., Ma, Z.-P., y Wang, L.-S. (2004). Petrogenesis of Carboniferous rift-related volcanic rocks in the Tianshan, northwestern China. Geological Society of America Bulletin, 116(3/4):419-433.

Yoder, H. S. y Tilley, C. E. (1962). Origin of basalt magmas: an experimental study of natural and synthetic rock systems. Journal of Petrology, 3:342-532.

Yuan, X., Asch, G., Bataille, K. Bock, G., y Bohm, N. (2006). Deep seismic images of the Southern Andes. Número 407 en Geological Society of America Special Paper, capítulo 3, pág. 61-72. Colorado. 
Zapata, T. y Folguera, A. (2005). Tectonic evolution of the Andean Fold and Thrust Belt of the southern Neuquén Basin, Argentina. En Veiga, G. D., Spaletti, L. A., Howell, J. A., y Schwarz, E., editores, The Neuquén Basin, Argentina: A case study in sequence stratigraphy and basin dynamics, pág. 37-56. Geological Society, London, Special Publications 252.

Zellmer, G. F., Sparks, R. S. J., Hawkesworth, C. J., y Wiedenbeck, M. (2003). Magma emplacement and remobilization timescales beneath Montserrat: Insights from $\mathrm{Sr}$ and $\mathrm{Ba}$ zonation in plagioclase phenocrysts. Jounal of Petrology, 44:1413-1431.

Zindler, A. y Hart, S. (1986). Chemical Geodynamics. Annual Review of Earth and Planetary Sciences, 14:493-571.

Zou, H., Zindler, A., Xu, X., y Qi, Q. (2000). Major, trace element, and Nd, Sr and Pb isotope studies of Cenozoic basalts in SE China: mantle sources, regional variations, and tectonic significance. Chemical Geology, 171:33-47. 
Anexo I:

Mapa geológico del CVPM 


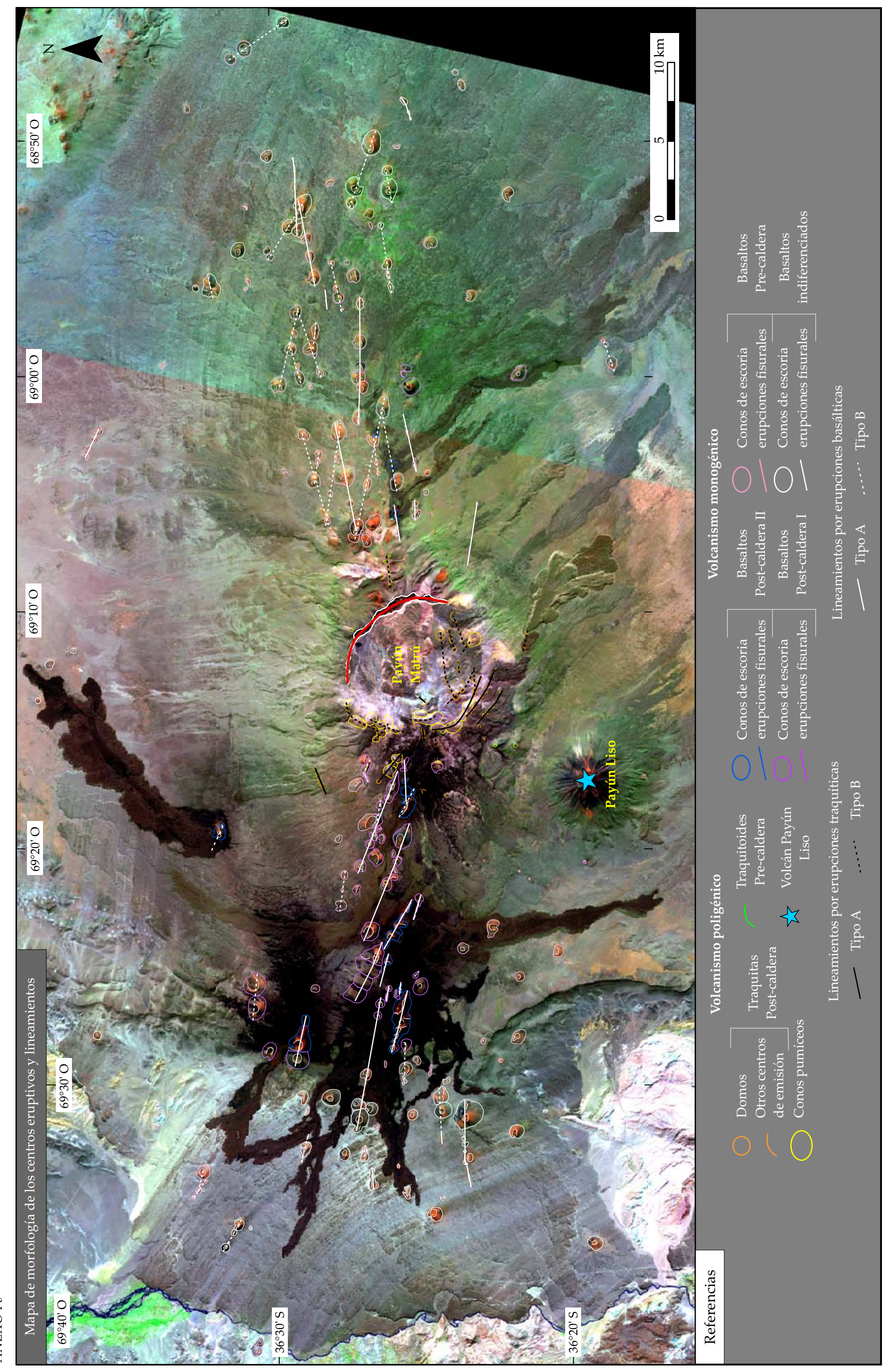


Anexo II:

Análisis químicos de roca total 


\begin{tabular}{|c|c|c|c|c|c|c|c|}
\hline Unidad & Muestra & $S$ & $\mathrm{O}$ & Unidad & Muestra & $S$ & $\mathrm{O}$ \\
\hline \multirow[t]{5}{*}{$\mathrm{T} \mathrm{v}$} & PM 38 & $36^{\circ} 24^{\prime} 40.3^{\prime \prime}$ & $69^{\circ} 14^{\prime} 59.4^{\prime \prime}$ & \multirow[t]{12}{*}{ T pre } & PMD-2 & - & - \\
\hline & STA 24 & $36^{\circ} 23^{\prime} 19.0^{\prime \prime}$ & $69^{\circ} 17^{\prime} 49.9^{\prime \prime}$ & & PY 1 & $36^{\circ} 21^{\prime} 56.0^{\prime \prime}$ & $69^{\circ} 08^{\prime} 10.1^{\prime \prime}$ \\
\hline & PMA 6 & $36^{\circ} 22^{\prime} 36,18^{\prime \prime}$ & $69^{\circ} 14^{\prime} 16,14^{\prime \prime}$ & & PY 10 & $36^{\circ} 24^{\prime} 37.5^{\prime \prime}$ & $69^{\circ} 06^{\prime} 36.0^{\prime \prime}$ \\
\hline & PMA 27-A & $36^{\circ} 25^{\prime} 41,28^{\prime \prime}$ & $69^{\circ} 09^{\prime} 36,54^{\prime \prime}$ & & STA 46-C & $36^{\circ} 28^{\prime} 22.7^{\prime \prime}$ & $69^{\circ} 16^{\prime} 20.4^{\prime \prime}$ \\
\hline & PMC 49 & $36^{\circ} 27^{\prime} 25,56^{\prime \prime}$ & $69^{\circ} 13^{\prime} 59,16^{\prime \prime}$ & & PMA 64 & $36^{\circ} 22^{\prime} 59,82^{\prime \prime}$ & $69^{\circ} 10^{\prime} 38,64^{\prime \prime}$ \\
\hline \multirow[t]{5}{*}{$\mathrm{T} \mathrm{bq}$} & PM 40 & $36^{\circ} 23^{\prime} 38.5^{\prime \prime}$ & $69^{\circ} 13^{\prime} 13.3^{\prime \prime}$ & & PMA 67 & $36^{\circ} 23^{\prime} 22,26^{\prime \prime}$ & $69^{\circ} 10^{\prime} 23,04 "$ \\
\hline & PM 47 & $36^{\circ} 26^{\prime} 27.3^{\prime \prime}$ & $69^{\circ} 22^{\prime} 57.5^{\prime \prime}$ & & PMA 70 & $36^{\circ} 22^{\prime} 22,5^{\prime \prime}$ & $69^{\circ} 11^{\prime} 15^{\prime \prime}$ \\
\hline & STA 25 & $36^{\circ} 18^{\prime} 32.8^{\prime \prime}$ & $69^{\circ} 17^{\prime} 52.7^{\prime \prime}$ & & PMA 74 & $36^{\circ} 23^{\prime} 43,92^{\prime \prime}$ & $69^{\circ} 10^{\prime} 6,48^{\prime \prime}$ \\
\hline & STA 37 & $36^{\circ} 27^{\prime} 55.2^{\prime \prime}$ & $69^{\circ} 18^{\prime} 29.5^{\prime \prime}$ & & PMA 76 & $36^{\circ} 23^{\prime} 55,86^{\prime \prime}$ & $69^{\circ} 10^{\prime} 1,02^{\prime \prime}$ \\
\hline & PMC 30 & $36^{\circ} 28^{\prime} 33,54^{\prime \prime}$ & $69^{\circ} 10^{\prime} 52,8^{\prime \prime}$ & & PMB 48 & $36^{\circ} 22^{\prime} 07,02^{\prime \prime}$ & $69^{\circ} 19^{\prime} 45,54^{\prime \prime}$ \\
\hline \multirow[t]{7}{*}{ TA pos } & PM 13 & $36^{\circ} 22^{\prime} 49.2^{\prime \prime}$ & $69^{\circ} 11^{\prime} 53.8^{\prime \prime}$ & & PMD 53 & $36^{\circ} 23^{\prime} 23,28^{\prime \prime}$ & $69^{\circ} 10^{\prime} 07,56^{\prime \prime}$ \\
\hline & PM 19 & $36^{\circ} 22^{\prime} 40.4^{\prime \prime}$ & $69^{\circ} 13^{\prime} 16.3^{\prime \prime}$ & & PMD 60 & $36^{\circ} 24^{\prime} 17,4^{\prime \prime}$ & $69^{\circ} 09^{\prime} 41,58^{\prime \prime}$ \\
\hline & PM 34 & $36^{\circ} 23^{\prime} 25.1^{\prime \prime}$ & $69^{\circ} 13^{\prime} 01.5^{\prime \prime}$ & \multirow[t]{5}{*}{ B posII } & PM 9 & $36^{\circ} 24^{\prime} 16.7^{\prime \prime}$ & $69^{\circ} 06^{\prime} 56.9^{\prime \prime}$ \\
\hline & STA 6-B & $36^{\circ} 20^{\prime} 00.1^{\prime \prime}$ & $69^{\circ} 18^{\prime} 42.6^{\prime \prime}$ & & PM 45 & $36^{\circ} 18^{\prime} 08,52^{\prime \prime}$ & $69^{\circ} 19^{\prime} 53,04^{\prime \prime}$ \\
\hline & STA 38 & $36^{\circ} 28^{\prime} 00.1^{\prime \prime}$ & $69^{\circ} 17^{\prime} 44.7^{\prime \prime}$ & & PM 46 & $36^{\circ} 20^{\prime} 16.2^{\prime \prime}$ & $69^{\circ} 23^{\prime} 44.0^{\prime \prime}$ \\
\hline & PMC 20 & $36^{\circ} 28^{\prime} 50,46^{\prime \prime}$ & $69^{\circ} 12^{\prime} 03,78^{\prime \prime}$ & & PY 13 & $36^{\circ} 23^{\prime} 44.9^{\prime \prime}$ & $69^{\circ} 03^{\prime} 29.6^{\prime \prime}$ \\
\hline & PMD 48 & $36^{\circ} 31^{\prime} 53,46^{\prime \prime}$ & $69^{\circ} 04^{\prime} 01,14^{\prime \prime}$ & & PY 14 & $36^{\circ} 23^{\prime} 26.2^{\prime \prime}$ & $69^{\circ} 02^{\prime} 33.7^{\prime \prime}$ \\
\hline \multirow[t]{7}{*}{$\operatorname{Ig} P$} & PM 14 & $36^{\circ} 22^{\prime} 30^{\prime \prime}$ & $69^{\circ} 11^{\prime} 49,44^{\prime \prime}$ & \multirow[t]{4}{*}{ B posI } & STA 16 & $36^{\circ} 23^{\prime} 07.8^{\prime \prime}$ & $69^{\circ} 21^{\prime} 00.6^{\prime \prime}$ \\
\hline & PM 24 & $36^{\circ} 22^{\prime} 51.2^{\prime \prime}$ & $69^{\circ} 09^{\prime} 37.4^{\prime \prime}$ & & STA 26 & $36^{\circ} 18^{\prime} 40.4^{\prime \prime}$ & $69^{\circ} 17^{\prime} 14.8^{\prime \prime}$ \\
\hline & PM 26 & $36^{\circ} 22^{\prime} 55.8^{\prime \prime}$ & $69^{\circ} 09^{\prime} 00.4^{\prime \prime}$ & & PMC 104 & $36^{\circ} 22^{\prime} 45,9^{\prime \prime}$ & $69^{\circ} 18^{\prime} 17,52^{\prime \prime}$ \\
\hline & PM 43 & $36^{\circ} 22^{\prime} 30.4^{\prime \prime}$ & $69^{\circ} 11^{\prime} 47.1^{\prime \prime}$ & & PMC 137 & $36^{\circ} 25^{\prime} 47,4^{\prime \prime}$ & $69^{\circ} 25^{\prime} 44,16^{\prime \prime}$ \\
\hline & PMB 4 & $36^{\circ} 22^{\prime} 30,96^{\prime \prime}$ & $69^{\circ} 11^{\prime} 49,44^{\prime \prime}$ & \multirow[t]{4}{*}{ B pre } & PY 5 & $36^{\circ} 18^{\prime} 09.2^{\prime \prime}$ & $69^{\circ} 04^{\prime} 41.5^{\prime \prime}$ \\
\hline & PMC 116-A & $36^{\circ} 21^{\prime} 19,26^{\prime \prime}$ & $69^{\circ} 20^{\prime} 08,76^{\prime \prime}$ & & PY 15 & $36^{\circ} 23^{\prime} 13.6^{\prime \prime}$ & $69^{\circ} 02^{\prime} 29.3^{\prime \prime}$ \\
\hline & PMB 44 & $36^{\circ} 23^{\prime} 13,56^{\prime \prime}$ & $69^{\circ} 18^{\prime} 35,34^{\prime \prime}$ & & STA 3 & $36^{\circ} 19^{\prime} 25.3^{\prime \prime}$ & $69^{\circ} 18^{\prime} 01.6^{\prime \prime}$ \\
\hline \multirow[t]{6}{*}{ T pre } & PM 15 & $36^{\circ} 22^{\prime} 34.5^{\prime \prime}$ & $69^{\circ} 11^{\prime} 53.8^{\prime \prime}$ & & STA 8 & $36^{\circ} 20^{\prime} 04.6^{\prime \prime}$ & $69^{\circ} 19^{\prime} 28.3^{\prime \prime}$ \\
\hline & PM 25 & $36^{\circ} 22^{\prime} 55.8^{\prime \prime}$ & $69^{\circ} 09^{\prime} 00.4^{\prime \prime}$ & \multirow[t]{3}{*}{ PL } & STA 50 & $36^{\circ} 29^{\prime} 35.5^{\prime \prime}$ & $69^{\circ} 16^{\prime} 30.2^{\prime \prime}$ \\
\hline & PM 27 & $36^{\circ} 22^{\prime} 50.9^{\prime \prime}$ & $69^{\circ} 10^{\prime} 59.5^{\prime \prime}$ & & STA 52 & $36^{\circ} 29^{\prime} 31.0^{\prime \prime}$ & $69^{\circ} 16^{\prime} 52.8^{\prime \prime}$ \\
\hline & PM 28 & $36^{\circ} 22^{\prime} 01.9^{\prime \prime}$ & $69^{\circ} 10^{\prime} 48.9^{\prime \prime}$ & & PMC56 & $36^{\circ} 29^{\prime} 11,7^{\prime \prime}$ & $69^{\circ} 17^{\prime} 43,2^{\prime \prime}$ \\
\hline & PM 31 & - & - & Basamento & STA 59-B & $36^{\circ} 27^{\prime} 15.7^{\prime \prime}$ & $69^{\circ} 20^{\prime} 34.8^{\prime \prime}$ \\
\hline & PM 44 & $36^{\circ} 22^{\prime} 26.2^{\prime \prime}$ & $69^{\circ} 12^{\prime} 04.3^{\prime \prime}$ & volcánico & STA 64-A & $36^{\circ} 27^{\prime} 22.9^{\prime \prime}$ & $69^{\circ} 20^{\prime} 45.2^{\prime \prime}$ \\
\hline
\end{tabular}

Tabla II.1: Ubicación de las muestras con análisis geoquímicos, isotópicos, de química mineral y con dataciones radimétricas. $\mathrm{T}$ v: Traquitas vítreas; $\mathrm{T}$ bq: Traquitas en bloque; TA pos: Traquiandesitas Post-caldera; Ig P: Ignimbrita Portezuelo; T pre: Traquitoides Pre-caldera; B posII: Basaltos Post-caldera II; B posI: Basaltos Post-caldera I; B pre: Basaltos Pre-caldera; PL: volcán Payún Liso indiferenciado. 


\begin{tabular}{lcccccccc}
\hline Unidad & \multicolumn{7}{c}{ Traquitas Post-caldera } \\
\hline Litofacies & \multicolumn{7}{c}{ Traquitas vítreas } & \multicolumn{3}{c}{ Traquitas en bloque } \\
\hline Muestra & PM-38 & STA 24 & PMA 6 PMA 27-A & PMC 49 & PM-40 & PM-47 & STA 25 \\
$\%$ & & & & & & & \\
$\mathrm{SiO}_{2}$ & 68,75 & 67,83 & 67,61 & 68,18 & 67,81 & 67,24 & 68,25 & 66,45 \\
$\mathrm{Al}_{2} \mathbf{O}_{3}$ & 14,93 & 15,26 & 15,58 & 15,65 & 14,9 & 15,63 & 14,87 & 15,59 \\
$\mathbf{F e}_{2} \mathbf{O}_{3}(\mathbf{T})$ & 2,89 & 2,94 & 3,02 & 3,1 & 2,97 & 2,95 & 3,05 & 2,89 \\
$\mathbf{M n O}$ & 0,113 & 0,124 & 0,125 & 0,128 & 0,122 & 0,108 & 0,13 & 0,12 \\
$\mathbf{M g O}$ & 0,26 & 0,28 & 0,31 & 0,32 & 0,27 & 0,32 & 0,35 & 0,29 \\
$\mathbf{C a O}$ & 0,63 & 0,64 & 0,7 & 0,7 & 0,64 & 0,71 & 0,76 & 0,7 \\
$\mathbf{N a}_{2} \mathbf{O}$ & 5,61 & 5,55 & 5,61 & 5,64 & 5,54 & 6,13 & 5,83 & 5,46 \\
$\mathbf{K}_{2} \mathbf{O}$ & 5,12 & 5,41 & 5,4 & 5,44 & 5,61 & 5,25 & 5,36 & 5,57 \\
$\mathrm{TiO}_{2}$ & 0,376 & 0,385 & 0,423 & 0,428 & 0,383 & 0,447 & 0,426 & 0,399 \\
$\mathbf{P}_{2} \mathbf{O}_{5}$ & 0,05 & 0,06 & 0,09 & 0,09 & 0,05 & 0,08 & 0,07 & 0,08 \\
$\mathbf{L O I}$ & 0,93 & 0,43 & 0,43 & 0,38 & 1,18 & 0,32 & 0,52 & 1,39 \\
Total & 99,67 & 98,92 & 99,29 & 100,1 & 99,48 & 99,18 & 99,61 & 98,94
\end{tabular}

\begin{tabular}{|c|c|c|c|c|c|c|c|c|}
\hline ppm & & & & & & & & \\
\hline $\mathrm{Sc}$ & 3 & 3 & 3 & 3 & 3 & 4 & 4 & 4 \\
\hline $\mathrm{Be}$ & 12 & 12 & 10 & 10 & 13 & 8 & 11 & 10 \\
\hline $\mathbf{V}$ & $<5$ & $<5$ & $<5$ & $<5$ & $<5$ & 5 & 5 & $<5$ \\
\hline $\mathrm{Ba}$ & 41 & 27 & 43 & 42 & 26 & 201 & 110 & 55 \\
\hline $\mathrm{Sr}$ & 11 & 6 & 9 & 8 & 4 & 33 & 33 & 14 \\
\hline$Y$ & 46,1 & 48 & 45 & 45 & 46 & 40,5 & 46,3 & 43 \\
\hline $\mathrm{Zr}$ & 717 & 829 & 897 & 898 & 791 & 851 & 783 & 846 \\
\hline $\mathrm{Cr}$ & $<20$ & $<20$ & $<20$ & $<20$ & $<20$ & $<20$ & $<20$ & $<20$ \\
\hline Co & 10 & 11 & 9 & 8 & 6 & 5 & 12 & 7 \\
\hline $\mathbf{N i}$ & $<20$ & $<20$ & $<20$ & $<20$ & $<20$ & $<20$ & $<20$ & $<20$ \\
\hline $\mathrm{Cu}$ & $<10$ & $<10$ & 80 & $<10$ & $<10$ & 20 & $<10$ & $<10$ \\
\hline $\mathrm{Zn}$ & 40 & 90 & 160 & 100 & 80 & 50 & $<30$ & 80 \\
\hline $\mathrm{Ga}$ & 20 & 26 & 23 & 22 & 27 & 23 & 23 & 25 \\
\hline $\mathrm{Ge}$ & 1,5 & 2 & 3 & 3 & 2 & 1,6 & 1,6 & 2 \\
\hline As & 10 & 11 & 18 & 15 & 10 & 5 & $<5$ & 13 \\
\hline $\mathbf{R b}$ & 235 & 258 & 201 & 196 & 277 & 187 & 225 & 232 \\
\hline $\mathrm{Nb}$ & 92,2 & 109 & 95 & 94 & 125 & 78,9 & 91,8 & 99 \\
\hline Mo & 13 & 19 & 13 & 14 & 17 & 5 & 7 & 15 \\
\hline
\end{tabular}

Tabla II.2: Análisis químicos de roca total. 


\begin{tabular}{|c|c|c|c|c|c|c|c|c|}
\hline \multirow{4}{*}{$\begin{array}{l}\text { Unidad } \\
\text { Litofacies } \\
\text { Muestra } \\
\text { ppm }\end{array}$} & \multicolumn{8}{|c|}{ Traquitas Post-caldera } \\
\hline & \multicolumn{5}{|c|}{ Traquitas vítreas } & \multicolumn{3}{|c|}{ Traquitas en bloque } \\
\hline & PM-38 & STA 24 & PMA 6 & PMA 27-A & PMC 49 & PM-40 & PM-47 & STA 25 \\
\hline & & & & & & & & \\
\hline Ag & $<0.5$ & 1,9 & 0,7 & 0,9 & 1,9 & $<0.5$ & $<0.5$ & 1,2 \\
\hline In & $<0.1$ & $<0.2$ & 0,2 & $<0.2$ & $<0.2$ & $<0.1$ & $<0.1$ & $<0.2$ \\
\hline Sn & 6 & 8 & 8 & 7 & 8 & 5 & 3 & 5 \\
\hline $\mathrm{Sb}$ & 0,8 & 3,5 & 9,2 & 7,1 & 1,4 & 0,5 & 0,4 & 6 \\
\hline Cs & 13,8 & 15,3 & 12,7 & 11,8 & 17 & 7,8 & 3,9 & 13,4 \\
\hline La & 57,4 & 72,2 & 62,5 & 61,3 & 62,1 & 52,1 & 65,1 & 67,6 \\
\hline $\mathrm{Ce}$ & 108 & 141 & 122 & 121 & 123 & 96 & 119 & 133 \\
\hline $\operatorname{Pr}$ & 11,3 & 12,8 & 10,5 & 10,6 & 13,1 & 9,97 & 12,5 & 11,9 \\
\hline $\mathbf{N d}$ & 38 & 42,6 & 35,4 & 36,6 & 45,2 & 34,5 & 43 & 38,5 \\
\hline Sm & 6,83 & 8,4 & 7,7 & 7,4 & 8,4 & 6,39 & 7,48 & 7,7 \\
\hline Eu & 0,268 & 0,31 & 0,62 & 0,61 & 0,31 & 0,646 & 0,45 & 0,42 \\
\hline $\mathrm{Gd}$ & 6,18 & 7,4 & 6,8 & 6,7 & 6,9 & 5,72 & 6,74 & 6,5 \\
\hline $\mathbf{T b}$ & 1,11 & 1,2 & 1,1 & 1,1 & 1,2 & 1 & 1,16 & 1,1 \\
\hline Dy & 6,89 & 7,6 & 6,7 & 6,6 & 7,6 & 6,15 & 7,06 & 6,8 \\
\hline Ho & 1,41 & 1,6 & 1,4 & 1,4 & 1,6 & 1,24 & 1,44 & 1,4 \\
\hline Er & 4,68 & 5,3 & 4,8 & 4,7 & 5,1 & 4,04 & 4,79 & 4,7 \\
\hline $\mathrm{Tm}$ & 0,84 & 0,89 & 0,8 & 0,79 & 0,85 & 0,711 & 0,863 & 0,77 \\
\hline $\mathbf{Y b}$ & 5,7 & 6,1 & 5,4 & 5,4 & 6,3 & 4,75 & 5,65 & 5,3 \\
\hline Lu & 0,809 & 0,93 & 0,86 & 0,87 & 1,09 & 0,712 & 0,821 & 0,83 \\
\hline Hf & 17,4 & 20,5 & 20,5 & 20,5 & 19,6 & 18,5 & 18,2 & 19,9 \\
\hline Ta & 8,7 & 9,5 & 8,2 & 8 & 8,9 & 6,52 & 8,74 & 8 \\
\hline $\mathbf{W}$ & 150 & 136 & 132 & 111 & 114 & 72,5 & 144 & 79 \\
\hline $\mathrm{Tl}$ & 0,79 & 1,9 & 2 & 1,6 & 0,3 & 0,11 & 0,07 & 0,3 \\
\hline $\mathrm{Pb}$ & 17 & 21 & 25 & 16 & 21 & 12 & 6 & 12 \\
\hline $\mathbf{B i}$ & 0,2 & $<0.4$ & 1,1 & 0,8 & $<0.4$ & $<0.1$ & 0,1 & $<0.4$ \\
\hline Th & 39,5 & 42,1 & 34,3 & 33,9 & 42,5 & 29,1 & 38,5 & 37,3 \\
\hline $\mathbf{U}$ & 11,8 & 11,9 & 9,2 & 9 & 12,5 & 7,64 & 7,5 & 10,1 \\
\hline
\end{tabular}

Tabla II.2: continúa de la página anterior. 


\begin{tabular}{|c|c|c|c|c|c|c|c|c|c|}
\hline \multirow{2}{*}{$\begin{array}{l}\text { Unidad } \\
\text { Litofacies }\end{array}$} & \multicolumn{2}{|c|}{ Traquitas Post-caldera } & \multicolumn{7}{|c|}{ Traquiandesitas Post-caldera } \\
\hline & \multicolumn{2}{|c|}{ Traquitas en bloque } & & & & & & & \\
\hline Muestra & STA 37 & PMC 30 & PM-13 & PM-19 & PM-34 & STA 6-B & STA 38 & PMC 20 & PMD 48 \\
\hline \multicolumn{10}{|l|}{$\%$} \\
\hline $\mathrm{SiO}_{2}$ & 66,48 & 67,61 & 60,08 & 53,77 & 54,43 & 58,39 & 52,75 & 55,61 & 54,22 \\
\hline $\mathrm{Al}_{2} \mathrm{O}_{3}$ & 15,49 & 16,03 & 17,41 & 17,62 & 17,53 & 18,04 & 17,63 & 17,36 & 17,65 \\
\hline $\mathrm{Fe}_{2} \mathrm{O}_{3}(\mathrm{~T})$ & 3,04 & 3,04 & 5,69 & 8,55 & 8,44 & 6,12 & 8,9 & 7,8 & 8,05 \\
\hline $\mathrm{MnO}$ & 0,116 & 0,116 & 0,131 & 0,143 & 0,141 & 0,14 & 0,154 & 0,149 & 0,15 \\
\hline $\mathrm{MgO}$ & 0,38 & 0,35 & 1,4 & 3,48 & 3,41 & 1,81 & 3,38 & 3,18 & 2,54 \\
\hline $\mathrm{CaO}$ & 0,89 & 0,79 & 3,19 & 6,76 & 6,47 & 4,15 & 6,86 & 6,05 & 6,63 \\
\hline $\mathrm{Na}_{2} \mathrm{O}$ & 5,56 & 6,05 & 5,81 & 4,67 & 4,66 & 5,34 & 4,52 & 4,99 & 4,97 \\
\hline $\mathrm{K}_{2} \mathrm{O}$ & 5,58 & 5,49 & 3,94 & 2,56 & 2,58 & 3,76 & 2,51 & 3,09 & 2,79 \\
\hline $\mathrm{TiO}_{2}$ & 0,457 & 0,468 & 1,27 & 1,701 & 1,705 & 1,312 & 1,874 & 1,536 & 1,839 \\
\hline $\mathbf{P}_{2} \mathrm{O}_{5}$ & 0,1 & 0,09 & 0,41 & 0,55 & 0,49 & 0,56 & 0,66 & 0,49 & 0,68 \\
\hline LOI & 0,55 & $-0,07$ & 0,31 & $<0.01$ & $<0.01$ & 0,42 & 0,38 & $-0,42$ & $-0,02$ \\
\hline Total & 98,66 & 99,96 & 99,63 & 99,57 & 99,83 & 100 & 99,62 & 99,81 & 99,49 \\
\hline \multicolumn{10}{|l|}{ ppm } \\
\hline Sc & 3 & 4 & 9 & 16 & 16 & 9 & 16 & 15 & 14 \\
\hline Be & 9 & 9 & 3 & 3 & 3 & 4 & 3 & 4 & 3 \\
\hline V & 20 & 5 & 51 & 159 & 154 & 77 & 171 & 144 & 151 \\
\hline Ba & 123 & 242 & 768 & 557 & 569 & 706 & 565 & 559 & 545 \\
\hline $\mathrm{Sr}$ & 41 & 41 & 423 & 680 & 671 & 502 & 694 & 537 & 641 \\
\hline $\mathbf{Y}$ & 45 & 40 & 25,6 & 30,3 & 23,6 & 27 & 30 & 30 & 31 \\
\hline $\mathrm{Zr}$ & 877 & 815 & 479 & 303 & 307 & 479 & 341 & 344 & 325 \\
\hline $\mathrm{Cr}$ & $<20$ & $<20$ & $<20$ & $<20$ & $<20$ & $<20$ & $<20$ & $<20$ & $<20$ \\
\hline Co & 8 & 5 & 14 & 29 & 22 & 11 & 26 & 23 & 23 \\
\hline $\mathrm{Ni}$ & $<20$ & $<20$ & $<20$ & 20 & 30 & $<20$ & 20 & $<20$ & $<20$ \\
\hline $\mathrm{Cu}$ & $<10$ & $<10$ & $<10$ & 30 & 20 & $<10$ & 30 & 20 & 20 \\
\hline $\mathrm{Zn}$ & 60 & 100 & 60 & 80 & 60 & 100 & 130 & 70 & 70 \\
\hline Ga & 24 & 22 & 25 & 23 & 20 & 23 & 23 & 23 & 24 \\
\hline Ge & 2 & 2 & 1,6 & 1,4 & 1,1 & 2 & 1 & 2 & 2 \\
\hline As & 10 & $<5$ & $<5$ & $<5$ & $<5$ & $<5$ & $<5$ & $<5$ & $<5$ \\
\hline $\mathbf{R b}$ & 230 & 195 & 93 & 61 & 55 & 89 & 70 & 79 & 67 \\
\hline $\mathrm{Nb}$ & 99 & 96 & 53,6 & 35,3 & 33,1 & 53 & 40 & 46 & 48 \\
\hline Mo & 10 & 7 & $<2$ & 2 & 3 & 2 & 3 & 3 & $<2$ \\
\hline
\end{tabular}

Tabla II.3: Análisis químicos de roca total. 


\begin{tabular}{|c|c|c|c|c|c|c|c|c|c|}
\hline \multirow{2}{*}{$\begin{array}{l}\text { Unidad } \\
\text { Litofacies }\end{array}$} & \multicolumn{2}{|c|}{ Traquitas Post-caldera } & \multicolumn{7}{|c|}{ Traquiandesitas Post-caldera } \\
\hline & \multicolumn{2}{|c|}{ Traquitas en bloque } & \multirow{3}{*}{ PM-13 } & \multirow{3}{*}{ PM-19 } & \multirow{3}{*}{ PM-34 } & \multirow{3}{*}{ STA 6-B } & \multirow{3}{*}{ STA 38} & \multirow{3}{*}{ PMC 20} & \multirow{3}{*}{ PMD 48} \\
\hline & STA 37 & PMC 30 & & & & & & & \\
\hline ppm & & & & & & & & & \\
\hline Ag & 0,7 & 3 & $<0.5$ & $<0.5$ & $<0.5$ & 0,9 & 0,7 & 0,8 & 0,8 \\
\hline In & $<0.2$ & $<0.2$ & $<0.1$ & $<0.1$ & $<0.1$ & $<0.2$ & $<0.2$ & $<0.2$ & $<0.2$ \\
\hline Sn & 5 & 6 & 3 & 2 & 2 & 3 & 2 & 3 & 3 \\
\hline $\mathrm{Sb}$ & 3,5 & $<0.5$ & $<0.2$ & $<0.2$ & $<0.2$ & 5,4 & 5,9 & $<0.5$ & $<0.5$ \\
\hline Cs & 11,9 & 9,8 & 0,9 & 1,6 & 1,7 & 0,9 & 2 & 3 & 0,9 \\
\hline $\mathrm{La}$ & 72,9 & 63,7 & 33,2 & 32,9 & 25,9 & 43,8 & 40,7 & 32,4 & 33,9 \\
\hline $\mathrm{Ce}$ & 141 & 122 & 72,3 & 63,9 & 52,7 & 91,3 & 85,5 & 67,8 & 72,2 \\
\hline Pr & 12,4 & 12 & 7,85 & 7,6 & 6,17 & 8,9 & 8,8 & 8,21 & 8,92 \\
\hline $\mathbf{N d}$ & 40,7 & 39,6 & 31,7 & 31,1 & 25,7 & 32,1 & 34,2 & 33,5 & 37,9 \\
\hline $\mathrm{Sm}$ & 8,1 & 7,4 & 6,39 & 6,51 & 5,32 & 7,3 & 7,9 & 7 & 8 \\
\hline $\mathbf{E u}$ & 0,55 & 0,77 & 2,13 & 2,07 & 1,8 & 2,27 & 2,38 & 2 & 2,33 \\
\hline Gd & 6,6 & 6 & 5,76 & 6,18 & 5,08 & 6,5 & 7,3 & 6,5 & 7,8 \\
\hline $\mathbf{T b}$ & 1,2 & 1 & 0,86 & 0,97 & 0,78 & 1 & 1,1 & 1 & 1,1 \\
\hline Dy & 7 & 6,4 & 4,78 & 5,21 & 4,39 & 5,2 & 5,8 & 5,5 & 6,3 \\
\hline Ho & 1,5 & 1,4 & 0,87 & 0,97 & 0,84 & 1 & 1,1 & 1,1 & 1,2 \\
\hline $\mathrm{Er}$ & 4,9 & 4,1 & 2,52 & 2,76 & 2,38 & 3 & 3,2 & 3,1 & 3,4 \\
\hline $\operatorname{Tm}$ & 0,82 & 0,74 & 0,382 & 0,396 & 0,343 & 0,44 & 0,47 & 0,46 & 0,49 \\
\hline $\mathbf{Y b}$ & 5,5 & 5,1 & 2,51 & 2,52 & 2,13 & 2,8 & 2,9 & 3 & 3,3 \\
\hline $\mathbf{L u}$ & 0,84 & 0,77 & 0,376 & 0,363 & 0,313 & 0,43 & 0,42 & 0,52 & 0,54 \\
\hline Hf & 19,9 & 18,2 & 10,8 & 7,1 & 6,8 & 10,6 & 8,1 & 8 & 7,9 \\
\hline $\mathrm{Ta}$ & 8,4 & 7,1 & 4,23 & 2,96 & 2,9 & 4 & 3,1 & 3,3 & 3,2 \\
\hline $\mathbf{W}$ & 88 & 101 & 73,9 & 89 & 98,8 & 43 & 73 & 96 & 103 \\
\hline $\mathrm{Tl}$ & 0,3 & 0,4 & 0,18 & 0,26 & 0,19 & 0,4 & 0,1 & 0,2 & 0,2 \\
\hline $\mathbf{P b}$ & 8 & 15 & 11 & 8 & 8 & 13 & 9 & 11 & 10 \\
\hline $\mathbf{B i}$ & $<0.4$ & $<0.4$ & $<0.1$ & 0,2 & 0,1 & $<0.4$ & $<0.4$ & $<0.4$ & $<0.4$ \\
\hline Th & 38,7 & 30 & 15,8 & 8,91 & 8,89 & 15,3 & 10,3 & 12,7 & 10,8 \\
\hline $\mathbf{U}$ & 9,6 & 9,1 & 3,03 & 2,5 & 2,23 & 3,2 & 2,9 & 3,5 & 1,5 \\
\hline
\end{tabular}

Tabla II.3: continúa de la página anterior. 


\begin{tabular}{|c|c|c|c|c|c|c|c|c|c|}
\hline \multirow{3}{*}{$\begin{array}{l}\text { Unidad } \\
\\
\text { Muestra } \\
\%\end{array}$} & \multicolumn{6}{|c|}{ Ignimbrita Portezuelo } & \multicolumn{3}{|c|}{ Traquitoides Pre-caldera } \\
\hline & \multicolumn{4}{|c|}{ roca total } & \multirow{2}{*}{$\begin{array}{c}\text { fiammes } \\
\text { PMB } 4\end{array}$} & \multirow{2}{*}{$\begin{array}{c}\text { spatter } \\
\text { PMC 116-A }\end{array}$} & \multirow[b]{2}{*}{ PM-15 } & \multirow[b]{2}{*}{ PM-25 } & \multirow[b]{2}{*}{ PM-27 } \\
\hline & PM-14 & PM-24 & PM-26 & PM-43 & & & & & \\
\hline $\mathrm{SiO}_{2}$ & 64,6 & 61,96 & 62,41 & 64,11 & 65,16 & 63,93 & 64,29 & 67,71 & 63,66 \\
\hline $\mathrm{Al}_{2} \mathrm{O}_{3}$ & 16,92 & 18,34 & 18,12 & 17,73 & 17,34 & 17,56 & 16,78 & 15,75 & 16,93 \\
\hline $\mathrm{Fe}_{2} \mathrm{O}_{3}(\mathrm{~T})$ & 3,4 & 3,71 & 3,56 & 3,6 & 3,38 & 3,53 & 3,89 & 3,34 & 3,95 \\
\hline $\mathrm{MnO}$ & 0,097 & 0,089 & 0,088 & 0,093 & 0,089 & 0,098 & 0,103 & 0,125 & 0,104 \\
\hline $\mathrm{MgO}$ & 0,57 & 0,82 & 0,75 & 0,68 & 0,61 & 0,58 & 0,85 & 0,28 & 0,93 \\
\hline $\mathrm{CaO}$ & 1,79 & 2,96 & 2,93 & 2,2 & 1,95 & 1,98 & 2,32 & 0,95 & 2,56 \\
\hline $\mathrm{Na}_{2} \mathrm{O}$ & 5,83 & 5,83 & 5,82 & 5,89 & 5,66 & 5,76 & 5,49 & 6,04 & 5,55 \\
\hline $\mathrm{K}_{2} \mathrm{O}$ & 4,98 & 4,02 & 4,01 & 4,56 & 4,96 & 5,27 & 4,46 & 4,94 & 4,21 \\
\hline $\mathrm{TiO}_{2}$ & 0,609 & 0,727 & 0,709 & 0,671 & 0,62 & 0,645 & 0,655 & 0,303 & 0,713 \\
\hline $\mathbf{P}_{2} \mathbf{O}_{5}$ & 0,15 & 0,16 & 0,16 & 0,07 & 0,17 & 0,18 & 0,24 & 0,12 & 0,24 \\
\hline LOI & 0,31 & 0,49 & 0,64 & 0,27 & 0,13 & 0,26 & 0,09 & 0,32 & 0,16 \\
\hline Total & 99,27 & 99,1 & 99,19 & 99,87 & 100,1 & 99,81 & 99,18 & 99,89 & 99,01 \\
\hline \multicolumn{10}{|l|}{ ppm } \\
\hline Sc & 5 & 5 & 4 & 4 & 4 & 4 & 5 & 5 & 4 \\
\hline Be & 6 & 5 & 5 & 6 & 6 & 7 & 6 & 6 & 6 \\
\hline $\mathbf{V}$ & 16 & 28 & 23 & 18 & 15 & 17 & 27 & $<5$ & 30 \\
\hline Ba & 624 & 698 & 698 & 652 & 599 & 625 & 585 & 506 & 607 \\
\hline $\mathrm{Sr}$ & 228 & 489 & 482 & 345 & 261 & 261 & 327 & 89 & 361 \\
\hline Y & 29,4 & 19,4 & 22,4 & 18,6 & 26 & 28 & 27 & 30,4 & 25,7 \\
\hline $\mathrm{Zr}$ & 569 & 441 & 435 & 516 & 565 & 576 & 516 & 467 & 480 \\
\hline $\mathrm{Cr}$ & $<20$ & $<20$ & $<20$ & $<20$ & $<20$ & $<20$ & $<20$ & $<20$ & $<20$ \\
\hline Co & 12 & 12 & 14 & 10 & 7 & 9 & 14 & 12 & 8 \\
\hline $\mathbf{N i}$ & $<20$ & $<20$ & 20 & $<20$ & $<20$ & $<20$ & $<20$ & $<20$ & $<20$ \\
\hline $\mathrm{Cu}$ & $<10$ & 20 & $<10$ & $<10$ & $<10$ & $<10$ & $<10$ & $<10$ & 20 \\
\hline $\mathrm{Zn}$ & 50 & 60 & 40 & $<30$ & 40 & 40 & 60 & 60 & $<30$ \\
\hline $\mathrm{Ga}$ & 23 & 22 & 24 & 21 & 23 & 24 & 21 & 22 & 17 \\
\hline $\mathrm{Ge}$ & 1,4 & 1,4 & 1,2 & 1,2 & 2 & 2 & 1,5 & 1,8 & 1,2 \\
\hline As & $<5$ & $<5$ & $<5$ & $<5$ & $<5$ & $<5$ & $<5$ & $<5$ & $<5$ \\
\hline $\mathbf{R b}$ & 160 & 103 & 122 & 134 & 169 & 161 & 140 & 144 & 116 \\
\hline $\mathrm{Nb}$ & 57,2 & 44,2 & 47,1 & 50,6 & 73 & 73 & 50,5 & 63,7 & 44,1 \\
\hline Mo & 9 & 5 & 6 & 4 & 6 & 7 & 5 & 2 & 5 \\
\hline
\end{tabular}

Tabla II.4: Análisis químicos de roca total. 


\begin{tabular}{|c|c|c|c|c|c|c|c|c|c|}
\hline \multirow{3}{*}{$\begin{array}{l}\text { Unidad } \\
\text { Muestra } \\
\text { ppm }\end{array}$} & \multicolumn{6}{|c|}{ Ignimbrita Portezuelo } & \multicolumn{3}{|c|}{ Traquitoides Pre-caldera } \\
\hline & \multicolumn{4}{|c|}{ roca total } & \multirow{2}{*}{$\begin{array}{c}\text { fiammes } \\
\text { PMB } 4\end{array}$} & \multirow{2}{*}{$\frac{\text { spatter }}{\text { PMC 116-A }}$} & \multirow[b]{2}{*}{ PM-15 } & \multirow[b]{2}{*}{ PM-25 } & \multirow[b]{2}{*}{ PM-27 } \\
\hline & PM-14 & PM-24 & PM-26 & PM-43 & & & & & \\
\hline Ag & $<0.5$ & $<0.5$ & $<0.5$ & $<0.5$ & 1,4 & 1,3 & $<0.5$ & $<0.5$ & $<0.5$ \\
\hline In & $<0.1$ & $<0.1$ & $<0.1$ & $<0.1$ & $<0.2$ & $<0.2$ & $<0.1$ & 0,2 & $<0.1$ \\
\hline Sn & 4 & 3 & 3 & 1 & 2 & 7 & 3 & 22 & 1 \\
\hline $\mathrm{Sb}$ & 0,3 & 0,2 & 0,2 & $<0.2$ & 0,7 & 0,6 & 0,2 & $<0.2$ & $<0.2$ \\
\hline Cs & 8,3 & 4,2 & 5,6 & 5 & 7,2 & 4,9 & 3,3 & 4,9 & 4,3 \\
\hline La & 37,4 & 26,2 & 28,7 & 19 & 35,9 & 37,2 & 39,1 & 53,5 & 37,7 \\
\hline $\mathrm{Ce}$ & 68,8 & 46,5 & 51 & 32,2 & 70,4 & 72,5 & 71,5 & 93,3 & 68,5 \\
\hline Pr & 7,32 & 5,02 & 5,47 & 3,31 & 7,85 & 7,98 & 7,62 & 9,13 & 7,47 \\
\hline $\mathrm{Nd}$ & 26,7 & 18,7 & 20 & 12,3 & 28,8 & 29 & 27 & 31 & 27,2 \\
\hline $\mathrm{Sm}$ & 4,87 & 3,47 & 3,68 & 2,41 & 5,7 & 5,6 & 5,07 & 5,38 & 5,04 \\
\hline Eu & 1,27 & 1,5 & 1,53 & 1,24 & 1,31 & 1,3 & 1,3 & 0,634 & 1,28 \\
\hline Gd & 4,59 & 3,24 & 3,41 & 2,35 & 4,8 & 5 & 4,61 & 4,69 & 4,42 \\
\hline $\mathrm{Tb}$ & 0,76 & 0,56 & 0,59 & 0,44 & 0,8 & 0,8 & 0,75 & 0,8 & 0,73 \\
\hline Dy & 4,48 & 3,25 & 3,37 & 2,73 & 4,6 & 4,8 & 4,42 & 4,83 & 4,34 \\
\hline Ho & 0,91 & 0,64 & 0,66 & 0,57 & 0,9 & 1 & 0,86 & 0,95 & 0,84 \\
\hline Er & 2,88 & 2,03 & 2,12 & 1,92 & 2,9 & 3 & 2,73 & 3 & 2,61 \\
\hline $\mathrm{Tm}$ & 0,481 & 0,329 & 0,353 & 0,342 & 0,47 & 0,48 & 0,444 & 0,507 & 0,428 \\
\hline $\mathbf{Y b}$ & 3,23 & 2,3 & 2,44 & 2,45 & 3,4 & 3,5 & 3 & 3,46 & 2,9 \\
\hline $\mathbf{L u}$ & 0,468 & 0,359 & 0,365 & 0,372 & 0,57 & 0,62 & 0,459 & 0,497 & 0,451 \\
\hline Hf & 12,8 & 9,9 & 10 & 11,1 & 12,8 & 13,2 & 11,6 & 10,5 & 10,6 \\
\hline Ta & 5,28 & 4 & 4,15 & 4,68 & 5,2 & 5,3 & 4,87 & 5,96 & 4,39 \\
\hline $\mathbf{W}$ & 132 & 99,5 & 107 & 100 & 91 & 112 & 108 & 105 & 66,3 \\
\hline $\mathrm{Tl}$ & 0,53 & 1,47 & 0,28 & 0,06 & 0,1 & 0,2 & 0,42 & 0,16 & 0,07 \\
\hline $\mathbf{P b}$ & 14 & 42 & 9 & 7 & 14 & 16 & 37 & 10 & 5 \\
\hline $\mathbf{B i}$ & $<0.1$ & 0,2 & $<0.1$ & $<0.1$ & $<0.4$ & $<0.4$ & $<0.1$ & $<0.1$ & $<0.1$ \\
\hline Th & 23,8 & 17,5 & 17,7 & 19,4 & 25,4 & 25,8 & 21,4 & 19 & 19,5 \\
\hline $\mathbf{U}$ & 7,11 & 4,65 & 5,3 & 5,95 & 7,6 & 7,4 & 6,29 & 4,93 & 5,87 \\
\hline
\end{tabular}

Tabla II.4: continúa de la página anterior. 


\begin{tabular}{lccccccccc}
\hline Unidad & \multicolumn{7}{c}{ Traquitoides Pre-caldera } \\
\hline Muestra & PM-28 & PM-31 & PM-44 & PMD-2 & PY 1 & PY 10 & STA 46-C & PMA 64 & PMA 67 \\
\hline$\%$ & & & & & & & & & \\
$\mathrm{SiO}_{2}$ & 63,03 & 56,54 & 57,82 & 62,57 & 66,6 & 59,96 & 60,92 & 60,3 & 63,99 \\
$\mathrm{Al}_{2} \mathbf{O}_{3}$ & 17,17 & 16,92 & 17,08 & 16,95 & 16,07 & 17,73 & 17,57 & 17,94 & 17,19 \\
$\mathrm{Fe}_{2} \mathbf{O}_{3}(\mathrm{~T})$ & 4,5 & 7,8 & 7,09 & 4,39 & 3,24 & 5,24 & 5,31 & 5,27 & 4,11 \\
$\mathbf{M n O}$ & 0,123 & 0,152 & 0,134 & 0,1 & 0,129 & 0,142 & 0,166 & 0,143 & 0,129 \\
$\mathbf{M g O}$ & 1,07 & 1,58 & 2,25 & 0,43 & 0,27 & 1,36 & 1,01 & 1,13 & 0,53 \\
$\mathbf{C a O}$ & 2,81 & 3,42 & 4,88 & 1,73 & 0,94 & 3,36 & 2,62 & 2,72 & 1,61 \\
$\mathbf{N a} \mathbf{O}_{2} \mathbf{O}$ & 5,55 & 5,69 & 5,04 & 5,81 & 6 & 5,44 & 5,72 & 5,95 & 5,81 \\
$\mathbf{K}_{2} \mathbf{O}$ & 4,04 & 4,54 & 3,03 & 4,87 & 5,02 & 3,73 & 3,49 & 4,69 & 5,04 \\
$\mathrm{TiO}_{2}$ & 0,771 & 1,555 & 1,222 & 0,767 & 0,292 & 0,891 & 0,686 & 0,943 & 0,575 \\
$\mathbf{P}_{2} \mathbf{O}_{5}$ & 0,29 & 0,69 & 0,44 & 0,18 & 0,14 & 0,48 & 0,42 & 0,42 & 0,19 \\
$\mathbf{L O I}$ & 0,36 & 0,5 & 0,51 & 0,99 & 0,36 & 0,55 & 0,72 & 0,05 & 0,27 \\
Total & 99,73 & 99,38 & 99,5 & 98,79 & 99,05 & 98,89 & 98,64 & 99,55 & 99,44
\end{tabular}

\begin{tabular}{|c|c|c|c|c|c|c|c|c|c|}
\hline $\mathrm{Sc}$ & 4 & 9 & 8 & 6 & 4 & 6 & 3 & 5 & 7 \\
\hline Be & 5 & 7 & 4 & 5 & 6 & 4 & 4 & 6 & 5 \\
\hline V & 35 & 43 & 89 & 19 & 6 & 39 & $<5$ & 28 & 13 \\
\hline $\mathrm{Ba}$ & 614 & 678 & 576 & 749 & 509 & 631 & 1065 & 674 & 872 \\
\hline $\mathrm{Sr}$ & 394 & 380 & 599 & 250 & 89 & 487 & 502 & 358 & 167 \\
\hline $\mathbf{Y}$ & 28,1 & 48 & 24,7 & 26,9 & 32 & 25 & 26 & 30 & 34 \\
\hline $\mathrm{Zr}$ & 483 & 716 & 363 & 515 & 581 & 418 & 395 & 681 & 586 \\
\hline $\mathrm{Cr}$ & $<20$ & $<20$ & $<20$ & $<20$ & $<20$ & $<20$ & $<20$ & $<20$ & $<20$ \\
\hline Co & 13 & 16 & 16 & 8 & 5 & 9 & 9 & 8 & 8 \\
\hline $\mathbf{N i}$ & $<20$ & 20 & $<20$ & $<20$ & $<20$ & $<20$ & $<20$ & $<20$ & $<20$ \\
\hline $\mathrm{Cu}$ & 10 & 30 & $<10$ & $<10$ & $<10$ & 20 & $<10$ & $<10$ & $<10$ \\
\hline $\mathrm{Zn}$ & 50 & 70 & 60 & 120 & 80 & 110 & 110 & 120 & 130 \\
\hline $\mathrm{Ga}$ & 21 & 24 & 20 & 22 & 25 & 19 & 22 & 20 & 21 \\
\hline $\mathrm{Ge}$ & 1,4 & 1,2 & 1,2 & 1,2 & 2 & 2 & 2 & 3 & 3 \\
\hline As & $<5$ & $<5$ & $<5$ & $<5$ & $<5$ & 6 & $<5$ & 10 & 7 \\
\hline $\mathbf{R b}$ & 128 & 157 & 83 & 147 & 168 & 77 & 85 & 133 & 127 \\
\hline $\mathrm{Nb}$ & 48,1 & 86,6 & 37,4 & 60,3 & 75 & 48 & 47 & 74 & 58 \\
\hline Mo & 6 & 7 & 4 & 4 & 4 & $<2$ & 5 & 4 & 2 \\
\hline
\end{tabular}

Tabla II.5: Análisis químicos de roca total. 


\begin{tabular}{|c|c|c|c|c|c|c|c|c|c|}
\hline \multirow{2}{*}{$\begin{array}{l}\text { Unidad } \\
\text { Muestra }\end{array}$} & \multicolumn{9}{|c|}{ Traquitoides Pre-caldera } \\
\hline & PM-28 & PM-31 & PM-44 & PMD-2 & PY 1 & PY 10 & STA 46-C & PMA 64 & PMA 67 \\
\hline \multicolumn{10}{|l|}{ ppm } \\
\hline Ag & $<0.5$ & $<0.5$ & $<0.5$ & $<0.5$ & $<0.5$ & 1,1 & 0,5 & 0,8 & 0,8 \\
\hline In & $<0.1$ & $<0.1$ & $<0.1$ & $<0.1$ & $<0.2$ & $<0.2$ & $<0.2$ & $<0.2$ & $<0.2$ \\
\hline Sn & 3 & 5 & 2 & 3 & 2 & 2 & 2 & 4 & 2 \\
\hline $\mathrm{Sb}$ & 0,2 & 0,3 & $<0.2$ & $<0.2$ & 8,9 & 9,2 & 4,4 & 10,2 & 8,6 \\
\hline Cs & 3,4 & 8,7 & 2,3 & 2,4 & 3,7 & 2,3 & 2,8 & 6,3 & 3,9 \\
\hline La & 38,5 & 59,7 & 30,7 & 33,8 & 59 & 40,3 & 56,5 & 47,5 & 49,7 \\
\hline $\mathrm{Ce}$ & 70,9 & 112 & 59,1 & 60,7 & 108 & 79,9 & 106 & 89,6 & 92,3 \\
\hline Pr & 7,66 & 12,6 & 6,88 & 6,52 & 9,2 & 7,13 & 9,88 & 8,09 & 8,3 \\
\hline $\mathrm{Nd}$ & 28,5 & 48,9 & 27 & 24 & 31,4 & 27 & 33,8 & 29,6 & 30,9 \\
\hline Sm & 5,3 & 9,36 & 5,24 & 4,62 & 5,8 & 5,9 & 6,7 & 6,3 & 6,9 \\
\hline $\mathbf{E u}$ & 1,4 & 2,2 & 1,74 & 1,46 & 0,73 & 1,76 & 2,07 & 1,67 & 1,64 \\
\hline Gd & 4,86 & 8,75 & 5 & 4,12 & 4,7 & 5,2 & 5,7 & 5,9 & 6 \\
\hline $\mathrm{Tb}$ & 0,75 & 1,42 & 0,81 & 0,7 & 0,8 & 0,8 & 0,9 & 0,9 & 0,9 \\
\hline Dy & 4,47 & 7,97 & 4,35 & 4,23 & 5,1 & 4,4 & 4,8 & 4,7 & 5,5 \\
\hline Ho & 0,87 & 1,54 & 0,84 & 0,87 & 1,1 & 0,9 & 1 & 0,9 & 1,1 \\
\hline Er & 2,73 & 4,6 & 2,49 & 2,73 & 3,4 & 2,6 & 2,9 & 3 & 3,5 \\
\hline $\mathrm{Tm}$ & 0,437 & 0,713 & 0,389 & 0,452 & 0,54 & 0,42 & 0,45 & 0,49 & 0,56 \\
\hline $\mathbf{Y b}$ & 2,97 & 4,69 & 2,54 & 3,11 & 3,7 & 2,9 & 2,8 & 3,5 & 3,9 \\
\hline Lu & 0,439 & 0,674 & 0,363 & 0,471 & 0,68 & 0,44 & 0,42 & 0,57 & 0,64 \\
\hline Hf & 10,9 & 15,4 & 8,3 & 11,7 & 11,5 & 9,7 & 9 & 13,9 & 12,5 \\
\hline Ta & 4,66 & 7,04 & 3,51 & 5,22 & 6,3 & 4,4 & 3,6 & 6 & 4,9 \\
\hline $\mathbf{W}$ & 110 & 103 & 89,3 & 64 & 21 & 55 & 73 & 56 & 73 \\
\hline $\mathrm{Tl}$ & 0,36 & 0,22 & 0,18 & 0,1 & 0,2 & 0,7 & 0,3 & 0,8 & 0,5 \\
\hline $\mathbf{P b}$ & 17 & 16 & 10 & 18 & 15 & 16 & 16 & 15 & 18 \\
\hline $\mathrm{Bi}$ & $<0.1$ & $<0.1$ & $<0.1$ & $<0.1$ & $<0.4$ & 0,5 & $<0.4$ & 0,7 & 0,6 \\
\hline Th & 19,5 & 27,1 & 13,7 & 20,5 & 22,2 & 16 & 9,9 & 20,2 & 17,4 \\
\hline $\mathbf{U}$ & 5,77 & 7,27 & 4,01 & 4,82 & 6,1 & 2,9 & 2,5 & 5,5 & 4,8 \\
\hline
\end{tabular}

Tabla II.5: continúa de la página anterior. 


\begin{tabular}{|c|c|c|c|c|c|c|c|c|}
\hline \multirow{2}{*}{$\begin{array}{l}\text { Unidad } \\
\text { Muestra }\end{array}$} & \multicolumn{5}{|c|}{ Traquitoides Pre-caldera } & \multicolumn{3}{|c|}{ Basaltos Post-caldera II } \\
\hline & PMA 70 & PMA 74 & PMA 76 & PMB 48 & PMD 53 & PM-9 & PM-45 & PM-46 \\
\hline \multicolumn{9}{|l|}{$\%$} \\
\hline $\mathrm{SiO}_{2}$ & 61,41 & 52,44 & 67,26 & 57,35 & 56,03 & 49,69 & 49,04 & 49,13 \\
\hline $\mathrm{Al}_{2} \mathrm{O}_{3}$ & 17,46 & 17,56 & 15,58 & 17,76 & 17,27 & 17,41 & 16,92 & 16,61 \\
\hline $\mathrm{Fe}_{2} \mathrm{O}_{3}(\mathrm{~T})$ & 5,84 & 9,01 & 3,85 & 6,35 & 7,56 & 10,5 & 10,71 & 10,17 \\
\hline $\mathrm{MnO}$ & 0,15 & 0,153 & 0,168 & 0,164 & 0,163 & 0,157 & 0,155 & 0,153 \\
\hline $\mathrm{MgO}$ & 1,15 & 2,54 & 0,12 & 1,82 & 1,59 & 4,45 & 6,44 & 5,72 \\
\hline $\mathrm{CaO}$ & 2,78 & 6,25 & 0,63 & 4,16 & 3,58 & 8,71 & 9,11 & 9,3 \\
\hline $\mathrm{Na}_{2} \mathrm{O}$ & 5,5 & 4,29 & 6,33 & 5,86 & 5,91 & 4,15 & 3,72 & 3,74 \\
\hline $\mathrm{K}_{2} \mathrm{O}$ & 3,66 & 3,19 & 4,92 & 3,8 & 4,26 & 1,83 & 1,49 & 1,56 \\
\hline $\mathrm{TiO}_{2}$ & 0,702 & 1,921 & 0,202 & 1,346 & 1,592 & 2,058 & 1,864 & 1,975 \\
\hline $\mathbf{P}_{2} \mathbf{O}_{5}$ & 0,47 & 0,8 & 0,04 & 0,61 & 0,75 & 0,56 & 0,49 & 0,43 \\
\hline LOI & $-0,09$ & 1,93 & 0,17 & 0,34 & 0,95 & $<0.01$ & $<0.01$ & 0,02 \\
\hline Total & 99,04 & 100,1 & 99,27 & 99,56 & 99,65 & 99,41 & 99,78 & 98,81 \\
\hline \multicolumn{9}{|l|}{ ppm } \\
\hline Sc & 3 & 13 & 4 & 7 & 9 & 20 & 24 & 26 \\
\hline Be & 4 & 5 & 10 & 3 & 9 & 2 & 2 & 2 \\
\hline V & 17 & 161 & $<5$ & 42 & 48 & 211 & 222 & 243 \\
\hline Ba & 1015 & 588 & 27 & 906 & 670 & 451 & 381 & 397 \\
\hline $\mathrm{Sr}$ & 572 & 657 & 5 & 608 & 401 & 801 & 688 & 640 \\
\hline Y & 22 & 34 & 61 & 28 & 47 & 25,9 & 24,1 & 24,6 \\
\hline $\mathrm{Zr}$ & 421 & 315 & 1081 & 370 & 666 & 197 & 181 & 175 \\
\hline $\mathrm{Cr}$ & $<20$ & $<20$ & $<20$ & $<20$ & $<20$ & 90 & 110 & 80 \\
\hline Co & 9 & 17 & 5 & 11 & 15 & 40 & 36 & 29 \\
\hline $\mathrm{Ni}$ & $<20$ & $<20$ & $<20$ & $<20$ & $<20$ & 60 & 80 & 50 \\
\hline $\mathrm{Cu}$ & $<10$ & 50 & $<10$ & $<10$ & 40 & 30 & 30 & 30 \\
\hline Zn & 130 & 150 & 160 & 70 & 80 & 90 & 70 & 60 \\
\hline Ga & 19 & 20 & 26 & 23 & 26 & 23 & 19 & 20 \\
\hline Ge & 2 & 3 & 3 & 2 & 2 & 1,4 & 1,3 & 1 \\
\hline As & 7 & 15 & 18 & $<5$ & 7 & $<5$ & $<5$ & $<5$ \\
\hline $\mathbf{R b}$ & 83 & 94 & 214 & 82 & 230 & 33 & 29 & 26 \\
\hline $\mathrm{Nb}$ & 48 & 45 & 101 & 57 & 119 & 26,3 & 20,6 & 19,5 \\
\hline Mo & $<2$ & 3 & $<2$ & 4 & 9 & 3 & $<2$ & $<2$ \\
\hline
\end{tabular}

Tabla II.6: Análisis químicos de roca total. 


\begin{tabular}{|c|c|c|c|c|c|c|c|c|}
\hline \multirow{2}{*}{$\frac{\text { Unidad }}{\text { Muestra }}$} & \multicolumn{5}{|c|}{ Traquitoides Pre-caldera } & \multicolumn{3}{|c|}{ Basaltos Post-caldera II } \\
\hline & PMA 70 & PMA 74 & PMA 76 & PMB 48 & PMD 53 & PM-9 & PM-45 & PM-46 \\
\hline \multicolumn{9}{|l|}{ ppm } \\
\hline Ag & 1,3 & 0,9 & 0,8 & 0,9 & 1,7 & $<0.5$ & $<0.5$ & $<0.5$ \\
\hline In & $<0.2$ & $<0.2$ & 0,2 & $<0.2$ & $<0.2$ & $<0.1$ & $<0.1$ & $<0.1$ \\
\hline Sn & 3 & 3 & 7 & 3 & 7 & 2 & 2 & 1 \\
\hline $\mathrm{Sb}$ & 5,3 & 9,6 & 6,9 & 1 & 1,5 & $<0.2$ & $<0.2$ & $<0.2$ \\
\hline Cs & 1,6 & 3,9 & 6,6 & 2,4 & 13,1 & 1,1 & 1,2 & 1 \\
\hline La & 46,4 & 42,2 & 85,3 & 41,5 & 61,9 & 23,6 & 20,4 & 20 \\
\hline $\mathrm{Ce}$ & 85,9 & 84,3 & 158 & 81,9 & 122 & 48,6 & 41,8 & 41,9 \\
\hline Pr & 7,81 & 8,36 & 14,1 & 9,56 & 14 & 5,91 & 5,27 & 5,24 \\
\hline $\mathrm{Nd}$ & 28,1 & 33,1 & 49,8 & 37,4 & 54,2 & 26,5 & 22,6 & 23,3 \\
\hline $\mathrm{Sm}$ & 5,8 & 7,8 & 10,1 & 7,5 & 10,8 & 5,68 & 4,89 & 5,23 \\
\hline Eu & 1,77 & 2,25 & 0,42 & 2,34 & 2,33 & 2,02 & 1,78 & 1,84 \\
\hline $\mathrm{Gd}$ & 4,9 & 7,4 & 9 & 6,5 & 10,1 & 5,72 & 5,04 & 5,19 \\
\hline $\mathrm{Tb}$ & 0,7 & 1,1 & 1,5 & 1 & 1,5 & 0,85 & 0,79 & 0,85 \\
\hline Dy & 4 & 5,9 & 8,8 & 5,3 & 8,9 & 4,61 & 4,34 & 4,57 \\
\hline Ho & 0,8 & 1,2 & 1,9 & 1 & 1,7 & 0,86 & 0,8 & 0,86 \\
\hline Er & 2,4 & 3,4 & 5,9 & 2,9 & 5 & 2,37 & 2,28 & 2,35 \\
\hline $\mathrm{Tm}$ & 0,38 & 0,52 & 0,96 & 0,43 & 0,77 & 0,33 & 0,328 & 0,323 \\
\hline $\mathbf{Y b}$ & 2,6 & 3,4 & 6,6 & 2,9 & 5,2 & 2,03 & 1,96 & 1,99 \\
\hline Lu & 0,4 & 0,51 & 1,03 & 0,48 & 0,89 & 0,288 & 0,277 & 0,287 \\
\hline Hf & 9 & 8,3 & 22,8 & 7,9 & 15,6 & 4,7 & 4,3 & 4,3 \\
\hline Ta & 3,9 & 3,8 & 8,3 & 3,8 & 7,1 & 2,42 & 2 & 1,78 \\
\hline $\mathbf{W}$ & 54 & 41 & 68 & 86 & 78 & 111 & 123 & 85,6 \\
\hline $\mathrm{Tl}$ & 0,6 & 0,5 & 0,6 & 0,2 & 0,2 & 0,16 & 0,15 & 0,09 \\
\hline $\mathrm{Pb}$ & 9 & 12 & 25 & 10 & 16 & 6 & 5 & 5 \\
\hline $\mathbf{B i}$ & 0,6 & 0,5 & 0,6 & $<0.4$ & $<0.4$ & $<0.1$ & $<0.1$ & $<0.1$ \\
\hline Th & 10,7 & 15,4 & 32,8 & 8,6 & 27,2 & 3,46 & 3,73 & 3,2 \\
\hline $\mathrm{U}$ & 2,5 & 2,1 & 8,6 & 2,4 & 8,1 & 1,09 & 1,11 & 0,94 \\
\hline
\end{tabular}

Tabla II.6: continúa de la página anterior. 


\begin{tabular}{|c|c|c|c|c|c|c|c|c|}
\hline \multirow{2}{*}{$\begin{array}{l}\text { Unidad } \\
\text { Muestra }\end{array}$} & \multicolumn{2}{|c|}{ Basaltos Post-caldera II } & \multicolumn{4}{|c|}{ Basaltos Post-caldera I } & \multicolumn{2}{|c|}{ Basaltos Pre-caldera } \\
\hline & PY 13 & PY 14 & STA 16 & STA 26 & PMC 104 & PMC 137 & PY 5 & PY 15 \\
\hline \multicolumn{9}{|l|}{$\%$} \\
\hline $\mathrm{SiO}_{2}$ & 48,15 & 48,87 & 47,21 & 47,16 & 48,33 & 46,94 & 48,69 & 46,52 \\
\hline $\mathrm{Al}_{2} \mathrm{O}_{3}$ & 17,57 & 17,88 & 16,23 & 17,8 & 17,65 & 17,41 & 17,59 & 17,4 \\
\hline $\mathrm{Fe}_{2} \mathrm{O}_{3}(\mathrm{~T})$ & 10,74 & 10,86 & 12,46 & 11,26 & 11,01 & 10,78 & 11,18 & 12,17 \\
\hline $\mathrm{MnO}$ & 0,162 & 0,165 & 0,182 & 0,168 & 0,164 & 0,159 & 0,166 & 0,168 \\
\hline $\mathrm{MgO}$ & 4,64 & 4,71 & 6,27 & 5,13 & 4,62 & 6,76 & 5,03 & 5,89 \\
\hline $\mathrm{CaO}$ & 9,07 & 9,14 & 9,78 & 9,18 & 9,34 & 10,46 & 9,35 & 10,3 \\
\hline $\mathrm{Na}_{2} \mathrm{O}$ & 4,13 & 4,08 & 3,57 & 4,14 & 4,11 & 3,56 & 3,9 & 3,37 \\
\hline $\mathrm{K}_{2} \mathrm{O}$ & 1,76 & 1,74 & 1,24 & 1,47 & 1,44 & 1,22 & 1,72 & 0,94 \\
\hline $\mathrm{TiO}_{2}$ & 2,073 & 2,118 & 2,307 & 2,271 & 2,28 & 2,062 & 2,4 & 2,358 \\
\hline $\mathbf{P}_{2} \mathrm{O}_{5}$ & 0,68 & 0,67 & 0,53 & 0,73 & 0,61 & 0,52 & 0,59 & 0,51 \\
\hline LOI & $-0,48$ & $-0,27$ & $-0,57$ & $-0,3$ & $-0,12$ & $-0,43$ & 0,33 & 0,19 \\
\hline Total & 98,5 & 99,97 & 99,22 & 99 & 99,45 & 99,44 & 100,9 & 99,8 \\
\hline \multicolumn{9}{|l|}{$p p m$} \\
\hline Sc & 20 & 20 & 27 & 21 & 23 & 27 & 22 & 25 \\
\hline $\mathrm{Be}$ & 3 & 3 & 2 & 2 & 2 & 1 & 2 & 2 \\
\hline $\mathbf{V}$ & 229 & 230 & 285 & 254 & 269 & 263 & 255 & 288 \\
\hline $\mathrm{Ba}$ & 434 & 439 & 314 & 441 & 358 & 339 & 386 & 327 \\
\hline $\mathrm{Sr}$ & 837 & 857 & 633 & 869 & 769 & 724 & 751 & 757 \\
\hline $\mathbf{Y}$ & 26 & 26 & 26 & 26 & 25 & 23 & 27 & 24 \\
\hline $\mathrm{Zr}$ & 207 & 209 & 179 & 191 & 188 & 159 & 197 & 131 \\
\hline $\mathrm{Cr}$ & 30 & 30 & 90 & 30 & 30 & 70 & 30 & 40 \\
\hline Co & 25 & 29 & 44 & 37 & 42 & 48 & 34 & 31 \\
\hline $\mathrm{Ni}$ & $<20$ & $<20$ & 50 & 30 & $<20$ & 30 & 20 & $<20$ \\
\hline $\mathrm{Cu}$ & 30 & 30 & 50 & 130 & 30 & 30 & 30 & 40 \\
\hline $\mathrm{Zn}$ & 140 & 130 & 140 & 120 & 80 & 80 & 130 & 150 \\
\hline $\mathrm{Ga}$ & 19 & 20 & 21 & 23 & 23 & 23 & 21 & 19 \\
\hline $\mathrm{Ge}$ & 2 & 2 & 2 & 1 & 2 & 2 & 1 & 3 \\
\hline As & $<5$ & 5 & $<5$ & $<5$ & $<5$ & $<5$ & $<5$ & 6 \\
\hline $\mathbf{R b}$ & 27 & 26 & 20 & 33 & 20 & 22 & 27 & 14 \\
\hline $\mathrm{Nb}$ & 27 & 27 & 19 & 26 & 27 & 24 & 27 & 16 \\
\hline Mo & $<2$ & $<2$ & 2 & 3 & $<2$ & $<2$ & $<2$ & $<2$ \\
\hline
\end{tabular}

Tabla II.7: Análisis químicos de roca total. 


\begin{tabular}{|c|c|c|c|c|c|c|c|c|}
\hline \multirow{2}{*}{$\begin{array}{l}\text { Unidad } \\
\text { Muestra } \\
\text { ppm }\end{array}$} & \multicolumn{2}{|c|}{ Basaltos Post-caldera II } & \multicolumn{4}{|c|}{ Basaltos Post-caldera I } & \multicolumn{2}{|c|}{ Basaltos Pre-caldera } \\
\hline & PY 13 & PY 14 & STA 16 & STA 26 & PMC 104 & PMC 137 & PY 5 & PY 15 \\
\hline Ag & 0,8 & 0,7 & $<0.5$ & $<0.5$ & $<0.5$ & $<0.5$ & $<0.5$ & 0,8 \\
\hline In & $<0.2$ & $<0.2$ & $<0.2$ & $<0.2$ & $<0.2$ & $<0.2$ & $<0.2$ & $<0.2$ \\
\hline Sn & 2 & 2 & 2 & 1 & 2 & 2 & 2 & 3 \\
\hline $\mathrm{Sb}$ & 8,9 & 4,8 & 2 & $<0.5$ & $<0.5$ & $<0.5$ & 6,5 & 8,4 \\
\hline Cs & 1,1 & 1 & 0,8 & 7,4 & 0,6 & 0,8 & 0,9 & 0,7 \\
\hline La & 26,8 & 27,1 & 24,4 & 31,1 & 21,6 & 19,6 & 26,7 & 18,1 \\
\hline $\mathrm{Ce}$ & 57,9 & 57,9 & 51,8 & 63,1 & 49,3 & 43,6 & 56,5 & 41 \\
\hline $\operatorname{Pr}$ & 6,05 & 6,08 & 6,46 & 7,67 & 6,46 & 5,71 & 5,99 & 4,61 \\
\hline Nd & 25,7 & 26,2 & 27,7 & 30,2 & 29,5 & 25,9 & 24,4 & 21,7 \\
\hline $\mathrm{Sm}$ & 6,5 & 6,9 & 6,7 & 7,2 & 6,7 & 6,1 & 6,3 & 6 \\
\hline $\mathbf{E u}$ & 2,27 & 2,22 & 2,12 & 2,52 & 2,2 & 2,06 & 2,17 & 2,13 \\
\hline Gd & 6,4 & 6,5 & 6,4 & 6,7 & 6,8 & 6,3 & 6,1 & 6,2 \\
\hline $\mathbf{T b}$ & 0,9 & 0,9 & 0,9 & 1 & 1 & 0,9 & 0,9 & 0,9 \\
\hline Dy & 4,8 & 4,8 & 5 & 5,1 & 5,4 & 5 & 4,9 & 4,6 \\
\hline Ho & 0,9 & 0,9 & 0,9 & 0,9 & 1 & 0,9 & 0,9 & 0,9 \\
\hline Er & 2,7 & 2,8 & 2,7 & 2,7 & 2,7 & 2,5 & 2,7 & 2,6 \\
\hline $\mathrm{Tm}$ & 0,4 & 0,41 & 0,37 & 0,37 & 0,38 & 0,35 & 0,37 & 0,37 \\
\hline $\mathbf{Y b}$ & 2,5 & 2,6 & 2,2 & 2,3 & 2,4 & 2,2 & 2,2 & 2,4 \\
\hline $\mathbf{L u}$ & 0,35 & 0,36 & 0,33 & 0,34 & 0,39 & 0,36 & 0,3 & 0,36 \\
\hline Hf & 5,5 & 5,4 & 4 & 4,7 & 4,7 & 4 & 4,8 & 4,1 \\
\hline Ta & 2,2 & 2,5 & 1,7 & 2,2 & 2,3 & 1,8 & 2,1 & 1,4 \\
\hline $\mathbf{W}$ & 49 & 91 & 61 & 63 & 158 & 99 & 70 & 49 \\
\hline $\mathrm{Tl}$ & 0,4 & 0,5 & $<0.1$ & 0,2 & $<0.1$ & $<0.1$ & 0,3 & 0,4 \\
\hline $\mathrm{Pb}$ & $<5$ & $<5$ & 8 & 5 & $<5$ & $<5$ & $<5$ & $<5$ \\
\hline $\mathbf{B i}$ & 0,5 & 0,6 & $<0.4$ & $<0.4$ & 0,5 & $<0.4$ & $<0.4$ & 0,6 \\
\hline Th & 3,2 & 3,2 & 2,8 & 2,9 & 2,4 & 2,4 & 3,3 & 2,2 \\
\hline $\mathbf{U}$ & 1 & 1 & 0,8 & 0,8 & 0,7 & 0,8 & 1 & 0,7 \\
\hline
\end{tabular}

Tabla II.7: continúa de la página anterior. 


\begin{tabular}{|c|c|c|c|c|c|c|c|}
\hline \multirow{2}{*}{$\begin{array}{l}\text { Unidad } \\
\text { Muestra } \\
\%\end{array}$} & \multicolumn{2}{|c|}{ Basaltos Pre-caldera } & \multicolumn{3}{|c|}{ Payún Liso } & \multicolumn{2}{|c|}{ Basamento volcánico } \\
\hline & STA 3 & STA 8 & STA 50 & STA 52 & PMC 56 & STA 59-B & STA 64-A \\
\hline $\mathrm{SiO}_{2}$ & 47,18 & 47,22 & 51,88 & 62,1 & 63,06 & 63,78 & 63,68 \\
\hline $\mathrm{Al}_{3} \mathrm{O}_{3}$ & 16,45 & 17,31 & 16,93 & 17,18 & 16,58 & 16,9 & 16,98 \\
\hline $\mathrm{Fe}_{2} \mathrm{O} 3(\mathrm{~T})$ & 11,8 & 11,35 & 9,14 & 5,33 & 4,97 & 3,96 & 4,03 \\
\hline $\mathrm{MnO}$ & 0,164 & 0,17 & 0,166 & 0,155 & 0,152 & 0,095 & 0,081 \\
\hline $\mathrm{MgO}$ & 7,35 & 6,59 & 2,96 & 0,99 & 0,99 & 1,74 & 1,36 \\
\hline $\mathrm{CaO}$ & 11,05 & 11,06 & 7,23 & 2,36 & 2,33 & 4,25 & 4,26 \\
\hline $\mathrm{Na}_{2} \mathrm{O}$ & 3,22 & 3,37 & 4,43 & 5,77 & 5,99 & 4,4 & 4,87 \\
\hline $\mathrm{K}_{2} \mathrm{O}$ & 0,89 & 1,06 & 2,65 & 3,99 & 4,19 & 2,64 & 2,52 \\
\hline $\mathrm{TiO}_{2}$ & 2,085 & 1,774 & 2,054 & 0,972 & 0,903 & 0,525 & 0,533 \\
\hline $\mathrm{P}_{2} \mathrm{O}_{5}$ & 0,35 & 0,43 & 0,95 & 0,37 & 0,33 & 0,24 & 0,24 \\
\hline LOI & 0,45 & $-0,08$ & 1,46 & 0,2 & 0,35 & 1,46 & 0,77 \\
\hline Total & 101 & 100,3 & 99,85 & 99,4 & 99,84 & 100 & 99,32 \\
\hline \multicolumn{8}{|l|}{ ppm } \\
\hline Sc & 29 & 29 & 12 & 6 & 7 & 6 & 6 \\
\hline Be & 2 & 2 & 3 & 4 & 4 & 2 & 2 \\
\hline $\mathbf{V}$ & 251 & 267 & 127 & 19 & 16 & 58 & 64 \\
\hline Ba & 237 & 345 & 586 & 954 & 942 & 831 & 853 \\
\hline Sr & 575 & 679 & 805 & 367 & 340 & 825 & 843 \\
\hline$Y$ & 22 & 21 & 34 & 35 & 33 & 13 & 13 \\
\hline $\mathrm{Zr}$ & 129 & 132 & 306 & 400 & 383 & 216 & 238 \\
\hline $\mathrm{Cr}$ & 180 & 80 & $<20$ & $<20$ & $<20$ & 30 & $<20$ \\
\hline Co & 47 & 44 & 22 & 7 & 9 & 17 & 14 \\
\hline $\mathrm{Ni}$ & 90 & 40 & $<20$ & $<20$ & $<20$ & 30 & $<20$ \\
\hline $\mathrm{Cu}$ & 60 & 50 & 30 & $<10$ & $<10$ & 20 & 10 \\
\hline $\mathrm{Zn}$ & 140 & 120 & 120 & 110 & 80 & 70 & 60 \\
\hline Ga & 20 & 21 & 20 & 23 & 25 & 19 & 19 \\
\hline Ge & 2 & 1 & 1 & 2 & 2 & 1 & 1 \\
\hline As & $<5$ & $<5$ & $<5$ & $<5$ & $<5$ & $<5$ & $<5$ \\
\hline $\mathbf{R b}$ & 12 & 21 & 51 & 82 & 90 & 92 & 88 \\
\hline $\mathrm{Nb}$ & 15 & 14 & 43 & 48 & 60 & 17 & 16 \\
\hline Mo & $<2$ & $<2$ & 3 & 3 & 2 & 5 & 3 \\
\hline
\end{tabular}

Tabla II.8: Análisis químicos de roca total. 


\begin{tabular}{|c|c|c|c|c|c|c|c|}
\hline \multirow{2}{*}{$\begin{array}{l}\text { Unidad } \\
\text { Muestra } \\
\text { ppm }\end{array}$} & \multicolumn{2}{|c|}{ Basaltos Pre-caldera } & \multicolumn{3}{|c|}{ Payún Liso } & \multicolumn{2}{|c|}{ Basamento volcánico } \\
\hline & STA 3 & STA 8 & STA 50 & STA 52 & PMC 56 & STA 59-B & STA 64-A \\
\hline Ag & $<0.5$ & $<0.5$ & $<0.5$ & $<0.5$ & 0,9 & $<0.5$ & $<0.5$ \\
\hline In & $<0.2$ & $<0.2$ & $<0.2$ & $<0.2$ & $<0.2$ & $<0.2$ & $<0.2$ \\
\hline Sn & 1 & 1 & 2 & 3 & 4 & 2 & $<1$ \\
\hline $\mathrm{Sb}$ & 3,4 & $<0.5$ & 3,7 & 9 & 1 & $>200$ & 18,7 \\
\hline Cs & $<0.5$ & 0,7 & 1,1 & $<0.5$ & 2,8 & 5,3 & 1,6 \\
\hline La & 14,8 & 21,2 & 47,2 & 58,1 & 49,4 & 37,3 & 35,3 \\
\hline $\mathrm{Ce}$ & 34,1 & 43,8 & 95,1 & 112 & 96,3 & 67,1 & 64,3 \\
\hline Pr & 3,88 & 5,4 & 10,4 & 10,7 & 10,9 & 6,25 & 5,84 \\
\hline Nd & 17,7 & 23 & 40,1 & 38 & 42 & 20,6 & 19,3 \\
\hline $\mathrm{Sm}$ & 4,9 & 5,6 & 9,2 & 8,2 & 8,1 & 4 & 3,7 \\
\hline Eu & 1,81 & 1,88 & 2,69 & 2,38 & 2,28 & 1,25 & 1,21 \\
\hline Gd & 5,1 & 5,2 & 8,3 & 7,3 & 7,1 & 3,4 & 3,1 \\
\hline $\mathrm{Tb}$ & 0,8 & 0,8 & 1,2 & 1,1 & 1,1 & 0,5 & 0,4 \\
\hline Dy & 4,3 & 4,2 & 6,6 & 6,2 & 6,2 & 2,4 & 2,3 \\
\hline Ho & 0,8 & 0,8 & 1,2 & 1,2 & 1,2 & 0,5 & 0,4 \\
\hline Er & 2,2 & 2,2 & 3,4 & 3,4 & 3,5 & 1,4 & 1,3 \\
\hline $\operatorname{Tm}$ & 0,32 & 0,31 & 0,48 & 0,52 & 0,52 & 0,21 & 0,19 \\
\hline $\mathbf{Y b}$ & 1,9 & 1,9 & 2,9 & 3,4 & 3,6 & 1,4 & 1,3 \\
\hline $\mathbf{L u}$ & 0,25 & 0,29 & 0,43 & 0,51 & 0,61 & 0,2 & 0,19 \\
\hline Hf & 3,3 & 3,3 & 6,8 & 9 & 8,8 & 5,3 & 5,3 \\
\hline Ta & 1,2 & 1,3 & 3,2 & 3,6 & 4 & 2 & 1,7 \\
\hline W & 54 & 50 & 59 & 46 & 119 & 104 & 76 \\
\hline $\mathrm{Tl}$ & $<0.1$ & $<0.1$ & 0,3 & 0,3 & $<0.1$ & 0,9 & 0,6 \\
\hline $\mathrm{Pb}$ & $<5$ & 300 & 7 & 12 & 10 & 13 & 11 \\
\hline $\mathrm{Bi}$ & $<0.4$ & $<0.4$ & $<0.4$ & $<0.4$ & $<0.4$ & 0,5 & $<0.4$ \\
\hline Th & 1,4 & 3,3 & 7,3 & 10,3 & 10,9 & 11,7 & 11,2 \\
\hline $\mathbf{U}$ & 0,4 & 0,9 & 2,2 & 2,2 & 2,7 & 3,3 & 3,2 \\
\hline
\end{tabular}

Tabla II.8: continúa de la página anterior. 


\section{Anexo III:}

\section{Análisis isotópicos de $\mathrm{Sr}$ y $\mathrm{Nd}$ en roca}

total

En la tabla que se muestra a continuación, los valores de ${ }^{87} \mathrm{Sr} /{ }^{86} \mathrm{Sr}$ situados en el extremo derecho de la tabla, son aquellos realizados en San Pablo, Brasil. Debido a que luego los análisis de la relación isotópica ${ }^{143} \mathrm{Nd} /{ }^{144} \mathrm{Nd}$ fueron realizados en Copenhagen, Dinamarca, y conjuntamente se realizó un análisis de los isótopos de $\mathrm{Sr}$, se utilizaron estos valores en el presente trabajo para una mayor coherencia. 


\begin{tabular}{|c|c|c|c|c|c|c|c|c|c|}
\hline Unidad/Litofacies & Muestra & ${ }^{87} \mathrm{Sr} /{ }^{86} \mathrm{Sr}$ & +/- ppm & $+/-$ abs & ${ }^{143} \mathrm{Nd} /{ }^{144} \mathrm{Nd}$ & +/- ppm & $+/-$ abs & ${ }^{87} \mathrm{Sr} /{ }^{86} \mathrm{Sr}$ & $+/-$ abs \\
\hline \multirow{2}{*}{$\begin{array}{c}\text { Traquitas } \\
\text { vítreas }\end{array}$} & STA 24 & 0,704666 & 10 & 0,000007 & 0,512770 & 14 & 0,000007 & 0,704402 & 0,000092 \\
\hline & PMA 6 & 0,704768 & 12 & 0,000008 & 0,512757 & 15 & 0,000008 & 0,704288 & 0,000027 \\
\hline \multirow{2}{*}{$\begin{array}{l}\text { Traquitas } \\
\text { en bloque }\end{array}$} & PM 40 & 0,704123 & 6 & 0,000004 & 0,512743 & 10 & 0,000005 & 0,704076 & 0,000035 \\
\hline & STA 25 & 0,704841 & 11 & 0,000008 & 0,512767 & 12 & 0,000006 & 0,704139 & 0,000031 \\
\hline \multirow{4}{*}{$\begin{array}{c}\text { Traquiandesitas } \\
\text { Post-caldera }\end{array}$} & PM 13 & 0,704029 & 7 & 0,000005 & 0,512767 & 10 & 0,000005 & 0,703985 & 0,000037 \\
\hline & PM 34 & 0,704082 & 5 & 0,000004 & 0,512766 & 14 & 0,000007 & 0,704021 & 0,000045 \\
\hline & STA 6-B & 0,704082 & 7 & 0,000005 & 0,512773 & 13 & 0,000007 & 0,703974 & 0,000036 \\
\hline & STA 38 & 0,704132 & 7 & 0,000005 & 0,512761 & 17 & 0,000009 & 0,703984 & 0,000037 \\
\hline \multirow{3}{*}{$\begin{array}{l}\text { Traquitas } \\
\text { Pre-caldera }\end{array}$} & PM 15 & 0,704079 & 6 & 0,000004 & 0,512769 & 12 & 0,000006 & 0,704024 & 0,000041 \\
\hline & PM 27 & 0,704087 & 8 & 0,000006 & 0,512761 & 14 & 0,000007 & 0,70397 & 0,000043 \\
\hline & PY 10 & 0,703855 & 7 & 0,000005 & 0,512807 & 15 & 0,000008 & 0,703802 & 0,000041 \\
\hline $\begin{array}{c}\text { Basaltos } \\
\text { Post-caldera II }\end{array}$ & PM 46 & 0,703924 & 7 & 0,000005 & 0,512746 & 13 & 0,000007 & 0,703865 & 0,000042 \\
\hline \multirow{3}{*}{$\begin{array}{c}\text { Basaltos } \\
\text { Pre-caldera }\end{array}$} & PY 5 & 0,703813 & 9 & 0,000006 & 0,512834 & 11 & 0,000006 & 0,703906 & 0,000035 \\
\hline & PY 15 & 0,703853 & 11 & 0,000008 & 0,512792 & 15 & 0,000008 & 0,703766 & 0,000031 \\
\hline & STA 8 & 0,703925 & 8 & 0,000006 & 0,512787 & 12 & 0,000006 & 0,703895 & 0,000042 \\
\hline Basamento & STA 59-B & & & & & & & 0,703848 & 0,000042 \\
\hline
\end{tabular}




\section{Anexo IV:}

\section{Análisis de la química mineral}

En primer lugar se muestran los análisis realizados sobre feldespatos alcalinos y plagioclasas, seguidos de olivina, piroxenos, anfíboles, biotita, y vidrio perteneciente a la base de la litofacies Traquitas vítreas, y de fiammes de la Ignimbrita Portezuelo. 


\section{Feldespatos}

\begin{tabular}{|c|c|c|c|c|c|c|c|c|c|}
\hline \multirow{4}{*}{$\begin{array}{l}\text { Litofacies } \\
\text { Muestra } \\
\text { Cristal } \\
\text { Punto }\end{array}$} & \multicolumn{6}{|c|}{ Traquitas vítreas } & \multicolumn{3}{|c|}{ Traquitas en bloque } \\
\hline & \multicolumn{6}{|c|}{ PMA 27-A } & \multicolumn{3}{|c|}{ PM 40} \\
\hline & \multicolumn{3}{|c|}{ Fk A } & \multicolumn{3}{|c|}{ Fk B } & \multicolumn{3}{|c|}{ Fk A } \\
\hline & 1 & 2 & 3 & 1 & 2 & 3 & 1 & 2 & 3 \\
\hline Ubicación & centro & medio & borde & centro & medio & borde & centro & medio & borde \\
\hline \multicolumn{10}{|l|}{$\%$} \\
\hline $\mathrm{SiO}_{2}$ & 66,385 & 67,054 & 66,273 & 66,588 & 64,861 & 66,104 & 65,769 & 66,215 & 66,084 \\
\hline $\mathrm{Al}_{2} \mathrm{O}_{3}$ & 19,848 & 19,818 & 19,901 & 19,839 & 19,932 & 19,664 & 19,687 & 19,683 & 19,558 \\
\hline $\mathrm{TiO}_{2}$ & 0,000 & 0,023 & 0,000 & 0,047 & 0,118 & 0,000 & 0,188 & 0,000 & 0,047 \\
\hline $\mathrm{Fe}_{2} \mathrm{O}_{3}$ & 0,163 & 0,260 & 0,353 & 0,288 & 0,243 & 0,146 & 0,194 & 0,411 & 0,304 \\
\hline $\mathrm{MnO}$ & 0,000 & 0,000 & 0,027 & 0,000 & 0,036 & 0,002 & 0,000 & 0,017 & 0,003 \\
\hline MgO & 0,005 & 0,006 & 0,005 & 0,000 & 0,000 & 0,000 & 0,000 & 0,012 & 0,000 \\
\hline $\mathrm{CaO}$ & 0,634 & 0,625 & 0,783 & 0,714 & 0,640 & 0,434 & 0,562 & 0,441 & 0,535 \\
\hline $\mathrm{Na}_{2} \mathrm{O}$ & 6,694 & 6,712 & 6,894 & 6,798 & 6,625 & 6,473 & 7,185 & 7,077 & 7,391 \\
\hline $\mathrm{K}_{2} \mathrm{O}$ & 6,799 & 6,978 & 6,695 & 6,631 & 6,710 & 7,255 & 6,227 & 6,399 & 5,605 \\
\hline $\mathrm{SrO}$ & 0,098 & 0,009 & 0,053 & 0,083 & 0,152 & 0,154 & 0,000 & 0,029 & 0,108 \\
\hline \multirow[t]{2}{*}{$\mathrm{BaO}$} & 0,000 & 0,022 & 0,027 & 0,072 & 0,101 & 0,012 & 0,118 & 0,075 & 0,101 \\
\hline & --- & --- & --- & --- & --- & --- & --- & --- & --- \\
\hline Total & 100,625 & 101,508 & 101,011 & 101,06 & 99,418 & 100,243 & 99,931 & 100,359 & 99,737 \\
\hline \multicolumn{10}{|c|}{$\mathrm{N}^{\circ}$ Cationes } \\
\hline Si & 11,8273 & 11,8469 & 11,7825 & 11,8178 & 11,7292 & 11,8440 & 11,7952 & 11,8252 & 11,8419 \\
\hline $\mathrm{Al}+3$ & 4,1676 & 4,1266 & 4,1700 & 4,1498 & 4,2480 & 4,1525 & 4,1611 & 4,1429 & 4,1306 \\
\hline $\mathrm{Ti}+4$ & 0,0000 & 0,0031 & 0,0000 & 0,0062 & 0,0160 & 0,0000 & 0,0254 & 0,0000 & 0,0063 \\
\hline $\mathrm{Fe}+3$ & 0,0219 & 0,0346 & 0,0472 & 0,0385 & 0,0331 & 0,0197 & 0,0262 & 0,0553 & 0,0410 \\
\hline Mn & 0,0000 & 0,0000 & 0,0040 & 0,0000 & 0,0056 & 0,0002 & 0,0000 & 0,0025 & 0,0005 \\
\hline Mg & 0,0012 & 0,0015 & 0,0014 & 0,0000 & 0,0000 & 0,0000 & 0,0000 & 0,0031 & 0,0000 \\
\hline $\mathrm{Ca}$ & 0,1210 & 0,1182 & 0,1491 & 0,1357 & 0,1239 & 0,0832 & 0,1080 & 0,0843 & 0,1028 \\
\hline $\mathrm{Na}$ & 2,3123 & 2,2994 & 2,3763 & 2,3390 & 2,3229 & 2,2488 & 2,4984 & 2,4503 & 2,5679 \\
\hline $\mathbf{K}$ & 1,5452 & 1,5727 & 1,5184 & 1,5014 & 1,5479 & 1,6582 & 1,4247 & 1,4579 & 1,2814 \\
\hline $\mathrm{Sr}$ & 0,0101 & 0,0010 & 0,0055 & 0,0086 & 0,0160 & 0,0160 & 0,0000 & 0,0030 & 0,0112 \\
\hline Ba & 0,0000 & 0,0015 & 0,0019 & 0,0050 & 0,0071 & 0,0009 & 0,0083 & 0,0053 & 0,0071 \\
\hline Total & 20,0067 & 20,0054 & 20,0563 & 20,0020 & 20,0497 & 20,0234 & 20,0474 & 20,0298 & 19,9906 \\
\hline An & 3,29 & 2,99 & 3,82 & 3,62 & 3,48 & 2,48 & 2,67 & 2,18 & 2,87 \\
\hline $\mathbf{A b}$ & 57,97 & 57,59 & 58,66 & 58,63 & 57,82 & 56,12 & 61,85 & 61,25 & 64,68 \\
\hline Or & 38,74 & 39,43 & 37,53 & 37,76 & 38,70 & 41,40 & 35,48 & 36,57 & 32,45 \\
\hline
\end{tabular}

Tabla IV.1: Análisis de la química mineral. 


\section{Feldespatos}

\begin{tabular}{|c|c|c|c|c|c|c|c|c|c|}
\hline Litofacies & \multicolumn{6}{|c|}{ Traquitas en bloque } & \multicolumn{3}{|c|}{ Traquiandesitas Post-caldera } \\
\hline Muestra & \multicolumn{6}{|c|}{ PM 40} & \multicolumn{3}{|c|}{ PM 34} \\
\hline Cristal & \multicolumn{3}{|c|}{ Fk B } & \multicolumn{3}{|c|}{ Fk C } & \multicolumn{3}{|c|}{$\mathrm{PlA}$} \\
\hline Punto & 1 & 2 & 3 & 1 & 2 & 3 & 1 & 2 & 3 \\
\hline Ubicación & centro & medio & borde & centro & medio & borde & centro & centro ext. & medio \\
\hline \multicolumn{10}{|l|}{$\%$} \\
\hline $\mathrm{SiO}_{2}$ & 65,620 & 66,433 & 65,227 & 64,844 & 65,346 & 65,536 & 52,128 & 49,433 & 52,383 \\
\hline $\mathrm{Al}_{2} \mathrm{O}_{3}$ & 19,631 & 19,919 & 19,653 & 18,933 & 19,286 & 19,670 & 30,982 & 32,359 & 30,381 \\
\hline $\mathrm{TiO}_{2}$ & 0,000 & 0,000 & 0,000 & 0,024 & 0,000 & 0,071 & 0,211 & 0,094 & 0,000 \\
\hline $\mathrm{Fe}_{2} \mathrm{O}_{3}$ & 0,230 & 0,371 & 0,361 & 0,171 & 0,320 & 0,273 & 0,487 & 0,494 & 0,309 \\
\hline $\mathrm{MnO}$ & 0,011 & 0,008 & 0,004 & 0,012 & 0,011 & 0,017 & 0,011 & 0,000 & 0,000 \\
\hline $\mathrm{MgO}$ & 0,001 & 0,003 & 0,006 & 0,000 & 0,007 & 0,001 & 0,061 & 0,031 & 0,050 \\
\hline $\mathrm{CaO}$ & 0,592 & 0,592 & 0,633 & 0,376 & 0,439 & 0,445 & 12,829 & 14,894 & 12,840 \\
\hline $\mathrm{Na}_{2} \mathrm{O}$ & 6,978 & 7,337 & 7,352 & 7,129 & 7,044 & 7,040 & 3,953 & 3,101 & 4,069 \\
\hline $\mathrm{K}_{2} \mathrm{O}$ & 6,143 & 5,849 & 5,511 & 6,292 & 6,150 & 6,422 & 0,343 & 0,219 & 0,354 \\
\hline $\mathrm{SrO}$ & 0,094 & 0,107 & 0,080 & 0,077 & 0,028 & 0,010 & 0,225 & 0,248 & 0,272 \\
\hline $\mathrm{BaO}$ & 0,000 & 0,000 & 0,000 & 0,138 & 0,000 & 0,017 & 0,048 & 0,043 & 0,000 \\
\hline
\end{tabular}

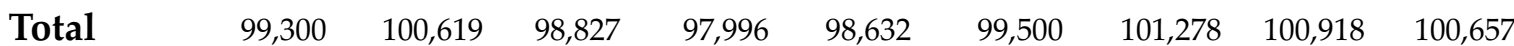

\section{$\mathbf{N}^{\circ}$ Cationes}

\begin{tabular}{llllllllll} 
Si & 11,8242 & 11,8070 & 11,7934 & 11,8691 & 11,8537 & 11,8026 & 9,3744 & 8,9835 & 9,4713 \\
Al+3 & 4,1691 & 4,1724 & 4,1880 & 4,0845 & 4,1233 & 4,1750 & 6,5667 & 6,9308 & 6,4741 \\
Ti+4 & 0,0000 & 0,0000 & 0,0000 & 0,0033 & 0,0000 & 0,0096 & 0,0286 & 0,0128 & 0,0000 \\
Fe+3 & 0,0312 & 0,0496 & 0,0491 & 0,0235 & 0,0437 & 0,0369 & 0,0659 & 0,0676 & 0,0420 \\
Mn & 0,0017 & 0,0011 & 0,0006 & 0,0018 & 0,0016 & 0,0026 & 0,0016 & 0,0000 & 0,0000 \\
Mg & 0,0001 & 0,0008 & 0,0015 & 0,0000 & 0,0020 & 0,0003 & 0,0163 & 0,0085 & 0,0134 \\
Ca & 0,1143 & 0,1127 & 0,1226 & 0,0738 & 0,0852 & 0,0859 & 2,4719 & 2,9001 & 2,4874 \\
Na & 2,4380 & 2,5283 & 2,5773 & 2,5299 & 2,4776 & 2,4581 & 1,3784 & 1,0928 & 1,4264 \\
K & 1,4122 & 1,3262 & 1,2712 & 1,4691 & 1,4232 & 1,4754 & 0,0787 & 0,0508 & 0,0817 \\
Sr & 0,0098 & 0,0110 & 0,0084 & 0,0082 & 0,0030 & 0,0011 & 0,0235 & 0,0262 & 0,0285 \\
Ba & 0,0000 & 0,0000 & 0,0000 & 0,0099 & 0,0000 & 0,0012 & 0,0034 & 0,0031 & 0,0000 \\
& & & & & & & & & \\
Total & 20,0006 & 20,0092 & 20,0122 & 20,0731 & 20,0132 & 20,0486 & 20,0093 & 20,0762 & 20,0248 \\
& & & & & & & & & \\
An & 3,12 & 3,11 & 3,29 & 2,00 & 2,21 & 2,16 & 63,08 & 71,85 & 62,52 \\
Ab & 61,34 & 63,55 & 64,76 & 61,84 & 62,11 & 61,12 & 34,84 & 26,83 & 35,45 \\
Or & 35,53 & 33,34 & 31,94 & 36,15 & 35,68 & 36,72 & 2,08 & 1,32 & 2,03 \\
\hline
\end{tabular}

Tabla IV.2: Análisis de la química mineral. 


\section{Feldespatos}

\begin{tabular}{|c|c|c|c|c|c|c|c|c|}
\hline \multirow{2}{*}{$\begin{array}{l}\text { Unidad } \\
\text { Muestra }\end{array}$} & \multicolumn{8}{|c|}{ Traquiandesitas Post-caldera } \\
\hline & \multicolumn{8}{|c|}{ PM 34} \\
\hline Cristal & \multicolumn{3}{|c|}{ PLA } & \multicolumn{5}{|c|}{ PL B } \\
\hline Punto & 4 & 5 & 6 & 1 & 2 & 3 & 4 & 5 \\
\hline Ubicación & medio & borde int. & borde & centro & medio & borde int. & borde & borde \\
\hline \multicolumn{9}{|l|}{$\%$} \\
\hline $\mathrm{SiO}_{2}$ & 52,158 & 54,192 & 51,460 & 46,701 & 48,234 & 47,377 & 50,069 & 56,644 \\
\hline $\mathrm{Al}_{2} \mathrm{O}_{3}$ & 30,182 & 28,578 & 30,320 & 34,362 & 33,019 & 34,445 & 31,917 & 27,274 \\
\hline $\mathrm{TiO}_{2}$ & 0,188 & 0,094 & 0,024 & 0,117 & 0,094 & 0,000 & 0,094 & 0,140 \\
\hline $\mathrm{Fe}_{2} \mathrm{O}_{3}$ & 0,535 & 0,413 & 0,533 & 0,578 & 0,422 & 0,516 & 0,672 & 0,546 \\
\hline $\mathrm{MnO}$ & 0,025 & 0,010 & 0,000 & 0,005 & 0,000 & 0,025 & 0,011 & 0,000 \\
\hline $\mathrm{MgO}$ & 0,026 & 0,023 & 0,076 & 0,054 & 0,076 & 0,058 & 0,061 & 0,066 \\
\hline $\mathrm{CaO}$ & 12,425 & 10,688 & 12,734 & 16,960 & 16,460 & 16,847 & 14,335 & 9,157 \\
\hline $\mathrm{Na}_{2} \mathrm{O}$ & 4,219 & 5,122 & 3,977 & 1,854 & 2,475 & 2,034 & 3,087 & 5,708 \\
\hline $\mathrm{K}_{2} \mathrm{O}$ & 0,386 & 0,568 & 0,394 & 0,099 & 0,096 & 0,127 & 0,283 & 0,805 \\
\hline $\mathrm{SrO}$ & 0,206 & 0,233 & 0,246 & 0,265 & 0,289 & 0,199 & 0,301 & 0,295 \\
\hline \multirow[t]{2}{*}{$\mathrm{BaO}$} & 0,021 & 0,049 & 0,029 & 0,000 & 0,000 & 0,067 & 0,010 & 0,000 \\
\hline & --- & --- & --- & --- & --- & --- & --- & --- \\
\hline Total & 100,371 & 99,968 & 99,792 & 100,995 & 101,165 & 101,695 & 100,840 & 100,635 \\
\hline
\end{tabular}

\section{$\mathrm{N}^{\circ}$ Cationes}

\begin{tabular}{lcccccccc} 
Si & 9,4619 & 9,8258 & 9,4004 & 8,5275 & 8,7780 & 8,5856 & 9,0894 & 10,1570 \\
Al+3 & 6,4531 & 6,1070 & 6,5277 & 7,3950 & 7,0822 & 7,3568 & 6,8287 & 5,7639 \\
Ti+4 & 0,0256 & 0,0128 & 0,0032 & 0,0161 & 0,0128 & 0,0000 & 0,0128 & 0,0189 \\
Fe+3 & 0,0730 & 0,0563 & 0,0732 & 0,0794 & 0,0577 & 0,0704 & 0,0919 & 0,0737 \\
Mn & 0,0038 & 0,0015 & 0,0000 & 0,0008 & 0,0000 & 0,0038 & 0,0016 & 0,0000 \\
Mg & 0,0072 & 0,0063 & 0,0206 & 0,0147 & 0,0207 & 0,0155 & 0,0166 & 0,0176 \\
Ca & 2,4151 & 2,0763 & 2,4923 & 3,3181 & 3,2095 & 3,2711 & 2,7881 & 1,7593 \\
Na & 1,4839 & 1,8005 & 1,4087 & 0,6563 & 0,8735 & 0,7146 & 1,0866 & 1,9844 \\
K & 0,0893 & 0,1313 & 0,0919 & 0,0231 & 0,0222 & 0,0294 & 0,0656 & 0,1842 \\
Sr & 0,0216 & 0,0245 & 0,0261 & 0,0280 & 0,0305 & 0,0209 & 0,0317 & 0,0307 \\
Ba & 0,0015 & 0,0035 & 0,0021 & 0,0000 & 0,0000 & 0,0048 & 0,0007 & 0,0000 \\
& --- & --- & --- & --- & --- & --- & -- & -- \\
Total & 20,0360 & 20,0457 & 20,0462 & 20,0589 & 20,0871 & 20,0729 & 20,0137 & 19,9896 \\
& & & & & & & & \\
An & 60,74 & 52,05 & 62,63 & 83,12 & 78,34 & 81,47 & 70,98 & 45,22 \\
Ab & 36,99 & 44,61 & 35,03 & 16,30 & 21,12 & 17,68 & 27,35 & 50,13 \\
Or & 2,26 & 3,34 & 2,34 & 0,57 & 0,54 & 0,85 & 1,67 & 4,65 \\
\hline
\end{tabular}

Tabla IV.3: Análisis de la química mineral. 


\section{Feldespatos}

\begin{tabular}{|c|c|c|c|c|c|c|c|c|}
\hline \multirow{4}{*}{$\begin{array}{l}\text { Unidad } \\
\text { Muestra } \\
\text { Cristal } \\
\text { Punto }\end{array}$} & \multicolumn{8}{|c|}{ Traquiandesitas Post-caldera } \\
\hline & \multicolumn{8}{|c|}{ PM 34} \\
\hline & \multicolumn{3}{|c|}{ PLC } & \multicolumn{3}{|c|}{ PL D } & \multicolumn{2}{|c|}{ PLP } \\
\hline & 1 & 2 & 3 & 1 & 2 & 3 & 1 & 2 \\
\hline Ubicación & centro & medio & borde & centro & medio & borde & centro & borde \\
\hline \multicolumn{9}{|l|}{$\%$} \\
\hline $\mathrm{SiO}_{2}$ & 58,995 & 58,885 & 57,640 & 57,639 & 56,407 & 56,037 & 55,973 & 57,143 \\
\hline $\mathrm{Al}_{2} \mathrm{O}_{3}$ & 26,010 & 25,304 & 26,327 & 26,736 & 27,396 & 27,604 & 26,275 & 27,122 \\
\hline $\mathrm{TiO}_{2}$ & 0,000 & 0,258 & 0,094 & 0,070 & 0,070 & 0,164 & 0,257 & 0,303 \\
\hline $\mathrm{Fe}_{2} \mathrm{O}_{3}$ & 0,374 & 0,397 & 0,526 & 0,525 & 0,525 & 0,608 & 0,646 & 0,738 \\
\hline $\mathrm{MnO}$ & 0,005 & 0,018 & 0,025 & 0,000 & 0,051 & 0,015 & 0,012 & 0,003 \\
\hline $\mathrm{MgO}$ & 0,068 & 0,061 & 0,073 & 0,038 & 0,078 & 0,076 & 0,071 & 0,043 \\
\hline $\mathrm{CaO}$ & 7,448 & 6,592 & 8,264 & 8,698 & 9,117 & 9,384 & 9,596 & 8,801 \\
\hline $\mathrm{Na}_{2} \mathrm{O}$ & 6,477 & 6,418 & 6,123 & 6,053 & 5,553 & 5,625 & 5,628 & 5,965 \\
\hline $\mathrm{K}_{2} \mathrm{O}$ & 1,370 & 1,607 & 1,047 & 1,052 & 0,903 & 0,830 & 0,904 & 0,952 \\
\hline SrO & 0,151 & 0,264 & 0,273 & 0,288 & 0,247 & 0,344 & 0,118 & 0,277 \\
\hline \multirow[t]{2}{*}{$\mathrm{BaO}$} & 0,062 & 0,084 & 0,017 & 0,000 & 0,122 & 0,044 & 0,100 & 0,136 \\
\hline & --- & --- & --- & --- & --- & --- & --- & --- \\
\hline Total & 0,959 & 888 &, 410 & 1,099 & 0,468 & 0,732 & 99,582 & 01,483 \\
\hline
\end{tabular}

\section{$\mathrm{N}^{\circ}$ Cationes}

\begin{tabular}{lrrrrrrrr} 
Si & 10,5029 & 10,5895 & 10,3441 & 10,2856 & 10,1393 & 10,0635 & 10,1739 & 10,1801 \\
$\mathbf{A l + 3}$ & 5,4575 & 5,3631 & 5,5685 & 5,6230 & 5,8039 & 5,8426 & 5,6288 & 5,6946 \\
Ti+4 & 0,0000 & 0,0349 & 0,0127 & 0,0094 & 0,0095 & 0,0222 & 0,0351 & 0,0406 \\
Fe+3 & 0,0501 & 0,0537 & 0,0710 & 0,0705 & 0,0710 & 0,0822 & 0,0884 & 0,0989 \\
Mn & 0,0008 & 0,0028 & 0,0039 & 0,0000 & 0,0077 & 0,0023 & 0,0019 & 0,0004 \\
Mg & 0,0180 & 0,0163 & 0,0196 & 0,0100 & 0,0208 & 0,0204 & 0,0193 & 0,0114 \\
Ca & 1,4206 & 1,2702 & 1,5889 & 1,6630 & 1,7558 & 1,8055 & 1,8689 & 1,6798 \\
Na & 2,2357 & 2,2378 & 2,1306 & 2,0942 & 1,9354 & 1,9585 & 1,9833 & 2,0605 \\
K & 0,3112 & 0,3688 & 0,2397 & 0,2395 & 0,2071 & 0,1901 & 0,2097 & 0,2165 \\
Sr & 0,0155 & 0,0275 & 0,0284 & 0,0298 & 0,0258 & 0,0359 & 0,0124 & 0,0286 \\
Ba & 0,0044 & 0,0059 & 0,0012 & 0,0000 & 0,0086 & 0,0031 & 0,0072 & 0,0095 \\
& --- & --- & --- & --- & --- & --- & --- & --- \\
Total & 20,0168 & 19,9705 & 20,0086 & 20,0250 & 19,9849 & 20,0263 & 20,0289 & 20,0211 \\
& & & & & & & & \\
An & 36,02 & 33,19 & 40,55 & 42,04 & 45,30 & 46,11 & 46,09 & 42,76 \\
Ab & 56,07 & 57,23 & 53,41 & 52,01 & 49,21 & 49,05 & 48,59 & 51,58 \\
Or & 7,91 & 9,58 & 6,04 & 5,95 & 5,48 & 4,84 & 5,31 & 5,66 \\
\hline
\end{tabular}

Tabla IV.4: Análisis de la química mineral. 


\section{Feldespatos}

\begin{tabular}{|c|c|c|c|c|c|c|c|c|c|}
\hline \multirow{4}{*}{$\begin{array}{l}\text { Unidad } \\
\text { Muestra } \\
\text { Cristal } \\
\text { Punto }\end{array}$} & \multicolumn{9}{|c|}{ Traquiandesitas Post-caldera } \\
\hline & \multicolumn{9}{|c|}{ STA 6-B } \\
\hline & \multicolumn{5}{|c|}{ PL A } & \multicolumn{4}{|c|}{ PL B } \\
\hline & 1 & 2 & 3 & 4 & 5 & 1 & 2 & 3 & 4 \\
\hline Ubicación & centro & medio & medio & borde int. & borde & centro & medio & medio & borde \\
\hline \multicolumn{10}{|l|}{$\%$} \\
\hline $\mathrm{SiO}_{2}$ & 57,647 & 57,743 & 56,806 & 56,778 & 57,53 & 54,737 & 54,707 & 54,973 & 56,366 \\
\hline $\mathrm{Al}_{2} \mathrm{O}_{3}$ & 26,453 & 26,189 & 26,644 & 26,901 & 27,053 & 28,606 & 28,757 & 28,283 & 27,900 \\
\hline $\mathrm{TiO}_{2}$ & 0,188 & 0,000 & 0,094 & 0,024 & 0,000 & 0,118 & 0,071 & 0,047 & 0,047 \\
\hline $\mathrm{Fe}_{2} \mathrm{O}_{3}$ & 0,491 & 0,506 & 0,364 & 0,478 & 0,500 & 0,521 & 0,634 & 0,530 & 0,503 \\
\hline $\mathrm{MnO}$ & 0,007 & 0,000 & 0,000 & 0,006 & 0,000 & 0,003 & 0,000 & 0,025 & 0,007 \\
\hline $\mathrm{MgO}$ & 0,061 & 0,038 & 0,043 & 0,038 & 0,040 & 0,079 & 0,023 & 0,060 & 0,055 \\
\hline $\mathrm{CaO}$ & 8,014 & 7,64 & 8,45 & 8,634 & 8,513 & 10,314 & 10,497 & 10,117 & 9,23 \\
\hline $\mathrm{Na}_{2} \mathrm{O}$ & 6,283 & 6,306 & 6,397 & 6,221 & 6,274 & 5,423 & 5,267 & 5,523 & 5,745 \\
\hline $\mathrm{K}_{2} \mathrm{O}$ & 0,846 & 0,83 & 0,683 & 0,695 & 0,720 & 0,458 & 0,505 & 0,514 & 0,616 \\
\hline $\mathrm{SrO}$ & 0,362 & 0,349 & 0,256 & 0,363 & 0,302 & 0,249 & 0,309 & 0,315 & 0,131 \\
\hline \multirow[t]{2}{*}{$\mathrm{BaO}$} & 0,082 & 0,152 & 0,131 & 0,038 & 0,111 & 0,019 & 0,024 & 0,017 & 0,012 \\
\hline & --- & --- & --- & --- & --- & --- & --- & --- & -- \\
\hline Total & 100,434 & 99,754 & 99,867 & 100,176 & 101,042 & 100,527 & 100,793 & 100,406 & 100,612 \\
\hline \multicolumn{10}{|c|}{$\mathbf{N}^{\circ}$ Cationes } \\
\hline Si & 10,3372 & 10,4099 & 10,2571 & 10,2244 & 10,2623 & 9,8579 & 9,8365 & 9,9141 & 10,0927 \\
\hline $\mathrm{Al}+3$ & 5,5907 & 5,5643 & 5,6701 & 5,7095 & 5,6875 & 6,0719 & 6,094 & 6,0115 & 5,8879 \\
\hline $\mathbf{T i}+4$ & 0,0254 & 0,0000 & 0,0128 & 0,0032 & 0,0000 & 0,0159 & 0,0096 & 0,0064 & 0,0063 \\
\hline $\mathrm{Fe}+3$ & 0,0663 & 0,0687 & 0,0495 & 0,0648 & 0,0671 & 0,0706 & 0,0857 & 0,0720 & 0,0677 \\
\hline Mn & 0,0011 & 0,0000 & 0,0000 & 0,0009 & 0,0000 & 0,0004 & 0,0000 & 0,0038 & 0,0010 \\
\hline $\mathrm{Mg}$ & 0,0162 & 0,0103 & 0,0116 & 0,0102 & 0,0107 & 0,0212 & 0,0061 & 0,0161 & 0,0147 \\
\hline $\mathrm{Ca}$ & 1,5397 & 1,4757 & 1,6348 & 1,6659 & 1,6269 & 1,9901 & 2,0223 & 1,9549 & 1,7707 \\
\hline $\mathrm{Na}$ & 2,1844 & 2,2042 & 2,2395 & 2,1721 & 2,1698 & 1,8936 & 1,8361 & 1,9314 & 1,9945 \\
\hline $\mathbf{K}$ & 0,1934 & 0,1908 & 0,1573 & 0,1595 & 0,1638 & 0,1052 & 0,1158 & 0,1184 & 0,1408 \\
\hline Sr & 0,0377 & 0,0365 & 0,0268 & 0,0379 & 0,0312 & 0,0260 & 0,0322 & 0,0329 & 0,0136 \\
\hline \multirow[t]{2}{*}{ Ba } & 0,0057 & 0,0108 & 0,0092 & 0,0027 & 0,0078 & 0,0014 & 0,0017 & 0,0012 & 0,0008 \\
\hline & --- & --- & --- & --- & --- & --- & --- & --- & --- \\
\hline Total & 19,9978 & 19,9711 & 20,0687 & 20,0511 & 20,0272 & 20,0543 & 20,0400 & 20,0626 & 19,9909 \\
\hline An & 39,82 & 38,60 & 40,85 & 42,19 & 41,46 & 50,20 & 51,26 & 49,22 & 45,51 \\
\hline$A b$ & 55,15 & 56,26 & 55,06 & 53,79 & 54,25 & 47,15 & 45,81 & 47,82 & 50,87 \\
\hline Or & 5,03 & 5,15 & 4,09 & 4,02 & 4,29 & 2,65 & 2,93 & 2,96 & 3,61 \\
\hline
\end{tabular}

Tabla IV.5: Análisis de la química mineral. 


\section{Feldespatos}

\begin{tabular}{|c|c|c|c|c|c|c|c|c|c|}
\hline Unidad & \multicolumn{9}{|c|}{ Traquiandesitas Post-caldera } \\
\hline Muestra & \multicolumn{9}{|c|}{ STA 6-B } \\
\hline Cristal & \multicolumn{3}{|c|}{$\mathrm{PlC}$} & & \multicolumn{4}{|c|}{ Pl D } & \\
\hline Punto & 1 & 2 & 3 & 4 & 1 & 2 & 3 & 4 & 5 \\
\hline Ubicación & centro & medio & borde int. & borde & centro & centro & medio & medio & medio \\
\hline \multicolumn{10}{|l|}{$\%$} \\
\hline $\mathrm{SiO}_{2}$ & 57,393 & 59,825 & 58,91 & 64,422 & 51,633 & 50,343 & 52,187 & 55,479 & 56,418 \\
\hline $\mathrm{Al}_{2} \mathrm{O}_{3}$ & 26,362 & 25,116 & 24,974 & 19,833 & 31,337 & 31,108 & 30,496 & 28,219 & 26,758 \\
\hline $\mathrm{TiO}_{2}$ & 0,024 & 0,141 & 0,000 & 0,187 & 0,000 & 0,000 & 0,000 & 0,165 & 0,094 \\
\hline $\mathrm{Fe}_{2} \mathrm{O}_{3}$ & 0,309 & 0,393 & 0,445 & 0,417 & 0,332 & 0,266 & 0,396 & 0,382 & 0,364 \\
\hline $\mathrm{MnO}$ & 0,002 & 0,000 & 0,000 & 0,011 & 0,000 & 0,009 & 0,000 & 0,010 & 0,000 \\
\hline $\mathrm{MgO}$ & 0,012 & 0,036 & 0,022 & 0,014 & 0,017 & 0,039 & 0,030 & 0,024 & 0,034 \\
\hline $\mathrm{CaO}$ & 7,950 & 6,228 & 6,216 & 1,009 & 13,371 & 13,627 & 12,637 & 9,873 & 8,365 \\
\hline $\mathrm{Na}_{2} \mathrm{O}$ & 6,800 & 7,337 & 7,154 & 6,419 & 3,739 & 3,609 & 4,162 & 5,571 & 6,245 \\
\hline $\mathrm{K}_{2} \mathrm{O}$ & 0,858 & 1,278 & 1,311 & 6,299 & 0,275 & 0,284 & 0,277 & 0,514 & 0,738 \\
\hline $\mathrm{SrO}$ & 0,305 & 0,308 & 0,269 & 0,160 & 0,356 & 0,238 & 0,356 & 0,292 & 0,245 \\
\hline \multirow[t]{2}{*}{$\mathrm{BaO}$} & 0,178 & 0,202 & 0,113 & 0,105 & 0,017 & 0,027 & 0,024 & 0,000 & 0,070 \\
\hline & --- & --- & --- & --- & --- & -- & -- & --- & --- \\
\hline Total & 100,193 & 100,864 & 99,416 & 98,876 & 101,077 & 99,55 & 100,564 & 100,53 & 99,33 \\
\hline
\end{tabular}

\section{$\mathbf{N}^{\circ}$ Cationes}

\begin{tabular}{lrrrrrrrrr} 
Si & 10,3353 & 10,658 & 10,6421 & 11,7035 & 9,3134 & 9,2333 & 9,4485 & 9,9712 & 10,2346 \\
Al+3 & 5,5951 & 5,2736 & 5,3172 & 4,2465 & 6,6619 & 6,7242 & 6,5073 & 5,9775 & 5,7209 \\
Ti+4 & 0,0032 & 0,0189 & 0,0000 & 0,0256 & 0,0000 & 0,0000 & 0,0000 & 0,0223 & 0,0128 \\
Fe+3 & 0,0419 & 0,0527 & 0,0605 & 0,057 & 0,0451 & 0,0368 & 0,054 & 0,0517 & 0,0497 \\
Mn & 0,0003 & 0,0000 & 0,0000 & 0,0017 & 0,0000 & 0,0013 & 0,0000 & 0,0015 & 0,0000 \\
Mg & 0,0031 & 0,0095 & 0,0060 & 0,0037 & 0,0047 & 0,0108 & 0,0082 & 0,0065 & 0,0091 \\
Ca & 1,5339 & 1,1888 & 1,2032 & 0,1965 & 2,5841 & 2,6778 & 2,4513 & 1,9012 & 1,6258 \\
Na & 2,3741 & 2,5344 & 2,5058 & 2,2610 & 1,3078 & 1,2833 & 1,4609 & 1,9413 & 2,1964 \\
K & 0,1970 & 0,2905 & 0,3022 & 1,4598 & 0,0633 & 0,0663 & 0,0640 & 0,1180 & 0,1708 \\
Sr & 0,0319 & 0,0318 & 0,0282 & 0,0168 & 0,0372 & 0,0253 & 0,0374 & 0,0304 & 0,0258 \\
Ba & 0,0125 & 0,0141 & 0,0080 & 0,0075 & 0,0012 & 0,0020 & 0,0017 & 0,0000 & 0,0049 \\
& --- & --- & --- & --- & --- & --- & --- & --- & --- \\
Total & 20,1285 & 20,0724 & 20,0731 & 19,9796 & 20,0187 & 20,0610 & 20,0333 & 20,0216 & 20,0509 \\
& & & & & & & & & \\
An & 37,74 & 30,07 & 30,42 & 5,41 & 65,64 & 66,67 & 61,98 & 48,40 & 41,05 \\
Ab & 57,22 & 62,43 & 61,91 & 57,36 & 32,75 & 31,65 & 36,38 & 48,64 & 54,59 \\
Or & 5,05 & 7,50 & 7,66 & 37,23 & 1,62 & 1,68 & 1,64 & 2,96 & 4,37 \\
\hline
\end{tabular}

Tabla IV.6: Análisis de la química mineral. 


\section{Feldespatos}

\begin{tabular}{|c|c|c|c|c|c|c|c|c|c|}
\hline \multirow{4}{*}{$\begin{array}{l}\text { Unidad } \\
\text { Muestra } \\
\text { Cristal } \\
\text { Punto }\end{array}$} & \multicolumn{9}{|c|}{ Traquiandesitas Post-caldera } \\
\hline & \multicolumn{3}{|c|}{ STA 6-B } & \multirow{2}{*}{\multicolumn{6}{|c|}{$\begin{array}{c}\text { STA } 38 \\
\text { Pl A }\end{array}$}} \\
\hline & \multicolumn{2}{|c|}{ Pl D } & \multirow{2}{*}{$\begin{array}{c}\text { Pl P } \\
1\end{array}$} & & & & & & \\
\hline & 6 & 7 & & 1 & 2 & 3 & 4 & 5 & 6 \\
\hline Ubicación & borde int. & borde & centro & centro & centro & medio & borde int. & medio & borde \\
\hline \multicolumn{10}{|l|}{$\%$} \\
\hline $\mathrm{SiO}_{2}$ & 58,945 & 59,014 & 61,261 & 55,588 & 55,51 & 55,698 & 58,560 & 55,896 & 59,828 \\
\hline $\mathrm{Al}_{2} \mathrm{O}_{3}$ & 25,766 & 25,809 & 23,145 & 27,422 & 27,72 & 26,982 & 26,284 & 27,696 & 23,525 \\
\hline $\mathrm{TiO}_{2}$ & 0,188 & 0,118 & 0,235 & 0,164 & 0,070 & 0,000 & 0,281 & 0,164 & 0,164 \\
\hline $\mathrm{Fe}_{2} \mathrm{O}_{3}$ & 0,625 & 0,419 & 0,667 & 0,607 & 0,547 & 0,506 & 0,464 & 0,365 & 0,509 \\
\hline $\mathrm{MnO}$ & 0,012 & 0,000 & 0,005 & 0,010 & 0,000 & 0,004 & 0,014 & 0,018 & 0,000 \\
\hline MgO & 0,024 & 0,036 & 0,024 & 0,033 & 0,063 & 0,046 & 0,047 & 0,058 & 0,042 \\
\hline $\mathrm{CaO}$ & 7,384 & 7,310 & 4,354 & 9,454 & 9,756 & 8,953 & 7,762 & 9,822 & 4,836 \\
\hline $\mathrm{Na}_{2} \mathrm{O}$ & 6,527 & 6,686 & 7,403 & 5,397 & 5,355 & 5,785 & 6,228 & 5,429 & 6,878 \\
\hline $\mathrm{K}_{2} \mathrm{O}$ & 0,978 & 0,973 & 2,583 & 0,833 & 0,754 & 0,977 & 1,132 & 0,726 & 2,553 \\
\hline $\mathrm{SrO}$ & 0,266 & 0,146 & 0,222 & 0,32 & 0,285 & 0,341 & 0,168 & 0,297 & 0,245 \\
\hline \multirow[t]{2}{*}{$\mathrm{BaO}$} & 0,067 & 0,16 & 0,048 & 0,019 & 0,029 & 0,137 & 0,043 & 0,053 & 0,205 \\
\hline & --- & --- & --- & --- & --- & --- & --- & --- & --- \\
\hline Total & 100,782 & 100,671 & 99,947 & 99,849 & 100,090 & 99,430 & 100,984 & 100,524 & 98,785 \\
\hline
\end{tabular}

\section{$\mathbf{N}^{\circ}$ Cationes}

\begin{tabular}{lccccccccc} 
Si & 10,5072 & 10,5241 & 10,9994 & 10,0651 & 10,0274 & 10,1375 & 10,4219 & 10,0511 & 10,8885 \\
Al+3 & 5,4130 & 5,4245 & 4,8979 & 5,8518 & 5,9017 & 5,7880 & 5,5131 & 5,8697 & 5,0460 \\
Ti+4 & 0,0252 & 0,0158 & 0,0317 & 0,0224 & 0,0096 & 0,0000 & 0,0376 & 0,0222 & 0,0224 \\
Fe+3 & 0,0839 & 0,0562 & 0,0902 & 0,0828 & 0,0743 & 0,0693 & 0,0621 & 0,0493 & 0,0698 \\
Mn & 0,0018 & 0,0000 & 0,0007 & 0,0016 & 0,0000 & 0,0006 & 0,0021 & 0,0028 & 0,0000 \\
Mg & 0,0065 & 0,0095 & 0,0065 & 0,0090 & 0,0171 & 0,0126 & 0,0126 & 0,0155 & 0,0113 \\
Ca & 1,4103 & 1,3966 & 0,8375 & 1,8340 & 1,8882 & 1,7459 & 1,4801 & 1,8923 & 0,9429 \\
Na & 2,2558 & 2,3118 & 2,5773 & 1,8948 & 1,8757 & 2,0415 & 2,1491 & 1,8929 & 2,4269 \\
K & 0,2223 & 0,2214 & 0,5916 & 0,1923 & 0,1739 & 0,2269 & 0,2571 & 0,1665 & 0,5928 \\
Sr & 0,0275 & 0,0151 & 0,0231 & 0,0336 & 0,0299 & 0,0360 & 0,0173 & 0,0310 & 0,0259 \\
Ba & 0,0047 & 0,0112 & 0,0034 & 0,0014 & 0,0020 & 0,0098 & 0,0030 & 0,0037 & 0,0146 \\
& --- & --- & --- & --- & --- & --- & --- & --- & --- \\
Total & 19,9581 & 19,9863 & 20,0592 & 19,9888 & 19,9997 & 20,0680 & 19,9560 & 19,9970 & 20,0411 \\
& & & & & & & & & \\
An & 36,67 & 35,68 & 21,34 & 47,21 & 48,32 & 43,89 & 38,33 & 48,25 & 24,20 \\
Ab & 57,54 & 58,44 & 63,91 & 47,90 & 47,25 & 50,28 & 55,01 & 47,48 & 60,63 \\
Or & 5,79 & 5,88 & 14,75 & 4,90 & 4,43 & 5,83 & 6,66 & 4,27 & 15,17 \\
\hline
\end{tabular}

Tabla IV.7: Análisis de la química mineral. 


\section{Feldespatos}

\begin{tabular}{|c|c|c|c|c|c|c|c|c|}
\hline \multirow{4}{*}{$\begin{array}{l}\text { Unidad } \\
\text { Muestra } \\
\text { Cristal } \\
\text { Punto }\end{array}$} & \multicolumn{8}{|c|}{ Traquiandesitas Post-caldera } \\
\hline & \multicolumn{8}{|c|}{ STA 38} \\
\hline & \multicolumn{4}{|c|}{ Pl B } & \multicolumn{4}{|c|}{$\mathrm{PlC}$} \\
\hline & 1 & 2 & 3 & 4 & 1 & 2 & 3 & 4 \\
\hline Ubicación & centro & medio & borde int. & borde & centro & centro & medio & medio \\
\hline \multicolumn{9}{|l|}{$\%$} \\
\hline $\mathrm{SiO}_{2}$ & 52,567 & 53,337 & 51,148 & 49,985 & 53,475 & 53,932 & 57,377 & 57,257 \\
\hline $\mathrm{Al}_{2} \mathrm{O}_{3}$ & 29,865 & 28,716 & 30,517 & 31,099 & 28,896 & 28,405 & 26,294 & 25,979 \\
\hline $\mathrm{TiO}_{2}$ & 0,210 & 0,047 & 0,210 & 0,093 & 0,070 & 0,140 & 0,117 & 0,047 \\
\hline $\mathrm{Fe}_{2} \mathrm{O}_{3}$ & 0,452 & 0,757 & 0,469 & 0,648 & 0,459 & 0,612 & 0,555 & 0,419 \\
\hline $\mathrm{MnO}$ & 0,000 & 0,032 & 0,000 & 0,000 & 0,031 & 0,000 & 0,018 & 0,012 \\
\hline $\mathrm{MgO}$ & 0,074 & 0,051 & 0,061 & 0,082 & 0,041 & 0,070 & 0,056 & 0,063 \\
\hline $\mathrm{CaO}$ & 12,166 & 10,86 & 12,782 & 13,400 & 11,197 & 10,409 & 8,123 & 7,747 \\
\hline $\mathrm{Na}_{2} \mathrm{O}$ & 4,266 & 4,739 & 3,928 & 3,464 & 4,734 & 4,875 & 5,864 & 6,17 \\
\hline $\mathrm{K}_{2} \mathrm{O}$ & 0,383 & $0,43,0$ & 0,326 & 0,217 & 0,583 & 0,657 & 1,187 & 1,201 \\
\hline $\mathrm{SrO}$ & 0,265 & 0,123 & 0,199 & 0,341 & 0,166 & 0,251 & 0,204 & 0,234 \\
\hline \multirow[t]{2}{*}{$\mathrm{BaO}$} & 0,017 & 0,000 & 0,000 & 0,062 & 0,000 & 0,000 & 0,000 & 0,061 \\
\hline & --- & --- & --- & --- & --- & --- & --- & --- \\
\hline Total & 100,265 & 99,092 & 99,641 & 99,392 & 99,653 & 99,351 & 99,794 & 99,190 \\
\hline \multicolumn{9}{|c|}{$\mathbf{N}^{\circ}$ Cationes } \\
\hline Si & 9,5336 & 9,7506 & 9,3523 & 9,1917 & 9,7338 & 9,8321 & 10,3498 & 10,3928 \\
\hline$A l+3$ & 6,3836 & 6,187 & 6,5764 & 6,7399 & 6,1991 & 6,1031 & 5,5899 & 5,5577 \\
\hline $\mathbf{T i}+4$ & 0,0287 & 0,0064 & 0,0289 & 0,0129 & 0,0096 & 0,0193 & 0,0159 & 0,0064 \\
\hline $\mathrm{Fe}+3$ & 0,0616 & 0,1041 & 0,0646 & 0,0896 & 0,0629 & 0,0839 & 0,0753 & 0,0573 \\
\hline Mn & 0,0000 & 0,005 & 0,0000 & 0,0000 & 0,0049 & 0,0000 & 0,0027 & 0,0019 \\
\hline Mg & 0,0201 & 0,014 & 0,0167 & 0,0225 & 0,0110 & 0,0191 & 0,0151 & 0,0170 \\
\hline $\mathrm{Ca}$ & 2,3640 & 2,1272 & 2,5040 & 2,6401 & 2,1837 & 2,0331 & 1,5699 & 1,5065 \\
\hline $\mathrm{Na}$ & 1,5002 & 1,6799 & 1,3925 & 1,2349 & 1,6708 & 1,7230 & 2,0508 & 2,1714 \\
\hline $\mathbf{K}$ & 0,0886 & 0,1003 & 0,0760 & 0,0510 & 0,1354 & 0,1528 & 0,2731 & 0,2782 \\
\hline Sr & 0,0278 & 0,013 & 0,0211 & 0,0364 & 0,0175 & 0,0266 & 0,0213 & 0,0246 \\
\hline \multirow[t]{2}{*}{$\mathrm{Ba}$} & 0,0012 & 0,0000 & 0,0000 & 0,0045 & 0,0000 & 0,0000 & 0,0000 & 0,0044 \\
\hline & --- & --- & --- & --- & --- & --- & --- & --- \\
\hline Total & 20,0095 & 19,9875 & 20,0325 & 20,0236 & 20,0287 & 19,9930 & 19,9637 & 20,0181 \\
\hline An & 60,07 & 54,59 & 63,23 & 67,47 & 54,93 & 52,34 & 40,64 & 38,42 \\
\hline $\mathbf{A b}$ & 37,68 & 42,85 & 34,87 & 31,13 & 41,69 & 43,78 & 52,38 & 54,49 \\
\hline Or & 2,26 & 2,56 & 1,90 & 1,40 & 3,38 & 3,88 & 6,98 & 7,09 \\
\hline
\end{tabular}

Tabla IV.8: Análisis de la química mineral. 


\section{Feldespatos}

\begin{tabular}{|c|c|c|c|c|c|c|c|c|c|}
\hline \multirow{4}{*}{$\begin{array}{l}\text { Unidad } \mathrm{T} \\
\text { Muestra } \\
\text { Cristal } \\
\text { Punto }\end{array}$} & \multicolumn{3}{|c|}{ Traquiandesitas Post-caldera } & \multicolumn{6}{|c|}{ Ignimbrita Portezuelo } \\
\hline & \multicolumn{3}{|c|}{ STA 38} & \multicolumn{6}{|c|}{ PM 14} \\
\hline & \multicolumn{2}{|c|}{$\mathrm{PlC}$} & \multirow{2}{*}{$\begin{array}{c}\mathrm{Pl} P \\
1\end{array}$} & \multicolumn{3}{|c|}{ Fk A } & \multicolumn{3}{|c|}{ Fk B } \\
\hline & 5 & 6 & & 1 & 2 & 3 & 1 & 2 & 3 \\
\hline Ubicación & borde int. & borde & centro & centro & medio & borde & centro & medio & borde \\
\hline \multicolumn{10}{|l|}{$\%$} \\
\hline $\mathrm{SiO}_{2}$ & 53,910 & 56,151 & 55,861 & 63,891 & 63,936 & 64,261 & 64,198 & 64,051 & 64,237 \\
\hline $\mathrm{Al}_{2} \mathrm{O}_{3}$ & 28,108 & 27,156 & 26,410 & 21,013 & 21,201 & 21,095 & 20,804 & 21,178 & 21,071 \\
\hline $\mathrm{TiO}_{2}$ & 0,234 & 0,093 & 0,349 & 0,117 & 0,093 & 0,070 & 0,047 & 0,000 & 0,023 \\
\hline $\mathrm{Fe}_{2} \mathrm{O}_{3}$ & 0,643 & 0,514 & 1,002 & 0,247 & 0,185 & 0,132 & 0,158 & 0,300 & 0,234 \\
\hline $\mathrm{MnO}$ & 0,016 & 0,000 & 0,012 & 0,011 & 0,000 & 0,000 & 0,014 & 0,005 & 0,018 \\
\hline $\mathrm{MgO}$ & 0,079 & 0,051 & 0,055 & 0,013 & 0,000 & 0,000 & 0,000 & 0,006 & 0,014 \\
\hline $\mathrm{CaO}$ & 10,150 & 8,901 & 8,148 & 2,257 & 2,275 & 2,252 & 1,983 & 2,466 & 2,307 \\
\hline $\mathrm{Na}_{2} \mathrm{O}$ & 5,116 & 5,585 & 6,013 & 7,006 & 7,116 & 7,377 & 7,031 & 7,097 & 7,181 \\
\hline $\mathrm{K}_{2} \mathrm{O}$ & 0,625 & 0,903 & 0,895 & 4,768 & 4,550 & 4,537 & 4,916 & 4,460 & 4,713 \\
\hline $\mathrm{SrO}$ & 0,155 & 0,221 & 0,137 & 0,153 & 0,169 & 0,250 & 0,087 & 0,176 & 0,094 \\
\hline \multirow[t]{2}{*}{$\mathrm{BaO}$} & 0,000 & 0,129 & 0,131 & 0,260 & 0,306 & 0,135 & 0,335 & 0,260 & 0,224 \\
\hline & --- & --- & --- & --- & --- & --- & --- & --- & --- \\
\hline Total & 99,035 & 99,706 & 99,012 & 99,736 & 99,830 & 100,110 & 99,573 & 99,998 & 100,11 \\
\hline
\end{tabular}

\section{$\mathbf{N}^{\circ}$ Cationes}

\begin{tabular}{lrrrrrrrrr} 
Si & 9,8554 & 10,1622 & 10,1901 & 11,4954 & 11,484 & 11,5055 & 11,5610 & 11,4849 & 11,5068 \\
Al+3 & 6,0561 & 5,7925 & 5,6780 & 4,4558 & 4,4880 & 4,4515 & 4,4156 & 4,4754 & 4,4485 \\
Ti+4 & 0,0321 & 0,0127 & 0,0478 & 0,0158 & 0,0126 & 0,0094 & 0,0063 & 0,0000 & 0,0031 \\
Fe+3 & 0,0884 & 0,0700 & 0,1375 & 0,0334 & 0,0250 & 0,0178 & 0,0215 & 0,0405 & 0,0316 \\
Mn & 0,0025 & 0,0000 & 0,0018 & 0,0016 & 0,0000 & 0,0000 & 0,0022 & 0,0008 & 0,0027 \\
Mg & 0,0215 & 0,0139 & 0,0150 & 0,0034 & 0,0000 & 0,0000 & 0,0000 & 0,0017 & 0,0037 \\
Ca & 1,9881 & 1,7259 & 1,5925 & 0,4351 & 0,4378 & 0,4320 & 0,3827 & 0,4738 & 0,4428 \\
Na & 1,8133 & 1,9599 & 2,1266 & 2,4442 & 2,4781 & 2,5610 & 2,4548 & 2,4674 & 2,4939 \\
K & 0,1458 & 0,2086 & 0,2083 & 1,0945 & 1,0425 & 1,0364 & 1,1293 & 1,0201 & 1,0770 \\
Sr & 0,0165 & 0,0232 & 0,0145 & 0,0159 & 0,0176 & 0,0259 & 0,0091 & 0,0183 & 0,0097 \\
Ba & 0,0000 & 0,0092 & 0,0094 & 0,0183 & 0,0215 & 0,0095 & 0,0236 & 0,0183 & 0,0157 \\
& --- & --- & --- & --- & --- & --- & --- & --- & --- \\
Total & 20,0198 & 19,9780 & 20,0217 & 20,0135 & 20,0071 & 20,0491 & 20,0062 & 20,0009 & 20,0355 \\
& & & & & & & & & \\
An & 50,57 & 44,54 & 40,67 & 11,25 & 11,39 & 11,27 & 9,80 & 12,31 & 11,20 \\
Ab & 45,75 & 49,91 & 53,82 & 60,98 & 61,99 & 63,00 & 61,38 & 61,72 & 61,74 \\
Or & 3,68 & 5,55 & 5,51 & 27,76 & 26,62 & 25,73 & 28,83 & 25,97 & 27,05 \\
\hline
\end{tabular}

Tabla IV.9: Análisis de la química mineral. 


\section{Feldespatos}

\begin{tabular}{|c|c|c|c|c|c|c|c|c|c|}
\hline \multirow{4}{*}{$\begin{array}{l}\text { Unidad } \\
\text { Muestra } \\
\text { Cristal } \\
\text { Punto }\end{array}$} & \multicolumn{9}{|c|}{ Ignimbrita Portezuelo } \\
\hline & \multirow{2}{*}{\multicolumn{5}{|c|}{ PM 14}} & \multicolumn{4}{|c|}{ PMB 44 (clasto de spatter) } \\
\hline & & & & & & \multicolumn{2}{|c|}{$\mathrm{Pl} \mathrm{a}$} & \multicolumn{2}{|c|}{$\mathrm{Plb}$} \\
\hline & 1 & 2 & 3 & 4 & 5 & 1 & 2 & 1 & 2 \\
\hline Ubicación & medio & centro & medio & borde int. & borde & borde & centro & borde & centro \\
\hline \multicolumn{10}{|l|}{$\%$} \\
\hline $\mathrm{SiO}_{2}$ & 63,870 & 64,038 & 63,775 & 64,074 & 63,771 & 58,290 & 57,580 & 63,360 & 63,280 \\
\hline $\mathrm{Al}_{2} \mathrm{O}_{3}$ & 21,377 & 21,318 & 21,619 & 21,132 & 21,444 & 25,370 & 25,260 & 20,950 & 20,330 \\
\hline $\mathrm{TiO}_{2}$ & 0,000 & 0,210 & 0,093 & 0,000 & 0,023 & 0,040 & 0,070 & 0,060 & 0,040 \\
\hline $\mathrm{Fe}_{2} \mathrm{O}_{3}$ & 0,240 & 0,258 & 0,288 & 0,286 & 0,281 & 0,430 & 0,490 & 0,280 & 0,220 \\
\hline $\mathrm{MnO}$ & 0,006 & 0,000 & 0,016 & 0,000 & 0,006 & - & - & - & - \\
\hline $\mathrm{MgO}$ & 0,000 & 0,000 & 0,011 & 0,011 & 0,018 & 0,020 & 0,050 & 0,010 & 0,000 \\
\hline $\mathrm{CaO}$ & 2,412 & 2,452 & 2,384 & 2,203 & 2,396 & 7,360 & 7,820 & 2,520 & 2,400 \\
\hline $\mathrm{Na}_{2} \mathrm{O}$ & 7,125 & 7,055 & 7,193 & 7,148 & 7,183 & 6,860 & 7,010 & 7,980 & 7,750 \\
\hline $\mathrm{K}_{2} \mathrm{O}$ & 4,374 & 4,619 & 4,291 & 4,816 & 4,455 & 0,810 & 0,790 & 3,960 & 4,160 \\
\hline $\mathrm{SrO}$ & 0,152 & 0,181 & 0,207 & 0,194 & 0,049 & - & - & - & - \\
\hline \multirow[t]{2}{*}{$\mathrm{BaO}$} & 0,340 & 0,246 & 0,134 & 0,229 & 0,203 & 0,040 & 0,150 & 0,180 & 0,420 \\
\hline & --- & --- & --- & --- & --- & --- & -- & --- & --- \\
\hline Total & 99,897 & 100,376 & 100,012 & 100,092 & 99,828 & 99,320 & 99,240 & 99,290 & 98,600 \\
\hline \multicolumn{10}{|c|}{$\mathbf{N}^{\circ}$ Cationes } \\
\hline Si & 11,4623 & 11,4492 & 11,4201 & 11,4926 & 11,4442 & 10,5320 & 10,4520 & 11,4400 & 11,5240 \\
\hline$A 1+3$ & 4,5214 & 4,4919 & 4,5625 & 4,4672 & 4,5355 & 5,4040 & 5,4040 & 4,4600 & 4,3640 \\
\hline $\mathrm{Ti}+4$ & 0,0000 & 0,0282 & 0,0126 & 0,0000 & 0,0032 & 0,0040 & 0,0080 & 0,0080 & 0,0040 \\
\hline $\mathrm{Fe}+3$ & 0,0324 & 0,0347 & 0,0388 & 0,0385 & 0,0379 & 0,0560 & 0,0680 & 0,0360 & 0,0320 \\
\hline Mn & 0,0010 & 0,0000 & 0,0024 & 0,0000 & 0,0009 & - & - & - & - \\
\hline Mg & 0,0000 & 0,0000 & 0,0030 & 0,0029 & 0,0047 & 0,0040 & 0,0120 & 0,0040 & 0,0000 \\
\hline $\mathrm{Ca}$ & 0,4638 & 0,4697 & 0,4575 & 0,4233 & 0,4606 & 1,4240 & 1,5200 & 0,4880 & 0,4680 \\
\hline $\mathrm{Na}$ & 2,4792 & 2,4454 & 2,4975 & 2,4857 & 2,4992 & 2,4040 & 2,4680 & 2,7920 & 2,7360 \\
\hline $\mathbf{K}$ & 1,0014 & 1,0535 & 0,9802 & 1,1020 & 1,0198 & 0,1880 & 0,1840 & 0,9120 & 0,9640 \\
\hline $\mathrm{Sr}$ & 0,0158 & 0,0188 & 0,0215 & 0,0202 & 0,0051 & - & - & - & - \\
\hline \multirow[t]{2}{*}{ Ba } & 0,0239 & 0,0172 & 0,0094 & 0,0161 & 0,0143 & 0,0040 & 0,0120 & 0,0120 & 0,0280 \\
\hline & --- & --- & --- & --- & --- & --- & --- & --- & --- \\
\hline Total & 20,0012 & 20,0087 & 20,0055 & 20,0485 & 20,0254 & 20,0320 & 20,1320 & 20,1560 & 20,1240 \\
\hline An & 12,04 & 12,20 & 12,08 & 10,96 & 11,65 & 35,36 & 36,32 & 11,58 & 11,17 \\
\hline$A b$ & 62,23 & 61,06 & 62,97 & 61,42 & 62,50 & 59,65 & 58,95 & 66,44 & 65,13 \\
\hline Or & 25,73 & 26,74 & 24,95 & 27,63 & 25,86 & 4,64 & 4,39 & 21,68 & 22,99 \\
\hline
\end{tabular}

Tabla IV.10: Análisis de la química mineral. 


\section{Feldespatos}

\begin{tabular}{|c|c|c|c|c|c|c|c|c|c|}
\hline Unidad & \multicolumn{6}{|c|}{ Ignimbrita Portezuelo } & \multicolumn{3}{|c|}{ Traquitoides Pre-caldera } \\
\hline Muestra & \multicolumn{6}{|c|}{ PMB 44 (clasto de spatter) } & \multicolumn{3}{|c|}{ PM 27} \\
\hline Cristal & \multicolumn{2}{|c|}{ Plc } & \multicolumn{2}{|c|}{$\mathrm{Ple}$} & \multicolumn{2}{|c|}{$\mathrm{Plg}$} & \multicolumn{3}{|c|}{$\mathrm{PlA}$} \\
\hline Punto & 1 & 2 & 1 & 2 & 1 & 2 & 1 & 2 & 3 \\
\hline Ubicación & borde & centro & borde & centro & borde & centro & centro & medio & medio \\
\hline \multicolumn{10}{|l|}{$\%$} \\
\hline $\mathrm{SiO}_{2}$ & 57,61 & 58,23 & 58,29 & 59,43 & 59,06 & 58,72 & 61,133 & 60,343 & 60,253 \\
\hline $\mathrm{Al}_{2} \mathrm{O}_{3}$ & 24,43 & 24,54 & 25,12 & 25,03 & 24,58 & 25,06 & 23,885 & 24,096 & 24,757 \\
\hline $\mathrm{TiO}_{2}$ & 0,04 & 0,05 & 0,08 & 0,07 & 0,06 & 0,08 & 0,072 & 0,191 & 0,000 \\
\hline $\mathrm{Fe}_{2} \mathrm{O}_{3}$ & 0,32 & 0,40 & 0,40 & 0,33 & 0,47 & 0,31 & 0,282 & 0,323 & 0,457 \\
\hline $\mathrm{MnO}$ & - & - & - & - & - & - & 0,010 & 0,012 & 0,000 \\
\hline $\mathrm{MgO}$ & 0,02 & 0,01 & 0,05 & 0,04 & 0,05 & 0,05 & 0,003 & 0,034 & 0,020 \\
\hline $\mathrm{CaO}$ & 7,35 & 7,24 & 7,48 & 7,14 & 6,72 & 7,49 & 5,291 & 5,457 & 6,118 \\
\hline $\mathrm{Na}_{2} \mathrm{O}$ & 7,20 & 7,05 & 6,92 & 7,19 & 7,22 & 6,92 & 7,487 & 7,503 & 7,226 \\
\hline $\mathrm{K}_{2} \mathrm{O}$ & 0,87 & 0,90 & 0,83 & 0,96 & 1,03 & 0,84 & 1,465 & 1,395 & 1,222 \\
\hline $\mathrm{SrO}$ & - & - & - & - & - & - & 0,192 & 0,220 & 0,229 \\
\hline \multirow[t]{2}{*}{$\mathrm{BaO}$} & 0,03 & 0,08 & 0,15 & 0,15 & 0,00 & 0,00 & 0,107 & 0,171 & 0,010 \\
\hline & --- & --- & --- & --- & --- & --- & --- & --- & --- \\
\hline Total & 97,92 & 98,60 & 99,43 & 100,40 & 99,23 & 99,54 & 99,926 & 99,745 & 100,291 \\
\hline \multicolumn{10}{|c|}{$N^{\circ}$ Cationes } \\
\hline Si & 10,576 & 10,612 & 10,540 & 10,628 & 10,668 & 10,584 & 10,9322 & 10,8359 & 10,7539 \\
\hline$A 1+3$ & 5,288 & 5,272 & 5,352 & 5,276 & 5,232 & 5,324 & 5,0339 & 5,0996 & 5,2076 \\
\hline $\mathrm{Ti}+4$ & 0,004 & 0,008 & 0,012 & 0,008 & 0,008 & 0,012 & 0,0096 & 0,0257 & 0,0000 \\
\hline $\mathrm{Fe}+3$ & 0,044 & 0,056 & 0,056 & 0,044 & 0,064 & 0,044 & 0,0380 & 0,0437 & 0,0613 \\
\hline Mn & - & - & - & - & - & - & 0,0015 & 0,0019 & 0,0000 \\
\hline $\mathrm{Mg}$ & 0,004 & 0,004 & 0,016 & 0,008 & 0,012 & 0,012 & 0,0009 & 0,0092 & 0,0052 \\
\hline $\mathrm{Ca}$ & 1,448 & 1,416 & 1,448 & 1,368 & 1,300 & 1,444 & 1,0137 & 1,0499 & 1,1700 \\
\hline $\mathrm{Na}$ & 2,560 & 2,488 & 2,424 & 2,496 & 2,352 & 2,416 & 2,5959 & 2,6123 & 2,5004 \\
\hline $\mathbf{K}$ & 0,204 & 0,208 & 0,192 & 0,220 & 0,236 & 0,192 & 0,3342 & 0,3196 & 0,2782 \\
\hline $\mathrm{Sr}$ & - & - & - & - & - & - & 0,0199 & 0,0229 & 0,0237 \\
\hline \multirow[t]{2}{*}{$\mathbf{B a}$} & 0,004 & 0,004 & 0,012 & 0,012 & 0,000 & 0,000 & 0,0075 & 0,0120 & 0,0007 \\
\hline & 0,004 & 0,012 & 0,012 & 0,008 & 0,008 & 0,008 & --- & --- & --- \\
\hline Total & 20,140 & 20,076 & 20,060 & 20,064 & 20,060 & 20,036 & 19,9873 & 20,0327 & 20,0010 \\
\hline An & 34,269 & 34,242 & 35,46 & 33,372 & 31,909 & 35,559 & 26,03 & 26,71 & 30,05 \\
\hline$A b$ & 60,706 & 60,285 & 59,33 & 60,863 & 62,123 & 59,472 & 65,37 & 65,04 & 62,93 \\
\hline Or & 4,838 & 5,07 & 4,671 & 5,355 & 5,817 & 4,766 & 8,60 & 8,26 & 7,02 \\
\hline
\end{tabular}

Tabla IV.11: Análisis de la química mineral. 


\section{Feldespatos}

\begin{tabular}{|c|c|c|c|c|c|c|c|c|c|}
\hline \multirow{4}{*}{$\begin{array}{l}\text { Unidad } \\
\text { Muestra } \\
\text { Cristal } \\
\text { Punto }\end{array}$} & \multicolumn{9}{|c|}{ Traquitoides Pre-caldera } \\
\hline & \multicolumn{9}{|c|}{ PM 27} \\
\hline & \multicolumn{2}{|c|}{$\mathrm{PlA}$} & \multicolumn{5}{|c|}{ Pl B } & \multicolumn{2}{|c|}{$\mathrm{PlC}$} \\
\hline & 4 & 5 & 1 & 2 & 3 & 4 & 5 & 1 & 2 \\
\hline Ubicación & borde int. & borde & centro & medio & medio & borde int. & borde & centro & centro \\
\hline \multicolumn{10}{|l|}{$\%$} \\
\hline $\mathrm{SiO}_{2}$ & 59,427 & 60,327 & 57,566 & 57,899 & 59,780 & 62,103 & 61,906 & 49,984 & 49,262 \\
\hline $\mathrm{Al}_{2} \mathrm{O}_{3}$ & 24,510 & 23,939 & 25,860 & 25,947 & 24,386 & 23,077 & 23,056 & 32,550 & 31,768 \\
\hline $\mathrm{TiO}_{2}$ & 0,000 & 0,164 & 0,071 & 0,000 & 0,048 & 0,119 & 0,096 & 0,118 & 0,024 \\
\hline $\mathrm{Fe}_{2} \mathrm{O}_{3}$ & 0,288 & 0,336 & 0,446 & 0,380 & 0,435 & 0,407 & 0,180 & 0,213 & 0,337 \\
\hline $\mathrm{MnO}$ & 0,000 & 0,000 & 0,000 & 0,000 & 0,007 & 0,010 & 0,003 & 0,012 & 0,031 \\
\hline $\mathrm{MgO}$ & 0,025 & 0,020 & 0,023 & 0,026 & 0,000 & 0,000 & 0,015 & 0,011 & 0,009 \\
\hline $\mathrm{CaO}$ & 5,644 & 5,387 & 7,460 & 7,717 & 5,750 & 4,013 & 4,161 & 14,351 & 14,054 \\
\hline $\mathrm{Na}_{2} \mathrm{O}$ & 7,236 & 7,354 & 6,671 & 6,620 & 7,411 & 7,518 & 7,677 & 3,044 & 3,205 \\
\hline $\mathrm{K}_{2} \mathrm{O}$ & 1,240 & 1,206 & 0,927 & 0,909 & 1,214 & 2,209 & 1,947 & 0,158 & 0,161 \\
\hline $\mathrm{SrO}$ & 0,244 & 0,115 & 0,321 & 0,194 & 0,195 & 0,192 & 0,111 & 0,220 & 0,133 \\
\hline \multirow[t]{2}{*}{$\mathrm{BaO}$} & 0,132 & 0,168 & 0,050 & 0,136 & 0,052 & 0,110 & 0,041 & 0,147 & 0,000 \\
\hline & --- & --- & --- & --- & --- & --- & --- & --- & --- \\
\hline Total & 98,746 & 99,016 & 99,396 & 99,828 & 99,278 & 99,759 & 99,193 & 100,808 & 98,984 \\
\hline \multicolumn{10}{|c|}{$N^{\circ}$ Cationes } \\
\hline Si & 10,7687 & 10,8800 & 10,4220 & 10,4342 & 10,7777 & 11,1145 & 11,1188 & 9,0587 & 9,0864 \\
\hline$A l+3$ & 5,2345 & 5,0884 & 5,5179 & 5,5110 & 5,1817 & 4,8676 & 4,8805 & 6,9526 & 6,9062 \\
\hline $\mathrm{Ti}+4$ & 0,0000 & 0,0223 & 0,0097 & 0,0000 & 0,0065 & 0,0161 & 0,0129 & 0,0161 & 0,0033 \\
\hline $\mathrm{Fe}+3$ & 0,0393 & 0,0456 & 0,0608 & 0,0515 & 0,0590 & 0,0548 & 0,0244 & 0,0291 & 0,0468 \\
\hline Mn & 0,0000 & 0,0000 & 0,0000 & 0,0000 & 0,0010 & 0,0016 & 0,0005 & 0,0018 & 0,0048 \\
\hline $\mathrm{Mg}$ & 0,0069 & 0,0053 & 0,0063 & 0,0069 & 0,0000 & 0,0000 & 0,0040 & 0,0031 & 0,0024 \\
\hline $\mathrm{Ca}$ & 1,0957 & 1,0409 & 1,4471 & 1,4901 & 1,1108 & 0,7695 & 0,8007 & 2,7866 & 2,7775 \\
\hline $\mathrm{Na}$ & 2,5422 & 2,5714 & 2,3416 & 2,3130 & 2,5905 & 2,6086 & 2,6735 & 1,0696 & 1,1462 \\
\hline $\mathbf{K}$ & 0,2867 & 0,2775 & 0,2141 & 0,2090 & 0,2793 & 0,5044 & 0,4461 & 0,0365 & 0,0380 \\
\hline $\mathrm{Sr}$ & 0,0256 & 0,0120 & 0,0337 & 0,0203 & 0,0204 & 0,0200 & 0,0116 & 0,0231 & 0,0142 \\
\hline \multirow[t]{2}{*}{ Ba } & 0,0094 & 0,0119 & 0,0036 & 0,0096 & 0,0037 & 0,0077 & 0,0029 & 0,0104 & 0,0000 \\
\hline & --- & --- & --- & --- & --- & --- & --- & --- & --- \\
\hline Total & 20,0089 & 19,9552 & 20,0568 & 20,0456 & 20,0304 & 19,9647 & 19,9757 & 19,9875 & 20,0259 \\
\hline An & 28,32 & 26,90 & 36,65 & 37,37 & 28,25 & 20,19 & 20,64 & 71,56 & 70,22 \\
\hline$A b$ & 64,20 & 65,70 & 57,96 & 57,22 & 64,69 & 66,71 & 67,95 & 27,24 & 28,83 \\
\hline Or & 7,48 & 7,39 & 5,39 & 5,41 & 7,07 & 13,10 & 11,41 & 1,19 & 0,96 \\
\hline
\end{tabular}

Tabla IV.12: Análisis de la química mineral. 
Feldespatos

\begin{tabular}{|c|c|c|c|c|c|c|c|c|}
\hline \multirow{4}{*}{$\begin{array}{l}\text { Unidad } \\
\text { Muestra } \\
\text { Cristal } \\
\text { Punto }\end{array}$} & \multicolumn{8}{|c|}{ Traquitoides Pre-caldera } \\
\hline & \multicolumn{6}{|c|}{ PM 27} & \multirow{2}{*}{\multicolumn{2}{|c|}{$\begin{array}{c}\text { PM } 28 \\
\text { PL A }\end{array}$}} \\
\hline & \multicolumn{4}{|c|}{$\mathrm{PlC}$} & \multicolumn{2}{|c|}{ PL P } & & \\
\hline & 3 & 4 & 5 & 6 & 1 & 2 & 1 & 2 \\
\hline Ubicación & medio & medio & borde int. & borde & centro & borde & centro & medio \\
\hline \multicolumn{9}{|l|}{$\%$} \\
\hline $\mathrm{SiO}_{2}$ & 53,326 & 61,232 & 60,301 & 59,892 & 60,079 & 60,5 & 54,249 & 55,318 \\
\hline $\mathrm{Al}_{2} \mathrm{O}_{3}$ & 29,843 & 24,029 & 24,748 & 24,351 & 24,743 & 24,48 & 29,514 & 28,921 \\
\hline $\mathrm{TiO}_{2}$ & 0,071 & 0,000 & 0,094 & 0,118 & 0,000 & 0,000 & 0,000 & 0,000 \\
\hline $\mathrm{Fe}_{2} \mathrm{O}_{3}$ & 0,295 & 0,300 & 0,161 & 0,396 & 0,449 & 0,427 & 0,680 & 0,579 \\
\hline $\mathrm{MnO}$ & 0,021 & 0,000 & 0,000 & 0,000 & 0,000 & 0,020 & 0,022 & 0,039 \\
\hline $\mathrm{MgO}$ & 0,028 & 0,016 & 0,003 & 0,002 & 0,014 & 0,023 & 0,039 & 0,034 \\
\hline $\mathrm{CaO}$ & 11,502 & 5,343 & 6,073 & 5,629 & 5,866 & 5,799 & 11,805 & 10,870 \\
\hline $\mathrm{Na}_{2} \mathrm{O}$ & 4,727 & 7,574 & 7,202 & 7,346 & 7,174 & 7,480 & 4,428 & 4,952 \\
\hline $\mathrm{K}_{2} \mathrm{O}$ & 0,291 & 1,415 & 1,115 & 1,341 & 1,184 & 1,331 & 0,356 & 0,400 \\
\hline $\mathrm{SrO}$ & 0,377 & 0,090 & 0,146 & 0,226 & 0,060 & 0,113 & 0,431 & 0,264 \\
\hline \multirow[t]{2}{*}{$\mathrm{BaO}$} & 0,067 & 0,102 & 0,069 & 0,126 & 0,239 & 0,093 & 0,051 & 0,098 \\
\hline & --- & --- & --- & --- & --- & --- & --- & --- \\
\hline Total & 100,547 & 100,101 & 99,911 & 99,426 & 99,808 & 100,267 & 101,575 & 101,474 \\
\hline
\end{tabular}

\section{$N^{\circ}$ Cationes}

\begin{tabular}{lrrrrrrrr} 
Si & 9,6275 & 10,9240 & 10,7806 & 10,7883 & 10,7673 & 10,8019 & 9,7005 & 9,8675 \\
Al+3 & 6,3500 & 5,0524 & 5,2146 & 5,1698 & 5,2264 & 5,1513 & 6,2199 & 6,0802 \\
Ti+4 & 0,0096 & 0,0000 & 0,0126 & 0,0160 & 0,0000 & 0,0000 & 0,0000 & 0,0000 \\
Fe+3 & 0,0400 & 0,0402 & 0,0217 & 0,0536 & 0,0606 & 0,0574 & 0,0915 & 0,0777 \\
Mn & 0,0032 & 0,0000 & 0,0000 & 0,0000 & 0,0000 & 0,0030 & 0,0033 & 0,0059 \\
Mg & 0,0077 & 0,0042 & 0,0007 & 0,0005 & 0,0037 & 0,0062 & 0,0104 & 0,0090 \\
Ca & 2,2249 & 1,0214 & 1,1632 & 1,0865 & 1,1265 & 1,1094 & 2,2617 & 2,0774 \\
Na & 1,6545 & 2,6199 & 2,4965 & 2,5655 & 2,4927 & 2,5893 & 1,5350 & 1,7126 \\
K & 0,0671 & 0,3221 & 0,2542 & 0,3082 & 0,2706 & 0,3032 & 0,0812 & 0,0911 \\
Sr & 0,0395 & 0,0093 & 0,0152 & 0,0236 & 0,0062 & 0,0117 & 0,0447 & 0,0273 \\
Ba & 0,0047 & 0,0071 & 0,0048 & 0,0089 & 0,0168 & 0,0065 & 0,0036 & 0,0068 \\
& --- & --- & --- & --- & --- & --- & --- & --- \\
Total & 20,0287 & 20,0006 & 19,9640 & 20,0209 & 19,9708 & 20,0400 & 19,9519 & 19,9554 \\
& & & & & & & & \\
An & 56,74 & 25,90 & 29,96 & 27,80 & 28,95 & 27,89 & 58,74 & 53,76 \\
Ab & 41,46 & 65,83 & 63,46 & 64,25 & 63,71 & 64,41 & 39,10 & 43,74 \\
Or & 1,80 & 8,27 & 6,58 & 7,94 & 7,35 & 7,70 & 2,16 & 2,50 \\
\hline
\end{tabular}

Tabla IV.13: Análisis de la química mineral. 


\section{Feldespatos}

\begin{tabular}{|c|c|c|c|c|c|c|c|c|c|}
\hline \multirow{4}{*}{$\begin{array}{l}\text { Unidad } \\
\text { Muestra } \\
\text { Cristal } \\
\text { Punto }\end{array}$} & \multicolumn{9}{|c|}{ Traquitoides Pre-caldera } \\
\hline & \multicolumn{9}{|c|}{ PM 28} \\
\hline & \multicolumn{2}{|c|}{ Pl A } & \multicolumn{4}{|c|}{ Pl B } & \multicolumn{3}{|c|}{$\mathrm{PlC}$} \\
\hline & 3 & 4 & 1 & 2 & 3 & 4 & 1 & 2 & 3 \\
\hline Ubicación & medio & borde & centro & medio & borde int. & borde & centro & centro & medio \\
\hline \multicolumn{10}{|l|}{$\%$} \\
\hline $\mathrm{SiO}_{2}$ & 55,570 & 57,620 & 56,554 & 57,553 & 57,823 & 60,167 & 58,079 & 57,181 & 59,976 \\
\hline $\mathrm{Al}_{2} \mathrm{O}_{3}$ & 28,676 & 26,473 & 26,413 & 26,890 & 26,027 & 25,817 & 27,190 & 27,291 & 25,350 \\
\hline $\mathrm{TiO}_{2}$ & 0,000 & 0,093 & 0,046 & 0,070 & 0,000 & 0,000 & 0,047 & 0,000 & 0,000 \\
\hline $\mathrm{Fe}_{2} \mathrm{O}_{3}$ & 0,583 & 0,348 & 0,505 & 0,558 & 0,455 & 0,406 & 0,289 & 0,350 & 0,348 \\
\hline $\mathrm{MnO}$ & 0,011 & 0,004 & 0,012 & 0,030 & 0,007 & 0,007 & 0,016 & 0,000 & 0,019 \\
\hline $\mathrm{MgO}$ & 0,068 & 0,043 & 0,009 & 0,025 & 0,002 & 0,025 & 0,025 & 0,019 & 0,042 \\
\hline $\mathrm{CaO}$ & 10,488 & 7,718 & 8,051 & 8,345 & 7,564 & 7,259 & 8,346 & 8,630 & 6,425 \\
\hline $\mathrm{Na}_{2} \mathrm{O}$ & 5,330 & 6,388 & 6,159 & 6,286 & 6,681 & 6,878 & 5,906 & 6,046 & 6,918 \\
\hline $\mathrm{K}_{2} \mathrm{O}$ & 0,453 & 0,857 & 0,562 & 0,744 & 0,738 & 0,653 & 0,696 & 0,643 & 1,021 \\
\hline $\mathrm{SrO}$ & 0,265 & 0,304 & 0,195 & 0,312 & 0,220 & 0,151 & 0,189 & 0,241 & 0,164 \\
\hline \multirow[t]{2}{*}{$\mathrm{BaO}$} & 0,026 & 0,086 & 0,164 & 0,010 & 0,107 & 0,163 & 0,087 & 0,064 & 0,055 \\
\hline & --- & --- & --- & --- & --- & --- & --- & --- & --- \\
\hline Total & 101,473 & 99,936 & 98,671 & 100,82 & 99,623 & 101,525 & 100,869 & 100,466 & 100,318 \\
\hline
\end{tabular}

\section{$\mathbf{N}^{\circ}$ Cationes}

\begin{tabular}{lrrrrrrrrr} 
Si & 9,9086 & 10,3668 & 10,3060 & 10,2811 & 10,4302 & 10,6086 & 10,3292 & 10,2386 & 10,6863 \\
$\mathbf{A l + 3}$ & 6,0264 & 5,6135 & 5,6729 & 5,6614 & 5,5333 & 5,3649 & 5,6992 & 5,7593 & 5,3233 \\
Ti+4 & 0,0000 & 0,0126 & 0,0064 & 0,0094 & 0,0000 & 0,0000 & 0,0063 & 0,0000 & 0,0000 \\
Fe+3 & 0,0782 & 0,0472 & 0,0693 & 0,0750 & 0,0617 & 0,0538 & 0,0386 & 0,0472 & 0,0467 \\
Mn & 0,0017 & 0,0006 & 0,0019 & 0,0045 & 0,0010 & 0,0010 & 0,0025 & 0,0000 & 0,0029 \\
Mg & 0,0182 & 0,0116 & 0,0026 & 0,0065 & 0,0004 & 0,0066 & 0,0066 & 0,0051 & 0,0111 \\
Ca & 2,0037 & 1,4878 & 1,5719 & 1,5971 & 1,4618 & 1,3713 & 1,5903 & 1,6556 & 1,2265 \\
Na & 1,8428 & 2,2284 & 2,1761 & 2,1770 & 2,3368 & 2,3512 & 2,0367 & 2,0991 & 2,3900 \\
K & 0,1031 & 0,1968 & 0,1306 & 0,1696 & 0,1699 & 0,1468 & 0,1579 & 0,1469 & 0,2321 \\
Sr & 0,0274 & 0,0317 & 0,0206 & 0,0323 & 0,0230 & 0,0154 & 0,0195 & 0,0250 & 0,0169 \\
Ba & 0,0018 & 0,0061 & 0,0117 & 0,0007 & 0,0075 & 0,0113 & 0,0060 & 0,0045 & 0,0039 \\
& --- & --- & --- & --- & --- & --- & --- & --- & --- \\
Total & 20,0120 & 20,0029 & 19,9699 & 20,0147 & 20,0256 & 19,9310 & 19,8929 & 19,9812 & 19,9397 \\
& & & & & & & & & \\
An & 51,05 & 38,46 & 40,72 & 40,97 & 37,13 & 35,59 & 42,25 & 42,75 & 32,13 \\
Ab & 46,32 & 56,40 & 55,64 & 54,74 & 58,43 & 60,35 & 53,45 & 53,40 & 61,77 \\
Or & 2,64 & 5,14 & 3,64 & 4,28 & 4,44 & 4,06 & 4,30 & 3,85 & 6,10 \\
\hline
\end{tabular}

Tabla IV.14: Análisis de la química mineral. 


\section{Feldespatos}

\begin{tabular}{|c|c|c|c|c|c|c|c|c|c|}
\hline \multirow{4}{*}{$\begin{array}{l}\text { Unidad } \\
\text { Muestra } \\
\text { Cristal } \\
\text { Punto }\end{array}$} & \multicolumn{9}{|c|}{ Traquitoides Pre-caldera } \\
\hline & \multicolumn{6}{|c|}{ PM 28} & \multirow{2}{*}{\multicolumn{3}{|c|}{$\begin{array}{c}\text { PY } 10 \\
\text { Pl A }\end{array}$}} \\
\hline & \multicolumn{4}{|c|}{$\mathrm{PlC}$} & \multicolumn{2}{|c|}{$\mathrm{Pl} \mathrm{P}$} & & & \\
\hline & 4 & 5 & 6 & 7 & 1 & 2 & 1 & 2 & 3 \\
\hline Ubicación & medio & medio & borde int. & borde & centro & borde & borde & centro & centro \\
\hline \multicolumn{10}{|l|}{$\%$} \\
\hline $\mathrm{SiO}_{2}$ & 59,537 & 59,504 & 58,664 & 59,096 & 61,424 & 59,517 & 61,256 & 52,038 & 54,645 \\
\hline $\mathrm{Al}_{2} \mathrm{O}_{3}$ & 25,151 & 25,321 & 25,018 & 25,364 & 24,882 & 25,166 & 23,921 & 30,786 & 28,266 \\
\hline $\mathrm{TiO}_{2}$ & 0,000 & 0,093 & 0,047 & 0,164 & 0,070 & 0,093 & 0,023 & 0,000 & 0,165 \\
\hline $\mathrm{Fe}_{2} \mathrm{O}_{3}$ & 0,208 & 0,411 & 0,488 & 0,370 & 0,254 & 0,286 & 0,290 & 0,121 & 0,218 \\
\hline $\mathrm{MnO}$ & 0,024 & 0,004 & 0,006 & 0,021 & 0,000 & 0,004 & 0,030 & 0,010 & 0,000 \\
\hline $\mathrm{MgO}$ & 0,027 & 0,000 & 0,006 & 0,000 & 0,009 & 0,019 & 0,000 & 0,015 & 0,000 \\
\hline $\mathrm{CaO}$ & 6,542 & 6,693 & 6,636 & 6,847 & 5,907 & 6,543 & 5,124 & 12,525 & 10,201 \\
\hline $\mathrm{Na}_{2} \mathrm{O}$ & 7,035 & 7,358 & 7,109 & 6,882 & 7,306 & 7,348 & 7,540 & 4,099 & 5,415 \\
\hline $\mathrm{K}_{2} \mathrm{O}$ & 1,034 & 0,754 & 0,703 & 0,820 & 1,371 & 0,721 & 1,564 & 0,260 & 0,477 \\
\hline $\mathrm{SrO}$ & 0,207 & 0,288 & 0,072 & 0,228 & 0,071 & 0,191 & 0,159 & 0,248 & 0,364 \\
\hline \multirow[t]{2}{*}{$\mathrm{BaO}$} & 0,060 & 0,143 & 0,034 & 0,011 & 0,126 & 0,121 & 0,067 & 0,000 & 0,000 \\
\hline & --- & --- & --- & --- & --- & --- & --- & --- & --- \\
\hline Total & 99,827 & 100,570 & 98,782 & 99,801 & 101,419 & 100,009 & 99,974 & 100,103 & 99,751 \\
\hline \multicolumn{10}{|c|}{$\mathbf{N}^{\circ}$ Cationes } \\
\hline Si & 10,6752 & 10,6145 & 10,6241 & 10,6013 & 10,8226 & 10,6535 & 10,9445 & 9,4415 & 9,9102 \\
\hline$A l+3$ & 5,3151 & 5,3235 & 5,3400 & 5,3628 & 5,1669 & 5,3093 & 5,0370 & 6,5830 & 6,0416 \\
\hline $\mathrm{Ti}+4$ & 0,0000 & 0,0125 & 0,0064 & 0,0221 & 0,0092 & 0,0125 & 0,0032 & 0,0000 & 0,0225 \\
\hline $\mathrm{Fe}+3$ & 0,0281 & 0,0552 & 0,0665 & 0,0499 & 0,0337 & 0,0385 & 0,0389 & 0,0166 & 0,0298 \\
\hline Mn & 0,0036 & 0,0005 & 0,0009 & 0,0031 & 0,0000 & 0,0006 & 0,0045 & 0,0016 & 0,0000 \\
\hline Mg & 0,0073 & 0,0000 & 0,0016 & 0,0000 & 0,0024 & 0,0050 & 0,0000 & 0,0040 & 0,0001 \\
\hline $\mathrm{Ca}$ & 1,2568 & 1,2793 & 1,2876 & 1,3160 & 1,1150 & 1,2548 & 0,9808 & 2,4348 & 1,9821 \\
\hline $\mathrm{Na}$ & 2,4459 & 2,5450 & 2,4961 & 2,3936 & 2,4958 & 2,5503 & 2,6120 & 1,4421 & 1,9041 \\
\hline $\mathbf{K}$ & 0,2366 & 0,1717 & 0,1625 & 0,1877 & 0,3081 & 0,1645 & 0,3565 & 0,0602 & 0,1103 \\
\hline Sr & 0,0215 & 0,0298 & 0,0075 & 0,0237 & 0,0073 & 0,0199 & 0,0165 & 0,0261 & 0,0383 \\
\hline \multirow[t]{2}{*}{ Ba } & 0,0042 & 0,0100 & 0,0024 & 0,0008 & 0,0087 & 0,0085 & 0,0047 & 0,0000 & 0,0000 \\
\hline & --- & --- & --- & --- & --- & --- & --- & --- & --- \\
\hline Total & 19,9944 & 20,0420 & 19,9956 & 19,9609 & 19,9698 & 20,0175 & 19,9986 & 20,0098 & 20,0388 \\
\hline An & 32,24 & 32,44 & 32,74 & 34,16 & 28,52 & 31,88 & 25,12 & 62,09 & 50,07 \\
\hline$A b$ & 61,69 & 63,06 & 63,09 & 61,03 & 63,43 & 63,79 & 65,79 & 36,39 & 47,19 \\
\hline Or & 6,07 & 4,50 & 4,17 & 4,81 & 8,05 & 4,33 & 9,10 & 1,52 & 2,73 \\
\hline
\end{tabular}

Tabla IV.15: Análisis de la química mineral. 


\section{Feldespatos}

\begin{tabular}{|c|c|c|c|c|c|c|c|c|c|}
\hline \multirow{4}{*}{$\begin{array}{l}\text { Unidad } \\
\text { Muestra } \\
\text { Cristal } \\
\text { Punto }\end{array}$} & \multicolumn{9}{|c|}{ Traquitoides Pre-caldera } \\
\hline & \multicolumn{9}{|c|}{ PY 10} \\
\hline & \multicolumn{4}{|c|}{ Pl A } & \multicolumn{5}{|c|}{$\mathrm{PlB}$} \\
\hline & 4 & 5 & 6 & 7 & 1 & 2 & 3 & 4 & 5 \\
\hline Ubicación & medio & medio & borde int. & borde & centro & centro & medio & medio & borde \\
\hline \multicolumn{10}{|l|}{$\%$} \\
\hline $\mathrm{SiO}_{2}$ & 56,785 & 56,872 & 63,102 & 62,212 & 64,669 & 62,386 & 64,394 & 62,544 & 61,398 \\
\hline $\mathrm{Al}_{2} \mathrm{O}_{3}$ & 27,038 & 26,508 & 22,760 & 22,679 & 20,769 & 22,240 & 20,270 & 22,257 & 23,384 \\
\hline $\mathrm{TiO}_{2}$ & 0,024 & 0,000 & 0,000 & 0,000 & 0,000 & 0,235 & 0,164 & 0,117 & 0,094 \\
\hline $\mathrm{Fe}_{2} \mathrm{O}_{3}$ & 0,356 & 0,221 & 0,207 & 0,214 & 0,233 & 0,384 & 0,132 & 0,303 & 0,426 \\
\hline $\mathrm{MnO}$ & 0,000 & 0,023 & 0,018 & 0,017 & 0,000 & 0,010 & 0,000 & 0,005 & 0,027 \\
\hline $\mathrm{MgO}$ & 0,007 & 0,027 & 0,008 & 0,017 & 0,004 & 0,000 & 0,003 & 0,023 & 0,002 \\
\hline $\mathrm{CaO}$ & 8,552 & 8,081 & 3,967 & 3,729 & 1,834 & 3,348 & 1,158 & 3,411 & 4,485 \\
\hline $\mathrm{Na}_{2} \mathrm{O}$ & 6,489 & 6,584 & 7,950 & 7,623 & 6,958 & 7,591 & 6,163 & 7,798 & 7,640 \\
\hline $\mathrm{K}_{2} \mathrm{O}$ & 0,572 & 0,659 & 2,103 & 2,666 & 4,665 & 2,853 & 6,669 & 2,573 & 1,536 \\
\hline $\mathrm{SrO}$ & 0,277 & 0,154 & 0,115 & 0,191 & 0,109 & 0,151 & 0,169 & 0,127 & 0,252 \\
\hline \multirow[t]{2}{*}{$\mathrm{BaO}$} & 0,100 & 0,027 & 0,086 & 0,255 & 0,142 & 0,153 & 0,096 & 0,097 & 0,136 \\
\hline & --- & --- & --- & --- & --- & --- & --- & --- & -- \\
\hline Total & 100,200 & 99,155 & 100,315 & 99,604 & 99,383 & 99,351 & 99,216 & 99,256 & 99,380 \\
\hline \multicolumn{10}{|c|}{$\mathbf{N}^{\circ}$ Cationes } \\
\hline Si & 10,2180 & 10,3124 & 11,2119 & 11,1781 & 11,6175 & 11,2282 & 11,6665 & 11,2464 & 11,0271 \\
\hline $\mathrm{Al}+3$ & 5,7341 & 5,6650 & 4,7661 & 4,8026 & 4,3973 & 4,7176 & 4,3281 & 4,7169 & 4,9497 \\
\hline $\mathbf{T i}+4$ & 0,0032 & 0,0000 & 0,0000 & 0,0000 & 0,0000 & 0,0318 & 0,0224 & 0,0158 & 0,0126 \\
\hline $\mathrm{Fe}+3$ & 0,0481 & 0,0302 & 0,0276 & 0,0289 & 0,0315 & 0,0520 & 0,0180 & 0,0410 & 0,0575 \\
\hline Mn & 0,0000 & 0,0035 & 0,0027 & 0,0027 & 0,0000 & 0,0015 & 0,0000 & 0,0007 & 0,0041 \\
\hline Mg & 0,0019 & 0,0072 & 0,0022 & 0,0046 & 0,0012 & 0,0000 & 0,0007 & 0,0063 & 0,0005 \\
\hline $\mathrm{Ca}$ & 1,6489 & 1,5700 & 0,7553 & 0,7178 & 0,3530 & 0,6457 & 0,2248 & 0,6572 & 0,8631 \\
\hline $\mathrm{Na}$ & 2,2639 & 2,3147 & 2,7387 & 2,6558 & 2,4234 & 2,6488 & 2,1648 & 2,7188 & 2,6605 \\
\hline $\mathbf{K}$ & 0,1313 & 0,1524 & 0,4768 & 0,6112 & 1,0691 & 0,6550 & 1,5414 & 0,5902 & 0,3520 \\
\hline Sr & 0,0289 & 0,0161 & 0,0119 & 0,0199 & 0,0113 & 0,0158 & 0,0177 & 0,0133 & 0,0262 \\
\hline \multirow[t]{2}{*}{$\mathrm{Ba}$} & 0,0071 & 0,0019 & 0,0060 & 0,0180 & 0,0100 & 0,0108 & 0,0068 & 0,0068 & 0,0096 \\
\hline & --- & --- & --- & --- & --- & --- & --- & --- & --- \\
\hline Total & 20,0853 & 20,0735 & 19,9990 & 20,0396 & 19,9143 & 20,0071 & 19,9911 & 20,0133 & 19,9629 \\
\hline An & 41,12 & 39,11 & 19,23 & 18,34 & 9,42 & 16,64 & 6,13 & 16,82 & 22,74 \\
\hline$A b$ & 55,49 & 57,08 & 68,66 & 66,02 & 62,67 & 66,62 & 54,73 & 68,20 & 68,02 \\
\hline Or & 3,39 & 3,81 & 12,10 & 15,64 & 27,91 & 16,75 & 39,14 & 14,98 & 9,24 \\
\hline
\end{tabular}

Tabla IV.16: Análisis de la química mineral. 


\section{Feldespatos}

\begin{tabular}{|c|c|c|c|c|c|c|c|}
\hline \multirow{4}{*}{$\begin{array}{l}\text { Unidad } \\
\text { Muestra } \\
\text { Cristal } \\
\text { Punto } \\
\end{array}$} & \multicolumn{7}{|c|}{ Traquitoides Pre-caldera } \\
\hline & \multicolumn{7}{|c|}{ PY 10} \\
\hline & \multicolumn{5}{|c|}{ PL C } & \multicolumn{2}{|c|}{ PL P } \\
\hline & 1 & 2 & 3 & 4 & 5 & 1 & 2 \\
\hline Ubicación & centro & medio & medio & borde int. & borde & centro & borde \\
\hline $\begin{array}{l}\% \\
\mathrm{SiO}_{2}\end{array}$ & 53,273 & 55,421 & 55,937 & 55,696 & 57,882 & 59,692 & 63,464 \\
\hline $\mathrm{Al}_{2} \mathrm{O}_{3}$ & 29,635 & 28,188 & 27,806 & 27,594 & 26,518 & 24,609 & 21,861 \\
\hline $\mathrm{TiO}_{2}$ & 0,000 & 0,047 & 0,094 & 0,141 & 0,141 & 0,188 & 0,094 \\
\hline $\mathrm{Fe}_{2} \mathrm{O}_{3}$ & 0,502 & 0,698 & 0,455 & 0,451 & 0,439 & 0,540 & 0,389 \\
\hline $\mathrm{MnO}$ & 0,017 & 0,000 & 0,001 & 0,000 & 0,000 & 0,000 & 0,000 \\
\hline $\mathrm{MgO}$ & 0,047 & 0,064 & 0,050 & 0,043 & 0,048 & 0,000 & 0,004 \\
\hline $\mathrm{CaO}$ & 11,870 & 10,018 & 9,578 & 9,577 & 8,152 & 5,905 & 3,148 \\
\hline $\mathrm{Na}_{2} \mathrm{O}$ & 4,531 & 5,701 & 5,847 & 5,796 & 6,287 & 7,302 & 7,680 \\
\hline $\mathrm{K}_{2} \mathrm{O}$ & 0,281 & 0,384 & 0,552 & 0,501 & 0,719 & 0,985 & 2,736 \\
\hline $\mathrm{SrO}$ & 0,291 & 0,171 & 0,145 & 0,357 & 0,266 & 0,264 & 0,163 \\
\hline \multirow[t]{2}{*}{$\mathrm{BaO}$} & 0,017 & 0,151 & 0,161 & 0,031 & 0,029 & 0,224 & 0,204 \\
\hline & --- & --- & --- & --- & --- & --- & --- \\
\hline tal & 100,463 & 100,844 & 100,626 & 100,187 & 100,482 & 99,710 & 99,744 \\
\hline
\end{tabular}

\section{$\mathbf{N}^{\circ}$ Cationes}

\begin{tabular}{lrrrrrrr} 
Si & 9,6284 & 9,9470 & 10,0452 & 10,0478 & 10,3547 & 10,7276 & 11,3519 \\
Al+3 & 6,3127 & 5,9626 & 5,8852 & 5,8672 & 5,5911 & 5,2125 & 4,6086 \\
Ti+4 & 0,0000 & 0,0064 & 0,0127 & 0,0192 & 0,0190 & 0,0254 & 0,0126 \\
Fe+3 & 0,0682 & 0,0943 & 0,0615 & 0,0612 & 0,0591 & 0,0731 & 0,0524 \\
Mn & 0,0026 & 0,0000 & 0,0002 & 0,0000 & 0,0000 & 0,0000 & 0,0000 \\
Mg & 0,0127 & 0,0172 & 0,0135 & 0,0114 & 0,0128 & 0,0000 & 0,0010 \\
Ca & 2,2985 & 1,9265 & 1,8429 & 1,8512 & 1,5625 & 1,1371 & 0,6033 \\
Na & 1,5879 & 1,9841 & 2,0360 & 2,0273 & 2,1808 & 2,5445 & 2,6635 \\
K & 0,0648 & 0,0879 & 0,1264 & 0,1152 & 0,1642 & 0,2259 & 0,6244 \\
Sr & 0,0305 & 0,0178 & 0,0151 & 0,0373 & 0,0276 & 0,0275 & 0,0169 \\
Ba & 0,0012 & 0,0106 & 0,0113 & 0,0022 & 0,0020 & 0,0157 & 0,0143 \\
& --- & --- & --- & --- & --- & --- & -- \\
Total & 20,0075 & 20,0542 & 20,0499 & 20,0400 & 19,9737 & 19,9894 & 19,9489 \\
& & & & & & & \\
An & 58,47 & 48,28 & 46,08 & 46,82 & 40,39 & 29,48 & 15,81 \\
Ab & 39,87 & 49,27 & 50,50 & 50,27 & 55,39 & 64,41 & 67,90 \\
Or & 1,66 & 2,45 & 3,42 & 2,91 & 4,22 & 6,12 & 16,28 \\
\hline
\end{tabular}

Tabla IV.17: Análisis de la química mineral. 
Feldespatos

\begin{tabular}{|c|c|c|c|c|c|c|c|c|}
\hline \multirow{4}{*}{$\begin{array}{l}\text { Unidad } \\
\text { Muestra } \\
\text { Cristal } \\
\text { Punto }\end{array}$} & \multicolumn{8}{|c|}{ Basaltos Post-caldera II } \\
\hline & \multicolumn{8}{|c|}{ PM 46} \\
\hline & \multicolumn{5}{|c|}{ Pl A } & \multicolumn{3}{|c|}{$\mathrm{PlB}$} \\
\hline & 1 & 2 & 3 & 4 & 5 & 1 & 2 & 3 \\
\hline Ubicación & centro & medio & borde int. & borde int. & borde & centro & borde int. & borde \\
\hline \multicolumn{9}{|l|}{$\%$} \\
\hline $\mathrm{SiO}_{2}$ & 48,193 & 47,113 & 46,868 & 49,271 & 51,116 & 47,121 & 46,188 & 49,441 \\
\hline $\mathrm{Al}_{2} \mathrm{O}_{3}$ & 33,295 & 34,233 & 33,842 & 32,542 & 30,956 & 32,980 & 33,497 & 31,397 \\
\hline $\mathrm{TiO}_{2}$ & 0,094 & 0,094 & 0,000 & 0,094 & 0,023 & 0,164 & 0,047 & 0,000 \\
\hline $\mathrm{Fe}_{2} \mathrm{O}_{3}$ & 0,510 & 0,673 & 0,583 & 0,520 & 0,748 & 0,829 & 0,600 & 0,675 \\
\hline $\mathrm{MnO}$ & 0,000 & 0,006 & 0,000 & 0,031 & 0,000 & 0,003 & 0,000 & 0,000 \\
\hline $\mathrm{MgO}$ & 0,069 & 0,071 & 0,066 & 0,102 & 0,100 & 0,055 & 0,058 & 0,145 \\
\hline $\mathrm{CaO}$ & 16,003 & 16,955 & 16,606 & 15,130 & 13,584 & 16,714 & 17,107 & 15,089 \\
\hline $\mathrm{Na}_{2} \mathrm{O}$ & 2,327 & 1,803 & 2,114 & 2,923 & 3,599 & 2,012 & 1,792 & 2,996 \\
\hline $\mathrm{K}_{2} \mathrm{O}$ & 0,073 & 0,047 & 0,120 & 0,141 & 0,295 & 0,161 & 0,082 & 0,165 \\
\hline $\mathrm{SrO}$ & 0,287 & 0,166 & 0,221 & 0,262 & 0,157 & 0,225 & 0,132 & 0,239 \\
\hline \multirow[t]{2}{*}{$\mathrm{BaO}$} & 0,000 & 0,094 & 0,045 & 0,197 & 0,062 & 0,007 & 0,010 & 0,000 \\
\hline & --- & --- & --- & --- & --- & --- & --- & --- \\
\hline Total & 100,850 & 101,255 & 100,464 & 101,212 & 100,641 & 100,271 & 99,513 & 100,146 \\
\hline \multicolumn{9}{|c|}{$\mathbf{N}^{\circ}$ Cationes } \\
\hline $\mathrm{Si}$ & 8,7783 & 8,5741 & 8,6005 & 8,9410 & 9,2762 & 8,6705 & 8,5618 & 9,0572 \\
\hline$A l+3$ & 7,1476 & 7,3427 & 7,3191 & 6,9599 & 6,6209 & 7,1523 & 7,3182 & 6,7789 \\
\hline $\mathbf{T i}+4$ & 0,0129 & 0,0129 & 0,0000 & 0,0128 & 0,0032 & 0,0227 & 0,0065 & 0,0000 \\
\hline $\mathrm{Fe}+3$ & 0,0699 & 0,0922 & 0,0805 & 0,0710 & 0,1022 & 0,1147 & 0,0837 & 0,0931 \\
\hline Mn & 0,0000 & 0,0009 & 0,0000 & 0,0048 & 0,0000 & 0,0005 & 0,0000 & 0,0000 \\
\hline Mg & 0,0187 & 0,0192 & 0,0179 & 0,0275 & 0,0272 & 0,0150 & 0,0160 & 0,0396 \\
\hline $\mathrm{Ca}$ & 3,1231 & 3,3059 & 3,2649 & 2,9417 & 2,6412 & 3,2952 & 3,3977 & 2,9615 \\
\hline $\mathrm{Na}$ & 0,8217 & 0,6360 & 0,7523 & 1,0283 & 1,2662 & 0,7180 & 0,6441 & 1,0640 \\
\hline $\mathbf{K}$ & 0,0169 & 0,0109 & 0,0280 & 0,0326 & 0,0682 & 0,0377 & 0,0195 & 0,0385 \\
\hline $\mathrm{Sr}$ & 0,0303 & 0,0175 & 0,0235 & 0,0276 & 0,0165 & 0,0240 & 0,0142 & 0,0254 \\
\hline \multirow[t]{2}{*}{$\mathrm{Ba}$} & 0,0000 & 0,0067 & 0,0033 & 0,0140 & 0,0044 & 0,0005 & 0,0007 & 0,0000 \\
\hline & --- & --- & --- & --- & --- & --- & --- & --- \\
\hline Total & 20,0194 & 20,0191 & 20,0899 & 20,0611 & 20,0263 & 20,0511 & 20,0625 & 20,0581 \\
\hline An & 78,99 & 83,57 & 80,76 & 73,42 & 66,50 & 81,44 & 83,70 & 73,04 \\
\hline $\mathbf{A b}$ & 20,58 & 15,99 & 18,47 & 25,43 & 31,68 & 17,62 & 15,80 & 26,02 \\
\hline Or & 0,42 & 0,44 & 0,77 & 1,15 & 1,82 & 0,94 & 0,50 & 0,94 \\
\hline
\end{tabular}

Tabla IV.18: Análisis de la química mineral. 


\section{Feldespatos}

\begin{tabular}{|c|c|c|c|c|c|c|c|c|c|}
\hline \multirow{4}{*}{$\begin{array}{l}\text { Unidad } \\
\text { Muestra } \\
\text { Cristal } \\
\text { Punto }\end{array}$} & \multicolumn{9}{|c|}{ Basaltos Post-caldera II } \\
\hline & \multicolumn{6}{|c|}{ PM 46} & \multirow{2}{*}{\multicolumn{3}{|c|}{$\begin{array}{c}\text { PY } 13 \\
\text { Pl A }\end{array}$}} \\
\hline & \multicolumn{4}{|c|}{$\mathrm{PlC}$} & \multicolumn{2}{|c|}{$\mathrm{PlP}$} & & & \\
\hline & 1 & 2 & 3 & 4 & 1 & 2 & 1 & 2 & 3 \\
\hline Ubicación & centro & medio & borde int. & borde & centro & borde & centro & medio & borde \\
\hline \multicolumn{10}{|l|}{$\%$} \\
\hline $\mathrm{SiO}_{2}$ & 48,124 & 48,419 & 46,768 & 52,349 & 50,078 & 50,791 & 49,228 & 49,490 & 46,246 \\
\hline $\mathrm{Al}_{2} \mathrm{O}_{3}$ & 33,343 & 33,256 & 33,569 & 29,742 & 30,449 & 30,309 & 30,966 & 30,968 & 33,489 \\
\hline $\mathrm{TiO}_{2}$ & 0,070 & 0,070 & 0,023 & 0,071 & 0,234 & 0,093 & 0,259 & 0,047 & 0,000 \\
\hline $\mathrm{Fe}_{2} \mathrm{O}_{3}$ & 0,524 & 0,347 & 0,733 & 0,714 & 0,512 & 0,997 & 0,727 & 0,739 & 0,539 \\
\hline $\mathrm{MnO}$ & 0,016 & 0,000 & 0,008 & 0,004 & 0,007 & 0,000 & 0,022 & 0,021 & 0,000 \\
\hline $\mathrm{MgO}$ & 0,059 & 0,068 & 0,099 & 0,126 & 0,126 & 0,111 & 0,073 & 0,086 & 0,090 \\
\hline $\mathrm{CaO}$ & 16,194 & 16,167 & 17,556 & 13,083 & 14,455 & 13,754 & 14,108 & 14,254 & 16,502 \\
\hline $\mathrm{Na}_{2} \mathrm{O}$ & 2,375 & 2,349 & 1,774 & 4,062 & 3,383 & 3,784 & 3,106 & 3,310 & 1,897 \\
\hline $\mathrm{K}_{2} \mathrm{O}$ & 0,092 & 0,136 & 0,083 & 0,297 & 0,178 & 0,235 & 0,210 & 0,224 & 0,098 \\
\hline $\mathrm{SrO}$ & 0,251 & 0,190 & 0,277 & 0,050 & 0,163 & 0,253 & 0,439 & 0,255 & 0,184 \\
\hline \multirow[t]{2}{*}{$\mathrm{BaO}$} & 0,017 & 0,000 & 0,081 & 0,050 & 0,000 & 0,000 & 0,064 & 0,000 & 0,000 \\
\hline & --- & --- & --- & --- & --- & --- & --- & --- & --- \\
\hline Total & 101,066 & 101,001 & 100,971 & 100,546 & 99,585 & 100,326 & 99,204 & 99,394 & 99,046 \\
\hline \multicolumn{10}{|c|}{$\mathrm{N}^{\circ}$ Cationes } \\
\hline Si & 8,7568 & 8,8022 & 8,5679 & 9,4871 & 9,2053 & 9,2718 & 9,1016 & 9,1252 & 8,5975 \\
\hline$A l+3$ & 7,1508 & 7,1254 & 7,2480 & 6,3527 & 6,5966 & 6,5209 & 6,7476 & 6,7298 & 7,3377 \\
\hline $\mathrm{Ti}+4$ & 0,0096 & 0,0096 & 0,0032 & 0,0096 & 0,0323 & 0,0128 & 0,0360 & 0,0065 & 0,0000 \\
\hline $\mathrm{Fe}+3$ & 0,0717 & 0,0474 & 0,1010 & 0,0973 & 0,0709 & 0,1370 & 0,1012 & 0,1026 & 0,0754 \\
\hline Mn & 0,0025 & 0,0000 & 0,0013 & 0,0006 & 0,0011 & 0,0000 & 0,0034 & 0,0033 & 0,0000 \\
\hline $\mathrm{Mg}$ & 0,0161 & 0,0185 & 0,0270 & 0,0339 & 0,0344 & 0,0302 & 0,0202 & 0,0236 & 0,0249 \\
\hline $\mathrm{Ca}$ & 3,1573 & 3,1489 & 3,4459 & 2,5403 & 2,8468 & 2,6901 & 2,7947 & 2,8159 & 3,2870 \\
\hline $\mathrm{Na}$ & 0,8381 & 0,8280 & 0,6301 & 1,4272 & 1,2055 & 1,3392 & 1,1135 & 1,1834 & 0,6839 \\
\hline $\mathbf{K}$ & 0,0214 & 0,0315 & 0,0193 & 0,0686 & 0,0418 & 0,0547 & 0,0496 & 0,0527 & 0,0233 \\
\hline $\mathrm{Sr}$ & 0,0265 & 0,0200 & 0,0295 & 0,0053 & 0,0174 & 0,0268 & 0,0471 & 0,0272 & 0,0198 \\
\hline \multirow[t]{2}{*}{$\mathrm{Ba}$} & 0,0012 & 0,0000 & 0,0058 & 0,0036 & 0,0000 & 0,0000 & 0,0047 & 0,0000 & 0,0000 \\
\hline & --- & --- & --- & --- & --- & --- & --- & --- & --- \\
\hline Total & 20,0520 & 20,0315 & 20,0790 & 20,0262 & 20,0523 & 20,0834 & 20,0196 & 20,0701 & 20,0495 \\
\hline An & 78,72 & 78,66 & 84,14 & 62,93 & 69,66 & 66,09 & 70,87 & 69,70 & 82,38 \\
\hline $\mathbf{A b}$ & 20,72 & 20,55 & 15,25 & 35,28 & 29,32 & 32,58 & 27,77 & 29,01 & 17,04 \\
\hline Or & 0,56 & 0,78 & 0,61 & 1,78 & 1,02 & 1,33 & 1,35 & 1,29 & 0,58 \\
\hline
\end{tabular}

Tabla IV.19: Análisis de la química mineral. 


\section{Feldespatos}

\begin{tabular}{|c|c|c|c|c|c|c|c|c|}
\hline Unidad & \multicolumn{8}{|c|}{ Basaltos Post-caldera II } \\
\hline Muestra & \multicolumn{8}{|c|}{ PY 13} \\
\hline Cristal & \multicolumn{6}{|c|}{ P1 B } & \multicolumn{2}{|c|}{$\mathrm{Pl} \mathrm{P}$} \\
\hline Punto & 1 & 2 & 3 & 4 & 5 & 6 & 1 & 2 \\
\hline Ubicación & centro & centro & medio & medio & borde int. & borde & centro & borde \\
\hline \multicolumn{9}{|l|}{$\%$} \\
\hline $\mathrm{SiO}_{2}$ & 48,032 & 47,420 & 47,720 & 47,637 & 50,785 & 51,331 & 50,736 & 50,983 \\
\hline $\mathrm{Al}_{2} \mathrm{O}_{3}$ & 33,225 & 33,631 & 32,760 & 32,898 & 30,889 & 30,241 & 30,571 & 30,759 \\
\hline $\mathrm{TiO}_{2}$ & 0,000 & 0,000 & 0,000 & 0,000 & 0,117 & 0,117 & 0,094 & 0,094 \\
\hline $\mathrm{Fe}_{2} \mathrm{O}_{3}$ & 0,850 & 0,645 & 0,643 & 0,712 & 0,758 & 0,889 & 0,698 & 1,012 \\
\hline $\mathrm{MnO}$ & 0,006 & 0,000 & 0,014 & 0,023 & 0,000 & 0,005 & 0,017 & 0,000 \\
\hline $\mathrm{MgO}$ & 0,059 & 0,052 & 0,083 & 0,083 & 0,122 & 0,170 & 0,137 & 0,116 \\
\hline $\mathrm{CaO}$ & 16,415 & 16,638 & 15,756 & 15,938 & 13,802 & 13,083 & 13,575 & 13,376 \\
\hline $\mathrm{Na}_{2} \mathrm{O}$ & 2,220 & 2,076 & 2,482 & 2,401 & 3,558 & 3,853 & 3,618 & 3,615 \\
\hline $\mathrm{K}_{2} \mathrm{O}$ & 0,147 & 0,088 & 0,120 & 0,132 & 0,264 & 0,250 & 0,378 & 0,269 \\
\hline $\mathrm{SrO}$ & 0,245 & 0,257 & 0,204 & 0,198 & 0,295 & 0,330 & 0,355 & 0,403 \\
\hline \multirow[t]{2}{*}{$\mathrm{BaO}$} & 0,046 & 0,038 & 0,012 & 0,000 & 0,091 & 0,110 & 0,000 & 0,063 \\
\hline & --- & --- & --- & --- & --- & --- & --- & --- \\
\hline Total & 101,246 & 100,844 & 99,795 & 100,022 & 100,681 & 100,379 & 100,180 & 100,689 \\
\hline
\end{tabular}

\section{$N^{\circ}$ Cationes}

\begin{tabular}{lrrrrrrrr} 
Si & 8,7407 & 8,6632 & 8,7910 & 8,7617 & 9,2335 & 9,3484 & 9,2687 & 9,2662 \\
Al+3 & 7,1258 & 7,2413 & 7,1128 & 7,1313 & 6,6190 & 6,4911 & 6,5822 & 6,5888 \\
Ti+4 & 0,0000 & 0,0000 & 0,0000 & 0,0000 & 0,0160 & 0,0160 & 0,0129 & 0,0128 \\
Fe+3 & 0,1164 & 0,0886 & 0,0892 & 0,0986 & 0,1037 & 0,1219 & 0,0960 & 0,1385 \\
Mn & 0,0009 & 0,0000 & 0,0022 & 0,0036 & 0,0000 & 0,0007 & 0,0027 & 0,0000 \\
Mg & 0,0160 & 0,0141 & 0,0229 & 0,0228 & 0,0330 & 0,0460 & 0,0373 & 0,0315 \\
Ca & 3,2005 & 3,2568 & 3,1100 & 3,1408 & 2,6886 & 2,5528 & 2,6571 & 2,6047 \\
Na & 0,7832 & 0,7355 & 0,8864 & 0,8561 & 1,2542 & 1,3607 & 1,2816 & 1,2738 \\
K & 0,0342 & 0,0205 & 0,0282 & 0,0311 & 0,0611 & 0,0580 & 0,0882 & 0,0623 \\
Sr & 0,0259 & 0,0272 & 0,0218 & 0,0211 & 0,0311 & 0,0348 & 0,0376 & 0,0424 \\
Ba & 0,0033 & 0,0027 & 0,0008 & 0,0000 & 0,0065 & 0,0079 & 0,0000 & 0,0045 \\
& --- & --- & --- & --- & --- & --- & -- & -- \\
Total & 20,0469 & 20,0499 & 20,0653 & 20,0670 & 20,0468 & 20,0384 & 20,0642 & 20,0255 \\
& & & & & & & & \\
An & 79,72 & 81,23 & 77,38 & 78,09 & 67,29 & 64,46 & 66,30 & 66,38 \\
Ab & 19,35 & 18,19 & 21,90 & 21,14 & 31,03 & 33,90 & 31,53 & 31,94 \\
Or & 0,93 & 0,57 & 0,72 & 0,77 & 1,67 & 1,64 & 2,17 & 1,68 \\
\hline
\end{tabular}

Tabla IV.20: Análisis de la química mineral. 


\begin{tabular}{|c|c|c|c|c|c|c|c|c|c|}
\hline \multicolumn{10}{|c|}{ Feldespatos } \\
\hline Unidad & \multicolumn{9}{|c|}{ Basaltos Pre-caldera } \\
\hline Muestra & \multicolumn{9}{|c|}{ PY 5} \\
\hline Cristal & \multicolumn{4}{|c|}{$\mathrm{Pl} \mathrm{A}$} & \multicolumn{5}{|c|}{ Pl B } \\
\hline Punto & 1 & 2 & 3 & 4 & 1 & 2 & 3 & 4 & 5 \\
\hline Ubicación & centro & medio & medio & borde & centro & medio & medio & medio & borde \\
\hline \multicolumn{10}{|l|}{$\%$} \\
\hline $\mathrm{SiO}_{2}$ & 46,738 & 50,440 & 48,864 & 50,181 & 49,836 & 51,572 & 50,469 & 48,804 & 51,888 \\
\hline $\mathrm{Al}_{2} \mathrm{O}_{3}$ & 33,157 & 30,994 & 32,263 & 30,613 & 32,454 & 31,303 & 32,455 & 32,725 & 30,509 \\
\hline $\mathrm{TiO}_{2}$ & 0,047 & 0,235 & 0,000 & 0,000 & 0,024 & 0,024 & 0,118 & 0,024 & 0,094 \\
\hline $\mathrm{Fe}_{2} \mathrm{O}_{3}$ & 0,458 & 0,752 & 0,582 & 0,631 & 0,554 & 0,499 & 0,554 & 0,643 & 0,727 \\
\hline $\mathrm{MnO}$ & 0,001 & 0,000 & 0,000 & 0,009 & 0,020 & 0,000 & 0,000 & 0,001 & 0,000 \\
\hline $\mathrm{MgO}$ & 0,069 & 0,103 & 0,080 & 0,082 & 0,076 & 0,090 & 0,088 & 0,067 & 0,110 \\
\hline $\mathrm{CaO}$ & 15,808 & 13,412 & 14,720 & 13,162 & 15,457 & 14,175 & 14,977 & 15,388 & 13,403 \\
\hline $\mathrm{Na}_{2} \mathrm{O}$ & 2,146 & 3,501 & 2,862 & 3,593 & 2,604 & 3,701 & 3,182 & 2,750 & 4,163 \\
\hline $\mathrm{K}_{2} \mathrm{O}$ & 0,064 & 0,207 & 0,170 & 0,225 & 0,117 & 0,198 & 0,150 & 0,124 & 0,280 \\
\hline $\mathrm{SrO}$ & 0,342 & 0,282 & 0,275 & 0,291 & 0,429 & 0,333 & 0,300 & 0,212 & 0,287 \\
\hline \multirow[t]{2}{*}{$\mathrm{BaO}$} & 0,000 & 0,019 & 0,000 & 0,000 & 0,002 & 0,034 & 0,000 & 0,084 & 0,077 \\
\hline & --- & --- & --- & --- & --- & --- & --- & --- & --- \\
\hline Total & 98,829 & 99,946 & 99,815 & 98,788 & 101,574 & 101,928 & 102,292 & 100,821 & 101,537 \\
\hline \multicolumn{10}{|c|}{$\mathbf{N}^{\circ}$ Cationes } \\
\hline Si & 8,6934 & 9,2181 & 8,9683 & 9,2701 & 8,9973 & 9,2546 & 9,0402 & 8,8880 & 9,3488 \\
\hline $\mathrm{Al}+3$ & 7,2686 & 6,6758 & 6,9788 & 6,6652 & 6,9055 & 6,6203 & 6,8516 & 7,0242 & 6,4785 \\
\hline $\mathrm{Ti}+4$ & 0,0066 & 0,0324 & 0,0000 & 0,0000 & 0,0032 & 0,0032 & 0,0158 & 0,0032 & 0,0127 \\
\hline $\mathrm{Fe}+3$ & 0,0642 & 0,1035 & 0,0803 & 0,0877 & 0,0753 & 0,0674 & 0,0747 & 0,0881 & 0,0986 \\
\hline Mn & 0,0002 & 0,0000 & 0,0000 & 0,0014 & 0,0030 & 0,0000 & 0,0000 & 0,0001 & 0,0000 \\
\hline Mg & 0,0190 & 0,0282 & 0,0219 & 0,0225 & 0,0206 & 0,0240 & 0,0234 & 0,0181 & 0,0295 \\
\hline $\mathrm{Ca}$ & 3,1504 & 2,6263 & 2,8945 & 2,6052 & 2,9899 & 2,7253 & 2,8742 & 3,0027 & 2,5872 \\
\hline $\mathrm{Na}$ & 0,7738 & 1,2406 & 1,0184 & 1,2871 & 0,9115 & 1,2878 & 1,1050 & 0,9710 & 1,4544 \\
\hline K & 0,0153 & 0,0482 & 0,0398 & 0,0531 & 0,0270 & 0,0453 & 0,0343 & 0,0287 & 0,0644 \\
\hline Sr & 0,0368 & 0,0298 & 0,0292 & 0,0312 & 0,0449 & 0,0346 & 0,0312 & 0,0224 & 0,0300 \\
\hline \multirow[t]{2}{*}{ Ba } & 0,0000 & 0,0014 & 0,0000 & 0,0000 & 0,0002 & 0,0024 & 0,0000 & 0,0060 & 0,0054 \\
\hline & --- & --- & --- & --- & --- & --- & --- & --- & --- \\
\hline Total & 20,0282 & 20,0042 & 20,0313 & 20,0235 & 19,9784 & 20,0649 & 20,0505 & 20,0525 & 20,1094 \\
\hline An & 80,15 & 67,31 & 73,42 & 66,30 & 76,38 & 67,39 & 71,83 & 75,05 & 63,20 \\
\hline $\mathbf{A b}$ & 19,46 & 31,44 & 25,58 & 32,37 & 22,94 & 31,45 & 27,32 & 24,09 & 35,12 \\
\hline Or & 0,38 & 1,26 & 1,00 & 1,34 & 0,68 & 1,16 & 0,85 & 0,86 & 1,69 \\
\hline
\end{tabular}

Tabla IV.21: Análisis de la química mineral. 


\section{Feldespatos}

\begin{tabular}{|c|c|c|c|c|c|c|c|}
\hline Unidad & \multicolumn{7}{|c|}{ Basaltos Pre-caldera } \\
\hline Muestra & \multicolumn{7}{|c|}{ PY 5} \\
\hline Cristal & \multicolumn{4}{|c|}{ Pl C } & \multicolumn{3}{|c|}{ Pl D } \\
\hline Punto & 1 & 2 & 3 & 4 & 1 & 2 & 3 \\
\hline Ubicación & centro & medio & medio & borde & centro & borde int. & borde \\
\hline \multicolumn{8}{|l|}{$\%$} \\
\hline $\mathrm{SiO}_{2}$ & 49,790 & 49,180 & 50,045 & 48,323 & 49,486 & 51,619 & 52,038 \\
\hline $\mathrm{Al}_{2} \mathrm{O}_{3}$ & 32,527 & 32,606 & 32,279 & 33,053 & 32,070 & 30,272 & 30,550 \\
\hline $\mathrm{TiO}_{2}$ & 0,047 & 0,094 & 0,000 & 0,094 & 0,188 & 0,024 & 0,164 \\
\hline $\mathrm{Fe}_{2} \mathrm{O}_{3}$ & 0,641 & 0,463 & 0,470 & 0,564 & 0,554 & 0,634 & 0,801 \\
\hline $\mathrm{MnO}$ & 0,006 & 0,018 & 0,004 & 0,037 & 0,000 & 0,000 & 0,011 \\
\hline $\mathrm{MgO}$ & 0,068 & 0,087 & 0,097 & 0,077 & 0,063 & 0,076 & 0,075 \\
\hline $\mathrm{CaO}$ & 15,561 & 15,410 & 14,295 & 15,674 & 14,546 & 12,823 & 12,983 \\
\hline $\mathrm{Na}_{2} \mathrm{O}$ & 2,863 & 2,830 & 3,062 & 2,659 & 3,113 & 4,053 & 4,102 \\
\hline $\mathrm{K}_{2} \mathrm{O}$ & 0,167 & 0,159 & 0,192 & 0,171 & 0,148 & 0,369 & 0,263 \\
\hline $\mathrm{SrO}$ & 0,247 & 0,332 & 0,165 & 0,202 & 0,179 & 0,108 & 0,326 \\
\hline \multirow[t]{2}{*}{$\mathrm{BaO}$} & 0,056 & 0,019 & 0,000 & 0,031 & 0,043 & 0,048 & 0,020 \\
\hline & --- & --- & --- & --- & --- & --- & --- \\
\hline
\end{tabular}

$\begin{array}{llllllll}\text { Total } & 101,973 & 101,198 & 100,609 & 100,885 & 100,392 & 100,025 & 101,334\end{array}$

\begin{tabular}{lccccccc}
$\mathbf{N}^{\circ}$ Cationes & & & & & & & \\
$\mathbf{S i}$ & 8,9659 & 8,9232 & 9,0818 & 8,8054 & 9,0237 & 9,4065 & 9,3757 \\
$\mathbf{A l + 3}$ & 6,9033 & 6,9724 & 6,9038 & 7,0985 & 6,8923 & 6,5015 & 6,4872 \\
$\mathbf{T i + 4}$ & 0,0064 & 0,0128 & 0,0000 & 0,0129 & 0,0258 & 0,0032 & 0,0223 \\
$\mathbf{F e + 3}$ & 0,0869 & 0,0632 & 0,0642 & 0,0773 & 0,0760 & 0,0869 & 0,1087 \\
$\mathbf{M n}$ & 0,0009 & 0,0028 & 0,0006 & 0,0057 & 0,0000 & 0,0000 & 0,0016 \\
$\mathbf{M g}$ & 0,0183 & 0,0235 & 0,0262 & 0,0209 & 0,0171 & 0,0207 & 0,0202 \\
$\mathbf{C a}$ & 3,0022 & 2,9956 & 2,7795 & 3,0600 & 2,8419 & 2,5035 & 2,5062 \\
$\mathbf{N a}$ & 0,9997 & 0,9956 & 1,0774 & 0,9394 & 1,1007 & 1,4320 & 1,4328 \\
$\mathbf{K}$ & 0,0384 & 0,0369 & 0,0444 & 0,0398 & 0,0345 & 0,0858 & 0,0605 \\
$\mathbf{S r}$ & 0,0257 & 0,0350 & 0,0173 & 0,0214 & 0,0190 & 0,0115 & 0,0341 \\
$\mathbf{B a}$ & 0,0039 & 0,0014 & 0,0000 & 0,0022 & 0,0031 & 0,0034 & 0,0014 \\
& --- & --- & --- & --- & --- & --- & -- \\
Total & 20,0516 & 20,0623 & 19,9951 & 20,0834 & 20,0340 & 20,0550 & 20,0507 \\
& & & & & & & \\
An & 74,40 & 74,56 & 71,37 & 75,84 & 71,54 & 62,31 & 62,96 \\
Ab & 24,56 & 24,50 & 27,49 & 23,12 & 27,52 & 35,48 & 35,51 \\
Or & 1,04 & 0,94 & 1,13 & 1,03 & 0,94 & 2,21 & 1,53 \\
\hline
\end{tabular}

Tabla IV.22: Análisis de la química mineral. 


\begin{tabular}{|c|c|c|c|c|c|c|}
\hline \multicolumn{7}{|c|}{ Feldespatos } \\
\hline Unidad & \multicolumn{6}{|c|}{ Basaltos Pre-caldera } \\
\hline Muestra & \multicolumn{6}{|c|}{ PY 5} \\
\hline Cristal & \multicolumn{4}{|c|}{ PlE } & \multicolumn{2}{|c|}{ Pl P } \\
\hline Punto & 1 & 2 & 3 & 4 & 1 & 2 \\
\hline Ubicación & centro & medio & medio & borde & centro & borde \\
\hline \multicolumn{7}{|l|}{$\%$} \\
\hline $\mathrm{SiO}_{2}$ & 51,771 & 52,170 & 52,546 & 51,240 & 51,640 & 52,080 \\
\hline $\mathrm{Al}_{2} \mathrm{O}_{3}$ & 30,228 & 29,962 & 29,586 & 28,002 & 30,840 & 30,543 \\
\hline $\mathrm{TiO}_{2}$ & 0,118 & 0,188 & 0,047 & 0,117 & 0,211 & 0,070 \\
\hline $\mathrm{Fe}_{2} \mathrm{O}_{3}$ & 0,567 & 0,487 & 0,519 & 3,006 & 0,882 & 0,980 \\
\hline $\mathrm{MnO}$ & 0,000 & 0,026 & 0,000 & 0,010 & 0,008 & 0,012 \\
\hline $\mathrm{MgO}$ & 0,073 & 0,042 & 0,063 & 2,405 & 0,090 & 0,111 \\
\hline $\mathrm{CaO}$ & 12,387 & 12,179 & 11,780 & 11,271 & 13,608 & 13,185 \\
\hline $\mathrm{Na}_{2} \mathrm{O}$ & 4,095 & 4,343 & 4,402 & 4,177 & 3,912 & 4,010 \\
\hline $\mathrm{K}_{2} \mathrm{O}$ & 0,254 & 0,293 & 0,357 & 0,282 & 0,287 & 0,342 \\
\hline SrO & 0,194 & 0,319 & 0,137 & 0,292 & 0,330 & 0,230 \\
\hline \multirow[t]{2}{*}{$\mathrm{BaO}$} & 0,000 & 0,031 & 0,000 & 0,000 & 0,033 & 0,018 \\
\hline & --- & --- & --- & --- & --- & --- \\
\hline Total & 99,686 & 100,040 & 99,437 & 100,803 & 101,842 & 101,582 \\
\hline \multicolumn{7}{|c|}{$\mathbf{N}^{\circ}$ Cationes } \\
\hline Si & 9,4439 & 9,4925 & 9,5897 & 9,3364 & 9,2828 & 9,3671 \\
\hline $\mathrm{Al}+3$ & 6,4987 & 6,4253 & 6,3636 & 6,0134 & 6,5337 & 6,4745 \\
\hline $\mathrm{Ti}+4$ & 0,0161 & 0,0257 & 0,0065 & 0,0160 & 0,0286 & 0,0095 \\
\hline $\mathrm{Fe}+3$ & 0,0778 & 0,0667 & 0,0712 & 0,4121 & 0,1194 & 0,1326 \\
\hline Mn & 0,0000 & 0,0039 & 0,0000 & 0,0015 & 0,0012 & 0,0018 \\
\hline Mg & 0,0199 & 0,0113 & 0,0171 & 0,6533 & 0,0241 & 0,0299 \\
\hline $\mathrm{Ca}$ & 2,4210 & 2,3744 & 2,3034 & 2,2004 & 2,6209 & 2,5408 \\
\hline $\mathrm{Na}$ & 1,4484 & 1,5321 & 1,5577 & 1,4758 & 1,3635 & 1,3983 \\
\hline K & 0,0592 & 0,0680 & 0,0832 & 0,0656 & 0,0658 & 0,0786 \\
\hline $\mathrm{Sr}$ & 0,0206 & 0,0336 & 0,0145 & 0,0308 & 0,0344 & 0,0240 \\
\hline \multirow[t]{2}{*}{ Ba } & 0,0000 & 0,0022 & 0,0000 & 0,0000 & 0,0023 & 0,0012 \\
\hline & --- & --- & --- & --- & --- & --- \\
\hline Total & 20,0055 & 20,0358 & 20,0069 & 20,2055 & 20,0767 & 20,0582 \\
\hline An & 61,83 & 60,05 & 58,55 & 59,14 & 64,97 & 63,44 \\
\hline $\mathbf{A b}$ & 36,68 & 38,20 & 39,35 & 39,12 & 33,36 & 34,59 \\
\hline Or & 1,50 & 1,75 & 2,10 & 1,74 & 1,67 & 1,97 \\
\hline
\end{tabular}

Tabla IV.23: Análisis de la química mineral. 


\section{Olivinas}

\begin{tabular}{|c|c|c|c|c|c|c|c|c|}
\hline \multirow{4}{*}{$\begin{array}{l}\text { Litofacies } \\
\text { Muestra } \\
\text { Cristal } \\
\text { Punto } \\
\end{array}$} & \multirow{3}{*}{\multicolumn{2}{|c|}{$\begin{array}{c}\text { Traquitas vítreas } \\
\text { PMA 27-A } \\
\text { OL }\end{array}$}} & \multicolumn{6}{|c|}{ Traquiandesitas Post-caldera } \\
\hline & & & \multicolumn{4}{|c|}{ PM 34} & \multirow{2}{*}{\multicolumn{2}{|c|}{$\frac{\text { STA 6-B }}{\text { OL }}$}} \\
\hline & & & \multicolumn{2}{|c|}{ OL A } & \multicolumn{2}{|c|}{ OL B } & & \\
\hline & 1 & 2 & 1 & 2 & 1 & 2 & 1 & 2 \\
\hline$\%$ & & & & & & & & \\
\hline $\mathrm{SiO}_{2}$ & 33,771 & 33,719 & 36,540 & 36,095 & 36,429 & 36,065 & 36,746 & 37,006 \\
\hline $\mathrm{TiO}_{2}$ & 0,000 & 0,021 & 0,065 & 0,043 & 0,130 & 0,000 & 0,044 & 0,000 \\
\hline $\mathrm{Al}_{2} \mathrm{O}_{3}$ & 0,004 & 0,032 & 0,035 & 0,061 & 0,003 & 0,031 & 0,054 & 0,027 \\
\hline $\mathrm{FeO}$ & 43,688 & 43,467 & 29,571 & 30,057 & 29,542 & 29,566 & 27,848 & 25,907 \\
\hline $\mathrm{MnO}$ & 2,809 & 2,615 & 0,711 & 0,586 & 0,740 & 0,676 & 1,050 & 0,992 \\
\hline MgO & 19,175 & 19,175 & 32,710 & 33,002 & 32,975 & 32,793 & 34,896 & 36,028 \\
\hline $\mathrm{CaO}$ & 0,155 & 0,186 & 0,253 & 0,211 & 0,332 & 0,237 & 0,109 & 0,104 \\
\hline $\mathrm{Na}_{2} \mathrm{O}$ & 0,000 & 0,013 & 0,000 & 0,000 & 0,010 & 0,000 & 0,035 & 0,007 \\
\hline $\mathrm{K}_{2} \mathrm{O}$ & 0,000 & 0,000 & 0,007 & 0,000 & 0,000 & 0,031 & 0,000 & 0,007 \\
\hline $\mathrm{Cr}_{2} \mathrm{O}_{3}$ & 0,000 & 0,000 & 0,000 & 0,035 & 0,000 & 0,000 & 0,000 & 0,000 \\
\hline $\mathrm{NiO}$ & 0,000 & 0,013 & 0,031 & 0,000 & 0,000 & 0,036 & 0,000 & 0,000 \\
\hline --- & --- & --- & --- & --- & --- & --- & --- & --- \\
\hline Total & 99,603 & 99,240 & 99,924 & 100,090 & 100,161 & 99,435 & 100,781 & 100,079 \\
\hline \multicolumn{9}{|c|}{$N^{\circ}$ Cationes } \\
\hline $\mathrm{Si}$ & 0,9990 & 0,9998 & 0,9900 & 0,9791 & 0,9851 & 0,9835 & 0,9799 & 0,9842 \\
\hline $\mathrm{Ti}+4$ & 0,0000 & 0,0005 & 0,0013 & 0,0009 & 0,0027 & 0,0000 & 0,0009 & 0,0000 \\
\hline$A 1+3$ & 0,0001 & 0,0011 & 0,0011 & 0,0019 & 0,0001 & 0,0010 & 0,0017 & 0,0008 \\
\hline $\mathrm{Fe}+2$ & 1,0808 & 1,0779 & 0,6700 & 0,6818 & 0,6681 & 0,6743 & 0,6210 & 0,5762 \\
\hline Mn & 0,0704 & 0,0657 & 0,0163 & 0,0135 & 0,0169 & 0,0156 & 0,0237 & 0,0224 \\
\hline Mg & 0,8456 & 0,8476 & 1,3212 & 1,3346 & 1,3294 & 1,3332 & 1,3872 & 1,4285 \\
\hline $\mathrm{Ca}$ & 0,0049 & 0,0059 & 0,0074 & 0,0061 & 0,0096 & 0,0069 & 0,0031 & 0,0030 \\
\hline $\mathrm{Na}$ & 0,0000 & 0,0007 & 0,0000 & 0,0000 & 0,0005 & 0,0000 & 0,0018 & 0,0004 \\
\hline $\mathbf{K}$ & 0,0000 & 0,0000 & 0,0002 & 0,0000 & 0,0000 & 0,0011 & 0,0000 & 0,0002 \\
\hline $\mathrm{Cr}+3$ & 0,0000 & 0,0000 & 0,0000 & 0,0008 & 0,0000 & 0,0000 & 0,0000 & 0,0000 \\
\hline \multirow[t]{2}{*}{$\mathrm{Ni}+2$} & 0,0000 & 0,0003 & 0,0007 & 0,0000 & 0,0000 & 0,0008 & 0,0000 & 0,0000 \\
\hline & --- & --- & --- & --- & --- & --- & --- & --- \\
\hline Total & 3,0009 & 2,9995 & 3,0082 & 3,0187 & 3,0124 & 3,0165 & 3,0193 & 3,0157 \\
\hline Fo & 42,35 & 42,57 & 65,81 & 65,75 & 65,99 & 65,90 & 68,27 & 70,47 \\
\hline $\mathbf{F a}$ & 57,65 & 57,43 & 34,19 & 34,25 & 34,01 & 34,10 & 31,73 & 29,53 \\
\hline
\end{tabular}

Tabla IV.24: Análisis de la química mineral. 


\section{Olivinas}

\begin{tabular}{|c|c|c|c|c|c|c|c|}
\hline \multicolumn{5}{|c|}{ Unidad Traquiandesitas Post-caldera Ignimbrita Potezuelo } & \multicolumn{3}{|c|}{ Traquitas Pre-caldera } \\
\hline Muestra & \multicolumn{2}{|c|}{ STA 38} & \multicolumn{2}{|c|}{ PM 14} & PM 27 & \multicolumn{2}{|c|}{ PM 28} \\
\hline Cristal & \multicolumn{2}{|c|}{ OL } & \multicolumn{2}{|c|}{ OL } & OL & \multicolumn{2}{|c|}{ OL } \\
\hline Punto & 1 & 2 & 1 & 2 & 1 & 1 & 2 \\
\hline \multicolumn{8}{|l|}{$\%$} \\
\hline $\mathrm{SiO}_{2}$ & 38,145 & 37,667 & 34,067 & 34,460 & 34,465 & 34,318 & 33,849 \\
\hline $\mathrm{TiO}_{2}$ & 0,089 & 0,000 & 0,000 & 0,000 & 0,000 & 0,000 & 0,085 \\
\hline $\mathrm{Al}_{2} \mathrm{O}_{3}$ & 0,034 & 0,047 & 0,011 & 0,000 & 0,018 & 0,004 & 0,000 \\
\hline $\mathrm{FeO}$ & 20,899 & 19,933 & 37,598 & 37,178 & 35,704 & 40,155 & 40,055 \\
\hline $\mathrm{MnO}$ & 0,268 & 0,299 & 1,620 & 1,623 & 1,354 & 1,674 & 1,665 \\
\hline $\mathrm{MgO}$ & 40,852 & 40,587 & 24,273 & 24,803 & 26,191 & 23,870 & 23,273 \\
\hline $\mathrm{CaO}$ & 0,173 & 0,210 & 0,148 & 0,164 & 0,135 & 0,164 & 0,543 \\
\hline $\mathrm{Na}_{2} \mathrm{O}$ & 0,000 & 0,009 & 0,000 & 0,012 & 0,026 & 0,062 & 0,000 \\
\hline $\mathrm{K}_{2} \mathrm{O}$ & 0,000 & 0,005 & 0,000 & 0,007 & 0,021 & 0,000 & 0,018 \\
\hline $\mathrm{Cr}_{2} \mathrm{O}_{3}$ & 0,002 & 0,000 & 0,000 & 0,000 & 0,000 & 0,012 & 0,060 \\
\hline $\mathrm{NiO}$ & 0,068 & 0,082 & 0,010 & 0,000 & 0,000 & 0,000 & 0,000 \\
\hline --- & --- & --- & --- & -- & --- & --- & --- \\
\hline Total & 100,530 & 98,838 & 97,728 & 98,245 & 97,914 & 100,259 & 99,549 \\
\hline \multicolumn{8}{|c|}{$\mathbf{N}^{\circ}$ Cationes } \\
\hline $\mathrm{Si}$ & 0,9823 & 0,9838 & 0,9923 & 0,9949 & 0,9904 & 0,9842 & 0,9805 \\
\hline $\mathbf{T i}+4$ & 0,0017 & 0,0000 & 0,0000 & 0,0000 & 0,0000 & 0,0000 & 0,0018 \\
\hline $\mathrm{Al}+3$ & 0,0010 & 0,0014 & 0,0004 & 0,0000 & 0,0006 & 0,0001 & 0,0000 \\
\hline $\mathrm{Fe}+2$ & 0,4501 & 0,4354 & 0,9159 & 0,8976 & 0,8580 & 0,9631 & 0,9703 \\
\hline $\mathbf{M n}$ & 0,0059 & 0,0066 & 0,0400 & 0,0397 & 0,0329 & 0,0407 & 0,0408 \\
\hline $\mathbf{M g}$ & 1,5683 & 1,5803 & 1,0540 & 1,0675 & 1,1220 & 1,0205 & 1,0050 \\
\hline $\mathrm{Ca}$ & 0,0048 & 0,0059 & 0,0046 & 0,0051 & 0,0042 & 0,0050 & 0,0169 \\
\hline $\mathrm{Na}$ & 0,0000 & 0,0005 & 0,0000 & 0,0007 & 0,0014 & 0,0035 & 0,0000 \\
\hline $\mathbf{K}$ & 0,0000 & 0,0002 & 0,0000 & 0,0002 & 0,0008 & 0,0000 & 0,0007 \\
\hline $\mathrm{Cr}+3$ & 0,0000 & 0,0000 & 0,0000 & 0,0000 & 0,0000 & 0,0003 & 0,0014 \\
\hline \multirow[t]{2}{*}{$\mathrm{Ni}+2$} & 0,0014 & 0,0017 & 0,0002 & 0,0000 & 0,0000 & 0,0000 & 0,0000 \\
\hline & --- & --- & --- & --- & --- & --- & --- \\
\hline Total & 3,0155 & 3,0158 & 3,0075 & 3,0056 & 3,0104 & 3,0173 & 3,0173 \\
\hline Fo & 77,47 & 78,14 & 52,44 & 53,25 & 55,74 & 50,41 & 49,85 \\
\hline $\mathbf{F a}$ & 22,53 & 21,86 & 47,56 & 46,75 & 44,26 & 49,59 & 50,15 \\
\hline
\end{tabular}

Tabla IV.25: Análisis de la química mineral. 


\section{Olivinas}

\begin{tabular}{|c|c|c|c|c|c|c|c|c|}
\hline \multirow{4}{*}{$\begin{array}{l}\text { Unidad } \\
\text { Muestra } \\
\text { Cristal } \\
\text { Punto }\end{array}$} & \multicolumn{6}{|c|}{ Basaltos Post-caldera II } & \multirow{2}{*}{\multicolumn{2}{|c|}{$\begin{array}{c}\text { Basaltos Pre-caldera } \\
\text { PY } 5\end{array}$}} \\
\hline & \multicolumn{4}{|c|}{ PM 46} & \multirow{2}{*}{\multicolumn{2}{|c|}{$\frac{\text { PY } 13}{\text { OL }}$}} & & \\
\hline & \multicolumn{2}{|c|}{ OL A } & \multicolumn{2}{|c|}{ OL B } & & & \multicolumn{2}{|c|}{ OL } \\
\hline & 1 & 2 & 1 & 2 & 1 & 2 & 1 & 2 \\
\hline \multicolumn{9}{|l|}{$\%$} \\
\hline $\mathrm{SiO}_{2}$ & 38,249 & 37,383 & 39,471 & 38,939 & 38,253 & 37,781 & 37,571 & 37,818 \\
\hline $\mathrm{TiO}_{2}$ & 0,000 & 0,134 & 0,023 & 0,000 & 0,022 & 0,000 & 0,022 & 0,022 \\
\hline $\mathrm{Al}_{2} \mathrm{O}_{3}$ & 0,048 & 0,029 & 0,048 & 0,023 & 0,021 & 0,059 & 0,045 & 0,047 \\
\hline $\mathrm{FeO}$ & 20,599 & 22,282 & 14,406 & 16,327 & 19,201 & 19,700 & 20,675 & 22,218 \\
\hline $\mathrm{MnO}$ & 0,280 & 0,335 & 0,220 & 0,188 & 0,252 & 0,321 & 0,301 & 0,344 \\
\hline $\mathrm{MgO}$ & 41,127 & 39,099 & 45,263 & 43,608 & 40,736 & 40,892 & 40,294 & 39,602 \\
\hline $\mathrm{CaO}$ & 0,314 & 0,246 & 0,294 & 0,247 & 0,234 & 0,259 & 0,264 & 0,216 \\
\hline $\mathrm{Na}_{2} \mathrm{O}$ & 0,000 & 0,026 & 0,000 & 0,010 & 0,002 & 0,042 & 0,032 & 0,001 \\
\hline $\mathrm{K}_{2} \mathrm{O}$ & 0,000 & 0,000 & 0,014 & 0,012 & 0,049 & 0,000 & 0,000 & 0,009 \\
\hline $\mathrm{Cr}_{2} \mathrm{O}_{3}$ & 0,054 & 0,000 & 0,009 & 0,035 & 0,000 & 0,000 & 0,002 & 0,044 \\
\hline $\mathrm{NiO}$ & 0,049 & 0,087 & 0,165 & 0,151 & 0,139 & 0,114 & 0,049 & 0,042 \\
\hline --- & --- & --- & --- & --- & --- & --- & --- & --- \\
\hline Total & 100,720 & 99,621 & 99,912 & 99,541 & 98,910 & 99,167 & 99,255 & 100,363 \\
\hline \multicolumn{9}{|c|}{$\mathbf{N}^{\circ}$ Cationes } \\
\hline Si & 0,9820 & 0,9800 & 0,9915 & 0,9909 & 0,9938 & 0,9827 & 0,9808 & 0,9824 \\
\hline $\mathbf{T i}+4$ & 0,0000 & 0,0026 & 0,0004 & 0,0000 & 0,0004 & 0,0000 & 0,0004 & 0,0004 \\
\hline $\mathrm{Al}+3$ & 0,0015 & 0,0009 & 0,0014 & 0,0007 & 0,0007 & 0,0018 & 0,0014 & 0,0014 \\
\hline $\mathrm{Fe}+2$ & 0,4423 & 0,4885 & 0,3026 & 0,3475 & 0,4171 & 0,4285 & 0,4514 & 0,4827 \\
\hline Mn & 0,0061 & 0,0074 & 0,0047 & 0,0040 & 0,0056 & 0,0071 & 0,0067 & 0,0076 \\
\hline Mg & 1,5741 & 1,5280 & 1,6950 & 1,6543 & 1,5776 & 1,5856 & 1,5681 & 1,5336 \\
\hline $\mathrm{Ca}$ & 0,0086 & 0,0069 & 0,0079 & 0,0067 & 0,0065 & 0,0072 & 0,0074 & 0,0060 \\
\hline $\mathbf{N a}$ & 0,0000 & 0,0013 & 0,0000 & 0,0005 & 0,0001 & 0,0021 & 0,0016 & 0,0000 \\
\hline $\mathbf{K}$ & 0,0000 & 0,0000 & 0,0004 & 0,0004 & 0,0016 & 0,0000 & 0,0000 & 0,0003 \\
\hline $\mathrm{Cr}+3$ & 0,0011 & 0,0000 & 0,0002 & 0,0007 & 0,0000 & 0,0000 & 0,0000 & 0,0009 \\
\hline \multirow[t]{2}{*}{$\mathrm{Ni}+2$} & 0,0010 & 0,0018 & 0,0033 & 0,0031 & 0,0029 & 0,0024 & 0,0010 & 0,0009 \\
\hline & --- & --- & --- & --- & --- & --- & --- & --- \\
\hline Total & 3,0167 & 3,0176 & 3,0075 & 3,0089 & 3,0063 & 3,0174 & 3,0188 & 3,0162 \\
\hline Fo & 77,83 & 75,50 & 84,65 & 82,48 & 78,87 & 78,45 & 77,39 & 75,77 \\
\hline $\mathbf{F a}$ & 22,17 & 24,50 & 15,35 & 17,52 & 21,13 & 21,55 & 22,61 & 24,23 \\
\hline
\end{tabular}

Tabla IV.26: Análisis de la química mineral. 


\section{Piroxenos}

Litofacies Traquitas vítreas Traquitas en bloque Traquiandesitas Post-caldera

\begin{tabular}{|c|c|c|c|c|c|c|c|c|}
\hline \multirow{3}{*}{$\begin{array}{l}\text { Muestra } \\
\text { Cristal } \\
\text { Punto } \\
\end{array}$} & \multirow{2}{*}{\multicolumn{2}{|c|}{$\begin{array}{c}\text { PMA 27-A } \\
\text { CPX }\end{array}$}} & \multirow{2}{*}{\multicolumn{2}{|c|}{$\frac{\mathrm{PM} 40}{\mathrm{CPX}}$}} & \multicolumn{4}{|c|}{ PM 34} \\
\hline & & & & & \multicolumn{2}{|c|}{ CPXA } & \multicolumn{2}{|c|}{ CPX B } \\
\hline & 1 & 2 & 1 & 2 & 1 & 2 & 1 & 2 \\
\hline Ubicación & centro & borde & centro & borde & centro & borde & centro & medio \\
\hline \multicolumn{9}{|l|}{$\%$} \\
\hline $\mathrm{SiO}_{2}$ & 52,162 & 52,390 & 51,932 & 51,538 & 51,322 & 51,078 & 51,855 & 49,367 \\
\hline $\mathrm{TiO}_{2}$ & 0,184 & 0,184 & 0,391 & 0,299 & 0,397 & 0,725 & 0,767 & 1,049 \\
\hline $\mathrm{Al}_{2} \mathrm{O}_{3}$ & 0,574 & 0,665 & 0,638 & 0,527 & 1,165 & 1,852 & 1,598 & 2,669 \\
\hline $\mathrm{FeO}$ & 13,289 & 13,390 & 12,246 & 13,069 & 9,272 & 9,474 & 8,957 & 8,654 \\
\hline $\mathrm{MnO}$ & 1,396 & 1,418 & 1,166 & 1,358 & 0,817 & 0,476 & 0,588 & 0,481 \\
\hline MgO & 13,055 & 12,923 & 13,010 & 13,062 & 14,104 & 14,838 & 14,945 & 14,388 \\
\hline $\mathrm{CaO}$ & 19,148 & 19,437 & 19,933 & 18,965 & 20,858 & 20,466 & 20,739 & 20,404 \\
\hline $\mathrm{Na}_{2} \mathrm{O}$ & 0,449 & 0,432 & 0,494 & 0,532 & 0,563 & 0,506 & 0,579 & 0,599 \\
\hline $\mathrm{K}_{2} \mathrm{O}$ & 0,000 & 0,030 & 0,000 & 0,010 & 0,000 & 0,010 & 0,000 & 0,000 \\
\hline \multirow[t]{2}{*}{$\mathrm{Cr}_{2} \mathrm{O}_{3}$} & 0,000 & 0,034 & 0,000 & 0,000 & 0,000 & 0,006 & 0,000 & 0,000 \\
\hline & --- & --- & --- & --- & -- & --- & --- & --- \\
\hline Total & 100,258 & 100,903 & 99,810 & 99,362 & 98,498 & 99,430 & 100,028 & 97,612 \\
\hline \multicolumn{9}{|c|}{$\mathbf{N}^{\circ}$ Cationes } \\
\hline Si & 1,9768 & 1,9745 & 1,9716 & 1,9714 & 1,9531 & 1,9227 & 1,9356 & 1,8919 \\
\hline $\mathrm{Ti}^{+4}$ & 0,0052 & 0,0052 & 0,0112 & 0,0086 & 0,0114 & 0,0205 & 0,0215 & 0,0302 \\
\hline $\mathrm{Al}^{+3}$ & 0,0256 & 0,0295 & 0,0285 & 0,0238 & 0,0523 & 0,0821 & 0,0703 & 0,1205 \\
\hline $\mathrm{Fe}^{+2}$ & 0,4212 & 0,4220 & 0,3888 & 0,4181 & 0,2951 & 0,2982 & 0,2796 & 0,2773 \\
\hline Mn & 0,0448 & 0,0453 & 0,0375 & 0,0440 & 0,0263 & 0,0152 & 0,0186 & 0,0156 \\
\hline Mg & 0,7375 & 0,7261 & 0,7363 & 0,7449 & 0,8001 & 0,8327 & 0,8317 & 0,8220 \\
\hline $\mathrm{Ca}$ & 0,7775 & 0,7849 & 0,8108 & 0,7773 & 0,8504 & 0,8254 & 0,8294 & 0,8378 \\
\hline $\mathbf{N a}$ & 0,0330 & 0,0315 & 0,0363 & 0,0395 & 0,0415 & 0,0370 & 0,0419 & 0,0445 \\
\hline K & 0,0000 & 0,0015 & 0,0000 & 0,0005 & 0,0000 & 0,0005 & 0,0000 & 0,0000 \\
\hline \multirow[t]{2}{*}{$\mathrm{Cr}^{+3}$} & 0,0000 & 0,0010 & 0,0000 & 0,0000 & 0,0000 & 0,0002 & 0,0000 & 0,0000 \\
\hline & --- & --- & --- & --- & --- & --- & --- & --- \\
\hline Total & 4,0217 & 4,0215 & 4,0211 & 4,0281 & 4,0302 & 4,0344 & 4,0286 & 4,0399 \\
\hline Wo & 39,25 & 39,68 & 41,09 & 39,17 & 43,13 & 41,87 & 42,33 & 42,90 \\
\hline En & 37,23 & 36,70 & 37,31 & 37,54 & 40,58 & 42,24 & 42,45 & 42,10 \\
\hline Fs & 23,52 & 23,62 & 21,60 & 23,29 & 16,30 & 15,90 & 15,22 & 15,00 \\
\hline
\end{tabular}

Tabla IV.27: Análisis de la química mineral. 


\section{Piroxenos}

\begin{tabular}{|c|c|c|c|c|c|c|c|c|c|}
\hline \multirow{4}{*}{$\begin{array}{l}\text { Unidad } \\
\text { Muestra } \\
\text { Cristal } \\
\text { Punto }\end{array}$} & \multicolumn{9}{|c|}{ Traquiandesitas Post-caldera } \\
\hline & \multicolumn{3}{|c|}{ PM 34} & \multicolumn{6}{|c|}{ STA 6-B } \\
\hline & \multicolumn{3}{|c|}{ CPX B } & \multicolumn{6}{|c|}{ CPX } \\
\hline & 3 & 4 & 5 & 1 & 2 & 3 & 4 & 5 & 6 \\
\hline Ubicación & medio & borde int. & borde & centro & centro ext. & medio & medio & borde int. & borde \\
\hline \multicolumn{10}{|l|}{$\%$} \\
\hline $\mathrm{SiO}_{2}$ & 51,878 & 50,421 & 49,803 & 49,177 & 47,966 & 52,463 & 52,473 & 52,431 & 51,133 \\
\hline $\mathrm{TiO}_{2}$ & 0,700 & 0,982 & 1,728 & 1,883 & 2,160 & 0,631 & 0,702 & 0,446 & 1,035 \\
\hline $\mathrm{Al}_{2} \mathrm{O}_{3}$ & 1,557 & 2,136 & 3,240 & 4,900 & 5,657 & 2,573 & 2,412 & 2,438 & 3,367 \\
\hline $\mathrm{FeO}$ & 9,046 & 8,724 & 9,235 & 8,486 & 8,935 & 7,755 & 7,885 & 7,605 & 8,065 \\
\hline $\mathrm{MnO}$ & 0,486 & 0,384 & 0,247 & 0,277 & 0,253 & 0,338 & 0,410 & 0,281 & 0,319 \\
\hline $\mathrm{MgO}$ & 14,829 & 14,940 & 14,020 & 13,724 & 13,606 & 15,523 & 15,365 & 15,543 & 14,623 \\
\hline $\mathrm{CaO}$ & 20,766 & 20,735 & 21,384 & 20,303 & 20,240 & 21,193 & 20,998 & 20,545 & 21,325 \\
\hline $\mathrm{Na}_{2} \mathrm{O}$ & 0,485 & 0,513 & 0,493 & 0,631 & 0,636 & 0,466 & 0,505 & 0,533 & 0,691 \\
\hline $\mathrm{K}_{2} \mathrm{O}$ & 0,000 & 0,000 & 0,003 & 0,013 & 0,020 & 0,000 & 0,013 & 0,023 & 0,000 \\
\hline \multirow[t]{2}{*}{$\mathrm{Cr}_{2} \mathrm{O}_{3}$} & 0,035 & 0,022 & 0,001 & 0,063 & 0,000 & 0,000 & 0,006 & 0,001 & 0,018 \\
\hline & --- & --- & --- & --- & --- & --- & --- & --- & --- \\
\hline Total & 99,780 & 98,856 & 100,154 & 99,457 & 99,473 & 100,943 & 100,768 & 99,847 & 100,576 \\
\hline \multicolumn{10}{|c|}{$\mathrm{N}^{\circ}$ Cationes } \\
\hline $\mathrm{Si}$ & 1,9405 & 1,9059 & 1,8658 & 1,8431 & 1,8047 & 1,9253 & 1,9302 & 1,9400 & 1,8923 \\
\hline $\mathrm{Ti}^{+4}$ & 0,0197 & 0,0279 & 0,0487 & 0,0531 & 0,0611 & 0,0174 & 0,0194 & 0,0124 & 0,0288 \\
\hline $\mathrm{Al}^{+3}$ & 0,0686 & 0,0952 & 0,1431 & 0,2164 & 0,2509 & 0,1113 & 0,1046 & 0,1063 & 0,1468 \\
\hline $\mathrm{Fe}^{+2}$ & 0,2830 & 0,2758 & 0,2893 & 0,2660 & 0,2811 & 0,2380 & 0,2426 & 0,2353 & 0,2496 \\
\hline Mn & 0,0154 & 0,0123 & 0,0078 & 0,0088 & 0,0081 & 0,0105 & 0,0128 & 0,0088 & 0,0100 \\
\hline Mg & 0,8269 & 0,8419 & 0,7830 & 0,7668 & 0,7632 & 0,8493 & 0,8426 & 0,8574 & 0,8067 \\
\hline $\mathrm{Ca}$ & 0,8322 & 0,8398 & 0,8583 & 0,8153 & 0,8159 & 0,8333 & 0,8276 & 0,8145 & 0,8456 \\
\hline $\mathrm{Na}$ & 0,0352 & 0,0376 & 0,0358 & 0,0459 & 0,0464 & 0,0331 & 0,0360 & 0,0383 & 0,0496 \\
\hline $\mathbf{K}$ & 0,0000 & 0,0000 & 0,0001 & 0,0006 & 0,0010 & 0,0000 & 0,0006 & 0,0011 & 0,0000 \\
\hline $\mathrm{Cr}^{+3}$ & 0,0010 & 0,0006 & 0,0000 & 0,0019 & 0,0000 & 0,0000 & 0,0002 & 0,0000 & 0,0005 \\
\hline & --- & --- & --- & --- & -- & --- & --- & --- & --- \\
\hline Total & 4,0225 & 4,0370 & 4,0320 & 4,0179 & 4,0324 & 4,0182 & 4,0164 & 4,0141 & 4,0300 \\
\hline Wo & 42,51 & 42,63 & 44,28 & 43,91 & 43,67 & 43,15 & 42,98 & 42,51 & 44,23 \\
\hline En & 42,24 & 42,74 & 40,39 & 41,29 & 40,85 & 43,98 & 43,76 & 44,75 & 42,19 \\
\hline Fs & 15,24 & 14,63 & 15,33 & 14,80 & 15,48 & 12,87 & 13,26 & 12,74 & 13,58 \\
\hline
\end{tabular}

Tabla IV.28: Análisis de la química mineral. 


\section{Piroxenos}

\begin{tabular}{|c|c|c|c|c|c|c|c|c|c|}
\hline & \multirow{2}{*}{\multicolumn{7}{|c|}{\begin{tabular}{c|c} 
Traquiandesitas Post-caldera & Ig \\
STA 38 &
\end{tabular}}} & \multicolumn{2}{|c|}{ Ignimbrita Portezuelo } \\
\hline & & & & & & & & \multirow{2}{*}{\multicolumn{2}{|c|}{$\begin{array}{l}\text { PM } 14 \\
\text { CPX }\end{array}$}} \\
\hline & \multicolumn{5}{|c|}{$\begin{array}{ll}\text { STA 38 } \\
\text { CPX A }\end{array}$} & & & \\
\hline & \multirow{2}{*}{$\frac{1}{\text { centro }}$} & \multirow{2}{*}{$\frac{2}{\text { medio }}$} & \multirow{2}{*}{$\frac{3}{\text { medio }}$} & \multirow{2}{*}{$\frac{4}{\text { medio }}$} & \multirow{2}{*}{$\frac{5}{\text { borde }}$} & \multicolumn{2}{|c|}{$\begin{array}{l}\text { Igni } \\
\text { CPX B } \\
1\end{array}$} & \multicolumn{2}{|c|}{$1 \quad 2$} \\
\hline $\begin{array}{l}\text { Unidad } \\
\text { Muestra } \\
\text { Cristal } \\
\text { Punto } \\
\text { Ubicación }\end{array}$ & & & & & & $\frac{1}{\text { centro }}$ & $\frac{2}{\text { borde }}$ & $\frac{1}{\text { centro }}$ & borde \\
\hline \multicolumn{10}{|l|}{$\%$} \\
\hline $\mathrm{SiO}_{2}$ & 51,850 & 52,077 & 52,022 & 51,968 & 51,609 & 52,143 & 51,766 & 51,369 & 51,733 \\
\hline $\mathrm{TiO}_{2}$ & 1,344 & 0,858 & 0,836 & 1,347 & 1,322 & 1,390 & 1,206 & 0,510 & 0,185 \\
\hline $\mathrm{Al}_{2} \mathrm{O}_{3}$ & 1,949 & 1,620 & 2,292 & 2,224 & 2,126 & 1,908 & 2,264 & 0,868 & 0,914 \\
\hline $\mathrm{FeO}$ & 9,545 & 9,670 & 8,871 & 8,749 & 9,002 & 9,172 & 8,608 & 10,343 & 11,515 \\
\hline $\mathrm{MnO}$ & 0,456 & 0,483 & 0,269 & 0,311 & 0,280 & 0,302 & 0,238 & 0,806 & 0,742 \\
\hline MgO & 14,372 & 14,385 & 14,158 & 14,236 & 14,125 & 14,389 & 14,314 & 13,567 & 12,689 \\
\hline $\mathrm{CaO}$ & 20,133 & 20,139 & 20,319 & 20,930 & 20,999 & 20,448 & 20,487 & 20,588 & 20,615 \\
\hline $\mathrm{Na}_{2} \mathrm{O}$ & 0,544 & 0,486 & 0,472 & 0,456 & 0,394 & 0,421 & 0,471 & 0,395 & 0,400 \\
\hline $\mathrm{K}_{2} \mathrm{O}$ & 0,028 & 0,031 & 0,009 & 0,007 & 0,000 & 0,016 & 0,000 & 0,017 & 0,012 \\
\hline \multirow{2}{*}{$\mathrm{Cr}_{2} \mathrm{O}_{3}$} & 0,059 & 0,000 & 0,000 & 0,000 & 0,018 & 0,000 & 0,016 & 0,051 & 0,038 \\
\hline & --- & --- & --- & --- & --- & --- & --- & --- & --- \\
\hline Total & 100,280 & 99,749 & 99,249 & 100,227 & 99,875 & 100,188 & 99,370 & 98,514 & 98,842 \\
\hline \multicolumn{10}{|c|}{$\mathrm{N}^{\circ}$ Cationes } \\
\hline $\mathrm{Si}$ & 1,9305 & 1,9490 & 1,9467 & 1,9299 & 1,9270 & 1,9378 & 1,9350 & 1,9618 & 1,9763 \\
\hline $\mathbf{T i}^{+4}$ & 0,0376 & 0,0241 & 0,0235 & 0,0376 & 0,0371 & 0,0389 & 0,0339 & 0,0147 & 0,0053 \\
\hline $\mathrm{Al}^{+3}$ & 0,0855 & 0,0715 & 0,1011 & 0,0974 & 0,0935 & 0,0836 & 0,0997 & 0,0391 & 0,0412 \\
\hline $\mathrm{Fe}^{+2}$ & 0,2972 & 0,3027 & 0,2776 & 0,2717 & 0,2811 & 0,2850 & 0,2691 & 0,3303 & 0,3679 \\
\hline Mn & 0,0144 & 0,0153 & 0,0085 & 0,0098 & 0,0089 & 0,0095 & 0,0075 & 0,0261 & 0,0240 \\
\hline Mg & 0,7977 & 0,8026 & 0,7898 & 0,7881 & 0,7862 & 0,7972 & 0,7976 & 0,7724 & 0,7226 \\
\hline $\mathrm{Ca}$ & 0,8032 & 0,8075 & 0,8147 & 0,8328 & 0,8401 & 0,8142 & 0,8205 & 0,8424 & 0,8438 \\
\hline $\mathrm{Na}$ & 0,0393 & 0,0353 & 0,0343 & 0,0328 & 0,0285 & 0,0303 & 0,0341 & 0,0292 & 0,0296 \\
\hline K & 0,0013 & 0,0015 & 0,0004 & 0,0003 & 0,0000 & 0,0007 & 0,0000 & 0,0008 & 0,0006 \\
\hline \multirow[t]{2}{*}{$\mathrm{Cr}^{+3}$} & 0,0017 & 0,0000 & 0,0000 & 0,0000 & 0,0005 & 0,0000 & 0,0005 & 0,0015 & 0,0012 \\
\hline & --- & --- & --- & --- & --- & --- & --- & --- & --- \\
\hline Total & 4,0085 & 4,0095 & 3,9966 & 4,0004 & 4,0031 & 3,9971 & 3,9980 & 4,0183 & 4,0124 \\
\hline Wo & 42,00 & 41,88 & 43,09 & 43,78 & 43,84 & 42,72 & 43,31 & 42,74 & 43,09 \\
\hline En & 41,71 & 41,63 & 41,78 & 41,43 & 41,03 & 41,83 & 42,10 & 39,18 & 36,90 \\
\hline Fs & 16,29 & 16,49 & 15,13 & 14,80 & 15,13 & 15,45 & 14,60 & 18,08 & 20,01 \\
\hline
\end{tabular}

Tabla IV.29: Análisis de la química mineral. 


\section{Piroxenos}

\begin{tabular}{|c|c|c|c|c|c|c|c|c|c|}
\hline \multicolumn{5}{|c|}{ Unidad Ignimbrita Portezuelo } & \multicolumn{5}{|c|}{ Traquitoides Pre-caldera } \\
\hline Muestra & \multicolumn{2}{|c|}{ PMB 44} & \multicolumn{2}{|c|}{ PM 27} & \multicolumn{2}{|c|}{ PM 28} & \multicolumn{3}{|c|}{ PY 10} \\
\hline Cristal & \multicolumn{2}{|c|}{ Cpxf } & \multicolumn{2}{|c|}{$\mathrm{Cpx}$} & \multicolumn{2}{|c|}{$\mathrm{Cpxb}$} & \multicolumn{3}{|c|}{$\mathrm{CPX}$} \\
\hline Punto & 1 & 2 & 1 & 2 & 1 & 2 & 1 & 2 & 3 \\
\hline Ubicación & centro & borde & centro & borde & centro & borde & centro & medio & borde \\
\hline \multicolumn{10}{|l|}{$\%$} \\
\hline $\mathrm{SiO}_{2}$ & 51,79 & 51,36 & 52,712 & 53,328 & 51,543 & 52,263 & 53,042 & 52,800 & 52,155 \\
\hline $\mathrm{TiO}_{2}$ & 0,36 & 0,33 & 0,438 & 0,440 & 0,399 & 0,329 & 0,163 & 0,304 & 0,543 \\
\hline $\mathrm{Al}_{2} \mathrm{O}_{3}$ & 0,76 & 0,8 & 0,932 & 1,033 & 0,990 & 1,011 & 0,767 & 0,804 & 2,517 \\
\hline $\mathrm{FeO}$ & 11,21 & 14,19 & 12,529 & 10,646 & 11,255 & 10,837 & 12,311 & 12,293 & 8,975 \\
\hline $\mathrm{MnO}$ & 0,93 & 0,99 & 0,927 & 0,734 & 0,757 & 0,725 & 0,961 & 1,045 & 0,426 \\
\hline $\mathrm{MgO}$ & 13,65 & 12,36 & 13,617 & 14,332 & 14,108 & 13,795 & 13,358 & 12,933 & 14,782 \\
\hline $\mathrm{CaO}$ & 20,47 & 20,78 & 19,075 & 19,919 & 20,088 & 20,307 & 19,128 & 19,379 & 19,743 \\
\hline $\mathrm{Na}_{2} \mathrm{O}$ & 0,32 & 0,52 & 0,484 & 0,453 & 0,415 & 0,470 & 0,381 & 0,385 & 0,575 \\
\hline $\mathrm{K}_{2} \mathrm{O}$ & 0,02 & 0,00 & 0,000 & 0,014 & 0,000 & 0,043 & 0,014 & 0,004 & 0,000 \\
\hline \multirow{2}{*}{$\mathrm{Cr}_{2} \mathrm{O}_{3}$} & 0,00 & 0,00 & 0,040 & 0,029 & 0,030 & 0,000 & 0,028 & 0,008 & 0,003 \\
\hline & --- & --- & --- & --- & --- & --- & --- & --- & --- \\
\hline Total & 99,73 & 100,43 & 100,755 & 100,928 & 99,584 & 99,781 & 100,154 & 99,955 & 99,719 \\
\hline \multicolumn{10}{|c|}{$\mathbf{N}^{\circ}$ Cationes } \\
\hline $\mathrm{Si}$ & 1,954 & 1,94 & 1,9736 & 1,9768 & 1,9514 & 1,9686 & 1,9939 & 1,9915 & 1,9413 \\
\hline $\mathrm{Ti}^{+4}$ & 0,01 & 0,009 & 0,0123 & 0,0123 & 0,0113 & 0,0093 & 0,0046 & 0,0086 & 0,0152 \\
\hline $\mathrm{Al}^{+3}$ & 0,034 & 0,035 & 0,0411 & 0,0451 & 0,0442 & 0,0449 & 0,0340 & 0,0357 & 0,1104 \\
\hline $\mathrm{Fe}^{+2}$ & 0,353 & 0,409 & 0,3923 & 0,3300 & 0,3564 & 0,3414 & 0,3870 & 0,3878 & 0,2794 \\
\hline Mn & 0,03 & 0,032 & 0,0294 & 0,0230 & 0,0243 & 0,0231 & 0,0306 & 0,0334 & 0,0134 \\
\hline Mg & 0,767 & 0,696 & 0,7601 & 0,7920 & 0,7962 & 0,7746 & 0,7486 & 0,7272 & 0,8203 \\
\hline $\mathrm{Ca}$ & 0,827 & 0,841 & 0,7652 & 0,7911 & 0,8148 & 0,8195 & 0,7704 & 0,7832 & 0,7874 \\
\hline $\mathbf{N a}$ & 0,024 & 0,038 & 0,0352 & 0,0326 & 0,0305 & 0,0343 & 0,0278 & 0,0281 & 0,0415 \\
\hline $\mathbf{K}$ & 0,001 & 0 & 0,0000 & 0,0007 & 0,0000 & 0,0021 & 0,0007 & 0,0002 & 0,0000 \\
\hline \multirow[t]{2}{*}{$\mathrm{Cr}^{+3}$} & 0,00 & 0,00 & 0,0012 & 0,0008 & 0,0009 & 0,0000 & 0,0008 & 0,0002 & 0,0001 \\
\hline & & & --- & --- & --- & --- & --- & --- & --- \\
\hline Total & 4 & 4 & 4,0105 & 4,0045 & 4,0300 & 4,0179 & 3,9983 & 3,9960 & 4,0090 \\
\hline Wo & 43,886 & 45,687 & 39,30 & 40,86 & 40,91 & 41,84 & 39,78 & 40,55 & 41,43 \\
\hline En & 40,705 & 37,785 & 39,04 & 40,91 & 39,98 & 39,55 & 38,66 & 37,65 & 43,16 \\
\hline Fs & 15,408 & 16,527 & 21,66 & 18,23 & 19,11 & 18,61 & 21,56 & 21,81 & 15,41 \\
\hline
\end{tabular}

Tabla IV.30: Análisis de la química mineral. 


\section{Piroxenos}

\begin{tabular}{|c|c|c|c|c|c|c|c|c|}
\hline \multirow{4}{*}{$\begin{array}{l}\text { Unidad } \\
\text { Muestra } \\
\text { Cristal } \\
\text { Punto }\end{array}$} & & \multicolumn{7}{|c|}{ Traquitoides Pre-caldera } \\
\hline & & \multirow{2}{*}{\multicolumn{4}{|c|}{ Glomerulo Cpx 1}} & \multirow{2}{*}{\multicolumn{3}{|c|}{ Cpx 14}} \\
\hline & & & & & & & & \\
\hline & 1 & 2 & 3 & 4 & 5 & 6 & 7 & 8 \\
\hline Ubicación & centro & medio & medio & medio & borde & centro & borde & borde \\
\hline \multicolumn{9}{|l|}{$\%$} \\
\hline $\mathrm{SiO}_{2}$ & 51,785 & 52,323 & 51,822 & 52,204 & 52,448 & 52,325 & 52,624 & 52,082 \\
\hline $\mathrm{TiO}_{2}$ & 0,199 & 0,281 & 0,434 & 0,352 & 0,316 & 0,187 & 0,152 & 0,269 \\
\hline $\mathrm{Al}_{2} \mathrm{O}_{3}$ & 1,230 & 1,399 & 1,487 & 1,211 & 1,343 & 0,734 & 0,639 & 0,729 \\
\hline $\mathrm{FeO}$ & 11,129 & 11,576 & 11,136 & 11,022 & 11,323 & 12,845 & 12,262 & 12,142 \\
\hline $\mathrm{MnO}$ & 0,771 & 0.800 & 0,755 & 0,833 & 0,792 & 0,980 & 1,060 & 1,084 \\
\hline $\mathrm{MgO}$ & 12,356 & 12,621 & 11,818 & 12,246 & 12,134 & 11,793 & 12,294 & 11,448 \\
\hline $\mathrm{CaO}$ & 19,352 & 19,371 & 20,442 & 19,786 & 19,911 & 19,953 & 19,600 & 19,976 \\
\hline $\mathrm{Na}_{2} \mathrm{O}$ & 0,562 & 0,629 & 0,483 & 0,608 & 0,595 & 0,430 & 0,335 & 0,419 \\
\hline $\mathrm{K}_{2} \mathrm{O}$ & 0,011 & 0,000 & 0,036 & 0,001 & 0,021 & 0,000 & 0,001 & 0,008 \\
\hline \multirow[t]{2}{*}{$\mathrm{Cr}_{2} \mathrm{O}_{3}$} & 0,000 & 0,011 & 0,000 & 0,000 & 0,024 & 0,037 & 0,044 & 0,009 \\
\hline & - & - & - & - & - & - & - & - \\
\hline Total & 97,395 & 99,011 & 98,414 & 98,264 & 98,906 & 99,284 & 99,011 & 98,165 \\
\hline \multicolumn{9}{|c|}{$\mathrm{N}^{\circ}$ Cationes } \\
\hline $\mathrm{Si}$ & 1,9954 & 1,9858 & 1,9818 & 1,9945 & 1,9926 & 1,9969 & 2,0052 & 2,0055 \\
\hline $\mathrm{Ti}^{+4}$ & 0,0058 & 0,0080 & 0,0125 & 0,0101 & 0,0090 & 0,0054 & 0,0044 & 0,0078 \\
\hline $\mathrm{Al}^{+3}$ & 0,0558 & 0,0626 & 0,0670 & 0,0545 & 0,0601 & 0,0330 & 0,0287 & 0,0331 \\
\hline $\mathrm{Fe}^{+2}$ & 0,3586 & 0,3674 & 0,3562 & 0,3522 & 0,3598 & 0,4100 & 0,3907 & 0,3910 \\
\hline Mn & 0,0252 & 0,0257 & 0,0245 & 0,0269 & 0,0255 & 0,0317 & 0,0342 & 0,0353 \\
\hline Mg & 0,7098 & 0,7141 & 0,6738 & 0,6975 & 0,6872 & 0,6709 & 0,6983 & 0,6571 \\
\hline $\mathrm{Ca}$ & 0,7989 & 0,7877 & 0,8376 & 0,8099 & 0,8105 & 0,8159 & 0,8002 & 0,8241 \\
\hline $\mathrm{Na}$ & 0,0420 & 0,0463 & 0,0358 & 0,0451 & 0,0438 & 0,0318 & 0,0248 & 0,0313 \\
\hline K & 0,0005 & 0,0000 & 0,0018 & 0,0001 & 0,0010 & 0,0000 & 0,0001 & 0,0004 \\
\hline \multirow[t]{2}{*}{$\mathrm{Cr}^{+3}$} & 0,0000 & 0,0003 & 0,0000 & 0,0000 & 0,0007 & 0,0011 & 0,0013 & 0,0003 \\
\hline & - & - & - & - & - & - & - & - \\
\hline Total & 3,9921 & 3,9979 & 3,9910 & 3,9907 & 3,9903 & 3,9966 & 3,9879 & 3,9859 \\
\hline Wo & 42,21 & 41,57 & 44,27 & 42,93 & 43,04 & 42,31 & 41,60 & 43,20 \\
\hline En & 37,51 & 37,69 & 35,61 & 36,97 & 36,49 & 34,79 & 36,31 & 34,45 \\
\hline Fs & 20,28 & 20,75 & 20,12 & 20,10 & 20,46 & 22,90 & 22,09 & 22,35 \\
\hline
\end{tabular}

Tabla IV.31: Análisis de la química mineral. 


\section{Piroxenos}

\begin{tabular}{|c|c|c|c|c|c|c|c|c|}
\hline Unidad & \multicolumn{8}{|c|}{ Traquitoides Pre-caldera } \\
\hline Muestra & & & & & & & & \\
\hline Cristal & \multicolumn{2}{|c|}{ OPX } & \multicolumn{6}{|c|}{ Glomerulo Opx 1} \\
\hline Punto & 1 & 2 & 1 & 2 & 3 & 4 & 5 & 6 \\
\hline Ubicación & centro & borde & centro & centro & medio & medio & medio & borde \\
\hline$\%$ & 52,608 & 52,655 & 51,829 & 51,637 & 51,368 & 52,721 & 52,351 & 52,058 \\
\hline $\mathrm{SiO}_{2}$ & 0,224 & 0,135 & 0,111 & 0,078 & 0,067 & 0,111 & 0,145 & 0,190 \\
\hline $\mathrm{TiO}_{2}$ & 0,310 & 0,244 & 0,336 & 0,388 & 0,324 & 0,331 & 0,330 & 0,310 \\
\hline $\mathrm{Al}_{2} \mathrm{O}_{3}$ & 26,037 & 25,544 & 27,274 & 27,139 & 26,715 & 27,645 & 26,518 & 27,021 \\
\hline $\mathrm{FeO}$ & 1,884 & 1,902 & 2,000 & 1,909 & 2,034 & 2,069 & 2,014 & 1,863 \\
\hline $\mathrm{MnO}$ & 18,008 & 17,965 & 16,683 & 16,623 & 16,585 & 16,613 & 16,597 & 16,471 \\
\hline $\mathrm{MgO}$ & 1,406 & 1,459 & 1,515 & 1,387 & 1,382 & 1,476 & 1,508 & 1,477 \\
\hline $\mathrm{CaO}$ & 0,022 & 0,021 & 0,026 & 0,000 & 0,052 & 0,035 & 0,014 & 0,026 \\
\hline $\mathrm{Na}_{2} \mathrm{O}$ & 0,011 & 0,010 & 0,000 & 0,000 & 0,000 & 0,036 & 0,007 & 0,013 \\
\hline $\mathrm{K}_{2} \mathrm{O}$ & 0,033 & 0,023 & 0,000 & 0,000 & 0,000 & 0,000 & 0,000 & 0,000 \\
\hline $\mathrm{Cr}_{2} \mathrm{O}_{3}$ & --- & --- & - & - & - & - & - & - \\
\hline Total & 100,544 & 99,957 & 99,772 & 99,161 & 98,527 & 101,036 & 99,484 & 99,429 \\
\hline \multicolumn{9}{|c|}{$\mathbf{N}^{\circ}$ Cationes } \\
\hline Si & 1,9991 & 2,0082 & 2,0006 & 2,0033 & 2,0049 & 2,0088 & 2,0166 & 2,0113 \\
\hline $\mathrm{Ti}^{+4}$ & 0,0064 & 0,0039 & 0,0032 & 0,0023 & 0,0020 & 0,0032 & 0,0042 & 0,0055 \\
\hline $\mathrm{Al}^{+3}$ & 0,0139 & 0,0110 & 0,0153 & 0,0178 & 0,0149 & 0,0149 & 0,0150 & 0,0141 \\
\hline $\mathrm{Fe}^{+2}$ & 0,8274 & 0,8147 & 0,8804 & 0,8805 & 0,8720 & 0,8809 & 0,8542 & 0,8731 \\
\hline Mn & 0,0606 & 0,0614 & 0,0654 & 0,0627 & 0,0673 & 0,0668 & 0,0657 & 0,0610 \\
\hline Mg & 1,0202 & 1,0215 & 0,9600 & 0,9614 & 0,9650 & 0,9436 & 0,9531 & 0,9487 \\
\hline $\mathrm{Ca}$ & 0,0572 & 0,0596 & 0,0626 & 0,0577 & 0,0578 & 0,0603 & 0,0622 & 0,0611 \\
\hline $\mathrm{Na}$ & 0,0016 & 0,0015 & 0,0020 & 0,0000 & 0,0040 & 0,0026 & 0,0010 & 0,0020 \\
\hline K & 0,0005 & 0,0005 & 0,0000 & 0,0000 & 0,0000 & 0,0017 & 0,0003 & 0,0007 \\
\hline $\mathrm{Cr}^{+3}$ & 0,0010 & 0,0007 & 0,0000 & 0,0000 & 0,0000 & 0,0000 & 0,0000 & 0,0000 \\
\hline & --- & -- & - & - & - & - & - & - \\
\hline Total & 3,9881 & 3,9831 & 3,9895 & 3,9856 & 3,9877 & 3,9827 & 3,9724 & 3,9774 \\
\hline Wo & 2,91 & 3,05 & 3,18 & 2,94 & 2,95 & 3,09 & 3,21 & 3,14 \\
\hline En & 51,91 & 52,19 & 48,77 & 48,99 & 49,18 & 48,35 & 49,25 & 48,80 \\
\hline Fs & 45,18 & 44,76 & 48,05 & 48,07 & 47,87 & 48,56 & 47,54 & 48,05 \\
\hline
\end{tabular}

Tabla IV.32: Análisis de la química mineral. 


\section{Piroxenos}

\begin{tabular}{|c|c|c|c|c|c|c|c|c|c|}
\hline Unidad & \multicolumn{5}{|c|}{ Traquitoides Pre-caldera } & \multicolumn{4}{|c|}{ Basaltos Post-caldera II } \\
\hline Muestra & \multicolumn{5}{|c|}{ PY 10} & \multicolumn{4}{|c|}{ PM 46} \\
\hline Cristal & \multicolumn{2}{|c|}{ Glomerulo Opx 1} & \multicolumn{3}{|c|}{ Glomerulo Opx 2} & \multicolumn{2}{|c|}{ CPX A } & \multicolumn{2}{|c|}{ CPX B } \\
\hline Punto & 7 & 8 & 9 & 10 & 11 & 1 & 2 & 1 & 2 \\
\hline Ubicación & medio & borde & centro & medio & centro & centro & borde & centro & medio \\
\hline \multicolumn{10}{|l|}{$\%$} \\
\hline $\mathrm{SiO}_{2}$ & 52,190 & 52,025 & 52,299 & 52,033 & 51,704 & 50,112 & 48,088 & 45,895 & 49,988 \\
\hline $\mathrm{TiO}_{2}$ & 0,156 & 0,246 & 0,167 & 0,234 & 0,167 & 1,282 & 1,881 & 1,863 & 1,166 \\
\hline $\mathrm{Al}_{2} \mathrm{O}_{3}$ & 0,313 & 0,342 & 0,348 & 0,332 & 0,295 & 4,278 & 6,490 & 8,156 & 4,856 \\
\hline $\mathrm{FeO}$ & 26,599 & 25,701 & 26,381 & 26,165 & 25,654 & 6,876 & 7,962 & 7,407 & 7,385 \\
\hline $\mathrm{MnO}$ & 1,900 & 2,009 & 1,974 & 2,003 & 2,023 & 0,131 & 0,138 & 0,113 & 0,135 \\
\hline $\mathrm{MgO}$ & 16,512 & 16,629 & 16,359 & 16,346 & 16,217 & 14,996 & 13,171 & 12,869 & 15,018 \\
\hline $\mathrm{CaO}$ & 1,391 & 1,509 & 1,444 & 1,390 & 1,367 & 22,552 & 22,346 & 22,373 & 22,082 \\
\hline $\mathrm{Na}_{2} \mathrm{O}$ & 0,016 & 0,019 & 0,046 & 0,050 & 0,062 & 0,361 & 0,564 & 0,393 & 0,299 \\
\hline $\mathrm{K}_{2} \mathrm{O}$ & 0,003 & 0,021 & 0,007 & 0,000 & 0,024 & 0,000 & 0,013 & 0,008 & 0,005 \\
\hline \multirow[t]{2}{*}{$\mathrm{Cr}_{2} \mathrm{O}_{3}$} & 0,000 & 0,003 & 0,025 & 0,000 & 0,024 & 0,281 & 0,000 & 0,119 & 0,119 \\
\hline & - & - & - & - & - & --- & --- & -- & --- \\
\hline Total & 99,080 & 98,503 & 99,050 & 98,554 & 97,537 & 100,868 & 100,654 & 99,195 & 101,052 \\
\hline \multicolumn{10}{|c|}{$\mathrm{N}^{\circ}$ Cationes } \\
\hline $\mathrm{Si}$ & 2,0184 & 2,0183 & 2,0217 & 2,0208 & 2,0264 & 1,8471 & 1,7878 & 1,7321 & 1,8391 \\
\hline $\mathrm{Ti}^{+4}$ & 0,0045 & 0,0072 & 0,0049 & 0,0068 & 0,0049 & 0,0355 & 0,0526 & 0,0529 & 0,0323 \\
\hline $\mathrm{Al}^{+3}$ & 0,0142 & 0,0157 & 0,0159 & 0,0152 & 0,0136 & 0,1859 & 0,2844 & 0,3628 & 0,2106 \\
\hline $\mathrm{Fe}^{+2}$ & 0,8603 & 0,8338 & 0,8529 & 0,8498 & 0,8408 & 0,2120 & 0,2475 & 0,2338 & 0,2272 \\
\hline Mn & 0,0622 & 0,0660 & 0,0646 & 0,0659 & 0,0672 & 0,0041 & 0,0044 & 0,0036 & 0,0042 \\
\hline Mg & 0,9520 & 0,9617 & 0,9427 & 0,9464 & 0,9475 & 0,8240 & 0,7300 & 0,7240 & 0,8237 \\
\hline $\mathrm{Ca}$ & 0,0576 & 0,0627 & 0,0598 & 0,0579 & 0,0574 & 0,8906 & 0,8901 & 0,9047 & 0,8704 \\
\hline $\mathrm{Na}$ & 0,0012 & 0,0014 & 0,0035 & 0,0037 & 0,0047 & 0,0258 & 0,0406 & 0,0287 & 0,0213 \\
\hline K & 0,0002 & 0,0010 & 0,0003 & 0,0000 & 0,0012 & 0,0000 & 0,0006 & 0,0004 & 0,0003 \\
\hline \multirow[t]{2}{*}{$\mathrm{Cr}^{+3}$} & 0,0000 & 0,0001 & 0,0008 & 0,0000 & 0,0007 & 0,0082 & 0,0000 & 0,0035 & 0,0034 \\
\hline & - & - & - & - & - & --- & --- & --- & --- \\
\hline Total & 3,9706 & 3,9679 & 3,9670 & 3,9666 & 3,9645 & 4,0332 & 4,0381 & 4,0465 & 4,0325 \\
\hline Wo & 2,98 & 3,26 & 3,11 & 3,02 & 3,00 & 46,13 & 47,55 & 48,48 & 45,20 \\
\hline En & 49,27 & 49,98 & 49,10 & 49,29 & 49,53 & 42,68 & 39,00 & 38,80 & 42,78 \\
\hline Fs & 47,75 & 46,76 & 47,79 & 47,69 & 47,47 & 11,19 & 13,46 & 12,72 & 12,02 \\
\hline
\end{tabular}

Tabla IV.33: Análisis de la química mineral. 


\begin{tabular}{|c|c|c|c|c|c|c|c|}
\hline & \multicolumn{7}{|c|}{ Piroxenos } \\
\hline Unidad & \multicolumn{5}{|c|}{ Basaltos Post-caldera II } & \multicolumn{2}{|c|}{ Basaltos Pre-caldera } \\
\hline Muestra & \multicolumn{2}{|c|}{ PM 46} & \multicolumn{3}{|c|}{ PY 13} & \multicolumn{2}{|c|}{ PY 5} \\
\hline Cristal & \multicolumn{2}{|c|}{ CPX B } & \multicolumn{3}{|c|}{ CPX } & \multicolumn{2}{|c|}{ CPX } \\
\hline Punto & 3 & 4 & 1 & 2 & 3 & 1 & 2 \\
\hline Ubicación & borde & borde & centro & medio & borde & centro & borde \\
\hline \multicolumn{8}{|l|}{$\%$} \\
\hline $\mathrm{SiO}_{2}$ & 49,603 & 47,191 & 50,113 & 49,078 & 50,105 & 49,220 & 47,193 \\
\hline $\mathrm{TiO}_{2}$ & 1,074 & 1,723 & 1,357 & 1,756 & 1,521 & 1,130 & 2,232 \\
\hline $\mathrm{Al}_{2} \mathrm{O}_{3}$ & 4,648 & 7,405 & 3,842 & 5,154 & 4,622 & 4,542 & 6,994 \\
\hline $\mathrm{FeO}$ & 6,735 & 7,095 & 7,228 & 6,833 & 7,081 & 7,566 & 8,054 \\
\hline $\mathrm{MnO}$ & 0,104 & 0,112 & 0,125 & 0,149 & 0,156 & 0,121 & 0,172 \\
\hline $\mathrm{MgO}$ & 15,015 & 13,239 & 14,653 & 14,091 & 14,095 & 14,630 & 12,928 \\
\hline $\mathrm{CaO}$ & 22,007 & 22,572 & 21,675 & 22,181 & 21,499 & 21,856 & 21,868 \\
\hline $\mathrm{Na}_{2} \mathrm{O}$ & 0,299 & 0,364 & 0,428 & 0,470 & 0,455 & 0,465 & 0,548 \\
\hline $\mathrm{K}_{2} \mathrm{O}$ & 0,002 & 0,000 & 0,000 & 0,011 & 0,000 & 0,000 & 0,000 \\
\hline $\mathrm{Cr}_{2} \mathrm{O}_{3}$ & 0,168 & 0,341 & 0,000 & 0,000 & 0,001 & 0,025 & 0,029 \\
\hline & --- & --- & --- & --- & --- & --- & --- \\
\hline Total & 99,653 & 100,041 & 99,422 & 99,723 & 99,536 & 99,556 & 100,018 \\
\hline \multicolumn{8}{|c|}{$\mathbf{N}^{\circ}$ Cationes } \\
\hline Si & 1,8461 & 1,7612 & 1,8711 & 1,8292 & 1,8648 & 1,8422 & 1,7669 \\
\hline $\mathrm{Ti}^{+4}$ & 0,0301 & 0,0483 & 0,0381 & 0,0492 & 0,0426 & 0,0318 & 0,0628 \\
\hline $\mathrm{Al}^{+3}$ & 0,2039 & 0,3257 & 0,1691 & 0,2264 & 0,2028 & 0,2003 & 0,3086 \\
\hline $\mathrm{Fe}^{+2}$ & 0,2096 & 0,2214 & 0,2257 & 0,2130 & 0,2204 & 0,2368 & 0,2522 \\
\hline Mn & 0,0033 & 0,0035 & 0,0039 & 0,0047 & 0,0049 & 0,0038 & 0,0055 \\
\hline Mg & 0,8331 & 0,7366 & 0,8156 & 0,7829 & 0,7820 & 0,8163 & 0,7216 \\
\hline $\mathrm{Ca}$ & 0,8776 & 0,9025 & 0,8671 & 0,8857 & 0,8573 & 0,8765 & 0,8772 \\
\hline $\mathrm{Na}$ & 0,0216 & 0,0263 & 0,0310 & 0,0340 & 0,0328 & 0,0338 & 0,0398 \\
\hline $\mathbf{K}$ & 0,0001 & 0,0000 & 0,0000 & 0,0005 & 0,0000 & 0,0000 & 0,0000 \\
\hline \multirow[t]{2}{*}{$\mathrm{Cr}^{+3}$} & 0,0049 & 0,0101 & 0,0000 & 0,0000 & 0,0000 & 0,0007 & 0,0009 \\
\hline & --- & --- & --- & --- & --- & --- & --- \\
\hline Total & 4,0302 & 4,0357 & 4,0217 & 4,0257 & 4,0076 & 4,0423 & 4,0354 \\
\hline Wo & 45,62 & 48,42 & 45,34 & 46,95 & 45,98 & 45,33 & 47,25 \\
\hline En & 43,31 & 39,52 & 42,65 & 41,50 & 41,94 & 42,22 & 38,87 \\
\hline Fs & 11,07 & 12,07 & 12,01 & 11,54 & 12,08 & 12,44 & 13,88 \\
\hline
\end{tabular}

Tabla IV.34: Análisis de la química mineral. 
Anfíboles

\begin{tabular}{|c|c|c|c|c|c|c|}
\hline \multirow{2}{*}{$\begin{array}{l}\text { Unidad } \\
\text { Muestra }\end{array}$} & \multirow{2}{*}{\multicolumn{2}{|c|}{$\begin{array}{c}\text { Traquiandesitas Post-caldera } \\
\text { STA 6-B }\end{array}$}} & \multicolumn{4}{|c|}{ Traquitoides Pre-caldera } \\
\hline & & & \multirow{2}{*}{\multicolumn{2}{|c|}{$\frac{\text { PM } 28}{\text { ANF }}$}} & \multicolumn{2}{|c|}{ PY 10} \\
\hline Cristal & \multicolumn{2}{|c|}{ ANF } & & & & \\
\hline Punto & 1 & 2 & 1 & 2 & 1 & 2 \\
\hline Ubicación & centro & borde & centro & borde & centro & borde \\
\hline \multicolumn{7}{|l|}{$\%$} \\
\hline $\mathrm{SiO}_{2}$ & 41,592 & 41,549 & 40,868 & 40,443 & 41,819 & 40,447 \\
\hline $\mathrm{TiO}_{2}$ & 5,358 & 4,723 & 4,280 & 4,098 & 4,680 & 6,083 \\
\hline $\mathrm{Al}_{2} \mathrm{O}_{3}$ & 11,861 & 11,983 & 12,539 & 12,333 & 12,096 & 12,959 \\
\hline $\mathrm{FeO}$ & 11,778 & 11,384 & 12,601 & 12,584 & 13,184 & 10,785 \\
\hline $\mathrm{MnO}$ & 0,158 & 0,236 & 0,170 & 0,193 & 0,269 & 0,173 \\
\hline MgO & 13,201 & 13,198 & 13,061 & 12,863 & 12,646 & 12,497 \\
\hline $\mathrm{CaO}$ & 11,010 & 11,175 & 10,823 & 11,190 & 10,829 & 11,170 \\
\hline $\mathrm{Na}_{2} \mathrm{O}$ & 2,637 & 2,606 & 2,748 & 2,571 & 2,682 & 2,736 \\
\hline $\mathrm{K}_{2} \mathrm{O}$ & 0,935 & 1,035 & 0,938 & 0,965 & 0,874 & 0,851 \\
\hline $\mathbf{F}$ & 0,056 & 0,049 & 0,000 & 0,052 & 0,000 & 0,050 \\
\hline $\mathrm{Cl}$ & 0,000 & 0,016 & 0,018 & 0,023 & 0,012 & 0,000 \\
\hline $\mathrm{Cr}_{2} \mathrm{O}_{3}$ & 0,020 & 0,017 & 0,009 & 0,000 & 0,000 & 0,000 \\
\hline --- & --- & --- & --- & --- & --- & --- \\
\hline Total & 98,607 & 97,970 & 98,054 & 97,313 & 99,091 & 97,750 \\
\hline \multicolumn{7}{|l|}{$\mathbf{N}^{\circ}$ Cationes } \\
\hline Si & 6,0990 & 6,1274 & 6,0501 & 6,0475 & 6,1293 & 5,9667 \\
\hline $\mathrm{Ti}+4$ & 0,5909 & 0,5238 & 0,4765 & 0,4608 & 0,5158 & 0,6748 \\
\hline $\mathrm{Al}+3$ & 2,0499 & 2,0827 & 2,1878 & 2,1735 & 2,0895 & 2,2532 \\
\hline $\mathrm{Fe}+2$ & 1,4444 & 1,4040 & 1,5601 & 1,5737 & 1,6160 & 1,3305 \\
\hline Mn & 0,0196 & 0,0294 & 0,0213 & 0,0244 & 0,0334 & 0,0216 \\
\hline Mg & 2,8858 & 2,9015 & 2,8824 & 2,8674 & 2,7630 & 2,7482 \\
\hline $\mathrm{Ca}$ & 1,7298 & 1,7657 & 1,7167 & 1,7928 & 1,7005 & 1,7655 \\
\hline $\mathrm{Na}$ & 0,7497 & 0,7453 & 0,7887 & 0,7453 & 0,7621 & 0,7827 \\
\hline $\mathbf{K}$ & 0,1750 & 0,1947 & 0,1772 & 0,1840 & 0,1635 & 0,1601 \\
\hline $\mathbf{F}$ & 0,0258 & 0,0231 & 0,0000 & 0,0244 & 0,0000 & 0,0232 \\
\hline $\mathrm{Cl}$ & 0,0000 & 0,0040 & 0,0046 & 0,0058 & 0,0029 & 0,0000 \\
\hline \multirow[t]{2}{*}{$\mathrm{Cr}+3$} & 0,0024 & 0,0020 & 0,0011 & 0,0000 & 0,0000 & 0,0000 \\
\hline & --- & --- & --- & --- & --- & --- \\
\hline Total & 15,7722 & 15,8035 & 15,8665 & 15,8997 & 15,7758 & 15,7264 \\
\hline $\mathrm{Mg} /\left(\mathrm{Mg}+\mathrm{Fe}^{+2}\right)$ & 0,6664 & 0,6739 & 0,6310 & 0,6738 & 0,6488 & 0,6457 \\
\hline
\end{tabular}

Tabla IV.35: Análisis de la química mineral. 


\begin{tabular}{|c|c|c|c|c|c|c|}
\hline \multicolumn{7}{|c|}{ Anfíboles } \\
\hline Unidad & \multicolumn{6}{|c|}{ Traquitoides Pre-caldera } \\
\hline Muestra & \multicolumn{6}{|c|}{ PY 10} \\
\hline Cristal & \multicolumn{6}{|c|}{ Anfibol 6} \\
\hline Punto & 1 & 2 & 3 & 4 & 5 & 6 \\
\hline Ubicación & medio & medio & medio & centro & borde & borde \\
\hline \multicolumn{7}{|l|}{$\%$} \\
\hline $\mathrm{SiO}_{2}$ & 40,697 & 40,267 & 40,664 & 40,552 & 40,442 & 40,313 \\
\hline $\mathrm{TiO}_{2}$ & 5,243 & 5,623 & 4,887 & 4,862 & 4,705 & 5,444 \\
\hline $\mathrm{Al}_{2} \mathrm{O}_{3}$ & 12,290 & 12,356 & 12,515 & 12,125 & 11,701 & 12,446 \\
\hline $\mathrm{FeO}$ & 12,730 & 12,801 & 12,651 & 12,689 & 13,597 & 12,456 \\
\hline $\mathrm{MnO}$ & 0,278 & 0,287 & 0,226 & 0,249 & 0,338 & 0,202 \\
\hline $\mathrm{MgO}$ & 13,189 & 13,041 & 12,918 & 12,734 & 12,805 & 12,889 \\
\hline $\mathrm{CaO}$ & 11,226 & 11,431 & 11,274 & 11,148 & 11,165 & 11,409 \\
\hline $\mathrm{Na}_{2} \mathrm{O}$ & 2,908 & 2,818 & 2,928 & 3,072 & 2,711 & 2,481 \\
\hline $\mathrm{K}_{2} \mathrm{O}$ & 0,987 & 1,009 & 0,896 & 0,945 & 0,977 & 0,972 \\
\hline $\mathbf{F}$ & 0,075 & 0,000 & 0,039 & 0,000 & 0,243 & 0,031 \\
\hline $\mathrm{Cl}$ & 0,053 & 0,031 & 0,034 & 0,031 & 0,043 & 0,010 \\
\hline $\mathrm{Cr}_{2} \mathrm{O}_{3}$ & - & - & - & - & - & - \\
\hline \multicolumn{7}{|l|}{--- } \\
\hline Total & 99,675 & 99,664 & 99,032 & 98,408 & 98,727 & 99,015 \\
\hline \multicolumn{7}{|l|}{$\mathbf{N}^{\circ}$ Cationes } \\
\hline Si & 5,9609 & 5,9047 & 5,9829 & 6,0102 & 6,0163 & 5,9352 \\
\hline $\mathbf{T i}+4$ & 0,5775 & 0,6201 & 0,5407 & 0,5419 & 0,5263 & 0,6027 \\
\hline $\mathrm{Al}+3$ & 2,1216 & 2,1355 & 2,1702 & 2,1180 & 2,0516 & 2,1597 \\
\hline $\mathrm{Fe}+2$ & 1,5594 & 1,5699 & 1,5567 & 1,5727 & 1,6916 & 1,5337 \\
\hline Mn & 0,0345 & 0,0357 & 0,0282 & 0,0313 & 0,0426 & 0,0252 \\
\hline Mg & 2,8799 & 2,8508 & 2,8336 & 2,8136 & 2,8399 & 2,8290 \\
\hline $\mathrm{Ca}$ & 1,7617 & 1,7959 & 1,7773 & 1,7703 & 1,7795 & 1,7997 \\
\hline $\mathrm{Na}$ & 0,8258 & 0,8012 & 0,8353 & 0,8829 & 0,7821 & 0,8111 \\
\hline $\mathbf{K}$ & 0,1844 & 0,1887 & 0,1682 & 0,1786 & 0,1854 & 0,1826 \\
\hline F & 0,0347 & 0,0000 & 0,0183 & 0,0000 & 0,1143 & 0,0145 \\
\hline $\mathrm{Cl}$ & 0,0132 & 0,0078 & 0,0084 & 0,0079 & 0,0109 & 0,0024 \\
\hline $\mathrm{Cr}+3$ & - & - & - & - & - & - \\
\hline Total & 15,9537 & 15,9103 & 15,9198 & 15,9275 & 16,0405 & 15,8960 \\
\hline $\mathrm{Mg} /\left(\mathrm{Mg}+\mathrm{Fe}^{+2}\right)$ & 0,0160 & 0,0164 & 0,0128 & 0,0146 & 0,0203 & 0,0115 \\
\hline
\end{tabular}

Tabla IV.36: Análisis de la química mineral. 


\section{Anfíboles}

\begin{tabular}{|c|c|c|c|c|c|}
\hline Unidad & \multicolumn{5}{|c|}{ Traquitoides Pre-caldera } \\
\hline Muestra & \multicolumn{5}{|c|}{ PY 10} \\
\hline Cristal & \multicolumn{2}{|c|}{ Anfibol 7} & \multicolumn{2}{|c|}{ Anfibol 8} & Anfíbol 9 \\
\hline Punto & 7 & 8 & 9 & 10 & 11 \\
\hline Ubicación & centro & borde & borde & centro & borde \\
\hline \multicolumn{6}{|l|}{$\%$} \\
\hline $\mathrm{SiO}_{2}$ & 40,484 & 40,726 & 39,869 & 39,273 & 40,743 \\
\hline $\mathrm{TiO}_{2}$ & 5,420 & 5,470 & 5,428 & 5,650 & 5,478 \\
\hline $\mathrm{Al}_{2} \mathrm{O}_{3}$ & 11,877 & 12,440 & 12,471 & 13,281 & 12,689 \\
\hline $\mathrm{FeO}$ & 12,415 & 12,893 & 12,331 & 12,907 & 12,943 \\
\hline $\mathrm{MnO}$ & 0,285 & 0,237 & 0,198 & 0,222 & 0,240 \\
\hline $\mathrm{MgO}$ & 13,127 & 12,538 & 12,717 & 12,535 & 12,503 \\
\hline $\mathrm{CaO}$ & 11,463 & 11,405 & 11,551 & 11,398 & 11,607 \\
\hline $\mathrm{Na}_{2} \mathrm{O}$ & 2,888 & 2,965 & 2,702 & 2,683 & 2,998 \\
\hline $\mathrm{K}_{2} \mathrm{O}$ & 0,963 & 0,910 & 0,962 & 0,971 & 0,916 \\
\hline $\mathbf{F}$ & 0,000 & 0,214 & 0,073 & 0,000 & 0,000 \\
\hline $\mathrm{Cl}$ & 0,004 & 0,017 & 0,014 & 0,012 & 0,041 \\
\hline $\mathrm{Cr}_{2} \mathrm{O}_{3}$ & - & - & - & - & - \\
\hline \multicolumn{6}{|l|}{--- } \\
\hline Total & 98,958 & 99,817 & 98,316 & 98,932 & 100,156 \\
\hline \multicolumn{6}{|l|}{$\mathrm{N}^{\circ}$ Cationes } \\
\hline Si & 5,9686 & 5,9654 & 5,9162 & 5,8042 & 5,9404 \\
\hline $\mathbf{T i}+4$ & 0,6009 & 0,6026 & 0,6057 & 0,6280 & 0,6006 \\
\hline $\mathrm{Al}+3$ & 2,0637 & 2,1475 & 2,1811 & 2,3133 & 2,1804 \\
\hline $\mathrm{Fe}+2$ & 1,5307 & 1,5793 & 1,5302 & 1,5953 & 1,5782 \\
\hline Mn & 0,0356 & 0,0294 & 0,0249 & 0,0278 & 0,0297 \\
\hline $\mathrm{Mg}$ & 2,8851 & 2,7378 & 2,8132 & 2,7617 & 2,7175 \\
\hline $\mathrm{Ca}$ & 1,8108 & 1,7899 & 1,8365 & 1,8049 & 1,8132 \\
\hline $\mathrm{Na}$ & 0,8256 & 0,8422 & 0,7775 & 0,7688 & 0,8474 \\
\hline $\mathbf{K}$ & 0,1811 & 0,1701 & 0,1821 & 0,1831 & 0,1703 \\
\hline $\mathbf{F}$ & 0,0000 & 0,0993 & 0,0343 & 0,0000 & 0,0000 \\
\hline $\mathrm{Cl}$ & 0,0090 & 0,0042 & 0,0036 & 0,0030 & 0,0101 \\
\hline $\mathrm{Cr}+3$ & - & - & - & - & - \\
\hline Total & 15,9110 & 15,9678 & 15,9053 & 15,8902 & 15,8878 \\
\hline $\mathrm{Mg} /\left(\mathrm{Mg}+\mathrm{Fe}^{+2}\right)$ & 0,0170 & 0,0135 & 0,0113 & 0,0119 & 0,0134 \\
\hline
\end{tabular}

Tabla IV.37: Análisis de la química mineral. 
Biotita

\begin{tabular}{|c|c|c|c|c|c|c|}
\hline \multirow{4}{*}{$\begin{array}{l}\text { Unidad } \\
\text { Muestra } \\
\text { Cristal } \\
\text { Punto }\end{array}$} & \multicolumn{6}{|c|}{ Traquitoides Pre-caldera } \\
\hline & \multirow{2}{*}{\multicolumn{2}{|c|}{$\frac{\mathrm{PM} 27}{\mathrm{Bt}}$}} & \multicolumn{4}{|c|}{ PY 10} \\
\hline & & & \multicolumn{2}{|c|}{$\mathrm{Bt}$} & \multicolumn{2}{|c|}{$\mathrm{Bt}(\mathrm{P})$} \\
\hline & 1 & 2 & 1 & 2 & 1 & 2 \\
\hline Ubicación & centro & borde & centro & borde & borde & centro \\
\hline \multicolumn{7}{|l|}{$\%$} \\
\hline $\mathrm{SiO}_{2}$ & 37,461 & 36,938 & 36,949 & 36,210 & 34,216 & 33,635 \\
\hline $\mathrm{TiO}_{2}$ & 7,037 & 7,317 & 6,544 & 5,650 & 5,476 & 5,638 \\
\hline $\mathrm{Al}_{2} \mathrm{O}_{3}$ & 13,648 & 14,106 & 13,788 & 13,775 & 13,073 & 13,165 \\
\hline $\mathrm{FeO}$ & 15,287 & 15,226 & 18,021 & 18,197 & 15,985 & 16,607 \\
\hline $\mathrm{MnO}$ & 0,188 & 0,202 & 0,297 & 0,280 & 0,185 & 0,193 \\
\hline $\mathrm{MgO}$ & 13,883 & 13,805 & 11,759 & 12,041 & 11,971 & 12,075 \\
\hline $\mathrm{CaO}$ & 0,018 & 0,052 & 0,000 & 0,024 & 0,020 & 0,018 \\
\hline $\mathrm{Na}_{2} \mathrm{O}$ & 0,938 & 0,867 & 0,794 & 0,752 & 0,681 & 0,817 \\
\hline $\mathrm{K}_{2} \mathrm{O}$ & 9,041 & 8,771 & 8,825 & 8,752 & 8,482 & 8,482 \\
\hline $\mathbf{F}$ & 0,244 & 0,250 & 0,098 & 0,000 & 0,261 & 0,398 \\
\hline $\mathrm{Cl}$ & 0,055 & 0,055 & 0,136 & 0,168 & 0,149 & 0,136 \\
\hline $\mathrm{BaO}$ & 0,322 & 0,727 & 0,433 & 0,338 & 0,354 & 0,382 \\
\hline --- & --- & --- & --- & --- & - & - \\
\hline Total & 98,122 & 98,317 & 97,645 & 96,186 & 90,852 & 91,547 \\
\hline \multicolumn{7}{|c|}{$N^{\circ}$ Cationes } \\
\hline Si & 5,4907 & 5,4147 & 5,5097 & 5,4884 & 5,4793 & 5,3836 \\
\hline $\mathbf{T i}+4$ & 0,7757 & 0,8066 & 0,7338 & 0,6440 & 0,6595 & 0,6786 \\
\hline $\mathrm{Al}+3$ & 2,3577 & 2,4371 & 2,4231 & 2,4608 & 2,4673 & 2,4835 \\
\hline $\mathrm{Fe}+2$ & 1,8738 & 1,8666 & 2,2473 & 2,3066 & 2,1407 & 2,2230 \\
\hline Mn & 0,0234 & 0,0251 & 0,0375 & 0,0359 & 0,0251 & 0,0262 \\
\hline Mg & 3,0336 & 3,0168 & 2,6141 & 2,7208 & 2,8579 & 2,8812 \\
\hline $\mathrm{Ca}$ & 0,0028 & 0,0082 & 0,0000 & 0,0039 & 0,0034 & 0,0032 \\
\hline $\mathrm{Na}$ & 0,2665 & 0,2465 & 0,2297 & 0,2210 & 0,2115 & 0,2536 \\
\hline K & 1,6905 & 1,6402 & 1,6788 & 1,6922 & 1,7328 & 1,7319 \\
\hline $\mathbf{F}$ & 0,1133 & 0,1157 & 0,0463 & 0,0000 & 0,1321 & 0,2013 \\
\hline $\mathrm{Cl}$ & 0,0136 & 0,0136 & 0,0344 & 0,0431 & 0,0403 & 0,0370 \\
\hline \multirow[t]{2}{*}{ Ba } & 0,0185 & 0,0418 & 0,0253 & 0,0201 & 0,0222 & 0,0239 \\
\hline & --- & --- & --- & --- & - & \\
\hline Total & 15,6601 & 15,6328 & 15,5799 & 15,6369 & 15,7722 & 15,9271 \\
\hline
\end{tabular}

Tabla IV.38: Análisis de la química mineral. 


\begin{tabular}{|c|c|c|c|}
\hline \multicolumn{4}{|c|}{ Vidrio } \\
\hline Litofacies/Unidad & Traquitas vítreas & \multicolumn{2}{|c|}{ Ignimbrita Portezuelo } \\
\hline Muestra & PMA 27-A & \multicolumn{2}{|c|}{ PM 14} \\
\hline Cristal & Vidrio Base & \multicolumn{2}{|c|}{ Vidrio Fiamme 1} \\
\hline Punto & 1 & 1 & 1 bis \\
\hline \multicolumn{4}{|l|}{$\%$} \\
\hline $\mathrm{SiO}_{2}$ & 68,805 & 64,637 & 66,627 \\
\hline $\mathrm{TiO}_{2}$ & 0,374 & 0,631 & 0,398 \\
\hline $\mathrm{Al}_{2} \mathrm{O}_{3}$ & 15,733 & 16,228 & 16,556 \\
\hline $\mathrm{FeO}$ & 2,569 & 2,585 & 2,615 \\
\hline $\mathrm{MnO}$ & 0,086 & 0,108 & 0,085 \\
\hline $\mathrm{MgO}$ & 0,275 & 0,404 & 0,382 \\
\hline $\mathrm{CaO}$ & 0,566 & 0,850 & 0,816 \\
\hline $\mathrm{Na}_{2} \mathrm{O}$ & 3,578 & 2,965 & 3,875 \\
\hline $\mathrm{K}_{2} \mathrm{O}$ & 5,785 & 6,547 & 6,665 \\
\hline $\mathbf{F}$ & 0,061 & 0,106 & 0,109 \\
\hline $\mathrm{Cl}$ & 0,354 & 0,141 & 0,220 \\
\hline--- & --- & --- & --- \\
\hline Total & 98,186 & 95,202 & 98,347 \\
\hline \multicolumn{4}{|l|}{$\mathrm{N}^{\circ}$ Cationes } \\
\hline Si & 2,3405 & 2,2849 & 2,2866 \\
\hline $\mathbf{T i}+4$ & 0,0096 & 0,0168 & 0,0103 \\
\hline $\mathrm{Al}+3$ & 0,6308 & 0,6761 & 0,6697 \\
\hline $\mathrm{Fe}+2$ & 0,0731 & 0,0764 & 0,0750 \\
\hline Mn & 0,0025 & 0,0032 & 0,0025 \\
\hline Mg & 0,0139 & 0,0213 & 0,0195 \\
\hline $\mathrm{Ca}$ & 0,0206 & 0,0322 & 0,0300 \\
\hline $\mathbf{N a}$ & 0,2360 & 0,2032 & 0,2579 \\
\hline $\mathbf{K}$ & 0,2510 & 0,2953 & 0,2918 \\
\hline $\mathbf{F}$ & 0,0065 & 0,0119 & 0,0118 \\
\hline \multirow[t]{2}{*}{$\mathrm{Cl}$} & 0,0204 & 0,0084 & 0,0128 \\
\hline & --- & --- & --- \\
\hline Total & 3,6050 & 3,6298 & 3,6677 \\
\hline Composición (TAS) & Riolitico & Traquitico & Traquitico \\
\hline
\end{tabular}

Tabla IV.39: Análisis de la química mineral. 


\section{Anexo V: \\ Cálculos de porcentajes de magmas máficos y félsicos en la mezcla de magmas}

El presente anexo muestra los resultados de los cálculos de los porcentajes de magmas máficos y félsicos involucrados en la mezcla de magmas y formación de rocas híbridas. En cada tabla se indican los extremos máficos y félsicos para la realización de los cálculos, asi como el error del ajuste. Como ya fue mencionado en la sección correspondiente, los cálculos para las muestras PY 10 y PMA 74 de los Traquitoides Pre-caldera no arrojan un error del ajuste aceptable. La formulación matemática utilizada en los cálculos se encuentra detallada en Bryan et al. (1969). 


\begin{tabular}{|c|c|c|c|c|c|c|c|}
\hline \multicolumn{8}{|c|}{ Traquitoides Pre-caldera } \\
\hline \multicolumn{8}{|c|}{$\mathrm{C}=\mathrm{PM} 27$} \\
\hline \multirow{3}{*}{$\mathrm{A}$} & Extremos & $\%$ en la mez & error $(\%)$ & & Extremos & $\%$ en la mez & error $(\%)$ \\
\hline & STA 3 & 0 & 2,16 & $\mathrm{~A}$ & PY 15 & 0 & 4,58 \\
\hline & PY 5 & 2,91 & 2,88 & & STA 3 & 7,03 & 4,39 \\
\hline \multirow[t]{6}{*}{ B } & PM 15 & 96,87 & 5,13 & $\mathrm{~B}$ & PM 14 & 47,13 & 25,54 \\
\hline & PM 25 & 0 & 4,23 & & PMB 4 & 45,77 & 25,52 \\
\hline & Total (\%) & 99,78 & & & Total (\%) & 99,93 & \\
\hline & $\begin{array}{l}\text { error } \\
\text { ajuste(\%) }\end{array}$ & 5,05 & & & $\begin{array}{l}\text { error } \\
\text { ajuste(\%) }\end{array}$ & 8,67 & \\
\hline & Suma A & \multicolumn{2}{|c|}{2,91} & & Suma A & \multicolumn{2}{|c|}{7,03} \\
\hline & Suma B & \multicolumn{2}{|c|}{96,87} & & Suma B & \multicolumn{2}{|c|}{92,9} \\
\hline \multirow{4}{*}{ A } & \multicolumn{7}{|c|}{$\mathrm{C}=\mathrm{PM} 28$} \\
\hline & Extremos & \multicolumn{2}{|c|}{$\%$ en la mezcla error $(\%)$} & & Extremos & \multicolumn{2}{|c|}{$\%$ en la mezcla error $(\%)$} \\
\hline & STA 3 & 0,00 & 3,13 & $\mathrm{~A}$ & PY 15 & 11,97 & 4,60 \\
\hline & PY 5 & 8,51 & 4,18 & & STA 3 & 0,00 & 4,41 \\
\hline \multirow[t]{6}{*}{ B } & PM 15 & 91,70 & 7,44 & $\mathrm{~B}$ & PM 14 & 58,55 & 25,66 \\
\hline & PM 25 & 0,00 & 6,12 & & PMB 4 & 30,06 & 25,64 \\
\hline & Total (\%) & 100,21 & & & Total (\%) & 100,59 & \\
\hline & $\begin{array}{l}\text { error } \\
\text { ajuste(\%) }\end{array}$ & 7,31 & & & $\begin{array}{l}\text { error } \\
\text { ajuste(\%) }\end{array}$ & 8,72 & \\
\hline & Suma A & \multicolumn{2}{|c|}{8,51} & & Suma A & \multicolumn{2}{|c|}{11,97} \\
\hline & Suma B & \multicolumn{2}{|c|}{91,70} & & Suma B & \multicolumn{2}{|c|}{88,61} \\
\hline \multicolumn{8}{|c|}{$C=P Y 10$} \\
\hline \multirow{3}{*}{ A } & Extremos & \multicolumn{2}{|c|}{$\%$ en la mezcla error (\%) } & & Extremos & \multicolumn{2}{|c|}{$\%$ en la mezcla error $(\%)$} \\
\hline & STA 3 & 0 & 6,66 & $\mathrm{~A}$ & PY 5 & 32,67 & 3,03 \\
\hline & PY 5 & 16,99 & 7,09 & & & & \\
\hline \multirow[t]{6}{*}{ B } & PM 28 & 47,46 & 17,49 & $\mathrm{~B}$ & PM 25 & 65,60 & 2,35 \\
\hline & PMA 67 & 34,29 & 16,27 & & & & \\
\hline & Total (\%) & 98,74 & & & Total (\%) & 98,26 & \\
\hline & $\begin{array}{l}\text { error } \\
\text { ajuste(\%) }\end{array}$ & 14,30 & & & $\begin{array}{l}\text { error } \\
\text { ajuste(\%) }\end{array}$ & 44,98 & \\
\hline & Suma A & & & & Suma A & & 67 \\
\hline & Suma B & & & & Suma B & & 60 \\
\hline
\end{tabular}

Tabla V.1: Resultado de los cálculos de porcentaje de magmas máficos y félsicos involucrados en la mezcla de magmas. A: muestras de los extremos máficos utilizadas en el cálculo. B: muestras de los extremos félsicos utilizadas en el cálculo. C: muestra de la roca híbrida resultante. 


\begin{tabular}{|c|c|c|c|c|c|c|c|}
\hline \multicolumn{8}{|c|}{ Traquitoides Pre-caldera } \\
\hline \multicolumn{4}{|c|}{$\mathrm{C}=\mathrm{PMA} 74$} & \multicolumn{4}{|c|}{$C=P M D-2$} \\
\hline \multirow{9}{*}{ B } & Extremos & \multicolumn{2}{|c|}{$\%$ en la mezcla error $(\%)$} & \multicolumn{2}{|r|}{ Extremos } & \multicolumn{2}{|c|}{$\%$ en la mezcla error $(\%$} \\
\hline & STA 8 & 0,00 & 12,16 & $\mathrm{~A}$ & PY 15 & 5,22 & 8,31 \\
\hline & PY 5 & 56,43 & 15,83 & & STA 3 & 0,00 & 7,97 \\
\hline & PMA 64 & 41,51 & 18,79 & B & PM 14 & 93,27 & 46,33 \\
\hline & PMA 67 & 0,00 & 14,57 & & PMB 4 & 0,00 & 46,29 \\
\hline & Total $(\%)$ & 97,94 & & & Total (\%) & 98,50 & \\
\hline & $\begin{array}{l}\text { error } \\
\text { ajuste(\%) }\end{array}$ & 18,65 & & & $\begin{array}{l}\text { error } \\
\text { ajuste(\%) }\end{array}$ & 15,73 & \\
\hline & Suma A & \multicolumn{2}{|c|}{56,43} & & Suma A & \multicolumn{2}{|c|}{5,22} \\
\hline & Suma B & \multicolumn{2}{|c|}{41,51} & & Suma B & \multicolumn{2}{|c|}{93,27} \\
\hline \multicolumn{8}{|c|}{ Traquitoides Pre-caldera } \\
\hline \multicolumn{8}{|c|}{$\mathrm{C}=\mathrm{PM} 34$} \\
\hline & Extremos & \multicolumn{2}{|c|}{$\%$ en la mezcla error $(\%)$} & \multirow{3}{*}{ A } & Extremos \% & \multicolumn{2}{|c|}{$\%$ en la mezcla error $(\%)$} \\
\hline \multirow[t]{2}{*}{ A } & PM 46 & \multirow[t]{2}{*}{55,11} & \multirow[t]{2}{*}{1,49} & & STA 16 & 19,53 & 3,38 \\
\hline & & & & & STA 26 & 39,78 & 4,13 \\
\hline \multirow[t]{6}{*}{ B } & \multirow[t]{2}{*}{ PM 13} & \multirow[t]{2}{*}{45,73} & \multirow[t]{2}{*}{1,27} & \multirow[t]{2}{*}{ B } & PM 14 & 21,38 & 4,19 \\
\hline & & & & & PM 26 & 20,22 & 4,92 \\
\hline & Total (\%) & \multicolumn{2}{|l|}{100,84} & & Total (\%) & \multicolumn{2}{|c|}{100,91} \\
\hline & $\begin{array}{l}\text { error } \\
\text { ajuste(\%) }\end{array}$ & \multicolumn{2}{|l|}{15,20} & & $\begin{array}{l}\text { error } \\
\text { ajuste(\%) }\end{array}$ & 4,13 & \\
\hline & Suma A & & & & Suma A & & \\
\hline & Suma B & & & & Suma B & & \\
\hline & & & $C=S I$ & A 6- & & & \\
\hline & Extremos & $\%$ en la mez & error $(\%)$ & & Extremos \% & 6 en la me & error (\%) \\
\hline A & STA 16 & 0,00 & 5,23 & A & STA 16 & 0,00 & 8,37 \\
\hline & STA 26 & 22,69 & 7,21 & & PY 5 & 30,70 & 9,80 \\
\hline & PM 46 & 0,00 & 8,81 & B & PMC 116-A & 37,18 & 9,05 \\
\hline B & PMC 116-A & 5,83 & 11,00 & & PM 26 & 31,71 & 10,44 \\
\hline & PM 26 & 27,15 & 4,95 & & Total (\%) & 99.59 & \\
\hline & PMA 64 & 44,78 & 11,74 & & error & & \\
\hline & Total (\%) & 100,45 & & & ajuste(\%) & 11,75 & \\
\hline & $\begin{array}{l}\text { error } \\
\text { ajuste(\%) }\end{array}$ & 4,23 & & & Suma A & & \\
\hline & & & & & Suma B & & \\
\hline & Suma B & & & & & & \\
\hline
\end{tabular}

Tabla V.2: Resultado de los cálculos de porcentaje de magmas máficos y félsicos involucrados en la mezcla de magmas. A: muestras de los extremos máficos utilizadas en el cálculo. B: muestras de los extremos félsicos utilizadas en el cálculo. C: muestra de la roca híbrida resultante. 


\begin{tabular}{|c|c|c|c|c|c|c|c|}
\hline \multicolumn{8}{|c|}{ Traquiandesitas Post-caldera } \\
\hline \multicolumn{8}{|c|}{$\mathrm{C}=\mathrm{PMC} 20$} \\
\hline \multirow{4}{*}{ A } & Extremos \% & n la me & rror (\%) & & Extremos & $\%$ en la me & $\operatorname{rror}(\%)$ \\
\hline & PY 15 & 0,00 & 3,60 & $\mathrm{~A}$ & STA 16 & 12,20 & 2,38 \\
\hline & STA 26 & 51,37 & 3,02 & & STA 26 & 42,03 & 2,91 \\
\hline & PM 46 & 5,56 & 2,05 & B & PM 14 & 41,72 & 2,95 \\
\hline \multirow[t]{8}{*}{ B } & PM 47 & 16,67 & 0,97 & & PM 26 & 4,93 & 3,47 \\
\hline & PMC 116-A & 17,44 & 2,27 & & & & \\
\hline & PM 26 & 9,83 & 1,61 & & Total (\%) & 100,88 & \\
\hline & Total (\%) & 100,86 & & & $\begin{array}{l}\text { error } \\
\text { ajuste(\%) }\end{array}$ & 2,91 & \\
\hline & $\begin{array}{l}\text { error } \\
\text { aiuste(\%) }\end{array}$ & 1,88 & & & Suma A & & \\
\hline & a)uste(to) & & & & Suma B & & \\
\hline & Suma A & & & & & & \\
\hline & Suma B & & & & & & \\
\hline
\end{tabular}

Tabla V.3: Resultado de los cálculos de porcentaje de magmas máficos y félsicos involucrados en la mezcla de magmas. A: muestras de los extremos máficos utilizadas en el cálculo. B: muestras de los extremos félsicos utilizadas en el cálculo. C: muestra de la roca híbrida resultante. 


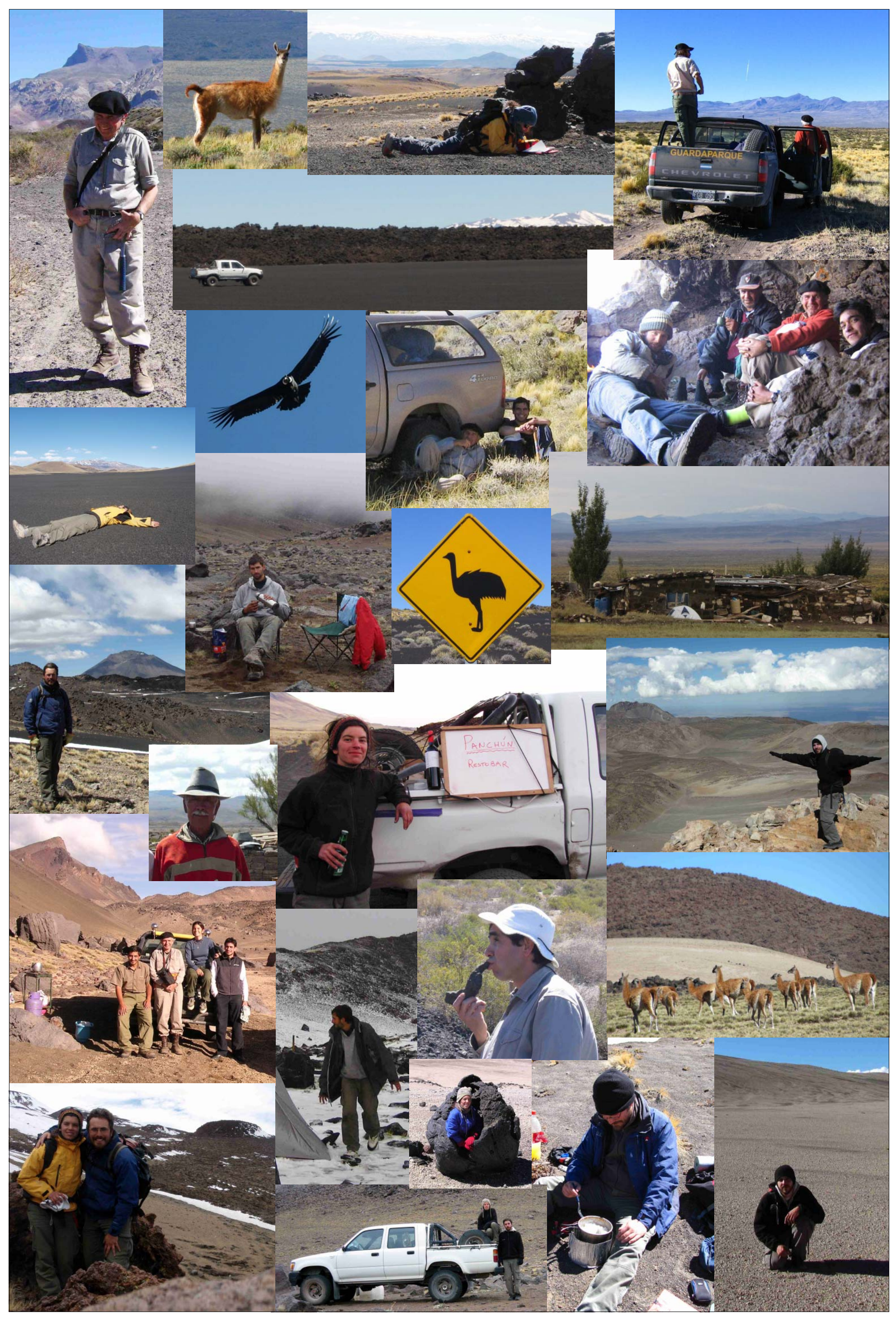

